\title{
DEVELOPMENT OF RYERSON'S HYPERLOOP POD SYSTEMS USING A MODULAR AND SYSTEMATIC APPROACH
}

\author{
By
}

Mohammed Mohiuddin Khan (Mohi Khan)

Bachelor of Engineering, Ryerson University (2016)

\begin{abstract}
A thesis
presented to Ryerson University

in partial fulfillment of the requirements for the degree of

Master of Applied Science in the program of Aerospace Engineering
\end{abstract}

Toronto, Ontario, Canada, 2019

(C) Mohammed Mohiuddin Khan, 2019 


\section{AUTHOR'S DECLARATION FOR ELECTRONIC SUBMISSION OF A THESIS}

I hereby declare that I am the sole author of this thesis. This is a true copy of the thesis, including any required final revisions, as accepted by my examiners.

I authorize Ryerson University to lend this thesis to other institutions or individuals for the purpose of scholarly research.

I further authorize Ryerson University to reproduce this thesis by photocopying or by other means, in total or in part, at the request of other institutions or individuals for the purpose of scholarly research.

I understand that my thesis may be made electronically available to the public. 


\title{
ABSTRACT
}

\section{Development Of Ryerson's Hyperloop Pod Systems Using A Modular And Systematic}

\section{Approach}

\author{
Mohammed Mohiuddin Khan (Mohi Khan) \\ Master of Applied Science, Aerospace Engineering, Ryerson University, Toronto (2019)
}

$\mathrm{R}^{\text {yerson International Hyperloop is a special projects team with the intent of developing }}$ a fully functioning Hyperloop Pod. The team believes in driving revolutionary change within the transportation industry, with the greater cause of saving time, and to help make Canadian cities more accessible. The Pod was designed using a systematic approach with modularity and reliability as major foci. Its design featured an innovative, student researched and developed linear induction based MagDrive, and MagLev systems for propulsion and levitation. The braking system featured a fail-safe pneumatic deployment system to facilitate braking at high speeds as well as a wireless "Keep Alive" command. The onboard hyperionics is entirely composed of student researched and developed components which provides an expansive communication range and the ability to transmit real time data back to the mission control through all states and stages of the Pod's run. 


\section{ACKNOWLEDGEMENTS}

The author would like to express his sincerest appreciation to his supervisor, Dr. Seyed M. Hashemi, who is an exceptional mentor to his students. Besides being remarkably knowledgeable, Dr. Hashemi also has great skill in explaining complex topics with great clarity and simplicity. His genuine attitude towards all his students has made him an extremely approachable person. Without his guidance and support, the Development of Ryerson's Hyperloop Pod would not have been possible.

The author would like to acknowledge members of Ryerson International Hyperloop for their endless contributions towards the development of the fifth mode of transportation. It was an honor working amongst such brilliant minds.

The author would like to recognize Ryerson International Hyperloop's cherished and generous supporters: Ryerson University, Office of the President, The Department of Aerospace Engineering, ANSYS Inc., MSC Software, and MiSUMi. Their unwavering support, whether monetary, material, or through words of advice, afforded the team the opportunity to see this design to its full potential.

The author feels extremely fortunate and grateful to the faculty advisors (Dr. Seyed M. Hashemi, Dr. Paul Walsh, Dr. Hamid Ghaemi, Dr. Kazem Fayazbakhsh, Cliff Chan, Peter Bradley, Jerry Karpynczyk, Francine Belnavis, Kim Gallo, Leah Rogan, Gerald Bootes, Zohair Khan, and Rose Ghamari) and industry advisors (Ron Bakowski, Rob Paterson, Gordon Cook, and Moeid Elahi) for their hard work throughout the year, and their dedication in making this design the best it could be.

The author would also like to thank SpaceX, The Boring Company, and Tesla for hosting the Hyperloop Pod Competitions, and providing teams the opportunity to showcase their skills.

Lastly, the author feels indebted to his parents and sister for their endless love, words of encouragement, and support over the years.

Without the support of all these people and organizations, the Development of Ryerson's First Hyperloop Pod would have remained an idea yet to be realized. 


\section{TABLE OF CONTENTS}

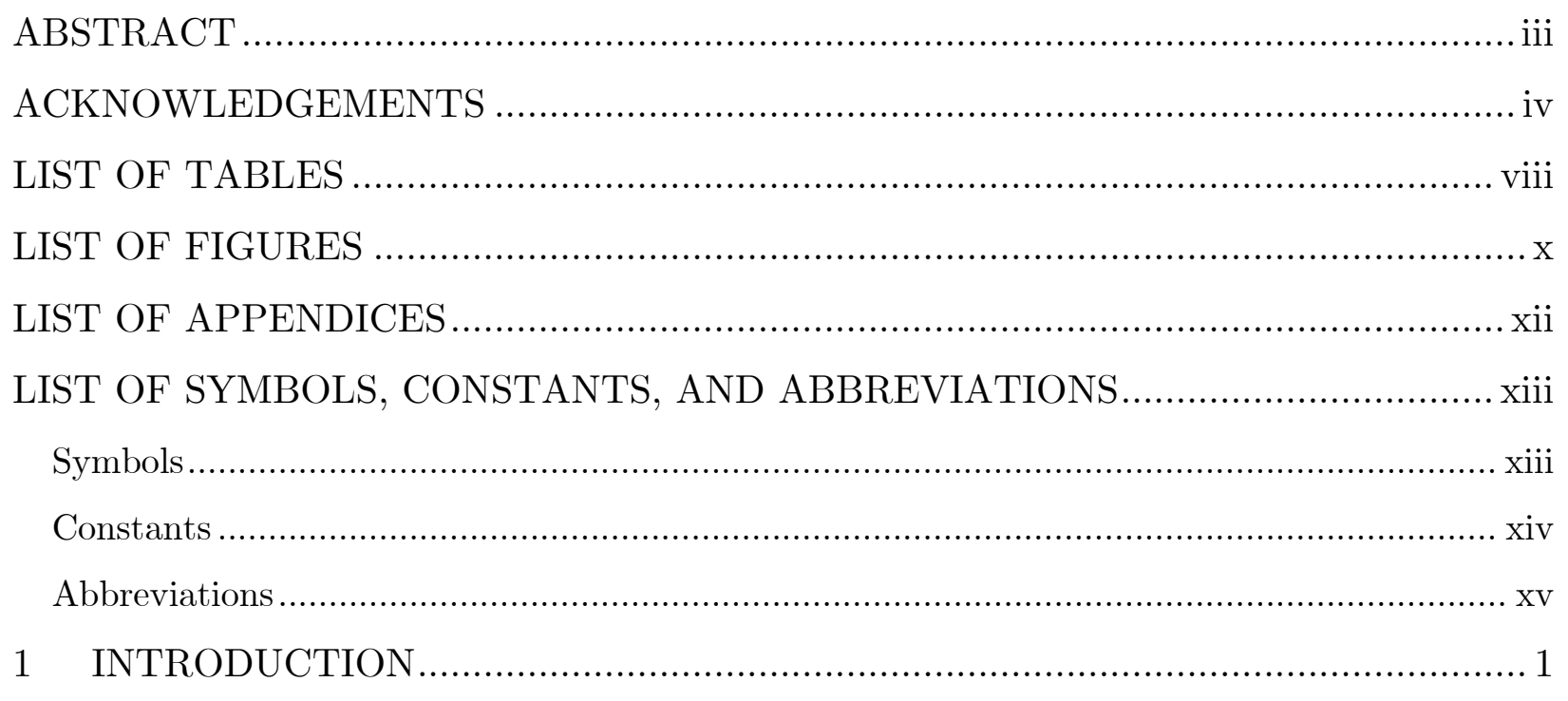

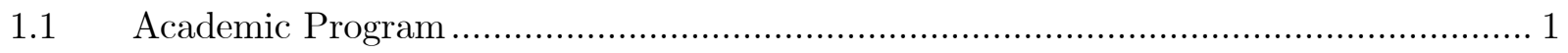

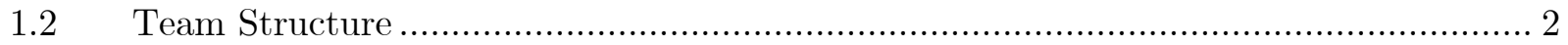

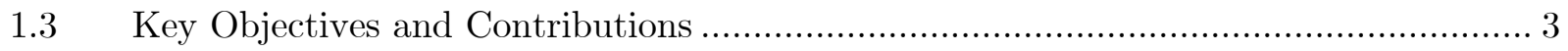

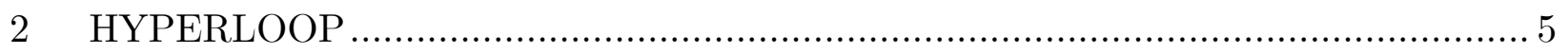

$2.1 \quad$ The Hyperloop Concept ………………………................................................... 5

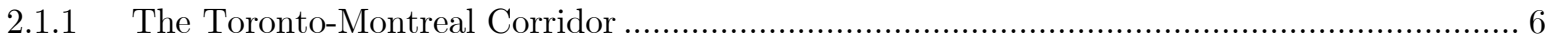

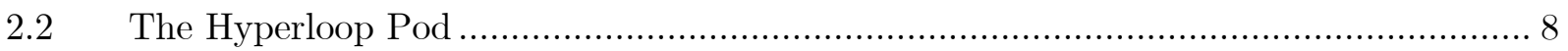

2.2.1 Hyperloop Pod Sub-Systems ................................................................................... 8

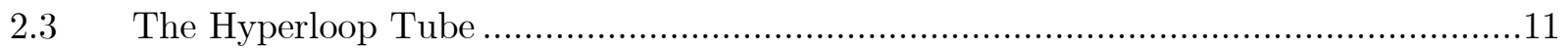

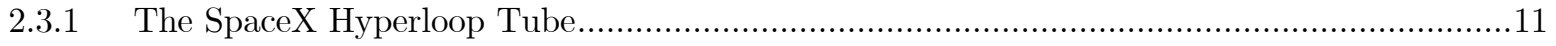

2.4 The SpaceX Hyperloop Operating Environment …………......................................13

2.4.1 Low Pressure Environment...……………………………………………………….....13

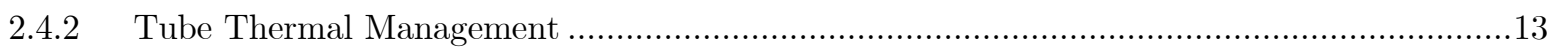

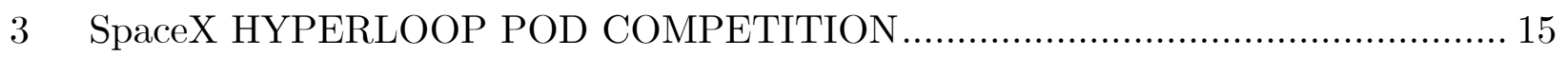

3.12019 Hyperloop Pod Competition ………………..............................................15

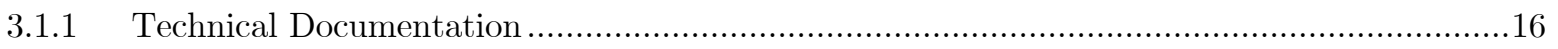

3.1.2 Technical Presentation ………………………………………………………………16

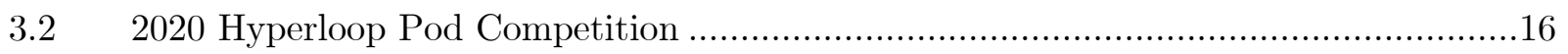

4 RYERSON'S HYPERLOOP POD ARCHITECTURE ……............................... 17 


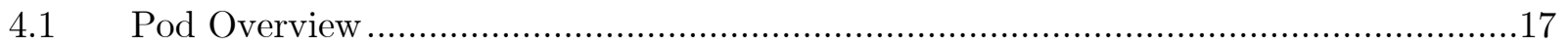

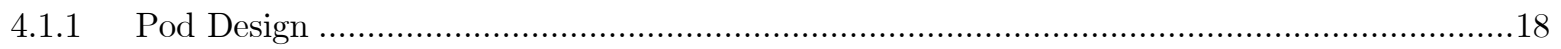

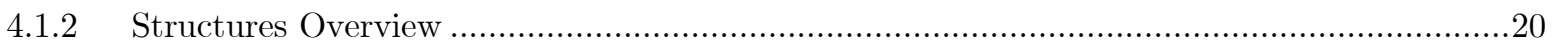

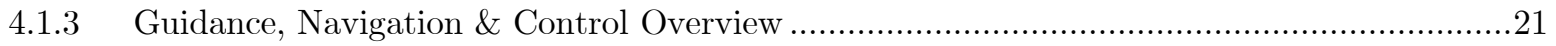

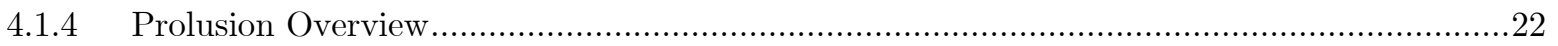

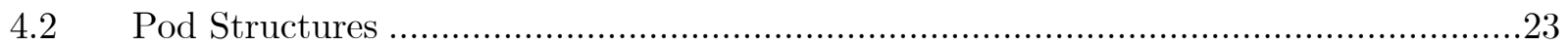

4.2.1 Pod Longitudinal Chassis Members (LCM) ......................................................................23

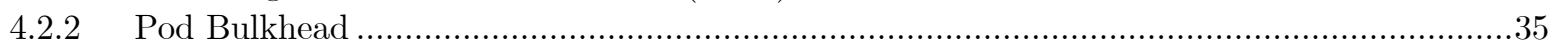

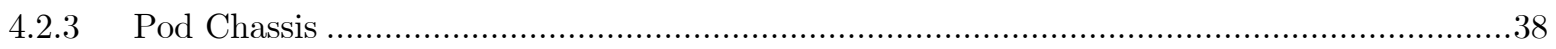

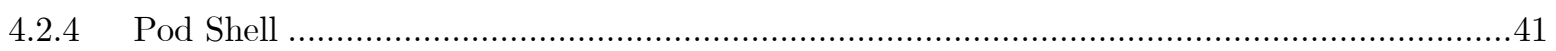

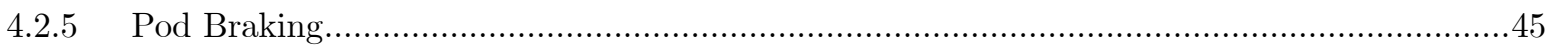

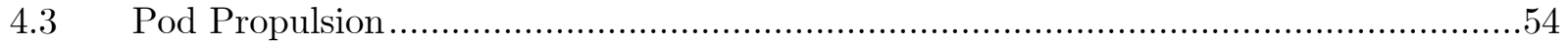

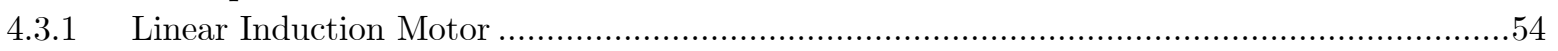

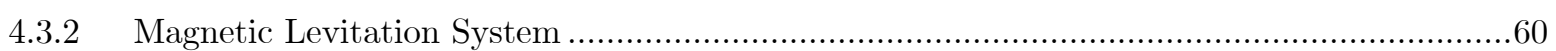

4.4 Pod Guidance, Navigation and Control .....................................................64

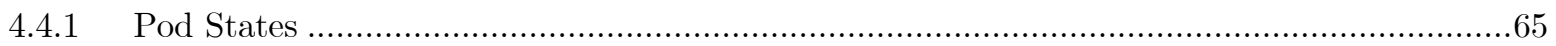

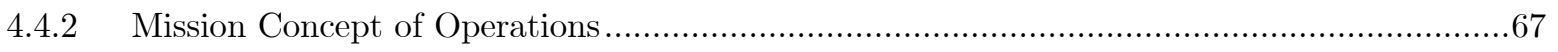

4.5 Testing Challenge

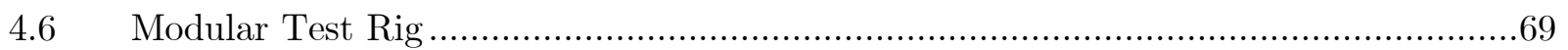

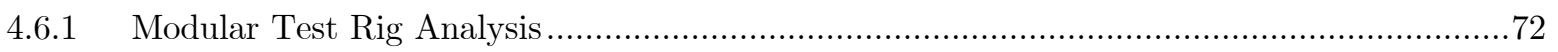

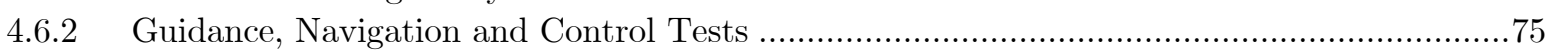

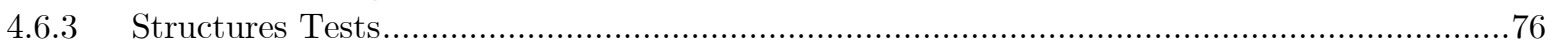

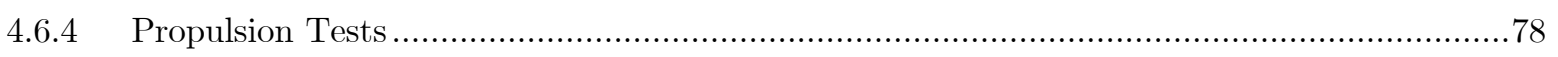

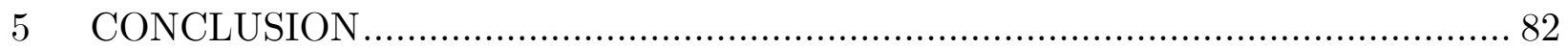

6 FUTURE WORK............................................................................ 83

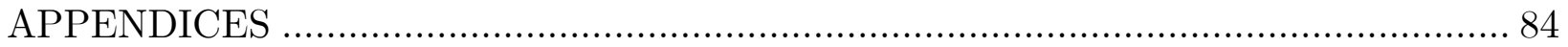

Appendix A.1 Final Pod Prototype ......................................................................... 84

Appendix A.2 Modular Test Rig Prototype ........................................................... 109

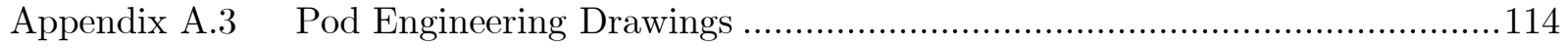

Appendix A.4 Modular Test Rig Engineering Drawings........................................... 133

Appendix A.5 LCM Load Case I (Pod Staging) Analysis Report .................................145

Appendix A.6 LCM Load Case II (Launch Phase) Analysis Report ..............................169

Appendix A.7 LCM Load Case III (Levitation Phase) Analysis Report...........................193

Appendix A.8 LCM Load Case IV (Braking Phase) Analysis Report ............................215

Appendix A.9 Bulkhead Load Case (Braking Phase) Analysis Report............................240

Appendix A.10 Chassis Load Case (Braking Phase) Analysis Report..............................261

Appendix A.11 MTR Track Load Case (Overspeed) Analysis Report.............................292 
Appendix A.12 MTR Shaft Load Case (Lock Up) Analysis Report................................313

Appendix A.13 Ryerson International Hyperloop Team Breakdown .................................333

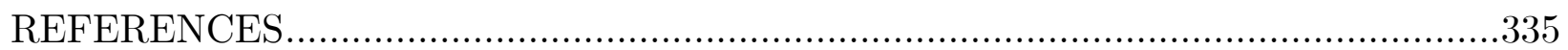




\section{LIST OF TABLES}

Table 1. SpaceX Hyperloop tube material specifications.............................................. 11

Table 2. SpaceX Hyperloop tube major dimensional specifications............................... 12

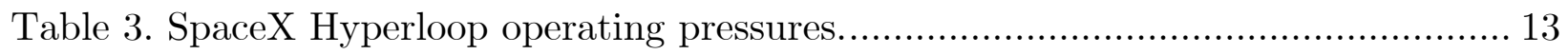

Table 4. Temperature range for SpaceX during the testing period. …............................ 14

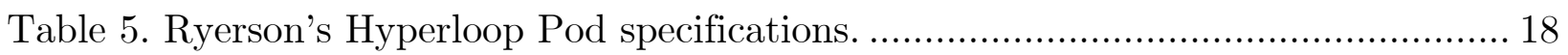

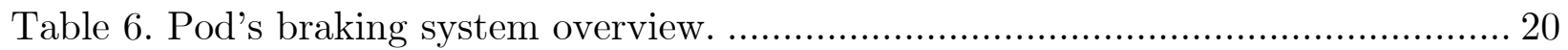

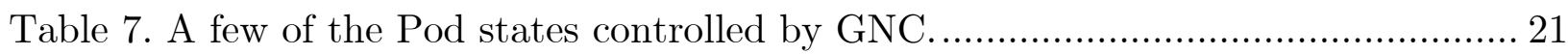

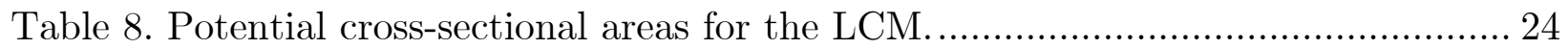

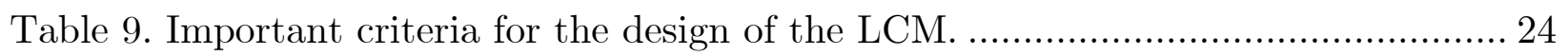

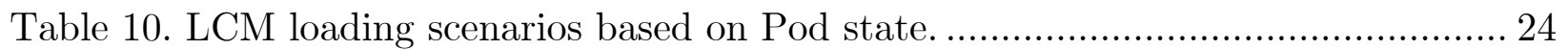

Table 11. Aluminum 6061-T6 material specification for the LCM.............................. 28

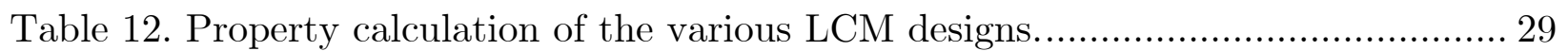

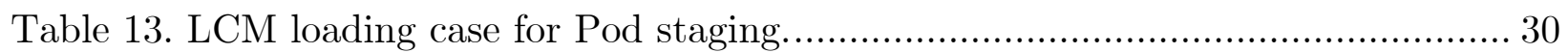

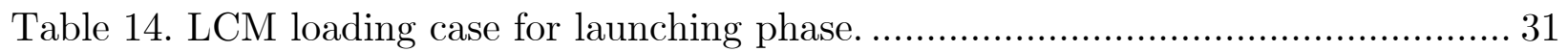

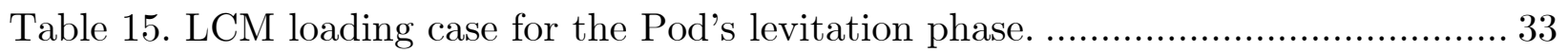

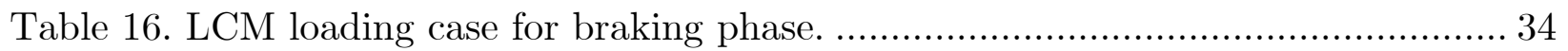

Table 17. Aluminum 6061-T6 material specification for the bulkhead......................... 36

Table 18. Dimensional specifications for the Pod Bulkhead......................................... 37

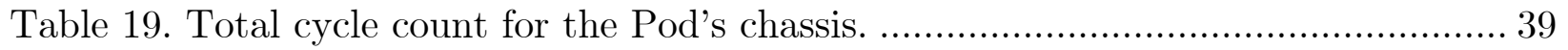

Table 20. Pod chassis loading during single operating braking system. ........................ 40

Table 21. HexTow AS4C 3K material specification for the Pod shell............................ 44

Table 22. Aeropoxy PR2032 and PH3665 material specification for the shell................ 45

Table 23. Pod braking system component list...................................................... 47

Table 24. Braking cycle count for pre and post Hyperloop run................................... 48

Table 25. Pneumatic braking piston specifications..................................................... 49

Table 26. Power requirements for a few braking components. .................................... 51

Table 27. Performance specification for nominal and off-nominal braking.................... 53

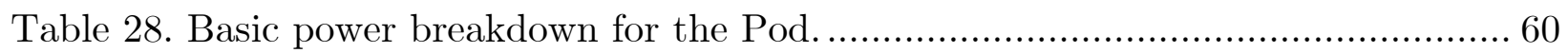

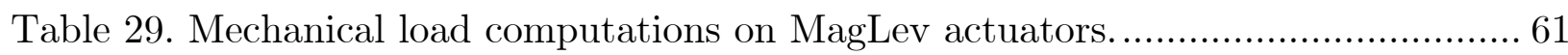

Table 30. Magnet grade specifications for N42 Magnets. ........................................... 62

Table 31. Magnet and backing plate specifications for Pod MagSkis............................. 63

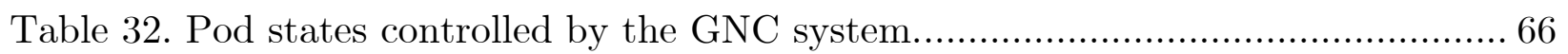

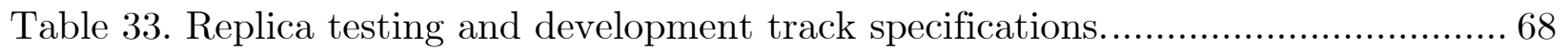

Table 34. Breakdown of the Modular Test Rig. ......................................................... 71

Table 35. Material selection breakdown for the Modular Test Rig................................ 71

Table 36. MTR Piston input and output braking force test. ....................................... 77 
Table 37. Parametric performance effects on MagLev ........................................ 81 


\section{LIST OF FIGURES}

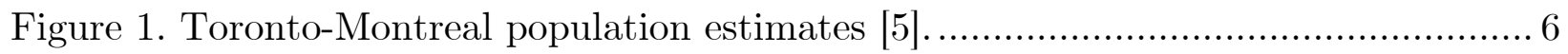

Figure 2. Commute times for the Toronto-Montreal corridor [6] ............................... 6

Figure 3. Energy consumption per passenger for various modes of transportation [1] .... 7

Figure 4. Concept architecture of a Hyperloop Pod as illustrated in the White Paper.... 8

Figure 5. The Hyperloop's propulsion system showcasing the rotor and stator [1] ........ 9

Figure 6. Ryerson International Hyperloop's pod architecture................................... 17

Figure 7. Ryerson's Hyperloop Pod design with an aerodynamic shell.......................... 18

Figure 8. Ryerson's Hyperloop Pod design showcasing its internal systems................... 19

Figure 9. Ryerson's Hyperloop Pod with its internal systems labelled.......................... 19

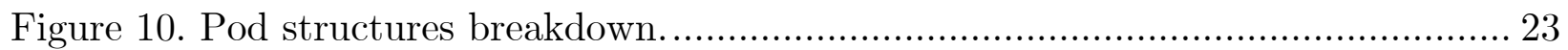

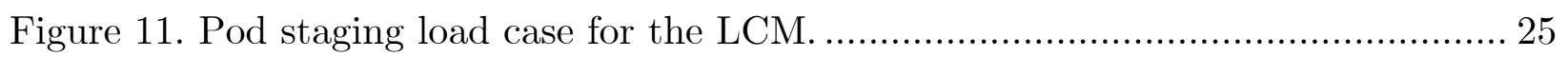

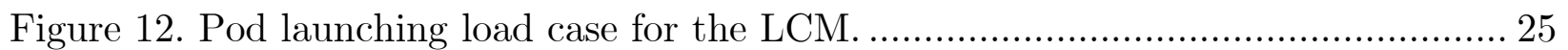

Figure 13. Pod levitation loading scenario for the LCM. ......................................... 26

Figure 14. Pod braking loading scenario for the LIM............................................... 26

Figure 15. Pod's LCM manufactured using anodized black Aluminum 6061-T6........... 28

Figure 16. ANSYS workflow setup for the Pod's LCM. ............................................ 30

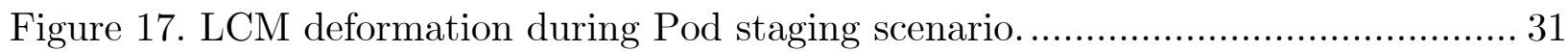

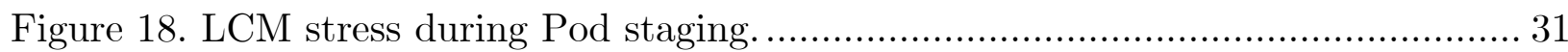

Figure 19. LCM deformation during Pod's launching phase. ……................................ 32

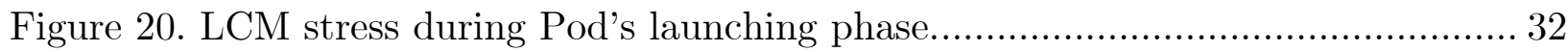

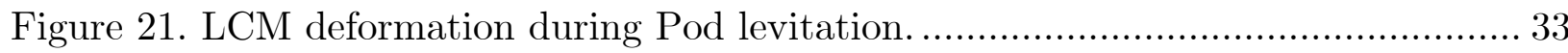

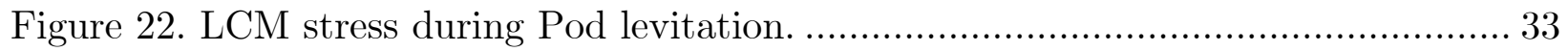

Figure 23. LCM Deformation During The Pod's Braking Phase................................... 34

Figure 24. LCM Stress For The Pod's Braking Phase.................................................. 35

Figure 25. Pod's bulkhead manufactured using anodized blue Aluminum 6061-T6 ...... 36

Figure 26. Pod bulkhead's deformation during Pod braking. ..................................... 37

Figure 27. Pod bulkhead's stresses during Pod braking. .............................................. 38

Figure 28. Assembled Hyperloop Pod chassis with the LCMs and bulkheads................ 39

Figure 29. Pod chassis deformation with one inoperable braking system..................... 40

Figure 30. Pod chassis stress with one inoperable braking system............................. 41

Figure 31. Area ratio vs bypass Mach number plot for varying Mach numbers. ........... 42

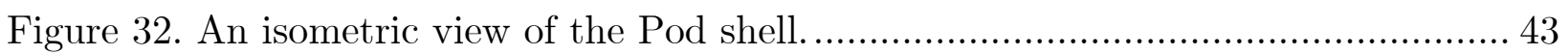

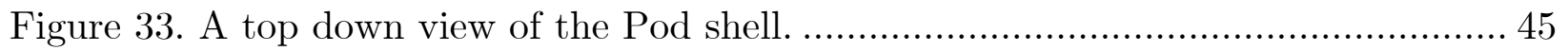

Figure 34. Acceptable Pod braking scenarios on the test track................................... 46

Figure 35. Unacceptable Pod braking scenarios on the test track............................... 46

Figure 36. Double acting pneumatic braking piston for the braking system [25]. .......... 48 
Figure 37. Carbon composite HPA pressure vessel for the braking system [26]........... 49

Figure 38. Retracted pneumatic braking schematic for one piston set..................... 50

Figure 39. Extended pneumatic braking schematic for one piston set...................... 50

Figure 40. Directional control valve with two solenoid valve coils [27]................... 51

Figure 41. Pod propulsion breakdown........................................................ 54

Figure 42. The formation of a LIM from a RIM by I. Boldea [28] .......................... 55

Figure 43. LIM forces adopted from S. P. Bhamidi [32] ................................. 56

Figure 44. Single layer winding configuration adopted from S. P. Bhamidi [32].......... 58

Figure 45. Double layer winding configuration adopted from S. P. Bhamidi [32]......... 58

Figure 46. Electrical power schematic for the propulsion system............................ 59

Figure 47. Assembled Hyperloop Pod MagLev system....................................... 60

Figure 48. Magnet Dimensional Parameters...................................................... 61

Figure 49. Demagnetization B-H curve for N42 Neodymium magnet [33].................. 62

Figure 50. Pod trajectory profile. ................................................................ 64

Figure 51. Ryerson International Hyperloop's mission concept of operations. .............. 67

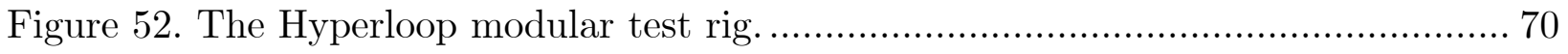

Figure 53. Motor performance plot for the MTR adapted from Oriental Motors [36]... 72

Figure 54. Shaft deformation during MTR lock up...................................... 73

Figure 55. Shaft stresses during MTR lock up. ......................................... 73

Figure 56. Track deformation during MTR lock up..................................... 73

Figure 57. Track stress during MTR lock up. ............................................... 74

Figure 58. Track deformation during MTR overspeed. .................................... 74

Figure 59. Track stress during MTR overspeed. ......................................... 75

Figure 60. The Integrated Pneumatic Braking System on the MTR. ...................... 76

Figure 61. Brake output force data for MTR pistons...................................... 78

Figure 62. Assembled Dual Axis Force Transducer for MagLev testing. .................... 79

Figure 63. MTR showcasing the mounted DAFT. ........................................ 79

Figure 64. MagLev test results for singular North-South period configuration............ 80

Figure 65. Simulated behavior of lift and drag with an extended velocity profile [40].. 81 


\section{LIST OF APPENDICES}

Appendix A.1 Final Pod Prototype .................................................................. 84

Appendix A.2 Modular Test Rig Prototype …......................................................... 109

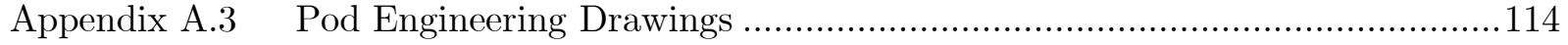

Appendix A.4 Modular Test Rig Engineering Drawings..............................................133

Appendix A.5 LCM Load Case I (Pod Staging) Analysis Report ..................................145

Appendix A.6 LCM Load Case II (Launch Phase) Analysis Report ...............................169

Appendix A.7 LCM Load Case III (Levitation Phase) Analysis Report...........................193

Appendix A.8 LCM Load Case IV (Braking Phase) Analysis Report ............................215

Appendix A.9 Bulkhead Load Case (Braking Phase) Analysis Report..........................240

Appendix A.10 Chassis Load Case (Braking Phase) Analysis Report...............................261

Appendix A.11 MTR Track Load Case (Overspeed) Analysis Report .............................292

Appendix A.12 MTR Shaft Load Case (Lock Up) Analysis Report.................................313

Appendix A.13 Ryerson International Hyperloop Team Breakdown …...........................333 


\section{LIST OF SYMBOLS, CONSTANTS, AND ABBREVIATIONS}

Symbols

$\begin{array}{ll}\gamma & \text { Isentropic Expansion Coefficient } \\ \lambda & \text { Wavelength } \\ \mu_{0} & \text { Permeability of Free Space } \\ \mu_{k, \text { Track }} & \text { Coefficient of Kinetic Friction } \\ \rho & \text { Density } \\ \rho_{r} & \text { Volume Resistivity } \\ \sigma & \text { Bending Stress } \\ \tau & \text { Pole Distance } \\ f & \text { Frequency } \\ a & \text { Edge Length } \\ a & \text { Pod Acceleration/Deceleration Under Time Step } \\ A & \text { Ampere } \\ A_{\text {Bypass }} & \text { Cross-Sectional Area of the Pod Bypass } \\ A_{\text {Piston }} & \text { Piston Head Cross-Section Area } \\ A_{\text {Pod }} & \text { Cross-Sectional Area of the Pod } \\ A_{\text {Tube }} & \text { Cross-Sectional Area of the Tube } \\ C G & \text { Center of Gravity } \\ d & \text { Diameter of Winding } \\ d A & \text { Infinitesimally Small Area } \\ F_{B} & \text { Newton's Second Law } \\ F_{\text {Brake }} & \text { Piston Braking Force } \\ F_{\text {Brake,Req }} & \text { Required Piston Braking Force } \\ F_{\text {LIM }} & \text { Generated LIM Thrust } \\ F_{S} & \text { Stator Thrust Force } \\ G & \text { Goodness Factor } \\ g_{e} & \text { Airgap Effectiveness } \\ g_{\text {Earth }} & \text { Force of Gravity (Earth) } \\ I & \text { Area Moment of Inertia } \\ I_{I} & \text { Stator Phase Current } \\ L_{S} & \text { Stator Core Length } \\ M & \text { Moment } \\ M & \text { Mach Number } \\ M_{\text {Bypass }} & \text { Pod Bypass Mach Number } \\ & \end{array}$




$\begin{array}{ll}M_{\text {Pod }} & \text { Pod Mach Number } \\ m_{\text {Pod }} & \text { Pod Mass } \\ N_{\text {Pod }} & \text { Pod Normal Force } \\ P & \text { Number of Poles } \\ P_{o} & \text { LIM Output Power } \\ P_{\text {Piston }} & \text { Internal Piston Pressure } \\ q & \text { Shear Flow } \\ R & \text { Stator Radius } \\ R_{2} & \text { Rotor Resistance } \\ r_{i} & \text { Inner Radius } \\ r_{O} & \text { Outer Radius } \\ S & \text { Pod Distance Under Particular Time Step } \\ S & \text { Slip } \\ S & \text { Soric } \\ t & \text { Time } \\ u & \text { Initial Pod Velocity } \\ V & \text { Final Pod Velocity } \\ V & \text { Voltage } \\ V_{\infty} & \text { Shear Force } \\ V_{c} & \text { Rotor Linear Speed } \\ V_{D C} & \text { Voltage DC } \\ V_{D C} & \text { Voltage AC } \\ V_{f} & \text { Pod Final Velocity } \\ V_{i} & \text { Pod Initial Velocity } \\ V_{R e f} & \text { Landing Reference Speed } \\ V_{S} & \text { Synchronous LIM Velocity } \\ W & \text { Watt } \\ y & \text { Vertical Distance (From The Neutral Axis) }\end{array}$

\section{Constants}

$\begin{array}{ll}\gamma & 1.4 \\ \mu_{0} & 4 \pi \times 10^{-7} \\ \pi & 3.14159 \\ \rho_{W} & 19.27 \times 10^{-9} \\ g & 9.81 \mathrm{~m} / \mathrm{s}^{2} \text { or } 32.17 \mathrm{ft} / \mathrm{s}^{2}\end{array}$




$\begin{array}{ll}\text { Abbreviations } \\ \text { BRK } & \text { Braking System } \\ \text { CDR } & \text { Critical Design Review } \\ \text { CFD } & \text { Computational Fluid Dynamics } \\ \text { CG } & \text { Center of Gravity } \\ \text { COTS } & \text { Commercial-Off-The-Shelf } \\ \text { DAFT } & \text { Dual Axis Force Transducer } \\ \text { DCV } & \text { Directional Control Valve } \\ \text { DOT } & \text { Department of Transportation } \\ \text { ECU } & \text { Electronic Control Unit } \\ \text { EPG } & \text { Electronic Pressure Gauge } \\ \text { EPR } & \text { Electronic Pressure Regulator } \\ \text { FEAS } & \text { Faculty of Engineering and Architectural Science } \\ \text { FEM } & \text { Finite Element Method } \\ \text { FoS } & \text { Factor of Safety } \\ \text { GNC } & \text { Guidance, Navigation \& Control } \\ \text { GS } & \text { Ground Station } \\ \text { HPA } & \text { High Pressure Air } \\ \text { HQ } & \text { Headquarters } \\ \text { ICASSE } & \text { International Conference on Aerospace System Science and Engineering } \\ \text { LCM } & \text { Longitudinal Chassis Member } \\ \text { LIM } & \text { Linear Induction Motor } \\ \text { MTR } & \text { Modular Test Rig } \\ \text { NASA } & \text { National Aeronautics and Space Administration } \\ \text { OPS } & \text { Operations } \\ \text { PDR } & \text { Preliminary Design Review } \\ \text { PRP } & \text { Propulsion } \\ \text { PWM } & \text { Pulse Width Modulation } \\ \text { RH } & \text { Ryerson International Hyperloop } \\ \text { RIM } & \text { Rotary Induction Motor } \\ \text { ROI } & \text { Return On Investment } \\ \text { SF } & \text { Safety Factor } \\ \text { SLF } & \text { Steady Level Flight } \\ \text { SRAD } & \text { Student Researched and Developed } \\ \text { STEM } & \text { Science, Technology, Engineering, and Mathematics } \\ \text { STR } & \text { Structures } \\ \text { TC } & \text { Transport Canada } \\ \text { VRR } & \text { Vehicle Readiness Review } \\ \text { VSM } & \text { Vehicle Stability Module } \\ & \text { DA } \\ \end{array}$




\section{INTRODUCTION}

This document outlines the design, manufacturing, and testing plans of Ryerson Pod Competition in Hawthorne, California.

\subsection{Academic Program}

Ryerson International Hyperloop ( $\mathrm{RH})$ is a special projects team for the Office of the President at Ryerson University, led by the author. The Department of Aerospace Engineering made numerous key resources accessible to $\mathrm{RH}$ which would otherwise have been impossible to obtain. These supportive services included: University recognition, University backing, funding, financial management, and countless University and departmental facilities. Although the University provides a portion of the funding through a yearly budget request, the team was responsible for securing its own funds and thus, the rest of the financial support came in the form of sponsorships, awards, and grants.

As the research team is primarily composed of engineering students, $\mathrm{RH}$ benefits from many of the departments within the Faculty of Engineering and Architectural Science (FEAS) to design, manufacture, and test the systems. The team has access to various facilities including, a subsonic wind tunnel, supersonic wind tunnel, stress and fatigue laboratories, additive manufacturing zones, as well as machine shops.

The team is primarily composed of Aerospace (85\%), Mechanical (5\%), and Electrical (5\%) Engineering students. However, the team encourages the contribution from varied academic disciplines with the expectation that a diverse organization will inspire the development of more sophisticated systems while offering a more realistic (and accurate) depiction of an industry environment.

During 2019, the team successfully recruited high school students to foster growth within Science, Technology, Engineering, and Mathematics (STEM) fields. In doing this, the team offers younger students the opportunity to develop their technical and communication skills early in their academic career. The team's long-term goal is to build an avenue where members apply their academic knowledge to real world situations and gain valuable experience preparing for their future careers in the industry. 


\subsection{Team Structure}

In order to delegate tasks efficiently, Ryerson Hyperloop was split into four major sub-teams - Operations (OPS), Structures (STR), Guidance, Navigation \& Control (GNC), and Propulsion (PRP) with each sub-team researching to produce an innovative, modular, and reliable design.

The sub-teams undertook a number of design projects while the administration, management, and operations were handled by the OPS sub-team. During the initial phase of the design, several workshops were conducted to identify areas of interest and to stimulate innovative system designs.

To ensure effective communication, $\mathrm{RH}$ utilized varied modes of communication, such as digital, oral, and written. The primary method of communication was through Slack, a virtual space that facilitated project discussions and decisions, collaborations, and conversations centered around the day-to-day operation of the team. In addition to the general team wide channels, each sub-team was assigned an exclusive channel that was dedicated to troubleshooting sub-team related issues and for promoting specific discussions.

The large amount of documentation generated by the team was sorted, stored, and shared on a working Team Drive through the university based Google Drive account. Google Drive is a cloud based file storage and synchronization service provided by Google. It allows users to upload, synchronize, and share their files to a working directory. Being the chief document storage directory, Google Drive served as one of the most vital resources in our effort to ensure smooth team operations.

In order to ensure progress and the transfer of information to new members, each sub-team met on a weekly basis. At these meetings, members presented their accomplishments as well as setbacks. Additionally, tasks that needed to be tackled in the upcoming weeks along with any pertinent information that required attention was discussed. To hold all members accountable, several systems of checks were established. In addition to weekly meetings, the team held three formal reviews: Preliminary Design Review (PDR), Critical Design Review (CDR), and Vehicle Readiness Review (VRR); all members were required to be in attendance at these reviews. The stakeholders such as the faculty advisors, industry advisors, and sponsors, who were invited to these reviews ensured sound technical decisions were made through all stages of development. At these meetings, the designs, analyses, manufacturing methods, and certification plans were presented. This ensured that the systems authorized to proceed to fabrication and testing met a predefined performance standard. Furthermore, it allowed for a clear understanding

of the work completed and the establishment of interfacing requirements between the 
various available systems. The panel also included industry professionals who were able to provide feedback and constructive criticism exposing oversights, errors, and incorrect assumptions.

This document was intended to be a detailed guide that contained all information pertinent to the design, build, and testing of Ryerson's first Hyperloop Pod. It also contained reasoning behind design decisions, analyses performed on designs, results from testing of individual components, and findings from full system testing. This document was also intended to serve as a reference for the subsequent team when making design or managerial decisions. The goal was to produce a document so robust such that the new team can operate independently with minimal input from the former team captain.

This system of organization was established in an attempt to ensure the deficiencies faced by other teams do not potentially affect $\mathrm{RH}$ and its operations. It was also done to curb any bad habits from cultivating during the design year. It also offers a foundation upon which to further improve the management of the team.

\subsection{Key Objectives and Contributions}

The objective of this thesis was to design, develop, and validate various Hyperloop Pod systems systematically and with modularity at the forefront. This was done by establishing the requirements defined within Elon Musk's Hyperloop Alpha document as the baseline set of requirements [1]. Aerospace methodologies and standards were heavily relied upon in the design and testing of the Hyperloop Pod systems. In addition, key engineering disciplines such as finite elements, stress analysis, outgassing of materials, space grade soldering techniques, optimization for weight and cost, were applied during the entire design process of the Hyperloop Pod systems. A of the key objectives that were considered during the design of the Hyperloop Pod systems were:

- Investigation of the requirements set by the Hyperloop concept.

- Establishment of the constraints, objectives, and requirements necessary for the development of the Hyperloop Pod systems.

- Development of the Pod architecture for the Hyperloop concept.

- Address technical and system testing challenges imposed when operating within the Hyperloop environment.

- Provide the design details of the Hyperloop Pod architecture to SpaceX for the SpaceX Hyperloop Pod Competitions.

- Present key tests performed on the developed Hyperloop systems and highlight future opportunities for research. 
The author's contribution throughout the development of the Hyperloop Pod systems allowed the author to present their research at Hexagon's Technologies In Action Conference, HxGN | LIVE in Las Vegas, Nevada, USA and at the International Conference on Aerospace System Science and Engineering (ICASSE) 2019 in Toronto, Ontario, Canada were the papers were also accepted for publication [2] and [3]. 


\section{HYPERLOOP}

\subsection{The Hyperloop Concept}

Currently, the four modes of transportation can be classified into the following categories: Road, Rail, Water, and Air. These modes of transportation tend to be slow, expensive, or a combination thereof. The Hyperloop is the next mode of transportation that aims to shift this notion by being fast and inexpensive after being commercialized.

Ever since the release of the Hyperloop Alpha document, great strides have been undertaken within the Hyperloop sphere [1]. This has been made possible by the research and developmental efforts being carried out by universities, and the industry. The newest mode of transportation is being developed to be safer, faster, economical, convenient, resilient to weather changes, and sustainable.

Current modes of transportation include - Air, Water, Rail, and Road where each of them are greatly impeded by air or water resistance at sea level. This prevents them from achieving high travel speeds. For example, an aircraft's Steady Level Flight (SLF) is at altitudes greater than $9,144 \mathrm{~m}(30,000 \mathrm{ft})$, resulting in a considerably lower aerodynamic drag. With aerodynamic or hydrodynamic drag increasing with the square of speed, a significantly large power input is required to go faster. This can be seen as power requirements need to be met with the cube of speed. The Hyperloop concept aims to circumvent this issue by placing a vehicle, in this case a Pod within a low pressure environment. This coupled with the implementation of contactless propulsion systems will aid in high speed travel that would otherwise have been extremely difficult to achieve at the ground level.

Furthermore, Elon Musk proposed that Hyperloop Pods could utilize air bearings or magnetic levitation for support, and could either be propelled via traditional motor and wheeled systems or via magnetic linear motors. Initial studies by SpaceX on the Hyperloop system extensively studied the route between its headquarters in Hawthorne (Los Angeles), California to San Francisco, California. From their research, a one-way trip should approximately take 35 minutes with a Pod departing each station every two minutes on average [1]. 


\subsubsection{The Toronto-Montreal Corridor}

After a global proposal to narrow down possible cities where the Hyperloop could be implemented, the Toronto-Montreal corridor was chosen to be one of the top contenders for the implementation of the fifth mode of transportation [4]. According to research, connecting these two Canadian cities together would create a supercluster of cities providing businesses with easy access to approximately 4.437 million Canadian for trade purposes as shown below [5].

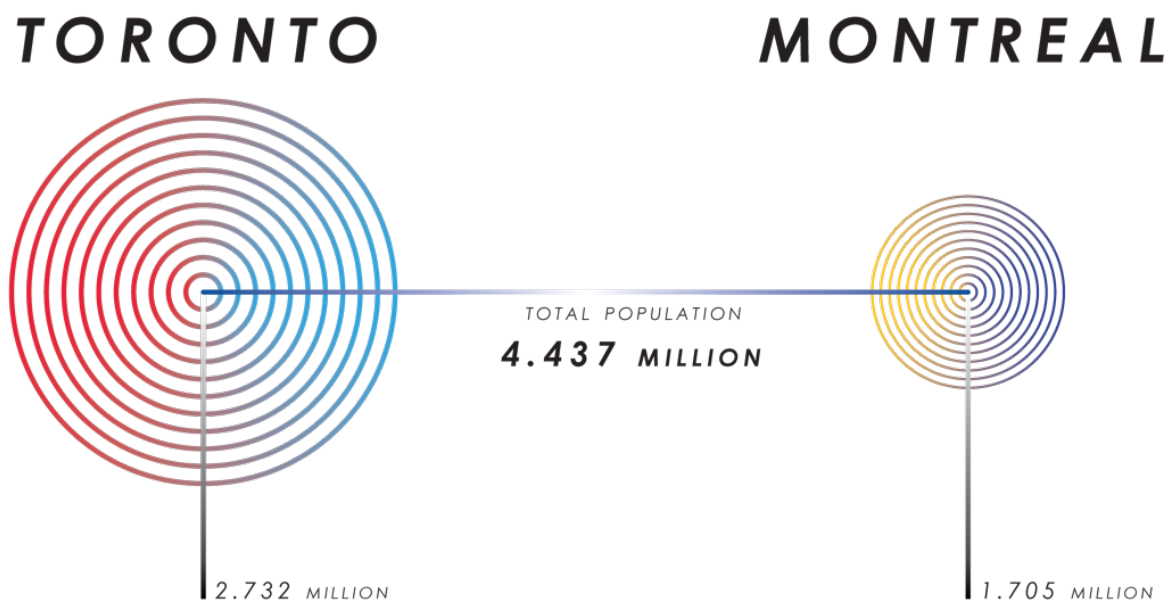

Figure 1. Toronto-Montreal population estimates [5].

Once the system is implemented, passengers on the Hyperloop can expect to travel between Toronto-Montreal in 35 minutes, leading to a dramatic reduction in commute times compared to the other modes of transportation as illustrated in Figure 2 [6].

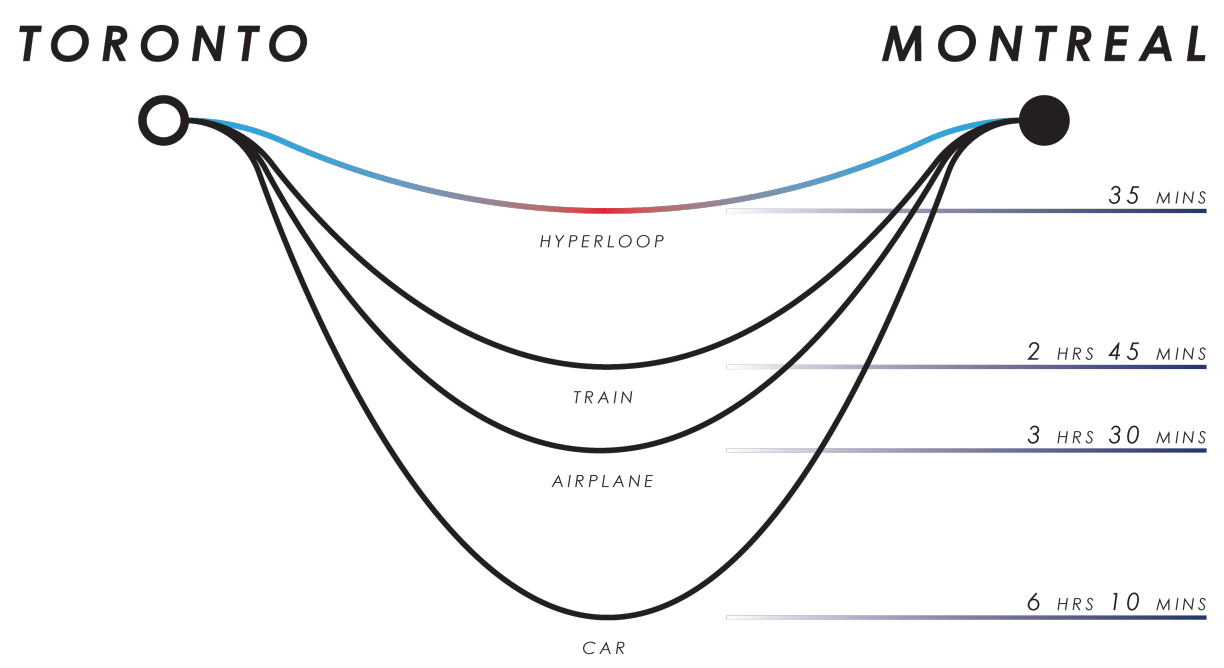

Figure 2. Commute times for the Toronto-Montreal corridor [6]. 
Figure 3 shows the energy consumption for a journey of about $600 \mathrm{~km}$ (373 miles) for the different modes of transportation such as Toronto-Montreal or Los Angeles-San Francisco. Furthermore, the energy costs of implementing either a passenger + cargo Hyperloop Pod or a passenger only Hyperloop Pod were significantly lower than the other modes of transportation in existence as shown in Figure 3 [1] and [7].

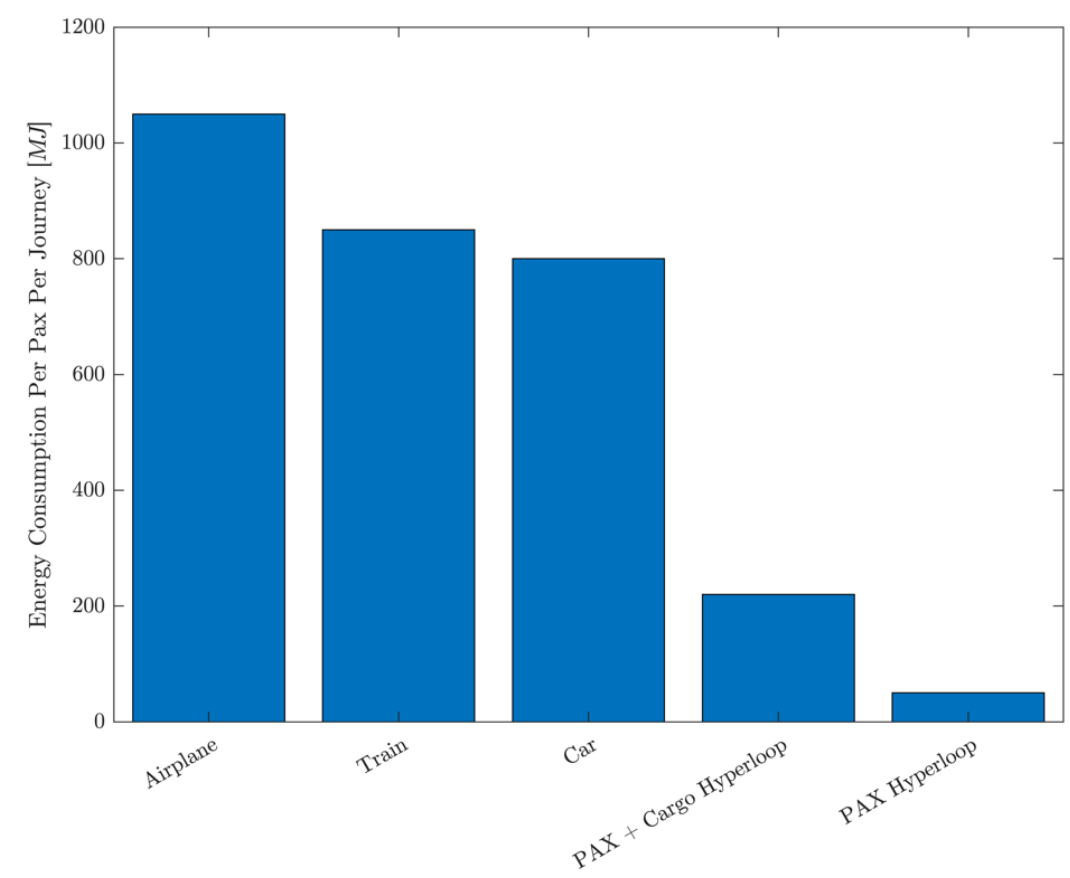

Figure 3. Energy consumption per passenger for various modes of transportation [1]. 


\subsection{The Hyperloop Pod}

Pods are currently being designed by the industry to accommodate between 28 to 40 people or a similar load in cargo [8]. With a Pod departing from its station every two minutes, commercial Pods are being designed to withstand cyclic and fatigue loads due to the continuous depressurization and pressurization of the environment within.

\subsubsection{Hyperloop Pod Sub-Systems}

Development of the passenger Hyperloop Pods has been attempted by various companies, and each has their own take on its design. A general Pod architecture as envisioned by Elon Musk within the White Paper has been illustrated in Figure 4.

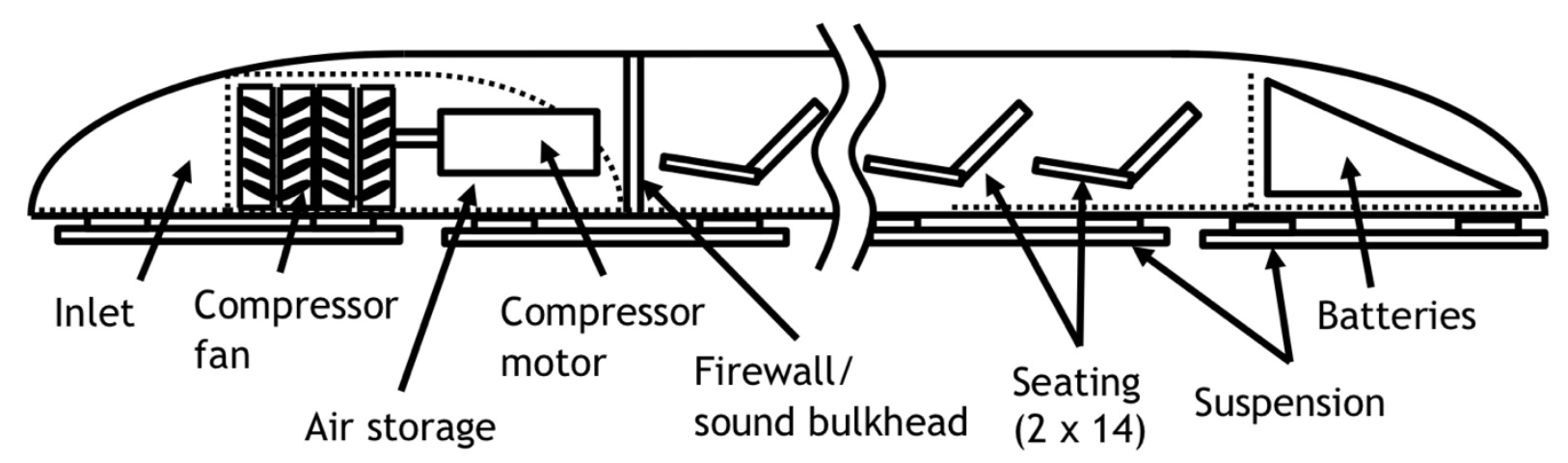

Figure 4. Concept architecture of a Hyperloop Pod as illustrated in the White Paper.

As illustrated above, the initial concept of the Hyperloop Pod included the following systems (from left-to-right):

1. Propulsion System: In order to be driven at the proposed speeds, the Pod requires the implementation of advanced linear motors. The moving element, also known as the rotor, will be located on the Pod itself. On the other hand, the stator or the stationary portion of the linear motor will be located on the tube. The implementation of such a system would allow for the Pod to accelerate up to 1,220 $\mathrm{kmph}$ or $760 \mathrm{mph}$ [1]. In order to ensure the comfort of the passengers at all times, acceleration and braking is expected to be kept below $1 \mathrm{~g}$ during nominal operations. 


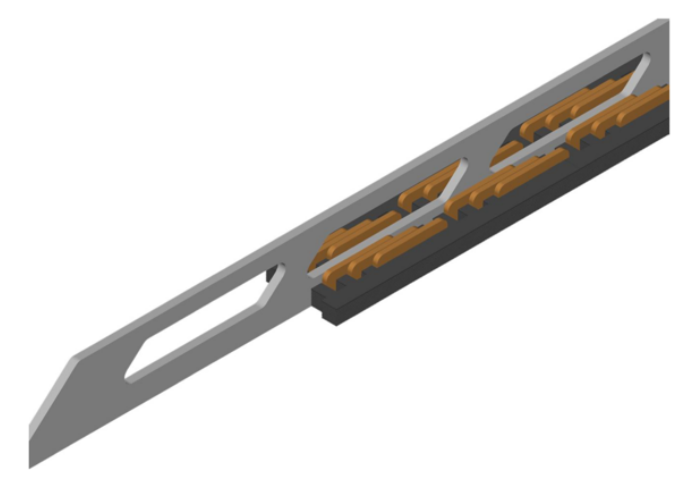

Figure 5. The Hyperloop's propulsion system showcasing the rotor and stator [1].

2. Compressor System: Initial designs included an onboard compressor for two reasons. It allowed for the Pod to travel with minimal gap between the tube and itself without the choking the flow around it. Current designs utilize a perforated leading edge of the Pod to channel the surrounding air around it. Additionally, if air bearings were being implemented to levitate the Pod, it served as inlet.

3. Passenger Support System: As the Hyperloop operates within a low pressure environment, a passenger support system is required onboard the Pod to circulate pressurized air. This support system needs to circulate, collect, filter, and recirculate clean air back into the cabin. This needs to be done all the while regulating and maintaining the Pod at a comfortable temperature.

4. Suspension System: In order to levitate or suspend a Pod at a predetermined height, various methods had been proposed. The three key methods include: traditional wheel and axle system, air bearings, and magnetic levitation system. For high speed travel, conventional wheel and axle systems tend to become impractical due to stability problems and frictional issues. On the other hand, air bearings or magnetic levitation tend to be more viable in this circumstance due to its extremely low drag stability advantages.

5. Power System: With the Hyperloop Pod not being powered by a ground power during its run, onboard batteries are required to keep its systems operational. This includes powering the passenger support systems, propulsion, telemetry, braking, and any other auxiliary systems. 
6. Braking System: The implementation of permanent magnets as the primary braking system is being thoroughly researched. Such a system would tremendously reduce wear-and-tear as no contacting parts are being used. For the purpose of redundancy, traditional contact braking methods need to also be implemented in the event additional braking force is required. 


\subsection{The Hyperloop Tube}

The Hyperloop concept utilizes a low pressure environment where the system is proposed to be a closed loop connecting two cities together. The drawing of a hard vacuum has been avoided due to the difficulties that would potentially arise in maintaining them. In addition, operating in a low pressure environment would allow for the implementation of Commercial-Off-The-Shelf (COTS) pumping systems. With the development of a few large scale Hyperloop tubes across the globe, research indicated that the dimensions of the tube are predominantly based on the route they will be covering. As a result, a prespecified final size for the Hyperloop tube has not been put out [9].

\subsubsection{The SpaceX Hyperloop Tube}

To accelerate the development of the Hyperloop concept, SpaceX independently developed the design and built a kilometer long Hyperloop test track located outside their HQ in Hawthorne, California.

The Hyperloop tube has been manufactured from steel due to its availability, low cost, strength, and weldability. The tube contains an Aluminum (Al) test track, and a sub-track that is mounted to a concrete base.

Table 1. SpaceX Hyperloop tube material specifications.

\begin{tabular}{lr}
\hline Hyperloop Tube Parameters & \multicolumn{1}{c}{ Value } \\
\hline Hyperloop Tube & ASTM A1018 Grade 36 \\
Test Track & Aluminum 6061-T6 \\
Sub-Track & Aluminum 6101-T61 \\
Mounting Base & Concrete \\
\hline
\end{tabular}

As per SpaceX's design, their Hyperloop Tube is said to be approximately a halfscale version of the full-scale production concept [10]. As a result, Ryerson's first Hyperloop Pod had been designed to meet the dimensional requirements of SpaceX's Hyperloop tube. Some of the key dimensions that were adhered during the entire design process have been outlined in Table 2 . 
Table 2. SpaceX Hyperloop tube major dimensional specifications.

\begin{tabular}{lr}
\hline Hyperloop Tube Parameters & Value \\
\hline Tube Length & $4150 \mathrm{ft}(1.25 \mathrm{~km})$ \\
Outer Diameter & $72 \mathrm{in}$ \\
Inner Diameter & $70.6 \mathrm{in}$ \\
Radius of Curvature & $>15$ miles $(24 \mathrm{~km})$ \\
\hline
\end{tabular}




\subsection{The SpaceX Hyperloop Operating Environment}

\subsubsection{Low Pressure Environment}

When operating within the Hyperloop environment, the Pods are subjected to a cyclic pressure loading due to the continuous depressurization and pressurization. This results in the structure experiencing fatigue stresses. The SpaceX Hyperloop operates at a minimum ambient pressure of $0.125 \mathrm{psi}$ [10]. This is done to support the various propulsion systems that were developed.

Table 3. SpaceX Hyperloop operating pressures.

\begin{tabular}{lr}
\hline Hyperloop Tube Parameters & \multicolumn{1}{c}{ Value } \\
\hline Number of Vacuum Pumps & 4 \\
Minimum Operating Pressure & $0.125 \mathrm{psi}(862 \mathrm{~Pa})$ \\
Maximum Operating Pressure & $14.7 \mathrm{psi}(0.102 \mathrm{MPa})$ \\
Pump Down Period & 45 minutes \\
Pump Up Period & 25 minutes \\
\hline
\end{tabular}

With the test track being located in Hawthorne, California, the operating pressure within the tube is highly dependent on the season, weather conditions, and time of day. With four vacuum pumps, the pump down time was approximately 45 minutes to reach an operating pressure $862 \mathrm{~Pa}$, while the pump up period took around 25 minutes.

\subsubsection{Tube Thermal Management}

The SpaceX Hyperloop Tube does not contain any thermal management control system. As a result, the tube's internal temperature is solely dictated by the season, weather conditions, and the time of day the test was scheduled for. Majority of the testing occurred during the weeks of July and the corresponding METAR data for the SpaceX facility has been tabulated in Table 4 [11]. 
Table 4. Temperature range for SpaceX during the testing period.

\begin{tabular}{lr}
\hline \multicolumn{1}{c}{ Parameter } & \multicolumn{1}{c}{ Value } \\
\hline General Testing Period & $10^{\text {th }}-21^{\text {st }}$ July \\
Maximum Temperature (High) & $23^{\circ} \mathrm{C}$ \\
Maximum Temperature (Average) & $21^{\circ} \mathrm{C}$ \\
Maximum Temperature (Low) & $18^{\circ} \mathrm{C}$ \\
Minimum Temperature (High) & $22^{\circ} \mathrm{C}$ \\
Minimum Temperature (Average) & $20^{\circ} \mathrm{C}$ \\
Minimum Temperature (Low) & $17^{\circ} \mathrm{C}$ \\
\hline
\end{tabular}

Since the tube temperature ranged from $35^{\circ} \mathrm{C}$ to $45^{\circ} \mathrm{C}$, Pod designs needed to account for degradation in the cooling by convection resulting from the low pressure environment. The loss in heat dissipation coupled with the frequency of Pod deployment in the full-scale version could result in thermal hotspots that needed to be accounted for in the Pod's thermal management system. 


\section{SpaceX HYPERLOOP POD COMPETITION}

In order to accelerate the development of the Hyperloop concept, SpaceX announced a Hyperloop Pod Competition utilizing their newly built mile long test track outside their HQ in Hawthorne, California. This was done to encourage innovation, research and development, and testing of the concept by student teams from across the United States and the globe.

Following the release of the White Paper in 2013, SpaceX announced the very first Hyperloop Competition in 2015 to accelerate the development of the Hyperloop concept. Universities from all across the world were tasked to design high speed Pods and to present it in January 2016. Top teams from all entries were selected to advance and build their prototypes.

Teams who were successful in manufacturing a prototype Pod were allowed to compete at the first ever Hyperloop Pod Competition 2017 where they raced their Pods on SpaceX's Hyperloop test track. After receiving a number of high quality submissions, the organizers subsequently held four more Hyperloop Pod Competitions.

\subsection{Hyperloop Pod Competition}

As with the previous iterations of the competition, the 2019 Hyperloop Pod Competition was judged solely on the Pod's top speed [1]. In addition to speed as a criterion, the designed Pod was required to propel or crawl itself to within $30 \mathrm{~m}$ of the exit airlock doors of the Hyperloop tube. During the entire 2019 Competition, Ryerson achieved the following.

- Being from the top $10 \%$ out of the 1,500 entries after being selected to proceed to the second round of the Hyperloop Pod Competition.

- Successfully passed the second round and got approved to proceed to the third round.

- Being from the top $8 \%$ after being selected for various technical interviews by the competition organizers.

- Received special invitations from SpaceX to attend both the 2018 and the 2019 Hyperloop Pod Competition in Hawthorne, California. 


\subsubsection{Technical Documentation}

After completion of all necessary legal and governance documentation, the team submitted a comprehensive design proposal to the competition officials. This document provided the judges with an overview of design and a means to perform a sanity check. This ensured the team was proceeding in the correct direction. In order to manage the number of teams, the organizers had the ability to down select teams at this stage.

After all the necessary approvals were received, a technical document was completed for the judges highlighting the design, analysis, and manufacturing plans for the Hyperloop Pod. Teams that fulfilled all the integral prerequisites set by the organizers were approved to proceed to the technical presentations portion of the competition.

\subsubsection{Technical Presentation}

Based on all the deliverables received by the competition judges, select teams were asked to present their designs via video conferencing technology to a judging panel consisting of engineers, technicians, safety officers, business personnel from SpaceX, The Boring Company, Tesla, and so forth. This format allowed the organizers and judges to better understand the Pod and provided the panel an opportunity to gain clarity (on technical issues). Furthermore, the team received valuable feedback on the designed Pod.

\subsection{Hyperloop Pod Competition}

The 2020 Hyperloop Pod Competition is planned to run within a $10 \mathrm{~km}$ Hyperloop tube rather than the kilometer long test track currently being used in Hawthorne, California. To help advance this emerging technology even further, the new track is no longer expected to be linear. It is proposed to have a curve of an unknown radius. Furthermore, this new track is proposed to have the same level of vacuum combability as the shorter Hyperloop tube [12]. 


\section{RYERSON'S HYPERLOOP POD ARCHITECTURE}

\subsection{Pod Overview}

Ryerson's Hyperloop Pod consisted of three major systems - Structures (STR), Guidance, Navigation \& Control (GNC), and Propulsion (PRP). Figure 6 illustrated the breakdown of the aforementioned systems into their characteristic sub-systems.

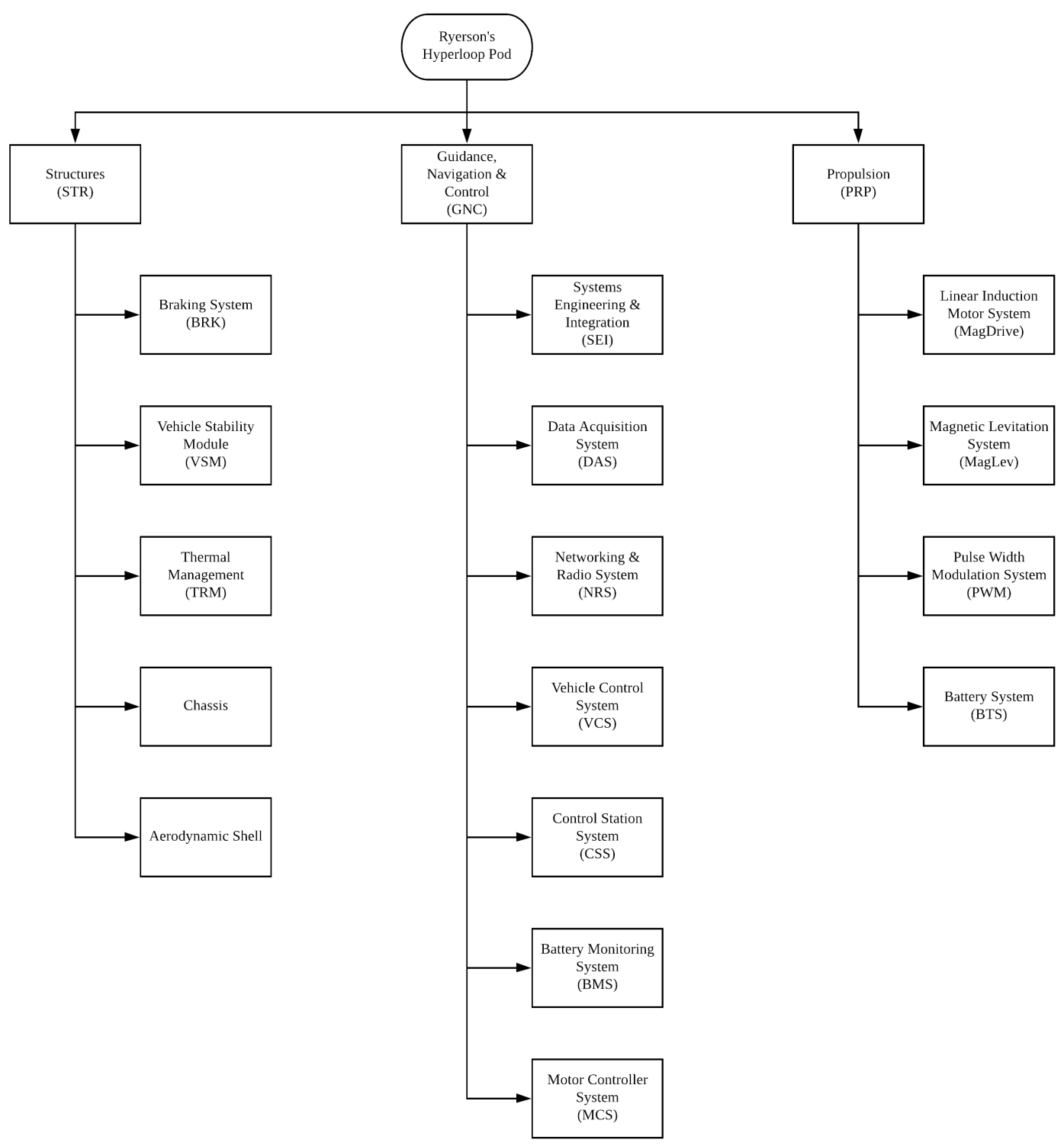

Figure 6. Ryerson International Hyperloop's pod architecture. 


\subsubsection{Pod Design}

Figure 7 and Figure 8 showcase the isometric view of Ryerson's Hyperloop Pod consisting of all its systems. The Pod designed for the Hyperloop Pod Competition measures in at $2.3 \mathrm{~m}$ in length, $0.5 \mathrm{~m}$ in width, $0.3 \mathrm{~m}$ in height, and a loaded weight of $140 \mathrm{~kg}$. The Pod's aforementioned systems have been shown and labelled in Figure 9, while its major specifications have been tabulated in Table 5.

Table 5. Ryerson's Hyperloop Pod specifications.

\begin{tabular}{lr}
\hline \multicolumn{1}{c}{ Overall Pod Parameters } & Value \\
\hline Pod Length & $2.3 \mathrm{~m}$ \\
Width & $0.5 \mathrm{~m}$ \\
Height & $0.3 \mathrm{~m}$ \\
Structures Weight & $29 \mathrm{~kg}$ \\
Propulsion Weight & $73 \mathrm{~kg}$ \\
Guidance, Navigation and Control Weight & $15 \mathrm{~kg}$ \\
Pod Weight (With Safety Margin) & $140 \mathrm{~kg}$ \\
\hline
\end{tabular}

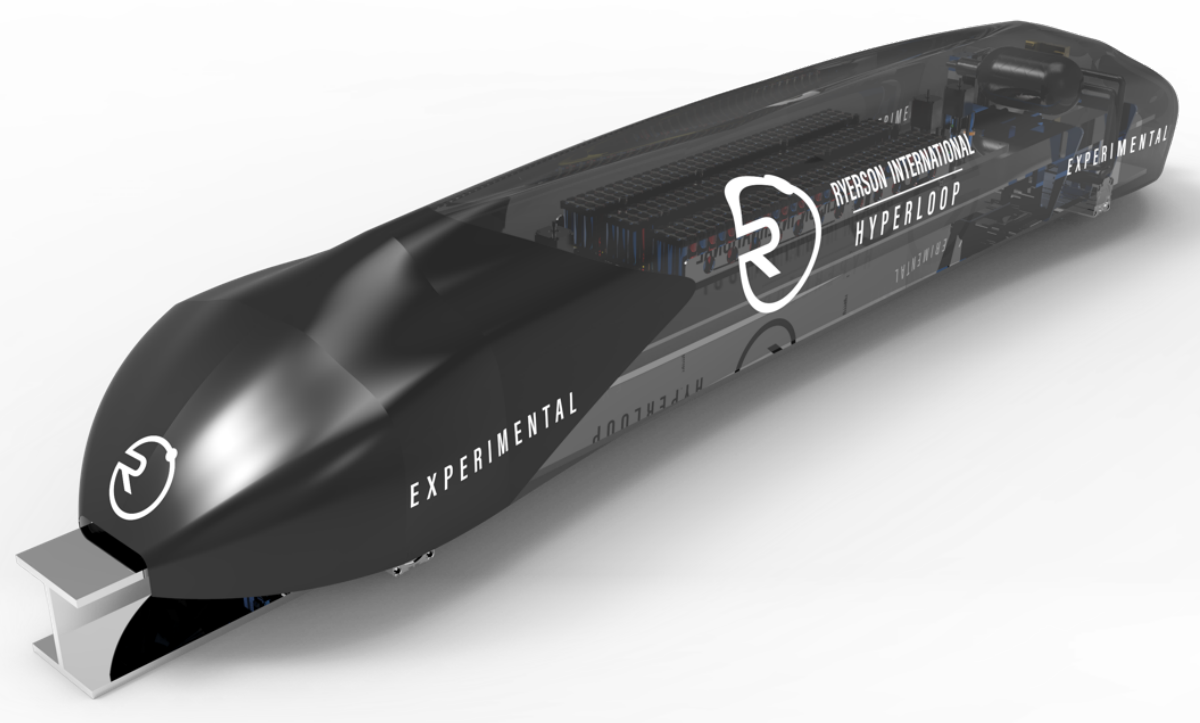

Figure 7. Ryerson's Hyperloop Pod design with an aerodynamic shell. 


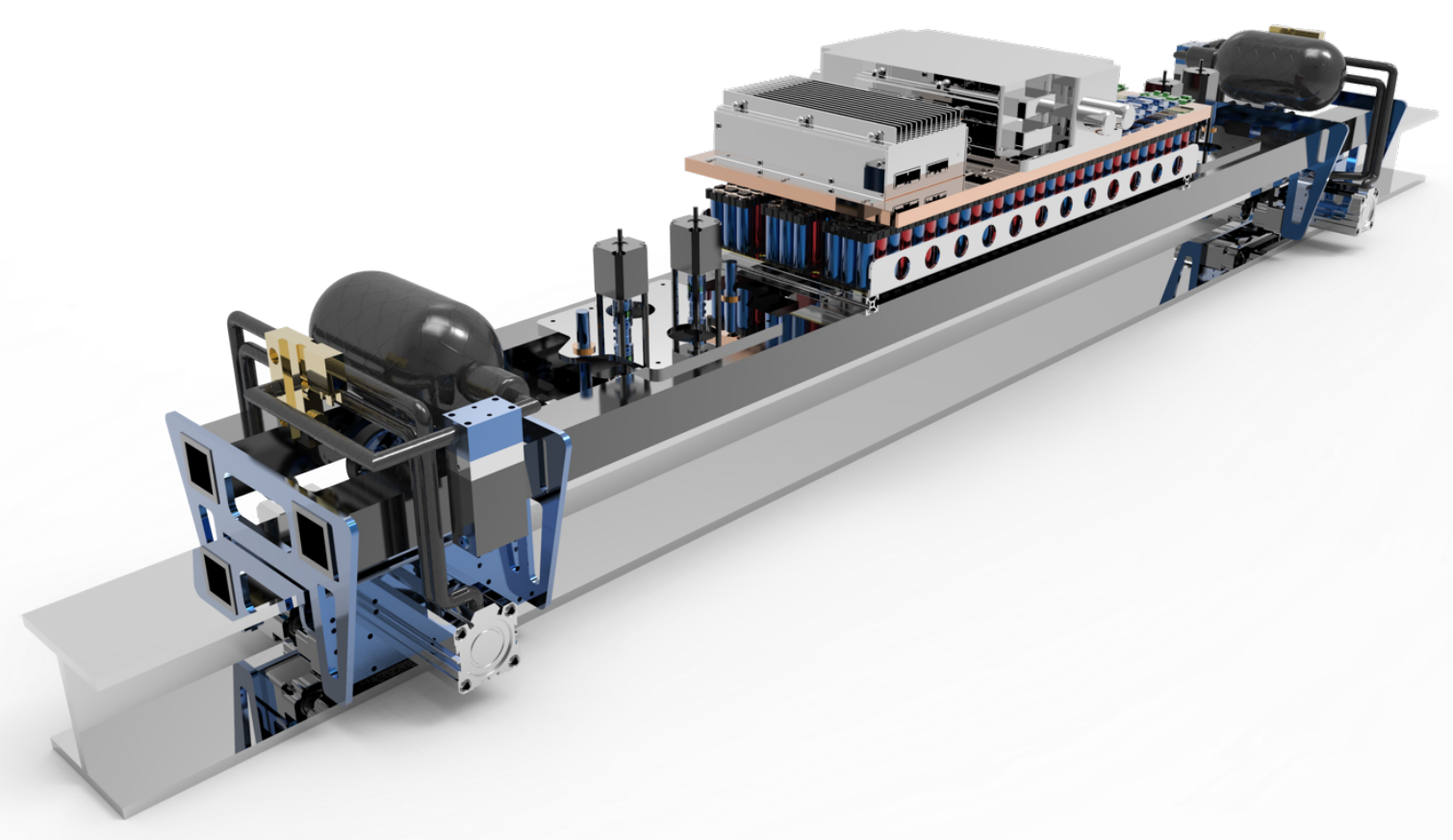

Figure 8. Ryerson's Hyperloop Pod design showcasing its internal systems.

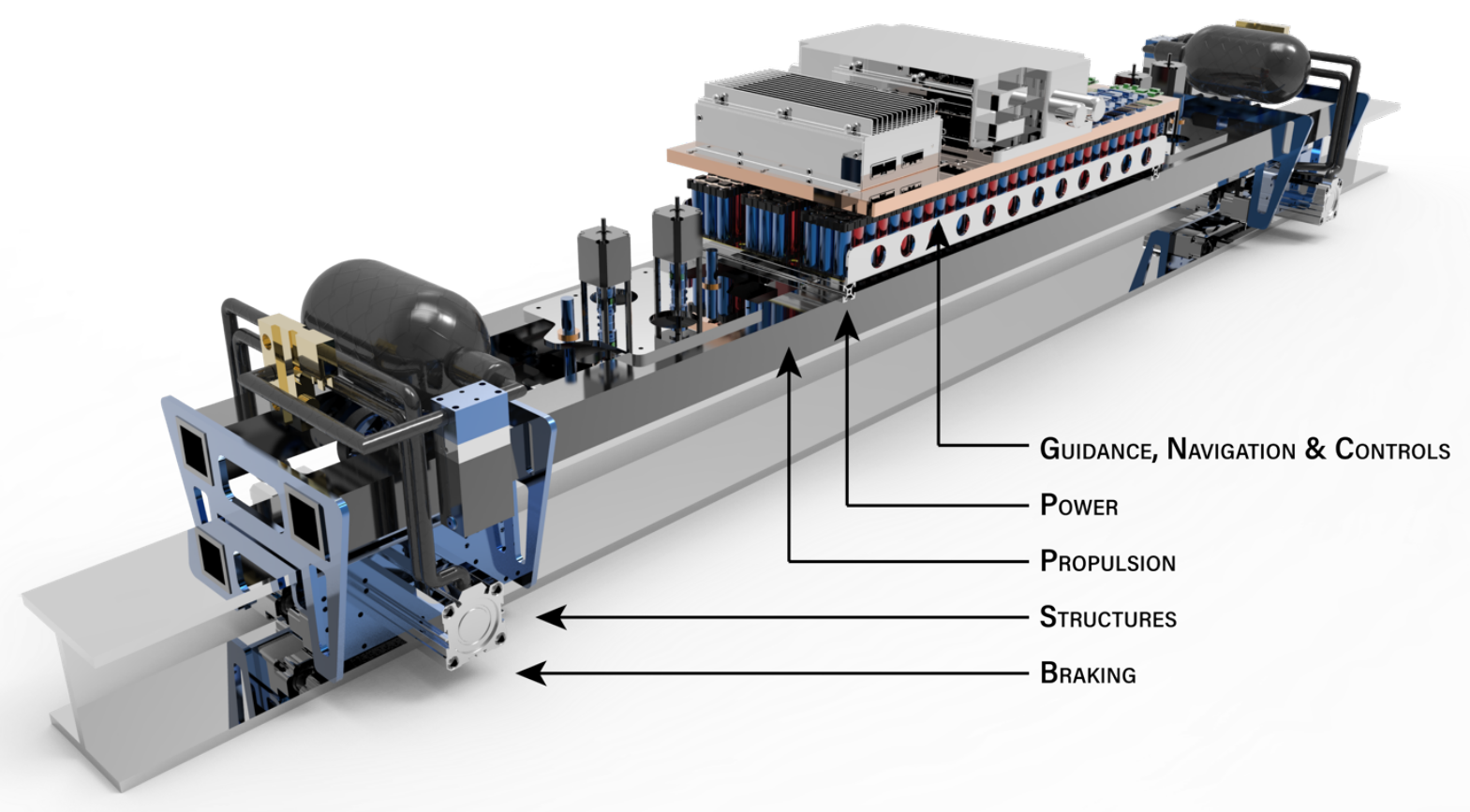

Figure 9. Ryerson's Hyperloop Pod with its internal systems labelled. 


\subsubsection{Structures Overview}

The Hyperloop Pod included two independent pneumatic braking systems that consist of two independent pairs of braking pistons as shown in Table 6 . The systems have been arranged in a forward, and aft configuration of the Hyperloop Pod. Both systems have their own pneumatic tank, control systems, control valves, and pneumatic tubing. This was done to prevent a cascading failure in the event a system failure was to occur.

Table 6. Pod's braking system overview.

\begin{tabular}{lr}
\hline \multicolumn{1}{c}{ Braking System Parameters } & Value \\
\hline Number of Independent Systems & 2 \\
Number of Pistons & 4 \\
System Weight & $14 \mathrm{~kg}$ \\
Nominal Braking Force & $900 \mathrm{~N}$ \\
Maximum Braking Force & $1800 \mathrm{~N}$ \\
\hline
\end{tabular}

When designing the chassis of the Pod, critical cases needed to be examined. These were the acceleration, levitation, and braking phases. System weights along with the phase particular loads were accounted for. In such load cases as the Center of Gravity (CG) position changed, it was also needed to be accounted for in the design.

The Pod's chassis consists of a forward and an aft bulkhead connected together by two longitudinal Aluminum extrusions referred to as Longitudinal Chassis Members (LCM). Aluminum extrusions were chosen for modularity and to aid the placement of all the Pod systems on it.

Although an aerodynamic shell was unnecessary due to the Pod operating in a low pressure environment, as per the competition requirements, completing a run with a shell simply added to the Pod's overall aesthetic and mass resulting in a lower top speed. Even though runs can be completed without a shell, one was still designed in order to place all the sponsor logos on the Pod. 


\subsubsection{Guidance, Navigation \& Control Overview}

As the Pod powers up, it automatically defaults to a "Safe To Approach" state. This is done only when the Pod is stationary, in good working condition without any major faults, and is safe for humans to approach it. Upon the completion of the necessary checks within the tube, the Pod will then have the potential of entering into the remaining states as shown in Table 7.

Table 7. A few of the Pod states controlled by GNC.

\begin{tabular}{ll}
\hline \multicolumn{1}{c}{ Pod State } & \multicolumn{1}{c}{ Description } \\
\hline Safe To Approach & Indicates that the Pod is stationary, in good working \\
& condition without any major faults, and is safe for humans \\
& to approach it. \\
& Performs final checks, and readies key systems for launch. \\
Ready To Launch & A non-nominal, unknow or unsafe event or a parameter \\
Fault & falls outside is envelope is detected, and Pod \\
& automatically comes to a stop. \\
\hline
\end{tabular}

In addition to performing all of the state transitions, GNC receives data from the Pod including its location within the tube, velocity data, acceleration data, temperatures and pressure, Pod health, and so on. This vital telemetry data is transmitted in real time to the mission control (ground station) for Pod status and analysis.

Although control decisions are taken autonomously onboard the Pod, the Pod has been designed in such a way that all the commands to initiate movement (from standstill) were required to be sent from the mission control. This built-in safety feature ensured that the Pod would consistently obey the incoming commands from the ground station. If for some reason the signal was lost, the Pod automatically defaults to the fault state and comes to a safe halt. 


\subsubsection{Prolusion Overview}

For propulsion, the Pod is propelled and levitated by a true contactless system as envisioned by Musk [1]. Propulsion is achieved by the MagDrive along the track through the means of electromagnetic induction via a Linear Induction Motor (LIM). The motor utilized an alternating current that is passed through its coils wound around a stator. By doing so, it created a changing magnetic field which in turn produced a force that propels the Pod forward.

In order to achieve the highest possible thrust, i.e. velocity, a three LIM propulsion system was initially designed. However, after further analysis, it was found that this sort of configuration would have diminishing returns. By performing a Return On Investment (ROI) analysis, the overall weight increase incurred as a result of the Pod being heavier would reduce the overall effectiveness of the levitation system. As a result, a single LIM configuration was opted for.

Magnetic levitation system was used to support the Pod at a predetermined height. The system consists of permanent N42 Neodymium magnets configured in a Halbach array to create a repulsive magnetic field to suspend the Pod. This resulted in a drag reduction when compared to wheeled systems at high speeds. 


\subsection{Pod Structures}

The breakdown of the Hyperloop Structures system has been illustrated in Figure 10, where the design of the Pod's chassis, and braking system were considered the topmost priority. This design approach allowed for the development of the overall Pod chassis required to mount all the other Pod systems to it.

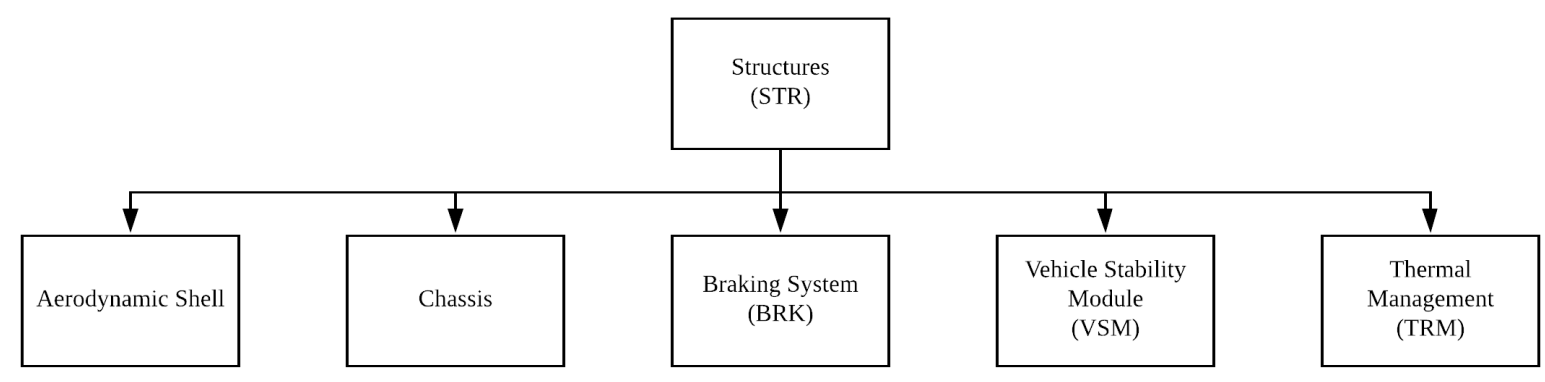

Figure 10. Pod structures breakdown.

Two major components for the Pod structure included the design, and development of the bulkheads, and the Longitudinal Chassis Members (LCM). The two aforementioned components form the Pod's chassis where a forward, and aft bulkheads are connected together via two LCMs. When designing these components, the principal design loads that were considered were the weight of the PRP system, GNC, and BRK systems.

\subsubsection{Pod Longitudinal Chassis Members (LCM)}

One of the design objectives was to ensure all the aforementioned systems had a mounting location on the LCM, while maintaining structural rigidity. Analysis conducted on the propulsion system required the optimal gap height between the LIM, and the track to be at $2 \mathrm{~mm}$. With the LCM holding the LIM in place, a design constraint allowed for a maximum deflection of the LCM to be lower than $1 \mathrm{~mm}$. 
Table 8. Potential cross-sectional areas for the LCM.

\begin{tabular}{lr}
\hline LCM & Cross-Section \\
\hline Design 1 & Circular \\
Design 2 & Tubular \\
Design 3 & Square Tubing \\
Design 4 & Hexagonal \\
Design 5 & Extrusion \\
Design 6 & Channels \\
Design 7 & L slots \\
\hline
\end{tabular}

Table 9 highlights the various criteria that were selected when designing the LCM after their individualistic priorities were established. Meanwhile, Table 8 showcases the different cross-sectional areas that were considered during its design [13].

Table 9. Important criteria for the design of the LCM.

\begin{tabular}{l|cccc}
\hline \multirow{2}{*}{ Ease of Use } & Ease of Use & Surface Area & Manufacturability & Cost \\
\cline { 2 - 5 } Surface Area & $\mathrm{N} / \mathrm{A}$ & 0 & 1 & 1 \\
Manufacturability & 1 & $\mathrm{~N} / \mathrm{A}$ & 1 & 1 \\
Cost & 0 & 0 & $\mathrm{~N} / \mathrm{A}$ & 0 \\
\hline
\end{tabular}

One of the scenarios that was analyzed is if the MagLev system does not perform as intended. If such a failure were to occur, it would result in the total Pod mass to be rested on the LCMs, and the bulkheads. The worst case scenario would occur if the rear braking system were to become inoperative. During such an event, the Pod's braking force would cause the front end to lock up while the aft portion to continue to move forward leading to the buckling of the LCMs. As a result, the Pod needed to fulfill any and all safety requirements during all its phases. And to do so, the various load cases that were analyzed have been tabulated below.

Table 10. LCM loading scenarios based on Pod state.

\begin{tabular}{lr}
\hline \multicolumn{1}{c}{ Case } & Pod State \\
\hline Loading Case I & Pod Staging \\
Loading Case II & Launch Phase \\
Loading Case III & Levitation Phase \\
Loading Case IV & Braking Phase \\
\hline
\end{tabular}




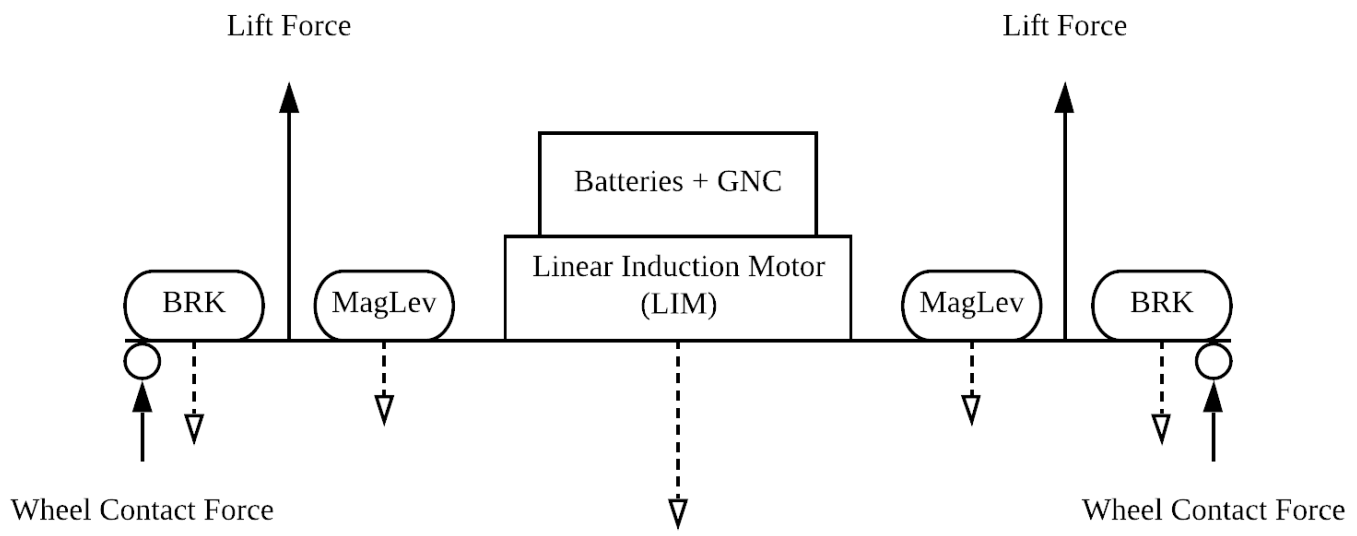

Figure 11. Pod staging load case for the LCM.

Figure 11 illustrates the schematic of the loading of the LCM as the Pod is lifted to be placed on the Hyperloop staging area. The dotted lines represent the weight of the respective systems on the LCM, while the solid lines represent a force being applied to the system. In this case, a contact force is applied by the stability modules, and the lift force that occurs when the Pod is lifted.

LIM Force

(Thrust Force)

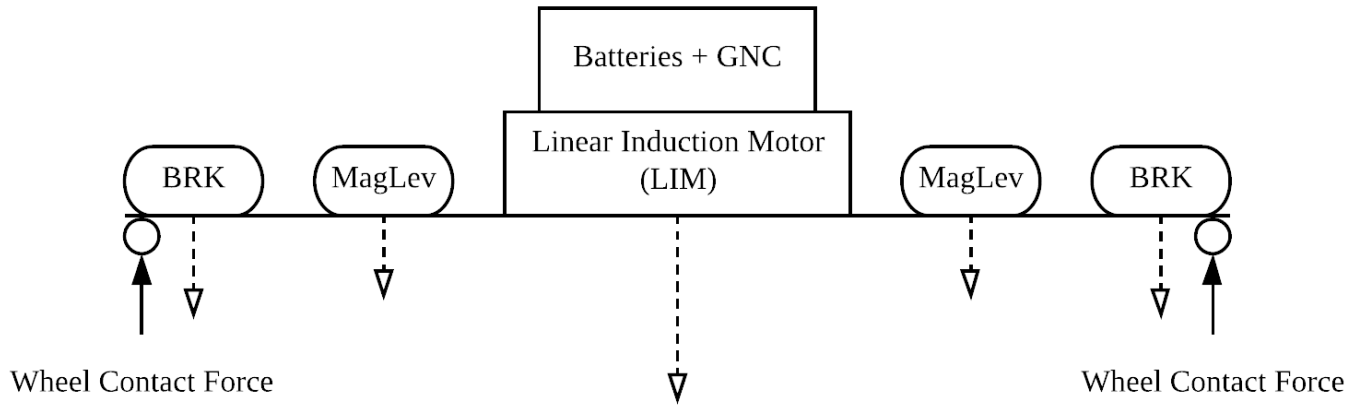

Figure 12. Pod launching load case for the LCM.

As the Pod enters the launch phase and begins its run, it generates thrust via the LIM. In addition to the system weights acting on the structure, the stability module (wheel contact force) would still be in contact with the test track as the Pod would not have gained sufficient speed for the MagLev system to levitate the Pod at this point. 


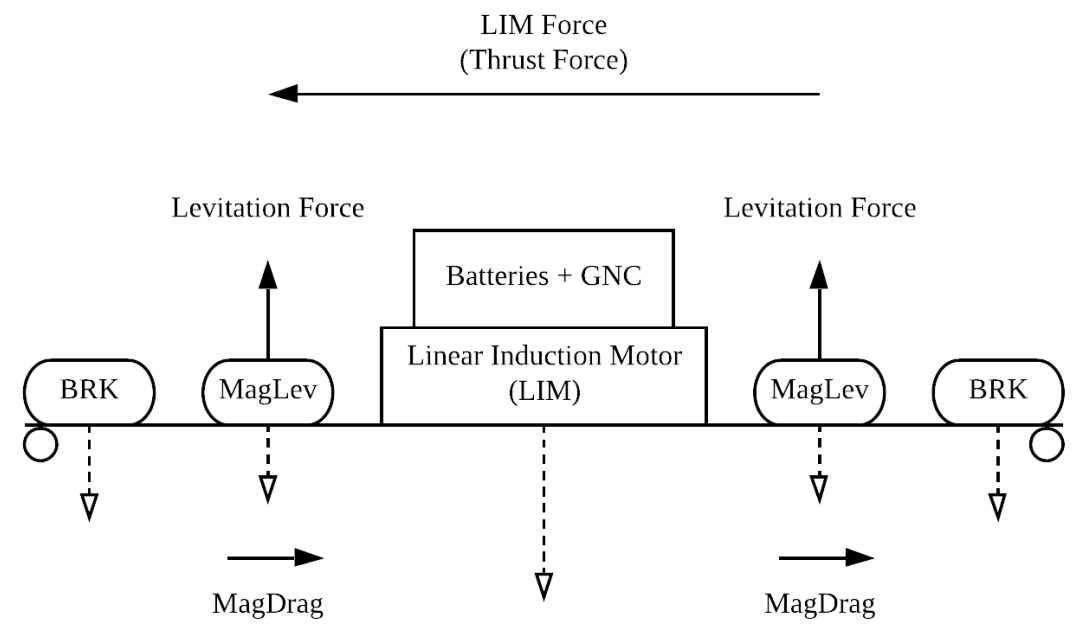

Figure 13. Pod levitation loading scenario for the LCM.

The above schematic represented the forces acting on the LCM as the Pod began its run, and levitates. As illustrated, the Pod experiences a thrust force generated by the LIM. In addition, once the MagLev system is deployed, a drag force is generated known as MagDrag.

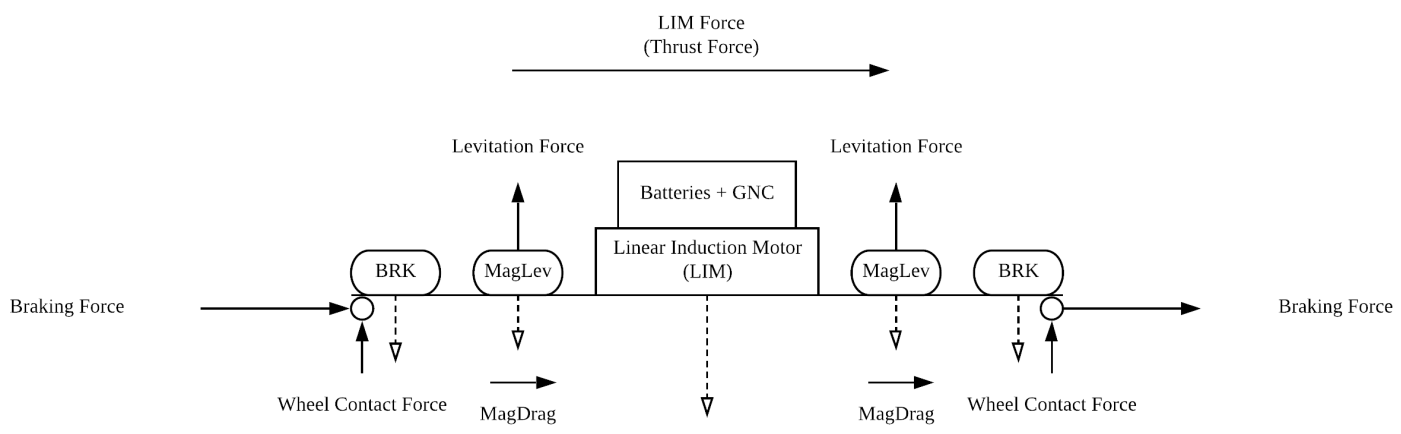

Figure 14. Pod braking loading scenario for the LIM.

As the Pod's braking sequence initiated, the braking force applied slows it down. To improve the Pod's braking profile, reversing the polarity (current) flowing to the LIM will subsequently cause it to generate thrust in the opposite direction to motion as shown in Figure 14. The final bit of braking power can be extracted from the Pod by deploying and bottoming out the MagLev system. In doing so, it will cause the generation of MagDrag, resulting in a much better braking profile. 
Under the aforementioned load cases, the objective was to find a suitable crosssection where the stresses, and deformation were minimized while maintaining a sufficient working area to mount the Pod systems. To do so, the area moment of inertia was maximized for the cross-sections outlined in Table 8, and the following equations were used.

Circular Cross-Section:

$$
I=\frac{\pi}{4} r_{o}^{4}
$$

Tubular Cross-Section:

$$
I=\frac{\pi}{4}\left(r_{o}^{4}-r_{i}^{4}\right)
$$

Square Cross-Section:

$$
I=\frac{a^{4}}{12}
$$

Hexagonal Cross-Section:

$$
I=\frac{5 \sqrt{3}}{16} a^{4}
$$

where for all the cross-sections, the area moment of inertia is denoted by $I$. For the circular, and tubular designs, the $r_{o}$ is its outer radius and $r_{i}$ is the inner radius. Whereas for the square, and hexagonal cross-sections, $a$ represented the length of its side.

The materials for the LCM were proposed to be either manufactured out of carbon fiber composite, steel or aluminum. Steel LCMs were ruled out due to the large weight penalty that would be incurred when used for the structure. On the other hand, the carbon fiber LCMs would provide the necessary strength while being lightweight. However, it was ruled out due the difficulties associated in manufacturing the long LCM pieces while maintaining a high tolerance. In the end, Aluminum 6061-T6 was selected for its optimal balance between its strength, and weight while being a material that is easy to be worked upon. The material specifications for the Aluminum have been tabulated in Table 11 [14], [15], and [16]. 
Table 11. Aluminum 6061-T6 material specification for the LCM.

\begin{tabular}{lr}
\hline \multicolumn{1}{c}{ Parameter } & Value \\
\hline Material & Aluminum \\
Specification & 6061 \\
Hardening & $\mathrm{T6}$ \\
Density & $2700 \mathrm{~kg} / \mathrm{m}^{3}$ \\
Modulus of Elasticity & $68.9 \mathrm{GPa}$ \\
Poissons Ratio & 0.33 \\
Ultimate Tensile Strength & $310 \mathrm{MPa}$ \\
Yield Tensile Strength & $276 \mathrm{MPa}$ \\
\hline
\end{tabular}

With the material specifications on hand, the properties for the LCM was calculated. Observing Table 12, a tubular LCM would be of an ideal weight while having a high enough area moment of inertia. However, with a circular and tubular cross-section, mounting other systems on the LCM would be difficult as it does not allow for the presence of a flat mounting surface. On the other hand, a hexagonal LCM would provide sufficient surface area for system mounting at the expense of the added weight.

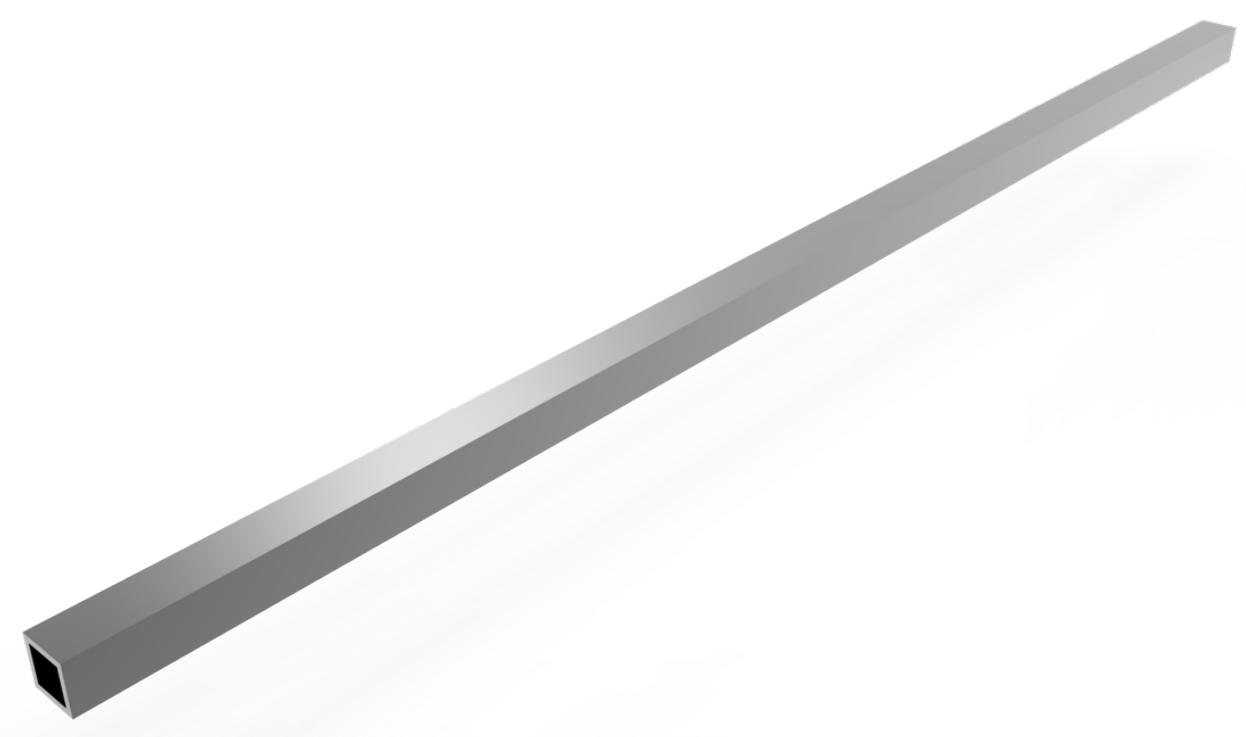

Figure 15. Pod's LCM manufactured using anodized black Aluminum 6061-T6. 
Aluminum extrusions were initially considered to be the best solution due to its high strength, area moment of inertia all the while having a low enough mass as shown in Table 12. In addition, the presence of T-slots would allow for the incorporation of a modular mounting method. During tests, it was found that placing systems on the exact mounting coordinates to be extremely difficult as a result of the slots. And replicating their location after a component swap was almost impossible. As a result, the extrusion was swapped out for traditional square tubing manufactured out of Aluminum 6061-T6 [17].

Table 12. Property calculation of the various LCM designs.

\begin{tabular}{llrr}
\hline \multicolumn{1}{c}{ LCM Design } & Volume & \multicolumn{1}{c}{ Mass } & Area Moment of Inertia \\
\hline Circular & $0.004 \mathrm{~m}^{3}$ & $10.945 \mathrm{~kg}$ & $3.65 \mathrm{kgm}^{2}$ \\
Tubular & $0.002 \mathrm{~m}^{3}$ & $4.788 \mathrm{~kg}$ & $1.597 \mathrm{kgm}^{2}$ \\
Square Tubing & $0.002 \mathrm{~m}^{3}$ & $6.097 \mathrm{~kg}$ & $2.034 \mathrm{kgm}^{2}$ \\
Hexagonal & $0.004 \mathrm{~m}^{3}$ & $11.314 \mathrm{~kg}$ & $3.786 \mathrm{kgm}^{2}$ \\
Extrusion & $0.002 \mathrm{~m}^{3}$ & $4.498 \mathrm{~kg}$ & $1.501 \mathrm{kgm}^{2}$ \\
\hline
\end{tabular}

\subsubsection{LCM Analysis}

To ensure the LCM met the structural requirements, the aforementioned crosssection (square tubing) was analyzed within ANSYS. Furthermore, to successfully design and validate the LCM, the braking phase was considered to be the most load bearing case on the Pod. As a result, its corresponding boundary conditions where the one ends of the LCM become locked up (clamped). This was in addition to the principal system loads occurring on the structure within ANSYS. Figure 16 highlighted the workflow setup for the various Pod loading scenarios within ANSYS Workbench. 


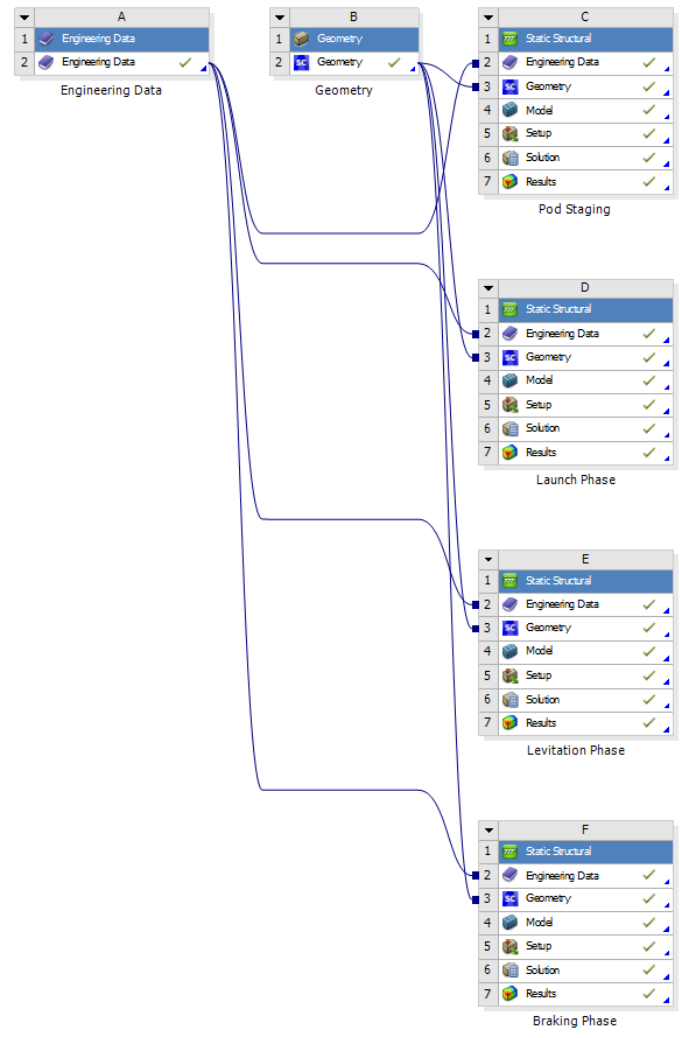

Figure 16. ANSYS workflow setup for the Pod's LCM.

\subsection{Loading Case I (Pod Staging)}

During the staging phase, the Pod is lifted via a forklift from the chassis. This resulted in the Pod to experience a lift force, and a reactionary force from the stability wheels on the LCM. In addition, the analysis accounted for the weights of all the Pod systems as illustrated in Figure 11.

Table 13. LCM loading case for Pod staging.

\begin{tabular}{lr}
\hline \multicolumn{1}{c}{ LCM Loading Parameters } & Value \\
\hline Braking System (Per System) & $74 \mathrm{~N}$ \\
MagLev System (Per System) & $84 \mathrm{~N}$ \\
LIM, Batteries \& GNC Systems & $403 \mathrm{~N}$ \\
Pod Staging Lift Load (Per System) & $687 \mathrm{~N}$ \\
\hline
\end{tabular}

Within the Pod staging load scenario as highlighted in Table 13, a maximum deformation of $0.55 \mathrm{~mm}$ was to be expected at the centroid of the LCM with a maximum stress value of $165.71 \mathrm{MPa}$ as illustrated in Figure 17 and Figure 18 respectively. 


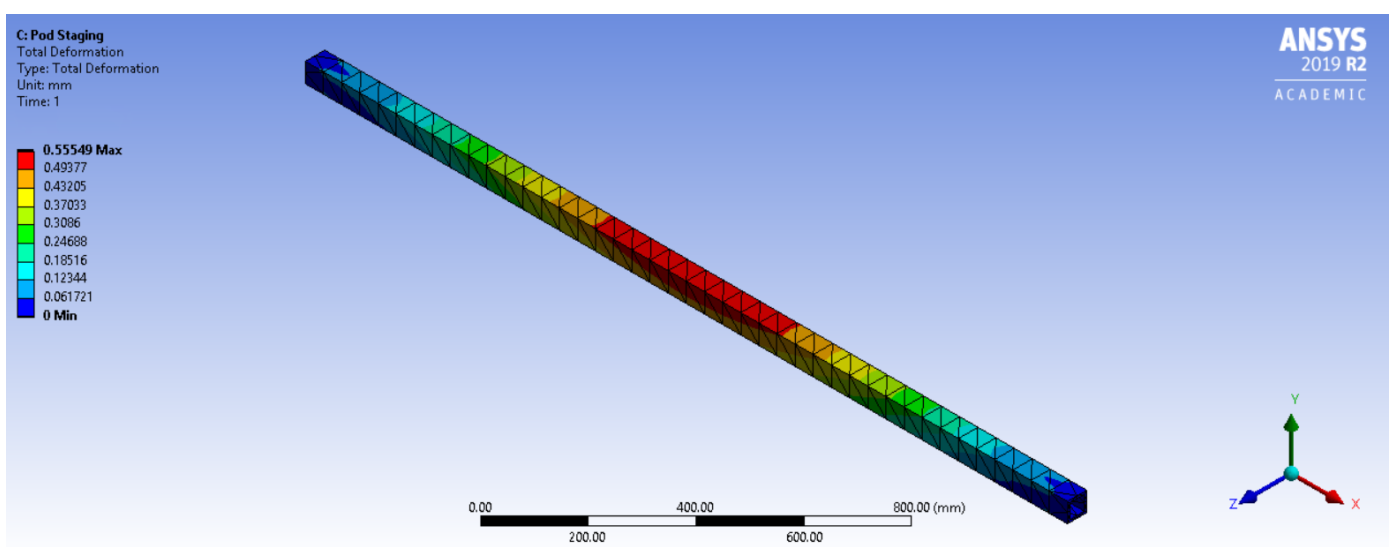

Figure 17. LCM deformation during Pod staging scenario.

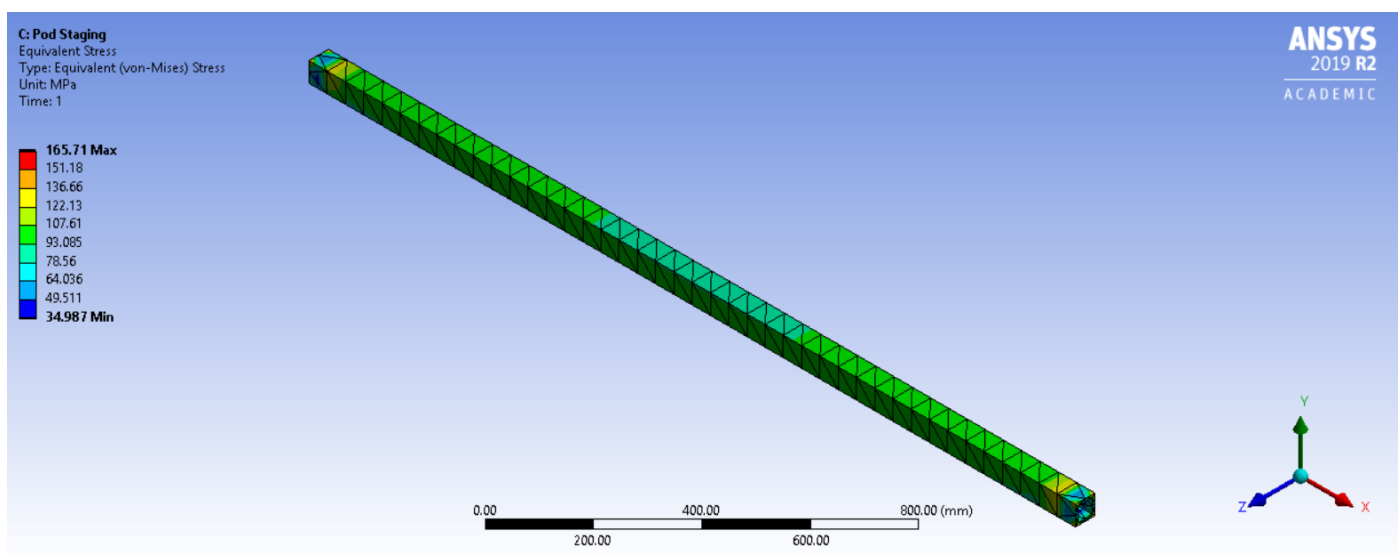

Figure 18. LCM stress during Pod staging.

\subsection{Loading Case II (Launch Phase)}

Once the Pod is placed on the test track, and launch clearance is obtained from SpaceX, only then will the Pod have the ability to go into the launch phase. As the Pod is launched, it experiences the thrust generated by the LIM. In addition to all the system weights acting on the chassis, the stability wheels would still apply a reactionary force on the Pod as a result of the low speed the Pod would be traveling at during this segment of its run.

Table 14. LCM loading case for launching phase.

\begin{tabular}{lr}
\hline \multicolumn{1}{c}{ LCM Loading Parameters } & \multicolumn{1}{c}{ Value } \\
\hline Braking System (Per System) & $74 \mathrm{~N}$ \\
MagLev System (Per System) & $84 \mathrm{~N}$ \\
LIM, Batteries \& GNC Systems & $403 \mathrm{~N}$ \\
Vehicle Stability Module (Per System) & $687 \mathrm{~N}$ \\
\hline
\end{tabular}


With the loading scenario highlighted in Table 14, a maximum deformation of 0.55 $\mathrm{mm}$ was observed at its center due to the weight of the LIM, batteries and the GNC system. Whereas, a maximum stress value of $165.71 \mathrm{MPa}$ was observed within the LCM. The deformations and stresses have been illustrated in Figure 19 and Figure 20 respectively.

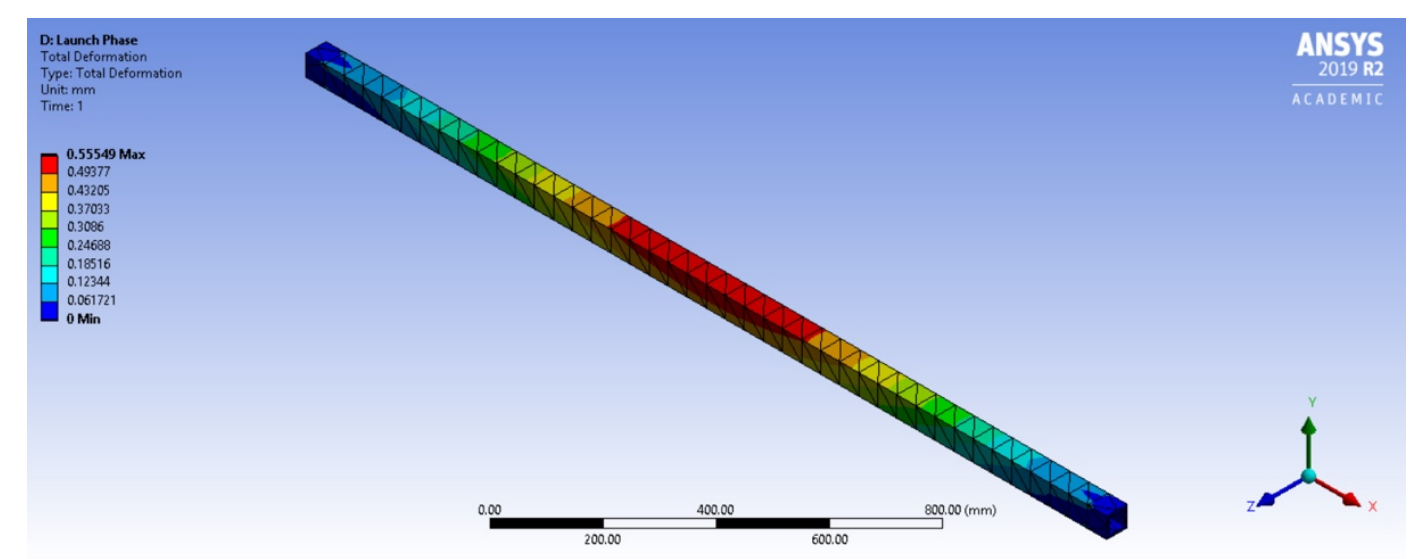

Figure 19. LCM deformation during Pod's launching phase.

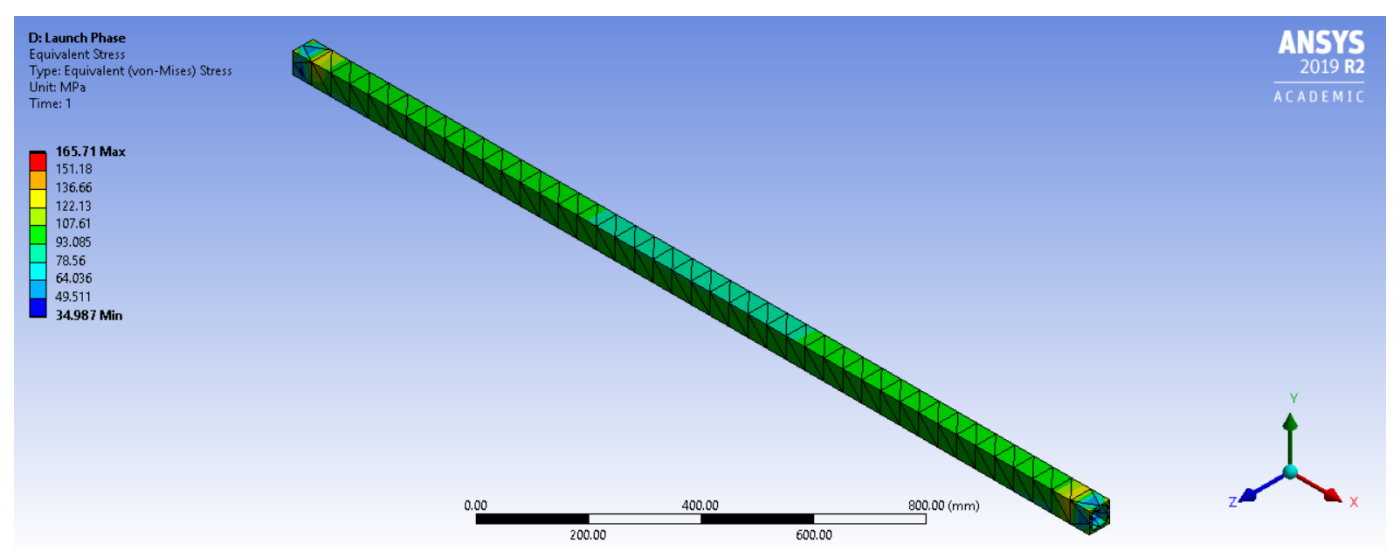

Figure 20. LCM stress during Pod's launching phase.

\subsection{Loading Case III (Levitation Phase)}

Further into the run, the Pod would have gathered enough speed allowing for the MagLev system to take over, and to support the Pod. During this phase, the aforementioned forces such as the thrust, system weights would continue to act on the structure. However, with the MagLev being initiated, the drag force generated by it will begin to have an effect on the Pod. With the Pod fully levitating, the contact force from the vehicle stability modules no longer act on it. 
Table 15. LCM loading case for the Pod's levitation phase.

\begin{tabular}{lr}
\hline \multicolumn{1}{c}{ LCM Loading Parameters } & \multicolumn{1}{c}{ Value } \\
\hline Braking System (Per System) & $74 \mathrm{~N}$ \\
MagLev System (Per System) & $687 \mathrm{~N}$ \\
LIM, Batteries \& GNC Systems & $403 \mathrm{~N}$ \\
\hline
\end{tabular}

Table 15 showcased the major system loads acting on the LCM during the levitation phase. As majority of the load is exerted upwards by the MagLev on the LCM, a maximum deflection of $0.68 \mathrm{~mm}$ and a stress value $165.09 \mathrm{MPa}$ was obtained. Figure 21 and Figure 22 showcase the contour plots for the new loading scenario.

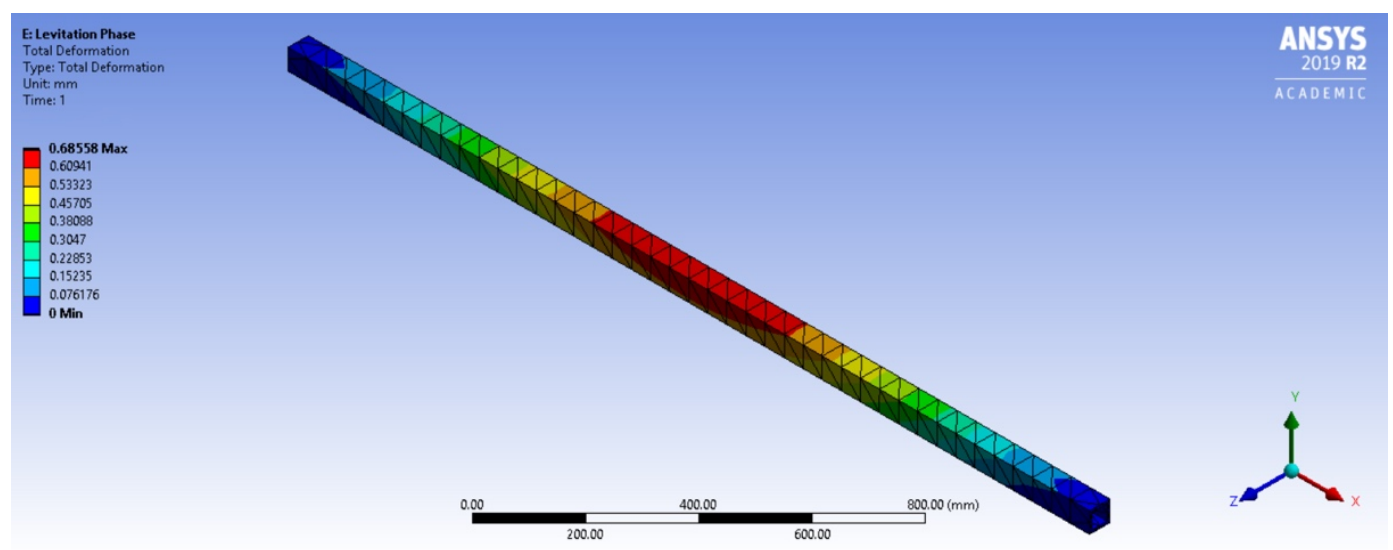

Figure 21. LCM deformation during Pod levitation.

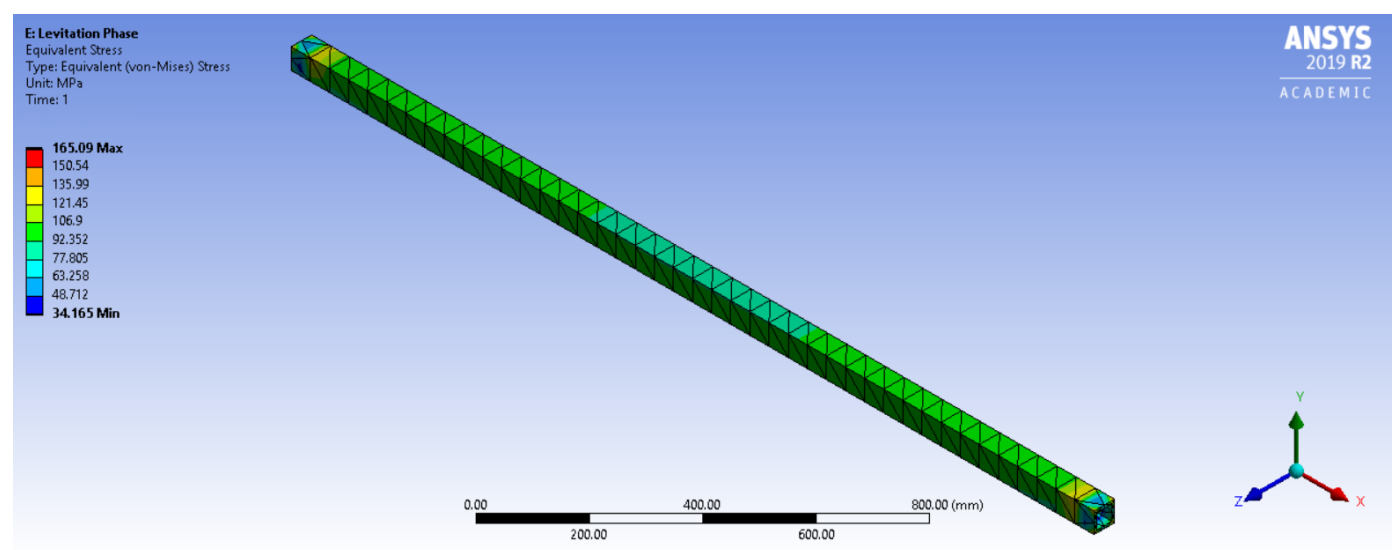

Figure 22. LCM stress during Pod levitation. 


\subsection{Loading Case IV (Braking Phase)}

When the Pod's braking sequence is initiated, the first major event that would occur is the deployment of the braking system. To take advantage of the onboard systems, additional braking power could be generated by reversing the polarity of the LIM. By doing so, the LIM would generate thrust in the opposite direction to motion, slowing the Pod down drastically. The final method of obtaining more braking power is through the deployment of the MagLev system. This would result in generation of MagDrag where even more braking power can be extracted from the system.

Table 16. LCM loading case for braking phase.

\begin{tabular}{lr}
\hline \multicolumn{1}{c}{ LCM Loading Parameters } & \multicolumn{1}{c}{ Value } \\
\hline Braking System (Per System) & $74 \mathrm{~N}$ \\
MagLev System (Per System) & $687 \mathrm{~N}$ \\
LIM, Batteries \& GNC Systems & $403 \mathrm{~N}$ \\
Vehicle Stability Module (Per System) & $687 \mathrm{~N}$ \\
Braking Lock-Up Force (Per System) & $1374 \mathrm{~N}$ \\
\hline
\end{tabular}

For the load case highlighted in Table 16, a maximum deformation of $0.55 \mathrm{~mm}$ was obtained as show in Figure 23. While its stress was found to be approximately 165.71 $\mathrm{MPa}$ as illustrated in Figure 24.

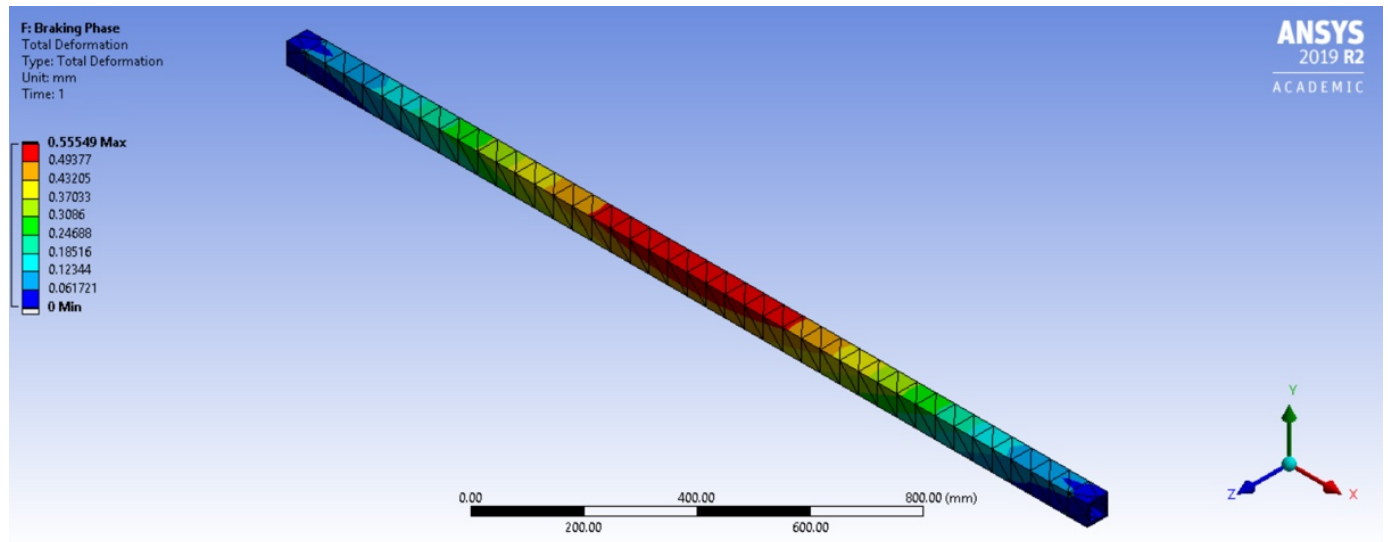

Figure 23. LCM Deformation During The Pod's Braking Phase. 


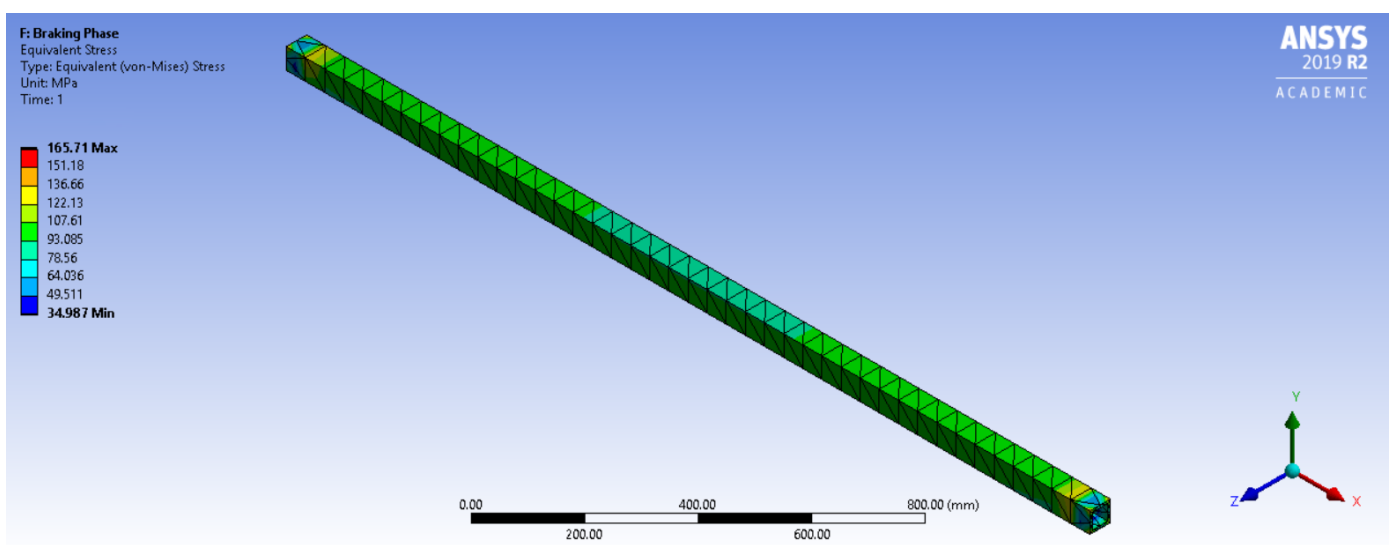

Figure 24. LCM Stress For The Pod's Braking Phase.

\subsubsection{Pod Bulkhead}

The bulkheads are a critical feature of the Pod's design. Being highly integrated within the Pod, they are used to transfer concentrated loads to the remainder of the Pod's structure [18]. In addition to the transfer of loads, they also provide support to the LCMs. The design of the bulkheads revolved around ensuring the Pod's structural rigidity was increased, and to ensure critical dimensions would be maintained during the Pod's braking phase.

The first step in the design of the bulkhead was to obtain the loads that acted on it. With the Pod being symmetrical about the vertical centerline, it resulted in a symmetrical load application as well. The Pod's bending stresses, and shear flow were obtained by the flexure formula.

$$
\sigma=\frac{M y}{I}
$$

where the $\sigma$ is the bending stresses undergone by the Pod due to a moment $M$ located at a $y$ distance from the neutral axis. Where the area moment of inertia for the component being analyzed was represented by $I$.

$$
q=\frac{V_{\infty}}{I} \int y d A
$$

where the shear flow for the bulkhead is denoted by $q, V_{\infty}$ is the shear force, $I$ is the area moment of inertia located at a $y$ distance from the neutral axis, and $d A$ is an infinitesimally small area under examination. 
With the LCMs being manufactured out of Aluminum, the bulkhead material was also chosen to be Aluminum 6061-T6 with its material specification being tabulated in Table 17 [17]. This was done as the forward, and rear bulkheads needed connected to the LCMs to form one superstructure.

Table 17. Aluminum 6061-T6 material specification for the bulkhead.

\begin{tabular}{lr}
\hline \multicolumn{1}{c}{ Parameter } & Value \\
\hline Material & Aluminum \\
Specification & 6061 \\
Hardening & $\mathrm{T6}$ \\
Density & $2700 \mathrm{~kg} / \mathrm{m}^{3}$ \\
Modulus of Elasticity & $68.9 \mathrm{GPa}$ \\
Poissons Ratio & 0.33 \\
Ultimate Tensile Strength & $310 \mathrm{MPa}$ \\
Yield Tensile Strength & $276 \mathrm{MPa}$ \\
\hline
\end{tabular}

Following the design principles used in the aerospace industry for aircraft wings, the bulkhead design utilized a rib-frame method. This was done to reduce the torsion that was generated as the braking system was engaged. In order to optimize the design while dealing with the stress, initially the bulkheads were made without any cutouts. Using an iterative design approach, the design was optimized to include cutouts where excess material was not required in order to cut down on weight as shown in Figure 25 and Table 18.

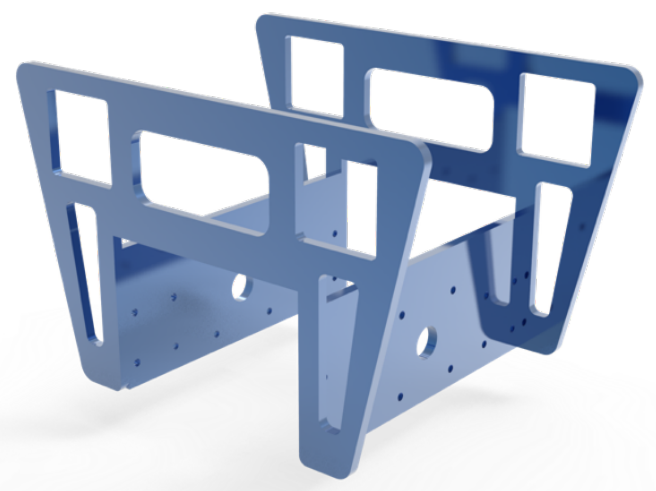

Figure 25. Pod's bulkhead manufactured using anodized blue Aluminum 6061-T6. 
Table 18. Dimensional specifications for the Pod Bulkhead.

\begin{tabular}{lr}
\hline \multicolumn{1}{c}{ Bulkhead Parameter } & Value \\
\hline Length & $17.27 \mathrm{~cm}$ \\
Width & $25.11 \mathrm{~cm}$ \\
Height & $18.16 \mathrm{~cm}$ \\
\hline
\end{tabular}

\subsubsection{Bulkhead Analysis}

Analysis on the bulkhead was performed for its worst case scenario which would occur during the Pod's braking phase where the two pneumatic pistons were expected to apply a braking force of $1,957 \mathrm{~N}$. Therefore, the bulkhead design was validated to withstand this load application.

Under the aforementioned load condition, a maximum deformation of $1.01 \mathrm{~mm}$ was to be expected as illustrated in Figure 26. In addition, this deformation occurred in the region where the two pneumatic pistons would be affixed to it. This occurs as a reactionary force is transmitted to the bulkhead during the braking sequence application. Additionally, maximum stress of $193.69 \mathrm{MPa}$ was observed in the Aluminum 6061-T6 bulkhead as shown in Figure 27. This was well below the yield and shear strengths.

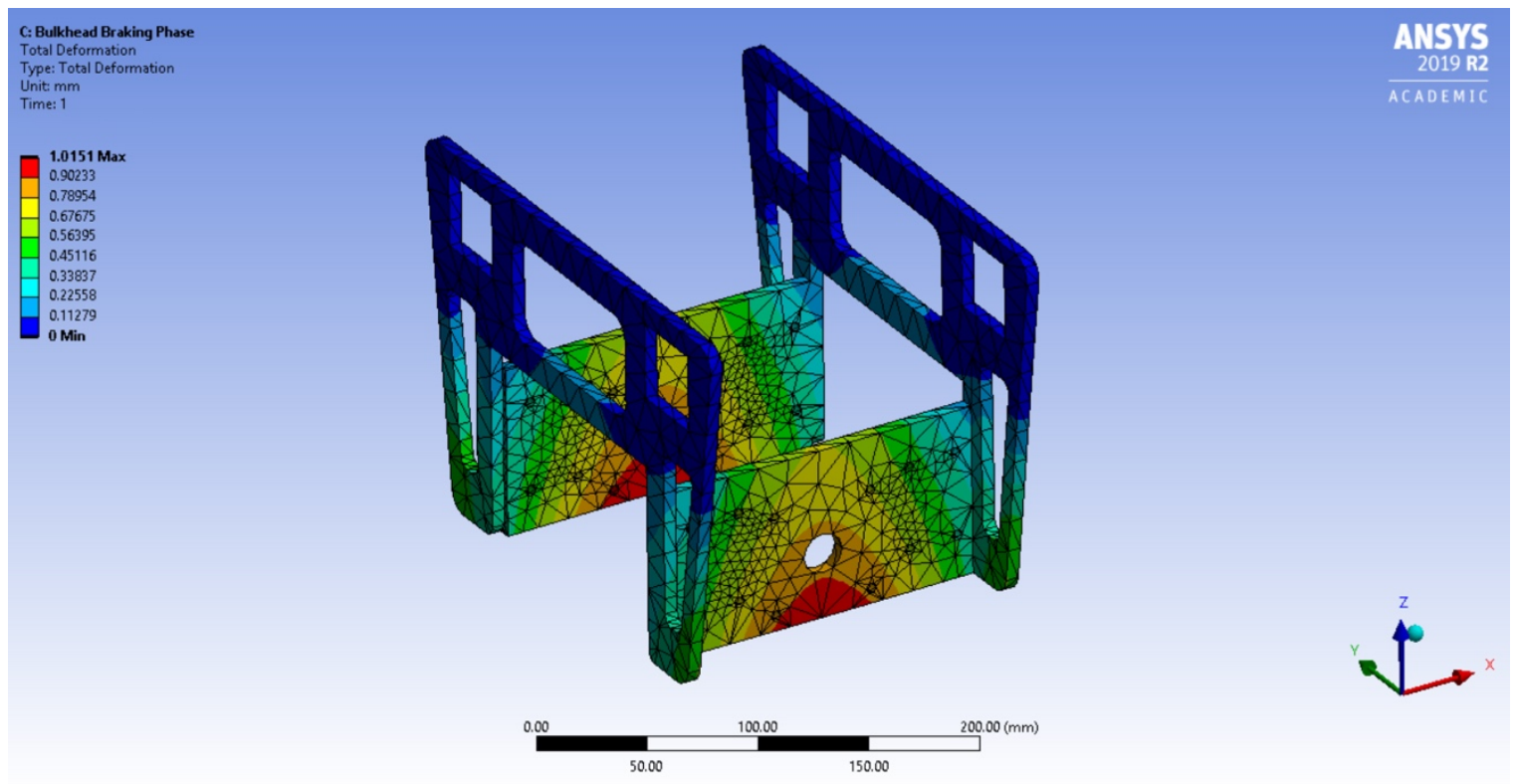

Figure 26. Pod bulkhead's deformation during Pod braking. 


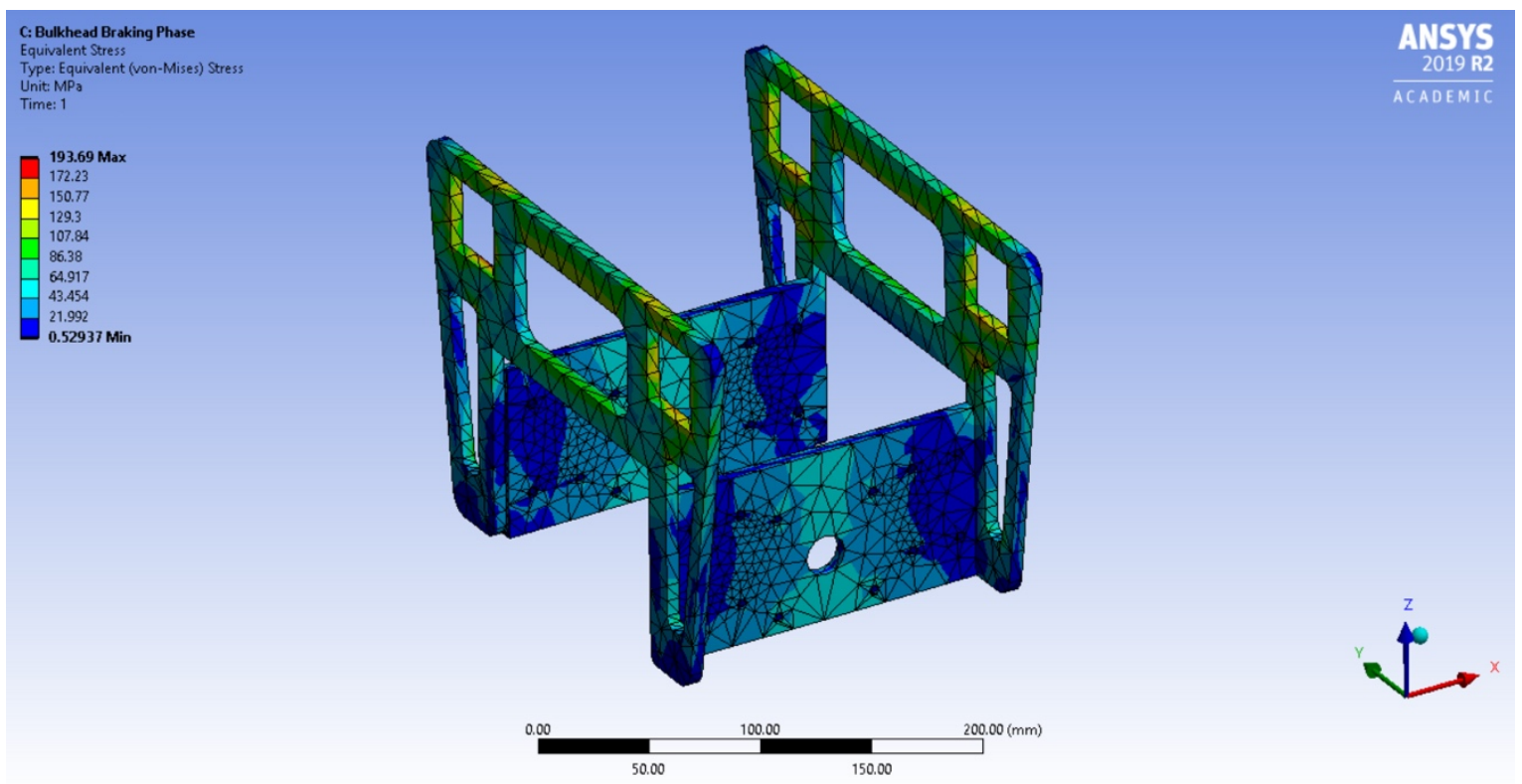

Figure 27. Pod bulkhead's stresses during Pod braking.

\subsubsection{Pod Chassis}

The forward and rear bulkhead connected the two LCMs together to create the Pod's chassis as illustrated in Figure 28. The LCM ran from one bulkhead to the other. As mentioned before, based on the application of the bulkheads and the LCMs within the Pod, both were selected to be manufactured out of Aluminum 6061-T6. It was done primarily due to its density, ultimate and yield strength, stiffness, temperature limits, producibility, repairability, cost, and availability. 


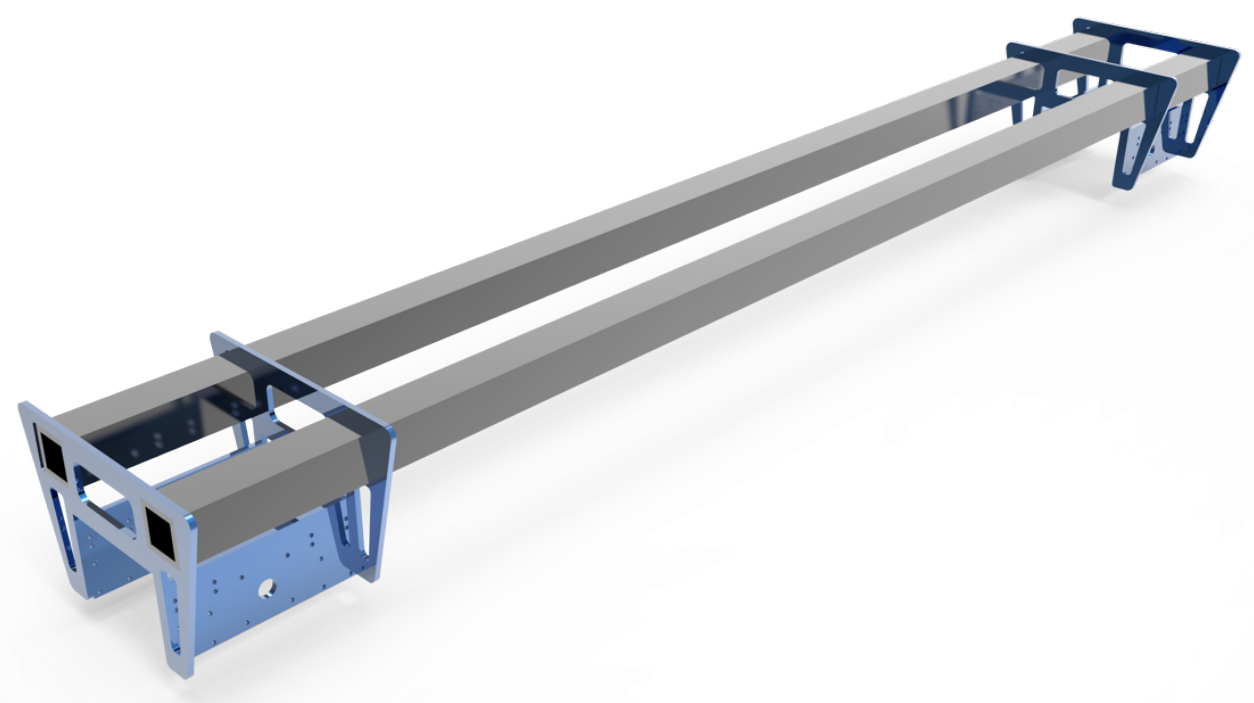

Figure 28. Assembled Hyperloop Pod chassis with the LCMs and bulkheads.

The Pod's chassis is subjected to a repeated cyclic loading, and the structure is expected to experience fatigue stress. Although this may be the case, the formation and propagation of cracks has been unaccounted for due to the low cycle count of this particular structure. For the Pod, one cyclic load is when the environment goes from ambient pressure to near vacuum, and back to ambient pressure [19]. The final Pod chassis conducting the run will have approximately ten cycles on it as outlined in the table below.

Table 19. Total cycle count for the Pod's chassis.

\begin{tabular}{lc}
\hline \multicolumn{1}{c}{ Cycle } & Number of Cycles \\
\hline Post Manufacturing Check & 2 \\
Test Vacuum Certification & 2 \\
Final Vacuum Certification & 2 \\
Hyperloop Tube Test & 3 \\
Hyperloop Tube Run & 1 \\
\hline
\end{tabular}




\subsubsection{Chassis Analysis}

Analysis was performed for this superstructure using the loadings that would be seen during the Pod's worst case scenario, being the braking phase. As buckling of the Pod chassis was a concern, it was analyzed through the assumption that this would occur in the event a braking system was inoperable while the other system applied maximum braking force cause one end of the Pod to lock up. This was done in addition to all the system loads being applied to it as tabulated within Table 20.

Table 20. Pod chassis loading during single operating braking system.

\begin{tabular}{lr}
\hline \multicolumn{1}{c}{ Chassis Loading Parameters } & \multicolumn{1}{c}{ Value } \\
\hline Braking System (Per System) & $74 \mathrm{~N}$ \\
MagLev System (Per System) & $687 \mathrm{~N}$ \\
LIM, Batteries \& GNC Systems & $403 \mathrm{~N}$ \\
Vehicle Stability Module (Per System) & $687 \mathrm{~N}$ \\
Braking Lock-Up Force (Per System) & $1374 \mathrm{~N}$ \\
\hline
\end{tabular}

Under the aforementioned worst case loading scenario where only one braking system functioned, a total of $14.162 \mathrm{~mm}$ of deformation was to be expected from the free end as shown in Figure 29. Although the chassis does not fail, this linear deformation could result in the other Pod systems to fail prematurely. With one braking system still operational, it would apply maximum force on the face of bulkhead that resulted in a stress value of 354.03 MPa as illustrated in Figure 30.

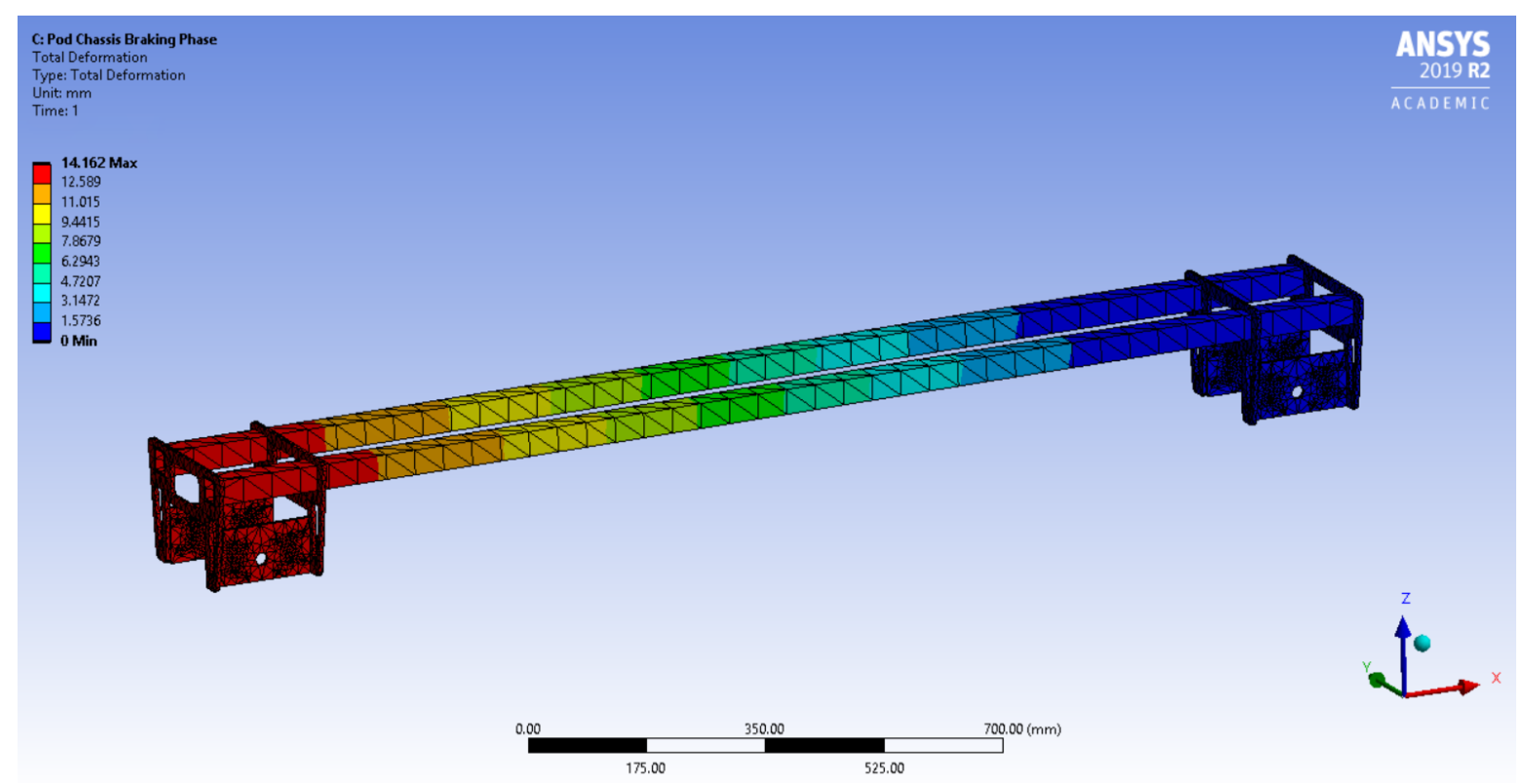

Figure 29. Pod chassis deformation with one inoperable braking system. 


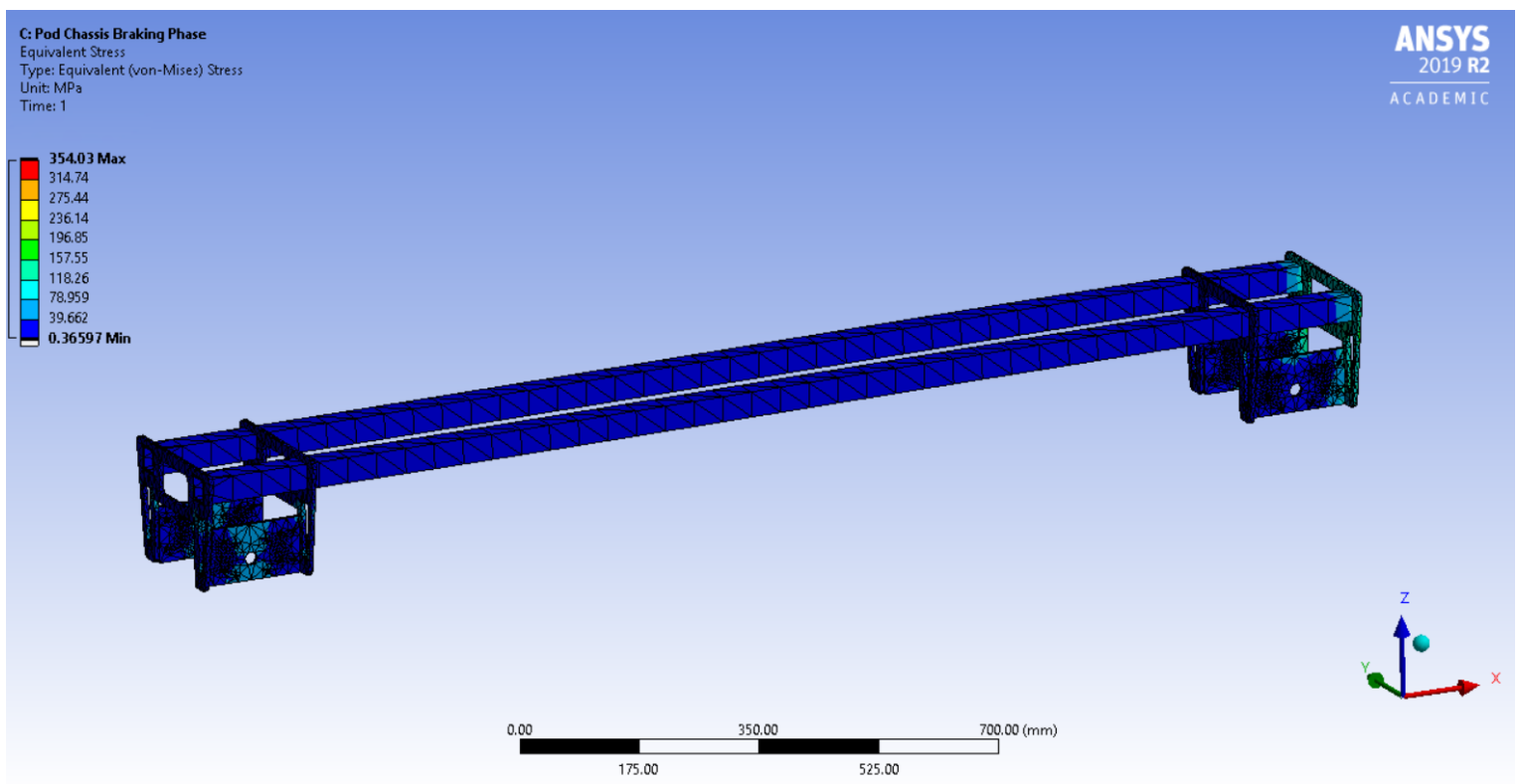

Figure 30. Pod chassis stress with one inoperable braking system.

\subsubsection{Pod Shell}

Operating in a low pressure or a near vacuum environment, a Pod shell is not a must have component. Although this may be the case, a shell was still designed for the Pod. In order to optimize speed and performance, the Pod's frontal area was minimized, and a streamlined shell was designed to reduce drag. In addition, the shell was designed to ensure whatever air that remained within the tube continuously flowed around the Pod. This was done to ensure the Kantrowitz limit was not reached during the high speed run $[20]$.

As the Pod's speed is further increased, not all of the air can flow around the Pod resulting in it being stagnated at the front. This stems when the tube walls are too close to the Pod's shell resulting in a syringe effect forcing the Pod to push this entire column of air built up in front of it [21]. The drag force originating from the pressure differential in front of and behind the Pod increases exponentially, and independently of the Hyperloop tube pressure. This following equation has been modified for the Hyperloop concept [22].

$$
\frac{A_{\text {Bypass }}}{A_{\text {Tube }}}=\left[\frac{\gamma-1}{\gamma+1}\right]^{\frac{1}{2}}\left[\frac{2 \gamma}{\gamma+1}\right]^{\frac{1}{\gamma-1}}\left[1+\frac{2}{\gamma-1} \frac{1}{M^{2}}\right]^{\frac{1}{2}}\left[1-\frac{\gamma-1}{2 \gamma} \frac{1}{M^{2}}\right]^{\frac{1}{\gamma-1}}
$$


Where $A_{\text {Bypass }}$ is the cross-sectional area free of the Pod, and $A_{\text {Tube }}$ is the total inner cross-sectional area of the Hyperloop tube. The isentropic expansion coefficient is given by $\gamma$, and $M$ denotes the Mach number of the Pod.

To better understand this coupling, we can assume that if the air around the Pod is moving at a relative Mach number, $M_{P o d}$. As the air moves, it needed to squeeze from the larger cross-sectional area of the tube to the smaller available area around the Pod, $A_{\text {Bypass }}$. Based on the isentropic flow equations, the relationship between the $M_{\text {Pod }}$ and $M_{\text {Bypass }}$ can be further simplified using the aforementioned area equation.

$$
\frac{A_{\text {Bypass }}}{A_{\text {Tube }}}=\frac{M_{\text {Pod }}}{M_{\text {Bypass }}}\left(\frac{1+\frac{\gamma-1}{2} M_{\text {Bypass }}^{2}}{1+\frac{\gamma-1}{2} M_{\text {Pod }}^{2}}\right)^{\frac{\gamma+1}{2(1-\gamma)}}
$$

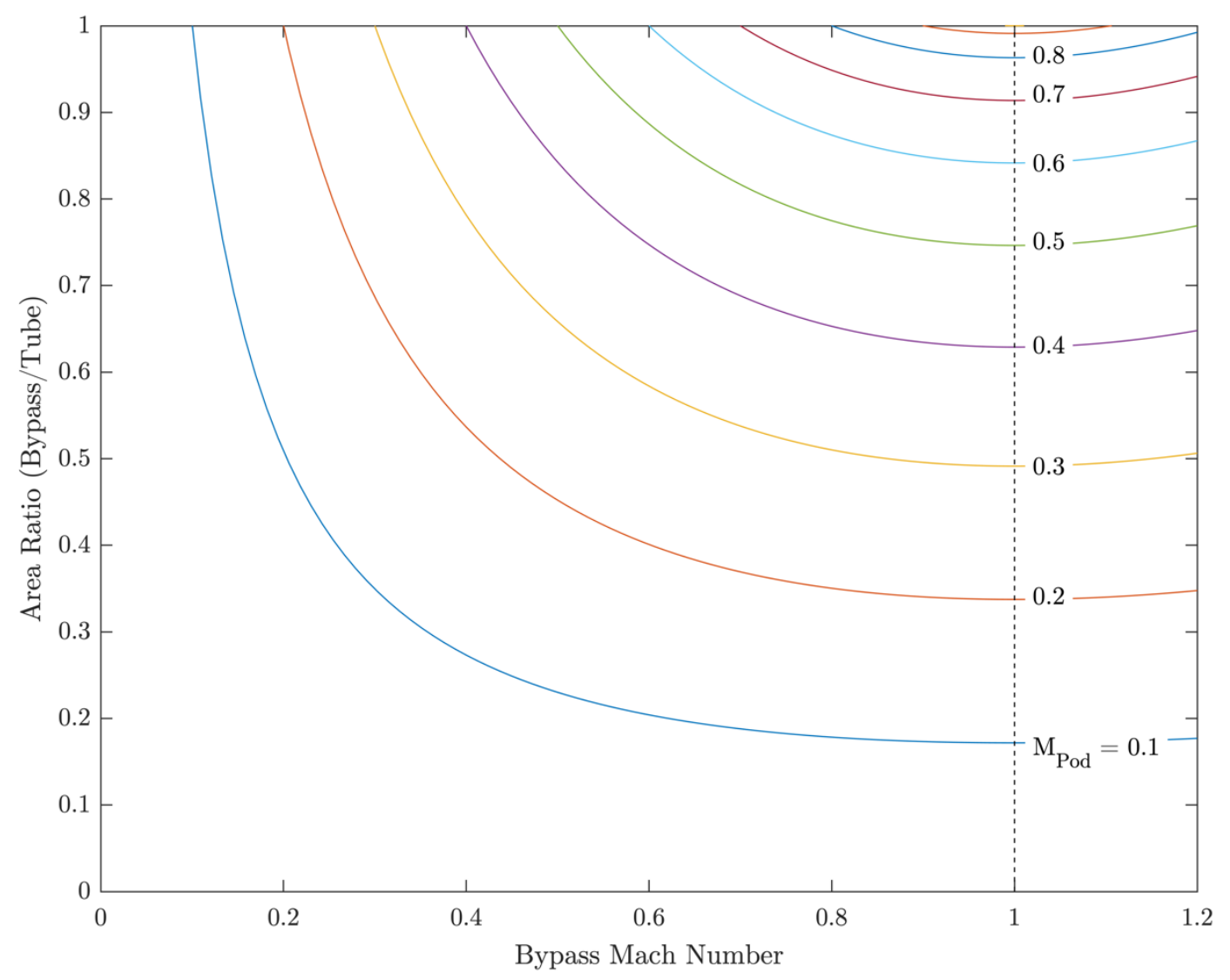

Figure 31. Area ratio vs bypass Mach number plot for varying Mach numbers. 
Figure 31 shows the family of curves for a ranging $M_{P o d}$ and $M_{\text {Bypass. }}$. For all the values of $M_{P o d}$, the minimum required area ratio occurs at a $M_{\text {Bypass }}$ of one. In other words, as this value equates to one it would result in the smallest possible value for the $A_{\text {Bypass }}$ or $A_{\text {Tube }}$ when the $M_{\text {Pod }}$ and $A_{\text {Pod }}$ are known. If the area of the tube is smaller than its minimum value, it would result in the mass flow rate to not flow freely around the Pod.

As the Pod reaches transonic speeds, the small volume of air present within the tube will begin to choke. There are certain sections around the Pod where the flow will be sonic. This so called sonic condition is known as the Kantrowitz limit where the mass flow rate around the Pod has reached it maximum value. In addition to the Pod's velocity, there is a minimum tube to Pod area ratio below which the flow will also be choked. As illustrated in Figure 31, if the Pod were required to travel faster, a larger $A_{\text {Bypass }}$ was needed and must be relative to the tube's area. For an $M_{P o d}$ of one, the area ratio almost equals one forcing the $A_{\text {Pod }}$ to be almost zero [9].

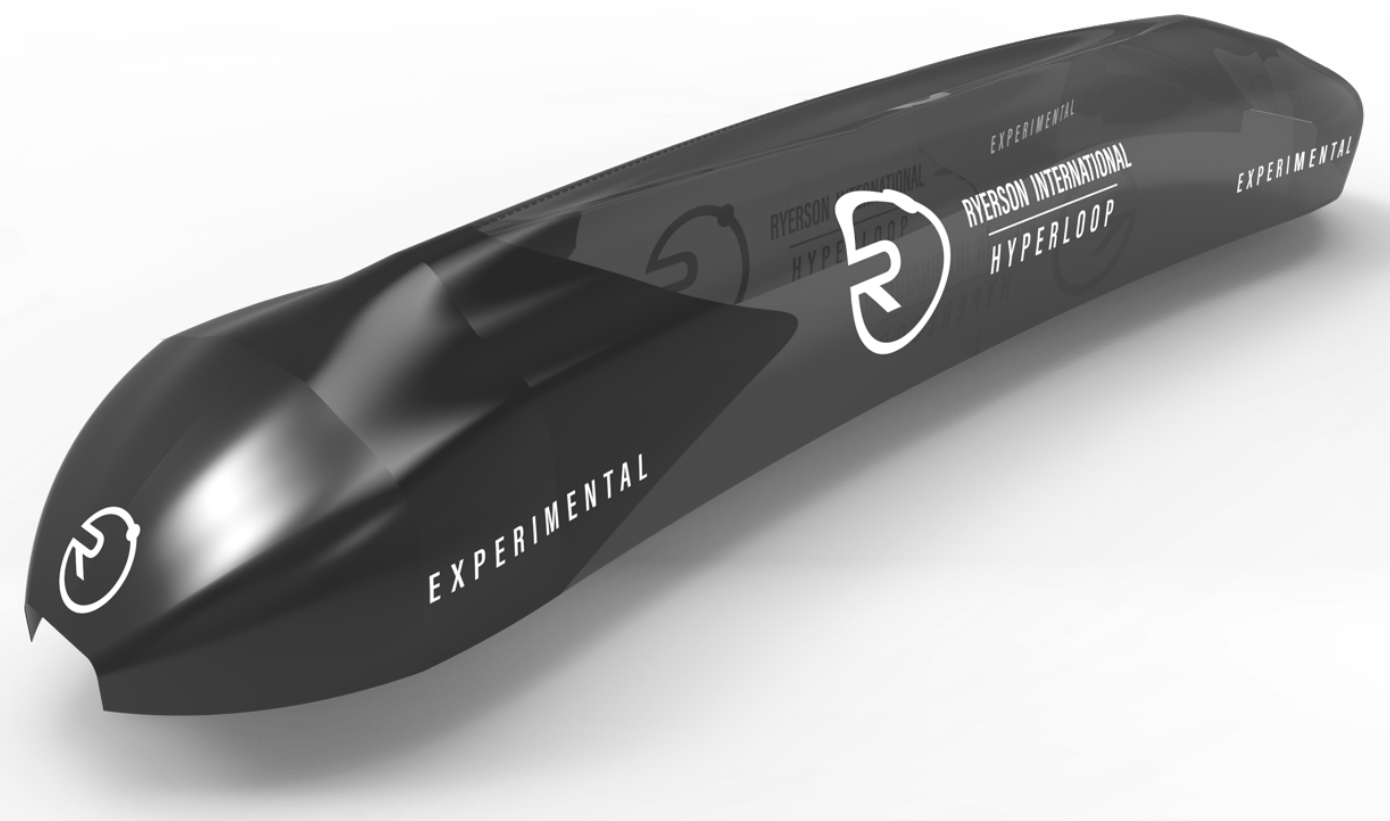

Figure 32. An isometric view of the Pod shell.

In order to optimize speed and performance without the incorporation of a front end compressor, the Pod's frontal area was minimized, and a streamlined shell was designed to reduce aerodynamic drag. In addition, the shell was designed to ensure whatever air is remaining within the tube continuously flows around the Pod without reaching the Kantrowitz limit. 
The completion of Finite Element Method (FEM) and Computational Fluid Dynamic (CFD) resulted the design shell as shown in Figure 32. To maintain a minimal cross-sectional area, the design incorporated a dog bone shape as illustrated in Figure 33. This was also done to ensure sufficient mass flow during the high speed run. A carbon composite laminate shell using a resin and hardener combination was selected to produce a lightweight component while enclosing all the Pod's systems.

\subsubsection{Shell Analysis}

The shell is a carbon fiber laminate with a Soric core. The laminate was designed to be quasi-isotropic with the following laminate, where $S$ describes the Soric core: [ [ 90 $4590]_{\mathrm{s}} S\left[\begin{array}{lll}90 & 45 & 90\end{array}\right]$ ]. For the laminate, HexTow AS4C 3K carbon fiber was used as it was a continuous, high strength, and high strain material. This laminate was surface treated by the supplier to improve the its handling characteristics, structural and mechanical properties as tabulated in Table 21 [23].

Table 21. HexTow AS4C 3K material specification for the Pod shell.

\begin{tabular}{lr}
\hline \multicolumn{1}{c}{ Parameter } & \multicolumn{1}{c}{ Value } \\
\hline Manufacturer & Hexcel Corporation \\
Specification & HexTow $A S 4 C$ 3K \\
Filament Count Tows & 3,000 \\
Tow Cross-Sectional Area & $0.11 \mathrm{~mm}^{2}$ \\
Filament Diameter & $6.9 \mathrm{microns}$ \\
Carbon Percentage & $94.0 \%$ \\
Density & $1780 \mathrm{~kg} / \mathrm{m}^{3}$ \\
Modulus of Elasticity & $231 \mathrm{GPa}$ \\
Tensile Strength & $4.723 \mathrm{GPa}$ \\
Yield Strength & $5.00 \mathrm{~m} / \mathrm{g}$ \\
Strain & $1.8 \%$ \\
\hline
\end{tabular}

To account for the thermal heating of the shell, the composite shell utilized Aeropoxy's PR2032 and PH3665. This particular resin-hardener combination provided a curing time of approximately two hours while being rated to a temperature of $93^{\circ} \mathrm{C}$. This provided ample amount of working time while ensuring the shell can withstand the California heat, and the heat generated by the systems during a full power run. The Aeropoxy's material specifications have been tabulated in Table 22 [24]. In addition, the shell will be locked onto the chassis using internal friction fit dowel locking system eliminating the need for drag inducing screws. 
Table 22. Aeropoxy PR2032 and PH3665 material specification for the shell.

\begin{tabular}{lr}
\hline \multicolumn{1}{c}{ Parameter } & Value \\
\hline Manufacturer & Aeropoxy \\
Resin & PR2032 \\
Hardener & $P H 3665$ \\
Density & $1134.94 \mathrm{~kg} / \mathrm{m}^{3}$ \\
Tensile Strength & $316.26 \mathrm{MPa}$ \\
Modulus of Elasticity & $21.02 \mathrm{GPa}$ \\
Pot Life & $2 \mathrm{hours}$ \\
Mix Ratio & $100: 27$ \\
Rated Temperature & $93{ }^{\circ} \mathrm{C}$ \\
\hline
\end{tabular}

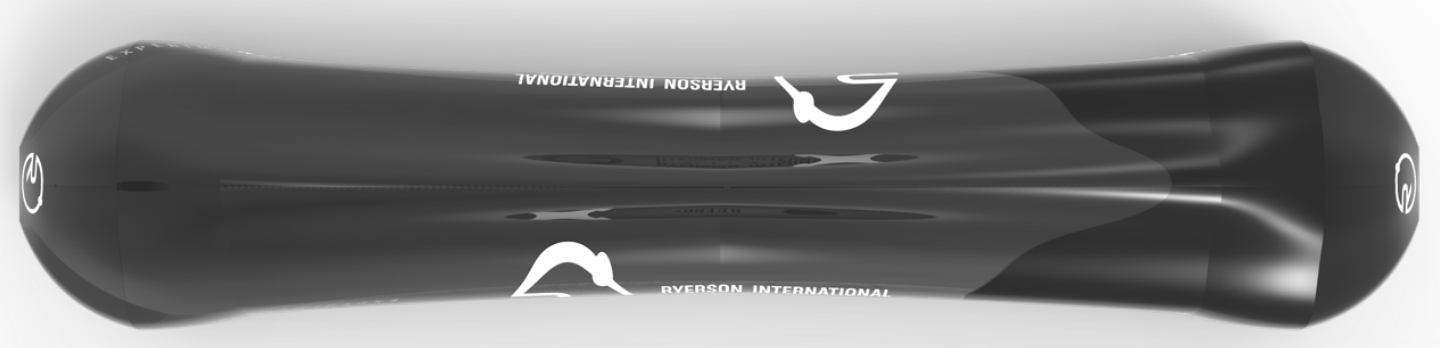

Figure 33. A top down view of the Pod shell.

\subsubsection{Pod Braking}

The Pod is required to have its own onboard braking system to slow it down as it approaches the end of the Hyperloop tube. Braking can be done in a variety of ways, with frictional braking being performed on the Hyperloop tube, concrete base, the Aluminum sub-track, or the test track itself. 
When the BRK system was designed, major consideration was put on ensuring that any surfaces used for braking does not get damaged as a result of it. This was done by selecting a braking material with a lower hardness value than the track. In addition, BRK was designed to wear rather than to exhibit sticking characteristics. Furthermore, analysis and reliability tests were conducted for the Pod's worst case scenarios. For example, having the one of the braking systems to become locked up resulted in the Pod to come an immediate stop. This was done in conjunction with the largest steps and variations in the Hyperloop tube. These considerations ensured the Pod's braking system behaved nominally and would not result in a system failure.
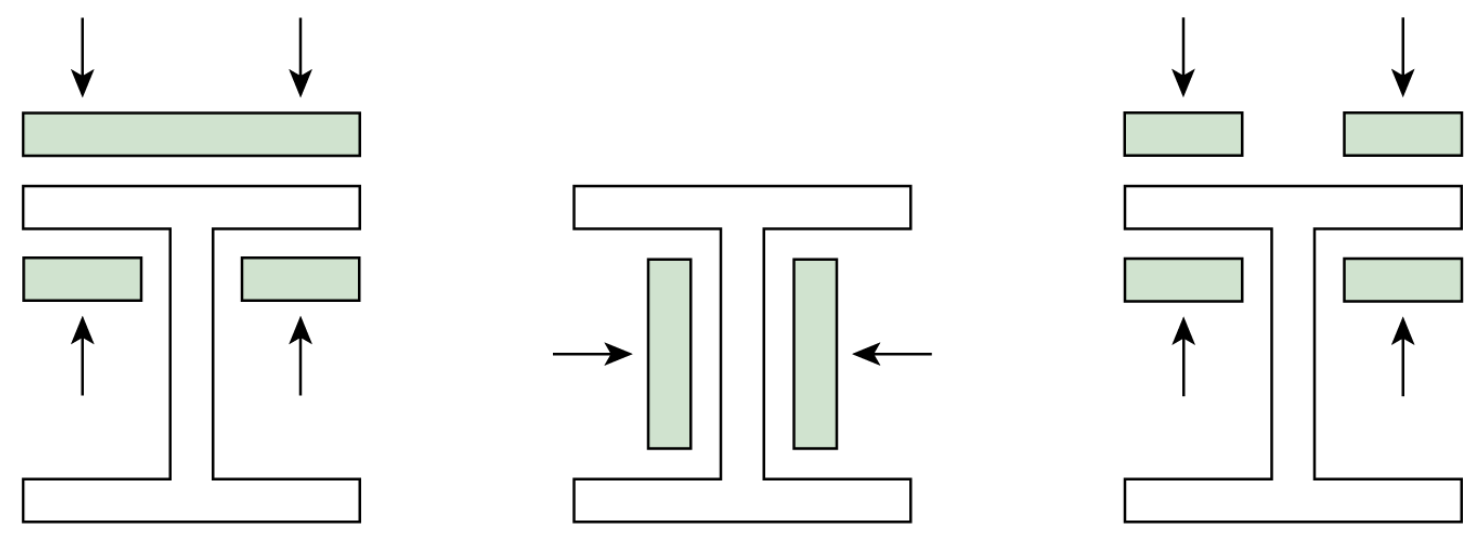

Figure 34. Acceptable Pod braking scenarios on the test track.
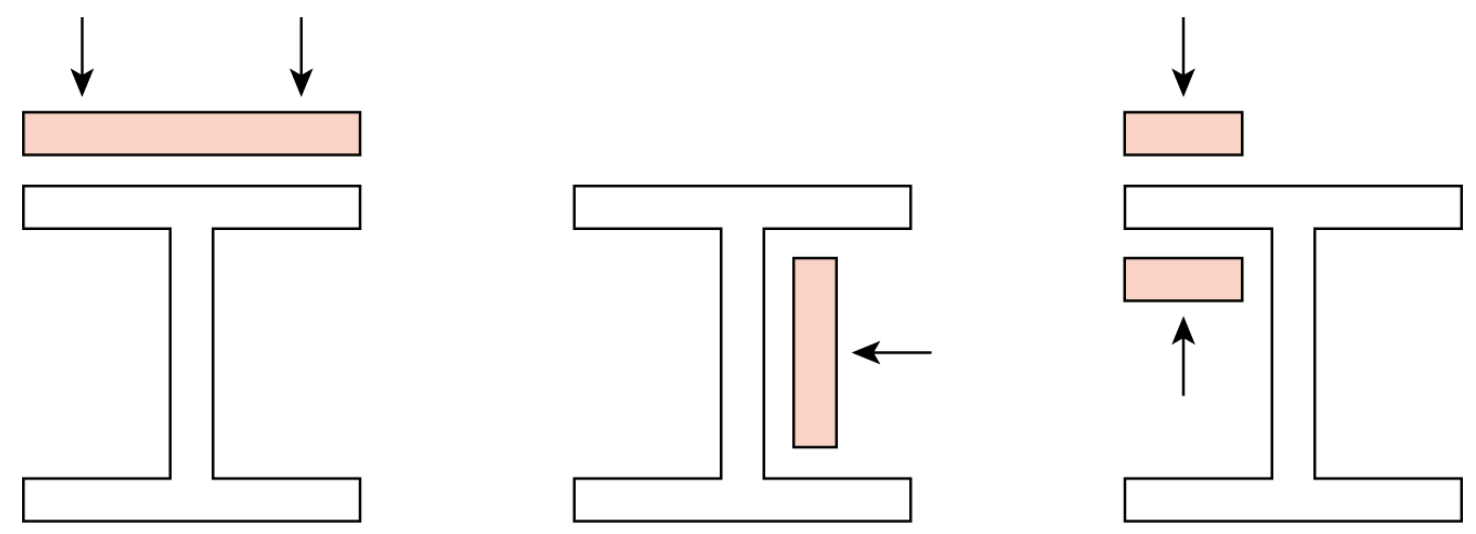

Figure 35. Unacceptable Pod braking scenarios on the test track.

As the Pod utilized the test track to perform its braking operations, it was made to be self-reacting and symmetric about the vertical axis of the track. In other words, the braking operation was made to clamp down on the test track as illustrated in Figure 34, rather than to push on it as shown in Figure 35. 


\subsubsection{Braking Configuration}

For effective and high braking performance, the system has been arranged in a forward, and aft configuration within the Hyperloop Pod. To ensure braking capabilities during all phases, BRK has two independent systems. Both the braking systems have its own pneumatic pressure vessels, control systems, control valves, and pneumatic tubing as highlighted in Table 23. This is done to prevent cascading failure in the event a system failure was to occur.

Table 23. Pod braking system component list.

\begin{tabular}{lr}
\hline \multicolumn{1}{c}{ Braking System Parameters } & Quantity \\
\hline Number of Independent Systems & 2 \\
Pneumatic Braking Pistons & 4 \\
Pressure Vessels & 2 \\
Pressure Regulators & 2 \\
Shut-Off Valves & 3 \\
Directional Control Valves (DCV) & 2 \\
Electronic Control Unit (ECU) & GNC \\
Power Source & Pod Batteries \\
\hline
\end{tabular}

The four pneumatic braking pistons placed on either side of the Pod have been designed to utilize the web of the test track during braking operations. To ensure the CG was located at its optimal point, all of the BRK components are placed on the top of the test track except for the pneumatic pistons.

For high performance braking, the pneumatic braking pistons supply a total of $1,957 \mathrm{~N}$ of braking power when a 10 bar internal supply pressure was maintained as shown in Table 25. Furthermore, as the Pod was expected to perform a number of braking cycles as highlighted in Table 24, a closed loop double acting piston was used. Such a piston allows for the extension and retraction without venting internal pressure during the various phases of the Pod as shown in Figure 36 [25]. 


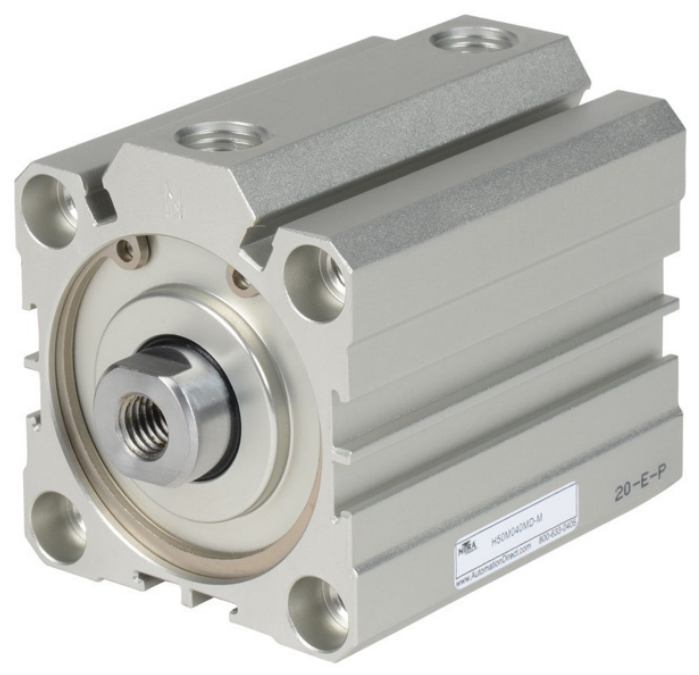

Figure 36. Double acting pneumatic braking piston for the braking system [25].

Table 24. Braking cycle count for pre and post Hyperloop run.

\begin{tabular}{lc}
\hline \multicolumn{1}{c}{ Braking Cycle } & Cycle Count \\
\hline Pre-Tube Brake Check & 2 \\
Test Track Brake Check & 1 \\
Airlock Closure Brake Check & 1 \\
Low Pressure Brake Check & 2 \\
Pre-Launch Brake Check & 2 \\
Pod Braking Phase & 1 \\
Pre-Crawl Braking Check & 1 \\
Crawl Braking Phase & 1 \\
\hline
\end{tabular}

This piston was chosen for its performance when compared with to mass. To ensure acceptable results, the worst case scenario was once again analyzed, where one braking system was considered to be inoperable. With the expected output force over the span of the braking time, enough braking force was generated to bring the Pod to a safe halt with a Factor of Safety (FoS) of two. 
Table 25. Pneumatic braking piston specifications.

\begin{tabular}{lr}
\hline \multicolumn{1}{c}{ Braking Piston } & Value \\
\hline Bore Size & $50 \mathrm{~mm}$ \\
Stroke Size & $40 \mathrm{~mm}$ \\
Mass & $0.73 \mathrm{~kg}$ \\
Maximum Braking Force & $1957 \mathrm{~N}$ \\
Minimum Supply Pressure & $10 \mathrm{Bar}$ \\
Tank Supply Pressure & $17.2 \mathrm{Bar}$ \\
\hline
\end{tabular}

To ensure safe operation of the braking system during any phase of the run, a minimum of 10 bar was required to be maintained within the system. Furthermore, to account for any leaks that that may occur as a of the system being manufactured in house, a pressure vessel capable of safely being pressurized up to 17.2 bar was selected. This was done through the usage of a High Pressure Air (HPA) carbon composite pressure vessel. In addition to being lightweight, and compact, the carbon fiber tanks have been certified by the Department of Transportation (DOT), and Transport Canada (TC) as illustrated in Figure 37 [26].

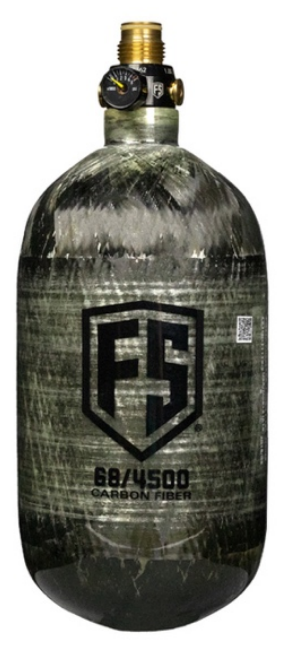

Figure 37. Carbon composite HPA pressure vessel for the braking system [26].

The selected pressure vessel has a volume of $0.0438 \mathrm{~cm}^{2}$ which is capable of supplying enough to the BRK system with a sizable Safety Factor (SF). For the Pod, it was pressurized to 17.2 bar. The inclusion of a four way, two position Directional Control Valve (DCV) within the system allowed for one supply pressure vessel to control two pistons simultaneously. With an electric switch, the DCV was supplied with $24 \mathrm{~V}$ that switched the position of the solenoid valve that directed the airflow allow for the piston to extend or retract the brakes [27]. 


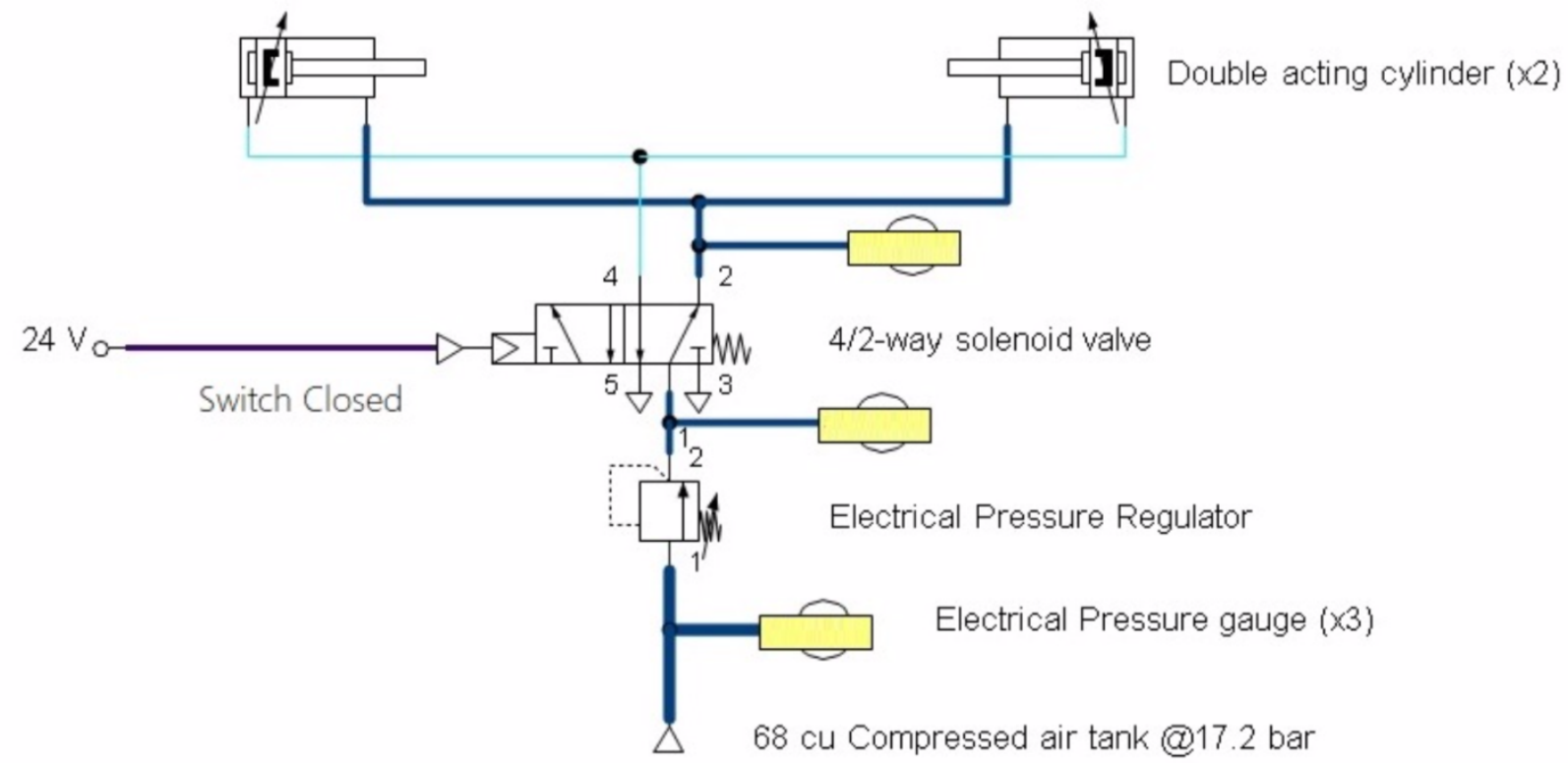

Figure 38. Retracted pneumatic braking schematic for one piston set.

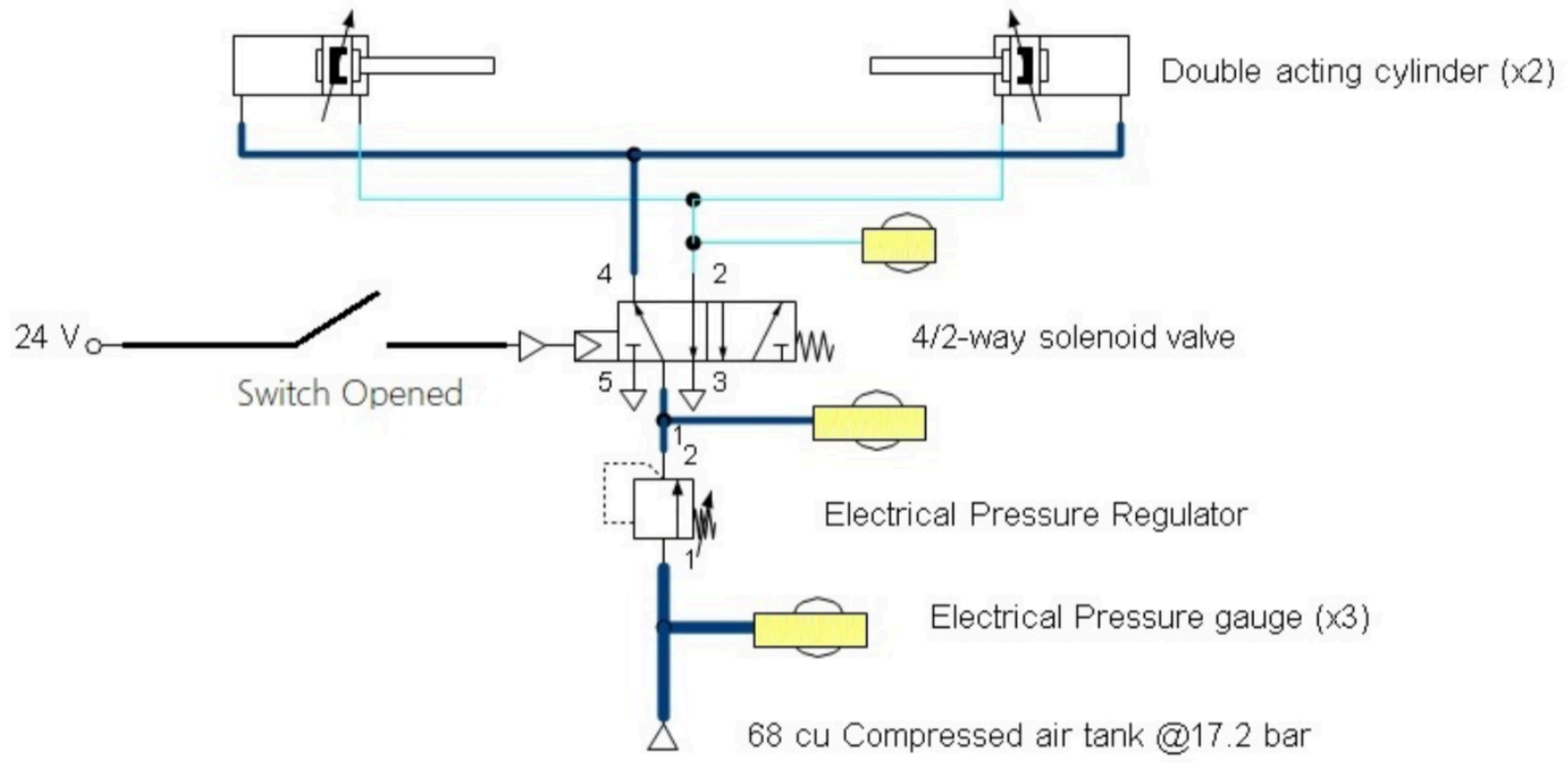

Figure 39. Extended pneumatic braking schematic for one piston set.

As the forward and aft braking systems were identical, Figure 38 was the schematic for a single pneumatic braking system. For the safety of the Pod, the Hyperloop tube, and all the involved personnel, the BRK system was designed with its default position being open. 


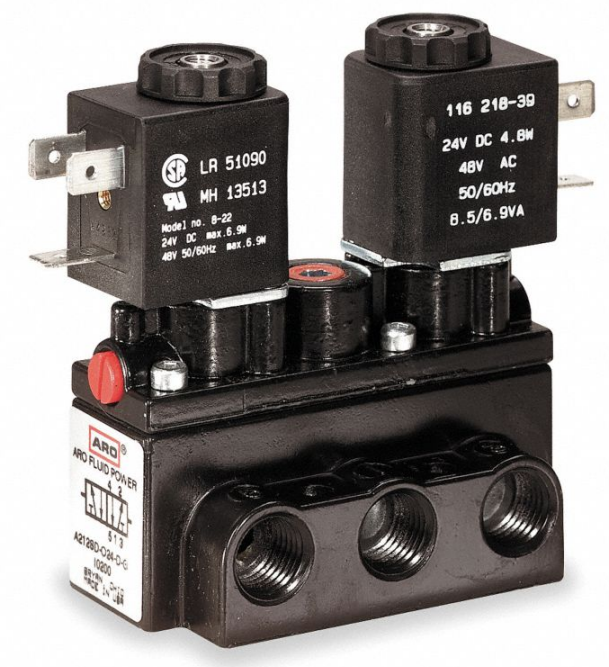

Figure 40. Directional control valve with two solenoid valve coils [27].

In the event of a power loss to any critical system, the braking system has been designed to automatically deploy as its design feature as illustrated in Figure 39. This ensured the Pod always comes to a safe halt. This was made possible as this particular DVC has a fast response time which dramatically reduced the amount of coasting time between when the polarity is reversed of MagDrive, and to when the brakes kick-in. However, during nominal system operations the power requirements for some of the BRK components such as the Electronic Pressure Regulator (EPR) and Electronic Pressure Gauge (EPG) have been outlined in Table 26.

Table 26. Power requirements for a few braking components.

\begin{tabular}{lr}
\hline \multicolumn{1}{c}{ Power Requirements } & Value \\
\hline DCV Voltage & $24 \mathrm{~V}$ \\
DCV Current & $0.3 \mathrm{~A}$ \\
DCV Power & $6.9 \mathrm{~W}$ \\
EPR Voltage & $24 \mathrm{~V}$ \\
EPR Current & $0.18 \mathrm{~A}$ \\
EPR Power & $4.32 \mathrm{~W}$ \\
EPG Voltage & $24 \mathrm{~V}$ \\
EPG Current & $0.0002 \mathrm{~mA}$ \\
EPG Power & $0.48 \mathrm{~W}$ \\
\hline
\end{tabular}




\subsubsection{Braking Analysis}

The Hyperloop Pod's braking system was designed to decelerate it from its maximum speed at the furthest possible braking engagement distance. This in combination with the assumption that only one BRK system was operating ensured that the shortest allowable braking distance was used. In order to compute the basic braking parameters, the following equation was used.

$$
v^{2}=u^{2}+2 a s
$$

where $v$, and $u$ is the initial and final velocities of the Pod, $a$ is the Pod's acceleration or deceleration over the time period under consideration, and $s$ denotes the distance being covered by the Pod under this particular time period. The aforementioned equation can be further simplified as the Pod was required to come to a safe halt, i.e. the final velocity needed to be zero.

$$
a=\frac{-v^{2}}{2 s}
$$

During the worst case scenario, the assumption made that only one braking system works nominally. Under this assumption, the braking force that needed to be applied by the piston to bring the Pod to a safe halt was calculated through the following equation.

$$
F_{B}=m_{\text {Pod }} a
$$

where $F_{B}$ in the aforementioned equation is derived from the Newton's Second Law, $m_{P o d}$ and $a_{P o d}$ are the mass and acceleration of the Pod.

$$
F_{\text {Brake, Req }}=\frac{F_{B}}{\mu_{k, \text { Track }} N_{\text {Pod }}}
$$

where $F_{\text {Brake,Req }}$ is the braking force required to be delivered from the pneumatic piston to safely stop the Pod, $F_{B}$ is the Newton's Second Law that was calculated from the Pod's mass, and deceleration rate. The coefficient of kinetic friction is denoted by $\mu_{k, T r a c k}$, and $N$ is the normal force generated from the Pod as it decelerated.

$$
F_{\text {Brake }}=P_{\text {Piston }} A_{\text {Piston }}
$$

where $F_{B r a k e}$ is the output force supplied by the pneumatic piston, $P_{\text {Piston }}$ is the internal pressure acting within the double acting piston and $A_{\text {Piston }}$ is its cross-sectional area. 


$$
F_{\text {Brake }}>F_{\text {Brake,Req }}
$$

To ensure the Pod always has the ability to safely stop, the braking force produced by the pneumatic pistons need to always be greater than the braking force required to stop the Pod. Using this criterion, the Pod was designed to have a SF of two when the brakes are engaged from its maximum possible speed. The nominal and off-nominal Pod braking distances required for it to come to a complete stop have been tabulated in Table 27.

Table 27. Performance specification for nominal and off-nominal braking.

\begin{tabular}{lr}
\hline \multicolumn{1}{c}{ Braking Parameter } & \multicolumn{1}{c}{ Value } \\
\hline Nominal Braking and Optimal Brake Performance & $58.62 \mathrm{~m}$ \\
Nominal Braking and Lower Brake Performance & $63.77 \mathrm{~m}$ \\
Off-Nominal Braking and Optimal Brake Performance & $117.24 \mathrm{~m}$ \\
Off-Nominal Braking and Lower Brake Performance & $127.55 \mathrm{~m}$ \\
\hline
\end{tabular}




\subsection{Pod Propulsion}

To effectively develop the Hyperloop Pod's Propulsion (PRP) system, it was broken down into its sub-systems as shown in Figure 41. The Linear Induction Motor (LIM), and the Magnetic Levitation System (MagLev) constituted a large part of the PRP system.

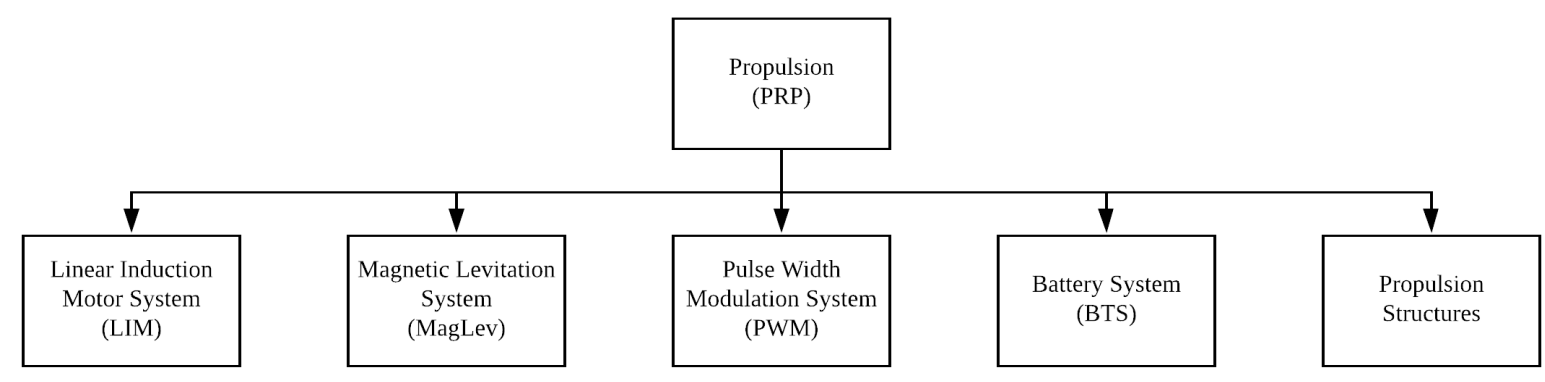

Figure 41. Pod propulsion breakdown.

In addition, as the Linear Induction Motor (LIM) and the Magnetic Levitation (MagLev) systems were the only onboard propulsion systems, it was considered to be the main focus of the PRP. The Pulse Width Modulation (PWM) system, and the batteries were considered to be auxiliary to the LIM and MagLev as they were COTS systems.

\subsubsection{Linear Induction Motor}

The basis of operation of a LIM is very similar to that of a Rotary Induction Motor (RIM). In a way, when a rotary motor is opened up, and flattened out, a LIM is obtained. This cutting process to form a LIM from a RIM has been illustrated in Figure 42 [28]. This in allows for the production of a linear force instead of a rotary torque that would otherwise be generated from a RIM. Based on the winding pattern, input current and voltage, and the supply input, the generated linear force from the LIM could be varied. 


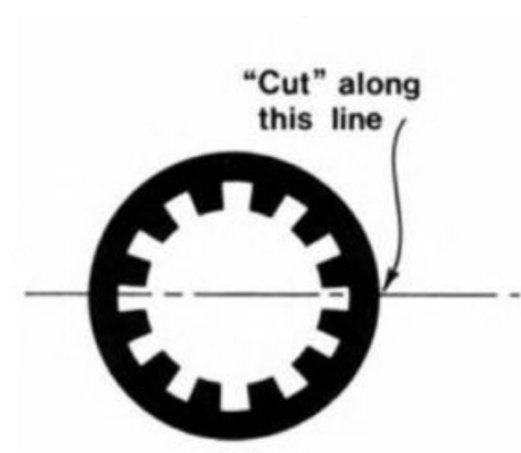

(a)

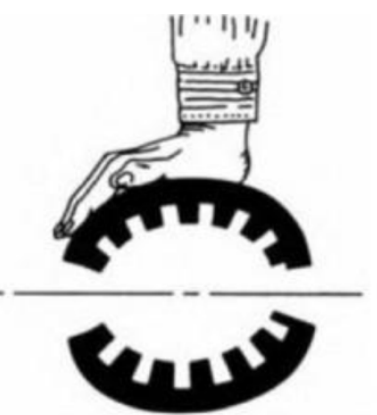

(b)

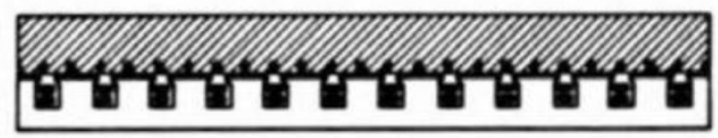

Figure 42. The formation of a LIM from a RIM by I. Boldea [28].

With the absence of mechanical gears, and transmission systems, a LIM results in higher efficiency, higher dynamic performance, and improved overall stability. These advantages in combination with its simple structure and low cost made it an ideal candidate for the Hyperloop [29].

A conventional RIM consists of a stator, and a rotor that form the main basis to produce the rotary torque. The stator consists of windings that are uniformly and sequentially placed within its slots. This configuration generated a sinusoidally distributed magnetic field. However, in the case of a LIM, instead of producing a rotating flux, the windings now created a flux in a linear direction [30].

In order for a voltage to be induced within, there needed to be relative motion between the conductor and the magnetic fields. As a result, this can be computed through the following equation.

$$
V_{s}=2 f \tau
$$

where $V_{s}$ is the LIM's synchronous velocity, $f$ is the input frequency, and $\tau$ is the distance between two poles on the circumference of the stator. This parameter is also known as the pole's pitch which can be further defined as follows.

$$
\tau=\frac{2 \pi R}{P}
$$


where $2 \pi R$ represents the circumference of a non-flattened out stator, and $P$ is the number of poles present in the motor. However, with the analysis being conducted for a LIM, the aforementioned equation can be modified as follows.

$$
\tau=\frac{L_{s}}{P}
$$

where the $2 \pi R$ can be equated to be the length of the LIM's stator core [31].

\subsubsection{LIM Forces}

As the LIM was supplied with power, three main forces that are generated are thrust, lateral and normal forces as illustrated in Figure 43. In the case of the Hyperloop Pod, the thrust acts along the longitudinal axis which is along the direction of the proposed motion. The lateral forces are the undesirable forces that tend to throw the stability of the Pod off axis as these were highly dependent on the stator orientation. While the normal force was perpendicular to the stator itself [28].

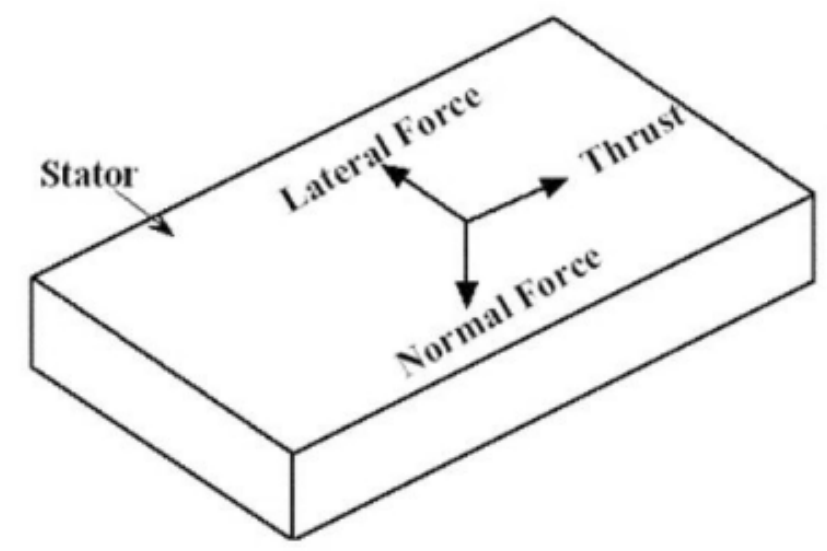

Figure 43. LIM forces adopted from S. P. Bhamidi [32].

\subsection{Thrust Force}

Under nominal Pod operations, the LIM should develop its thrust force proportional to the square of the supplied voltage. This application tends to reduce slip similar to that of an induction motor with high resistance. This thrust force could be computed through the following equation. 


$$
F_{S}=\frac{P_{o}}{V_{c}}
$$

where $F_{S}$ is the amount of thrust produced by the LIM, $P_{o}$ is the output power of the LIM, and $V_{c}$ is the linear speed of the rotor.

\subsection{Lateral Force}

The lateral forces generated from the LIM tend to throw off the stability of the Pod. These occur as a result of the asymmetric position of the stator within the LIM. These forces tend to be small in magnitude resulting in a negligible displacement away from the nominal CG configuration. Furthermore, simply through the incorporation of the Vehicle Stability Module (VSM), which were a small set of mechanical wheels meant to help guide the Pod corrected any instability issues that stemmed from this force.

\subsection{Normal Forces}

The implementation of a single sided LIM within the Pod generated a large normal force due to its asymmetry in topology resulting from a single stator. At the LIM's synchronous speed, the force generated was attractive and got reduced as Pod speed was decreased. In certain cases, especially during high frequency operations, and at certain speeds, this force tends to be repulsive.

However, if the LIM was configured to be double sided, a reaction plate would have been placed between the two stators instead of a single stator. This would result in a normal force to be generated between one stator, and the reaction plate which would ideally be equal and opposite to that of the second stator. This would result in a net force of zero. This would only result when this plate is located asymmetrically between the two stators.

\subsubsection{LIM Winding Configuration}

In order to produce an effective and efficient LIM, its windings were done in a variety of different of configurations. The prominent ones included a single, double, and the triple layer configurations. For the single layer configuration, the number of coils was one half the number of slots available as shown in Figure 44. This resulted in each slot contains only one coil side with such a configuration. With the convenience it provided during the coil assembly, and the need to not have coil-coil insulation that resulted from a single winding layer made it ideal. This configuration is generally used within a single phase motor. 


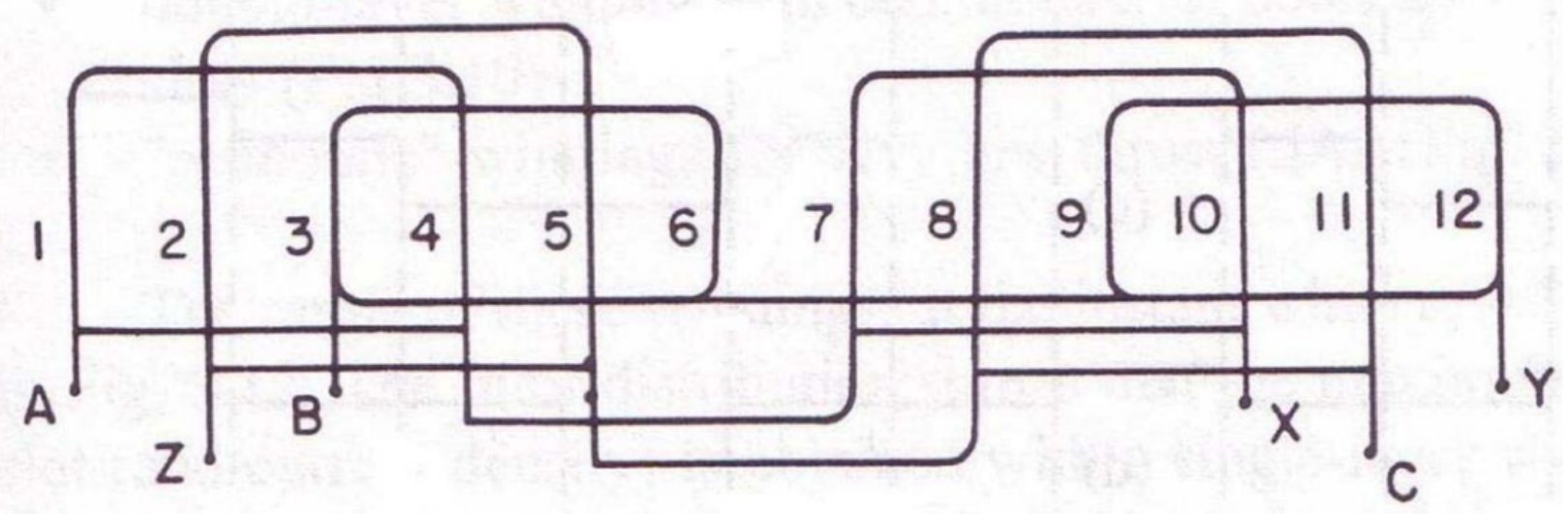

Figure 44. Single layer winding configuration adopted from S. P. Bhamidi [32].

However, most induction motors above a few kilowatts utilize double layer windings. Within this configuration, there were two set of windings of different phases placed within the same slot, except at the end slots as shown in Figure 45. Each coil had two sides to ensures that the windings were placed identically resulting in a balanced arrangement with all the three phases.

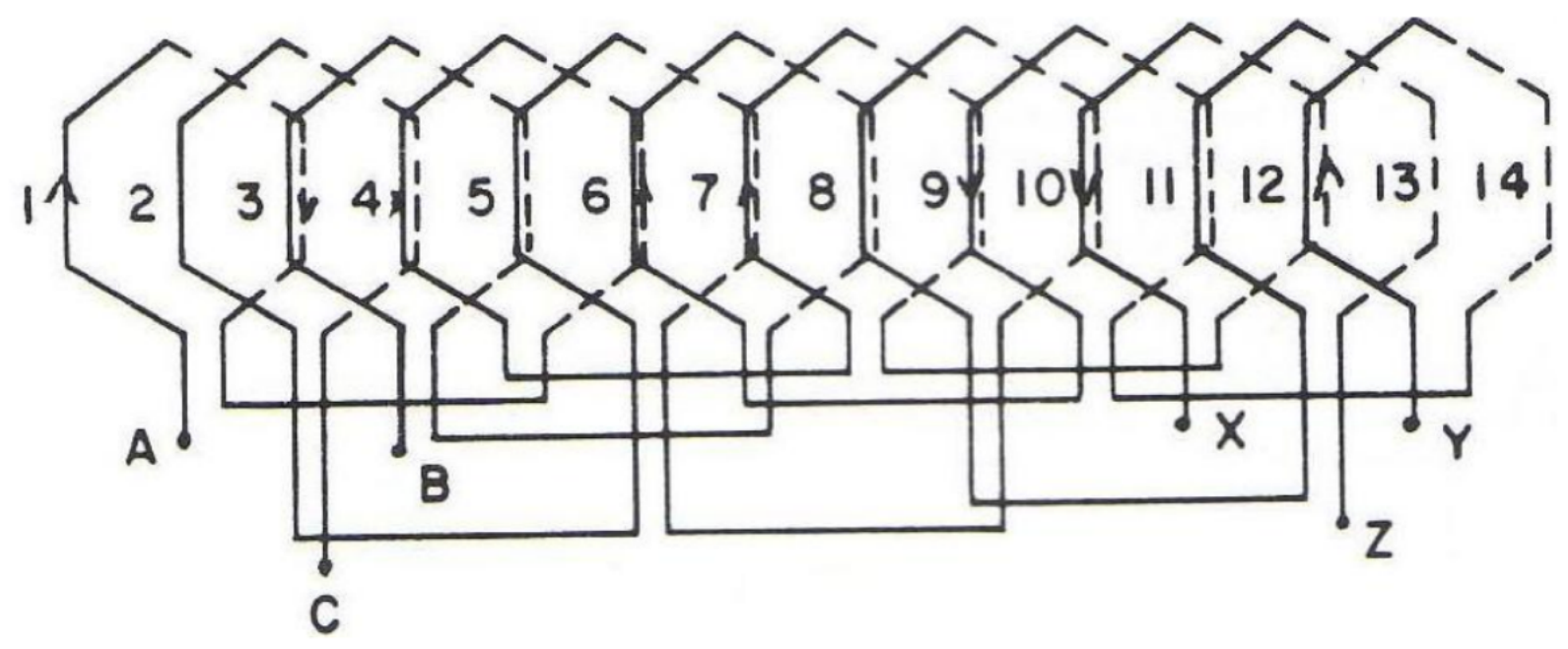

Figure 45. Double layer winding configuration adopted from S. P. Bhamidi [32].

To ensure the same amount of current flowed in each layer, the number of windings and the parallel arrangement depended on the size of each slot. Assuming the permeability of free space $\left(\mu_{0}\right)$ was $4 \pi \times 10^{-7}$, and the copper's volume resistivity $\left(\rho_{\mathrm{r}}\right)$ was $19.27 \times 10^{-9}$, the following equation was used. 


$$
g_{e}=\frac{2 \mu_{0} f \tau^{2}}{\pi\left(\frac{\rho_{r}}{d}\right) G}
$$

where $g_{e}$ is the effectiveness of the airgap, $f$ is the electrical frequency, $\rho_{r}$ is the conductor's volume resistivity, $d$ is its diameter, and $G$ is the Goodness factor. The resulting thrust required to be generated by the LIM could be calculated as follows.

$$
F_{L I M}=\frac{m I_{1}{ }^{2} R_{2}}{\left[\frac{1}{(S G)^{2}}+1\right] V_{S} S}
$$

With overall trajectory of the Pod being dictated by the thrust output from the MagDrive system, i.e. the LIM. In order for the Pod to move at approximately $45 \mathrm{~m} / \mathrm{s}$, the power specifications have been outlined in Table 28 while the schematic for the propulsion system is shown in Figure 46.

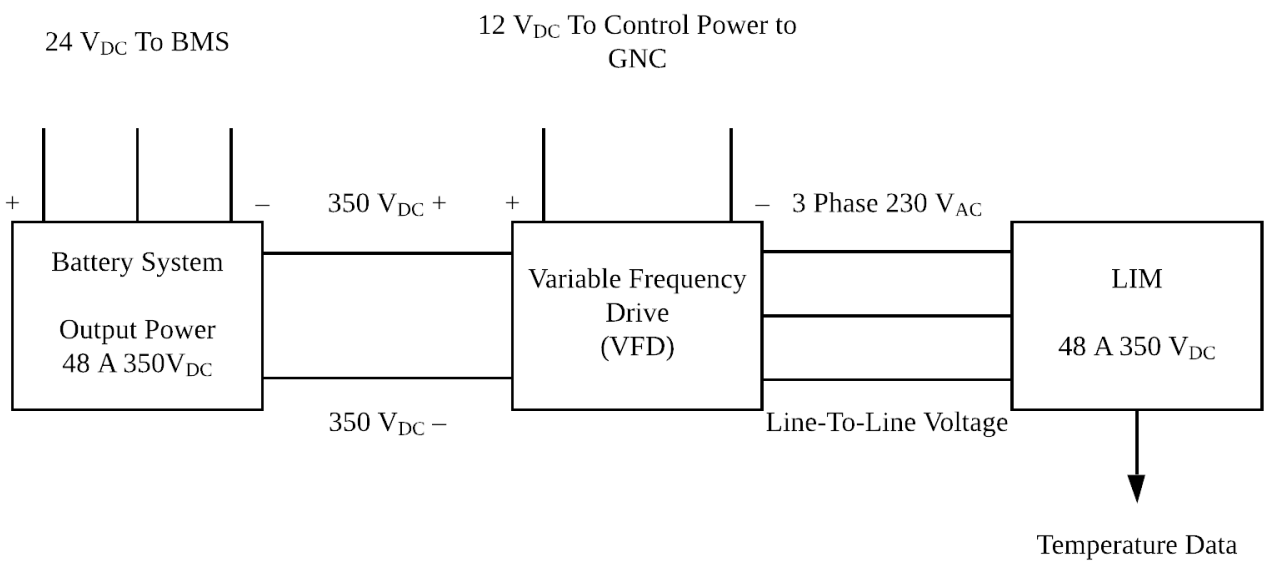

Figure 46. Electrical power schematic for the propulsion system. 
Table 28. Basic power breakdown for the Pod.

\begin{tabular}{lr}
\hline \multicolumn{1}{c}{ Parameter } & Value \\
\hline Battery System Current Output To VFD & $48 \mathrm{~A}$ \\
Battery System Voltage Output To VFD & $350 V_{D C}$ \\
Battery System Voltage Output To BMS & $24 V_{D C}$ \\
VFD Current Output To LIM & $48 \mathrm{~A}$ \\
VFD Voltage Output To LIM & $350 V_{D C}$ \\
VFD Voltage Output To GNC & $12 V_{D C}$ \\
\hline
\end{tabular}

\subsubsection{Magnetic Levitation System}

To improve the Pod's efficiency and to reduce the contact friction generated from a wheeled system, the Pod utilized a passive Magnetic Levitation (MagLev) system at high speeds as shown in Figure 47. The MagLev system consisted of the MagLev Actuator, and MagSkis. The inclusion of the MagLev Actuator allowed for the MagSkis to move along the normal direction. By doing so, the magnetic levitation force could be precisely controlled to ensure the Pod was maintained at constant height above the test track. Furthermore, through testing and optimization, it was found that the LIM should be maintained at a height of approximately $3 \mathrm{~mm}$ above the track to generate the largest amount of thrust while minimizing MagDrag.

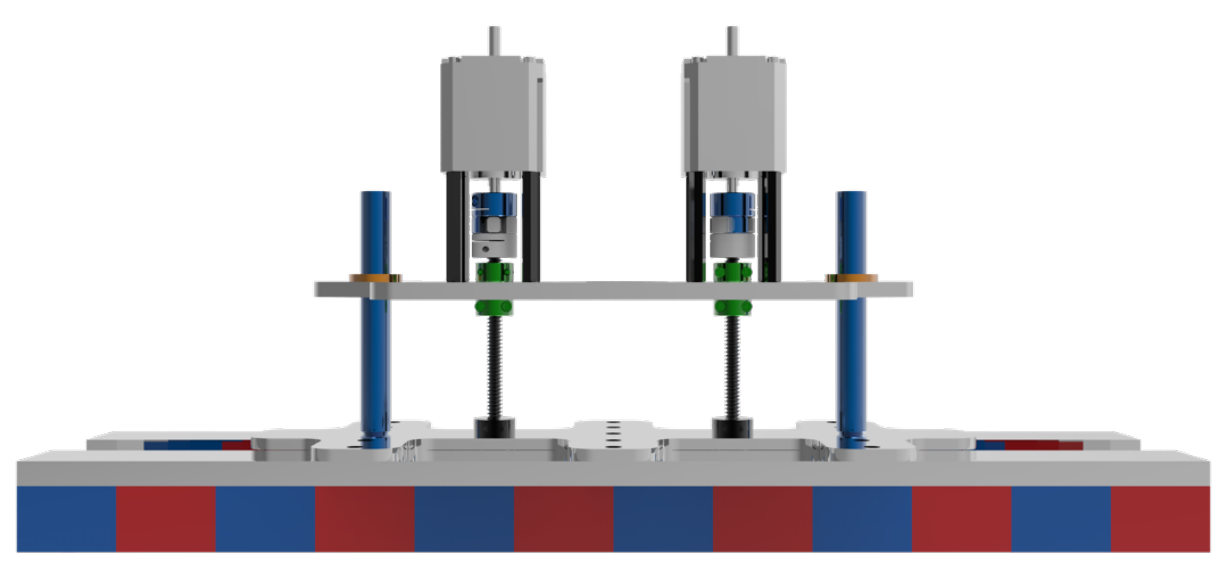

Figure 47. Assembled Hyperloop Pod MagLev system. 
To levitate the Pod while maintaining the LIM at the predetermined height, a total of 24 permanent magnets were attached to the steel backing plate. The magnetic force generated from the magnets will induce both a levitating force, and a magnetic drag force (MagDrag). As a result, the magnets and the steel backing plate made up the highest percentage of the total system mass. This was done to ensure the system produced the necessary levitating force. Furthermore, this was done as they were the only components that created, and channeled the magnetic fields within the MagLev system.

Using a coefficient of dynamic friction of 0.15 , the torque needed to move the MagLev system up and down was found to be $0.305762 \mathrm{~N}$ and $0.091579 \mathrm{~N}$ respectively as shown in Table 29. As a result, the total torque required to actuate the mechanical system was low. Therefore, the motor was selected based upon its rated force to effectively actuate the system upwards and downwards. In addition, this was done with a FoS of 1.3 to ensure system reliability at all times.

Table 29. Mechanical load computations on MagLev actuators.

\begin{tabular}{lr}
\hline \multicolumn{1}{c}{ Parameter } & \multicolumn{1}{c}{ Value } \\
\hline Coefficient of Dynamic Friction & 0.15 \\
System Raise Required Torque & $0.305762 \mathrm{Nm}$ \\
System Lower Required Torque & $0.091579 \mathrm{Nm}$ \\
Lead Screw Calculation & $1.5875 \mathrm{~mm}$ \\
Thread Count & 16 Threads $/ \mathrm{in}$ \\
Pitch Diameter & $6.35 \mathrm{~mm}$ \\
Factor of Safety & 2 \\
\hline
\end{tabular}

Due to the MagLev generating a levitation force and MagDrag acting on the system, axial, bending, and shear loadings would be induced on the linear guides. As a result, the guides were designed to withstand the forces along these directions.

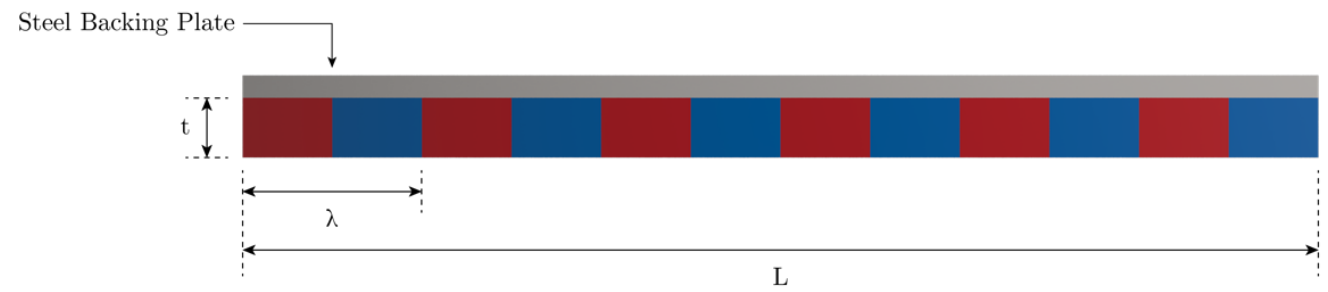

Figure 48. Magnet Dimensional Parameters. 
With the goal being to create an optimized MagLev, an appropriate grade of magnet needed to be selected. With a variety of magnetic field strengths being available, analysis showed that grades above N52 experienced a noticeable increase in its demagnetization effects as shown in Figure 49. This graph provided information on its strength and demagnetization properties based on operating temperatures. As a result, a magnet grade of N42 was selected, and its properties have been tabulated in Table 30 [33].

Table 30. Magnet grade specifications for N42 Magnets.

\begin{tabular}{lr}
\hline \multicolumn{1}{c}{ Parameter } & \multicolumn{1}{c}{ Value } \\
\hline Magnet Grade & $\mathrm{N} 42$ \\
Weight & $0.2766 \mathrm{~kg}$ \\
Length & $38.1 \mathrm{~mm}$ \\
Width & $38.1 \mathrm{~mm}$ \\
Thickness & $25.4 \mathrm{~mm}$ \\
Rated Pull Force & $688 \mathrm{~N}$ \\
Maximum Operating Temperature & $80^{\circ} \mathrm{C}$ \\
Br Max & $13,200 \mathrm{Gauss}$ \\
B-H Max & $42 \mathrm{MGOe}$ \\
\hline
\end{tabular}

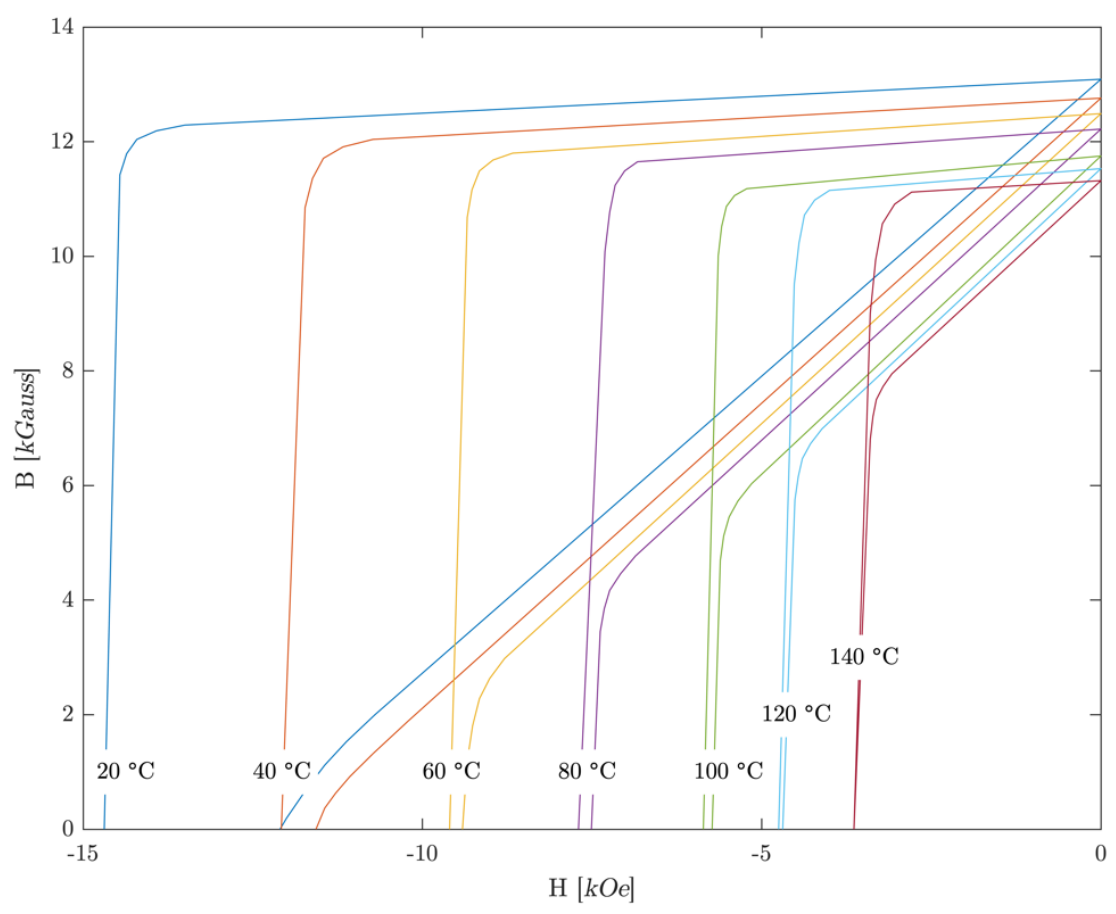

Figure 49. Demagnetization B-H curve for N42 Neodymium magnet [33]. 
Table 31. Magnet and backing plate specifications for Pod MagSkis.

\begin{tabular}{lr}
\hline \multicolumn{1}{c}{ Parameter } & \multicolumn{1}{c}{ Value } \\
\hline Wavelength $(\lambda)$ & $76.2 \mathrm{~mm}$ \\
Length $(\mathrm{L})$ & $457.2 \mathrm{~mm}$ \\
Width $(\mathrm{w})$ & $38.1 \mathrm{~mm}$ \\
Magnet Thickness $\left(\mathrm{t}_{\mathrm{Mag}}\right)$ & $25.4 \mathrm{~mm}$ \\
Backing Plate Thickness $\left(\mathrm{t}_{\text {plate }}\right)$ & $9.525 \mathrm{~mm}$ \\
Total Number of Periods & 24 \\
\hline
\end{tabular}




\subsection{Pod Guidance, Navigation and Control}

Figure 50 illustrates the Pod's trajectory for the entire duration of the Hyperloop run. As seen from the graph, the run had been classified into four distinct categories Launch, Levitation, Braking, and Crawling phases. Each of which engaged certain systems. This graph provided an operating envelope for the Pod during nominal and an off-nominal Hyperloop runs.

The plot included two distinct acceleration curves representing the Pod's maximum $\left(2.55 \mathrm{~m} / \mathrm{s}^{2}\right)$, and minimum $\left(1.25 \mathrm{~m} / \mathrm{s}^{2}\right)$ acceleration profiles based on the LIM's expected performance data. Once levitation velocity of $45 \mathrm{~m} / \mathrm{s}$ is attained, the MagLev system is activated. Whereby, acceleration is expected to decrease by a slight amount due to MagDrag being generated by the MagLev. At the conclusion of the levitation phase, the braking sequence is initiated.

All the profiles including the two acceleration, levitation, and braking phases were computed by equating their slopes to be solved for the distance they intersected at. Knowing that the MagLev system took approximately 0.5 s to extend or retract, the point at which the system began to have an effect on the run was calculated through basic dynamic equation as follows.

$$
V_{f}=V_{i}+a t
$$

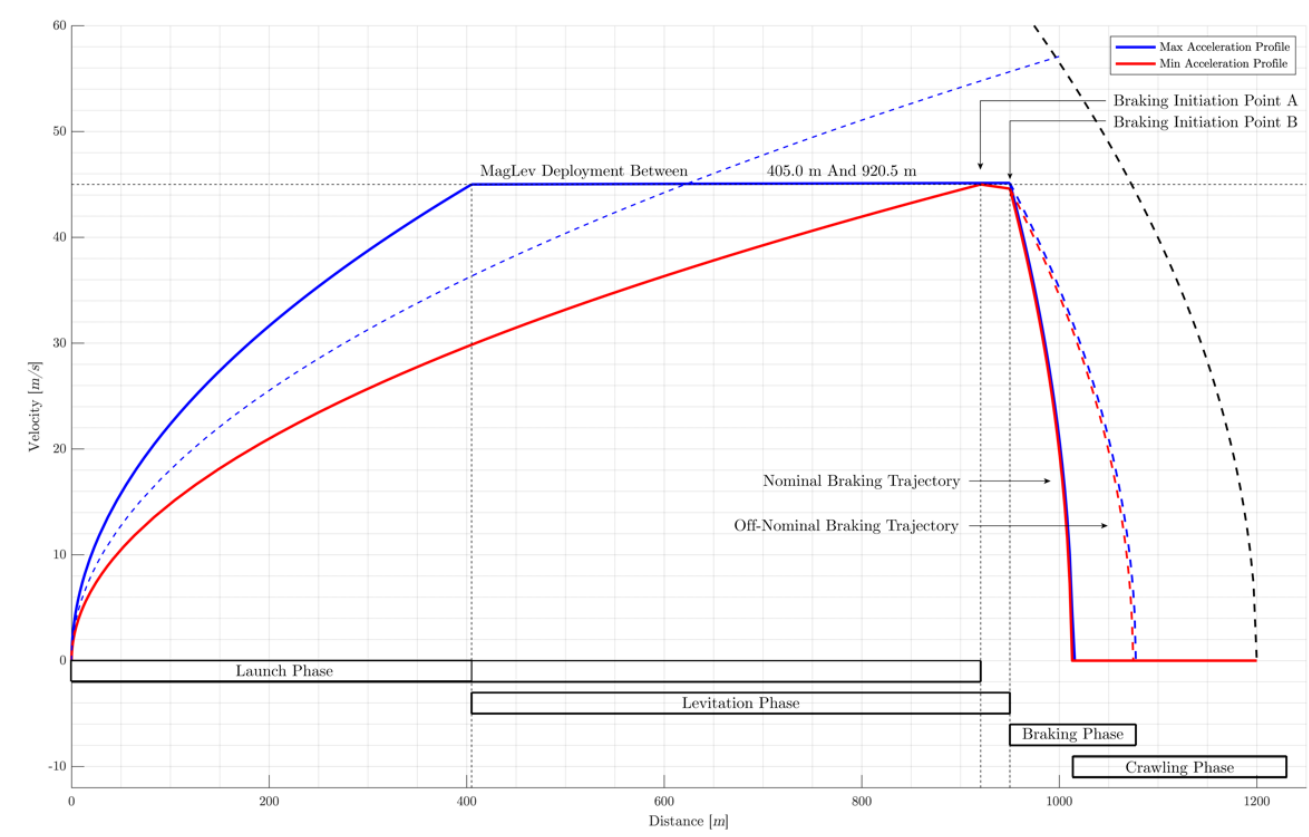

Figure 50. Pod trajectory profile. 
In addition to the acceleration and levitation profiles, the Pod's nominal and offnominal braking scenarios were accounted for. This was done to highlight the effects of braking when one braking system became inoperable. With a delay of about $0.5 \mathrm{~s}$ needed for the pneumatic braking lines to be fully pressurized, the braking sequence was made to be activated at the $927 \mathrm{~m}$ mark. By doing so, it allowed for Pod to be at full power and to begin braking at full force as it reached the $950 \mathrm{~m}$ marker within the Hyperloop tube.

With braking being the most critical phase within the entire run, the activation of its sequence was made to be dynamically computed. This was particularly crucial as testing within the Hyperloop tube had not been conducted before. By doing so, if the Pod experienced higher acceleration and the Pod velocity exceeded its target velocity, the braking sequence would be initiated earlier. This was done to ensure enough braking was available to bring the Pod to a safe halt. However, if the Pod performs with a lower acceleration, the braking sequence would be activated at a much later point.

Once the Pod comes to a safe halt and if it underwent nominal operations, the crawling phase could be activated. This would allow it to move forward at a low speed of $1 \mathrm{~m} / \mathrm{s}$ until the forward range sensor detects the end of the Hyperloop tube approximately $20 \mathrm{~m}$ away. With the controllers running at a frequency of $20 \mathrm{~Hz}, 50 \mathrm{~ms}$ per loop, a lag in position of approximately $3 \mathrm{~m}$ was to be expected and was accounted for in the telemetry data.

\subsubsection{Pod States}

As Hyperloop Pods are expected to travel at high speeds, the designed Pod was made to be fully autonomous with a constant stream of data transmitted to the Ground Station (GS). The Pod has a total of seven states that assist it in completing its mission. Once powered up, it automatically defaults to a "Safe To Approach" state. This is done only when the Pod is stationary, in good working condition without any major faults, and is safe for humans to approach it. Upon the completion of the necessary checks within the tube, the Pod then has the capability to go into the remaining states as shown in Table 32 .

After receiving necessary approvals from the launch authorities, the Pod is entered into the Ready To Launch state, where final braking checks are performed. The Pod also verifies all temperature readings to be within their operational limits. During this phase, the laser sensor required to measure its location within the tube is verified to be receiving nominal data. Upon the successful completion of all requirements, the Pod is accelerated to its predefined target velocity of $45 \mathrm{~m} / \mathrm{s}$. As levitation speed is attained, the MagLev system is deployed whereby, the Pod is lifted off its wheels greatly reducing drag, and improving its linear acceleration. 
To ensure safety of Hyperloop tube, the Pod, and all the personnel involved, regardless of the MagLev functionality, the Pod is entered into the braking state $0.5 \mathrm{~s}$ before reaching the $950 \mathrm{~m}$ mark. This ensured both the forward, and aft braking system's pressure lines are fully charged and ready to be engaged at the $950 \mathrm{~m}$ milestone. For added safety in the event the Pod fails to identity the $950 \mathrm{~m}$ navigational marker, a second redundant braking trigger point was built into the system once the final $76 \mathrm{~m}$ are remaining. The ensured the Pod automatically deployed its brakes as it arrived at the redundant trigger point.

At any point during the run, if the Pod encounters an anomaly, a critical system failure, system error, or a loss in communication with the GS, the Pod automatically transitioned into the fault state. This transition activates the braking system whereby it is brought to a safe halt no matter the earlier state of the Pod.

Table 32. Pod states controlled by the GNC system.

\begin{tabular}{|c|c|}
\hline Pod State & Description \\
\hline Safe To Approach & $\begin{array}{l}\text { Indicated that the Pod is stationary, in good working } \\
\text { condition without any major faults, and is safe for humans } \\
\text { to approach it. }\end{array}$ \\
\hline Ready To Launch & $\begin{array}{l}\text { Performed final checks, and readies key systems for } \\
\text { launch. }\end{array}$ \\
\hline Launch & The Pod is accelerated to the predefined target velocity. \\
\hline Levitation & $\begin{array}{l}\text { During a nominal Pod launch, and upon reaching a } \\
\text { predefined velocity, the MagLev system is deployed to } \\
\text { achieve levitation. }\end{array}$ \\
\hline Braking & Brings the Pod to a safe halt. \\
\hline Crawl & $\begin{array}{l}\text { Moves the Pod at a very low speed using manual control } \\
\text { from the GS. }\end{array}$ \\
\hline Fault & $\begin{array}{l}\text { A non-nominal, unknow or unsafe event or a parameter } \\
\text { fell outside its operating envelope was detected, and Pod } \\
\text { automatically comes to a stop. }\end{array}$ \\
\hline
\end{tabular}




\subsubsection{Mission Concept of Operations}

Figure 51 provides a detailed overview of the nominal mission concept of operations of the Pod. Within this breakdown, the mission was categorized into three distinct phases - Pre-Launch, Launch, and Post-Launch. Each of these categories consist of various system interactions with real time Pod telemetry being transmitted back to the GS for viewing and analysis.

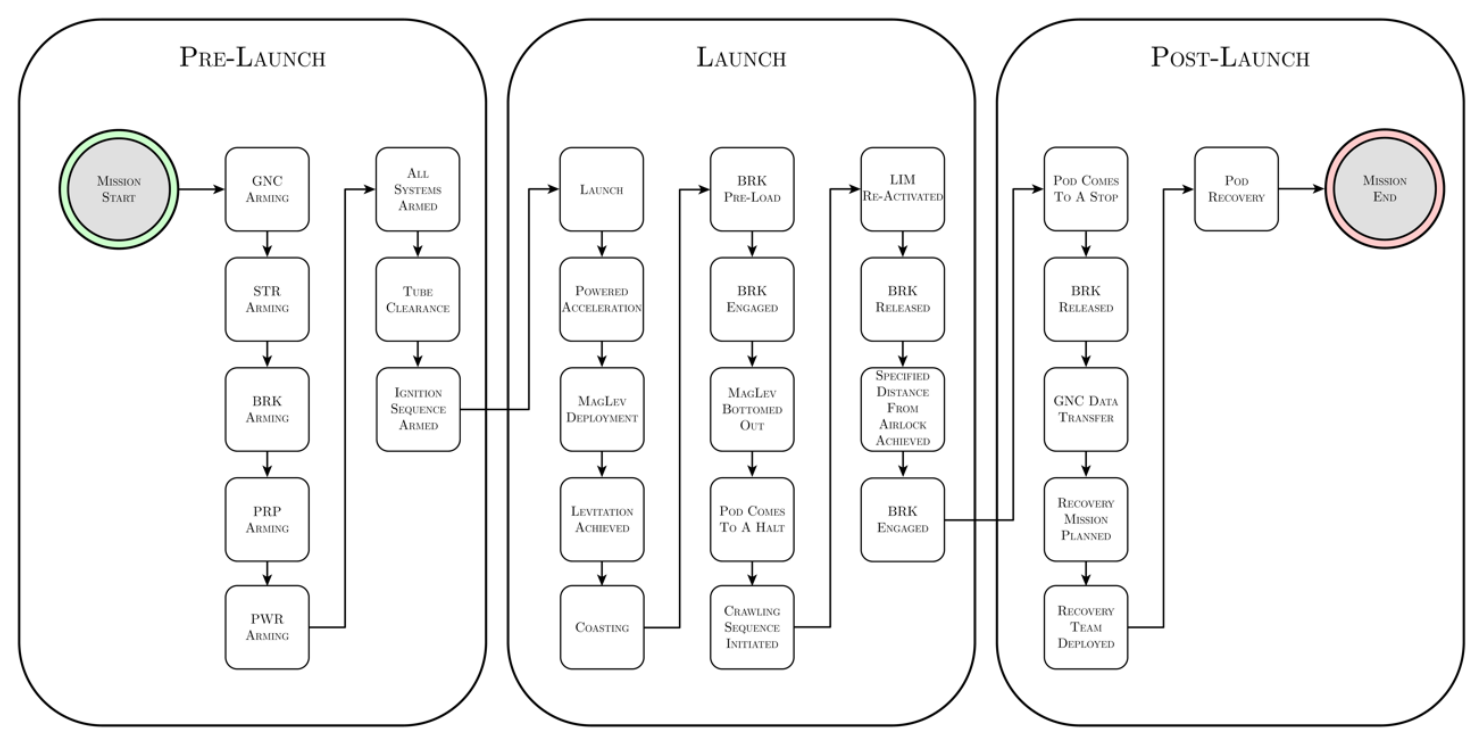

Figure 51. Ryerson International Hyperloop's mission concept of operations. 


\subsection{Testing Challenge}

With the Hyperloop tube being located in Hawthorne, California, the Hyperloop Pod needed to be tested to ensure all its systems met certain standards. This was very critical as the Pod needed to operate within a low pressure environment, using the predefined track specifications at a varying temperature rage.

As a university team, the possibility of travelling to Hawthorne, California more than once a year was out of question mainly due to logistical and economic difficulties. To overcome this, a possible solution that was looked into was to design and build an exact replica of the test track used within the Hyperloop tube. In doing so, testing could be conducted without the need to make multiple trips to Hawthorne. In addition, such a development would open the doors to an iterative design process where even minor modifications in the design could be tested, and validated at a very rapid pace.

In order to replicate the test track, approximately $45 \mathrm{~m}$ was needed to have substantial linear length in order to gather meaningful results. As the Pod utilized a LIM and MagLev systems, the test track was required to be manufactured out of a similar material in order to ensure results obtained from the replica track would still be comparable with the test track in Hawthorne, California. The breakdown for such a test track has been tabulated in Table 33 .

Table 33. Replica testing and development track specifications.

\begin{tabular}{lr}
\hline \multicolumn{1}{c}{ Parameter } \\
\hline Test Track & Value \\
Material & Replica Testing \& Development Track \\
Designation & Aluminum \\
Stock Profile & Flat Plate \\
Finished Profile & $I-$ Beam \\
Linear Length & $45 \mathrm{~m}$ \\
Total Length & $135 \mathrm{~m}$ \\
Width & $127 \mathrm{~mm}$ \\
Height & $127 \mathrm{~mm}$ \\
Thickness & $10.46 \mathrm{~mm}$ \\
Cost & $C A D \$ 84.65 \mathrm{per} \mathrm{m}$ \\
\hline
\end{tabular}

Being a downtown university, square footage is a sought after, and an expensive commodity. As a result, the possibility of acquiring the necessary square footage to lay down a track along with its accompanying safety measures was next to impossible. Therefore, alternative methods of testing, and validating the systems were looked into. 


\subsection{Modular Test Rig}

With aircraft structures subjected to high level of forces and shocks, ensuring such components passed all the necessary aviation standards is critical step within its design process. [34] The aerospace industry performs a series of quality control tests during the components lifecycle including during its design, manufacturing, and service life.

For example, the landing of an aircraft exposes the landing gear to significantly high forces when compared to all other phases. As a result, aircraft brake dynamometer testing is used to simulate real life operating conditions including take-off, taxi, and landing. During testing, its wheels are accelerated to its landing reference speed ( $\left.\mathrm{V}_{\mathrm{Ref}}\right)$ [35]. Upon reaching $\mathrm{V}_{\text {Ref, }}$, the gear is dropped to simulate similar loads experienced by aircraft during a real landing. Such a process allowed for the determination of all the loads accurately while observing its behavior and response. By having rigorous testing and validation standards, today's aircraft structures are designed with sufficient margins to account for any loads it may see throughout its lifespan.

With the aerospace and the landing gear industry using such tools for its tests, an innovative approach was taken to design an in-house Hyperloop systems test rig. The modular test rig that was developed was made to accommodate tests from STR, GNC, and PRP. Furthermore, it allowed for the validation of said systems individually, or while being integrated in combination and in conjunction with each other. Figure 52 showcases the Modular Test Rig (MTR) designed to test and validate the various Hyperloop systems. Internally, this test rig is also referred to as "The Doughnut". 


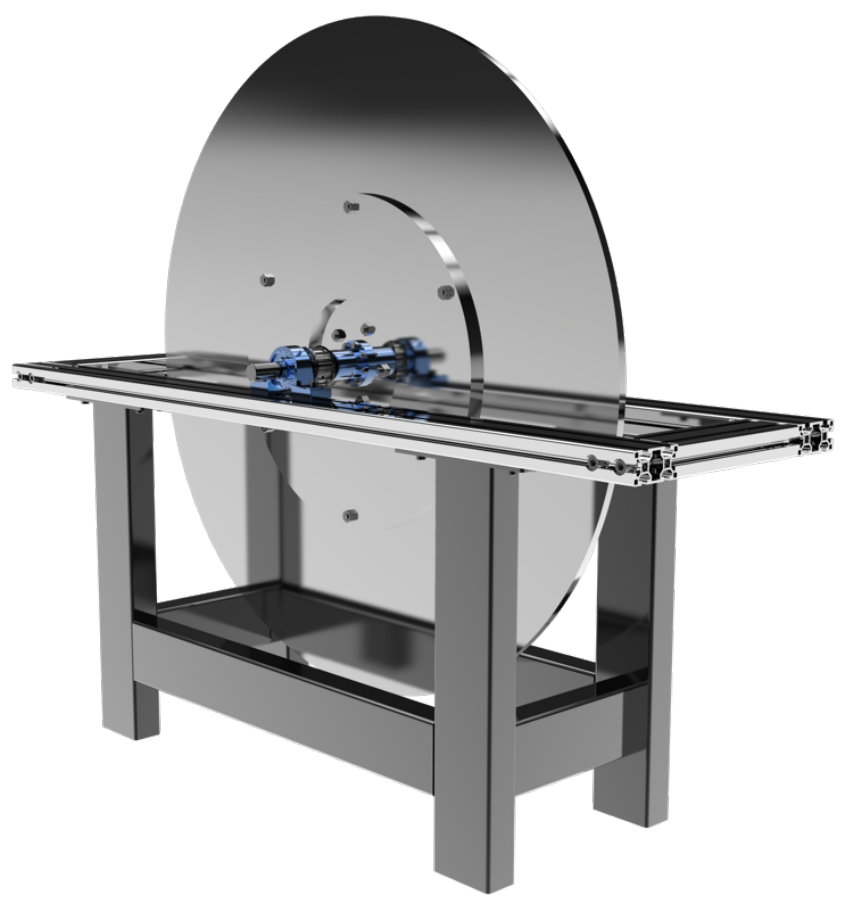

Figure 52. The Hyperloop modular test rig.

Furthermore, the need to lay down the guide rail as outlined in Table 33 was completely eliminated after the MTR was made to rotate about the axis. By doing so, instead of having a $45 \mathrm{~m}$ test track, an infinite track was achieved. Through this approach the MTR occupied minimal square footage of approximately $1.4 \mathrm{~m}^{2}$. Rather than the 93 $\mathrm{m}^{2}$ that would have otherwise been needed to lay down the $45 \mathrm{~m}$ of the required test track.

Observing Figure 52 and going from bottom to top of the MTR, it could be broken down into its support frame, system mounting frame, track, and the motor itself. This breakdown has been illustrated below. 
Table 34. Breakdown of the Modular Test Rig.

\begin{tabular}{ll}
\hline \multicolumn{1}{c}{ Component } & \multicolumn{1}{c}{ Purpose } \\
\hline Support Frame & $\begin{array}{l}\text { Supported the MTR and allowed for it to be bolted to the } \\
\text { ground. }\end{array}$ \\
System Mounting Frame & $\begin{array}{l}\text { Allowed for the integration of the track to the MTR and } \\
\text { provided a modular method to test various Hyperloop } \\
\text { systems. } \\
\text { Allowed for the characterization of system behaviors such as } \\
\text { STrack }\end{array}$ \\
STR, GNC, and PRP. \\
Provided a means to rotate the track at a specified RPM. \\
\hline
\end{tabular}

The development and manufacturing of the MTR utilized a similar material to that of the actual Hyperloop test track. This allowed for the characterization of the Hyperloop systems, and ensured similar behavior would be observed had the same tests been conducted in Hawthorne, California. This was critical to generate the necessary test data required to validate the various Hyperloop systems. Furthermore, the performance of MagLev, MagDrive, Eddie Current Braking, and GNC tests were critical as they were highly dependent on the material properties of the track being used.

The material breakdown for the major MTR components have been defined in Table 35. Whereas, Figure 53 highlights the motor's performance. Observing its speed and torque characteristics, continuous operation of the MTR was possible when its operated within the continuous duty region. Whereas, the limited duty region was primarily reserved to aid in the acceleration of the MTR [36].

Table 35. Material selection breakdown for the Modular Test Rig.

\begin{tabular}{lr}
\hline \multicolumn{1}{c}{ Component } & Material Selection \\
\hline Support Frame & High Strength Steel \\
System Mounting Frame & Aluminum Al 6105-T6 \\
Track & Guide Rail Replication \\
Motor & $120 \mathrm{~W}(1 / 6 \mathrm{HP})$ Brushless DC Motor \\
\hline
\end{tabular}




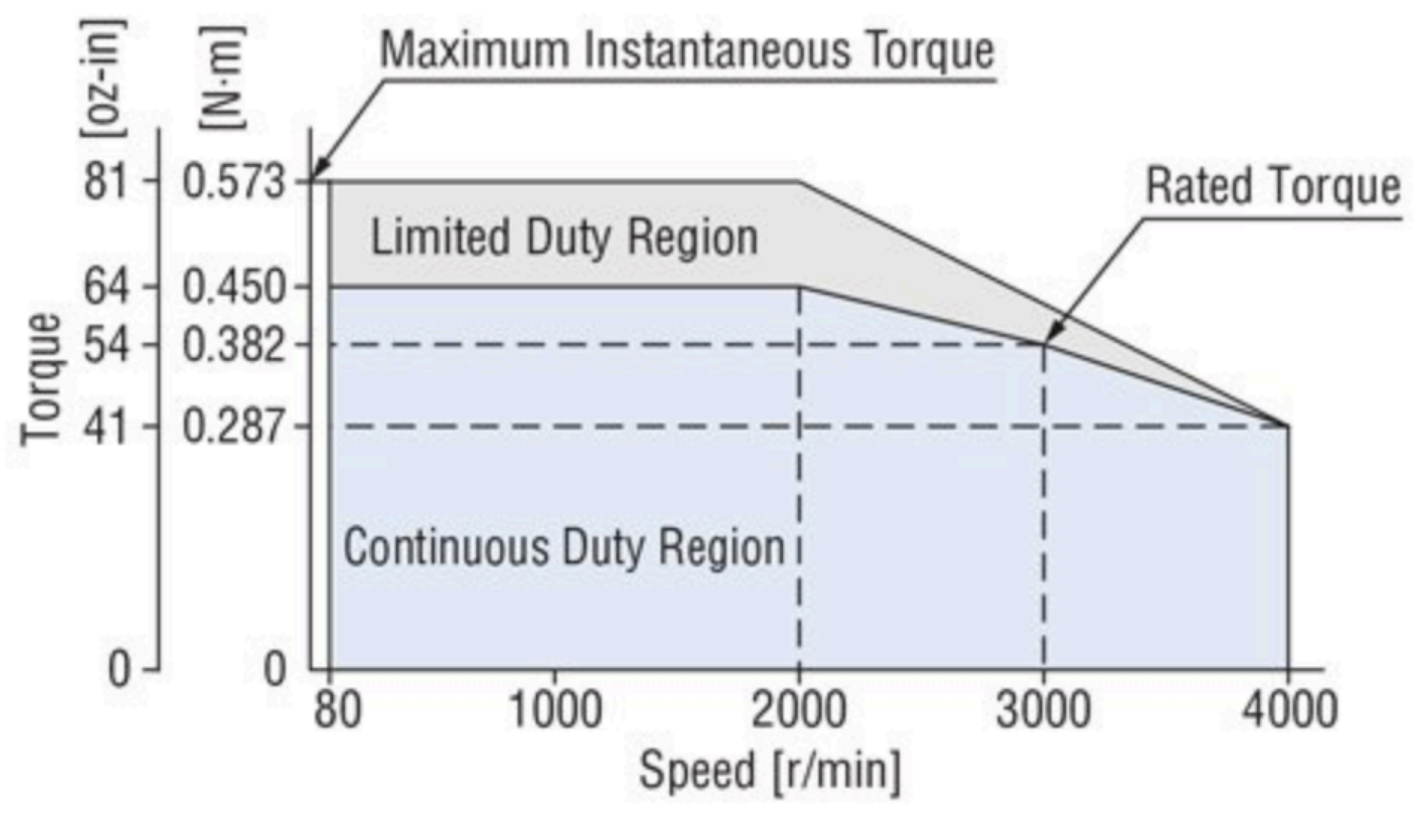

Figure 53. Motor performance plot for the MTR adapted from Oriental Motors [36].

\subsubsection{Modular Test Rig Analysis}

Before the MTR could be used for the Hyperloop systems tests, the test track and its supporting shaft were analyzed to ensure it met the necessary safety standards. During the analysis, it was subjected two worst case scenarios.

\subsubsection{Load Case I (MTR Lock-Up)}

The first being, the shaft would inadvertently locked-up which in turn would cause the track to experience a lock-up as well causing it to come to an abrupt stop. Under this load condition, the shaft is expected to have a deformation of $0.0925 \mathrm{~mm}$, while it experienced a stress value of $26.615 \mathrm{MPa}$ as shown in Figure 54 and Figure 55 respectively. 


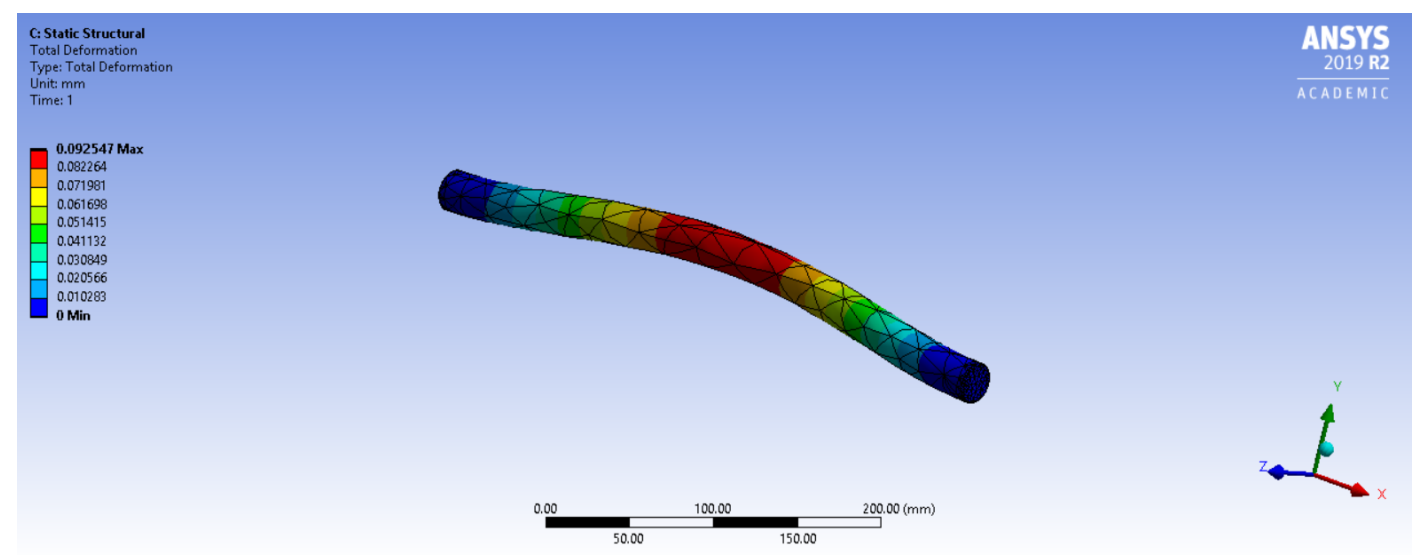

Figure 54. Shaft deformation during MTR lock up.

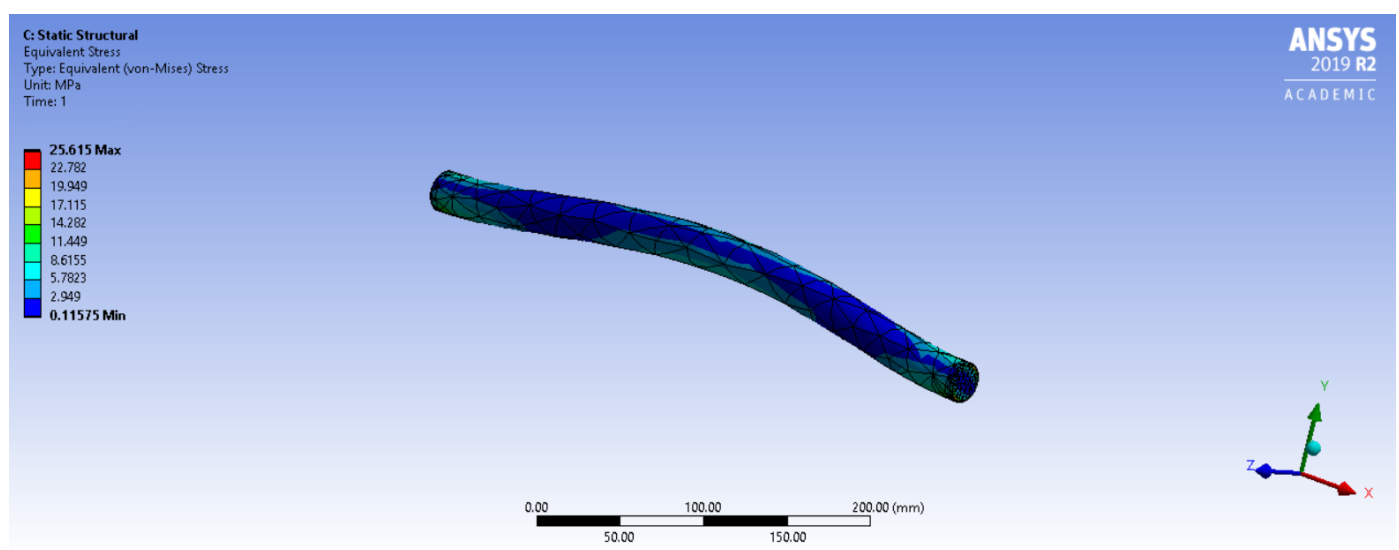

Figure 55. Shaft stresses during MTR lock up.

Meanwhile, under this same loading condition, the track experienced a deformation of $0.00208 \mathrm{~mm}$ outwards as illustrated in Figure 56. Whereas Figure 57 displays the track stress that was computed to be $1.978 \mathrm{MPa}$.

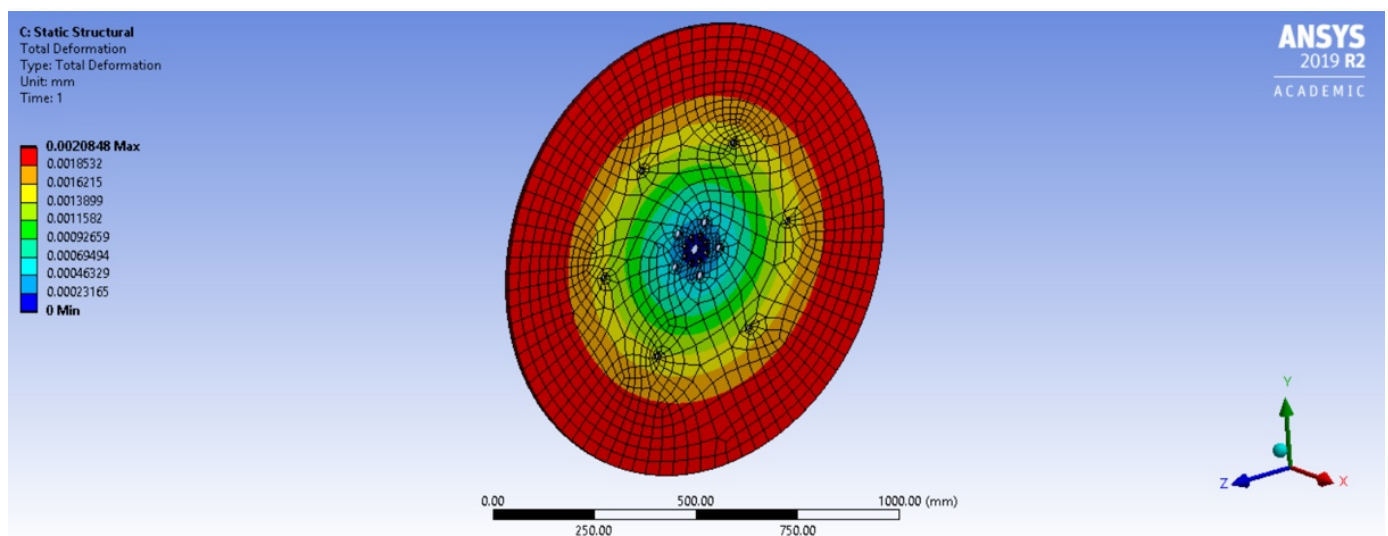

Figure 56. Track deformation during MTR lock up. 


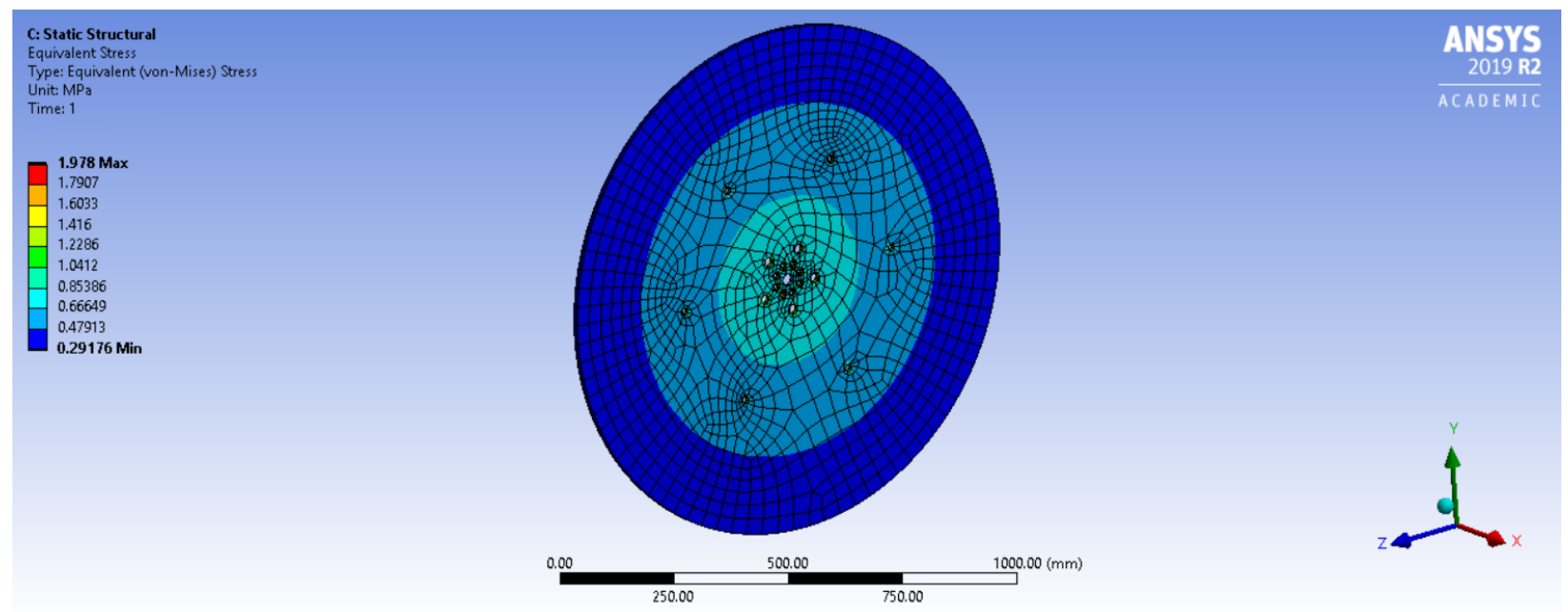

Figure 57. Track stress during MTR lock up.

\subsubsection{Load Case II (MTR Overspeed)}

Under this loading scenario, it was assumed that the overspeed limit built into the MTR malfunctioned. This caused the track to increase its angular acceleration up to a high rated velocity of $50 \mathrm{rad} / \mathrm{s}$. Under this load case, a deformation of $0.00208 \mathrm{~mm}$ was to be expected as illustrated in Figure 58. Whereas, an internal stress of 1.978 MPa was generated within it as shown in Figure 59.

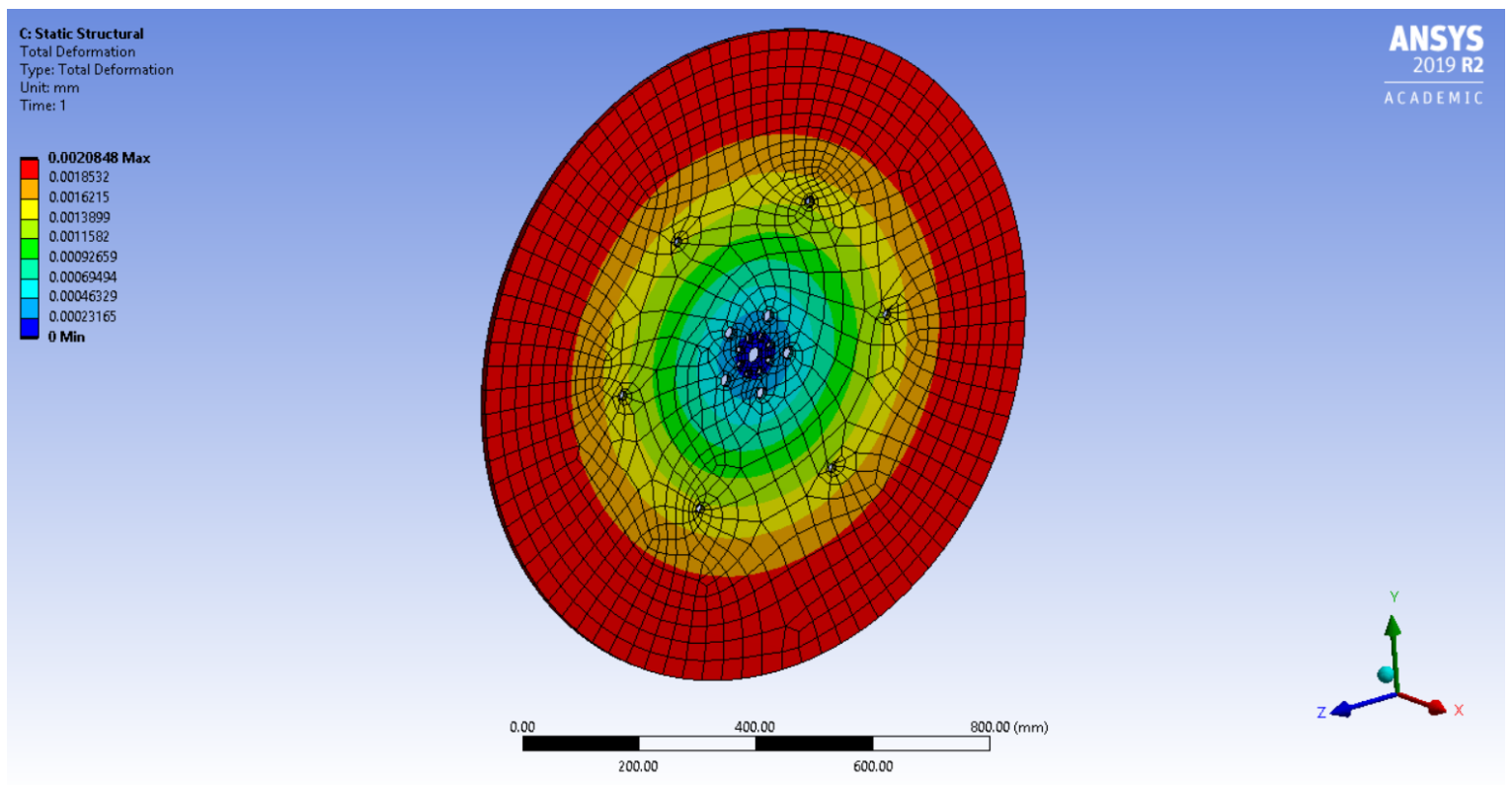

Figure 58. Track deformation during MTR overspeed. 


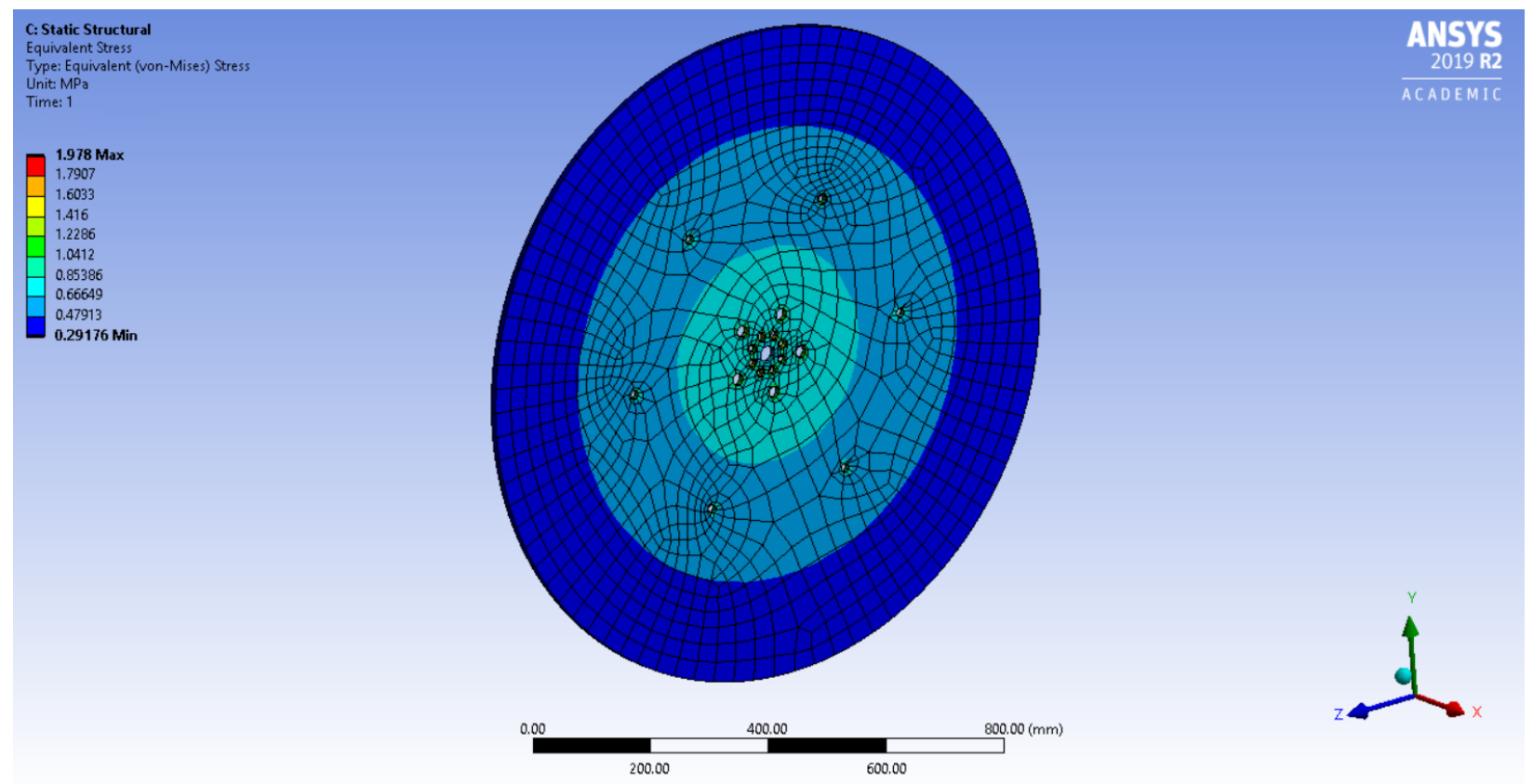

Figure 59. Track stress during MTR overspeed.

\subsubsection{Guidance, Navigation and Control Tests}

Although the Pod operates autonomously, a constant stream of data flows between the Pod and the Ground Station (GS). With data continuously transmitted some of the parameters monitored by the Pod and sent to the GS were its position, velocity and acceleration, Pod health, temperatures and pressures, and so on.

With the Hyperloop Pod operating in a low pressure environment, initial GNC tests were performed in a pressurized environment. Although this was the case, final Pod electronics needed to be vacuum certified, and thermally rated. This included the use of space grade solder while being in a controlled environment, and x-ray imaging of all the joints to guarantee performance when operated in a low pressure environment. All soldering and electrical work was conducted by following National Aeronautics and Space Administration (NASA) technical standards to ensure the highest levels of performance [37].

The Hyperloop tube has a reflective circumferential tape placed at regular intervals for navigation purposes [10]. In order to make use of this tube feature, GNC's navigation mechanism consisted of a stripe counting sensor that provided the absolute position of the Pod within the Hyperloop tube. Testing of the stripe counter was conducted on the MTR to ensure the Pod's navigation mechanism performed as intended. It also allowed for the necessary fine tuning in order to compensate for the reflectivity of the test track's material, which was Aluminum. This was important as a laser beam needed to be reflected off it. 
Furthermore, the fluorescent lighting setup within the tube could be replicated, and accounted for in order to generate accurate results. With the accuracy of the stripe counter being critical to the Pod, the drift occurring as the position and velocity errors over time needed to be quantified in order to demonstrate its accuracies.

\subsubsection{Structures Tests}

During the design of the braking system, key considerations included the distance required to stop, braking effectiveness, system reliability, resulting temperature change, and so on. As the Pod underwent various state changes, multiple tests were conducted using the MTR to characterize them.

As the Pod contained two independent pneumatic braking systems, each system had the ability to deploy two brake pistons simultaneously. As outlined previously, to ensure stability of the Pod during all braking phases, the systems were placed at the forward, and aft locations of the Pod. To validate this setup, a simplification was made where only one of the two systems was mounted on the MTR. By doing so, the braking tests in a way were performed for the worst case scenario, i.e. one system was considered to be inoperative. This particular setup can be observed in Figure 60 where the two pneumatic pistons were mounted to the mounting frame on either side of the MTR.

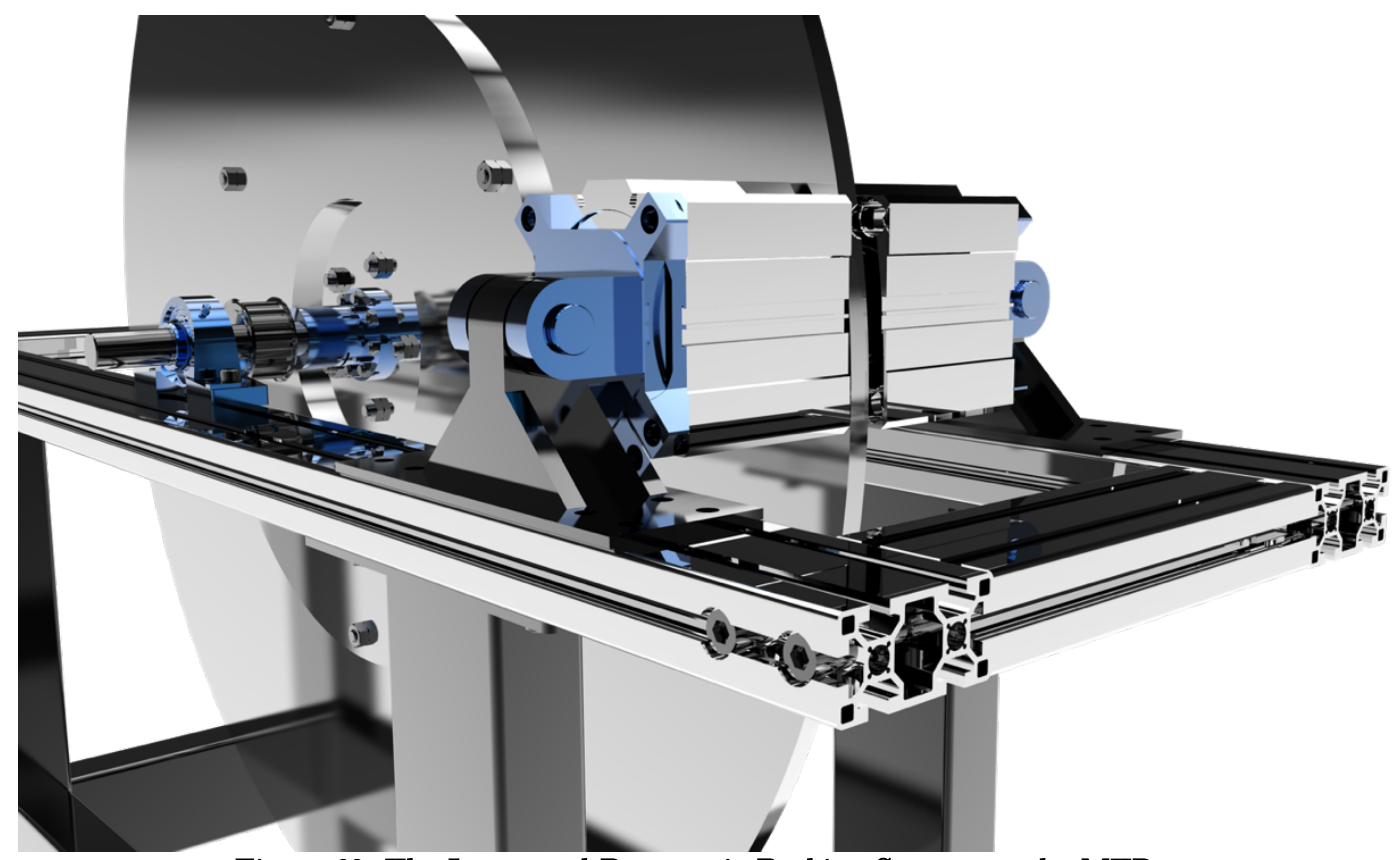

Figure 60. The Integrated Pneumatic Braking System on the MTR.

With the MTR being manufactured out of nearly the same material as the Hyperloop test track, the MTR could also be used to obtain the braking systems thermal 
characteristics under the worst case scenario. With one system inoperative, results showed that a temperature change of $11.895^{\circ} \mathrm{C}$ would occur. As a result of heat being dissipated between the braking system and the track itself. Without having the ability to install the entire MTR in a pressure chamber, such tests could only be performed in a pressurized environment. As such, the only source of heat dissipation would be conduction. With convection not cooling the braking system, a higher temperature change was expected, and was accounted for within the design.

Furthermore, to ensure all the pistons outputted an equal amount of braking force, they were also tested and validated on the MTR. During these tests, internal piston pressure was capped at $0.42 \mathrm{MPa}$ to ensure the safety of all the personnel involved. The results obtained from the MTR piston tests have been tabulated in Table 36.

Table 36. MTR Piston input and output braking force test.

\begin{tabular}{lc}
\hline Piston Test Parameter & Input Pressure / Output Braking Force \\
\hline Piston Test 1 & $0.10 \mathrm{MPa} / 800 \mathrm{~N}$ \\
Piston Test 2 & $0.14 \mathrm{MPa} / 956 \mathrm{~N}$ \\
Piston Test 3 & $0.18 \mathrm{MPa} / 1,272 \mathrm{~N}$ \\
Piston Test 4 & $0.21 \mathrm{MPa} / 1,504 \mathrm{~N}$ \\
Piston Test 5 & $0.28 \mathrm{MPa} / 2,077 \mathrm{~N}$ \\
Piston Test 6 & $0.35 \mathrm{MPa} / 2,602 \mathrm{~N}$ \\
Piston Test 7 & $0.42 \mathrm{MPa} / 3,158 \mathrm{~N}$ \\
\hline
\end{tabular}

Figure 61 showcases the data points obtained from the MTR testing of the pneumatic braking pistons. Observing the theoretical and experimental plots, a deviation of $11.70 \%$ occurred between the pneumatic pistons [38]. This slight deviation was to be expected as testing was conducted using an analogue pressure gauge to dial in the piston's internal pressure. However, having the gauge replaced with a digital one should resolve this issue. 


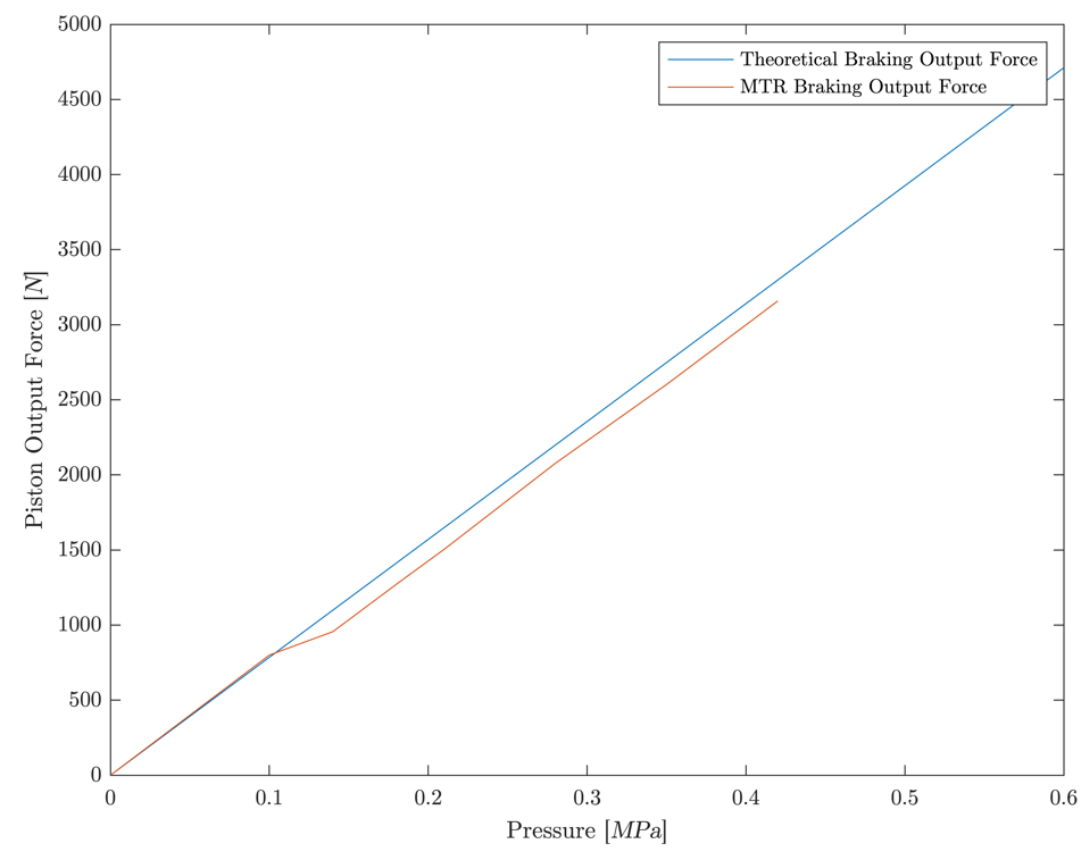

Figure 61. Brake output force data for MTR pistons.

\subsubsection{Propulsion Tests}

With the propulsion system capable of propelling and levitating the Pod through a true contactless system, the systems were developed from the ground up to cater to the specific requirements of the Hyperloop Pod. As a result, the Student Researched And Developed (SRAD) systems such as MagLev and MagDrive needed to be validated using the MTR.

MagLev is derived from the magnetic levitation system that is used to support the Pod along the normal axis at high speeds [39]. It uses a Halbach array to induce a repulsive magnetic field to suspend the Pod at a predefined altitude or height. With the system being SRAD, it needed to be validated thoroughly on the MTR to show that a sufficient force or lift was developed in order to levitate the Pod. To do so on the MTR, a Dual Axis Force Transducer (DAFT) was developed for the MTR as shown in Figure 62. 


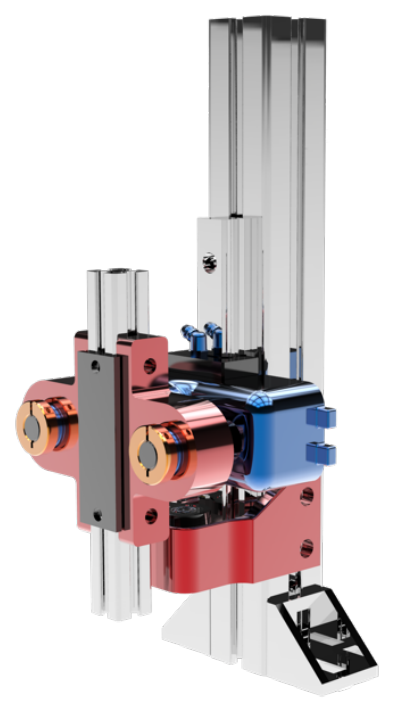

Figure 62. Assembled Dual Axis Force Transducer for MagLev testing.

The DAFT was capable of measuring the lift and drag forces, or the levitation force and MagDrag generated by MagLev when deployed. In addition, it was made to sense these forces as a function of the MTR's rotational velocity.

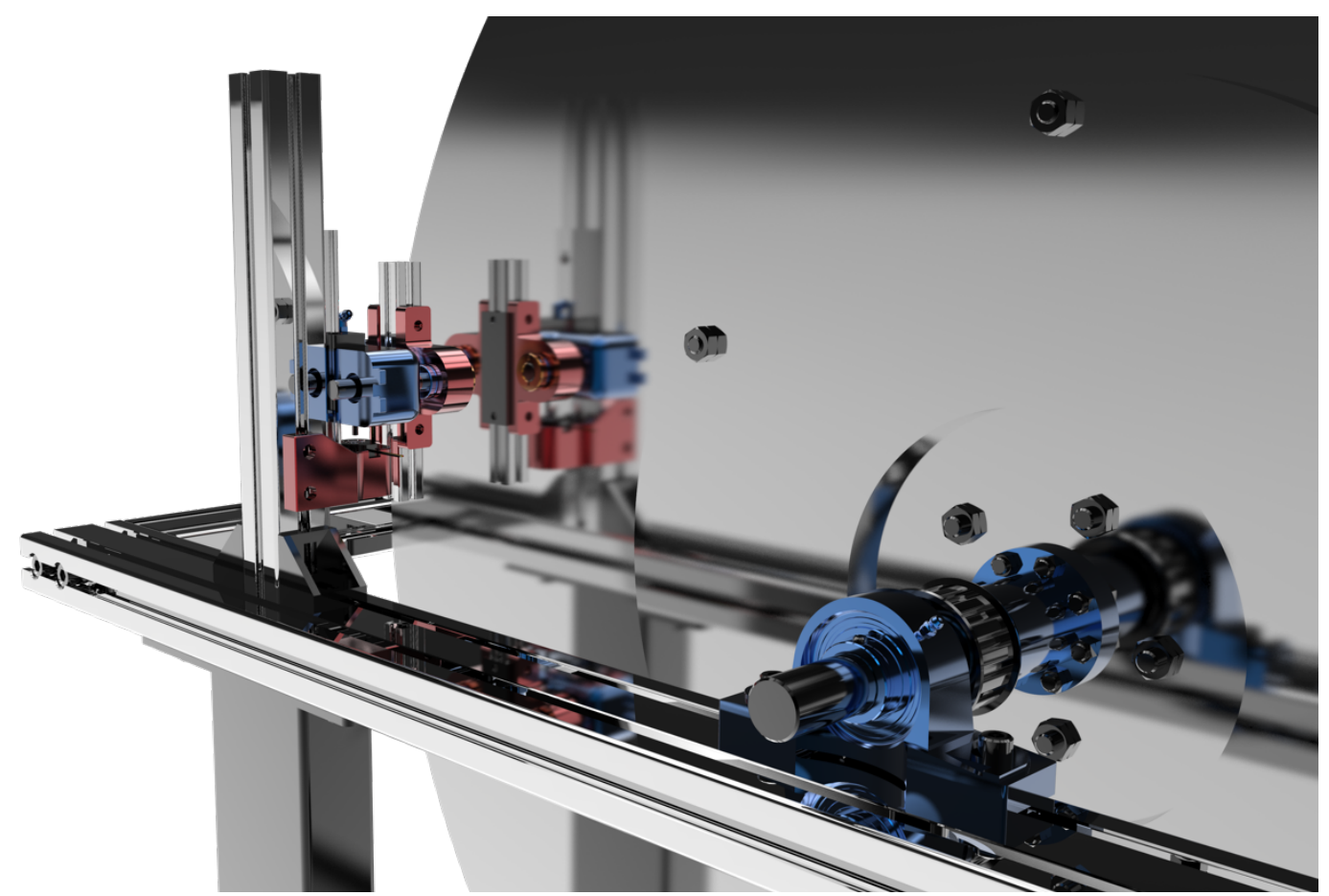

Figure 63. MTR showcasing the mounted DAFT. 
Tests were performed utilizing the DAFT on the MTR with a singular North-South (N-S) period configuration of N42 magnets measuring $25.4 \mathrm{~mm}$ by $25.4 \mathrm{~mm}$ by $12.7 \mathrm{~mm}$ in dimension.

The results obtained from MTR tests were used to generate a theoretical profile of the MagLev's behavior. The creation of this profile allowed for the characterization of the MagLev system's performance. The MTR was able to run up to a peak velocity of $15 \mathrm{~m} / \mathrm{s}$ while holding the rotations at a constant speed reliably. In Figure 64, the reading taken between zero and $5 \times 10^{4}$ clearly demonstrate the ramp up in the MTR's speed as it was powered up. As peak velocity was achieved around the $5.5 \times 10^{4}$ reading mark, the lift to drag, or levitation force to MagDrag was observed to be almost one, and can be seen in Figure 64 as well.

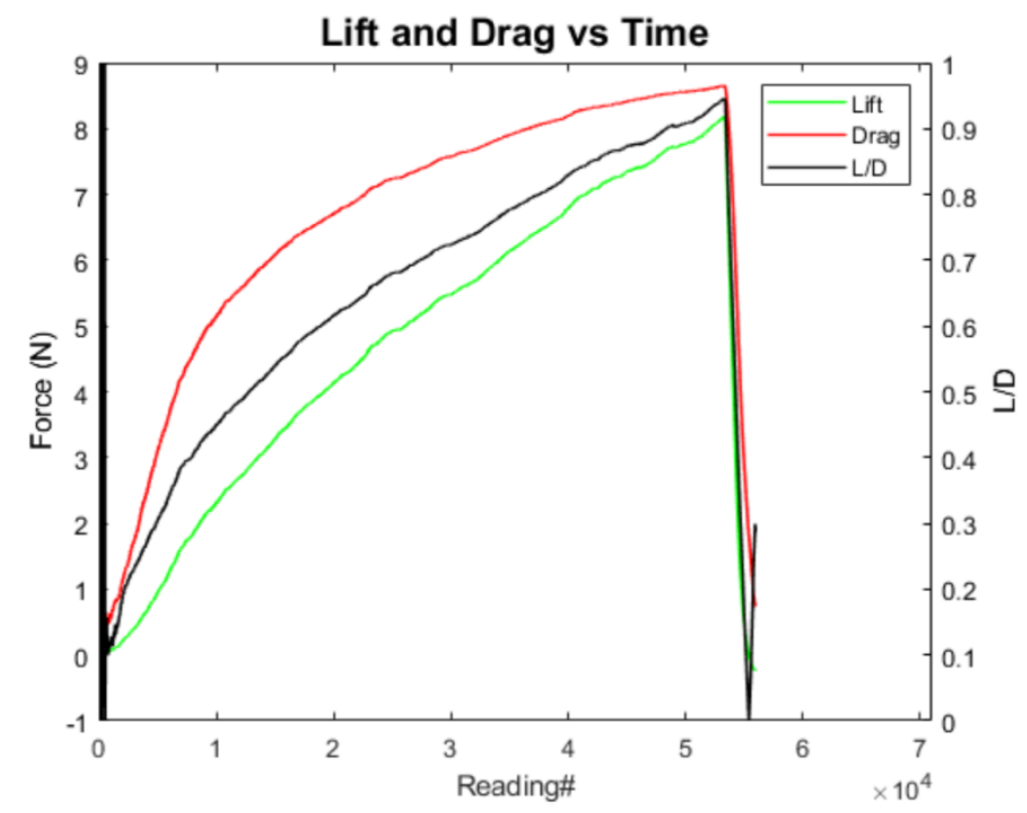

Figure 64. MagLev test results for singular North-South period configuration. 


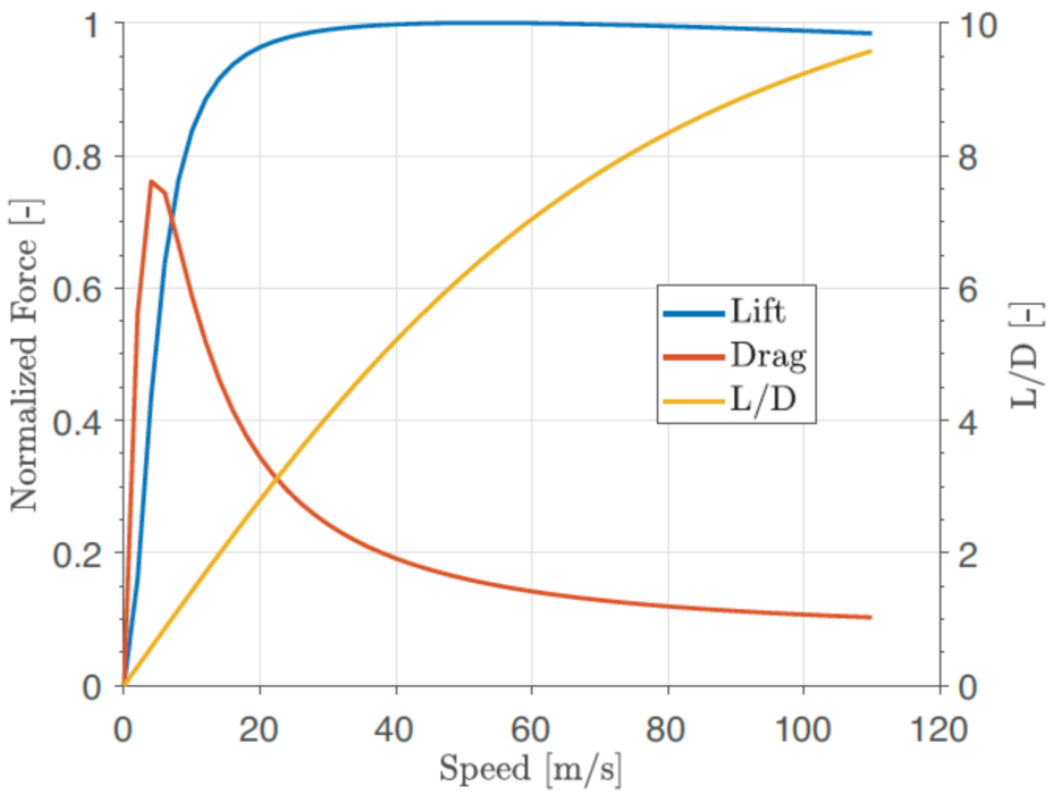

Figure 65. Simulated behavior of lift and drag with an extended velocity profile [40].

With the results obtained, the theoretical profile was generated to show MagLev's behavior had the speed been increased further to the speeds seen by the Hyperloop Pod [40]. Some significant observations that could be made from Figure 65 included the discernibility of the crossover point. This is where MagDrag began to depreciate considerably as the lift or levitation force continued to increase. This occurred up to a certain speed, in this case $70 \mathrm{~m} / \mathrm{s}$ after which both the parameters began to plateau.

The development of the theoretical profile aided in better understanding of the system if it is modified through a change its array, number of periods, magnet strength, and so on as tabulated below [40].

Table 37. Parametric performance effects on MagLev.

\begin{tabular}{lccc}
\hline \multicolumn{1}{c}{ Design Parameter } & Effect on Lift & Effect of L/D & Effect on Weight \\
\hline Array Wavelength & Slight Decrease & Square Root Increase & Increase \\
Number of Periods & Linear Increase & No Effect & Increase \\
Array Width & Linear Increase & No Effect & Increase \\
Array Thickness & Squared Increase & Negligible & Increase \\
Magnet Grade & Increase & No Effect & No Effect \\
Back Plate Thickness & Slight Increase & Negligible & Increase \\
Nominal Gap Height & Inverse Square Decrease & No Effect & No Effect \\
\hline
\end{tabular}




\section{CONCLUSION}

The objective of the research work was to design Ryerson's first Hyperloop Pod for the fifth mode of transportation, the Hyperloop. With this new mode of transportation still in its infancy, the challenge was to design and develop its systems and to have them tested in a university environment. In doing so, new requirements, constraints, guidelines, objectives, and standards were developed and explored for the Hyperloop. Any issues and unknowns were solved by applying aerospace engineering knowledge and its principles.

Furthermore, key ideas from the aerospace industry led to the development of the modular test rig that proved to be a very reliable and unique testing rig for the developed Hyperloop systems. The employment of a multidisciplinary approach coupled with various engineering management resources enabled the team to define the problem at its most basic level. This simplified approach permitted various designs, components, and systems to be tested utilizing the MTR to its full potential. This was extremely important in the development of the Hyperloop systems.

The design of Ryerson's Pod for the Hyperloop Pod Competition contributed towards the advancement of Ryerson University and the Department of Aerospace Engineering within the Hyperloop industry. Furthermore, the developed design achieved success at various stages of the Hyperloop Pod Competition.

Based on Ryerson International Hyperloop's performance, the team received a special invitation from SpaceX to attend the 2019 Hyperloop Pod Competition in Hawthorne, California after having previously also attended the 2018 Hyperloop Pod Competition. 


\section{FUTURE WORK}

Although tremendous strides were made within the development of the Hyperloop, various areas of deficiencies have been identified in team organization, documentation, analysis, and testing procedures. New methods are continuously being introduced to address issues both in coordination and communication between the various systems. With the integration of these new methods, time spent on the assembly and systems engineering is greatly reduced as components would interface seamlessly.

Since development of the Hyperloop is ongoing, the following are some potential points of research:

- Optimization of the thermal management solutions required to dissipate heat generated from the LIM, BRK, and GNC systems.

- Braking system characterization when operating within low pressure or near vacuum environments.

- Characterization of permanent magnet's behavior within low pressure or near vacuum environments.

- Development of a fatigue model for Pod structures to better understand Hyperloop's cyclical loading that occurs every 35 minutes.

- Composite testing to observe the laminates' behavior as it undergoes constant depressurization and pressurization.

- Optimization of the MagLev system to better support a higher Pod mass during the levitation phase.

- Characterization of the MagDrag to aid in extracting additional braking power from the MagLev system.

- Optimization of the MagDrive system to reduce its overall mass while improving its thrust capabilities within a low pressure environment.

- Manufacturing of a larger modular test rig capable of conducting high speed tests for full scale Hyperloop systems.

- Development of standardized and certified Hyperloop components and systems that could easily be implemented within Hyperloop Pods. (Similar to standardized aerospace components).

- Development of a legal framework for the Hyperloop, including constraints, guidelines, certification standards, and testing procedures. 


\section{APPENDICES}

Appendix A.1 Final Pod Prototype 


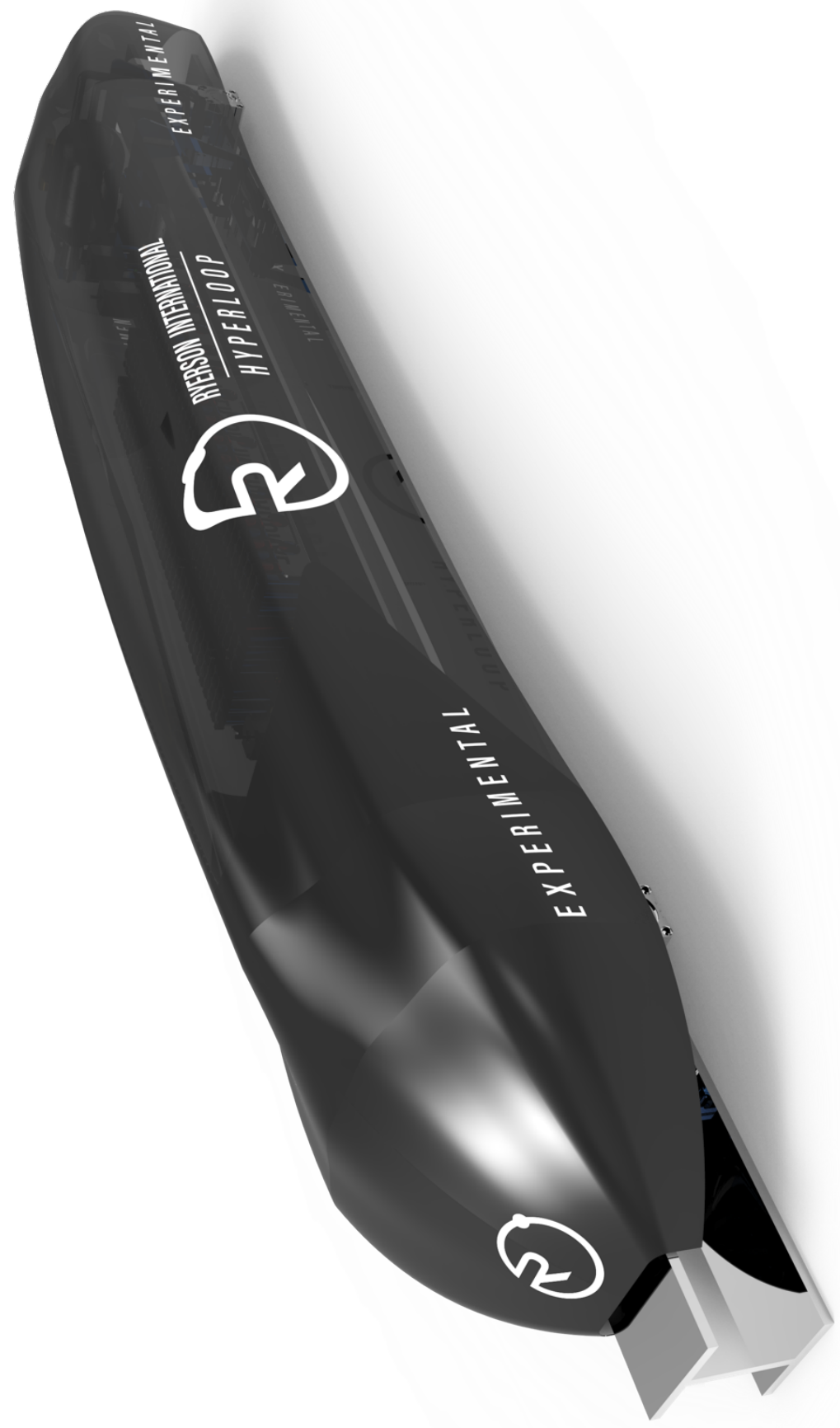




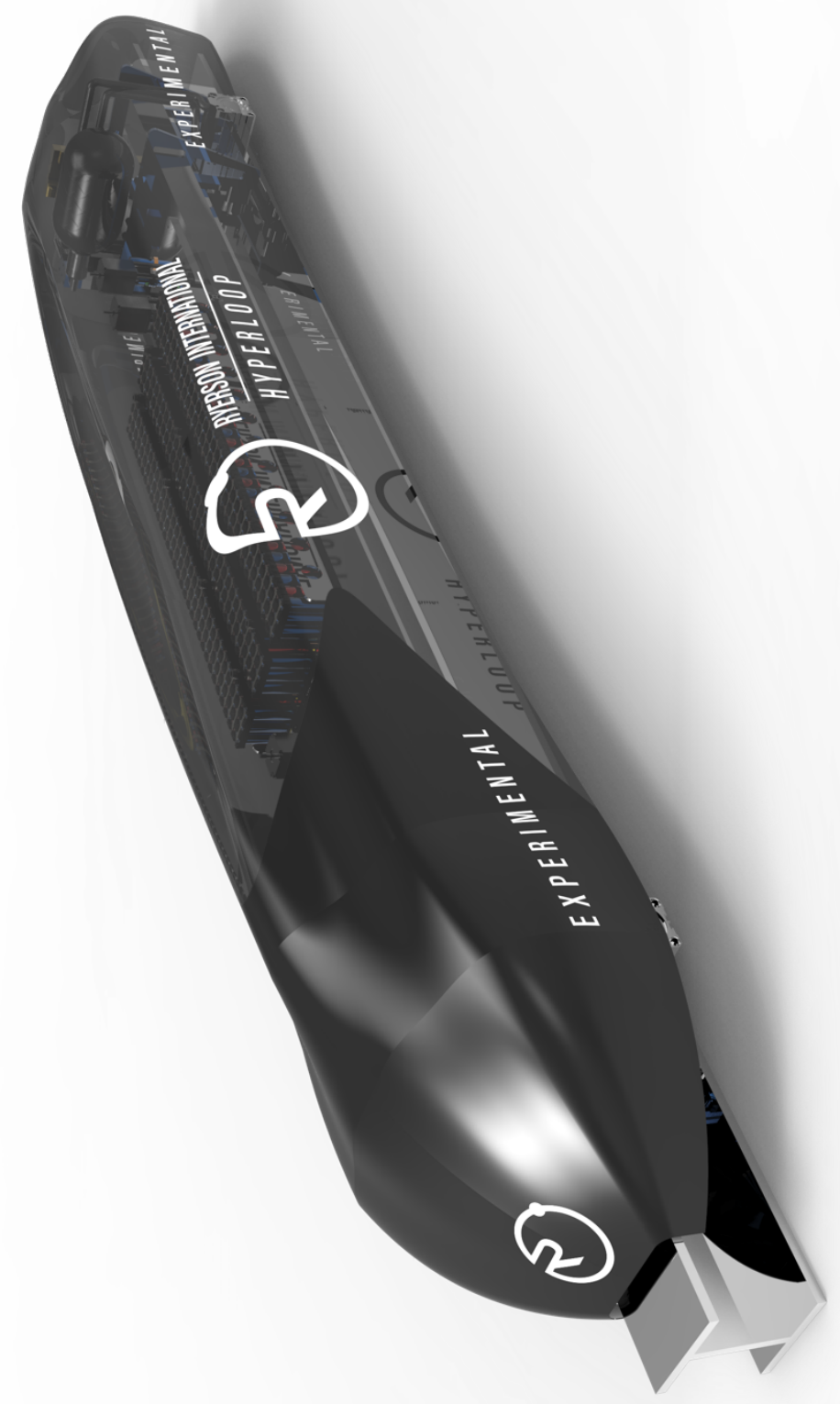




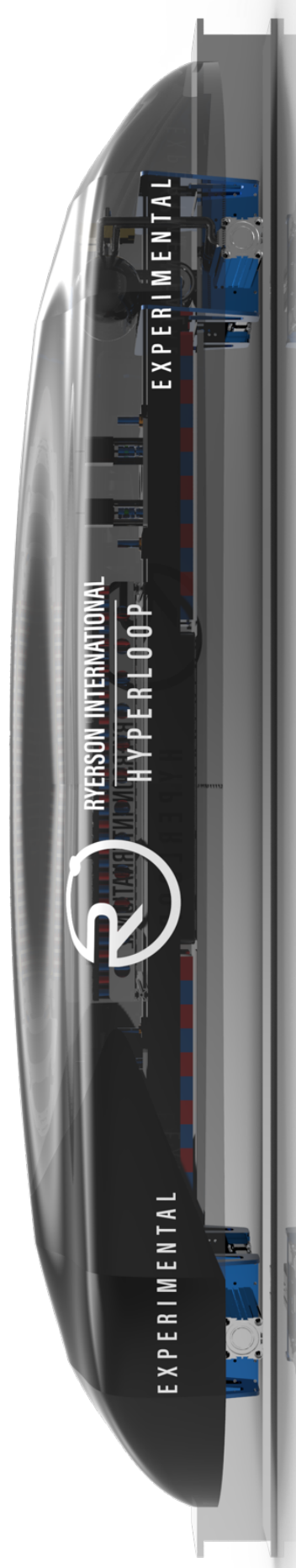




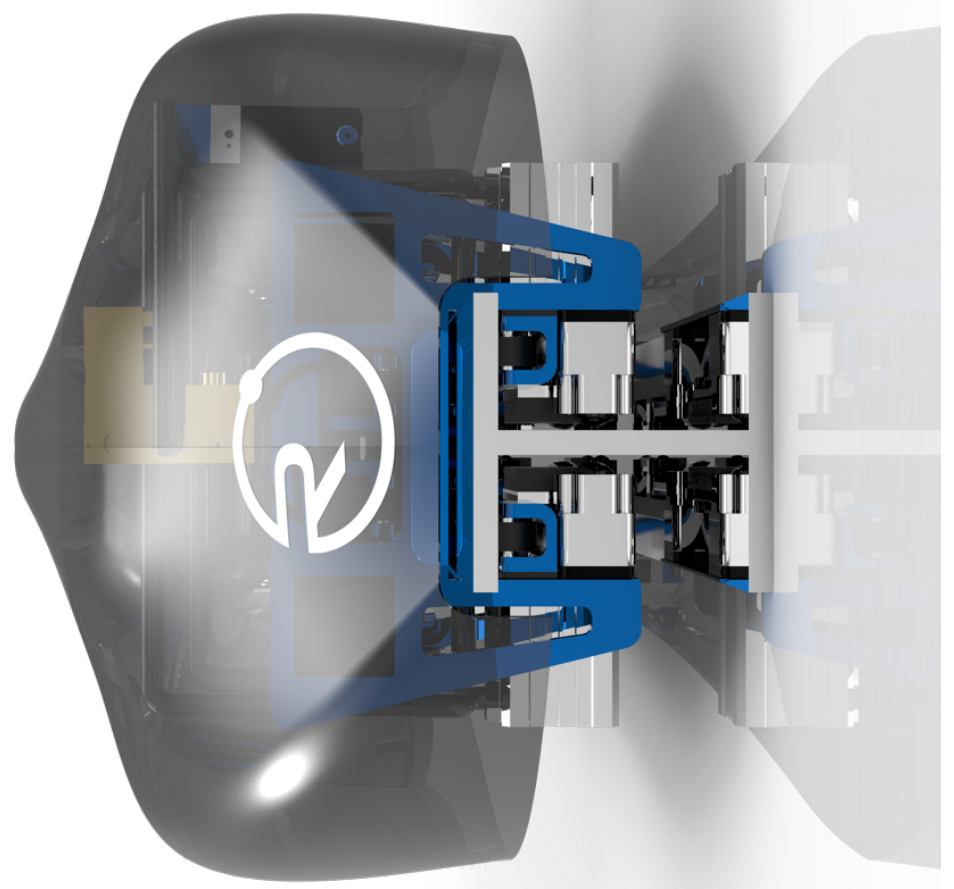




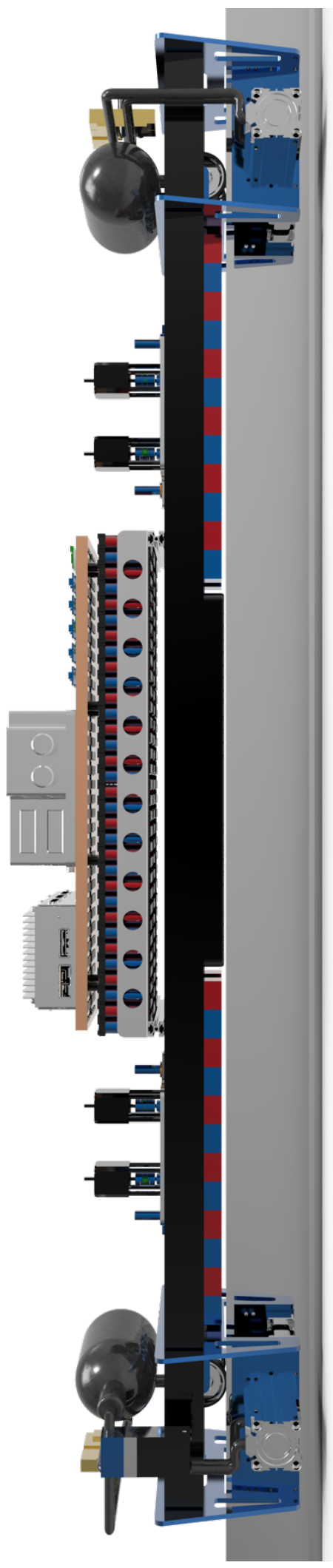




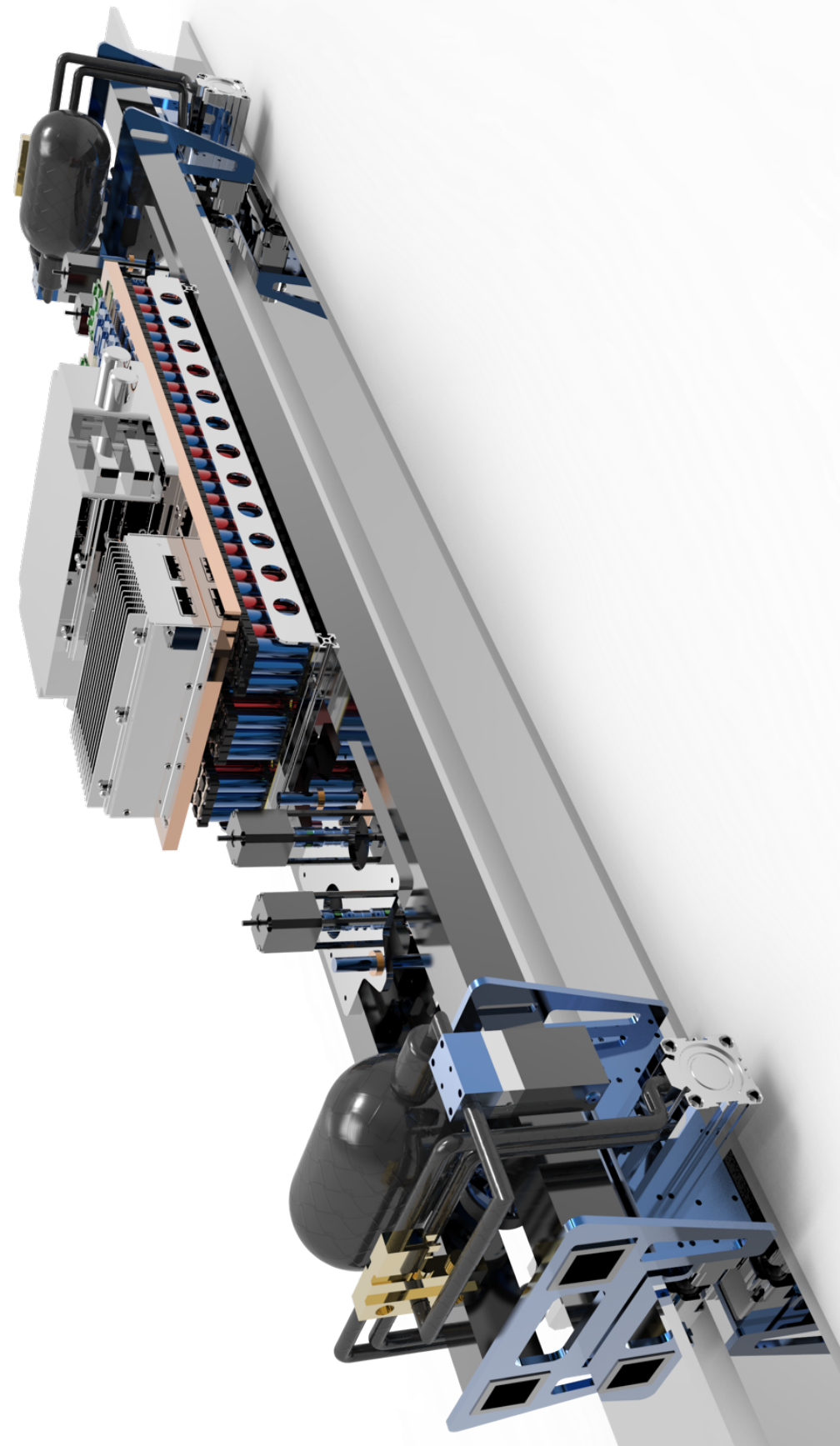




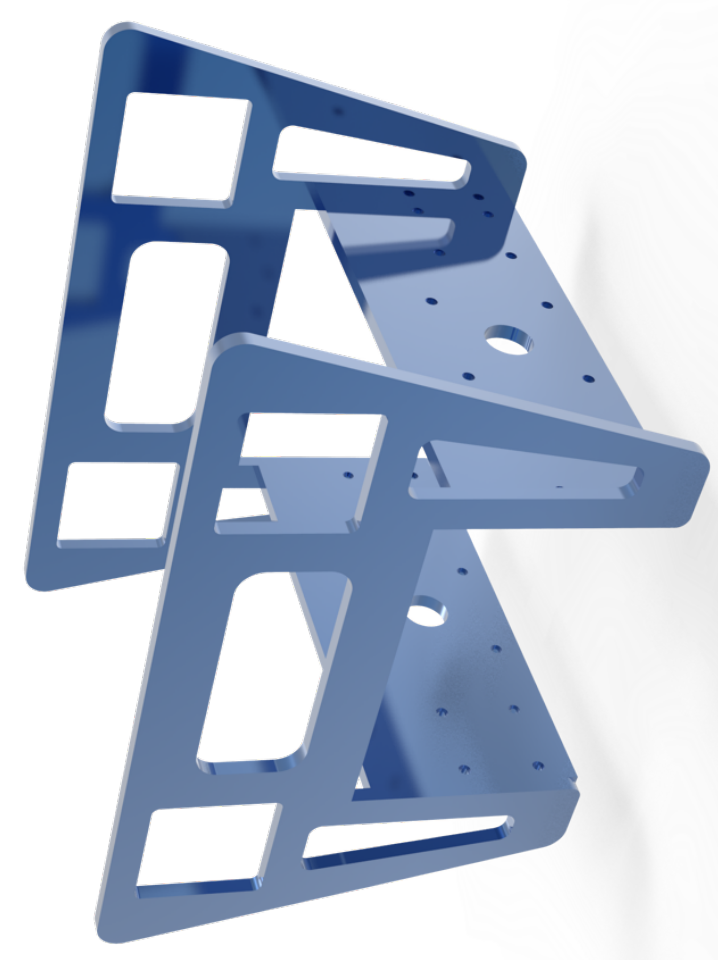




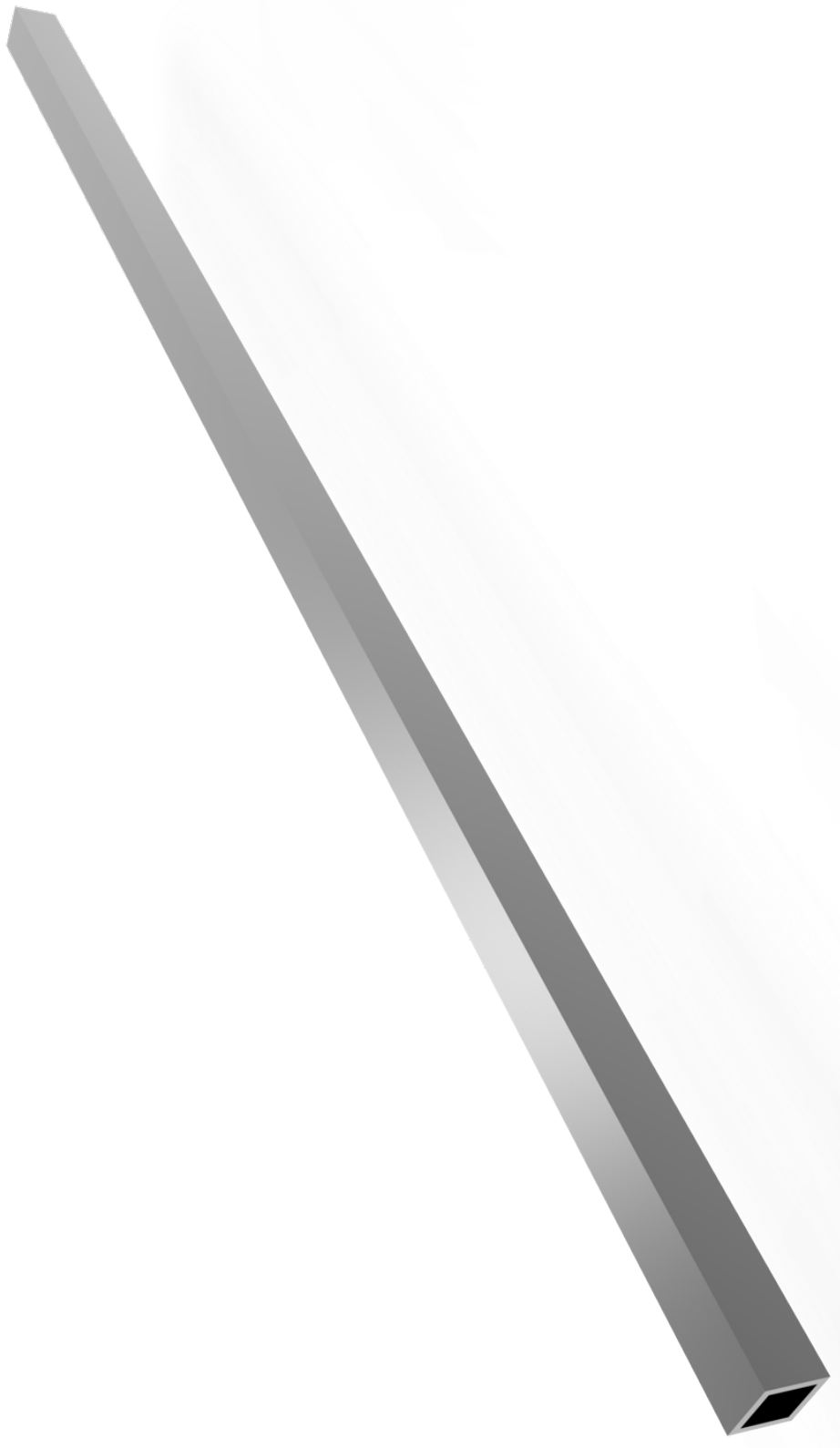




$$
\mathbb{1}
$$




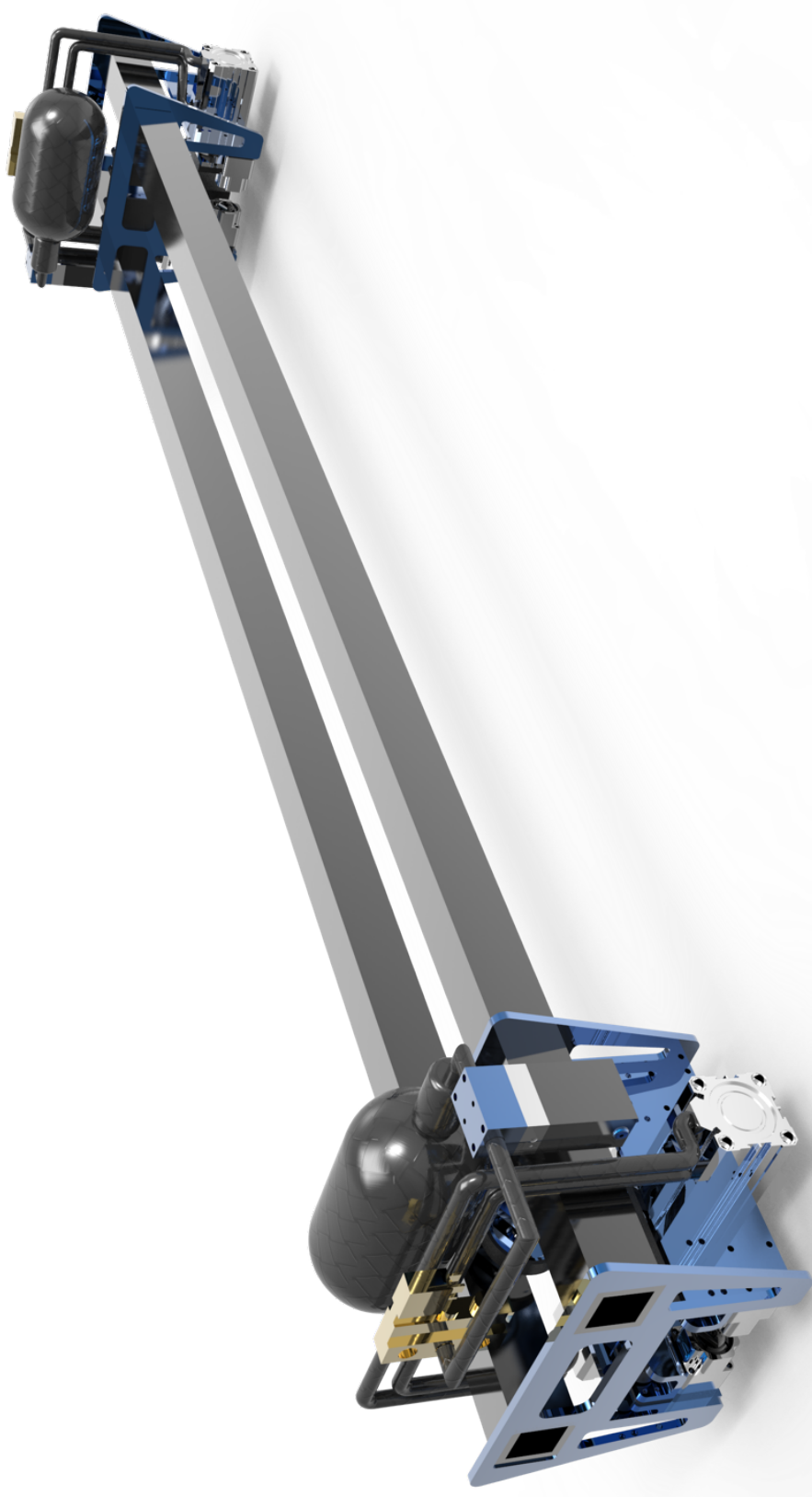




$$
8
$$




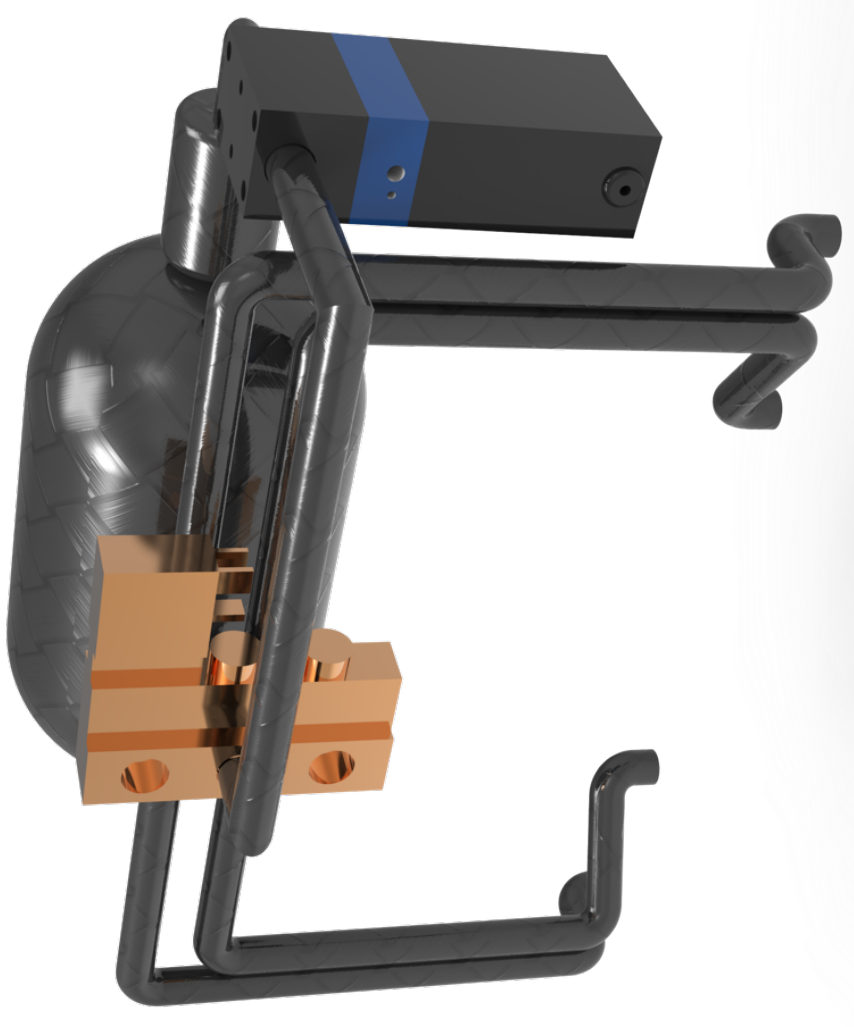




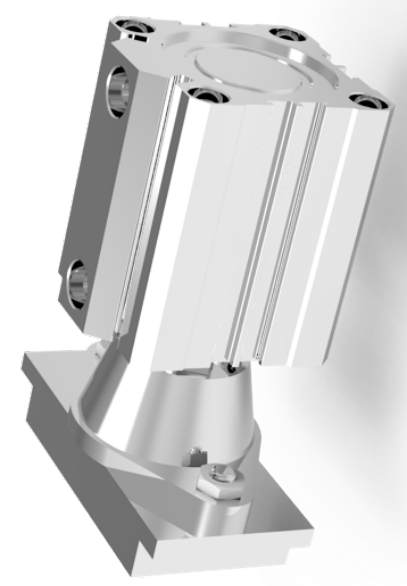



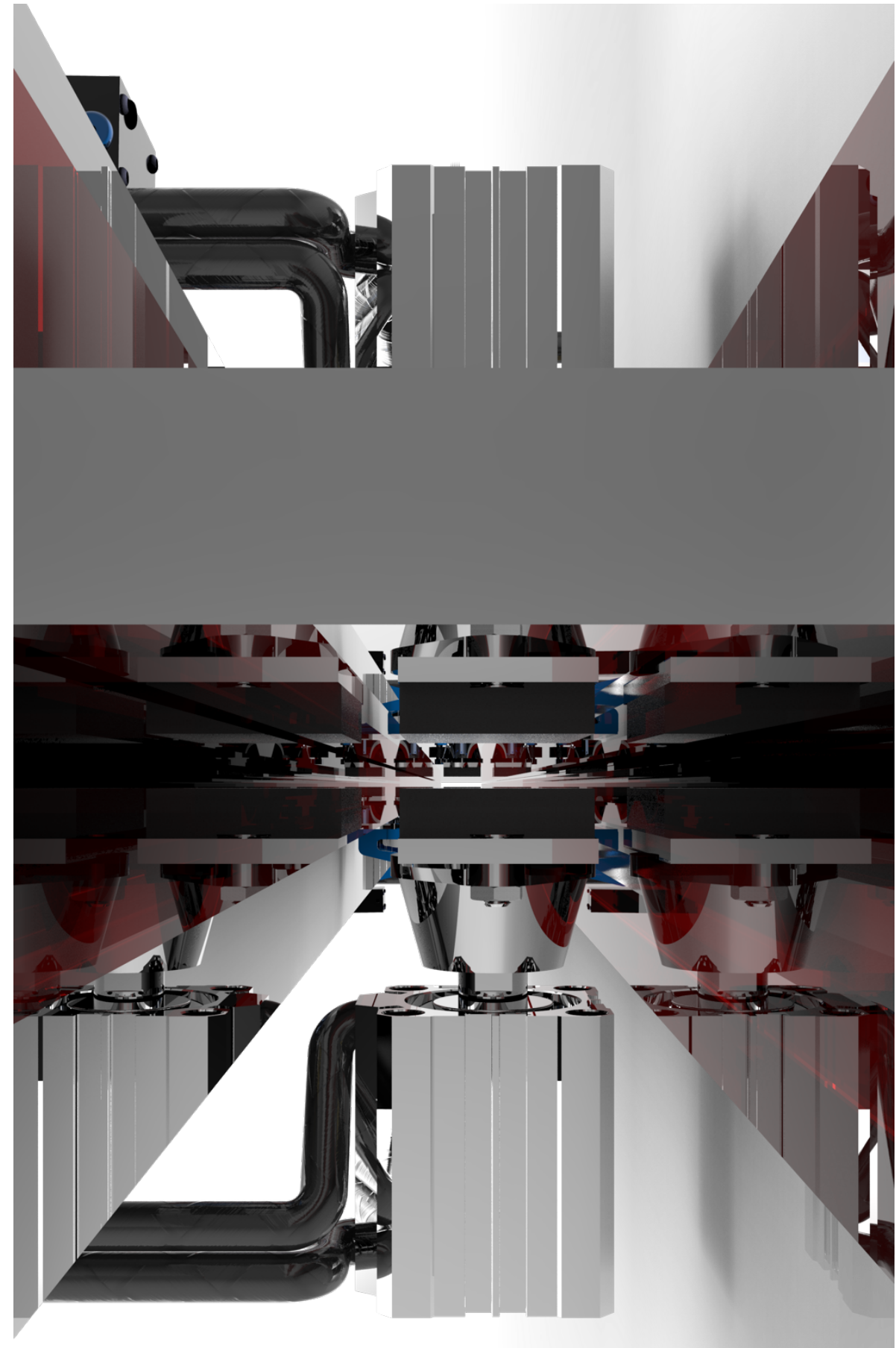


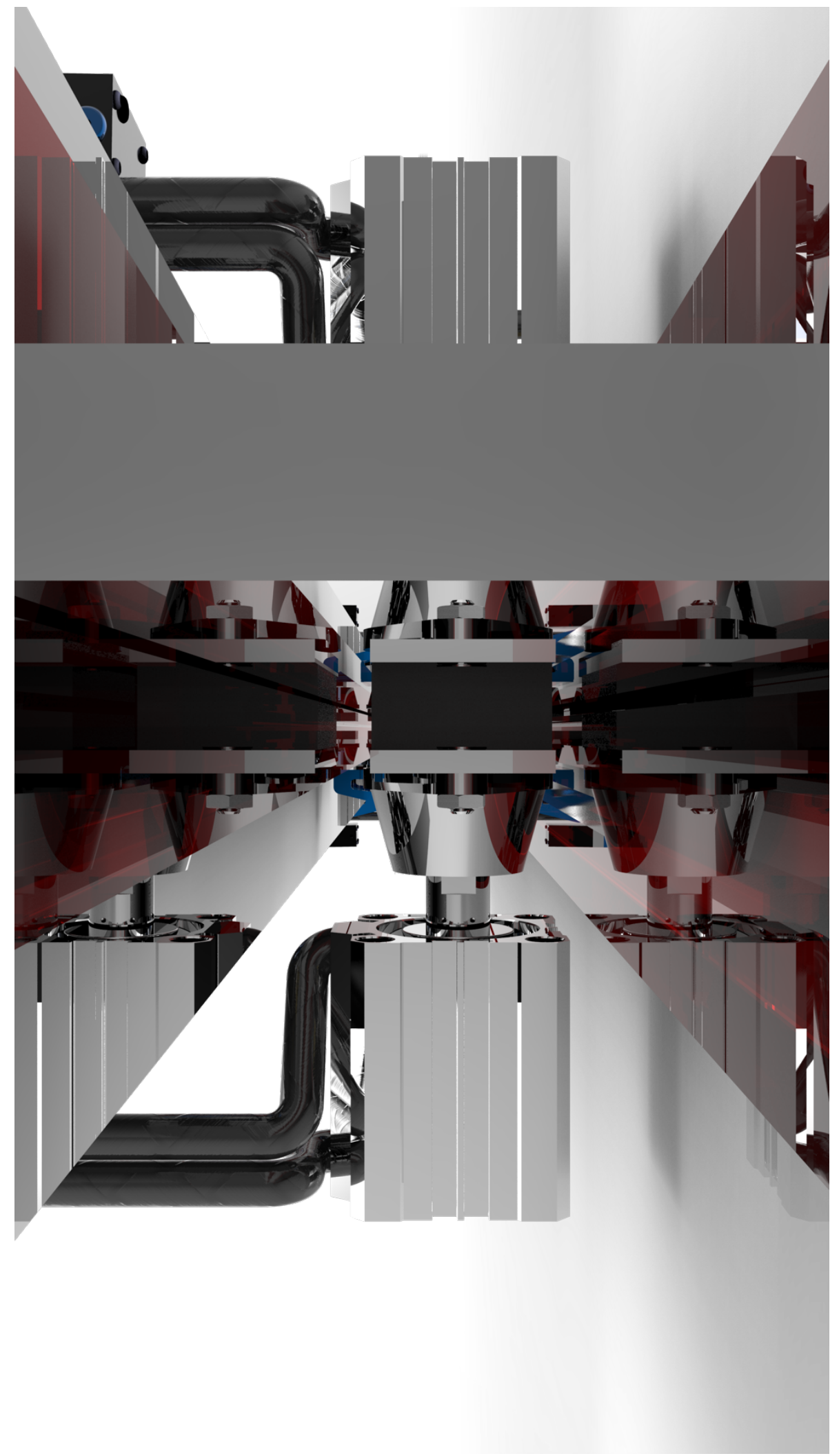




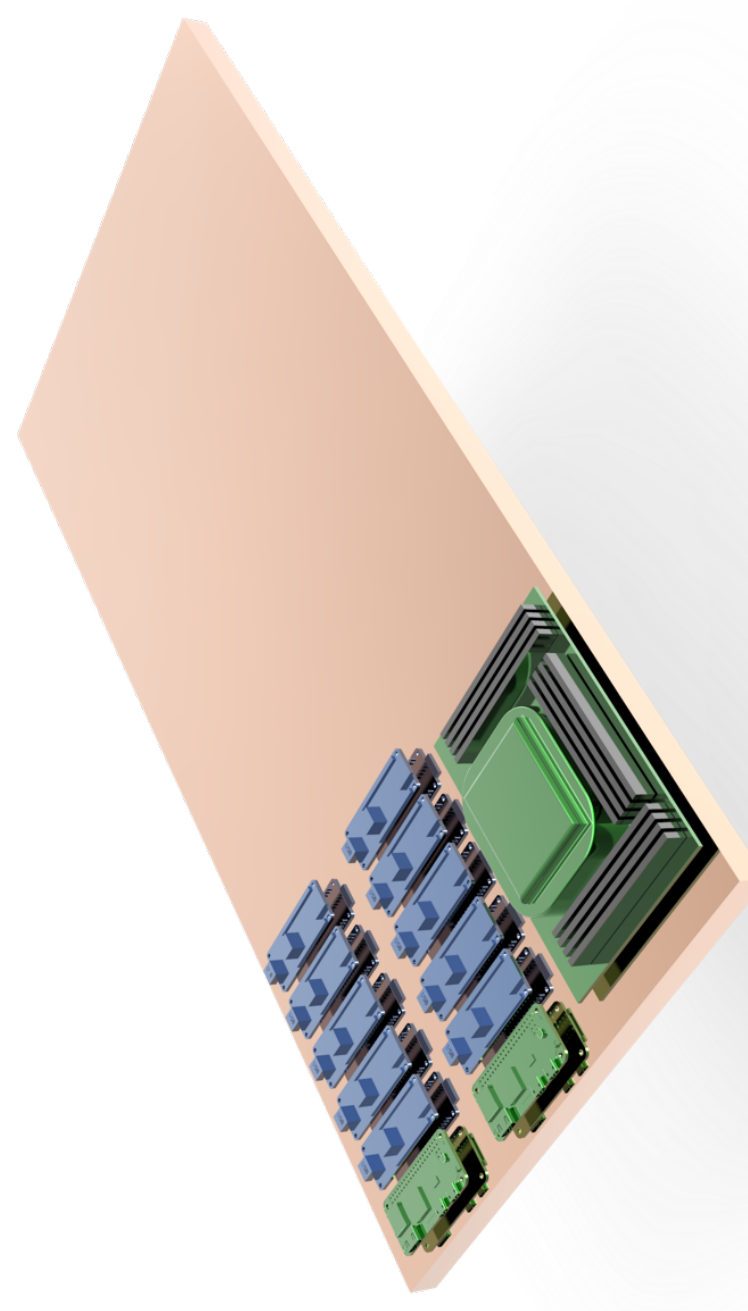




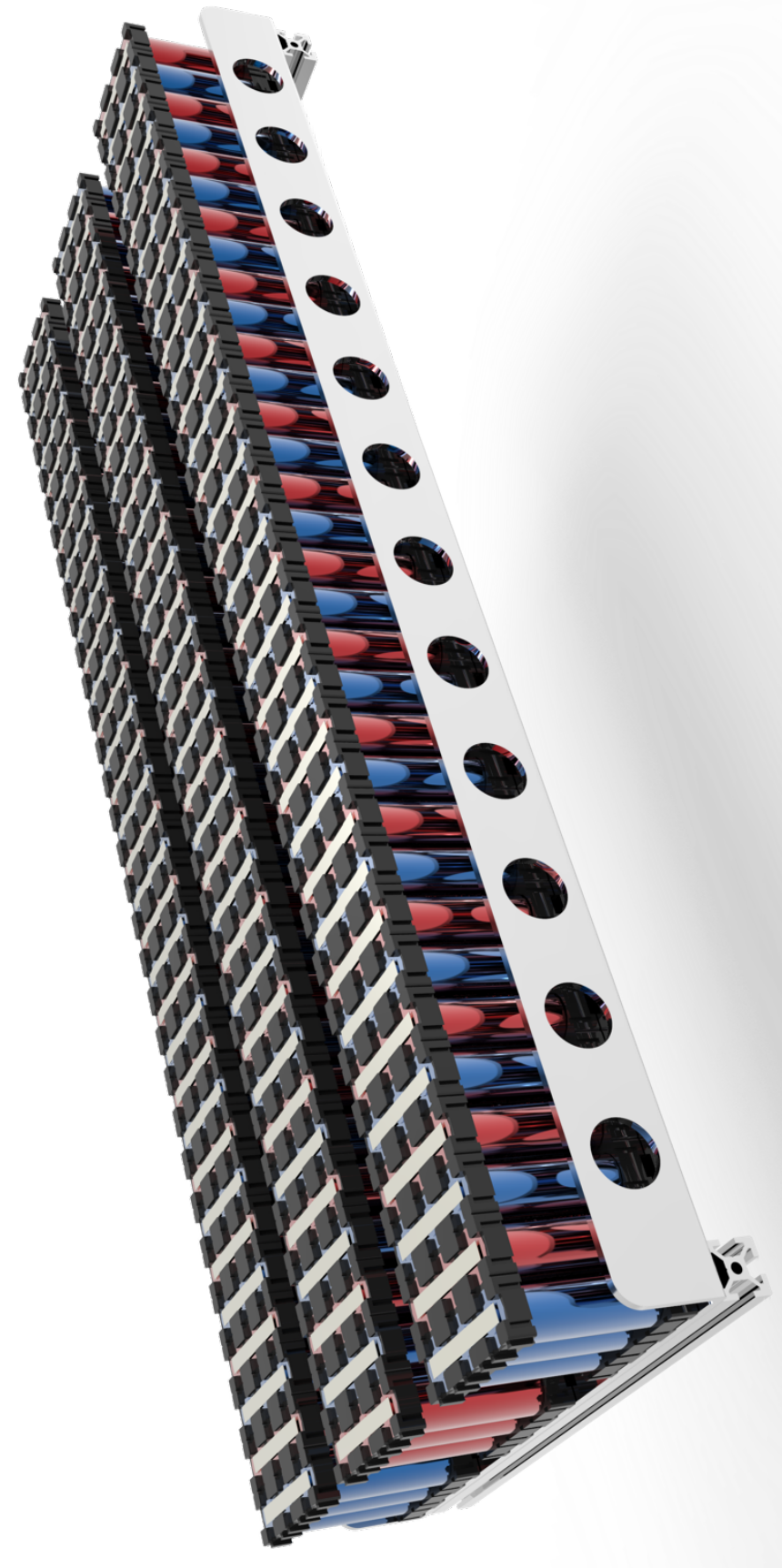




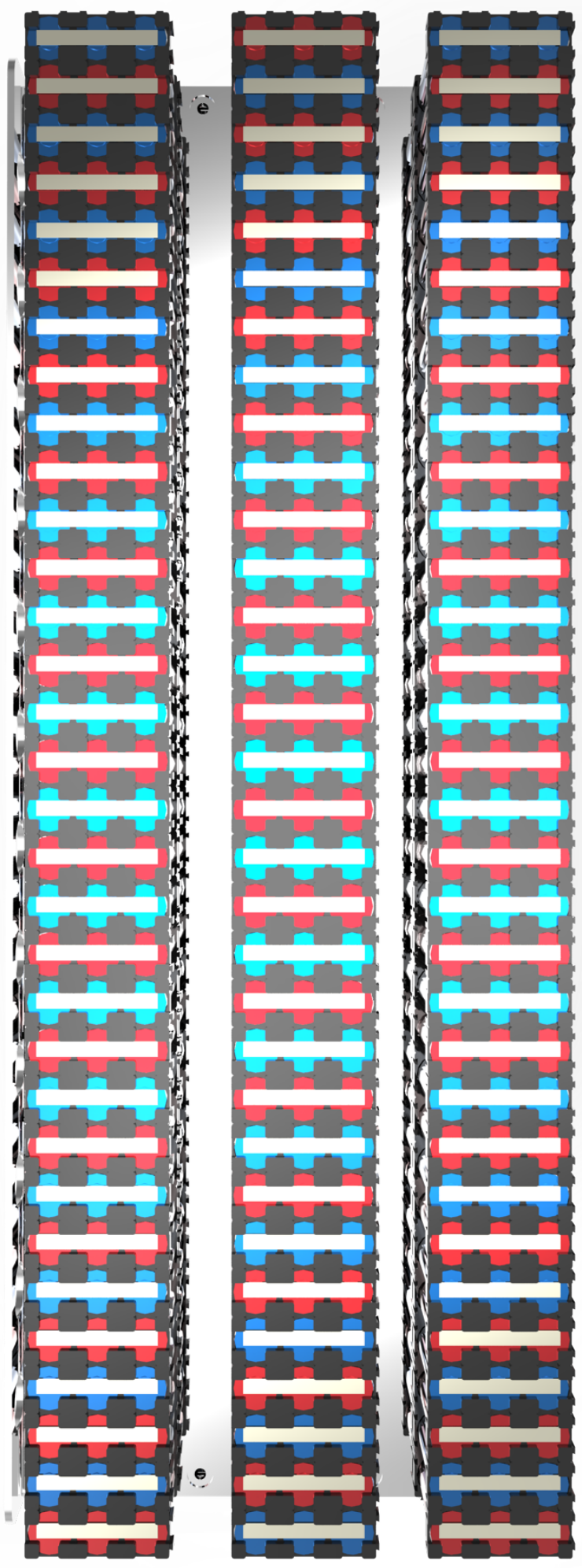




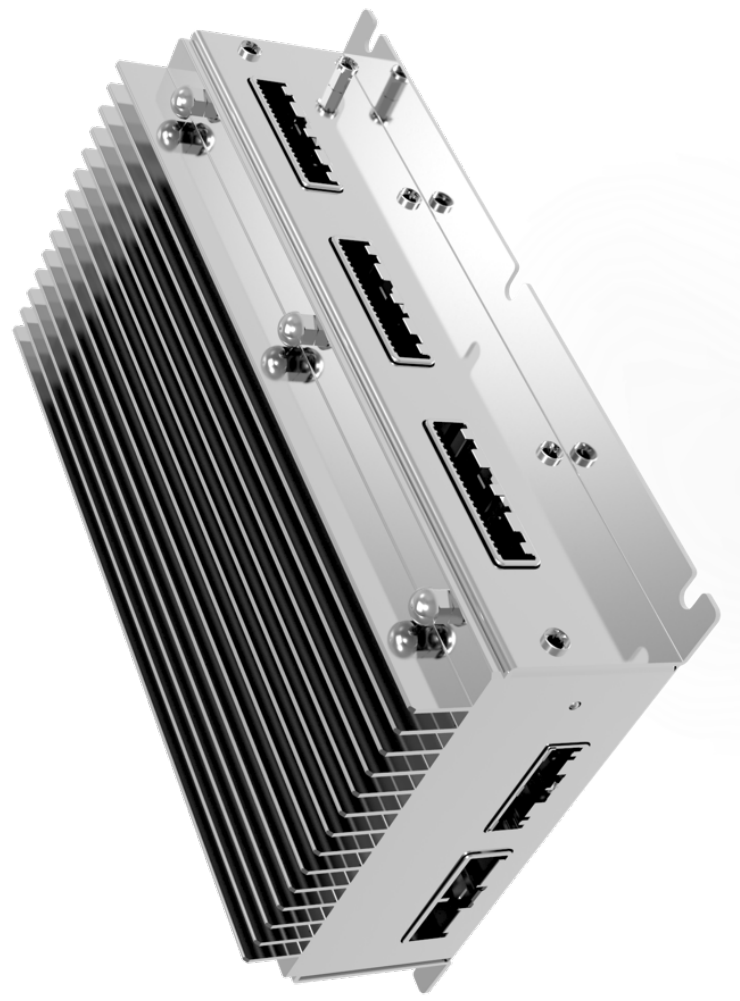




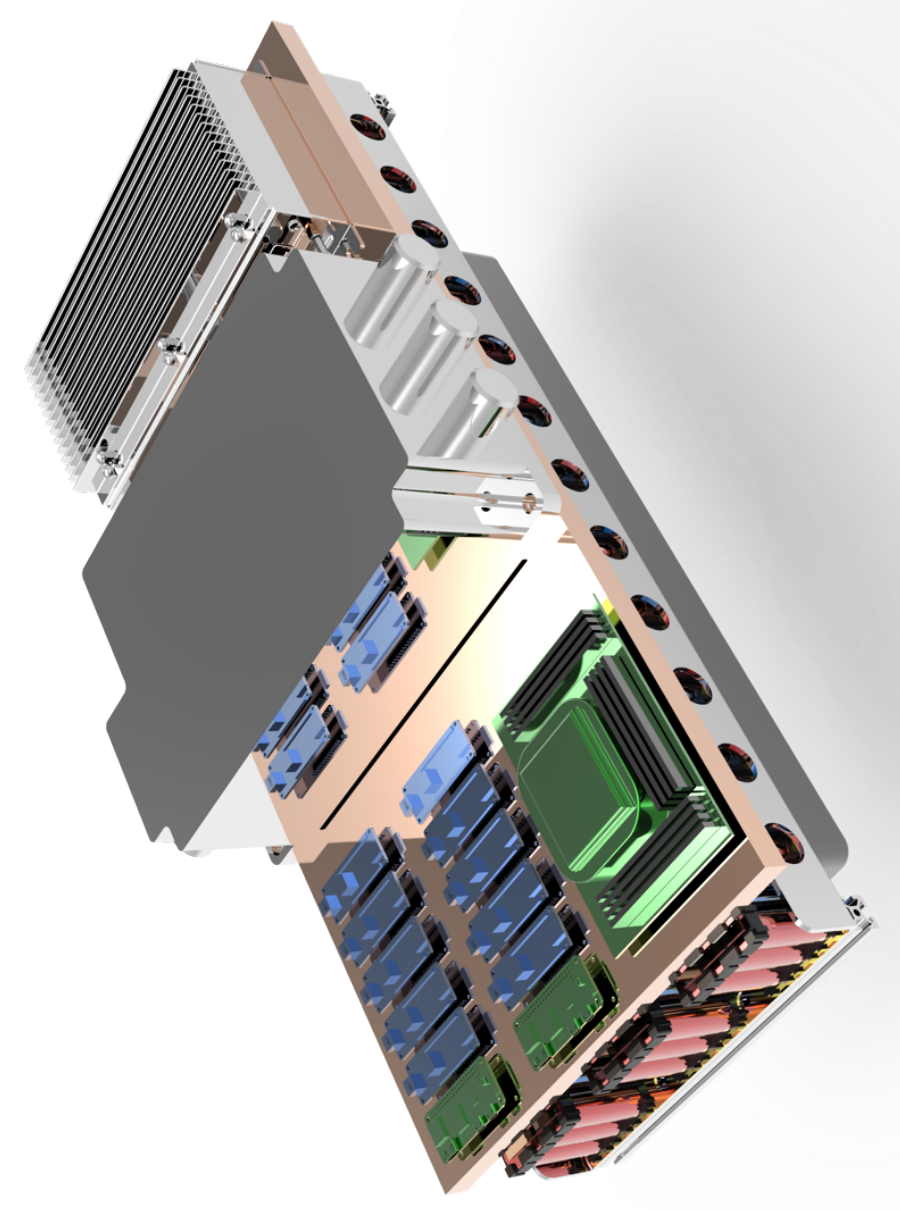




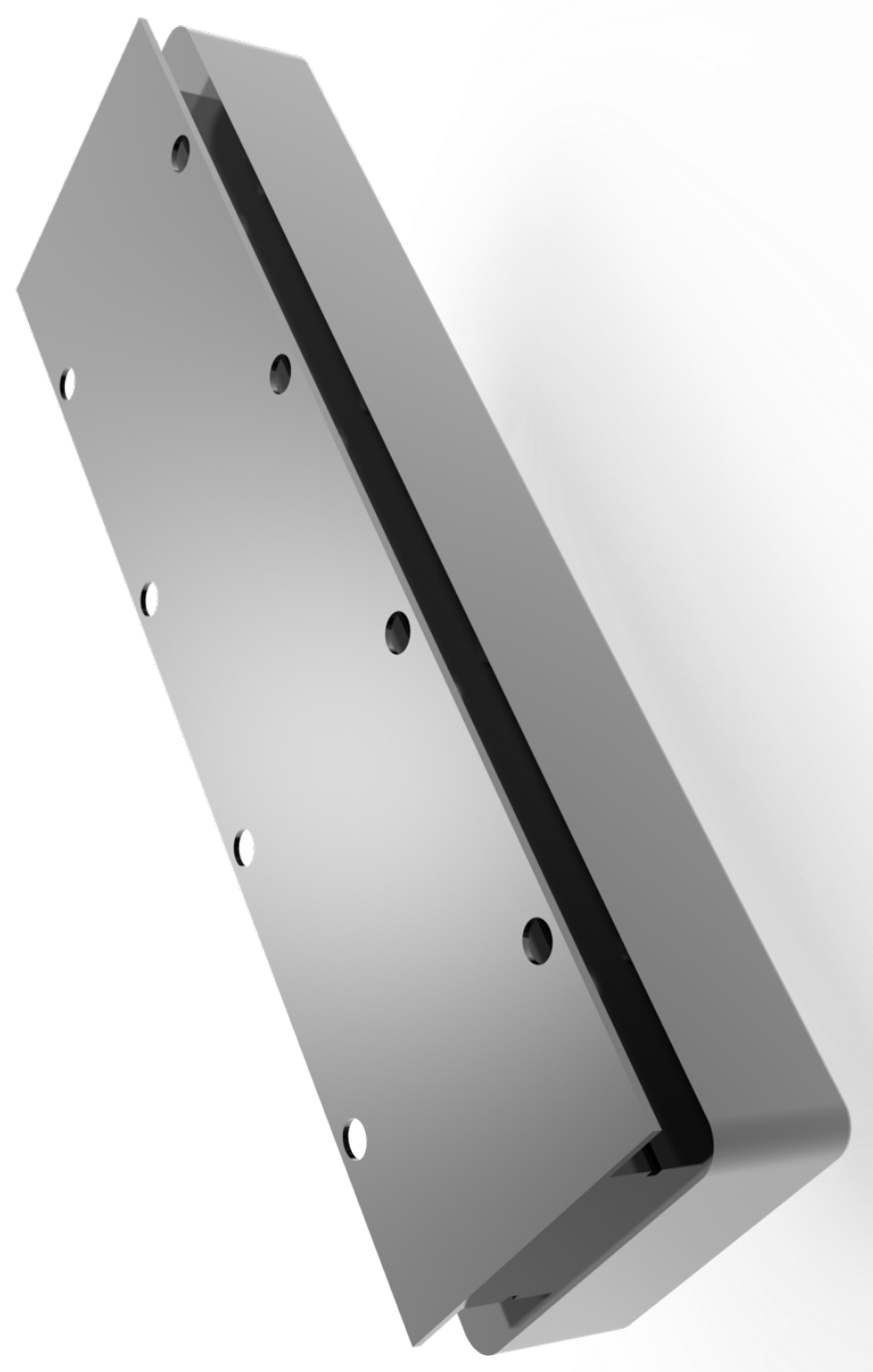

105 


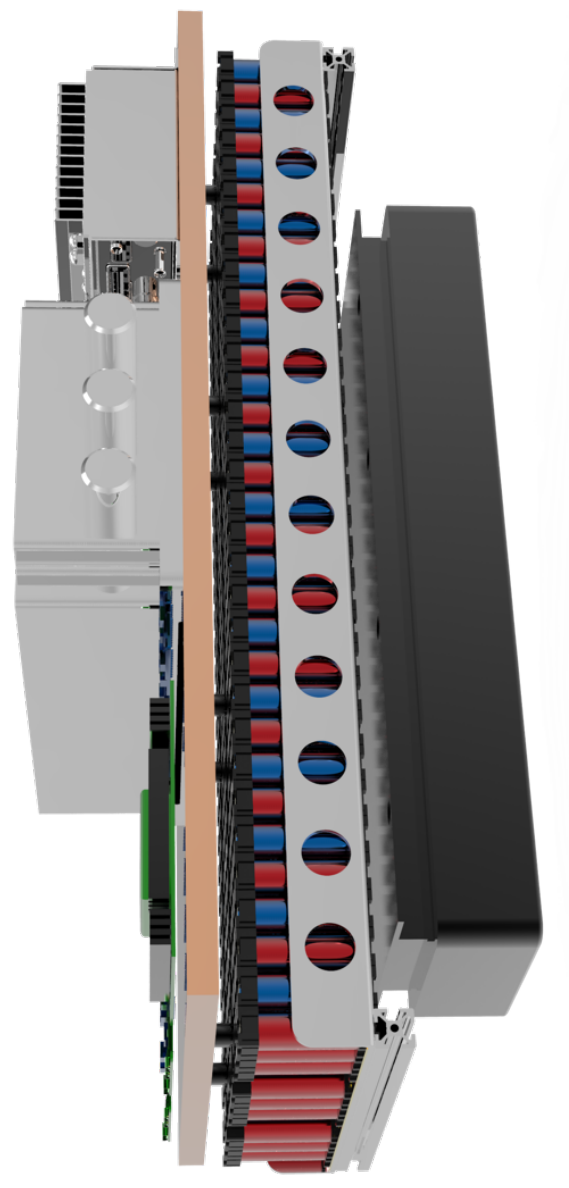




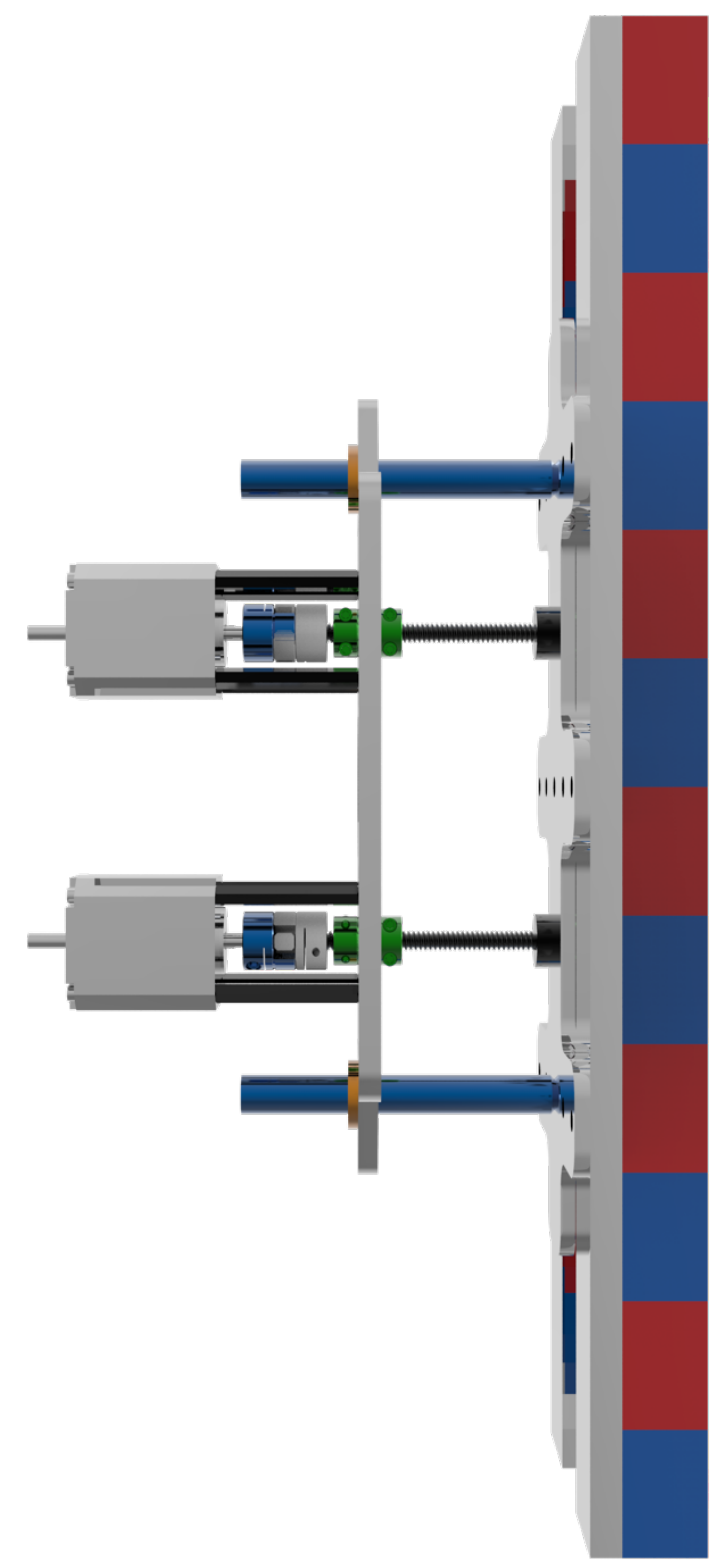




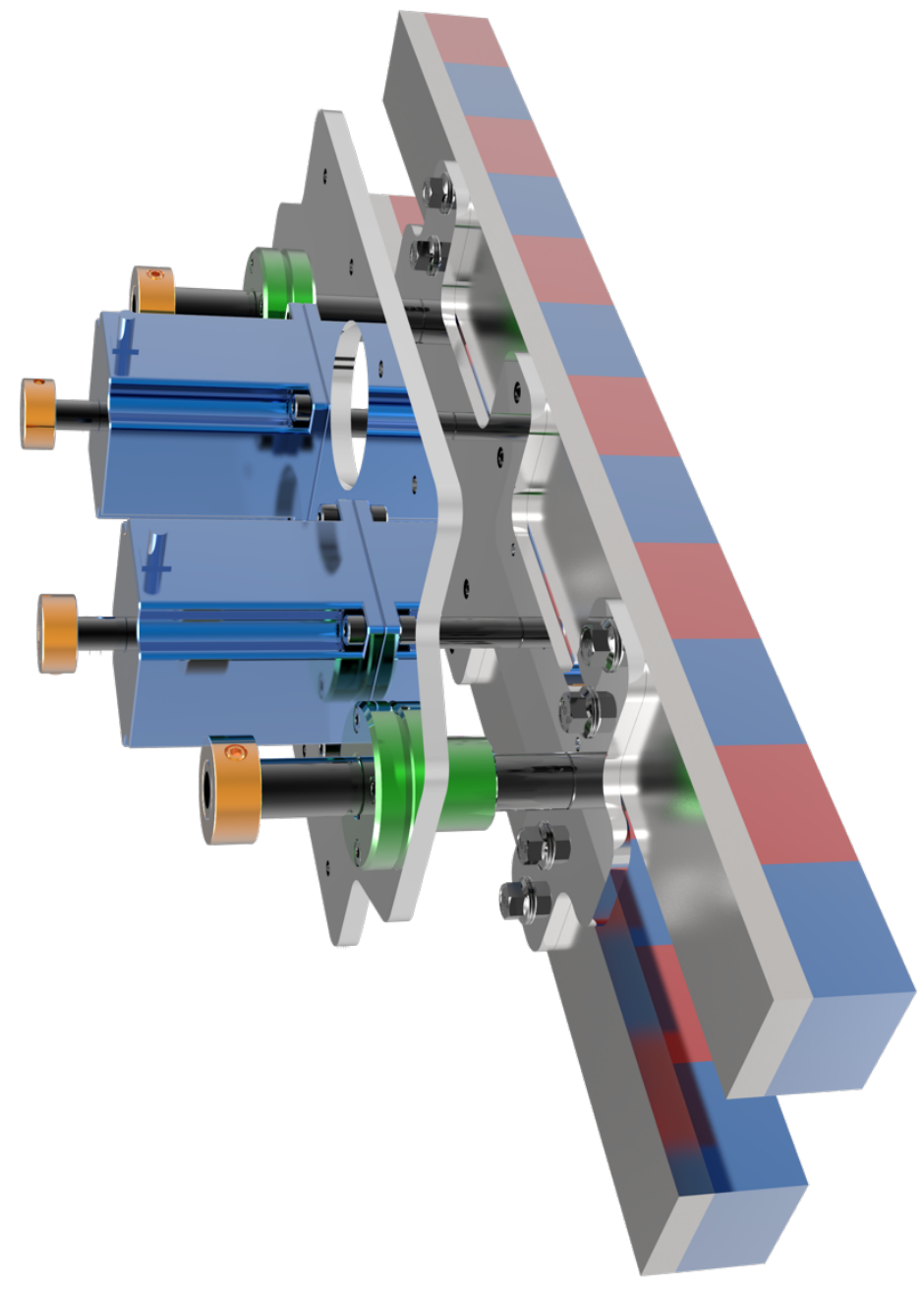


Appendix A.2 Modular Test Rig Prototype 


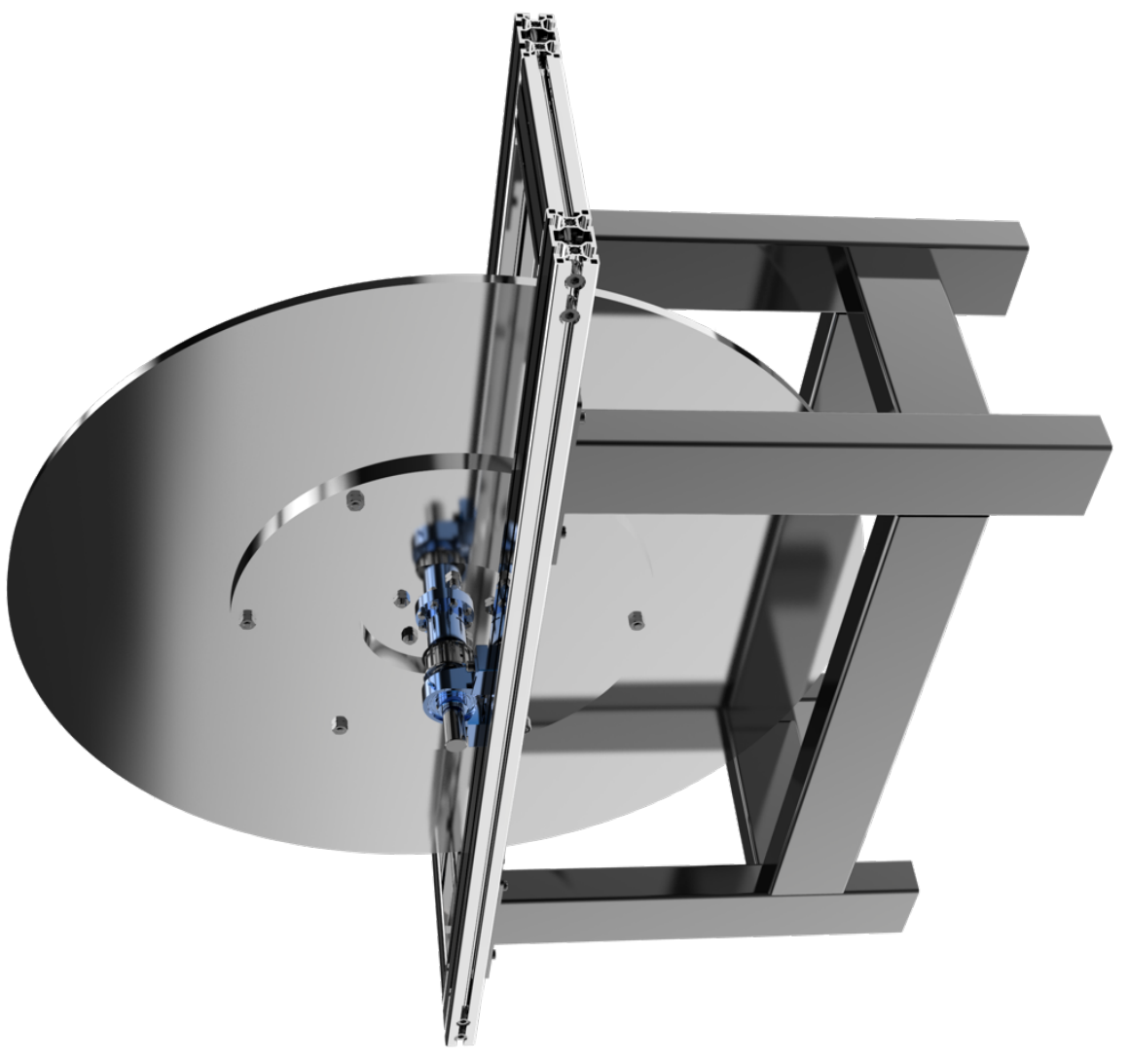




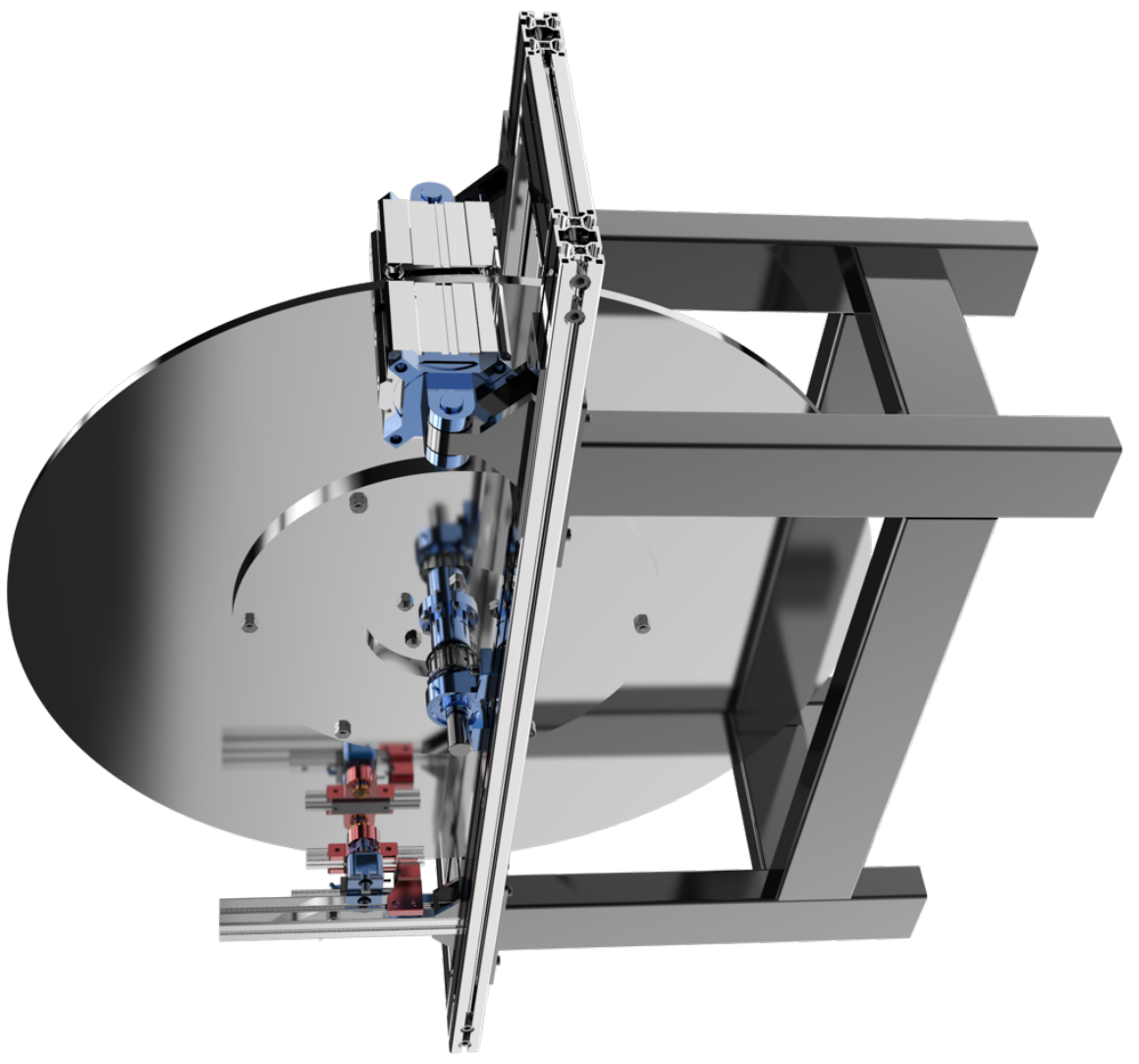




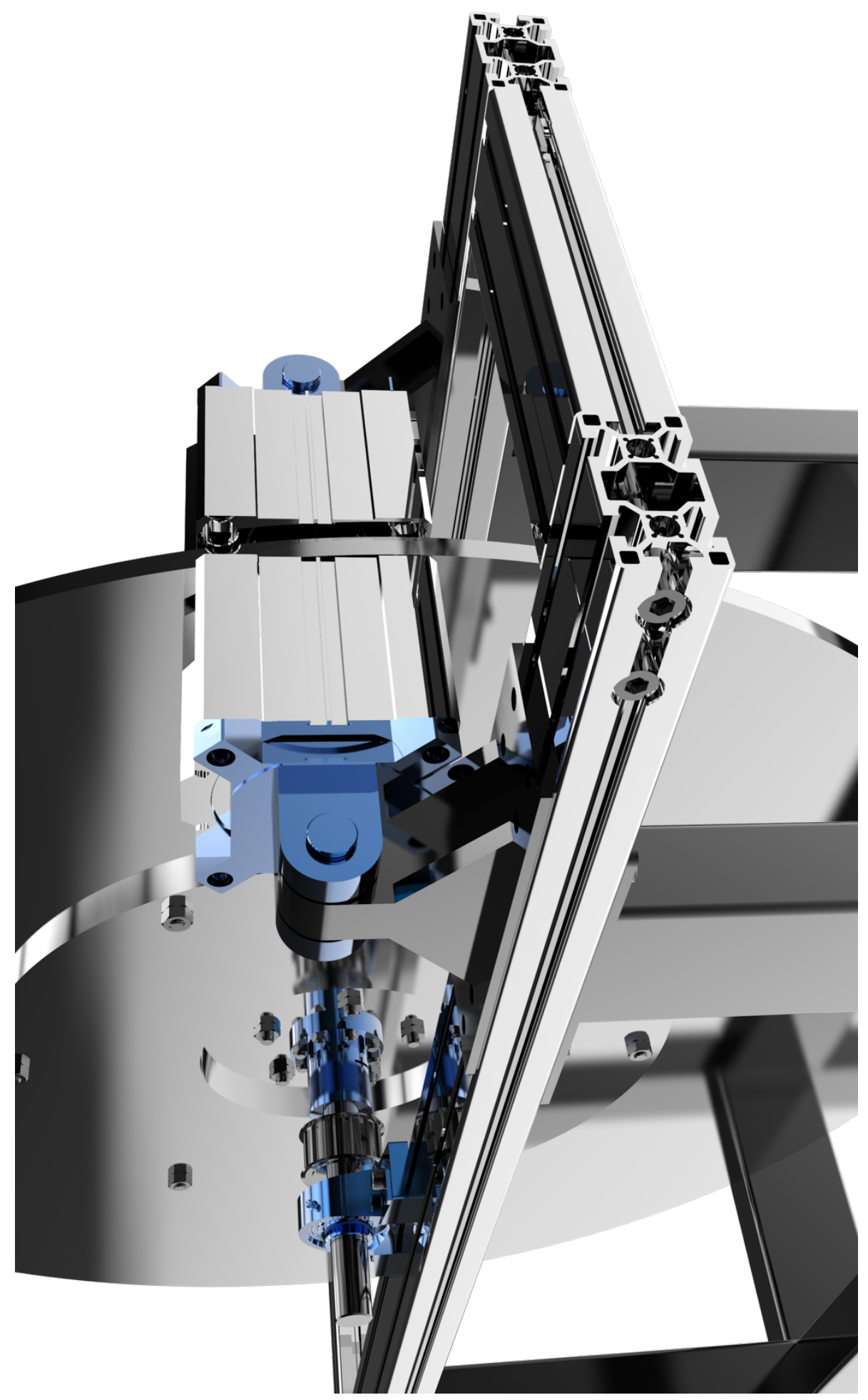




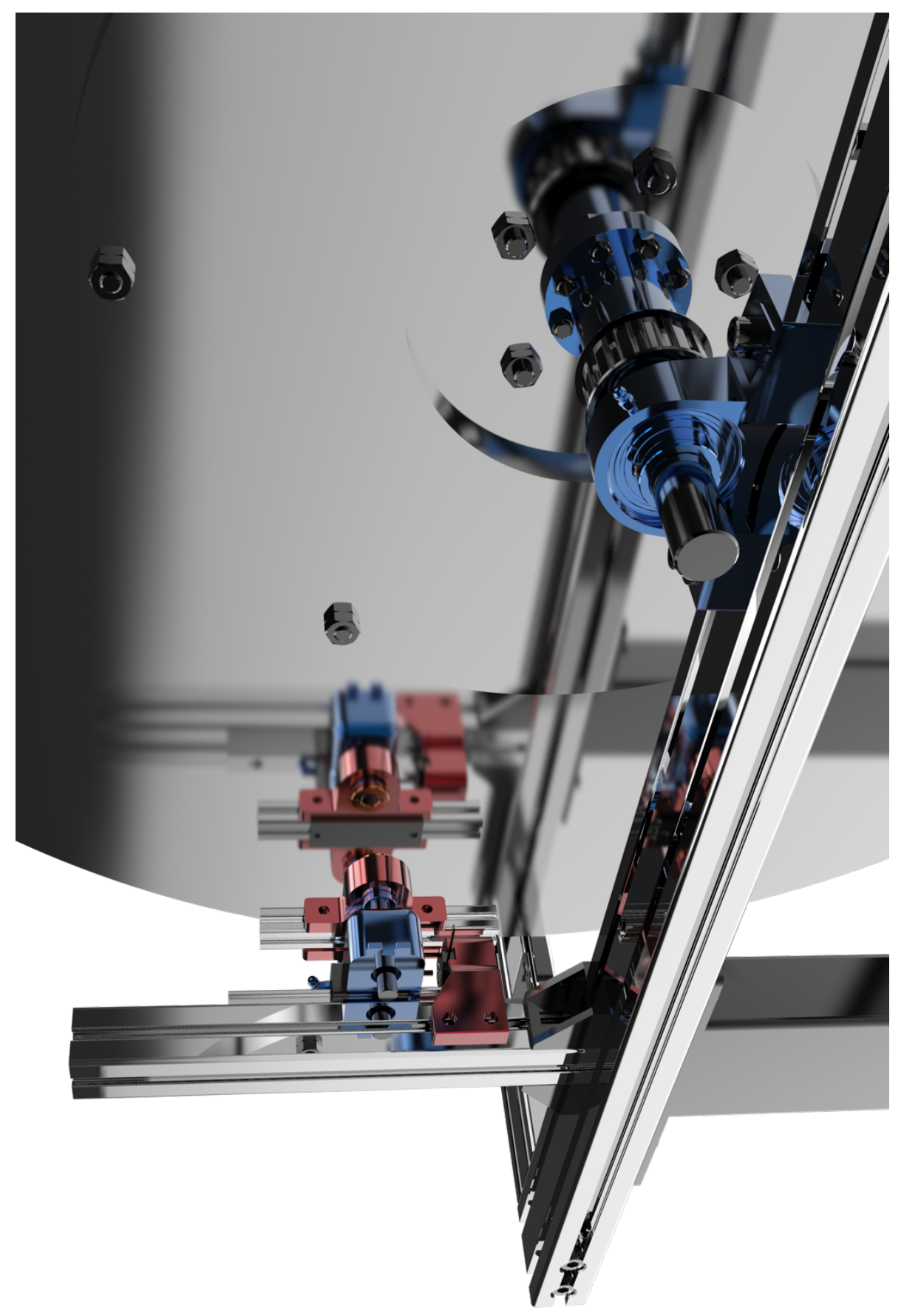


Appendix A.3 Pod Engineering Drawings 


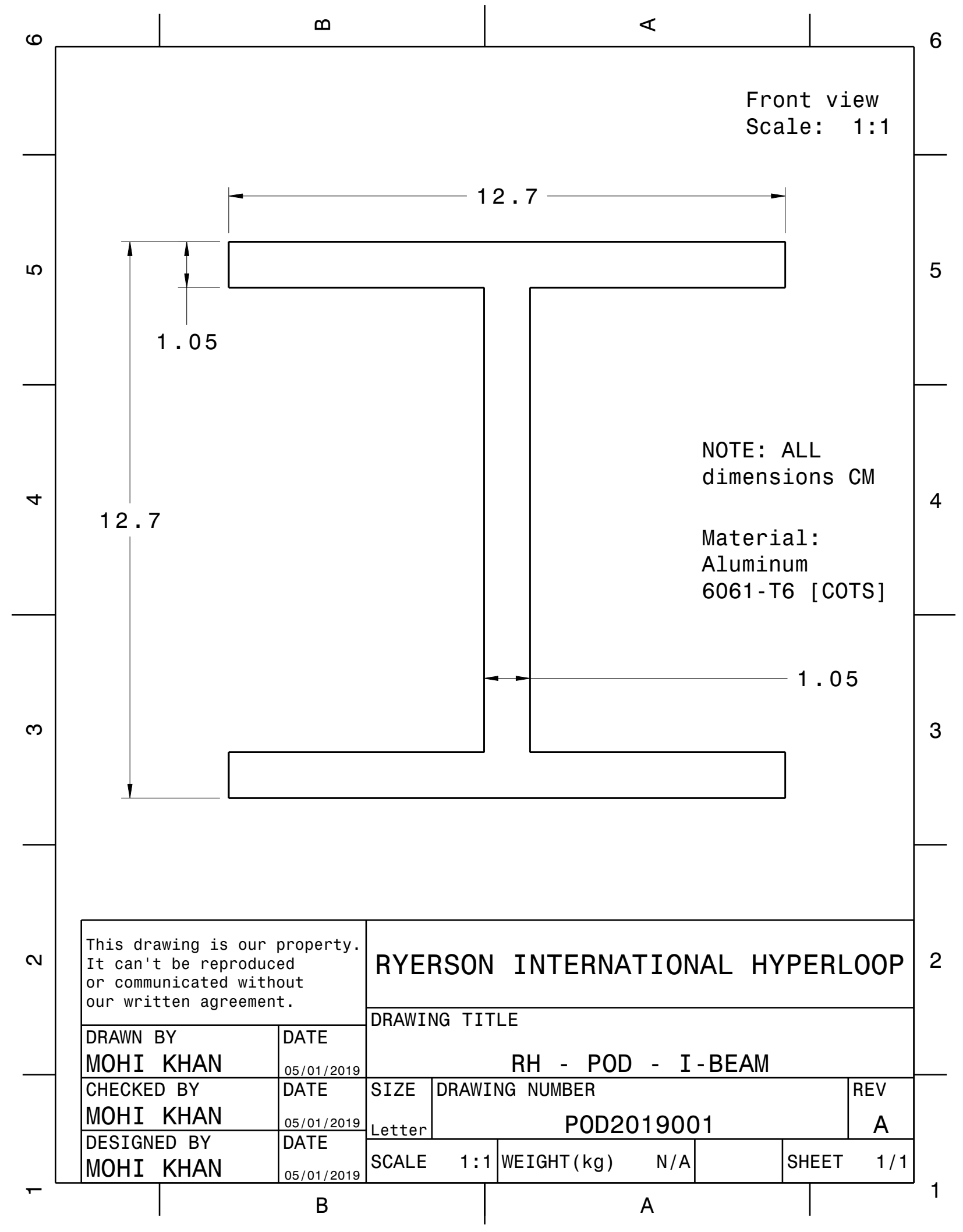




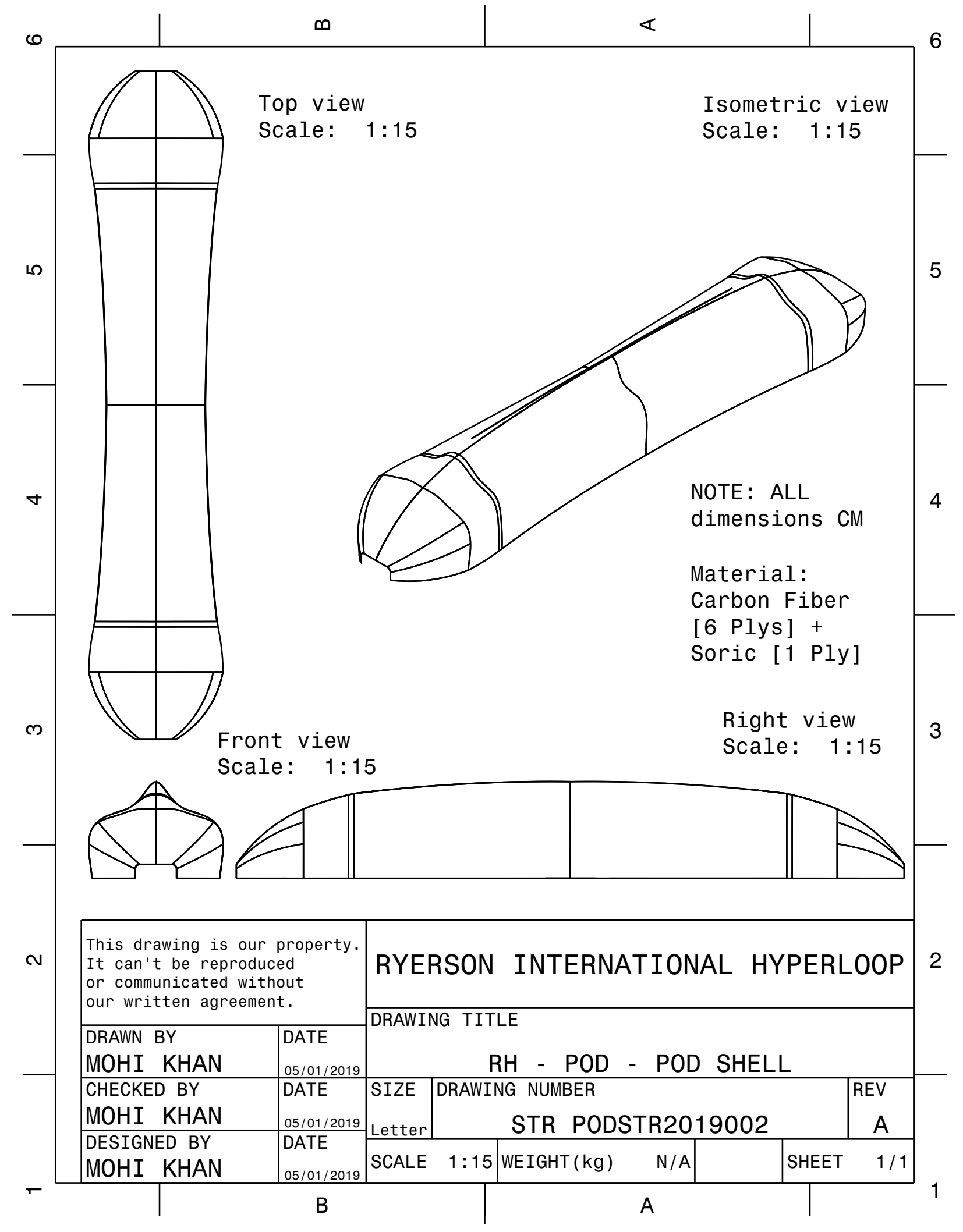




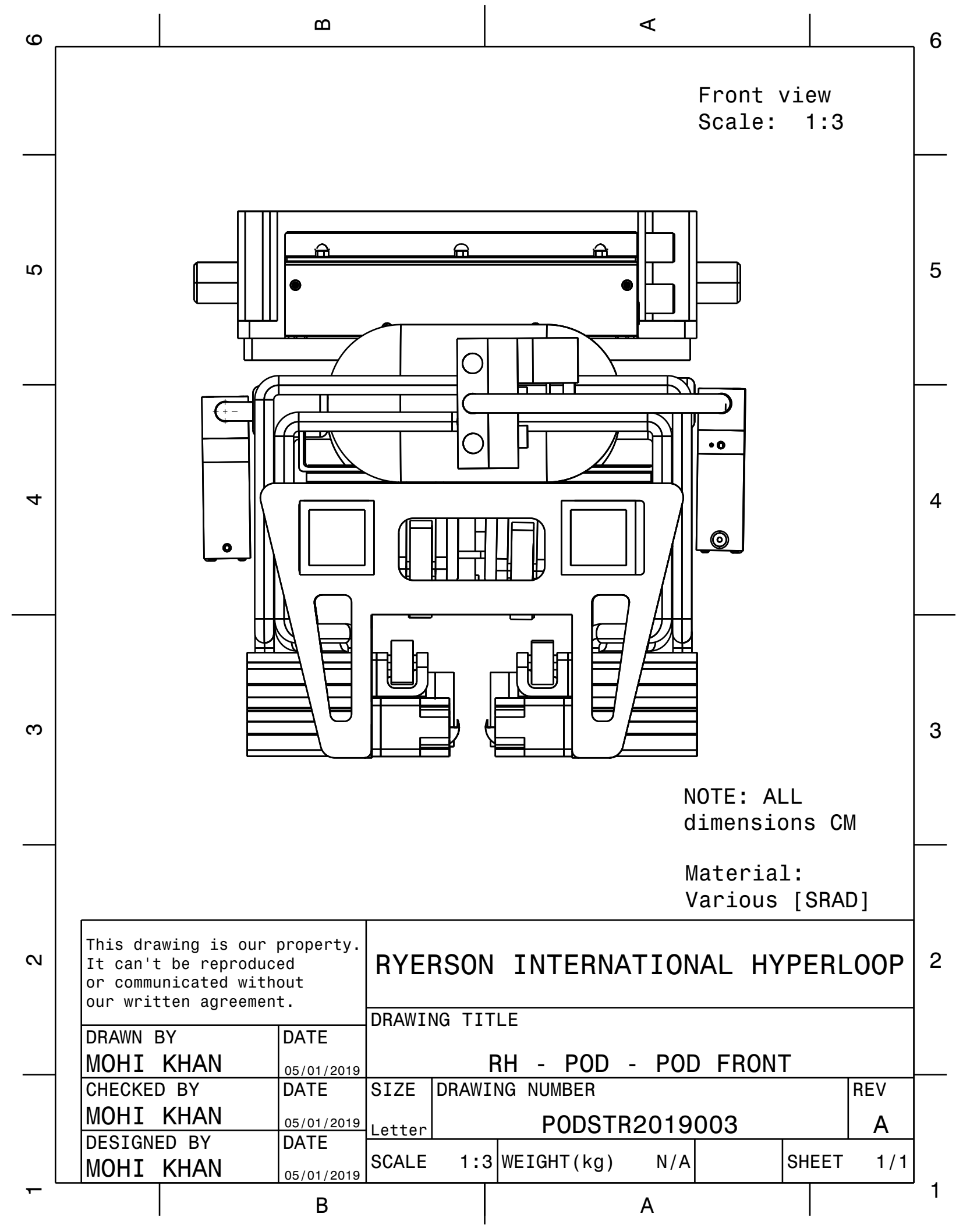




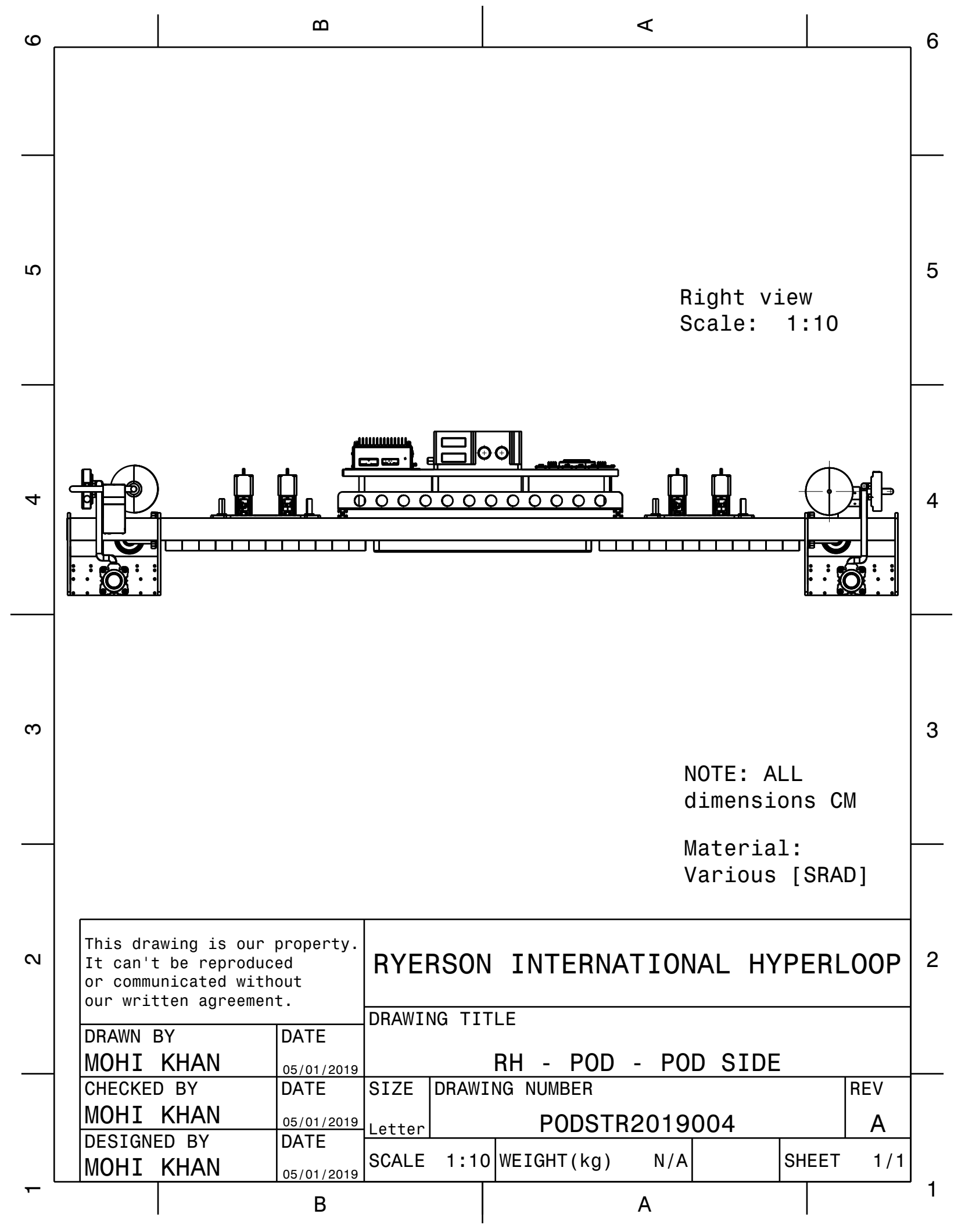




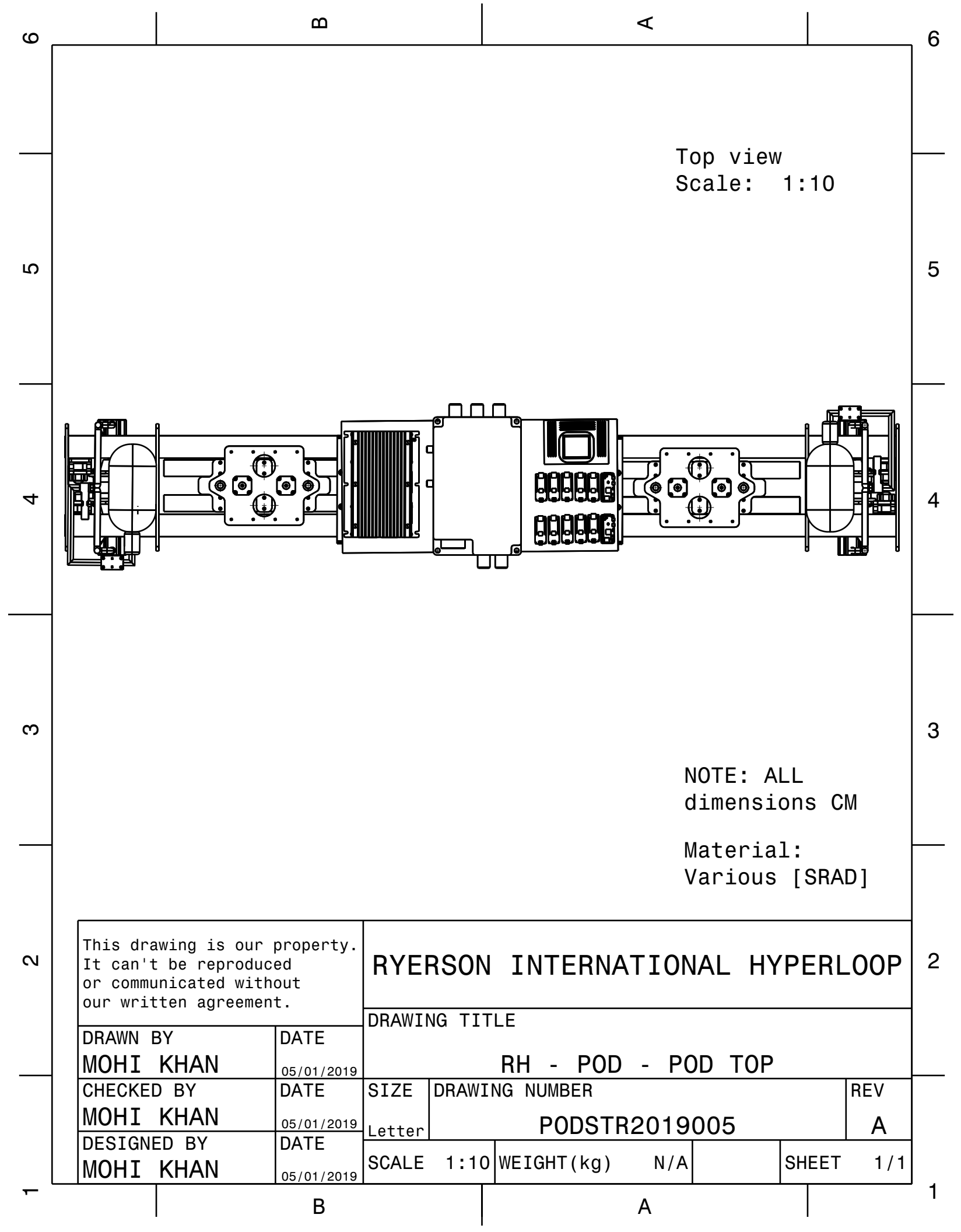




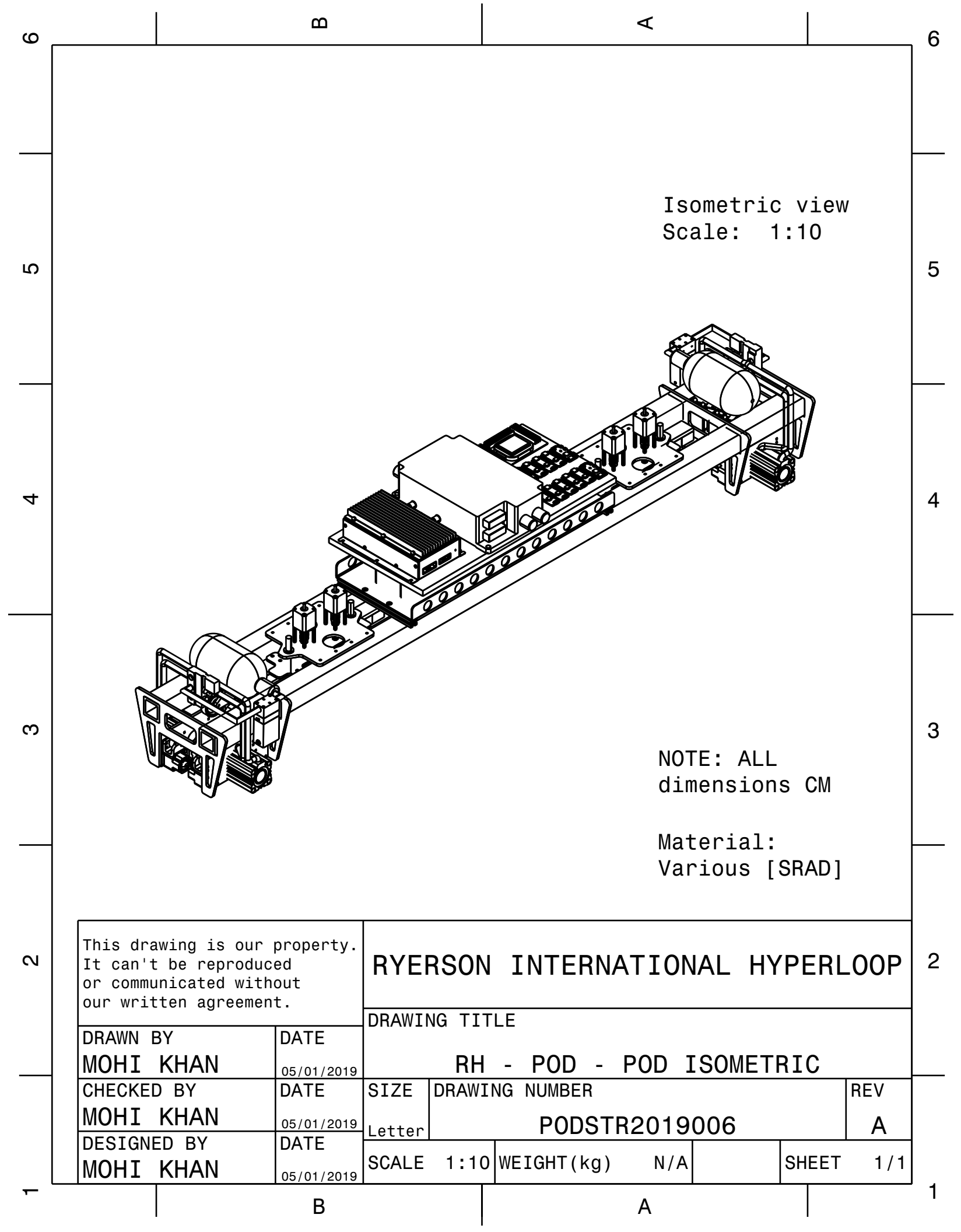




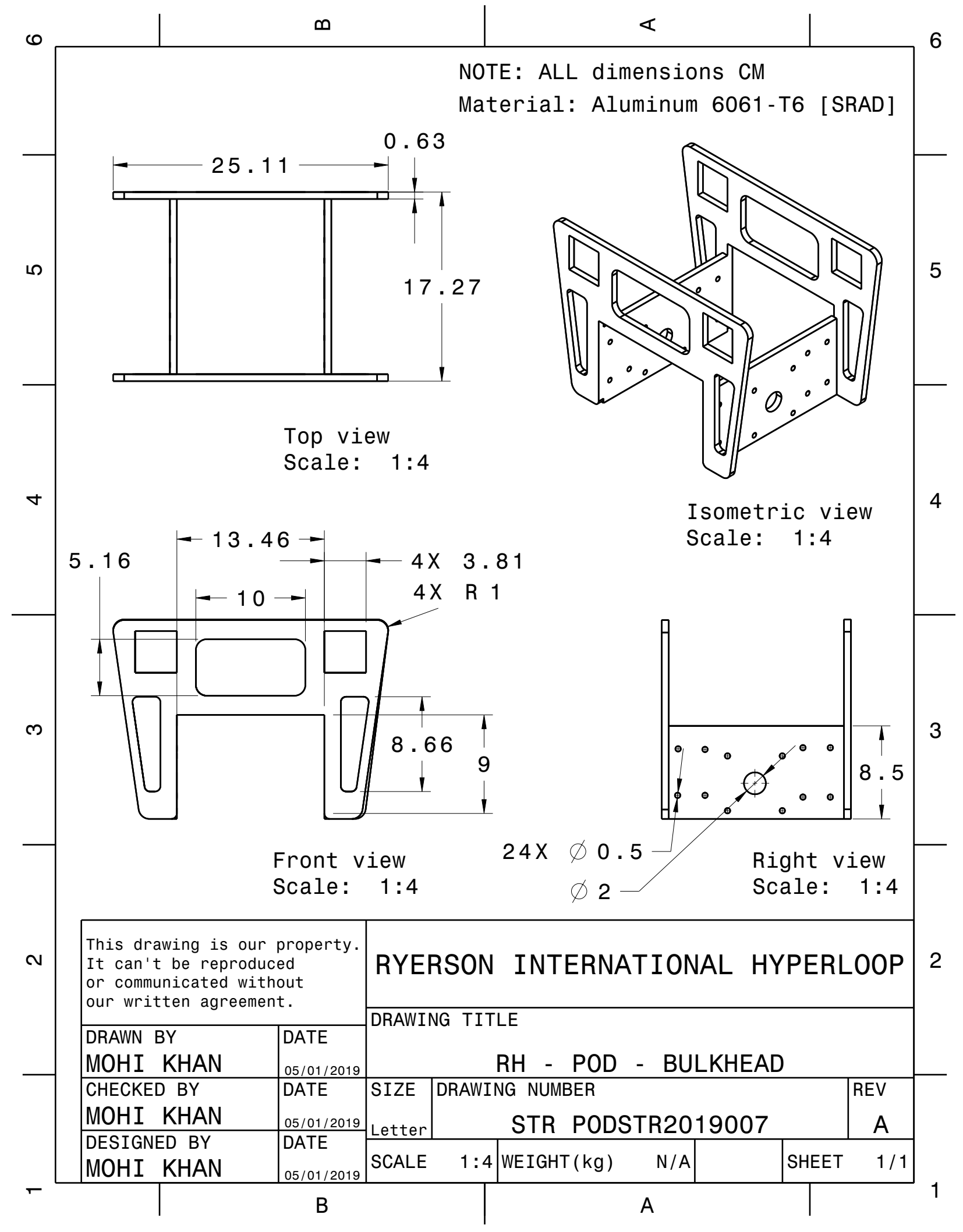




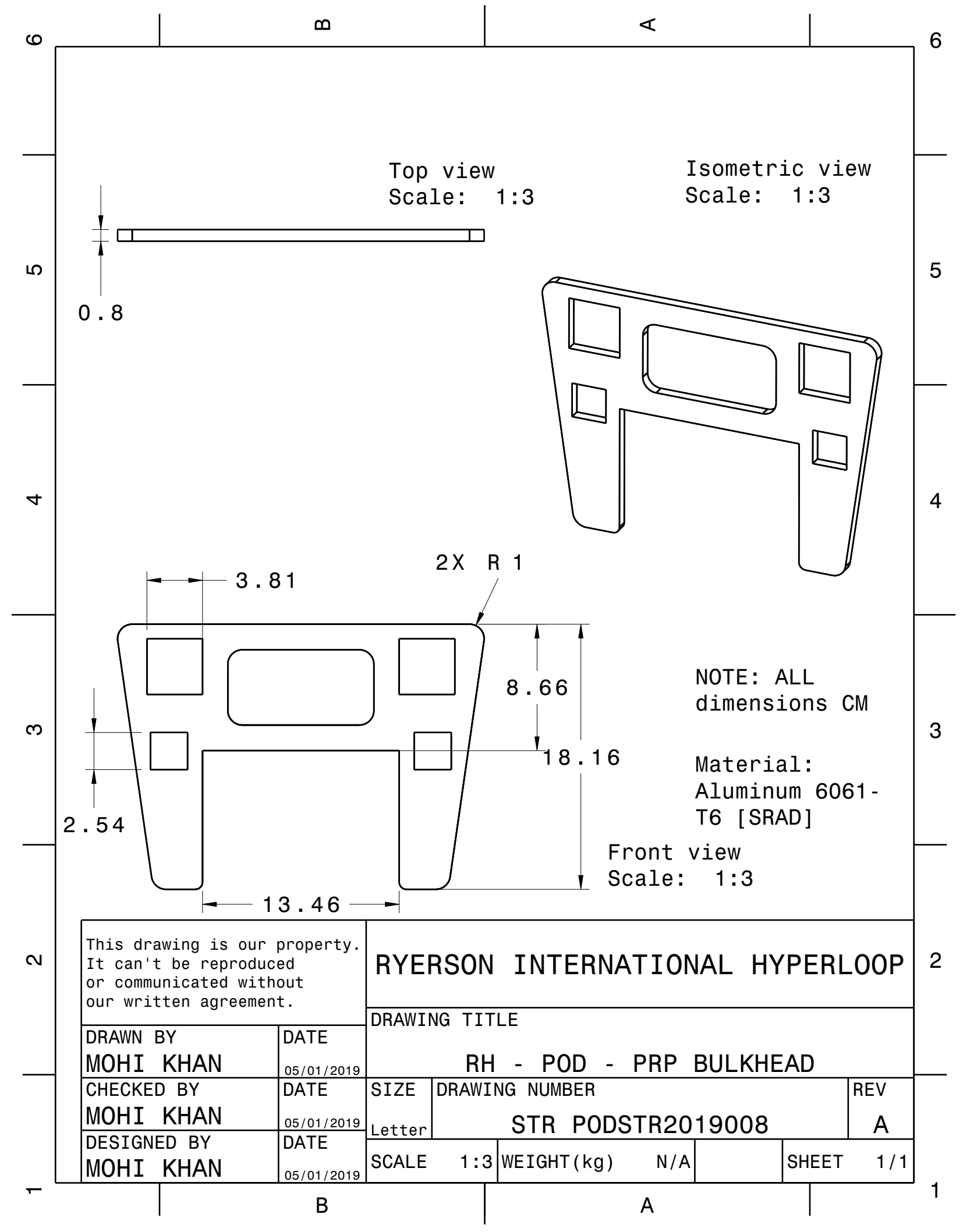




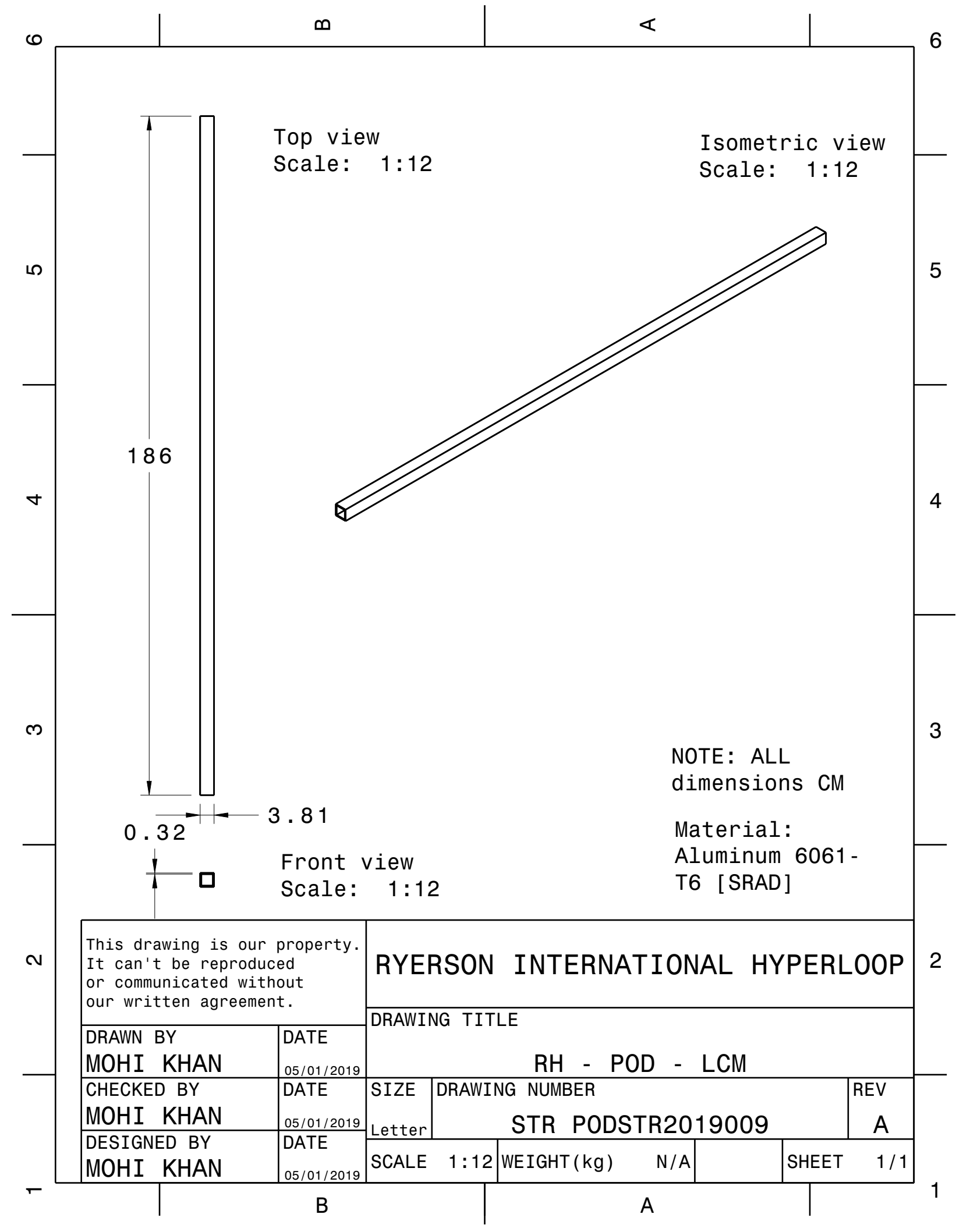




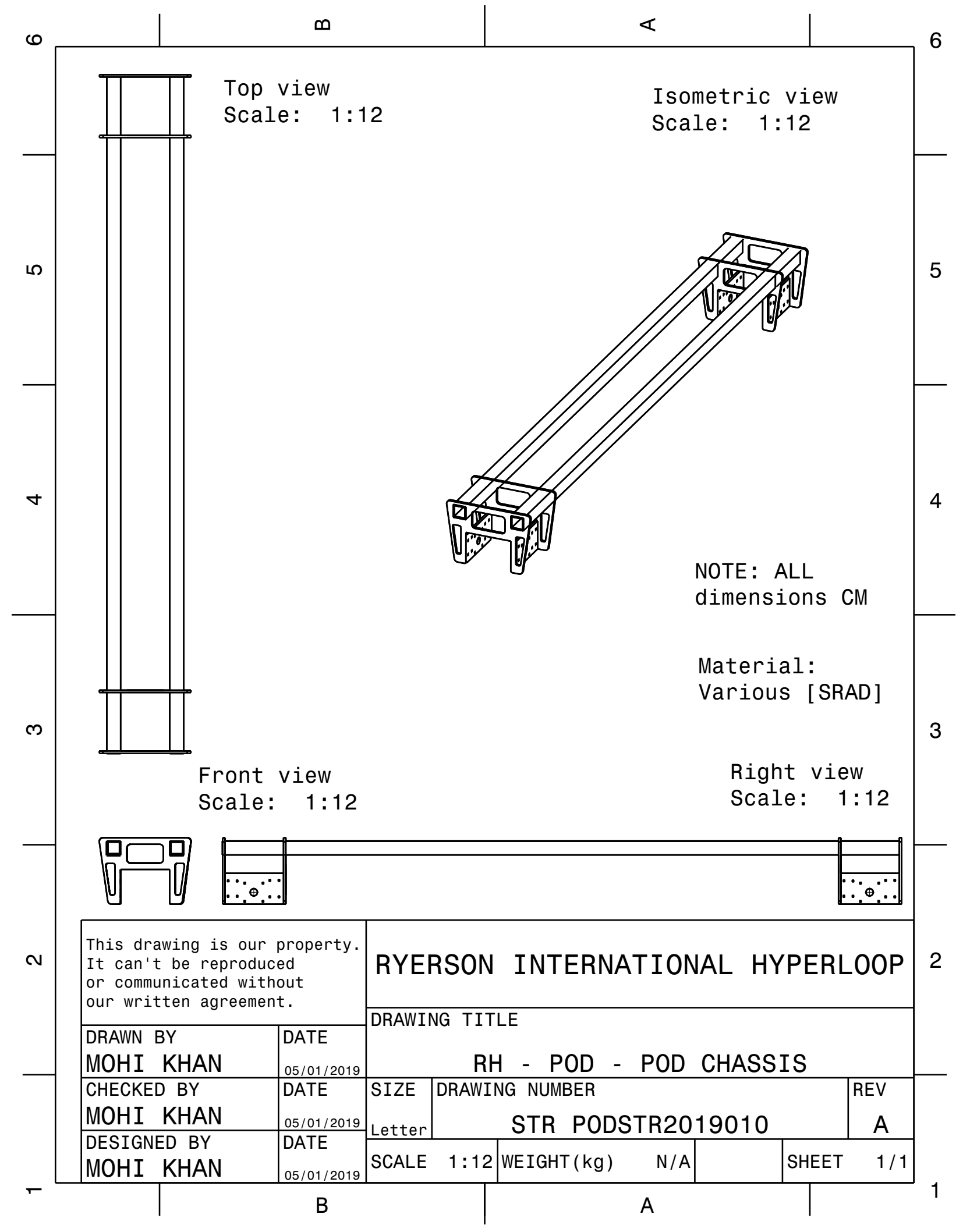




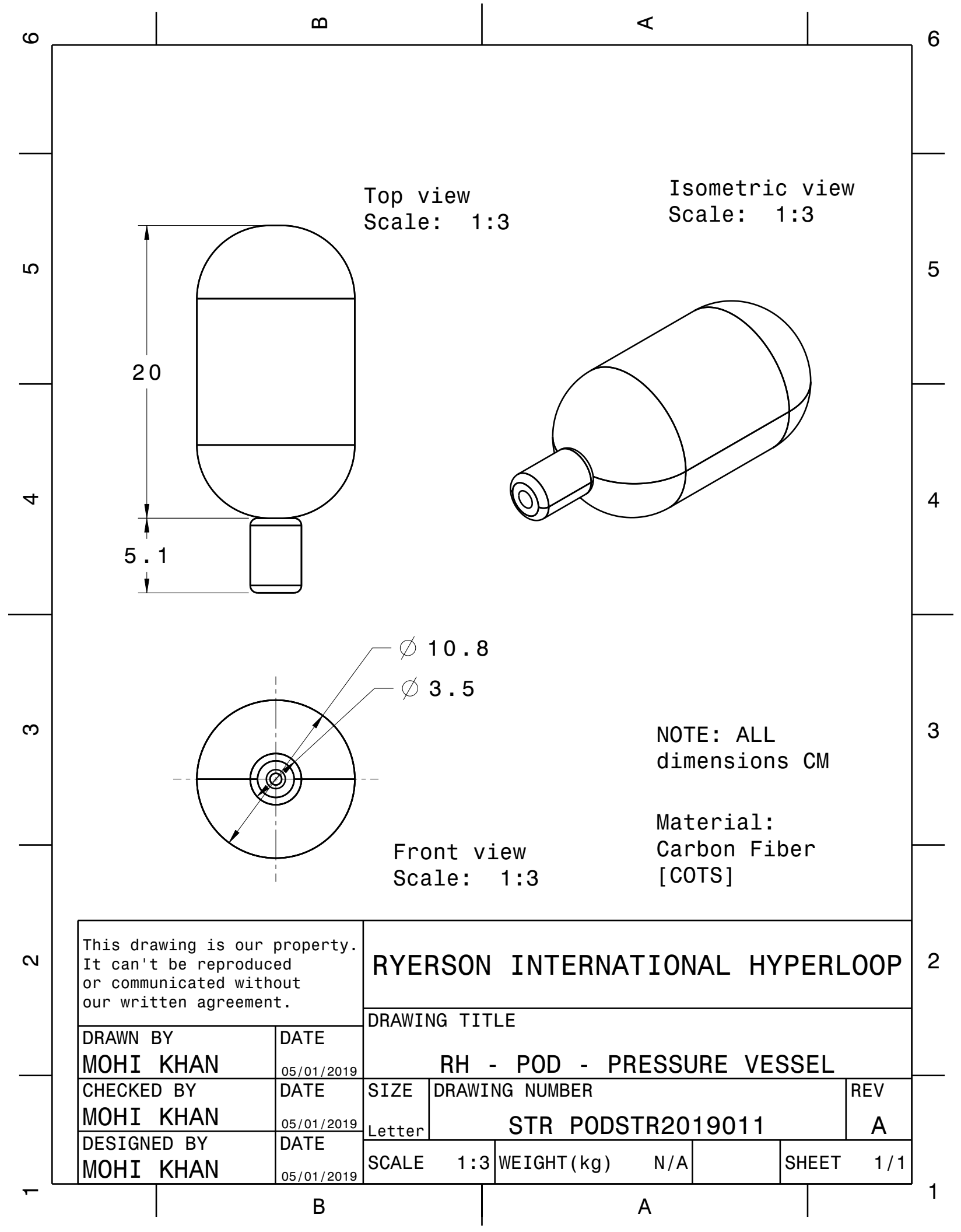




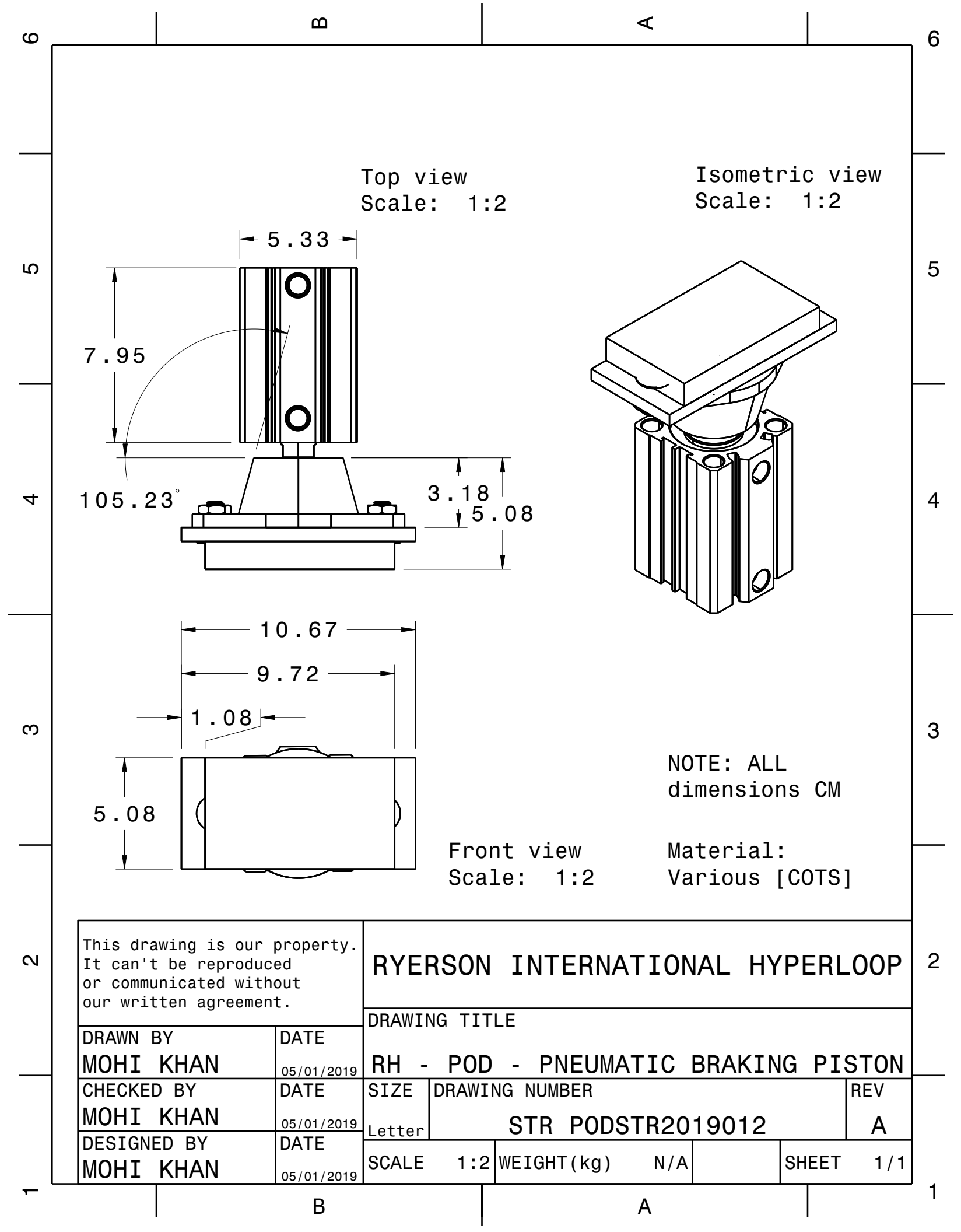




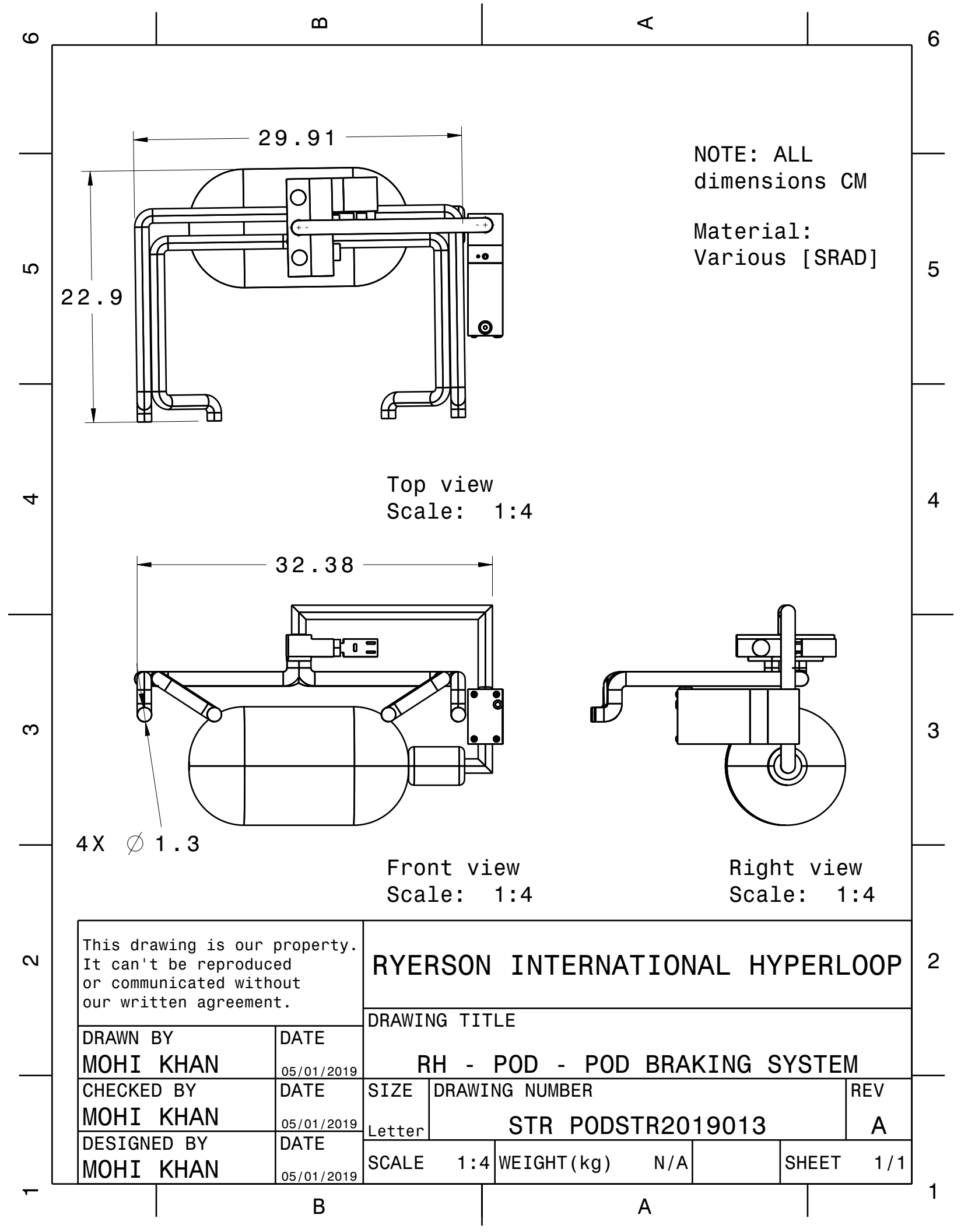




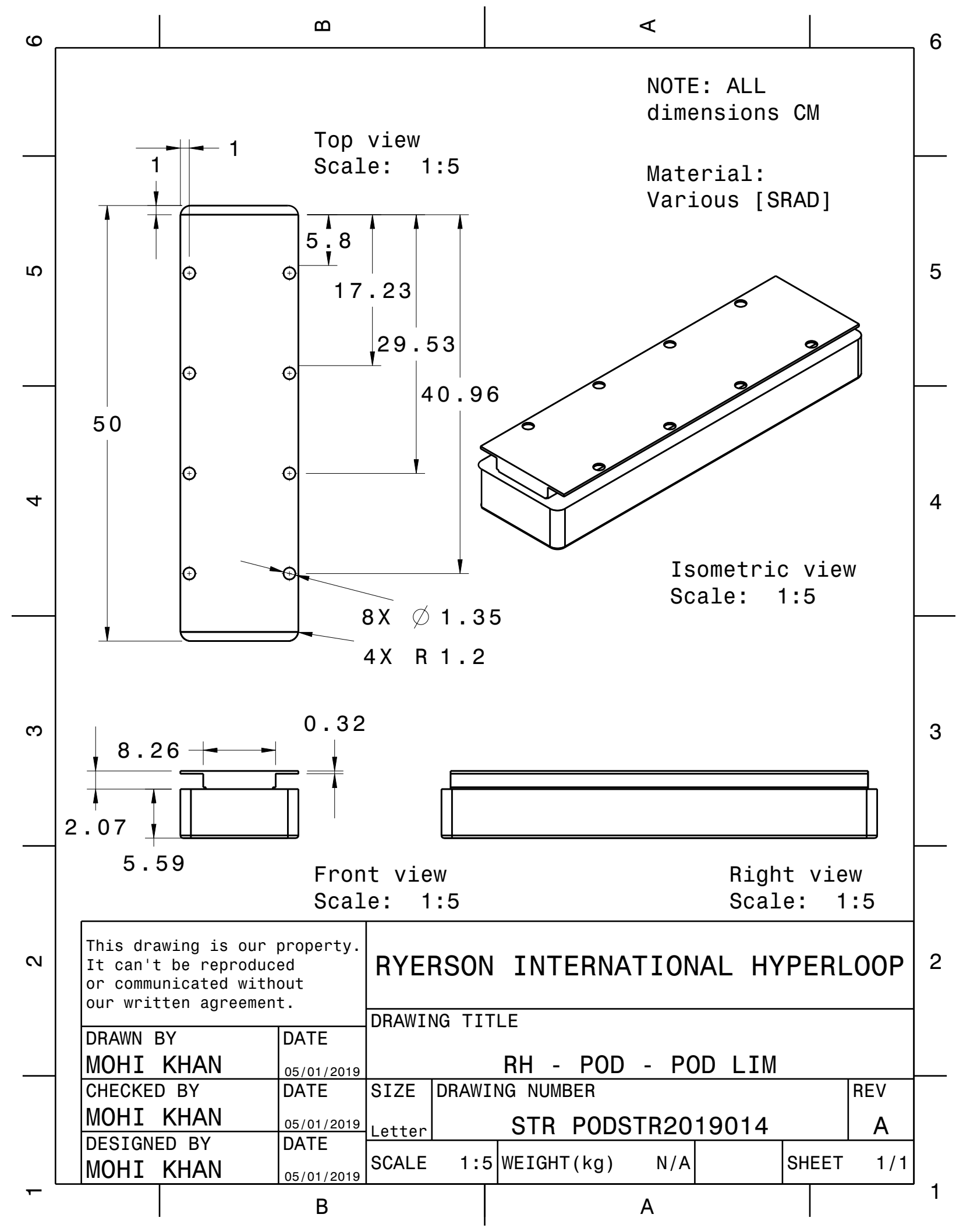




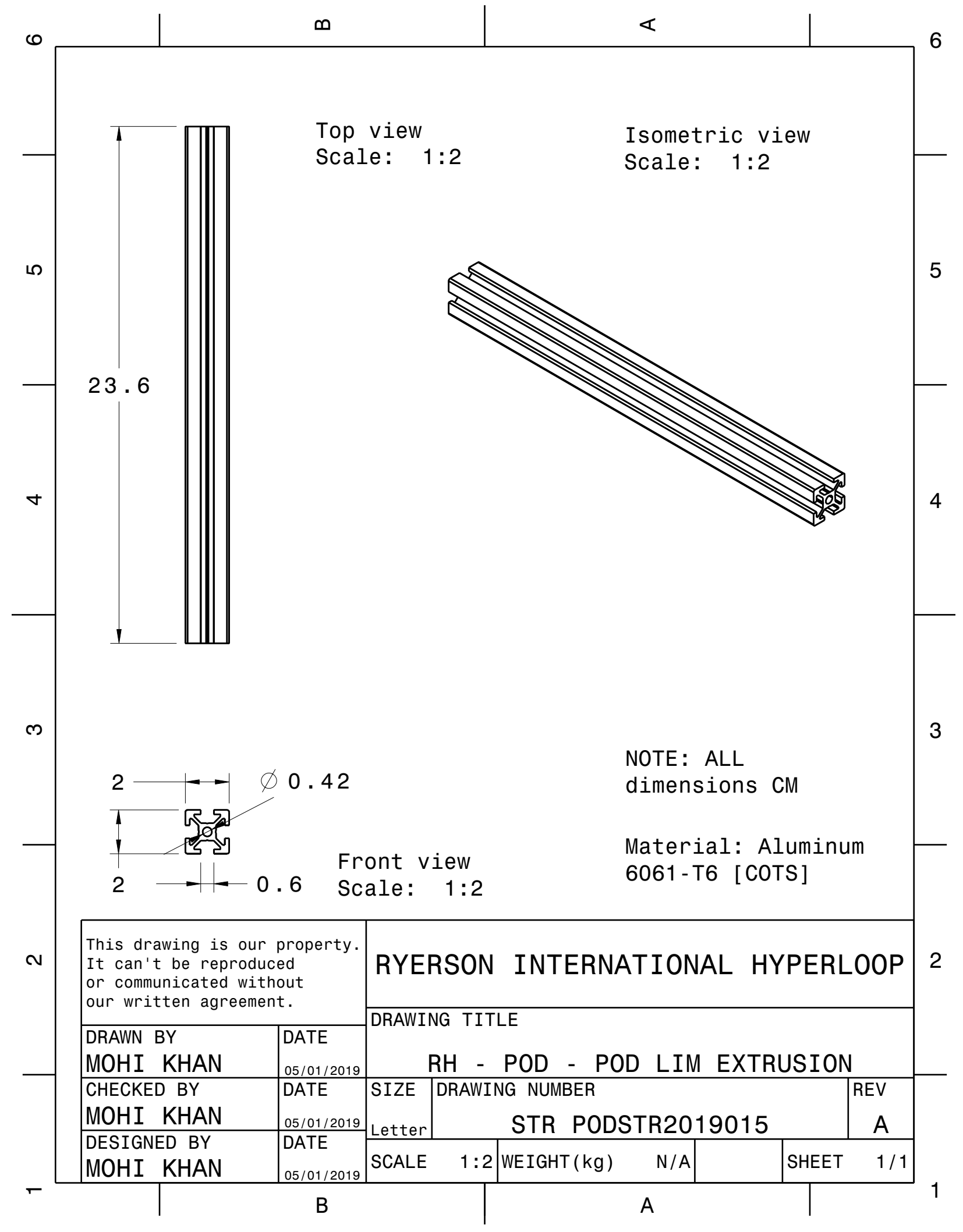




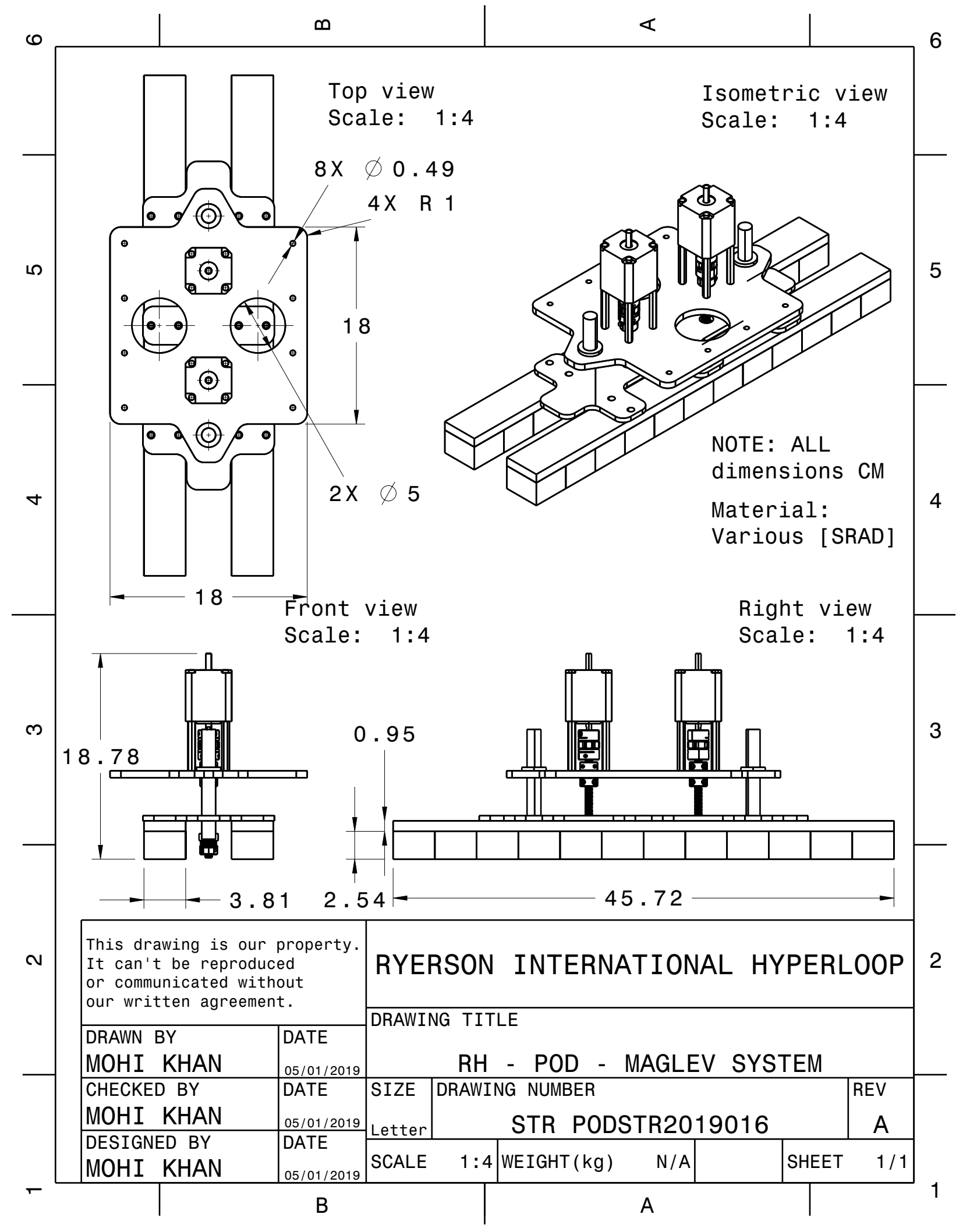




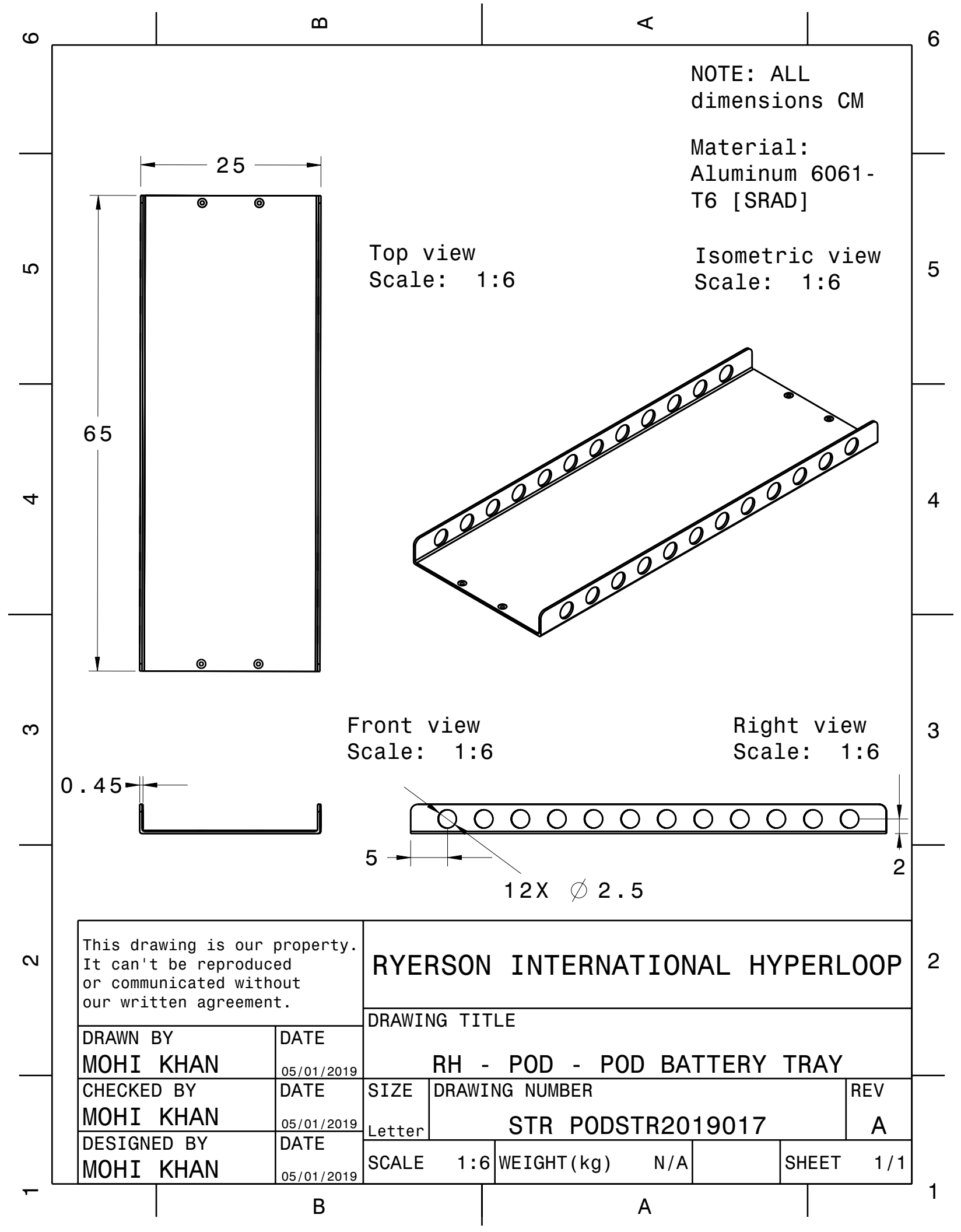




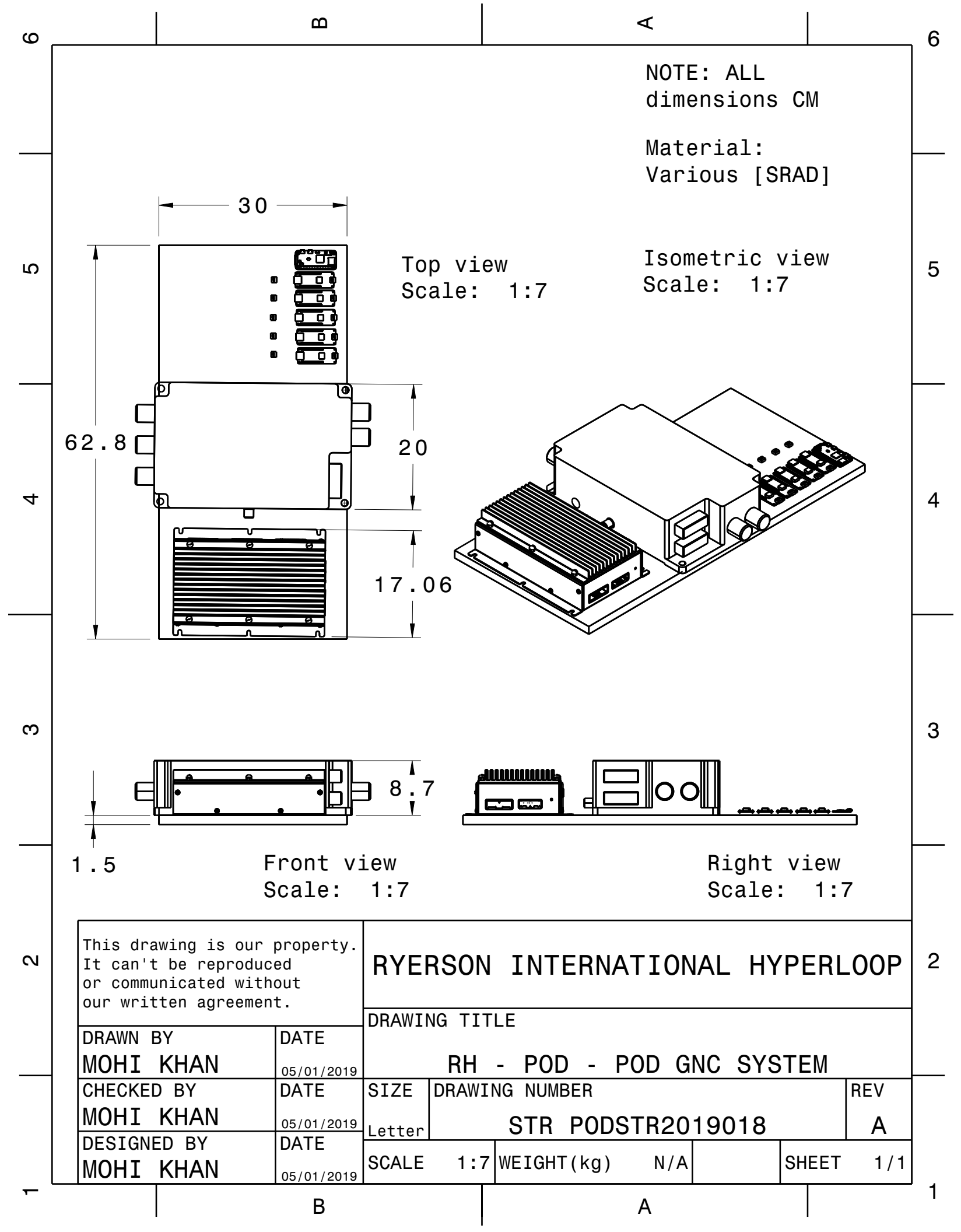


Appendix A.4 Modular Test Rig Engineering Drawings 


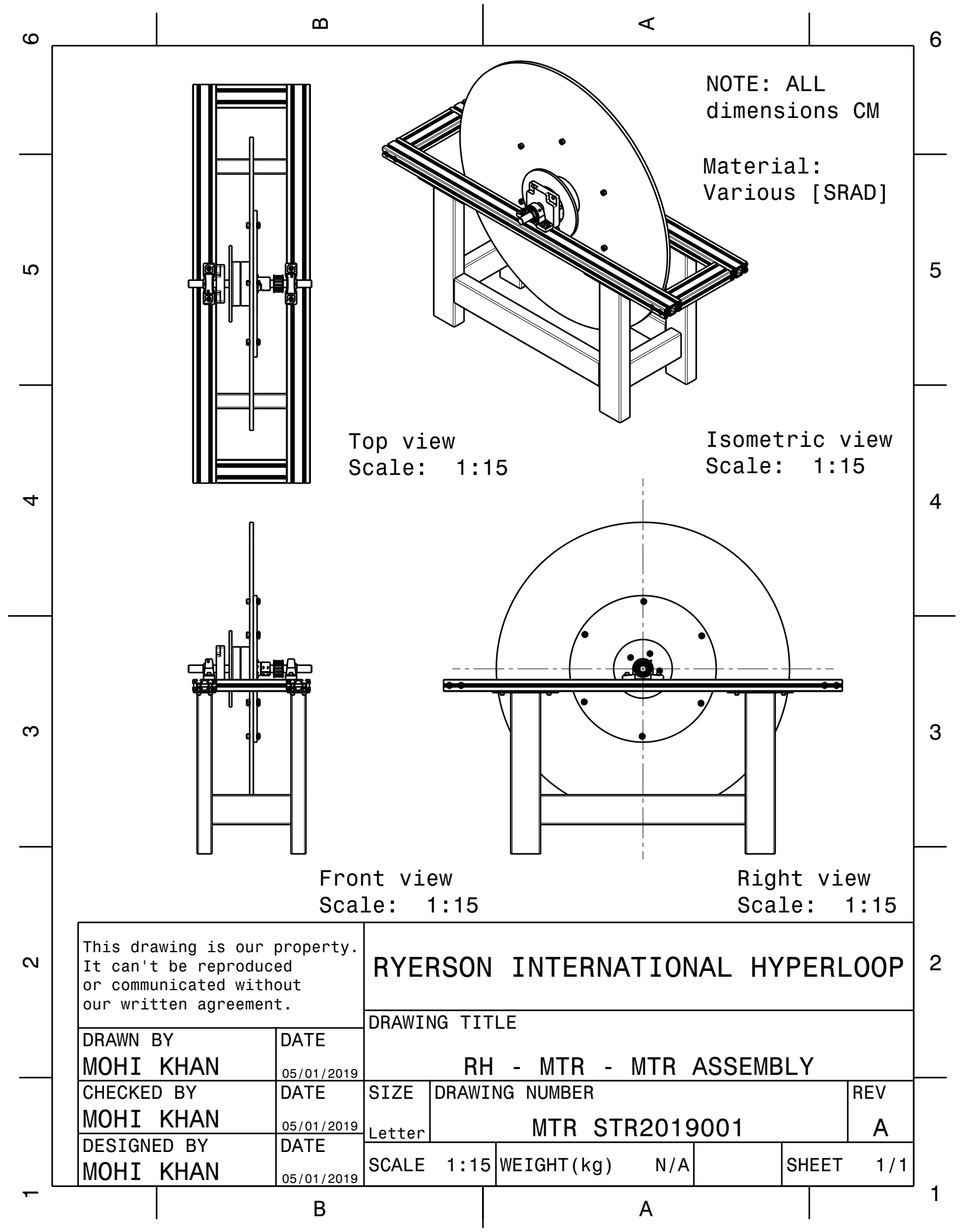




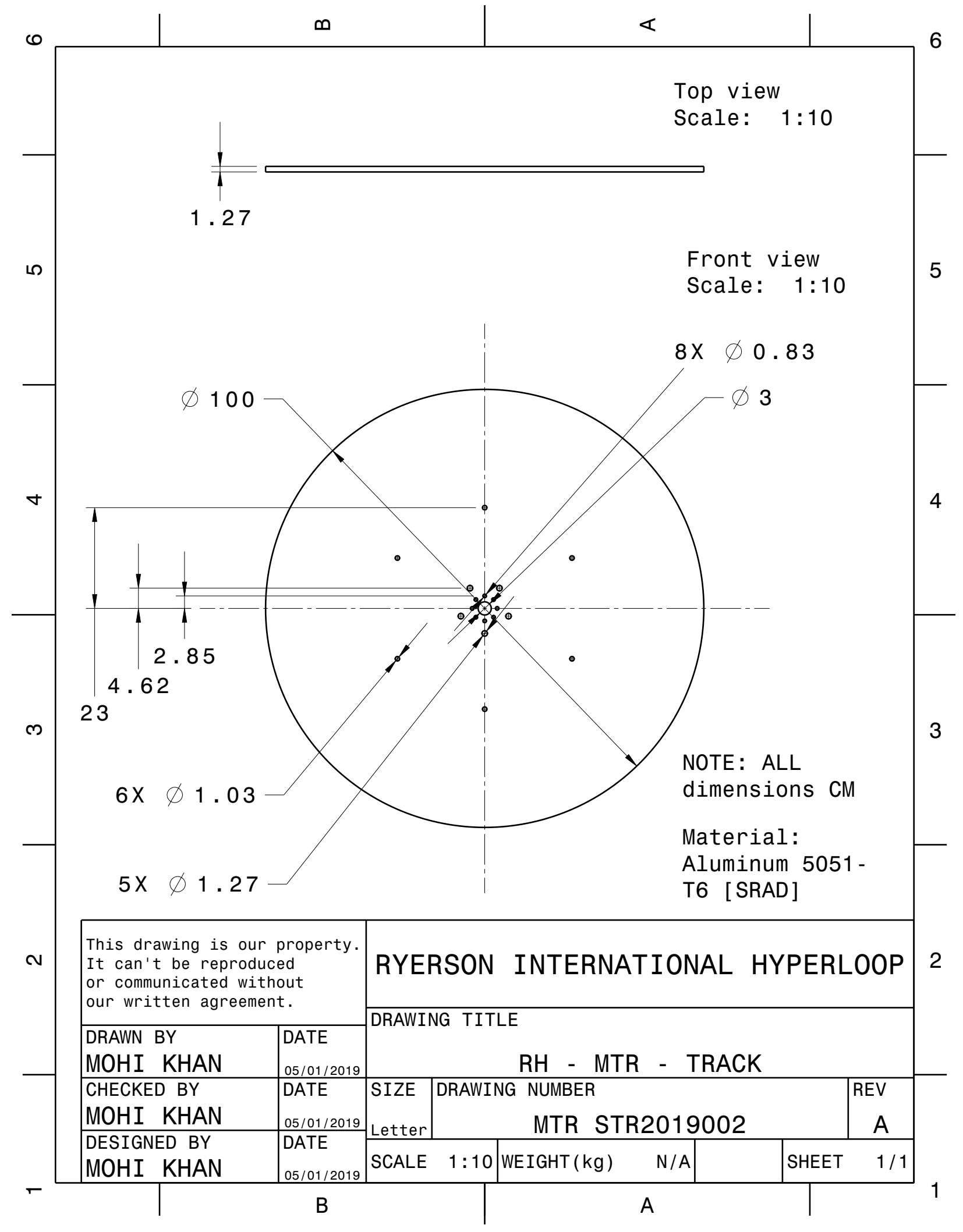




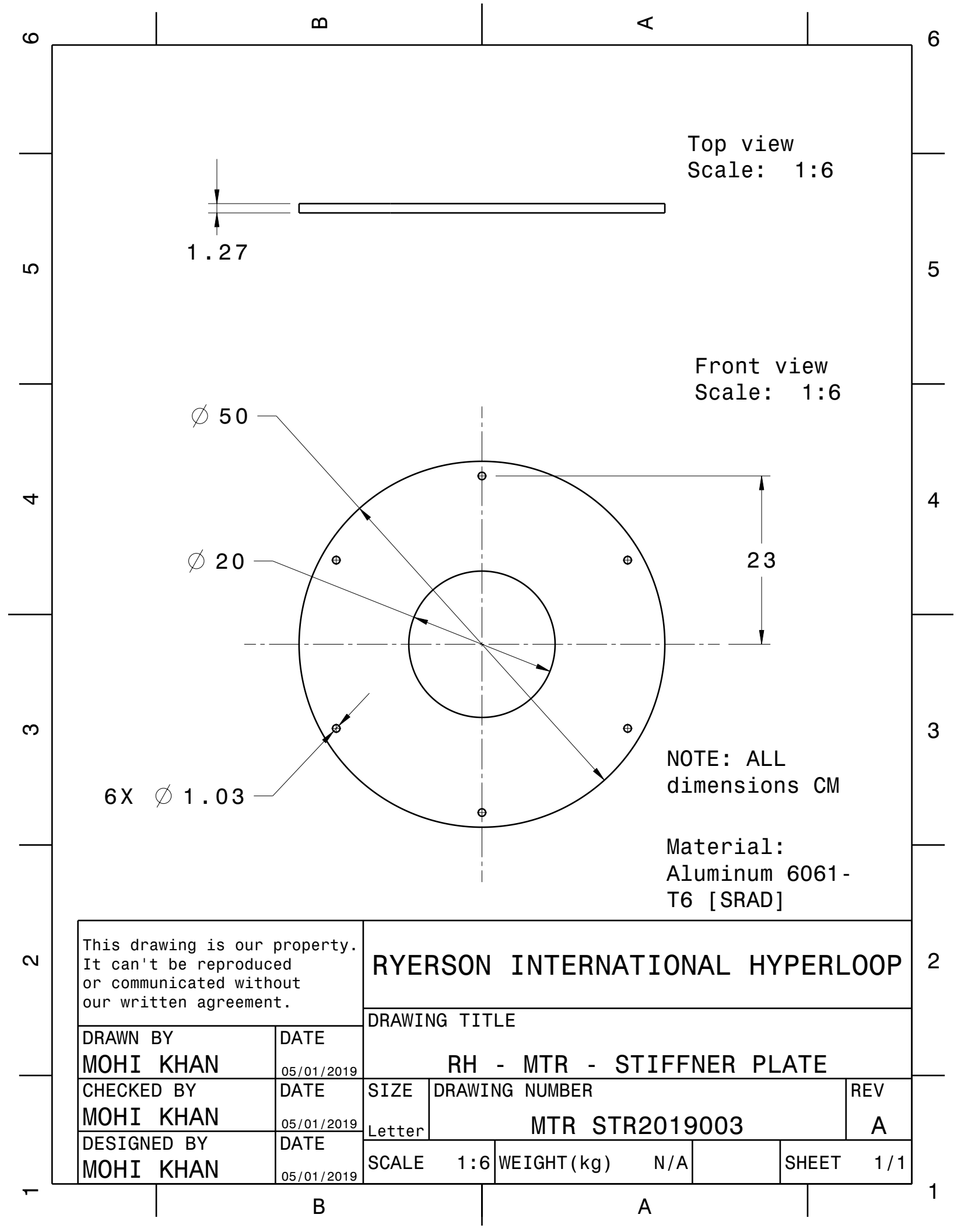




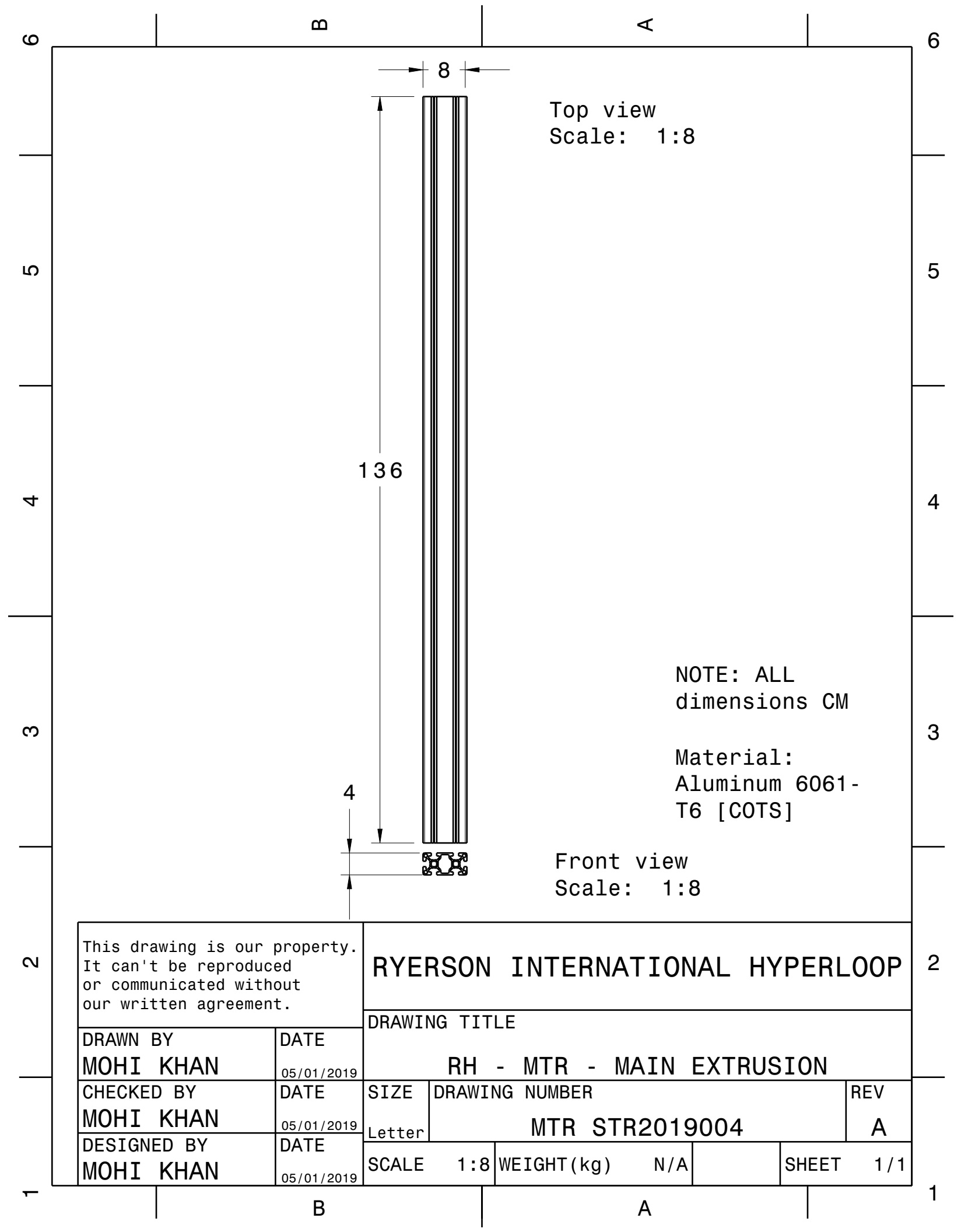




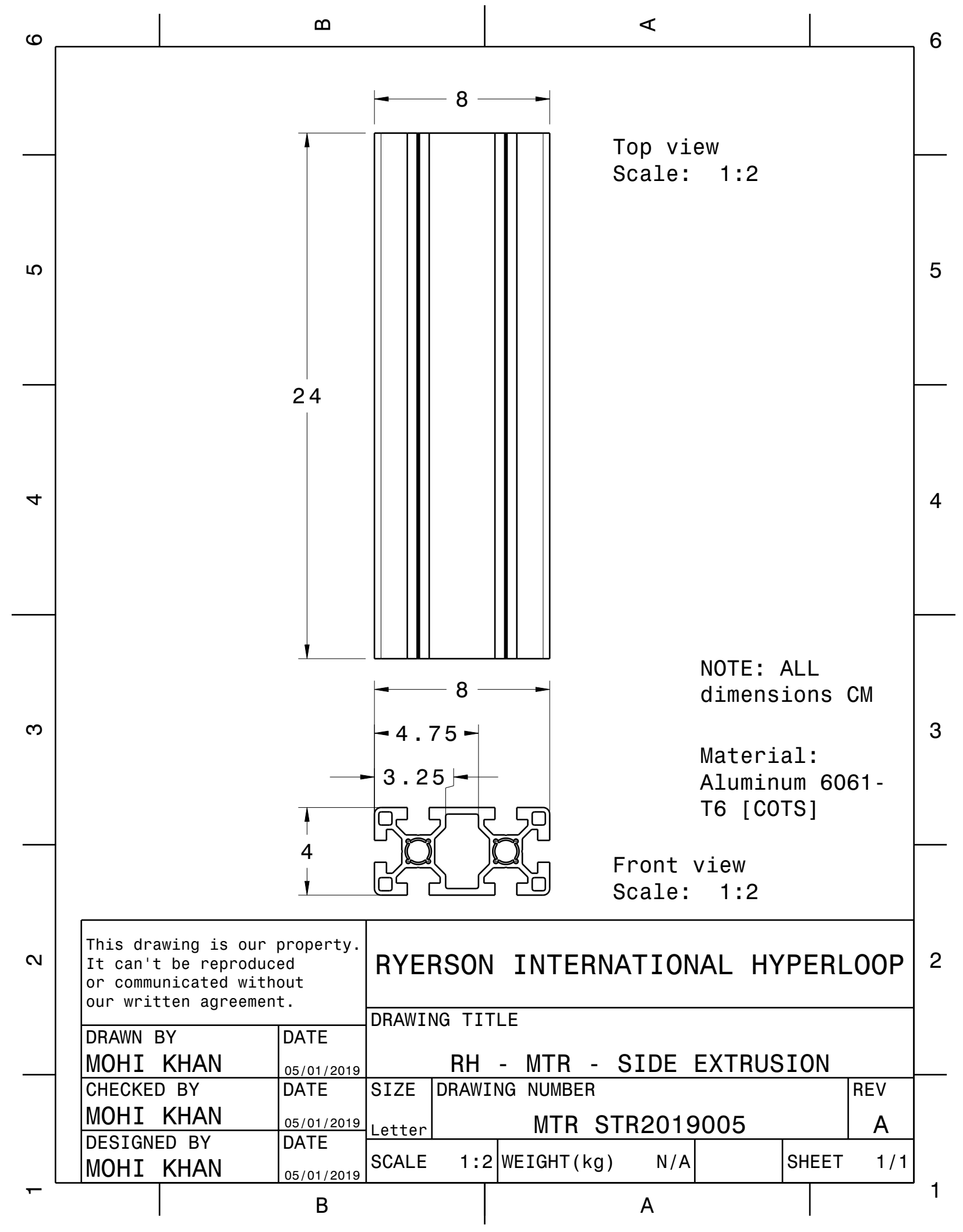




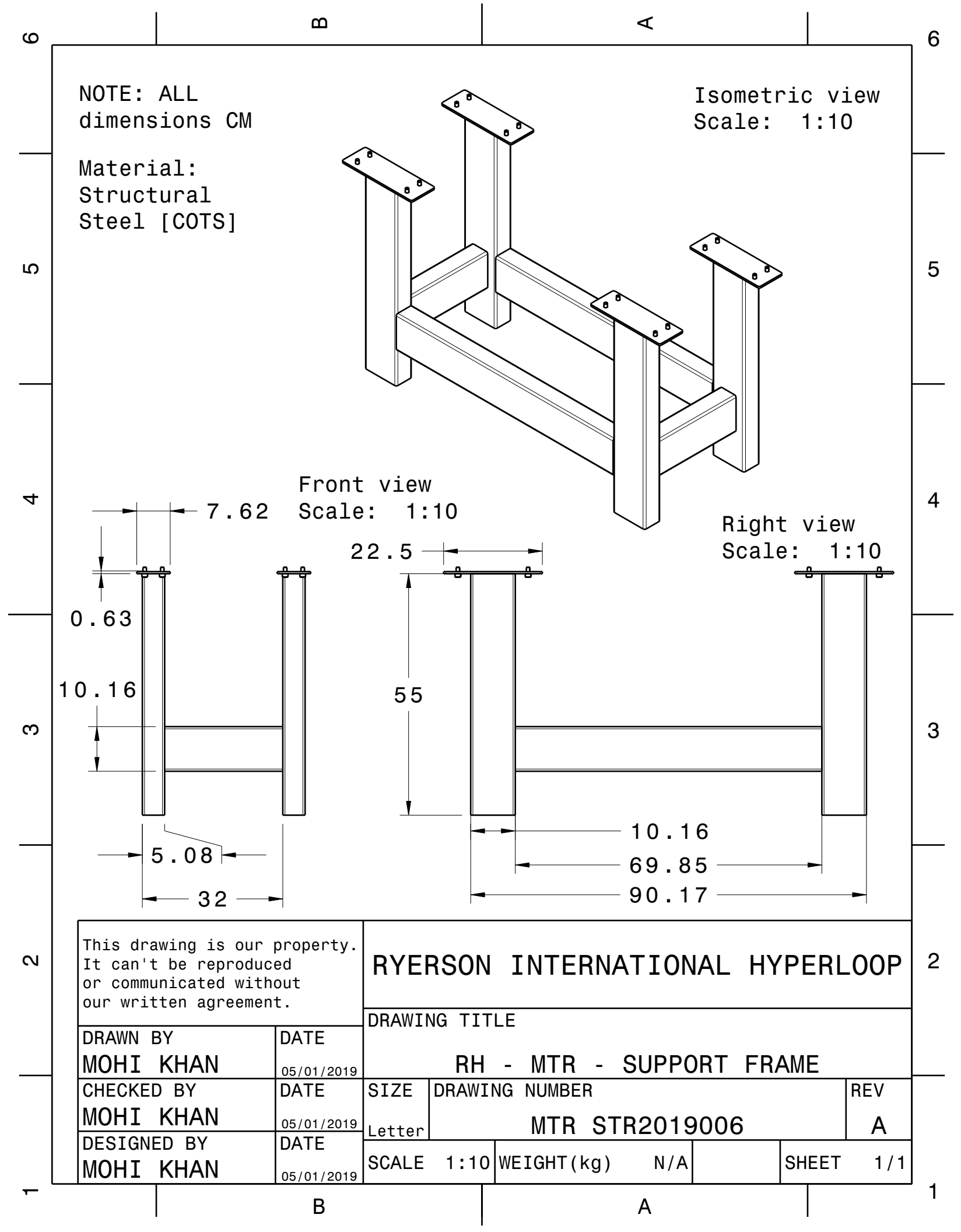




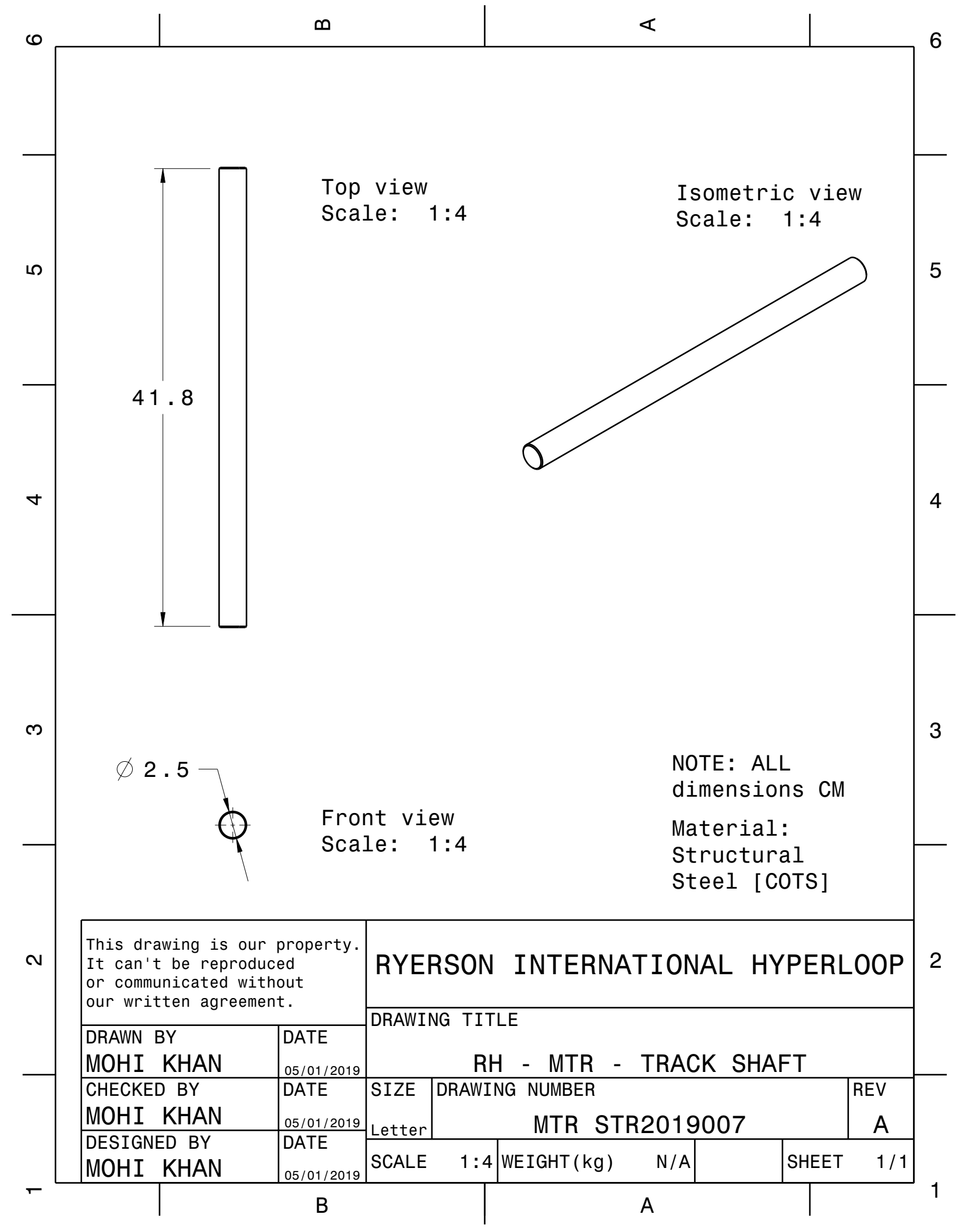




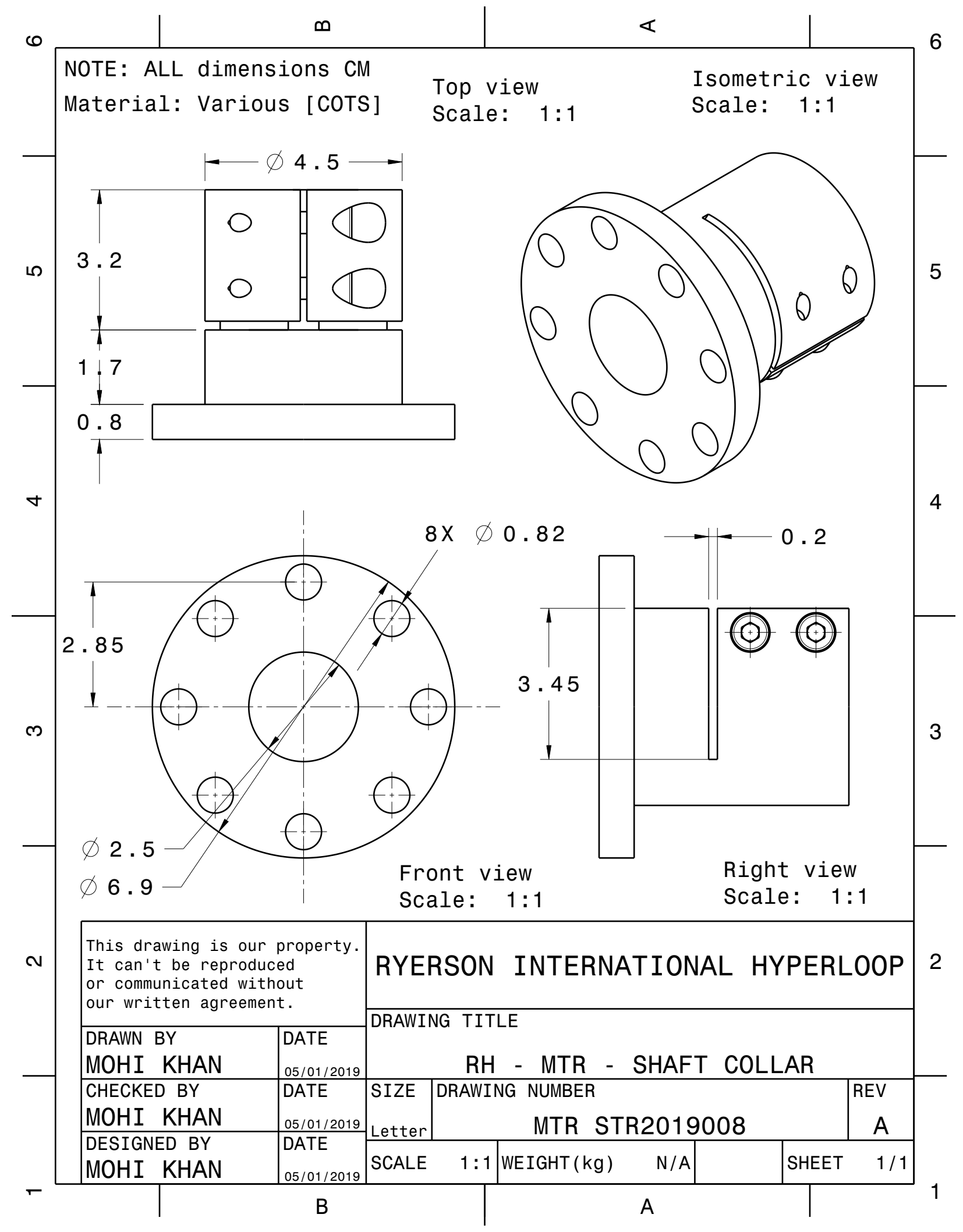




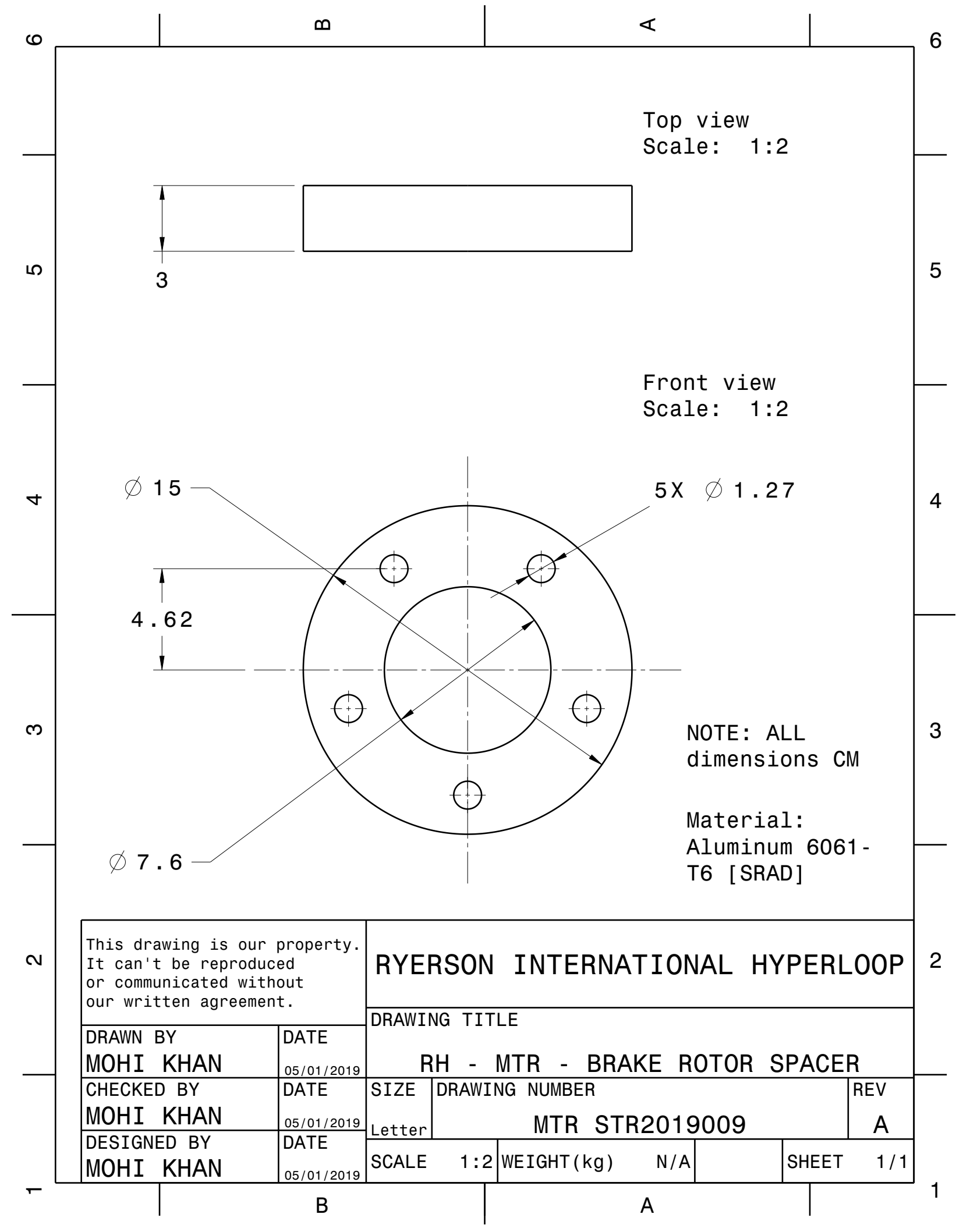




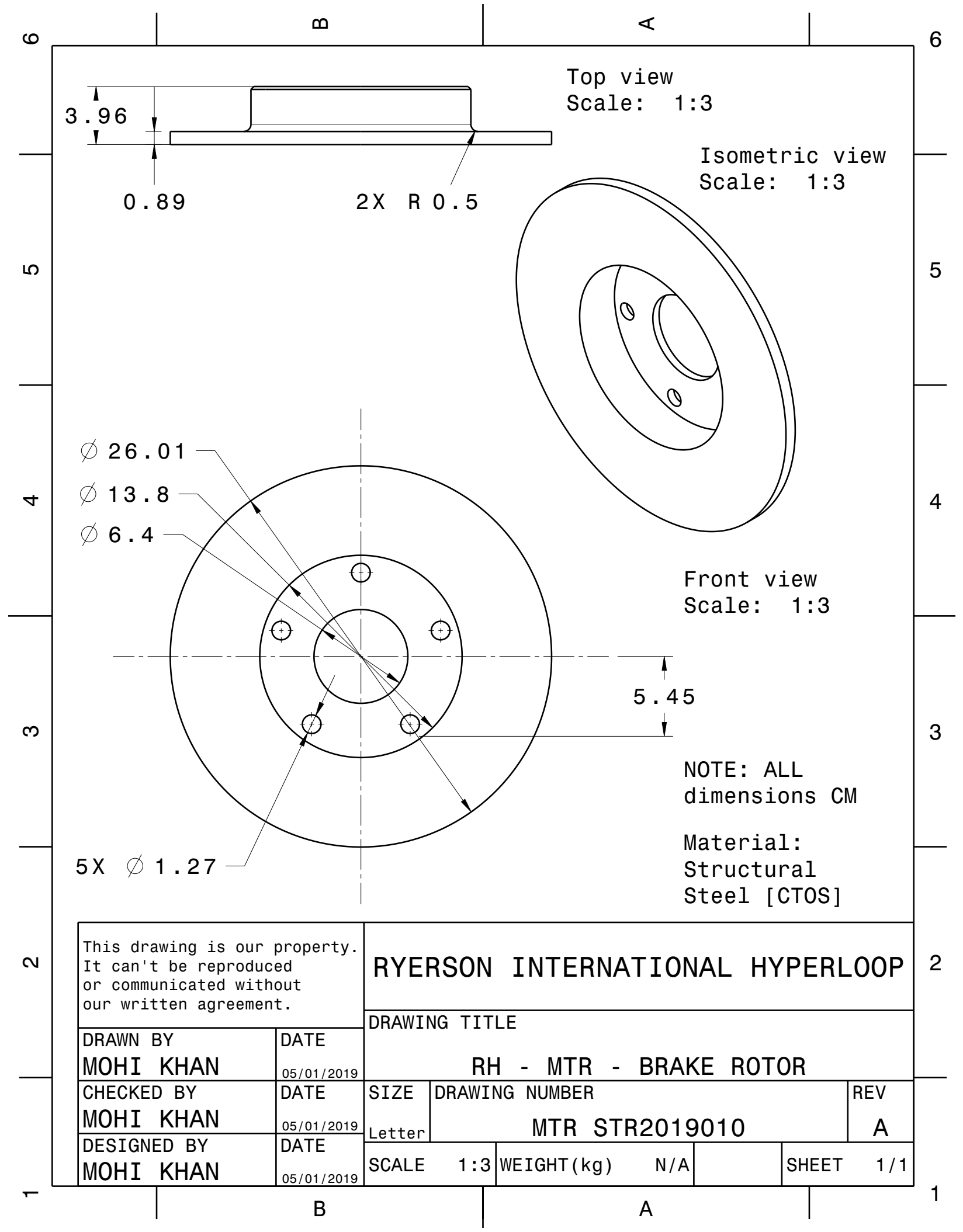




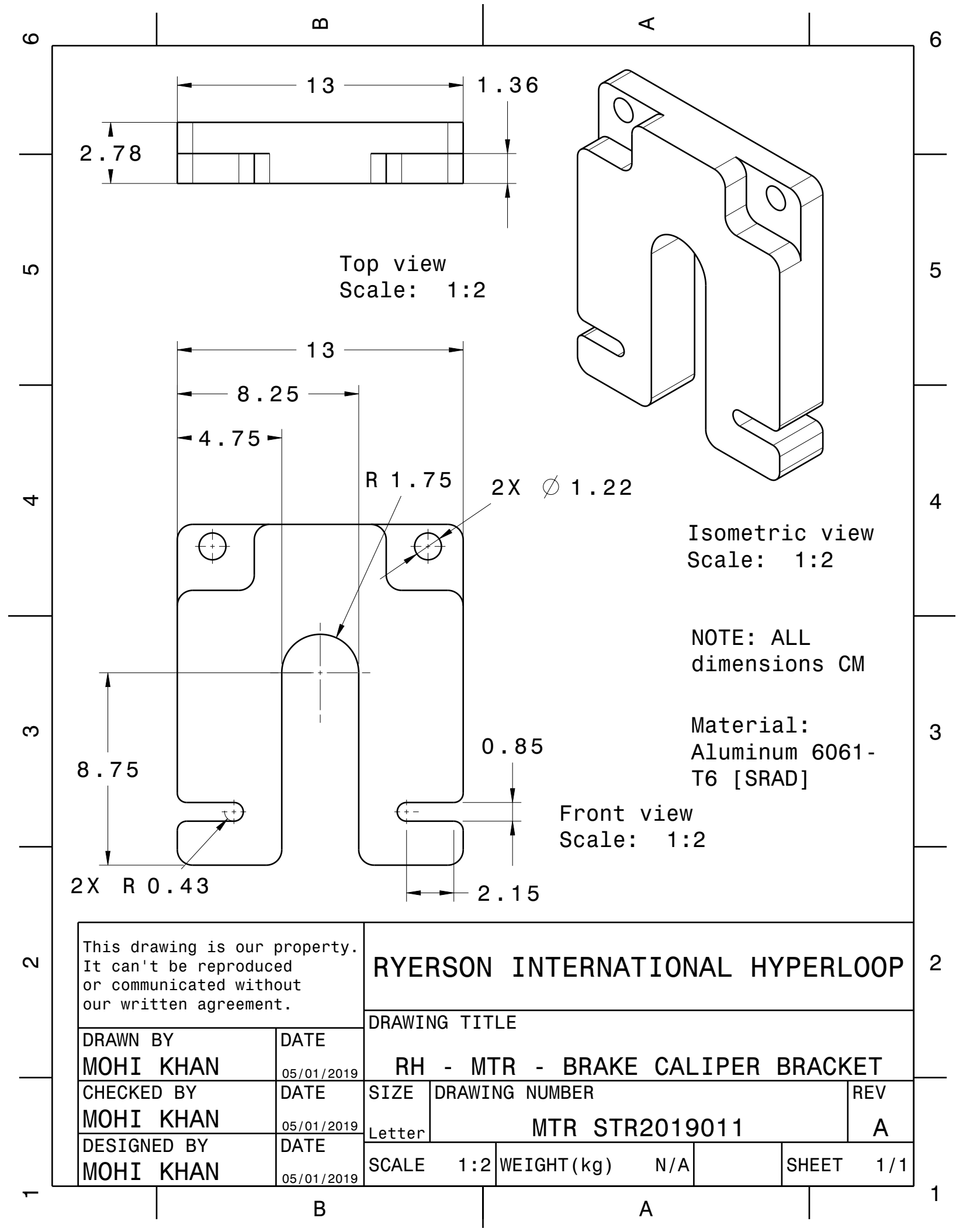


Appendix A.5 LCM Load Case I (Pod Staging) Analysis Report 


\section{MNSYS}

Project*

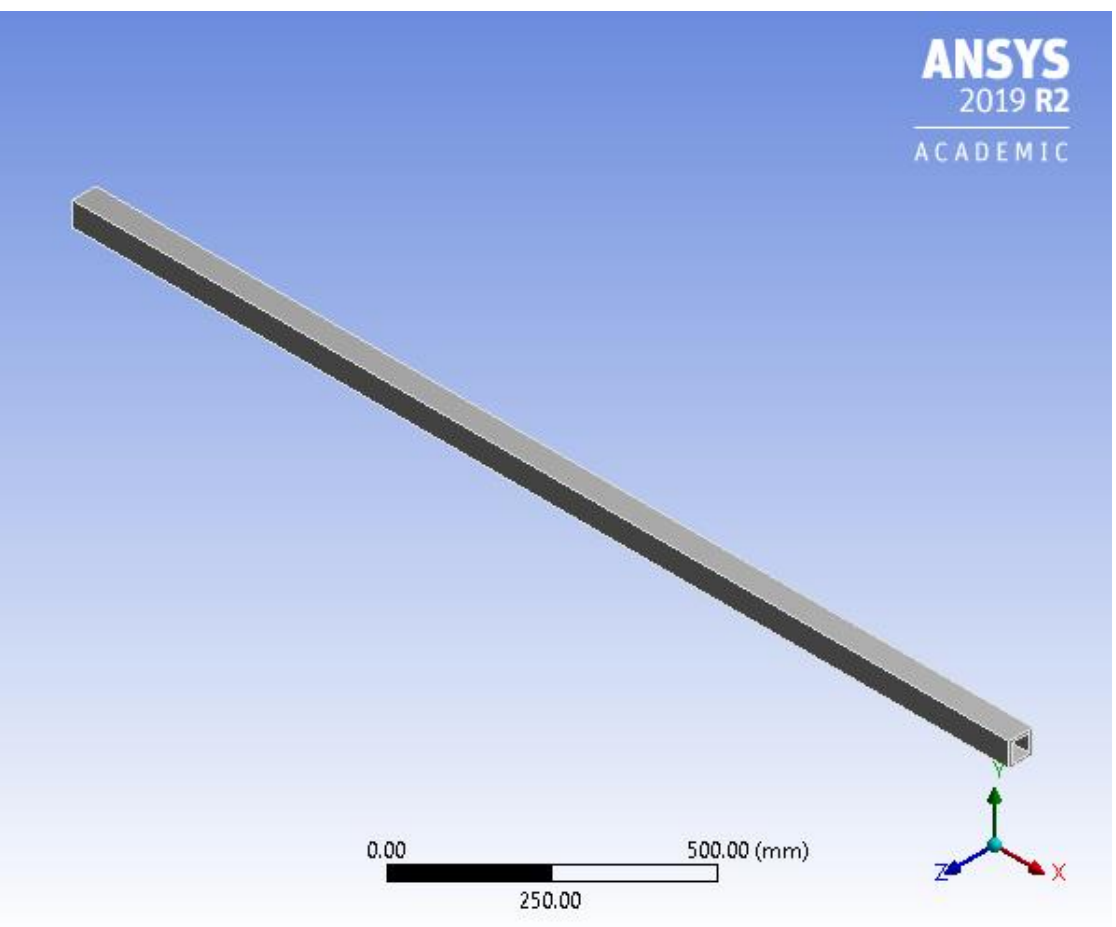




\section{Contents}

- Units

- Model (C4)

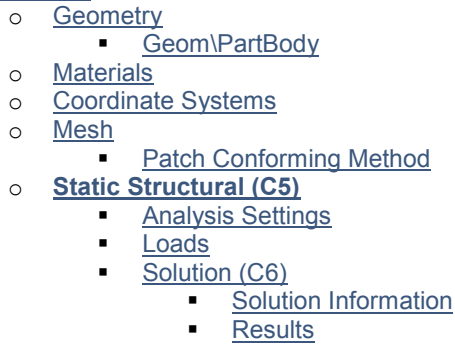

- Material Data

- Aluminum Alloy

\section{Units}

TABLE 1

\begin{tabular}{|r|c|}
\hline Unit System & Metric $(\mathrm{mm}, \mathrm{kg}, \mathrm{N}, \mathrm{s}, \mathrm{mV}, \mathrm{mA})$ Degrees rad/s Celsius \\
\hline Angle & Degrees \\
\hline Rotational Velocity & rad/s \\
\hline Temperature & Celsius \\
\hline
\end{tabular}

\section{Model (C4)}

\section{Geometry}

TABLE 2

Model (C4) > Geometry

\begin{tabular}{|c|c|}
\hline \multirow{2}{*}{\multicolumn{2}{|c|}{ Geometry }} \\
\hline & \\
\hline \multicolumn{2}{|r|}{ Fully Defined } \\
\hline \multicolumn{2}{|r|}{ Definition } \\
\hline Source & $\begin{array}{c}\text { C:IUsersIDIAPM5991OneDrive - Dentsply SironalDesktop\ANSYS } \\
\text { Analysis|LCM_filesIdp0|GeomIDMIGeom.scdoc }\end{array}$ \\
\hline Type & SpaceClaim \\
\hline Length Unit & Meters \\
\hline Element Control & Program Controlled \\
\hline Display Style & Body Color \\
\hline \multicolumn{2}{|r|}{ Bounding Box } \\
\hline Length $\mathrm{X}$ & 2000. $\mathrm{mm}$ \\
\hline Length $Y$ & $50.8 \mathrm{~mm}$ \\
\hline Length Z & $50.8 \mathrm{~mm}$ \\
\hline
\end{tabular}




\begin{tabular}{|c|c|}
\hline \multicolumn{2}{|c|}{ Properties } \\
\hline Volume & $2.2581 \mathrm{e}+006 \mathrm{~mm}^{3}$ \\
\hline Mass & $6.2548 \mathrm{~kg}$ \\
\hline Scale Factor Value & 1. \\
\hline \multicolumn{2}{|c|}{ Statistics } \\
\hline Bodies & 1 \\
\hline Active Bodies & 1 \\
\hline Nodes & 2261 \\
\hline Elements & 1143 \\
\hline Mesh Metric & None \\
\hline \multicolumn{2}{|c|}{ Update Options } \\
\hline Assign Default Material & No \\
\hline \multicolumn{2}{|c|}{ Basic Geometry Options } \\
\hline Solid Bodies & Yes \\
\hline Surface Bodies & Yes \\
\hline Line Bodies & Yes \\
\hline Parameters & Independent \\
\hline \multicolumn{2}{|l|}{ Parameter Key } \\
\hline Attributes & Yes \\
\hline \multicolumn{2}{|l|}{ Attribute Key } \\
\hline Named Selections & Yes \\
\hline \multicolumn{2}{|l|}{ Named Selection Key } \\
\hline Material Properties & Yes \\
\hline \multicolumn{2}{|c|}{ Advanced Geometry Options } \\
\hline Use Associativity & Yes \\
\hline Coordinate Systems & Yes \\
\hline \multicolumn{2}{|l|}{ Coordinate System Key } \\
\hline $\begin{array}{r}\text { Reader Mode Saves } \\
\text { Updated File }\end{array}$ & No \\
\hline Use Instances & Yes \\
\hline Smart CAD Update & Yes \\
\hline $\begin{array}{r}\text { Compare Parts On } \\
\text { Update }\end{array}$ & No \\
\hline Analysis Type & 3-D \\
\hline $\begin{array}{r}\text { Mixed Import } \\
\text { Resolution }\end{array}$ & None \\
\hline Clean Bodies On Import & No \\
\hline $\begin{array}{r}\text { Stitch Surfaces On } \\
\text { Import }\end{array}$ & None \\
\hline $\begin{array}{r}\text { Decompose Disjoint } \\
\text { Geometry }\end{array}$ & Yes \\
\hline $\begin{array}{r}\text { Enclosure and } \\
\text { Symmetry Processing }\end{array}$ & Yes \\
\hline
\end{tabular}

TABLE 3

Model (C4) > Geometry > Parts

Object Name GeomIPartBody

State Meshed

Graphics Properties 


\begin{tabular}{|c|c|}
\hline Visible & Yes \\
\hline Transparency & 1 \\
\hline \multicolumn{2}{|c|}{ Definition } \\
\hline Suppressed & No \\
\hline Stiffness Behavior & Flexible \\
\hline Coordinate System & Default Coordinate System \\
\hline Reference Temperature & By Environment \\
\hline Treatment & None \\
\hline \multicolumn{2}{|c|}{ Material } \\
\hline Assignment & Aluminum Alloy \\
\hline Nonlinear Effects & Yes \\
\hline Thermal Strain Effects & Yes \\
\hline \multicolumn{2}{|c|}{ Bounding Box } \\
\hline Length X & 2000. $\mathrm{mm}$ \\
\hline Length $Y$ & $50.8 \mathrm{~mm}$ \\
\hline Length Z & $50.8 \mathrm{~mm}$ \\
\hline \multicolumn{2}{|c|}{ Properties } \\
\hline Volume & $2.2581 \mathrm{e}+006 \mathrm{~mm}^{3}$ \\
\hline Mass & $6.2548 \mathrm{~kg}$ \\
\hline Centroid X & -1000. mm \\
\hline Centroid $Y$ & $25.4 \mathrm{~mm}$ \\
\hline Centroid Z & $25.4 \mathrm{~mm}$ \\
\hline Moment of Inertia Ip1 & $4203.5 \mathrm{~kg} \cdot \mathrm{mm}^{2}$ \\
\hline Moment of Inertia Ip2 & $2.087 \mathrm{e}+006 \mathrm{~kg} \cdot \mathrm{mm}^{2}$ \\
\hline Moment of Inertia Ip3 & $2.087 \mathrm{e}+006 \mathrm{~kg} \cdot \mathrm{mm}^{2}$ \\
\hline \multicolumn{2}{|c|}{ Statistics } \\
\hline Nodes & 2261 \\
\hline Elements & 1143 \\
\hline Mesh Metric & None \\
\hline \multicolumn{2}{|c|}{ CAD Attributes } \\
\hline PartTolerance: & 0.00000001 \\
\hline Color:175.143.175 & \\
\hline
\end{tabular}

FIGURE 1

Model (C4) $>$ Geometry > Figure 


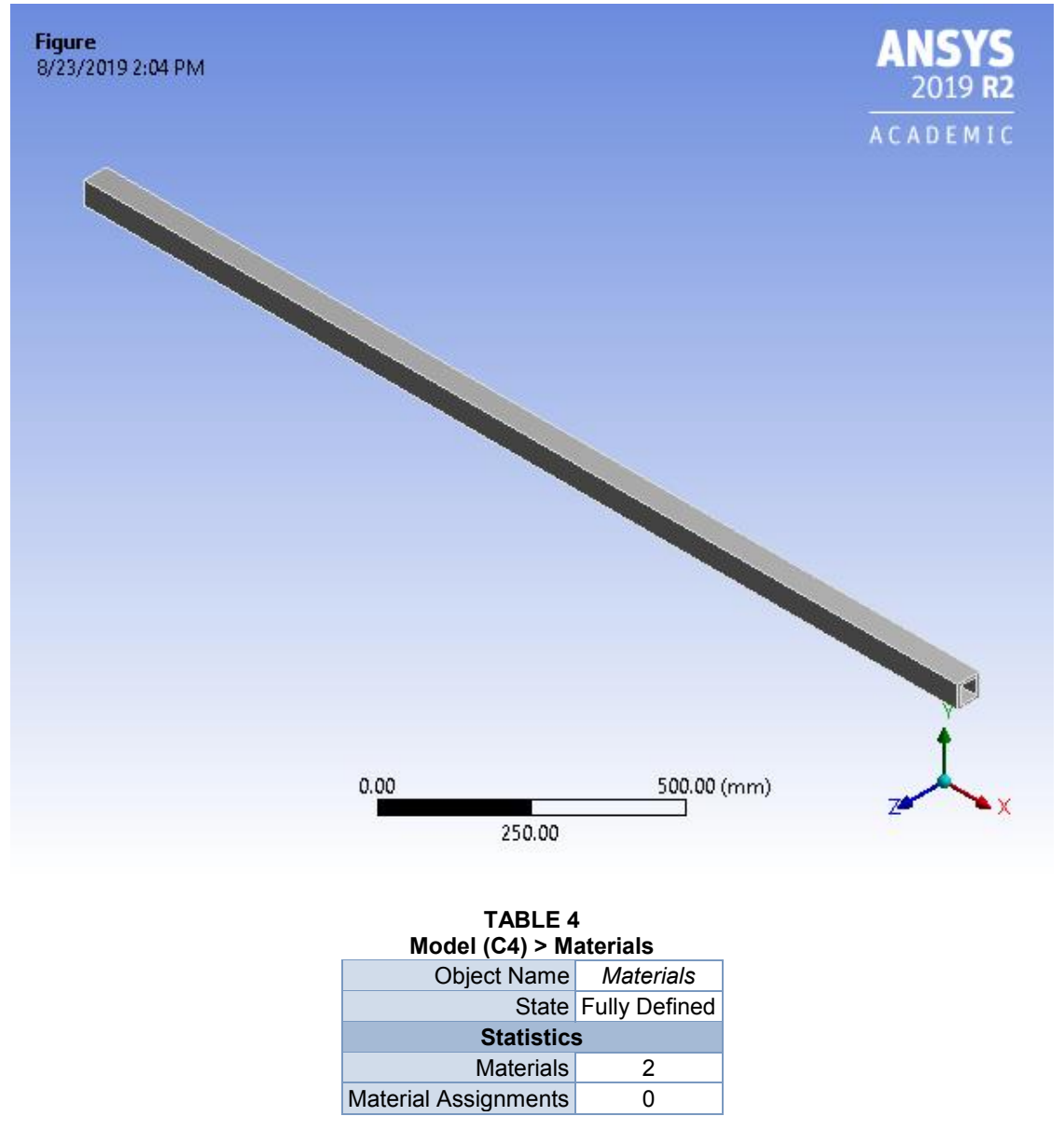

\section{Coordinate Systems}

\section{TABLE 5}

Model (C4) > Coordinate Systems > Coordinate System

\begin{tabular}{|r|c|}
\hline Object Name & Global Coordinate System \\
\hline State & Fully Defined \\
\hline Definition \\
\hline Type & Cartesian \\
\hline Coordinate System ID & 0. \\
\hline \multicolumn{2}{|c|}{ Origin } \\
\hline Origin X & $0 . \mathrm{mm}$ \\
\hline
\end{tabular}




\begin{tabular}{|r|r|}
\hline Origin $Y$ & $0 . \mathrm{mm}$ \\
\hline Origin Z & $0 . \mathrm{mm}$ \\
\hline \multicolumn{2}{|c|}{ Directional Vectors } \\
\hline X Axis Data & {$[1.0 .0]$.} \\
\hline Y Axis Data & {$[0.1 .0]$.} \\
\hline Z Axis Data & {$[0.0 .1]$.} \\
\hline
\end{tabular}

Mesh

TABLE 6

Model (C4) $>$ Mesh

\begin{tabular}{|c|c|}
\hline \\
\hline Object Name & Mesh \\
\hline State & Solved \\
\hline \multicolumn{2}{|l|}{ Display } \\
\hline Display Style & Use Geometry Setting \\
\hline \multicolumn{2}{|c|}{ Defaults } \\
\hline Physics Preference & Mechanical \\
\hline Element Order & Program Controlled \\
\hline Element Size & Default \\
\hline \multicolumn{2}{|l|}{ Sizing } \\
\hline Use Adaptive Sizing & Yes \\
\hline Resolution & Default (2) \\
\hline Mesh Defeaturing & Yes \\
\hline Defeature Size & Default \\
\hline Transition & Fast \\
\hline Span Angle Center & Fine \\
\hline Initial Size Seed & Assembly \\
\hline Bounding Box Diagonal & $2001.3 \mathrm{~mm}$ \\
\hline Average Surface Area & $71346 \mathrm{~mm}^{2}$ \\
\hline Minimum Edge Length & $38.1 \mathrm{~mm}$ \\
\hline \multicolumn{2}{|l|}{ Quality } \\
\hline Check Mesh Quality & Yes, Errors \\
\hline Error Limits & Standard Mechanical \\
\hline Target Quality & Default $(0.050000)$ \\
\hline Smoothing & Medium \\
\hline Mesh Metric & None \\
\hline \multicolumn{2}{|l|}{ Inflation } \\
\hline Use Automatic Inflation & None \\
\hline Inflation Option & Smooth Transition \\
\hline Transition Ratio & 0.272 \\
\hline Maximum Layers & 5 \\
\hline Growth Rate & 1.2 \\
\hline Inflation Algorithm & Pre \\
\hline View Advanced Options & No \\
\hline \multicolumn{2}{|l|}{ Advanced } \\
\hline Number of CPUs for Parallel Part Meshing & Program Controlled \\
\hline Straight Sided Elements & No \\
\hline Rigid Body Behavior & Dimensionally Reduced \\
\hline
\end{tabular}




\begin{tabular}{|r|c|}
\hline Triangle Surface Mesher & Program Controlled \\
\hline Topology Checking & Yes \\
\hline Pinch Tolerance & Please Define \\
\hline Generate Pinch on Refresh & No \\
\hline Statistics & \\
\hline Nodes & 2261 \\
\hline Elements & 1143 \\
\hline
\end{tabular}

TABLE 7

Model (C4) $>$ Mesh $>$ Mesh Controls Object Name Patch Conforming Method

\begin{tabular}{|r|c|}
\hline State & Fully Defined \\
\hline Scoping Method & Geometry Selection \\
\hline Geometry & 1 Body \\
\hline Duppressed & No \\
\hline Method & Tetrahedrons \\
\hline Algorithm & Patch Conforming \\
\hline Element Order & Use Global Setting \\
\hline
\end{tabular}

FIGURE 2

Model (C4) > Mesh > Figure 


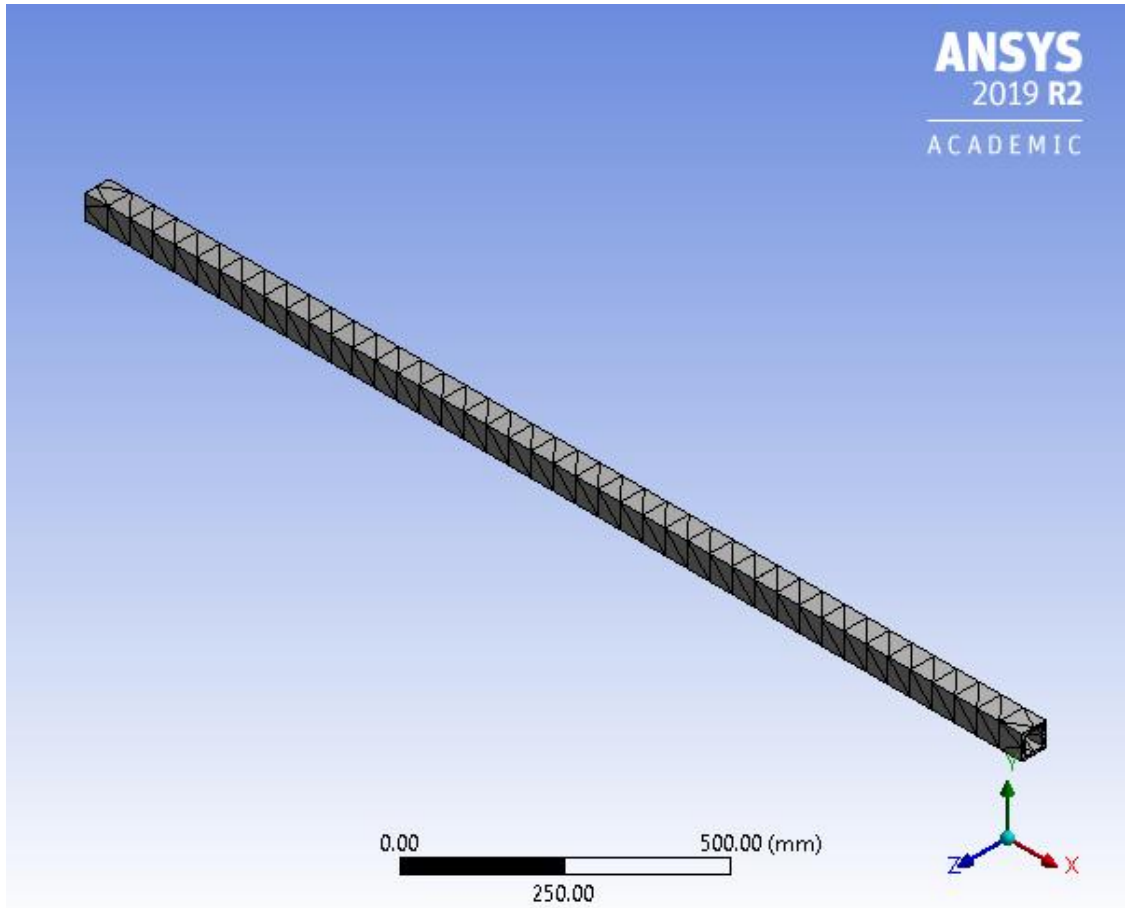

\section{Static Structural (C5)}

TABLE 8

Model (C4) > Analysis

\begin{tabular}{|c|c|}
\hline Object Name & Static Structural (C5) \\
\hline State & Solved \\
\hline \multicolumn{2}{|c|}{ Definition } \\
\hline Physics Type & Structural \\
\hline Analysis Type & Static Structural \\
\hline Solver Target & Mechanical APDL \\
\hline \multicolumn{2}{|c|}{ Options } \\
\hline Environment Temperature & 22. ${ }^{\circ} \mathrm{C}$ \\
\hline Generate Input Only & No \\
\hline
\end{tabular}

TABLE 9

Model (C4) > Static Structural (C5) > Analysis Settings

\begin{tabular}{|r|c|}
\hline Object Name & Analysis Settings \\
\hline State & Fully Defined \\
\hline & Step Controls \\
\hline
\end{tabular}




\begin{tabular}{|c|c|}
\hline Number Of Steps & 1. \\
\hline Current Step Number & 1. \\
\hline Step End Time & 1. $s$ \\
\hline Auto Time Stepping & Program Controlled \\
\hline \multicolumn{2}{|r|}{ Solver Controls } \\
\hline Solver Type & Program Controlled \\
\hline Weak Springs & Off \\
\hline Solver Pivot Checking & Program Controlled \\
\hline Large Deflection & Off \\
\hline Inertia Relief & Off \\
\hline \multicolumn{2}{|r|}{ Rotordynamics Controls } \\
\hline Coriolis Effect & Off \\
\hline \multicolumn{2}{|r|}{ Restart Controls } \\
\hline $\begin{array}{r}\text { Generate Restart } \\
\text { Points }\end{array}$ & Program Controlled \\
\hline $\begin{array}{r}\text { Retain Files After Full } \\
\text { Solve }\end{array}$ & No \\
\hline Combine Restart Files & Program Controlled \\
\hline \multicolumn{2}{|r|}{ Nonlinear Controls } \\
\hline $\begin{array}{r}\text { Newton-Raphson } \\
\text { Option }\end{array}$ & Program Controlled \\
\hline Force Convergence & Program Controlled \\
\hline Moment Convergence & Program Controlled \\
\hline $\begin{array}{l}\text { Displacement } \\
\text { Convergence }\end{array}$ & Program Controlled \\
\hline Rotation Convergence & Program Controlled \\
\hline Line Search & Program Controlled \\
\hline Stabilization & Program Controlled \\
\hline \multicolumn{2}{|r|}{ Output Controls } \\
\hline Stress & Yes \\
\hline Surface Stress & No \\
\hline Back Stress & No \\
\hline Strain & Yes \\
\hline Contact Data & Yes \\
\hline Nonlinear Data & No \\
\hline Nodal Forces & No \\
\hline Contact Miscellaneous & No \\
\hline General Miscellaneous & No \\
\hline Store Results At & All Time Points \\
\hline $\begin{array}{r}\text { Result File } \\
\text { Compression }\end{array}$ & Program Controlled \\
\hline \multicolumn{2}{|r|}{ Analysis Data Management } \\
\hline Solver Files Directory & $\begin{array}{c}\text { C:IUsersIDIAPM599IOneDrive - Dentsply SironalDesktop\ANSYS } \\
\text { AnalysisILCM_filesIdp0ISYSIMECH }\end{array}$ \\
\hline Future Analysis & None \\
\hline $\begin{array}{r}\text { Scratch Solver Files } \\
\text { Directory }\end{array}$ & \\
\hline Save MAPDL db & No \\
\hline Contact Summary & Program Controlled \\
\hline
\end{tabular}




\begin{tabular}{|r|c|}
\hline Delete Unneeded Files & Yes \\
\hline Nonlinear Solution & No \\
\hline Solver Units & Active System \\
\hline Solver Unit System & $\mathrm{nmm}$ \\
\hline
\end{tabular}

FIGURE 3

Model (C4) > Static Structural (C5) > Figure

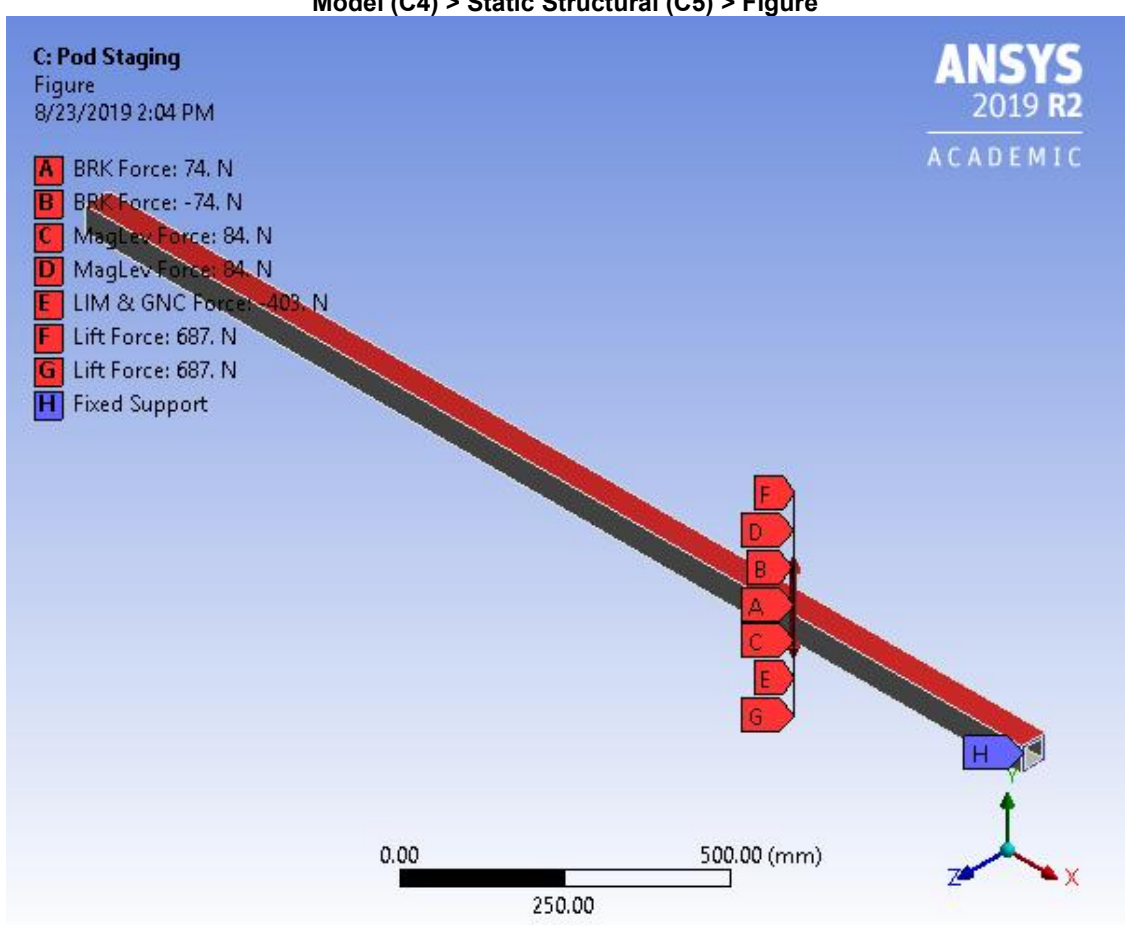

TABLE 10

Model (C4) $>$ Static Structural (C5) $>$ Loads

\begin{tabular}{|c|c|c|c|c|c|c|c|c|c|}
\hline $\begin{array}{l}\text { Object } \\
\text { Name }\end{array}$ & BRK Force & $\begin{array}{c}\text { BRK } \\
\text { Force }\end{array}$ & $\begin{array}{c}\text { MagLev } \\
\text { Force }\end{array}$ & $\begin{array}{c}\text { MagLev } \\
\text { Force }\end{array}$ & $\begin{array}{c}\text { LIM \& } \\
\text { GNC } \\
\text { Force }\end{array}$ & Lift Force & $\begin{array}{c}\text { Lift } \\
\text { Force }\end{array}$ & $\begin{array}{l}\text { Thermal } \\
\text { Condition }\end{array}$ & $\begin{array}{c}\text { Fixed } \\
\text { Support }\end{array}$ \\
\hline State & \multicolumn{9}{|c|}{ Fully Defined } \\
\hline \multicolumn{10}{|c|}{ Scope } \\
\hline $\begin{array}{l}\text { Scoping } \\
\text { Method }\end{array}$ & \multicolumn{9}{|c|}{ Geometry Selection } \\
\hline Geometry & \multicolumn{7}{|c|}{1 Face } & 1 Body & $\begin{array}{c}2 \\
\text { Faces }\end{array}$ \\
\hline \multicolumn{10}{|c|}{ Definition } \\
\hline
\end{tabular}




\begin{tabular}{|c|c|c|c|c|c|c|c|c|}
\hline Type & \multicolumn{6}{|c|}{ Force } & \multirow[t]{2}{*}{\begin{tabular}{c|} 
Thermal \\
Condition
\end{tabular}} & \multirow[t]{2}{*}{$\begin{array}{c}\text { Fixed } \\
\text { Support }\end{array}$} \\
\hline Define By & Components & Vector & Components & Vector & Components & Vector & & \\
\hline $\begin{array}{r}\text { Coordinate } \\
\text { System }\end{array}$ & $\begin{array}{c}\text { Global } \\
\text { Coordinate } \\
\text { System }\end{array}$ & & $\begin{array}{c}\text { Global } \\
\text { Coordinate } \\
\text { System }\end{array}$ & & $\begin{array}{l}\text { Global } \\
\text { Coordinate } \\
\text { System }\end{array}$ & & & \\
\hline $\begin{array}{r}\mathrm{X} \\
\text { Component }\end{array}$ & $\begin{array}{c}0 . \mathrm{N} \\
\text { (ramped) }\end{array}$ & & 0. N (ramped) & & $\begin{array}{c}0 . \mathrm{N} \\
\text { (ramped) }\end{array}$ & & & \\
\hline $\begin{array}{r}\mathrm{Y} \\
\text { Component }\end{array}$ & $\begin{array}{c}-74 . \mathrm{N} \\
\text { (ramped) }\end{array}$ & & -84. N (ramped) & & $\begin{array}{l}687 . \mathrm{N} \\
\text { (ramped) }\end{array}$ & & & \\
\hline $\begin{array}{r}\mathrm{Z} \\
\text { Component }\end{array}$ & $\begin{array}{c}0 . \mathrm{N} \\
\text { (ramped) }\end{array}$ & & 0. N (ramped) & & $\begin{array}{c}0 . \mathrm{N} \\
\text { (ramped) }\end{array}$ & & & \\
\hline Suppressed & \multicolumn{8}{|c|}{ No } \\
\hline Magnitude & & $\begin{array}{c}-74 . \mathrm{N} \\
\text { (ramped) }\end{array}$ & & $\begin{array}{c}-403 . \mathrm{N} \\
\text { (ramped) }\end{array}$ & & $\begin{array}{c}687 . \mathrm{N} \\
\text { (ramped) }\end{array}$ & $\begin{array}{c}80 .{ }^{\circ} \mathrm{C} \\
\text { (ramped) }\end{array}$ & \\
\hline Direction & & Defined & & Defined & & Defined & & \\
\hline
\end{tabular}

FIGURE 4

Model (C4) > Static Structural (C5) > BRK Force

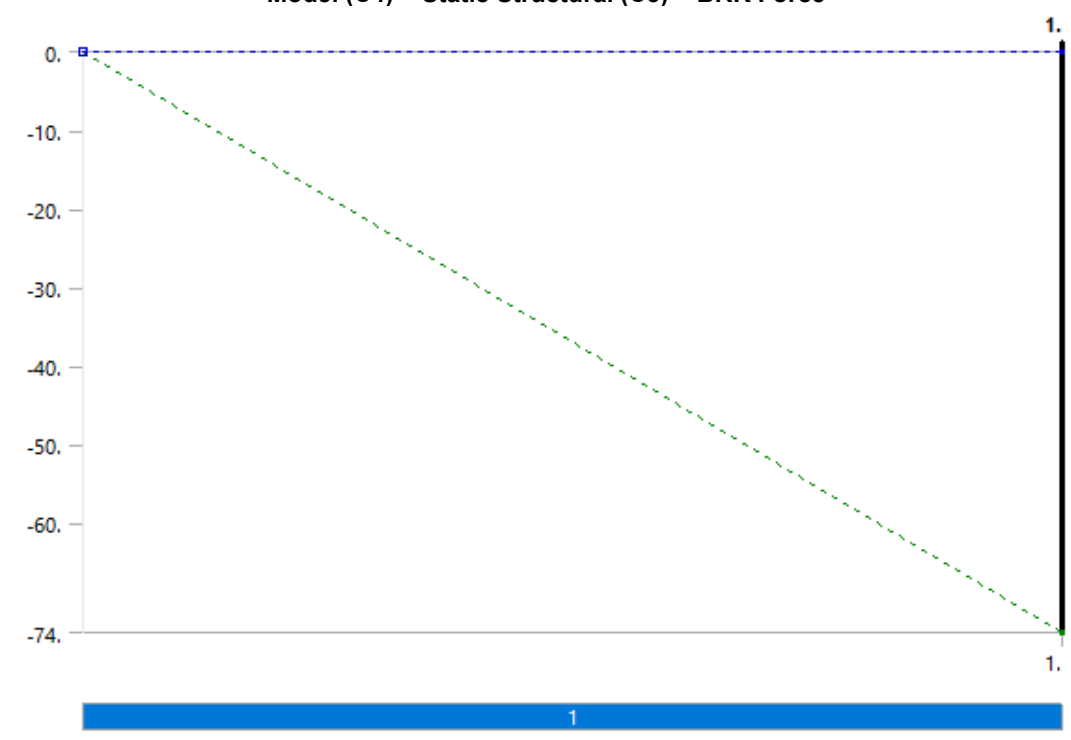

FIGURE 5

Model (C4) > Static Structural (C5) > BRK Force 


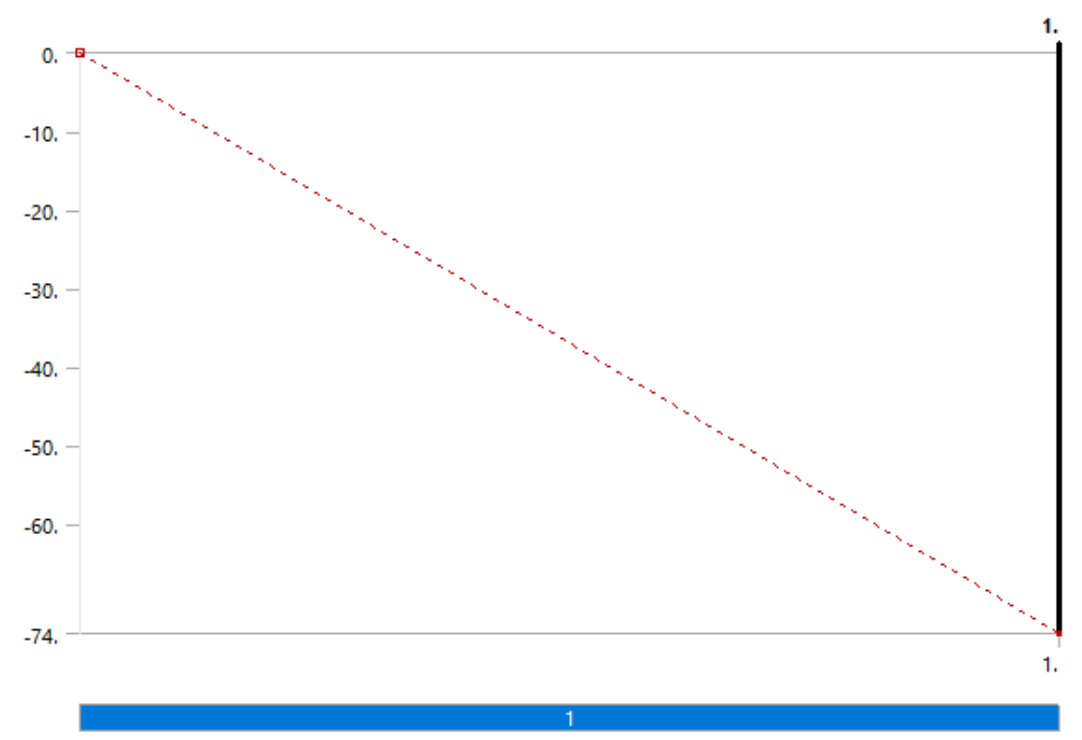

FIGURE 6

Model (C4) > Static Structural (C5) > MagLev Force

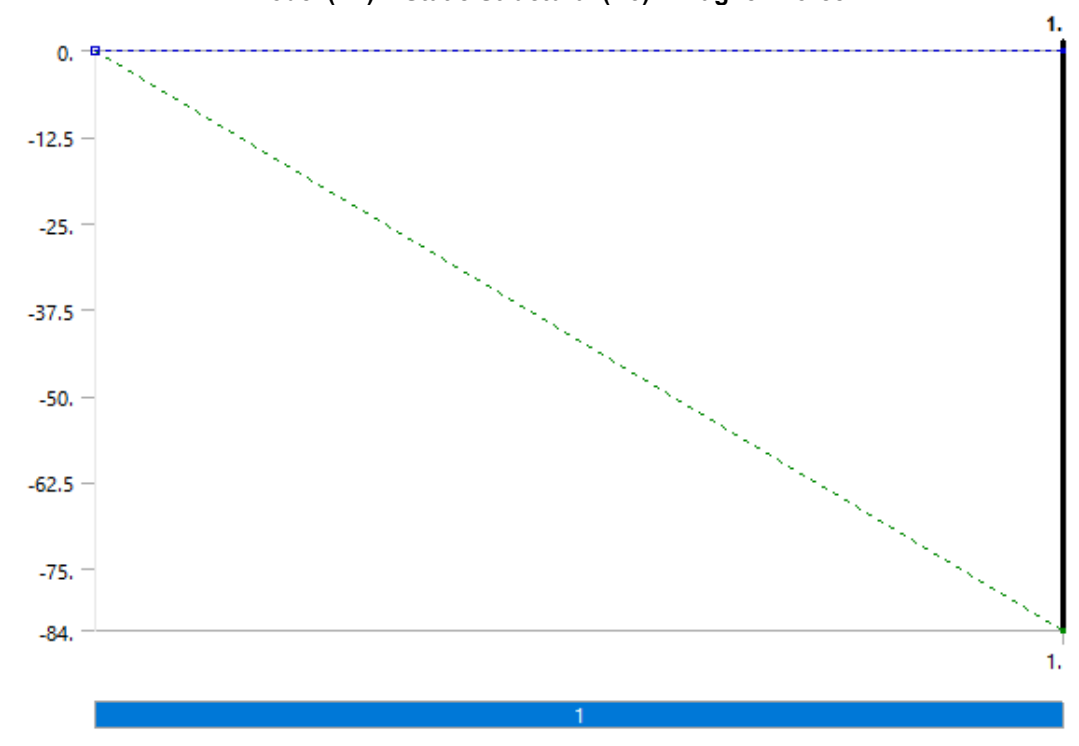


FIGURE 7

Model (C4) > Static Structural (C5) > MagLev Force

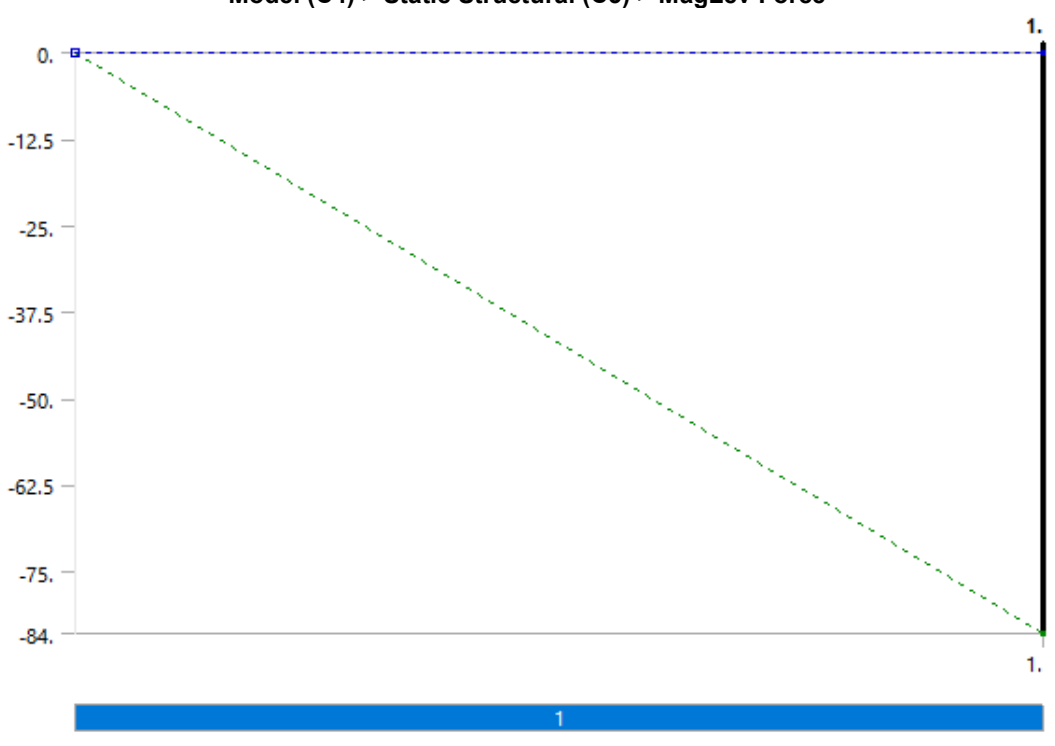

FIGURE 8

Model (C4) > Static Structural (C5) > LIM \& GNC Force 


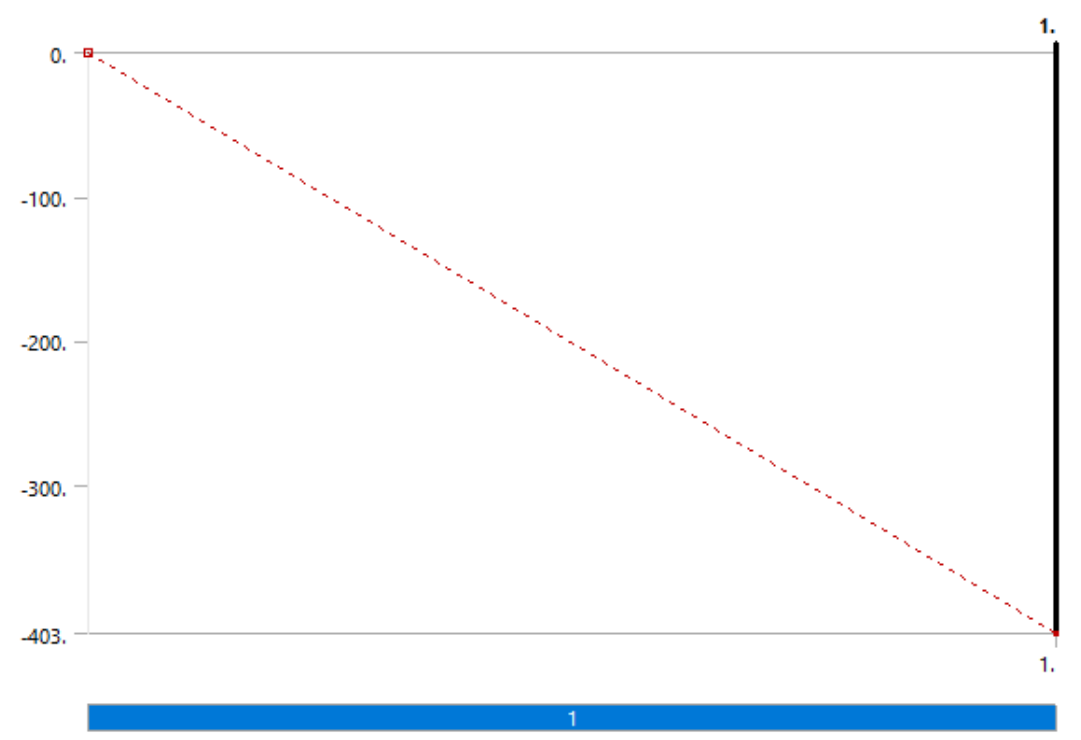

FIGURE 9

Model (C4) $>$ Static Structural (C5) $>$ Lift Force

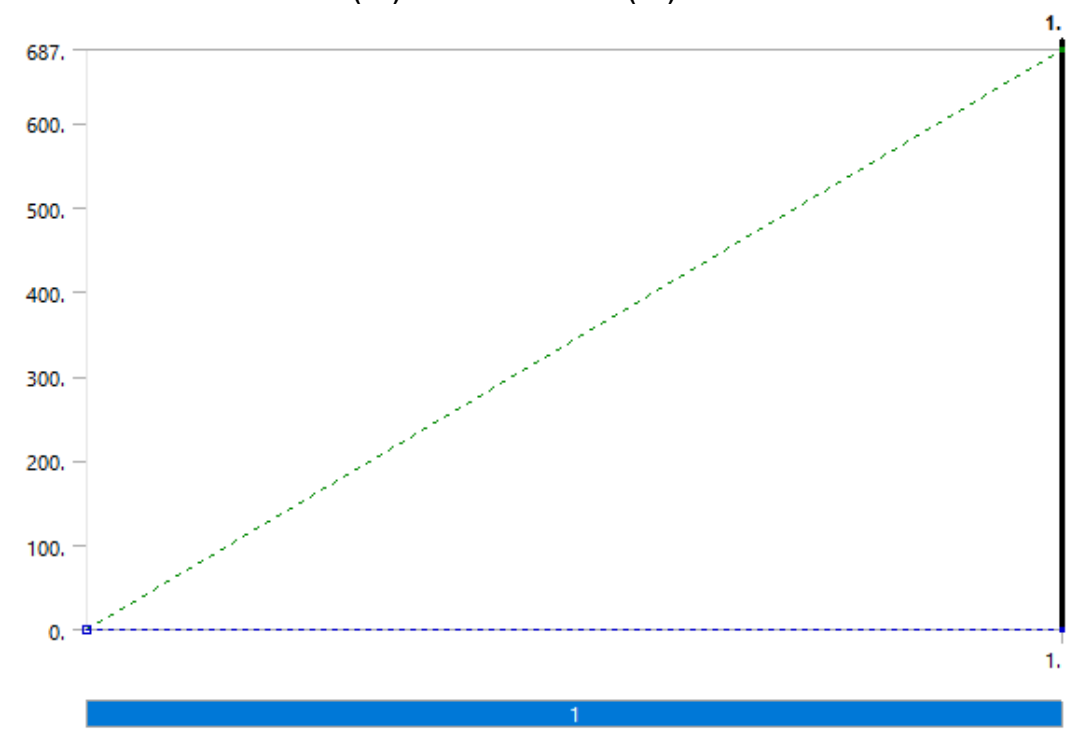


FIGURE 10

Model (C4) > Static Structural (C5) > Lift Force

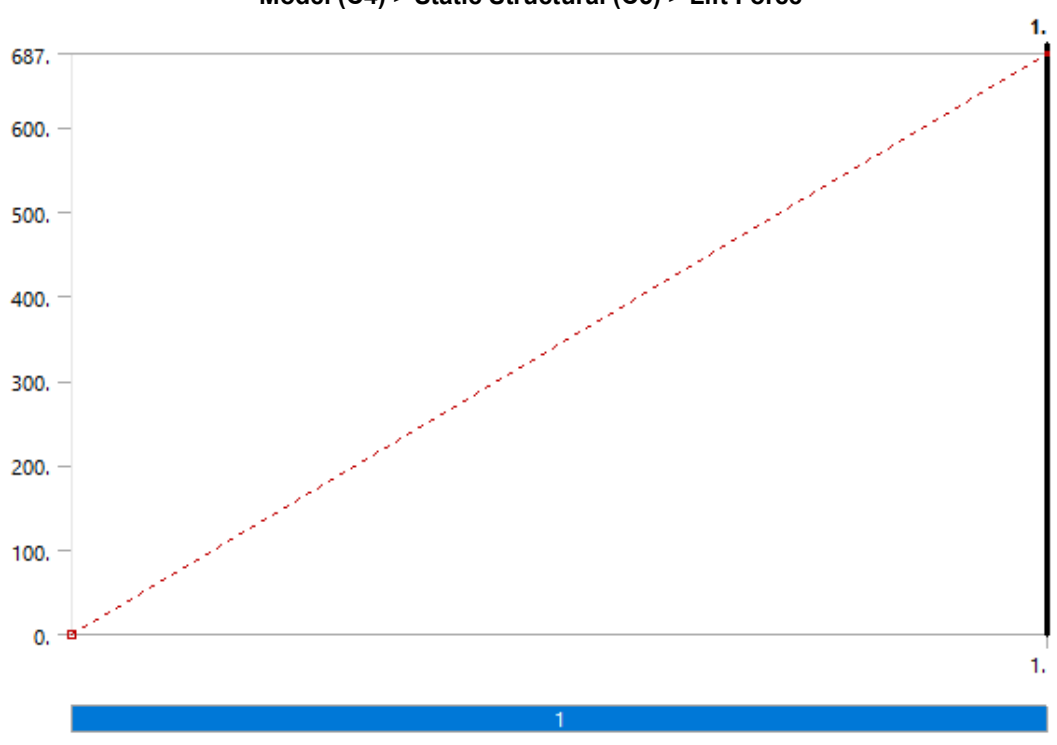

FIGURE 11

Model (C4) $>$ Static Structural (C5) $>$ Thermal Condition 


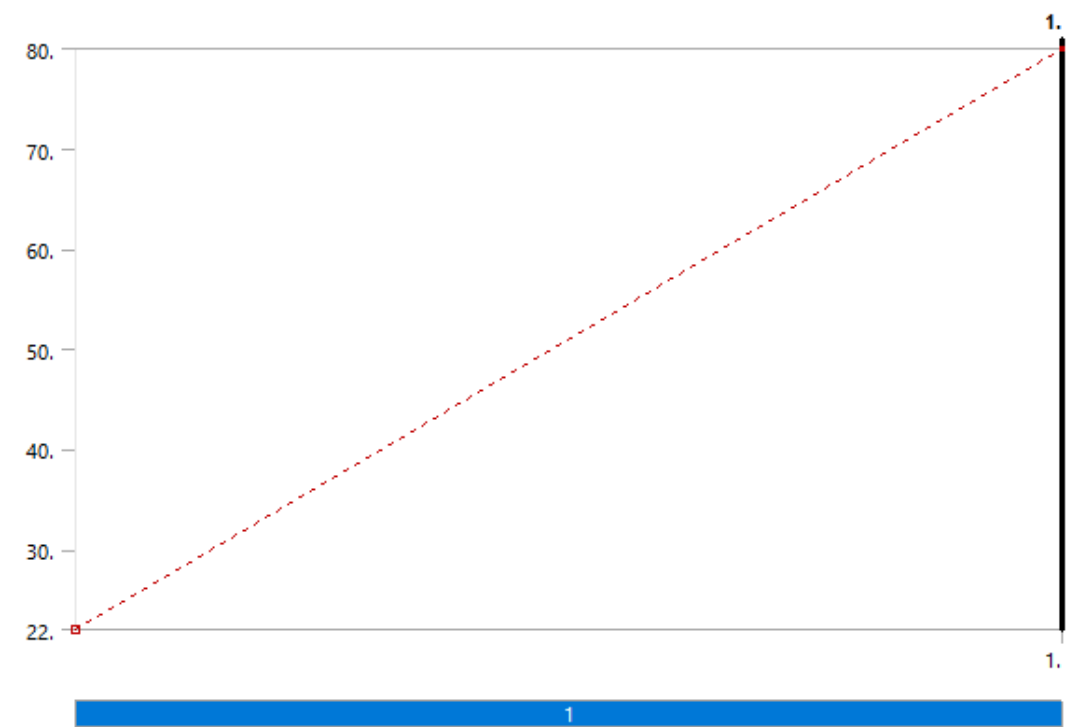

Solution (C6)

TABLE 11

Model (C4) $>$ Static Structural (C5) > Solution

\begin{tabular}{|c|c|}
\hline Object Name & Solution (C6) \\
\hline State & Solved \\
\hline \multicolumn{2}{|c|}{ Adaptive Mesh Refinement } \\
\hline Max Refinement Loops & 1. \\
\hline Refinement Depth & 2. \\
\hline \multicolumn{2}{|l|}{ Information } \\
\hline Status & Done \\
\hline MAPDL Elapsed Time & 3. $\mathrm{s}$ \\
\hline MAPDL Memory Used & 266. MB \\
\hline MAPDL Result File Size & $1.25 \mathrm{MB}$ \\
\hline \multicolumn{2}{|l|}{ Post Processing } \\
\hline Beam Section Results & No \\
\hline Demand Stress/Strain & No \\
\hline
\end{tabular}

TABLE 12

Model (C4) $>$ Static Structural (C5) > Solution (C6) $>$ Solution Information

\begin{tabular}{|r|c|}
\hline Object Name & Solution Information \\
\hline State & Solved \\
\hline Solution Information \\
\hline Solution Output & Solver Output \\
\hline Newton-Raphson Residuals & 0 \\
\hline
\end{tabular}




\begin{tabular}{|r|c|}
\hline Identify Element Violations & 0 \\
\hline Update Interval & $2.5 \mathrm{~s}$ \\
\hline Display Points & All \\
\hline FE Connection Visibility \\
\hline Activate Visibility & Yes \\
\hline Display & All FE Connectors \\
\hline Draw Connections Attached To & All Nodes \\
\hline Line Color & Connection Type \\
\hline Visible on Results & No \\
\hline Line Thickness & Single \\
\hline Display Type & Lines \\
\hline
\end{tabular}

TABLE 13

Model (C4) > Static Structural (C5) > Solution (C6) $>$ Results

\begin{tabular}{|c|c|c|}
\hline Object Name & Total Deformation & Equivalent Stress \\
\hline State & & Solved \\
\hline \multicolumn{3}{|c|}{ Scope } \\
\hline Scoping Method & \multicolumn{2}{|c|}{ Geometry Selection } \\
\hline Geometry & \multicolumn{2}{|r|}{ All Bodies } \\
\hline \multicolumn{3}{|c|}{ Definition } \\
\hline Type & Total Deformation & Equivalent (von-Mises) Stress \\
\hline By & \multicolumn{2}{|r|}{ Time } \\
\hline Display Time & \multicolumn{2}{|r|}{ Last } \\
\hline Calculate Time History & \multicolumn{2}{|r|}{ Yes } \\
\hline \multicolumn{3}{|l|}{ Identifier } \\
\hline Suppressed & \multicolumn{2}{|r|}{ No } \\
\hline \multicolumn{3}{|c|}{ Results } \\
\hline Minimum & $0 . \mathrm{mm}$ & $34.987 \mathrm{MPa}$ \\
\hline Maximum & $0.55549 \mathrm{~mm}$ & $165.71 \mathrm{MPa}$ \\
\hline Average & $0.26761 \mathrm{~mm}$ & $95.926 \mathrm{MPa}$ \\
\hline Minimum Occurs On & \multicolumn{2}{|c|}{ Geom\PartBody } \\
\hline Maximum Occurs On & \multicolumn{2}{|r|}{ GeomlPartBody } \\
\hline \multicolumn{3}{|c|}{ Information } \\
\hline Time & \multicolumn{2}{|r|}{ 1. $s$} \\
\hline Load Step & \multicolumn{2}{|r|}{1} \\
\hline Substep & \multicolumn{2}{|r|}{1} \\
\hline Iteration Number & \multicolumn{2}{|r|}{1} \\
\hline \multicolumn{3}{|c|}{ Integration Point Results } \\
\hline Display Option & & Averaged \\
\hline Average Across Bodies & & No \\
\hline
\end{tabular}

FIGURE 12

Model (C4) $>$ Static Structural $($ C5) $>$ Solution (C6) $>$ Total Deformation 


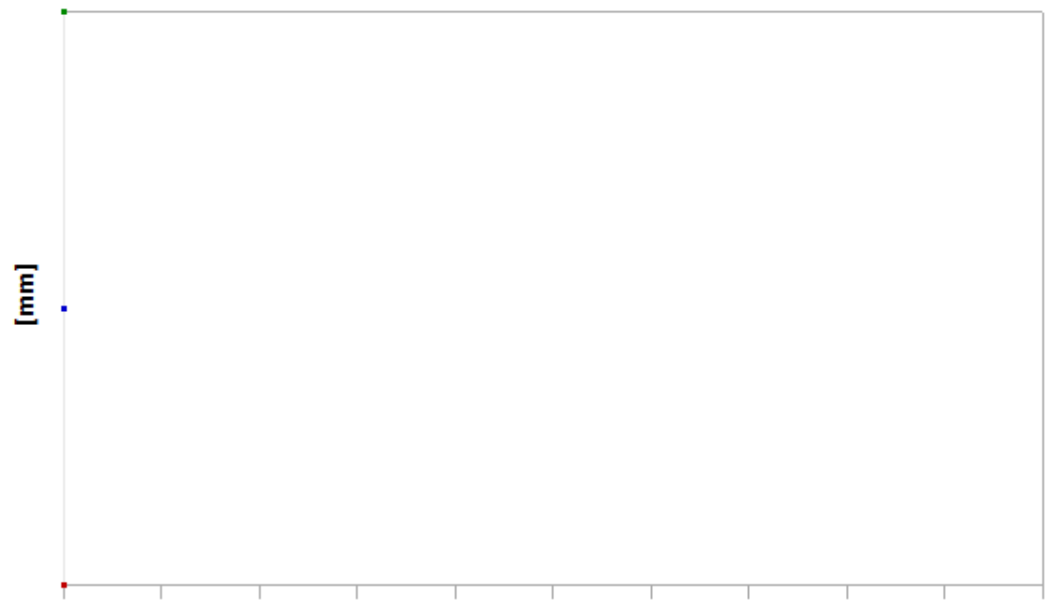

[s]

TABLE 14

Model (C4) > Static Structural (C5) > Solution (C6) $>$ Total Deformation

Time [s] Minimum [mm] Maximum [mm] Average [mm]

\begin{tabular}{l|l|l|l}
\hline 1. & 0. & 0.55549 & 0.26761
\end{tabular}

FIGURE 13

Model (C4) $>$ Static Structural (C5) $>$ Solution (C6) $>$ Total Deformation $>$ Figure 


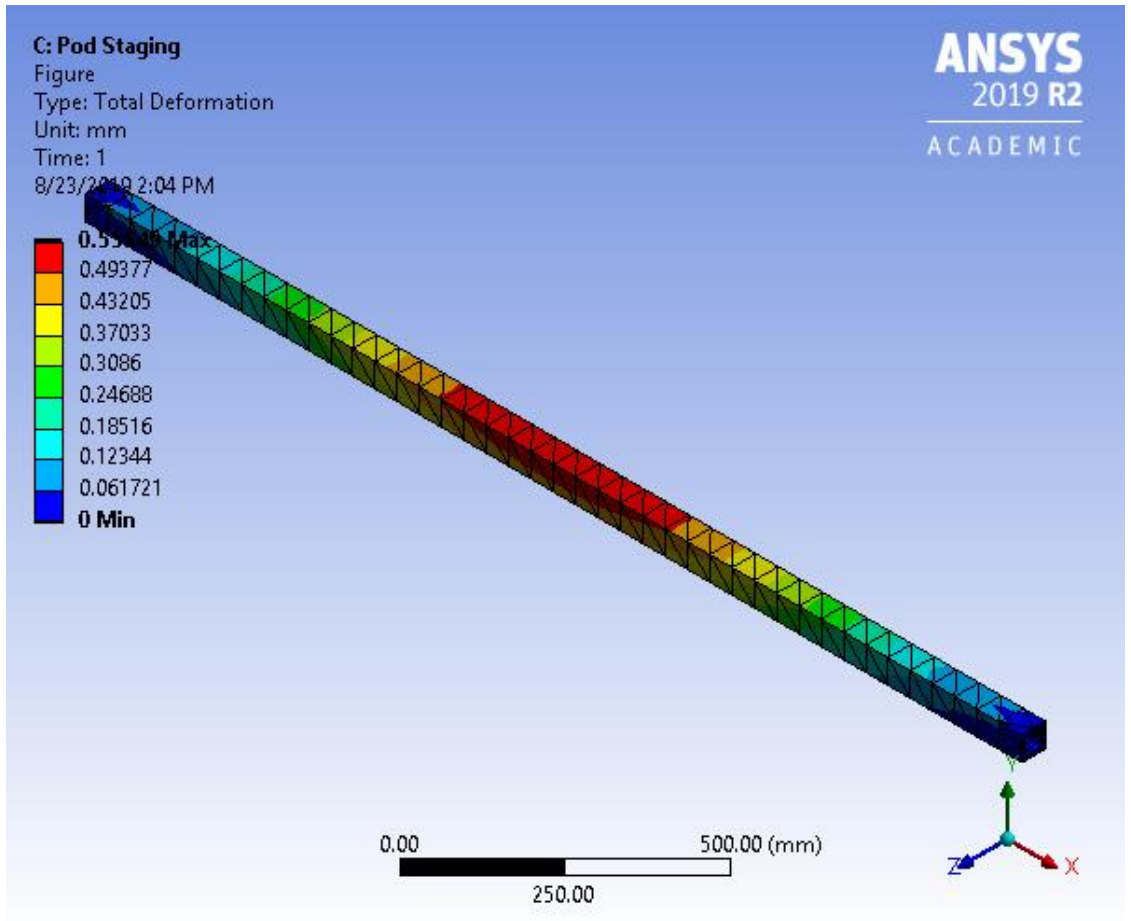

FIGURE 14

Model (C4) > Static Structural (C5) > Solution (C6) > Equivalent Stress 


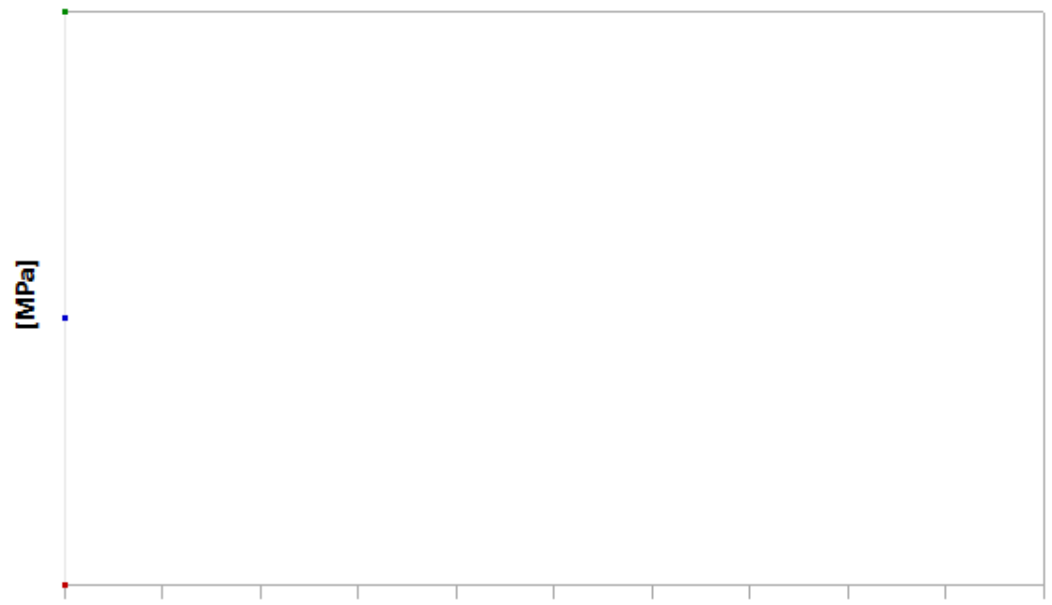

[s]

TABLE 15

Model (C4) > Static Structural (C5) $>$ Solution (C6) $>$ Equivalent Stress

Time [s] Minimum [MPa] Maximum [MPa] Average [MPa]

\begin{tabular}{l|l|l|r}
\hline 1. & 34.987 & 165.71 & 95.926
\end{tabular}

FIGURE 15

Model (C4) $>$ Static Structural (C5) $>$ Solution (C6) $>$ Equivalent Stress $>$ Figure 


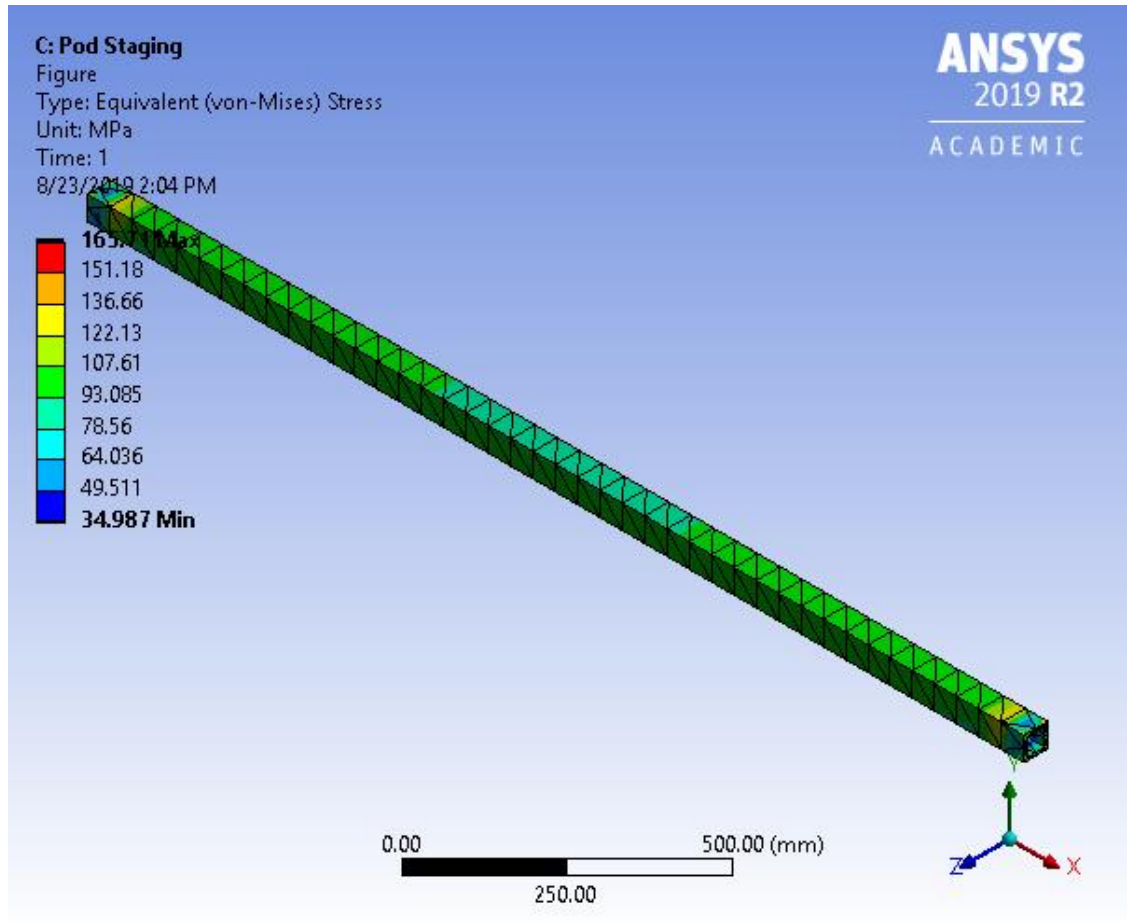

\section{Material Data}

\section{Aluminum Alloy}

TABLE 16

Aluminum Alloy $>$ Constants

\begin{tabular}{|c|c|c|}
\hline \multicolumn{2}{|r|}{ Density } & $2.77 \mathrm{e}-006 \mathrm{~kg} \mathrm{~mm} \wedge-3$ \\
\hline \multicolumn{2}{|c|}{ Coefficient of Thermal Expansion } & $2.3 e-005 C^{\wedge}-1$ \\
\hline \multicolumn{2}{|c|}{ Specific Heat } & $8.75 e+005 m J k g^{\wedge}-1 C^{\wedge}-1$ \\
\hline \multicolumn{3}{|c|}{$\begin{array}{c}\text { TABLE } 17 \\
\text { Aluminum Alloy }>\text { Color }\end{array}$} \\
\hline Red & Green & Blue \\
\hline 138 & 104 & 46 \\
\hline
\end{tabular}

TABLE 18

Aluminum Alloy $>$ Compressive Ultimate Strength

Compressive Ultimate Strength $\mathrm{MPa}$ 
TABLE 19

Aluminum Alloy $>$ Compressive Yield Strength

Compressive Yield Strength $\mathrm{MPa}$

280

TABLE 20

Aluminum Alloy $>$ Tensile Yield Strength

Tensile Yield Strength MPa

280

TABLE 21

Aluminum Alloy $>$ Tensile Ultimate Strength

Tensile Ultimate Strength $\mathrm{MPa}$

310

TABLE 22

Aluminum Alloy $>$ Isotropic Secant Coefficient of Thermal Expansion

Zero-Thermal-Strain Reference Temperature C

22

TABLE 23

Aluminum Alloy $>$ Isotropic Thermal Conductivity Thermal Conductivity $\mathrm{W} \mathrm{mm}^{\wedge}-1 \mathrm{C}^{\wedge}-1$ Temperature $\mathrm{C}$

\begin{tabular}{|c|c|}
\hline 0.114 & -100 \\
\hline 0.144 & 0 \\
\hline 0.165 & 100 \\
\hline 0.175 & 200 \\
\hline
\end{tabular}

TABLE 24

Aluminum Alloy $>$ S-N Curve

Alternating Stress MPa Cycles R-Ratio

\begin{tabular}{|c|c|c|}
\hline 275.8 & 1700 & -1 \\
\hline 241.3 & 5000 & -1 \\
\hline 206.8 & 34000 & -1 \\
\hline 172.4 & $1.4 \mathrm{e}+005$ & -1 \\
\hline 137.9 & $8 . \mathrm{e}+005$ & -1 \\
\hline 117.2 & $2.4 \mathrm{e}+006$ & -1 \\
\hline 89.63 & $5.5 \mathrm{e}+007$ & -1 \\
\hline 82.74 & $1 . \mathrm{e}+008$ & -1 \\
\hline 170.6 & 50000 & -0.5 \\
\hline 139.6 & $3.5 \mathrm{e}+005$ & -0.5 \\
\hline 108.6 & $3.7 \mathrm{e}+006$ & -0.5 \\
\hline 87.91 & $1.4 \mathrm{e}+007$ & -0.5 \\
\hline 77.57 & $5 . \mathrm{e}+007$ & -0.5 \\
\hline 72.39 & $1 . \mathrm{e}+008$ & -0.5 \\
\hline 144.8 & 50000 & 0 \\
\hline 120.7 & $1.9 \mathrm{e}+005$ & 0 \\
\hline 103.4 & $1.3 \mathrm{e}+006$ & 0 \\
\hline 93.08 & $4.4 \mathrm{e}+006$ & 0 \\
\hline & & \\
\hline
\end{tabular}




\begin{tabular}{|c|c|c|}
\hline 86.18 & $1.2 \mathrm{e}+007$ & 0 \\
\hline 72.39 & $1 . e+008$ & 0 \\
\hline 74.12 & $3 . e+005$ & 0.5 \\
\hline 70.67 & $1.5 \mathrm{e}+006$ & 0.5 \\
\hline 66.36 & $1.2 \mathrm{e}+007$ & 0.5 \\
\hline 62.05 & $1 . e+008$ & 0.5 \\
\hline
\end{tabular}

TABLE 25

Aluminum Alloy > Isotropic Resistivity Resistivity ohm $\mathrm{mm}$ Temperature C

\begin{tabular}{|c|c|}
\hline $2.43 e-005$ & 0 \\
\hline $2.67 e-005$ & 20 \\
\hline $3.63 e-005$ & 100 \\
\hline
\end{tabular}

TABLE 26

Aluminum Alloy $>$ Isotropic Elasticity

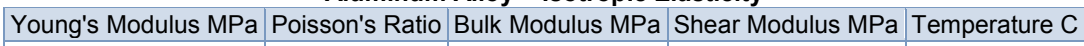

71000

0.33

69608

26692

TABLE 27

Aluminum Alloy > Isotropic Relative Permeability Relative Permeability 
Appendix A.6 LCM Load Case II (Launch Phase) Analysis Report 


\section{MNSYS}

\section{Project}

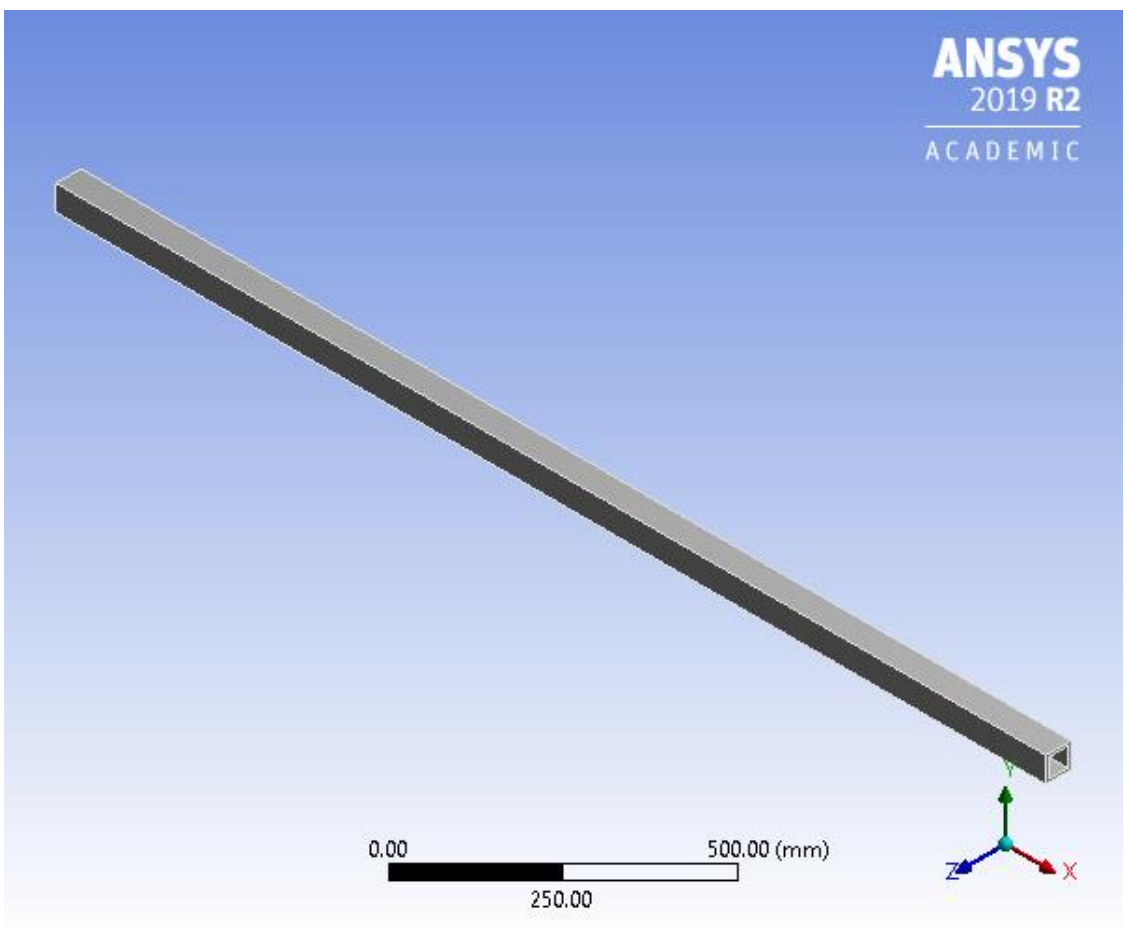




\section{Contents}

- Units

- Model (D4)

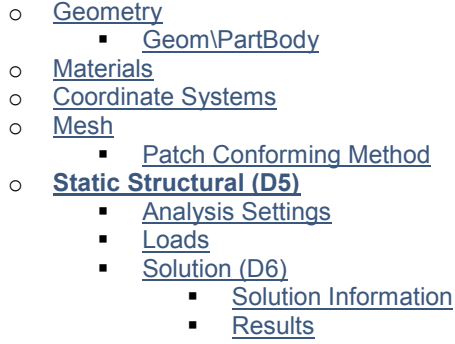

- Material Data

- Aluminum Alloy

\section{Units}

TABLE 1

\begin{tabular}{|r|c|}
\hline Unit System & Metric $(\mathrm{mm}, \mathrm{kg}, \mathrm{N}, \mathrm{s}, \mathrm{mV}, \mathrm{mA})$ Degrees rad/s Celsius \\
\hline Angle & Degrees \\
\hline Rotational Velocity & rad/s \\
\hline Temperature & Celsius \\
\hline
\end{tabular}

\section{Model (D4)}

\section{Geometry}

TABLE 2

Model (D4) > Geometry

\begin{tabular}{|c|c|}
\hline \multirow{2}{*}{\multicolumn{2}{|c|}{ Geometry }} \\
\hline & \\
\hline \multicolumn{2}{|r|}{ Fully Defined } \\
\hline \multicolumn{2}{|r|}{ Definition } \\
\hline Source & $\begin{array}{c}\text { C:IUsersIDIAPM5991OneDrive - Dentsply SironalDesktop\ANSYS } \\
\text { Analysis|LCM_filesIdp0|GeomIDMIGeom.scdoc }\end{array}$ \\
\hline Type & SpaceClaim \\
\hline Length Unit & Meters \\
\hline Element Control & Program Controlled \\
\hline Display Style & Body Color \\
\hline \multicolumn{2}{|r|}{ Bounding Box } \\
\hline Length $\mathrm{X}$ & 2000. $\mathrm{mm}$ \\
\hline Length $Y$ & $50.8 \mathrm{~mm}$ \\
\hline Length Z & $50.8 \mathrm{~mm}$ \\
\hline
\end{tabular}




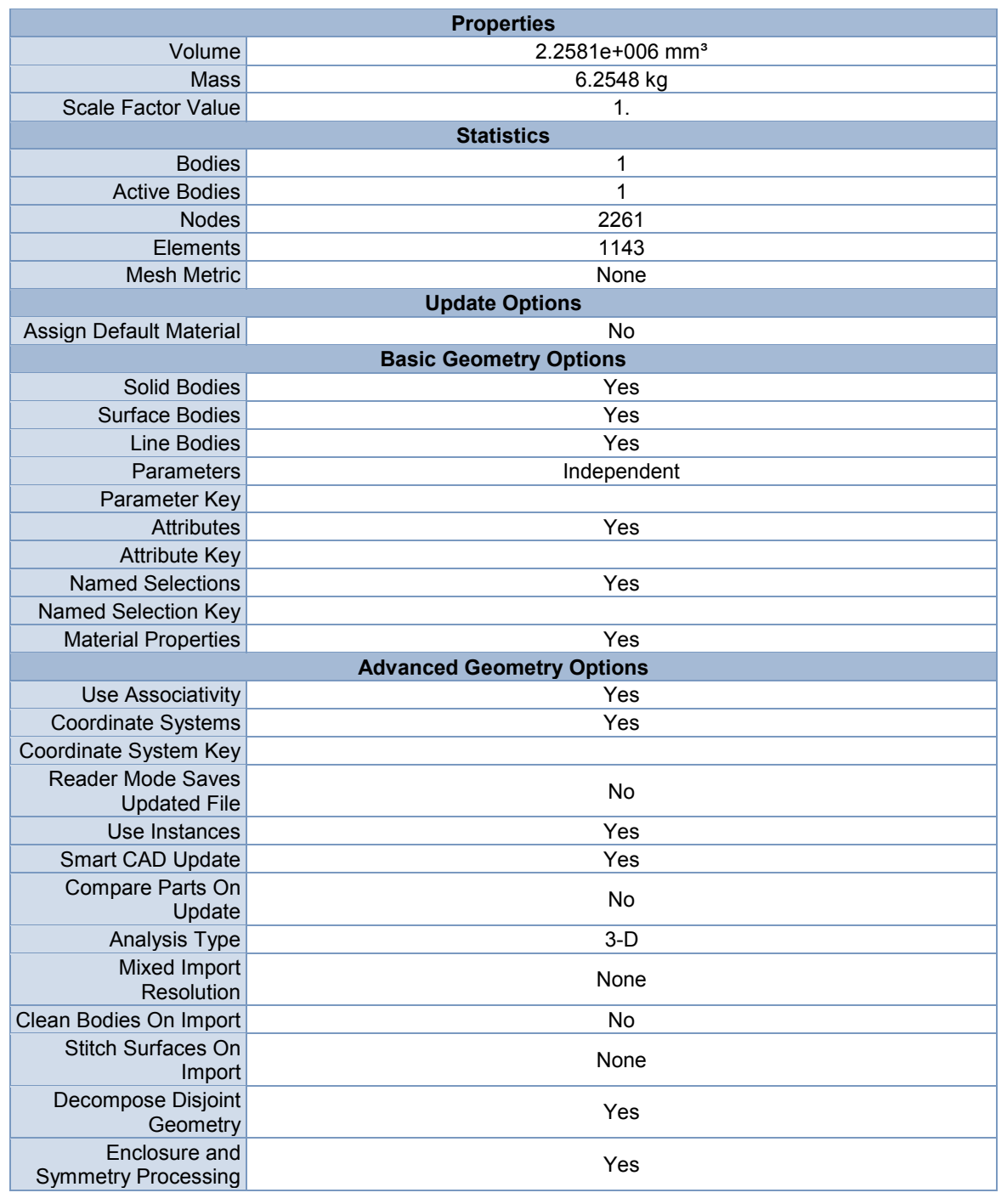

TABLE 3

Model (D4) $>$ Geometry > Parts

Object Name GeomIPartBody

State Meshed

Graphics Properties 


\begin{tabular}{|c|c|}
\hline Visible & Yes \\
\hline Transparency & 1 \\
\hline \multicolumn{2}{|c|}{ Definition } \\
\hline Suppressed & No \\
\hline Stiffness Behavior & Flexible \\
\hline Coordinate System & Default Coordinate System \\
\hline Reference Temperature & By Environment \\
\hline Treatment & None \\
\hline \multicolumn{2}{|c|}{ Material } \\
\hline Assignment & Aluminum Alloy \\
\hline Nonlinear Effects & Yes \\
\hline Thermal Strain Effects & Yes \\
\hline \multicolumn{2}{|c|}{ Bounding Box } \\
\hline Length X & 2000. $\mathrm{mm}$ \\
\hline Length $Y$ & $50.8 \mathrm{~mm}$ \\
\hline Length Z & $50.8 \mathrm{~mm}$ \\
\hline \multicolumn{2}{|c|}{ Properties } \\
\hline Volume & $2.2581 \mathrm{e}+006 \mathrm{~mm}^{3}$ \\
\hline Mass & $6.2548 \mathrm{~kg}$ \\
\hline Centroid X & -1000. mm \\
\hline Centroid $Y$ & $25.4 \mathrm{~mm}$ \\
\hline Centroid Z & $25.4 \mathrm{~mm}$ \\
\hline Moment of Inertia Ip1 & $4203.5 \mathrm{~kg} \cdot \mathrm{mm}^{2}$ \\
\hline Moment of Inertia Ip2 & $2.087 \mathrm{e}+006 \mathrm{~kg} \cdot \mathrm{mm}^{2}$ \\
\hline Moment of Inertia Ip3 & $2.087 \mathrm{e}+006 \mathrm{~kg} \cdot \mathrm{mm}^{2}$ \\
\hline \multicolumn{2}{|c|}{ Statistics } \\
\hline Nodes & 2261 \\
\hline Elements & 1143 \\
\hline Mesh Metric & None \\
\hline \multicolumn{2}{|c|}{ CAD Attributes } \\
\hline PartTolerance: & 0.00000001 \\
\hline Color:175.143.175 & \\
\hline
\end{tabular}

FIGURE 1

Model (D4) > Geometry > Figure 


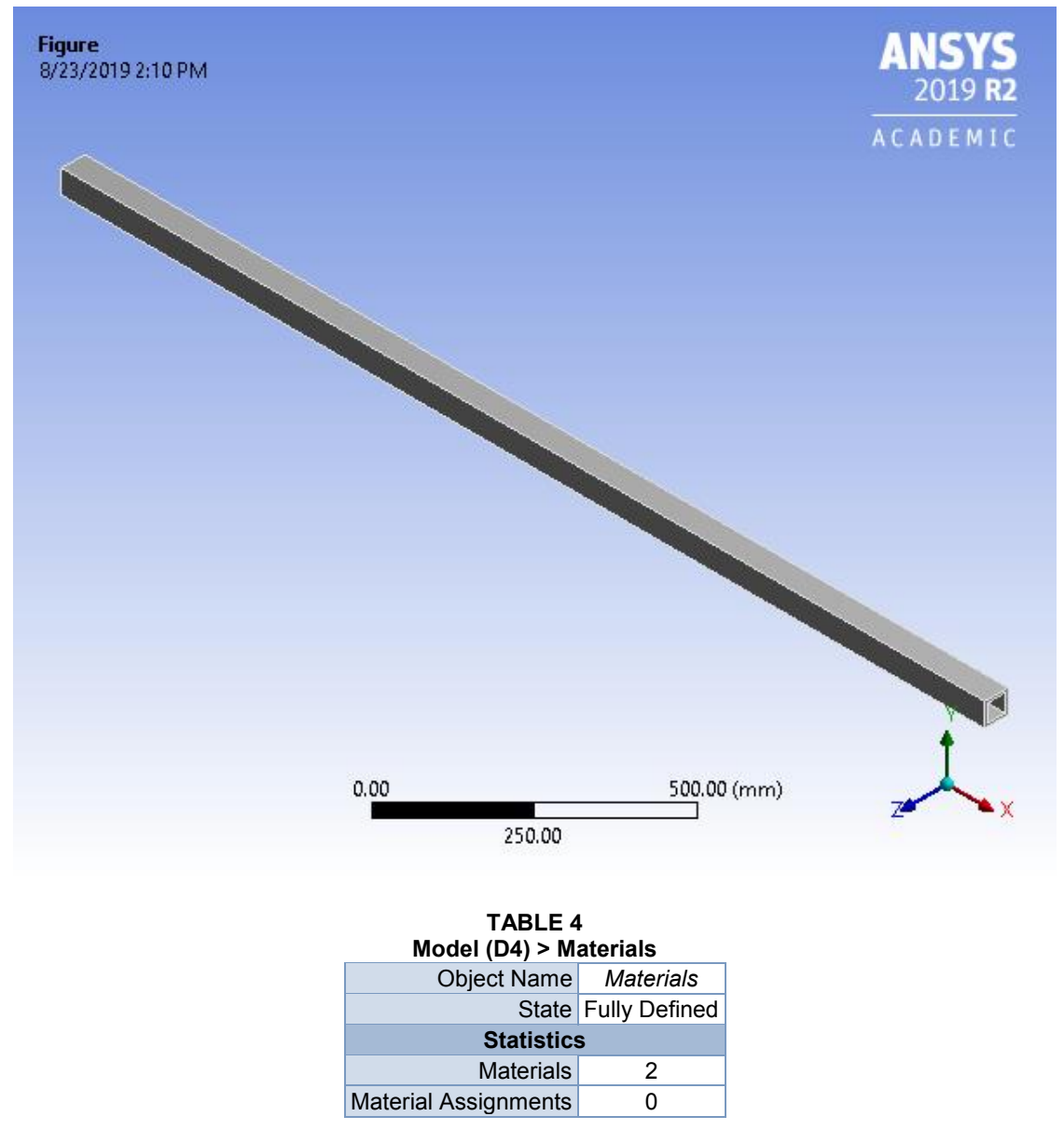

\section{Coordinate Systems}

\section{TABLE 5}

Model (D4) > Coordinate Systems > Coordinate System

\begin{tabular}{|r|c|}
\hline Object Name & Global Coordinate System \\
\hline State & Fully Defined \\
\hline Definition \\
\hline Type & Cartesian \\
\hline Coordinate System ID & 0. \\
\hline \multicolumn{2}{|c|}{ Origin } \\
\hline Origin X & $0 . \mathrm{mm}$ \\
\hline
\end{tabular}




\begin{tabular}{|r|r|}
\hline Origin $Y$ & $0 . \mathrm{mm}$ \\
\hline Origin Z & $0 . \mathrm{mm}$ \\
\hline \multicolumn{2}{|c|}{ Directional Vectors } \\
\hline X Axis Data & {$[1.0 .0]$.} \\
\hline Y Axis Data & {$[0.1 .0]$.} \\
\hline Z Axis Data & {$[0.0 .1]$.} \\
\hline
\end{tabular}

Mesh

TABLE 6

Model (D4) $>$ Mesh

\begin{tabular}{|c|c|}
\hline \\
\hline Object Name & Mesh \\
\hline State & Solved \\
\hline \multicolumn{2}{|l|}{ Display } \\
\hline Display Style & Use Geometry Setting \\
\hline \multicolumn{2}{|c|}{ Defaults } \\
\hline Physics Preference & Mechanical \\
\hline Element Order & Program Controlled \\
\hline Element Size & Default \\
\hline \multicolumn{2}{|l|}{ Sizing } \\
\hline Use Adaptive Sizing & Yes \\
\hline Resolution & Default (2) \\
\hline Mesh Defeaturing & Yes \\
\hline Defeature Size & Default \\
\hline Transition & Fast \\
\hline Span Angle Center & Fine \\
\hline Initial Size Seed & Assembly \\
\hline Bounding Box Diagonal & $2001.3 \mathrm{~mm}$ \\
\hline Average Surface Area & $71346 \mathrm{~mm}^{2}$ \\
\hline Minimum Edge Length & $38.1 \mathrm{~mm}$ \\
\hline \multicolumn{2}{|l|}{ Quality } \\
\hline Check Mesh Quality & Yes, Errors \\
\hline Error Limits & Standard Mechanical \\
\hline Target Quality & Default $(0.050000)$ \\
\hline Smoothing & Medium \\
\hline Mesh Metric & None \\
\hline \multicolumn{2}{|l|}{ Inflation } \\
\hline Use Automatic Inflation & None \\
\hline Inflation Option & Smooth Transition \\
\hline Transition Ratio & 0.272 \\
\hline Maximum Layers & 5 \\
\hline Growth Rate & 1.2 \\
\hline Inflation Algorithm & Pre \\
\hline View Advanced Options & No \\
\hline \multicolumn{2}{|l|}{ Advanced } \\
\hline Number of CPUs for Parallel Part Meshing & Program Controlled \\
\hline Straight Sided Elements & No \\
\hline Rigid Body Behavior & Dimensionally Reduced \\
\hline
\end{tabular}




\begin{tabular}{|r|c|}
\hline Triangle Surface Mesher & Program Controlled \\
\hline Topology Checking & Yes \\
\hline Pinch Tolerance & Please Define \\
\hline Generate Pinch on Refresh & No \\
\hline Statistics & \\
\hline Nodes & 2261 \\
\hline Elements & 1143 \\
\hline
\end{tabular}

TABLE 7

Model (D4) $>$ Mesh $>$ Mesh Controls Object Name Patch Conforming Method

\begin{tabular}{|r|c|}
\hline State & Fully Defined \\
\hline Scoping Method & Geometry Selection \\
\hline Geometry & 1 Body \\
\hline Duppressed & No \\
\hline Method & Tetrahedrons \\
\hline Algorithm & Patch Conforming \\
\hline Element Order & Use Global Setting \\
\hline
\end{tabular}

FIGURE 2

Model (D4) > Mesh > Figure 


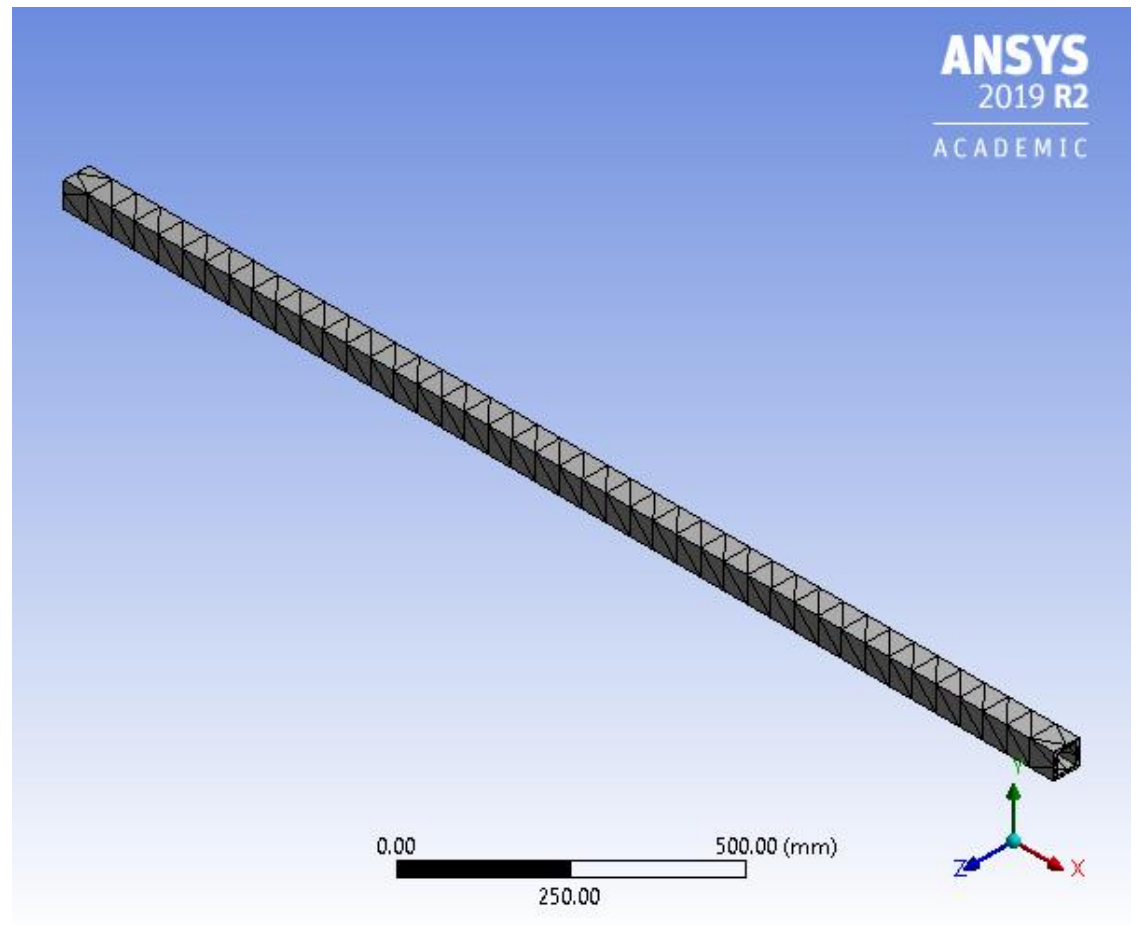

\section{Static Structural (D5)}

TABLE 8

Model (D4) > Analysis

\begin{tabular}{|c|c|}
\hline Object Name & Static Structural (D5) \\
\hline State & Solved \\
\hline \multicolumn{2}{|c|}{ Definition } \\
\hline Physics Type & Structural \\
\hline Analysis Type & Static Structural \\
\hline Solver Target & Mechanical APDL \\
\hline \multicolumn{2}{|c|}{ Options } \\
\hline Environment Temperature & 22. ${ }^{\circ} \mathrm{C}$ \\
\hline Generate Input Only & No \\
\hline
\end{tabular}

TABLE 9

Model (D4) > Static Structural (D5) > Analysis Settings

\begin{tabular}{|r|c|}
\hline Object Name & Analysis Settings \\
\hline State & Fully Defined \\
\hline & Step Controls \\
\hline
\end{tabular}




\begin{tabular}{|c|c|}
\hline Number Of Steps & 1. \\
\hline Current Step Number & 1. \\
\hline Step End Time & 1. $s$ \\
\hline Auto Time Stepping & Program Controlled \\
\hline \multicolumn{2}{|r|}{ Solver Controls } \\
\hline Solver Type & Program Controlled \\
\hline Weak Springs & Off \\
\hline Solver Pivot Checking & Program Controlled \\
\hline Large Deflection & Off \\
\hline Inertia Relief & Off \\
\hline \multicolumn{2}{|r|}{ Rotordynamics Controls } \\
\hline Coriolis Effect & Off \\
\hline \multicolumn{2}{|r|}{ Restart Controls } \\
\hline Generate Restart Points & Program Controlled \\
\hline $\begin{array}{r}\text { Retain Files After Full } \\
\text { Solve }\end{array}$ & No \\
\hline Combine Restart Files & Program Controlled \\
\hline \multicolumn{2}{|r|}{ Nonlinear Controls } \\
\hline $\begin{array}{r}\text { Newton-Raphson } \\
\text { Option }\end{array}$ & Program Controlled \\
\hline Force Convergence & Program Controlled \\
\hline Moment Convergence & Program Controlled \\
\hline $\begin{array}{l}\text { Displacement } \\
\text { Convergence }\end{array}$ & Program Controlled \\
\hline Rotation Convergence & Program Controlled \\
\hline Line Search & Program Controlled \\
\hline Stabilization & Program Controlled \\
\hline \multicolumn{2}{|r|}{ Output Controls } \\
\hline Stress & Yes \\
\hline Surface Stress & No \\
\hline Back Stress & No \\
\hline Strain & Yes \\
\hline Contact Data & Yes \\
\hline Nonlinear Data & No \\
\hline Nodal Forces & No \\
\hline Contact Miscellaneous & No \\
\hline General Miscellaneous & No \\
\hline Store Results At & All Time Points \\
\hline $\begin{array}{r}\text { Result File } \\
\text { Compression }\end{array}$ & Program Controlled \\
\hline \multicolumn{2}{|r|}{ Analysis Data Management } \\
\hline Solver Files Directory & 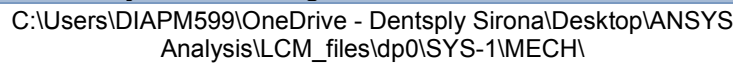 \\
\hline Future Analysis & None \\
\hline \multicolumn{2}{|l|}{$\begin{array}{r}\text { Scratch Solver Files } \\
\text { Directory }\end{array}$} \\
\hline Save MAPDL db & No \\
\hline Contact Summary & Program Controlled \\
\hline Delete Unneeded Files & Yes \\
\hline
\end{tabular}




\begin{tabular}{|r|c|}
\hline Nonlinear Solution & No \\
\hline Solver Units & Active System \\
\hline Solver Unit System & $\mathrm{nmm}$ \\
\hline
\end{tabular}

FIGURE 3

Model (D4) > Static Structural (D5) > Figure

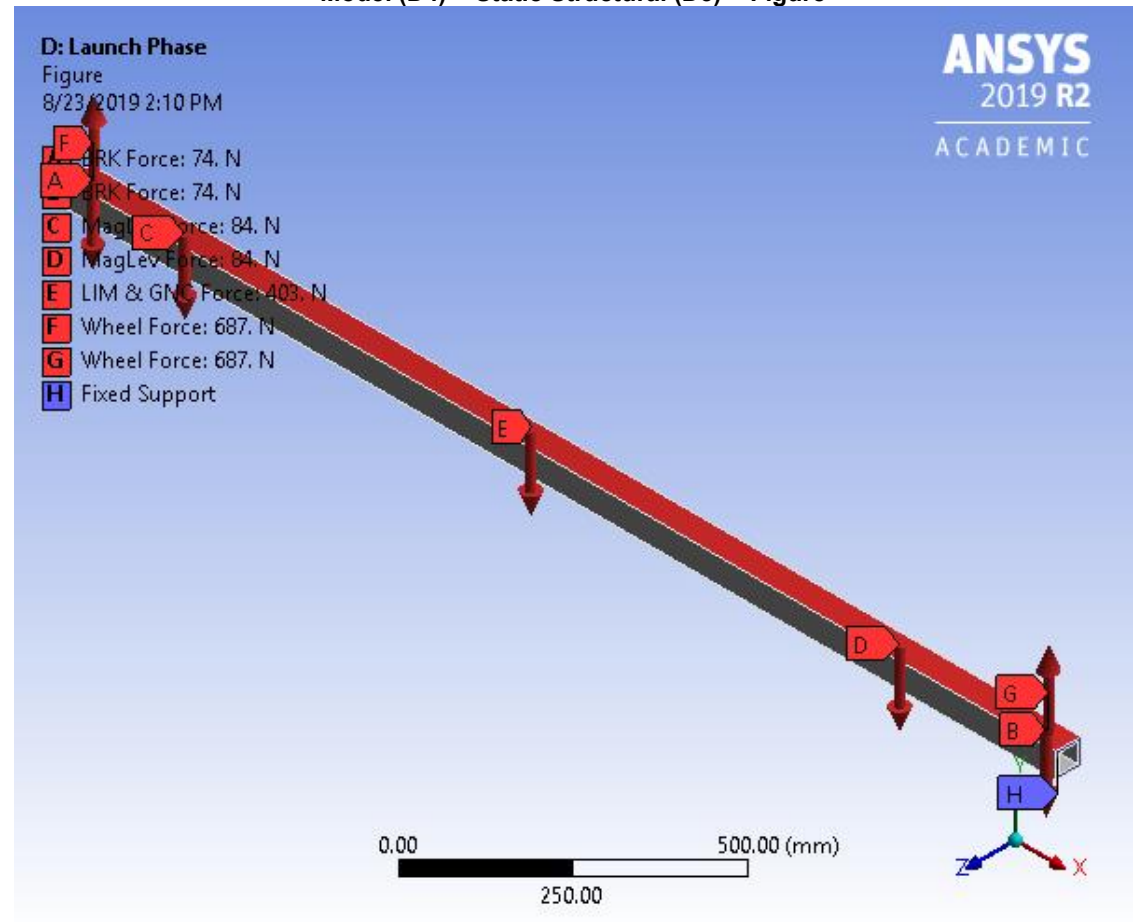

TABLE 10

Model (D4) $>$ Static Structural (D5) $>$ Loads

\begin{tabular}{|c|c|c|c|c|c|c|c|c|c|}
\hline \multicolumn{10}{|c|}{ Ivioder $\left(\mathrm{U}^{4}\right)>$ static structural $(\mathrm{U})>$ Loaus } \\
\hline Object Name & $\begin{array}{l}\text { Thermal } \\
\text { Condition }\end{array}$ & $\begin{array}{l}\text { BRK } \\
\text { Force }\end{array}$ & $\begin{array}{l}\text { BRK } \\
\text { Force }\end{array}$ & $\begin{array}{c}\text { MagLev } \\
\text { Force }\end{array}$ & $\begin{array}{c}\text { MagLev } \\
\text { Force }\end{array}$ & $\begin{array}{c}\text { LIM \& } \\
\text { GNC } \\
\text { Force }\end{array}$ & $\begin{array}{l}\text { Wheel } \\
\text { Force }\end{array}$ & $\begin{array}{l}\text { Wheel } \\
\text { Force }\end{array}$ & $\begin{array}{l}\text { Fixed } \\
\text { Support }\end{array}$ \\
\hline State & \multicolumn{9}{|c|}{ Fully Defined } \\
\hline \multicolumn{10}{|c|}{ Scope } \\
\hline $\begin{array}{l}\text { Scoping } \\
\text { Method }\end{array}$ & \multicolumn{9}{|c|}{ Geometry Selection } \\
\hline Geometry & 1 Body & & & & 1 Face & & & & 2 Faces \\
\hline \multicolumn{10}{|c|}{ Definition } \\
\hline Type & $\begin{array}{l}\text { Thermal } \\
\text { Condition }\end{array}$ & & & & Force & & & & $\begin{array}{l}\text { Fixed } \\
\text { Support }\end{array}$ \\
\hline
\end{tabular}




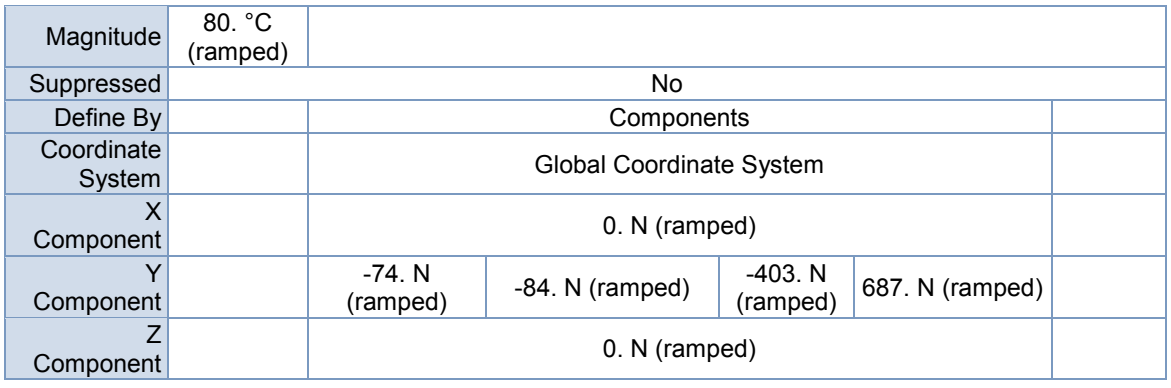

FIGURE 4

Model (D4) > Static Structural (D5) > Thermal Condition

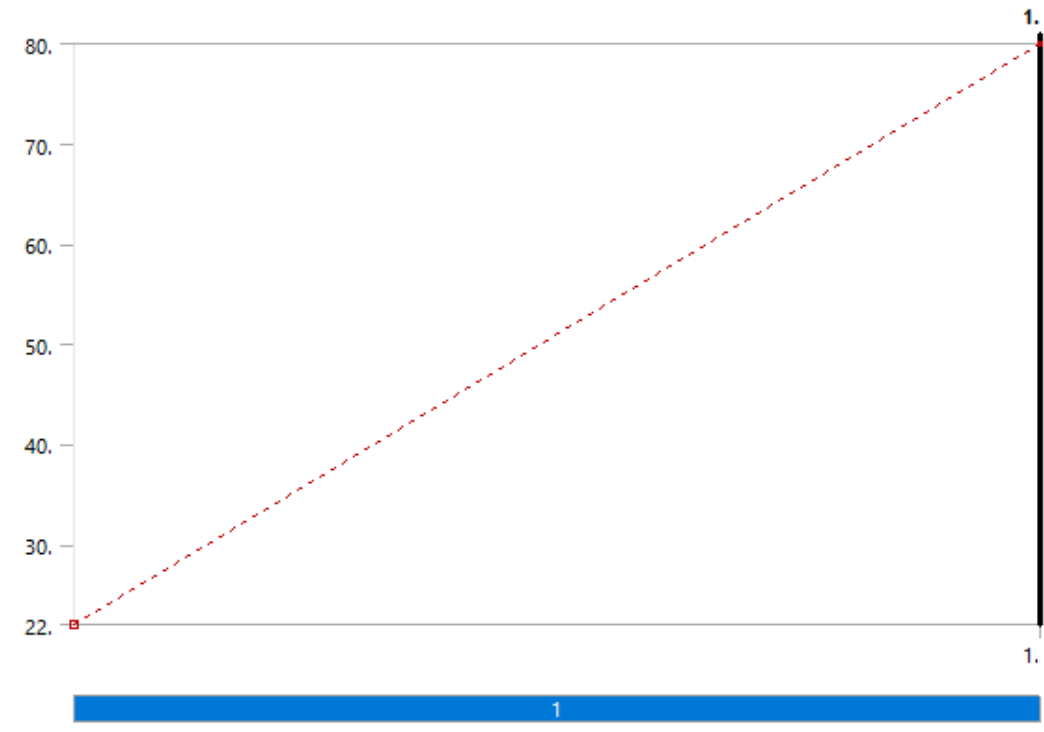

FIGURE 5

Model (D4) > Static Structural (D5) > BRK Force 


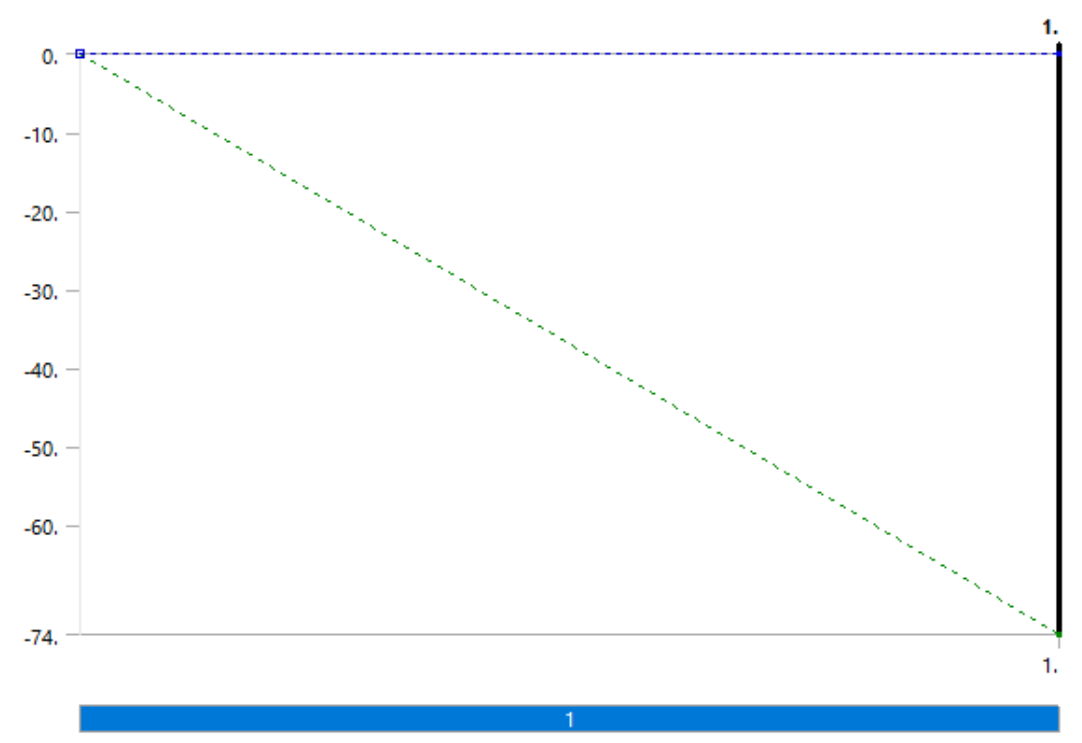

FIGURE 6

Model (D4) > Static Structural (D5) $>$ BRK Force

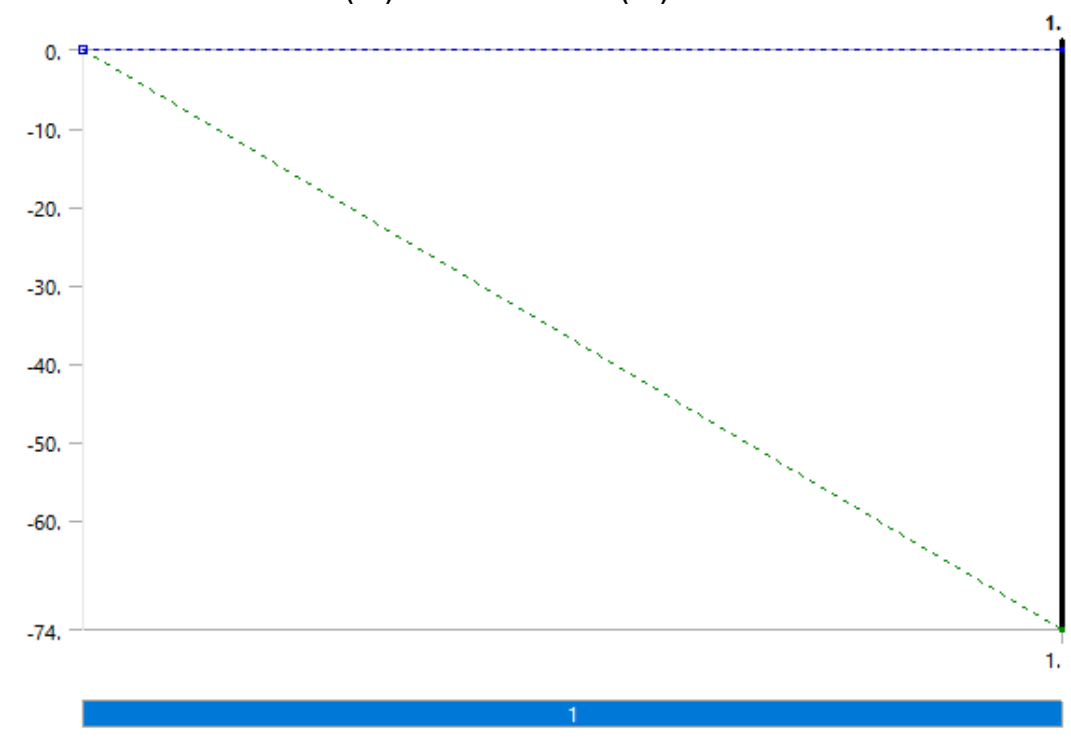


FIGURE 7

Model (D4) > Static Structural (D5) > MagLev Force

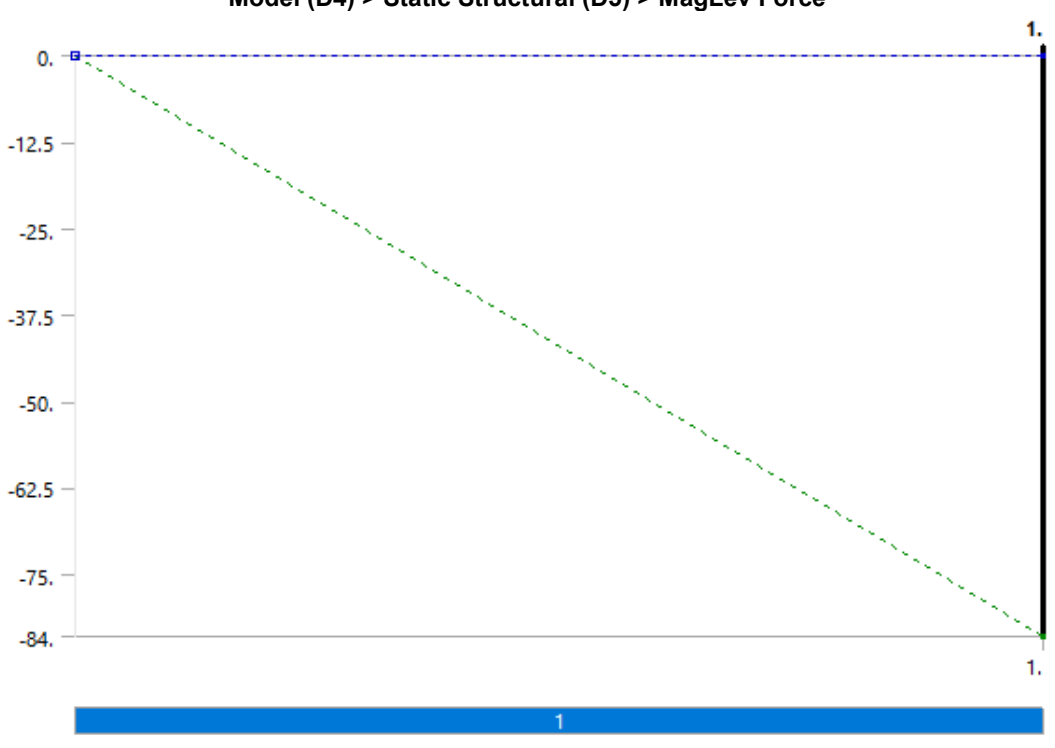

FIGURE 8

Model (D4) > Static Structural (D5) > MagLev Force 


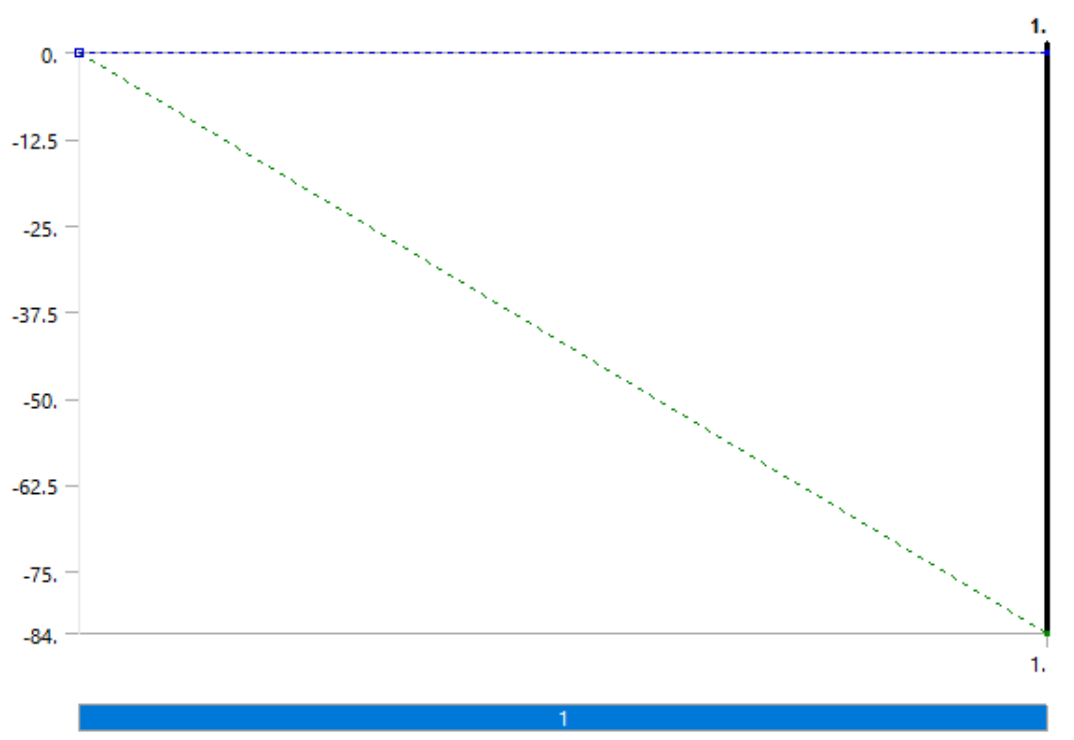

FIGURE 9

Model (D4) > Static Structural (D5) > LIM \& GNC Force

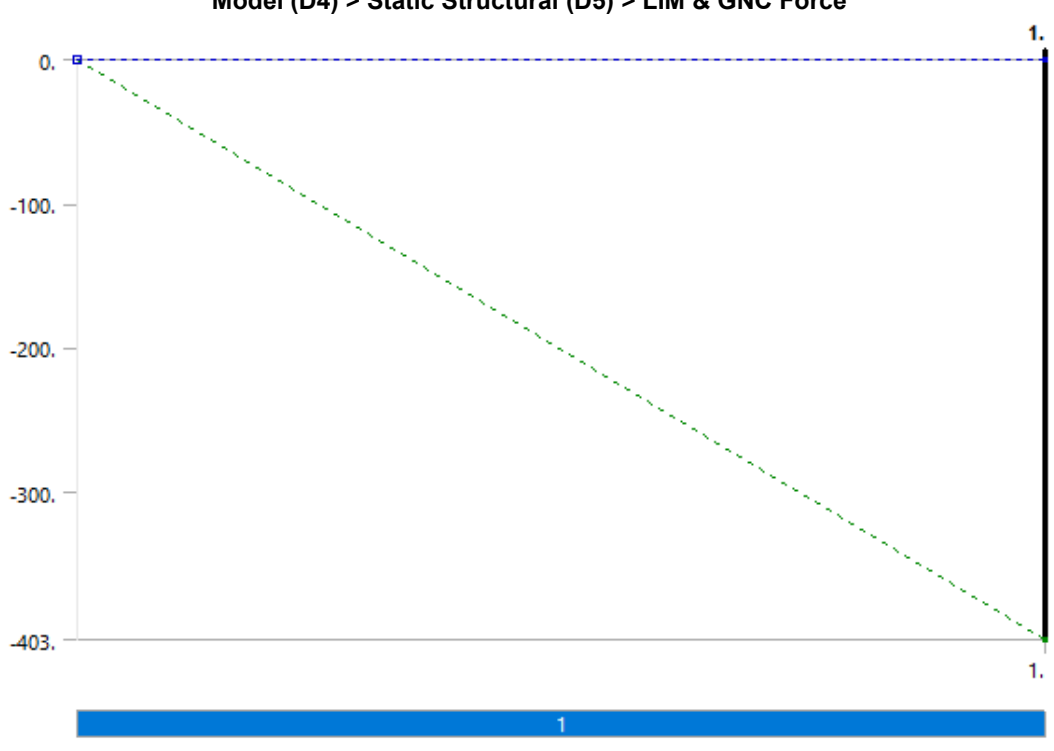


FIGURE 10

Model (D4) > Static Structural (D5) > Wheel Force

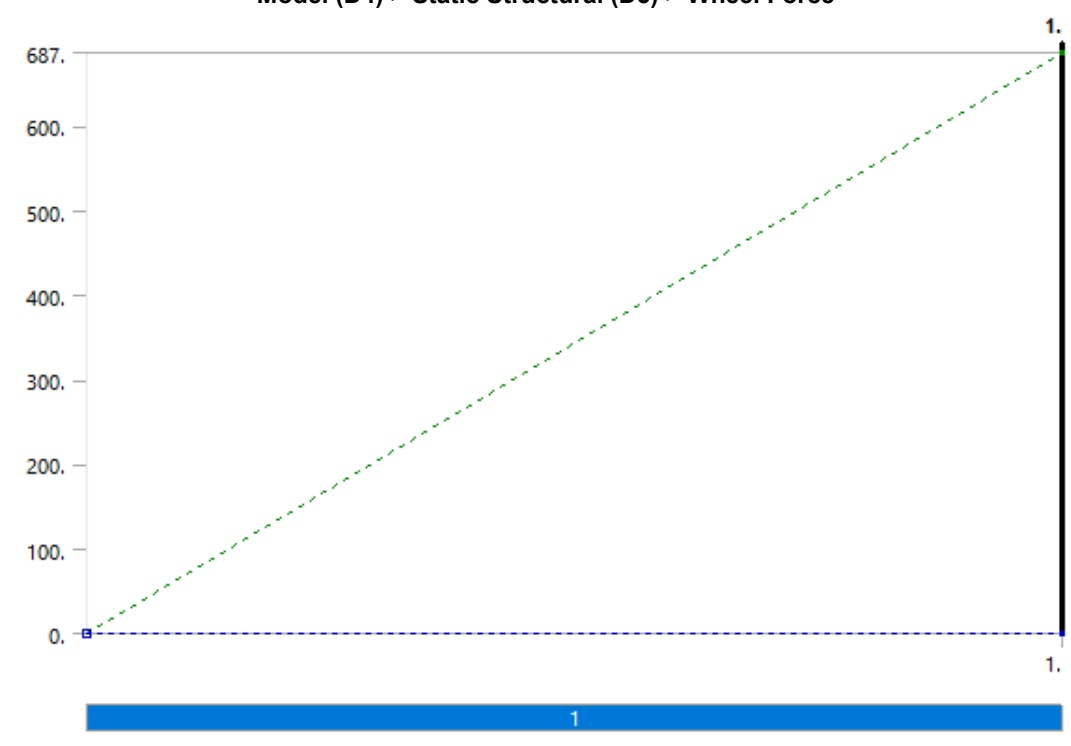

FIGURE 11

Model (D4) > Static Structural (D5) > Wheel Force 


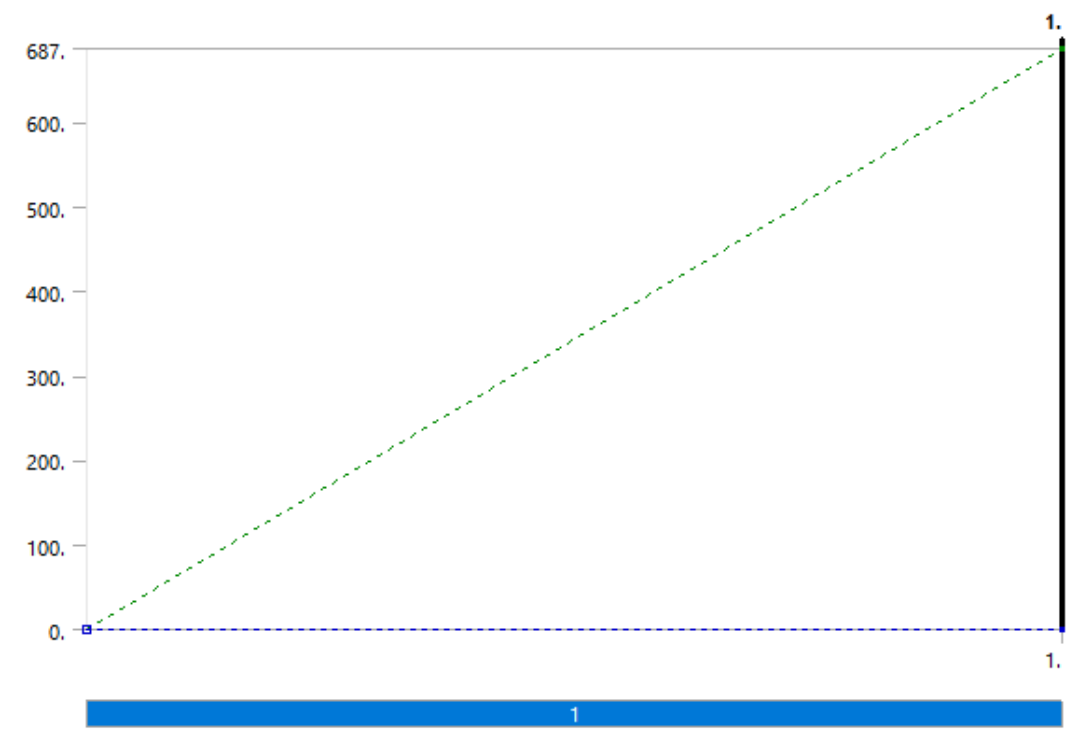

Solution (D6)

TABLE 11

Model (D4) $>$ Static Structural (D5) > Solution

\begin{tabular}{|c|c|}
\hline Object Name & Solution (D6) \\
\hline State & Solved \\
\hline \multicolumn{2}{|c|}{ Adaptive Mesh Refinement } \\
\hline Max Refinement Loops & 1. \\
\hline Refinement Depth & 2. \\
\hline \multicolumn{2}{|l|}{ Information } \\
\hline Status & Done \\
\hline MAPDL Elapsed Time & 3. $\mathrm{s}$ \\
\hline MAPDL Memory Used & 266. MB \\
\hline MAPDL Result File Size & $1.25 \mathrm{MB}$ \\
\hline \multicolumn{2}{|l|}{ Post Processing } \\
\hline Beam Section Results & No \\
\hline Demand Stress/Strain & No \\
\hline
\end{tabular}

TABLE 12

Model (D4) > Static Structural (D5) > Solution (D6) > Solution Information

\begin{tabular}{|r|c|}
\hline Object Name & Solution Information \\
\hline State & Solved \\
\hline Solution Information \\
\hline Solution Output & Solver Output \\
\hline Newton-Raphson Residuals & 0 \\
\hline
\end{tabular}




\begin{tabular}{|r|c|}
\hline Identify Element Violations & 0 \\
\hline Update Interval & $2.5 \mathrm{~s}$ \\
\hline Display Points & All \\
\hline FE Connection Visibility \\
\hline Activate Visibility & Yes \\
\hline Display & All FE Connectors \\
\hline Draw Connections Attached To & All Nodes \\
\hline Line Color & Connection Type \\
\hline Visible on Results & No \\
\hline Line Thickness & Single \\
\hline Display Type & Lines \\
\hline
\end{tabular}

TABLE 13

Model (D4) $>$ Static Structural (D5) $>$ Solution (D6) $>$ Results

\begin{tabular}{|c|c|c|}
\hline & & \\
\hline Object Name & Total Deformation & Equivalent Stress \\
\hline State & \multicolumn{2}{|r|}{ Solved } \\
\hline \multicolumn{3}{|c|}{ Scope } \\
\hline Scoping Method & \multicolumn{2}{|c|}{ Geometry Selection } \\
\hline Geometry & \multicolumn{2}{|c|}{ All Bodies } \\
\hline \multicolumn{3}{|c|}{ Definition } \\
\hline Type & Total Deformation & Equivalent (von-Mises) Stress \\
\hline By & \multicolumn{2}{|r|}{ Time } \\
\hline Display Time & \multicolumn{2}{|r|}{ Last } \\
\hline Calculate Time History & \multicolumn{2}{|r|}{ Yes } \\
\hline \multicolumn{3}{|l|}{ Identifier } \\
\hline Suppressed & \multicolumn{2}{|r|}{ No } \\
\hline \multicolumn{3}{|c|}{ Results } \\
\hline Minimum & 0. $\mathrm{mm}$ & $34.987 \mathrm{MPa}$ \\
\hline Maximum & $0.55549 \mathrm{~mm}$ & $165.71 \mathrm{MPa}$ \\
\hline Average & $0.26761 \mathrm{~mm}$ & $95.926 \mathrm{MPa}$ \\
\hline Minimum Occurs On & \multicolumn{2}{|c|}{ GeomIPartBody } \\
\hline Maximum Occurs On & \multicolumn{2}{|c|}{ Geom\PartBody } \\
\hline \multicolumn{3}{|c|}{ Information } \\
\hline Time & \multicolumn{2}{|r|}{ 1. $s$} \\
\hline Load Step & \multicolumn{2}{|r|}{1} \\
\hline Substep & \multicolumn{2}{|r|}{1} \\
\hline Iteration Number & \multicolumn{2}{|r|}{1} \\
\hline \multicolumn{3}{|c|}{ Integration Point Results } \\
\hline Display Option & & Averaged \\
\hline Average Across Bodies & & No \\
\hline
\end{tabular}

FIGURE 12

Model (D4) $>$ Static Structural (D5) > Solution (D6) $>$ Total Deformation 


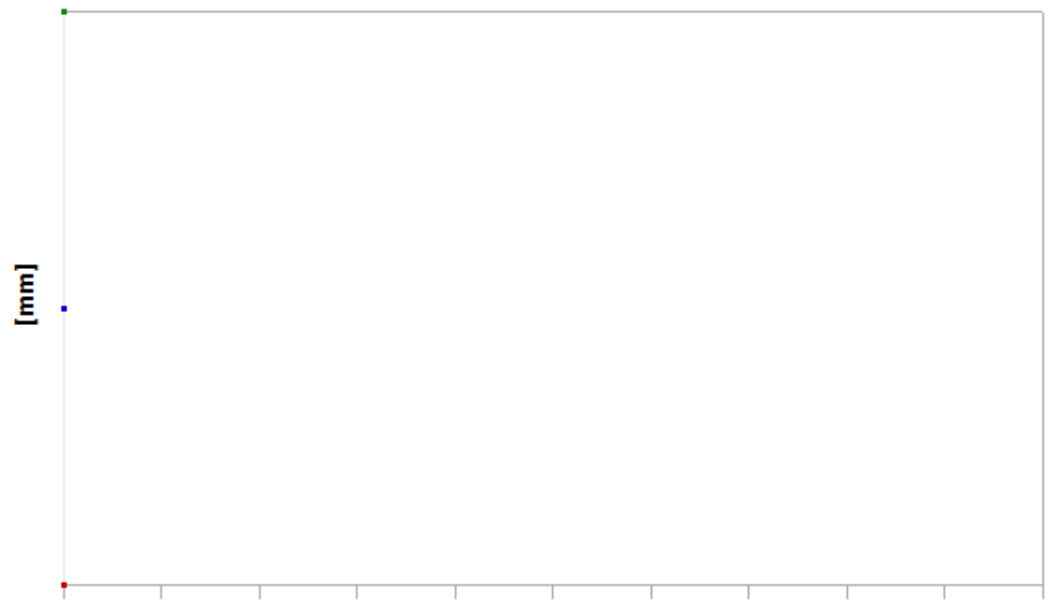

[s]

TABLE 14

Model (D4) $>$ Static Structural (D5) $>$ Solution (D6) $>$ Total Deformation

Time [s] Minimum [mm] Maximum [mm] Average [mm]

\begin{tabular}{l|l|l|l}
\hline 1. & 0. & 0.55549 & 0.26761
\end{tabular}

FIGURE 13

Model (D4) > Static Structural (D5) $>$ Solution (D6) $>$ Total Deformation $>$ Figure 


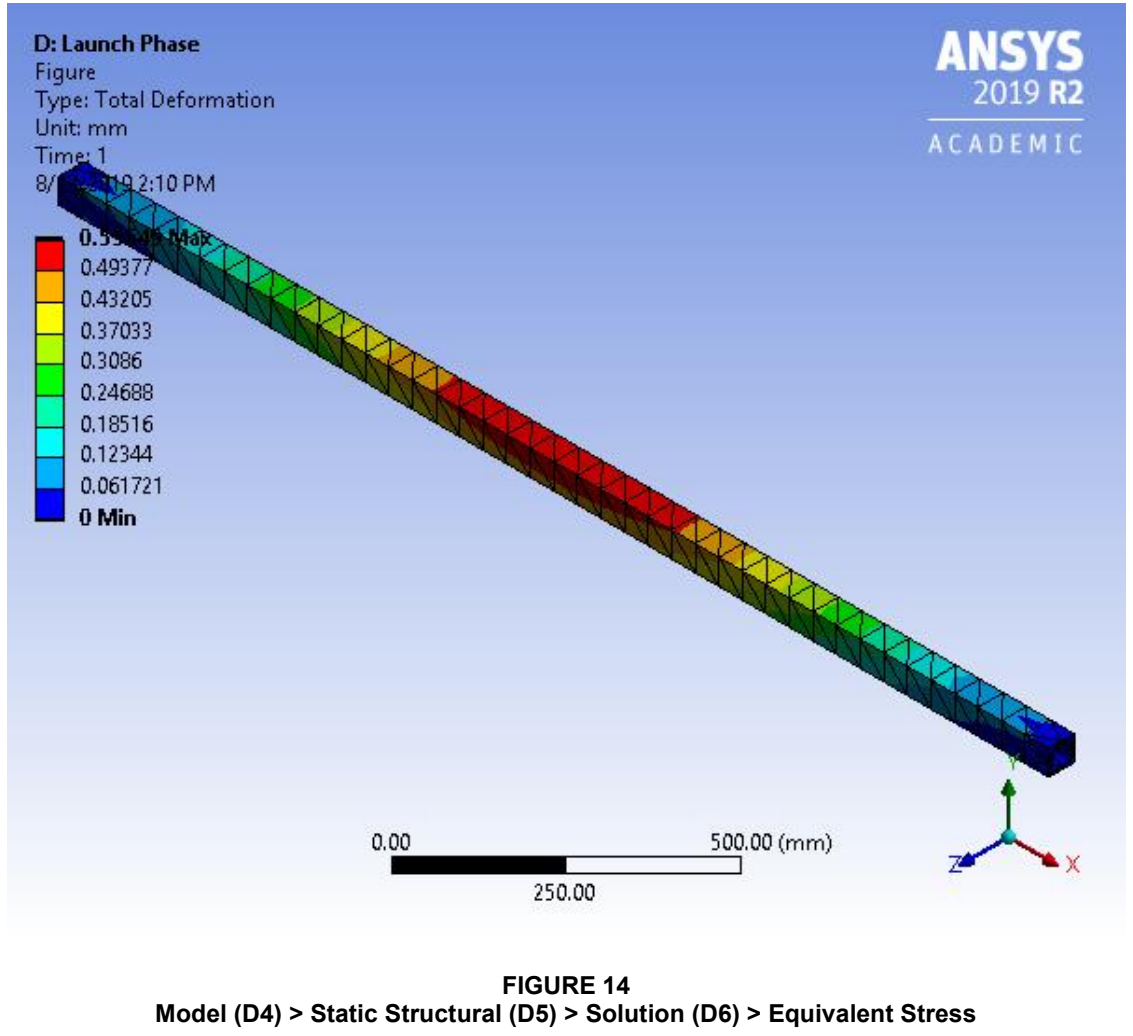




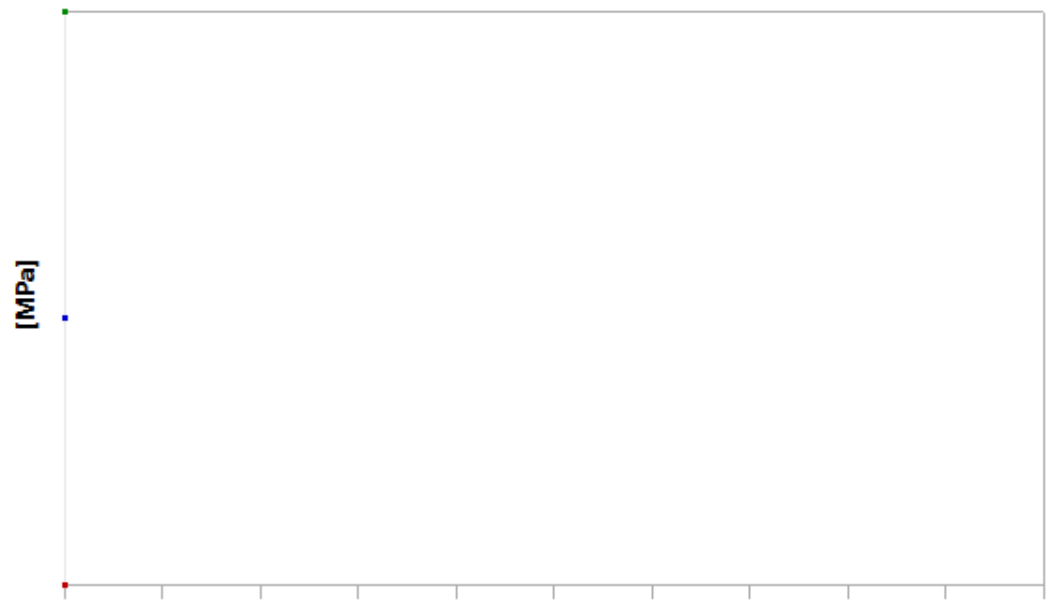

[s]

TABLE 15

Model (D4) > Static Structural (D5) > Solution (D6) > Equivalent Stress

Time [s] Minimum [MPa] Maximum [MPa] Average [MPa]

\begin{tabular}{l|l|l|r}
\hline 1. & 34.987 & 165.71 & 95.926
\end{tabular}

FIGURE 15

Model (D4) > Static Structural (D5) > Solution (D6) > Equivalent Stress > Figure 


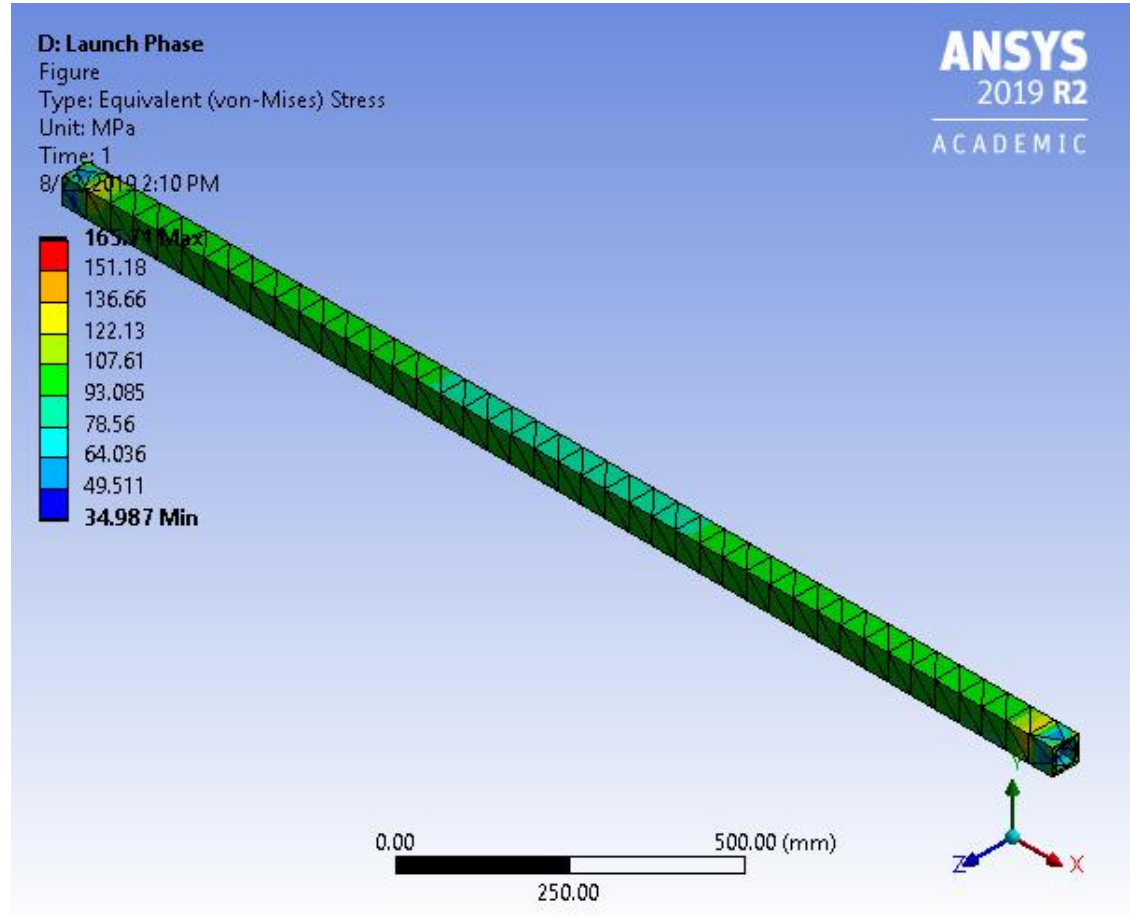

\section{Material Data}

\section{Aluminum Alloy}

TABLE 16

Aluminum Alloy $>$ Constants

\begin{tabular}{|c|c|c|}
\hline \multicolumn{2}{|r|}{ Density } & $2.77 \mathrm{e}-006 \mathrm{~kg} \mathrm{~mm} \wedge-3$ \\
\hline \multicolumn{2}{|c|}{ Coefficient of Thermal Expansion } & $2.3 e-005 C^{\wedge}-1$ \\
\hline \multicolumn{2}{|c|}{ Specific Heat } & $8.75 e+005 m J k g^{\wedge}-1 C^{\wedge}-1$ \\
\hline \multicolumn{3}{|c|}{$\begin{array}{c}\text { TABLE } 17 \\
\text { Aluminum Alloy }>\text { Color }\end{array}$} \\
\hline Red & Green & Blue \\
\hline 138 & 104 & 46 \\
\hline
\end{tabular}

TABLE 18

Aluminum Alloy $>$ Compressive Ultimate Strength

Compressive Ultimate Strength $\mathrm{MPa}$ 
TABLE 19

Aluminum Alloy $>$ Compressive Yield Strength

Compressive Yield Strength $\mathrm{MPa}$

280

TABLE 20

Aluminum Alloy $>$ Tensile Yield Strength

Tensile Yield Strength MPa

280

TABLE 21

Aluminum Alloy $>$ Tensile Ultimate Strength

Tensile Ultimate Strength $\mathrm{MPa}$

310

TABLE 22

Aluminum Alloy $>$ Isotropic Secant Coefficient of Thermal Expansion

Zero-Thermal-Strain Reference Temperature C

22

TABLE 23

Aluminum Alloy $>$ Isotropic Thermal Conductivity Thermal Conductivity $\mathrm{W} \mathrm{mm}^{\wedge}-1 \mathrm{C}^{\wedge}-1$ Temperature $\mathrm{C}$

\begin{tabular}{|c|c|}
\hline 0.114 & -100 \\
\hline 0.144 & 0 \\
\hline 0.165 & 100 \\
\hline 0.175 & 200 \\
\hline
\end{tabular}

TABLE 24

Aluminum Alloy $>$ S-N Curve

Alternating Stress MPa Cycles R-Ratio

\begin{tabular}{|c|c|c|}
\hline 275.8 & 1700 & -1 \\
\hline 241.3 & 5000 & -1 \\
\hline 206.8 & 34000 & -1 \\
\hline 172.4 & $1.4 \mathrm{e}+005$ & -1 \\
\hline 137.9 & $8 . \mathrm{e}+005$ & -1 \\
\hline 117.2 & $2.4 \mathrm{e}+006$ & -1 \\
\hline 89.63 & $5.5 \mathrm{e}+007$ & -1 \\
\hline 82.74 & $1 . \mathrm{e}+008$ & -1 \\
\hline 170.6 & 50000 & -0.5 \\
\hline 139.6 & $3.5 \mathrm{e}+005$ & -0.5 \\
\hline 108.6 & $3.7 \mathrm{e}+006$ & -0.5 \\
\hline 87.91 & $1.4 \mathrm{e}+007$ & -0.5 \\
\hline 77.57 & $5 . \mathrm{e}+007$ & -0.5 \\
\hline 72.39 & $1 . \mathrm{e}+008$ & -0.5 \\
\hline 144.8 & 50000 & 0 \\
\hline 120.7 & $1.9 \mathrm{e}+005$ & 0 \\
\hline 103.4 & $1.3 \mathrm{e}+006$ & 0 \\
\hline 93.08 & $4.4 \mathrm{e}+006$ & 0 \\
\hline & & \\
\hline
\end{tabular}




\begin{tabular}{|c|c|c|}
\hline 86.18 & $1.2 \mathrm{e}+007$ & 0 \\
\hline 72.39 & $1 . \mathrm{e}+008$ & 0 \\
\hline 74.12 & $3 . \mathrm{e}+005$ & 0.5 \\
\hline 70.67 & $1.5 \mathrm{e}+006$ & 0.5 \\
\hline 66.36 & $1.2 \mathrm{e}+007$ & 0.5 \\
\hline 62.05 & $1 . \mathrm{e}+008$ & 0.5 \\
\hline
\end{tabular}

TABLE 25

Aluminum Alloy > Isotropic Resistivity Resistivity ohm $\mathrm{mm}$ Temperature C

\begin{tabular}{|c|c|}
\hline $2.43 e-005$ & 0 \\
\hline $2.67 e-005$ & 20 \\
\hline $3.63 e-005$ & 100 \\
\hline
\end{tabular}

TABLE 26

Aluminum Alloy $>$ Isotropic Elasticity

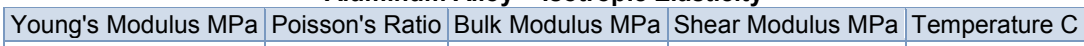

71000

0.33

69608

26692

TABLE 27

Aluminum Alloy > Isotropic Relative Permeability Relative Permeability 
Appendix A.7 LCM Load Case III (Levitation Phase) Analysis Report 


\section{MNSYS}

\section{Project}

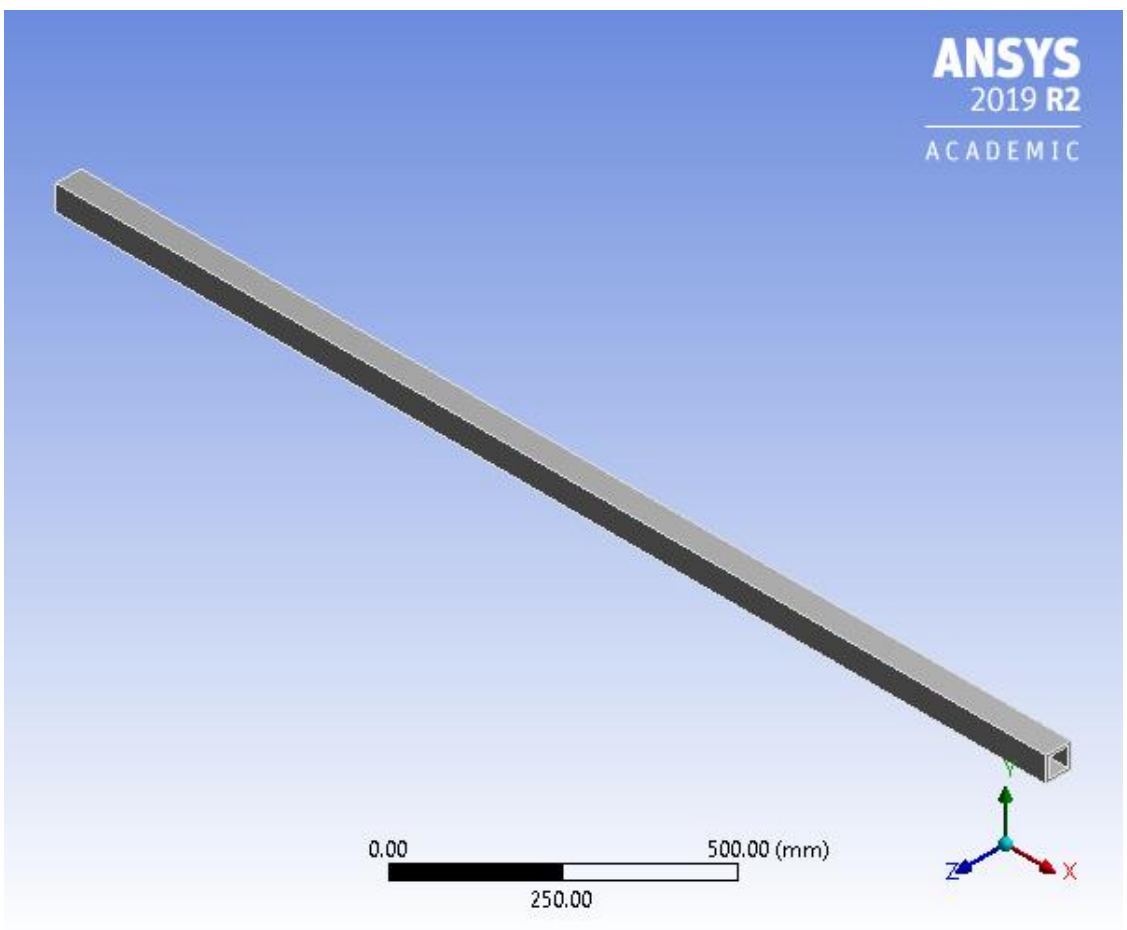




\section{Contents}

- Units

- Model (E4)

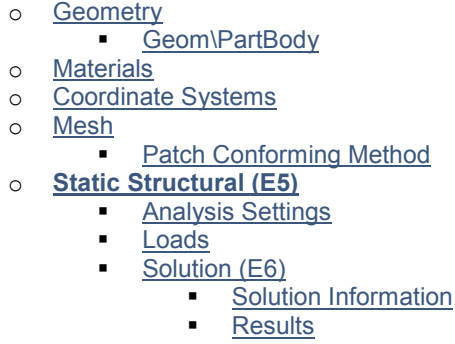

- Material Data

- Aluminum Alloy

\section{Units}

TABLE 1

\begin{tabular}{|r|c|}
\hline Unit System & Metric $(\mathrm{mm}, \mathrm{kg}, \mathrm{N}, \mathrm{s}, \mathrm{mV}, \mathrm{mA})$ Degrees rad/s Celsius \\
\hline Angle & Degrees \\
\hline Rotational Velocity & rad/s \\
\hline Temperature & Celsius \\
\hline
\end{tabular}

\section{Model (E4)}

\section{Geometry}

TABLE 2

Model (E4) > Geometry

\begin{tabular}{|c|c|}
\hline \multirow{2}{*}{\multicolumn{2}{|c|}{ Geometry }} \\
\hline & \\
\hline \multicolumn{2}{|r|}{ Fully Defined } \\
\hline \multicolumn{2}{|r|}{ Definition } \\
\hline Source & $\begin{array}{c}\text { C:IUsersIDIAPM5991OneDrive - Dentsply SironalDesktop\ANSYS } \\
\text { Analysis|LCM_filesIdp0|GeomIDMIGeom.scdoc }\end{array}$ \\
\hline Type & SpaceClaim \\
\hline Length Unit & Meters \\
\hline Element Control & Program Controlled \\
\hline Display Style & Body Color \\
\hline \multicolumn{2}{|r|}{ Bounding Box } \\
\hline Length $\mathrm{X}$ & 2000. $\mathrm{mm}$ \\
\hline Length $Y$ & $50.8 \mathrm{~mm}$ \\
\hline Length Z & $50.8 \mathrm{~mm}$ \\
\hline
\end{tabular}




\begin{tabular}{|c|c|}
\hline \multicolumn{2}{|c|}{ Properties } \\
\hline Volume & $2.2581 \mathrm{e}+006 \mathrm{~mm}^{3}$ \\
\hline Mass & $6.2548 \mathrm{~kg}$ \\
\hline Scale Factor Value & 1. \\
\hline \multicolumn{2}{|c|}{ Statistics } \\
\hline Bodies & 1 \\
\hline Active Bodies & 1 \\
\hline Nodes & 2261 \\
\hline Elements & 1143 \\
\hline Mesh Metric & None \\
\hline \multicolumn{2}{|c|}{ Update Options } \\
\hline Assign Default Material & No \\
\hline \multicolumn{2}{|c|}{ Basic Geometry Options } \\
\hline Solid Bodies & Yes \\
\hline Surface Bodies & Yes \\
\hline Line Bodies & Yes \\
\hline Parameters & Independent \\
\hline \multicolumn{2}{|l|}{ Parameter Key } \\
\hline Attributes & Yes \\
\hline \multicolumn{2}{|l|}{ Attribute Key } \\
\hline Named Selections & Yes \\
\hline \multicolumn{2}{|l|}{ Named Selection Key } \\
\hline Material Properties & Yes \\
\hline \multicolumn{2}{|c|}{ Advanced Geometry Options } \\
\hline Use Associativity & Yes \\
\hline Coordinate Systems & Yes \\
\hline \multicolumn{2}{|l|}{ Coordinate System Key } \\
\hline $\begin{array}{r}\text { Reader Mode Saves } \\
\text { Updated File }\end{array}$ & No \\
\hline Use Instances & Yes \\
\hline Smart CAD Update & Yes \\
\hline $\begin{array}{r}\text { Compare Parts On } \\
\text { Update }\end{array}$ & No \\
\hline Analysis Type & 3-D \\
\hline $\begin{array}{r}\text { Mixed Import } \\
\text { Resolution }\end{array}$ & None \\
\hline Clean Bodies On Import & No \\
\hline $\begin{array}{r}\text { Stitch Surfaces On } \\
\text { Import }\end{array}$ & None \\
\hline $\begin{array}{r}\text { Decompose Disjoint } \\
\text { Geometry }\end{array}$ & Yes \\
\hline $\begin{array}{r}\text { Enclosure and } \\
\text { Symmetry Processing }\end{array}$ & Yes \\
\hline
\end{tabular}

TABLE 3

Model (E4) $>$ Geometry $>$ Parts

Object Name GeomlPartBody

State Meshed

Graphics Properties 


\begin{tabular}{|c|c|}
\hline Visible & Yes \\
\hline Transparency & 1 \\
\hline \multicolumn{2}{|c|}{ Definition } \\
\hline Suppressed & No \\
\hline Stiffness Behavior & Flexible \\
\hline Coordinate System & Default Coordinate System \\
\hline Reference Temperature & By Environment \\
\hline Treatment & None \\
\hline \multicolumn{2}{|c|}{ Material } \\
\hline Assignment & Aluminum Alloy \\
\hline Nonlinear Effects & Yes \\
\hline Thermal Strain Effects & Yes \\
\hline \multicolumn{2}{|c|}{ Bounding Box } \\
\hline Length $X$ & 2000. $\mathrm{mm}$ \\
\hline Length $Y$ & $50.8 \mathrm{~mm}$ \\
\hline Length Z & $50.8 \mathrm{~mm}$ \\
\hline \multicolumn{2}{|c|}{ Properties } \\
\hline Volume & $2.2581 \mathrm{e}+006 \mathrm{~mm}^{3}$ \\
\hline Mass & $6.2548 \mathrm{~kg}$ \\
\hline Centroid $\mathrm{X}$ & $-1000 . \mathrm{mm}$ \\
\hline Centroid $\mathrm{Y}$ & $25.4 \mathrm{~mm}$ \\
\hline Centroid Z & $25.4 \mathrm{~mm}$ \\
\hline Moment of Inertia Ip1 & $4203.5 \mathrm{~kg} \cdot \mathrm{mm}^{2}$ \\
\hline Moment of Inertia Ip2 & $2.087 \mathrm{e}+006 \mathrm{~kg} \cdot \mathrm{mm}^{2}$ \\
\hline Moment of Inertia Ip3 & $2.087 \mathrm{e}+006 \mathrm{~kg} \cdot \mathrm{mm}^{2}$ \\
\hline \multicolumn{2}{|c|}{ Statistics } \\
\hline Nodes & 2261 \\
\hline Elements & 1143 \\
\hline Mesh Metric & None \\
\hline \multicolumn{2}{|c|}{ CAD Attributes } \\
\hline PartTolerance: & 0.00000001 \\
\hline Color:175.143.175 & \\
\hline
\end{tabular}

FIGURE 1

Model (E4) $>$ Geometry $>$ Geom $>$ PartBody $>$ Figure 


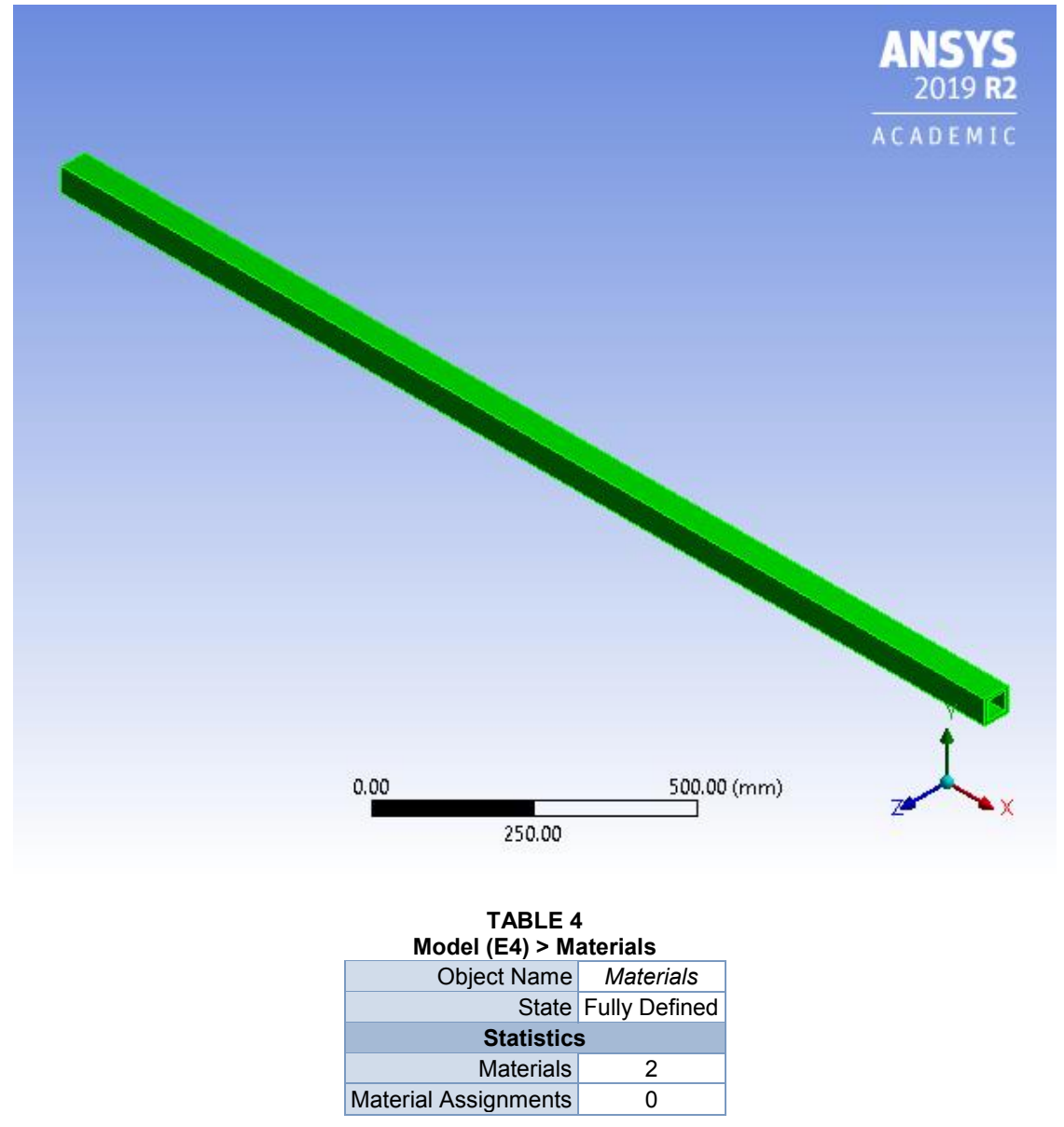

\section{Coordinate Systems}

\section{TABLE 5}

Model (E4) > Coordinate Systems > Coordinate System

\begin{tabular}{|r|c|}
\hline Object Name & Global Coordinate System \\
\hline State & Fully Defined \\
Definition \\
\hline Type & Cartesian \\
\hline Coordinate System ID & 0. \\
\hline Origin \\
\hline Origin X & $0 . \mathrm{mm}$ \\
\hline
\end{tabular}




\begin{tabular}{|r|r|}
\hline Origin $Y$ & $0 . \mathrm{mm}$ \\
\hline Origin Z & $0 . \mathrm{mm}$ \\
\hline \multicolumn{2}{|c|}{ Directional Vectors } \\
\hline X Axis Data & {$[1.0 .0]$.} \\
\hline Y Axis Data & {$[0.1 .0]$.} \\
\hline Z Axis Data & {$[0.0 .1]$.} \\
\hline
\end{tabular}

Mesh

TABLE 6

Model (E4) $>$ Mesh

Object Name

\begin{tabular}{|c|c|}
\hline \\
\hline Object Name & Mesh \\
\hline State & Solved \\
\hline \multicolumn{2}{|l|}{ Display } \\
\hline Display Style & Use Geometry Setting \\
\hline \multicolumn{2}{|l|}{ Defaults } \\
\hline Physics Preference & Mechanical \\
\hline Element Order & Program Controlled \\
\hline Element Size & Default \\
\hline \multicolumn{2}{|l|}{ Sizing } \\
\hline Use Adaptive Sizing & Yes \\
\hline Resolution & Default (2) \\
\hline Mesh Defeaturing & Yes \\
\hline Defeature Size & Default \\
\hline Transition & Fast \\
\hline Span Angle Center & Fine \\
\hline Initial Size Seed & Assembly \\
\hline Bounding Box Diagonal & $2001.3 \mathrm{~mm}$ \\
\hline Average Surface Area & $71346 \mathrm{~mm}^{2}$ \\
\hline Minimum Edge Length & $38.1 \mathrm{~mm}$ \\
\hline \multicolumn{2}{|l|}{ Quality } \\
\hline Check Mesh Quality & Yes, Errors \\
\hline Error Limits & Standard Mechanical \\
\hline Target Quality & Default $(0.050000)$ \\
\hline Smoothing & Medium \\
\hline Mesh Metric & None \\
\hline \multicolumn{2}{|l|}{ Inflation } \\
\hline Use Automatic Inflation & None \\
\hline Inflation Option & Smooth Transition \\
\hline Transition Ratio & 0.272 \\
\hline Maximum Layers & 5 \\
\hline Growth Rate & 1.2 \\
\hline Inflation Algorithm & Pre \\
\hline View Advanced Options & No \\
\hline \multicolumn{2}{|l|}{ Advanced } \\
\hline Number of CPUs for Parallel Part Meshing & Program Controlled \\
\hline Straight Sided Elements & No \\
\hline Rigid Body Behavior & Dimensionally Reduced \\
\hline
\end{tabular}




\begin{tabular}{|r|c|}
\hline Triangle Surface Mesher & Program Controlled \\
\hline Topology Checking & Yes \\
\hline Pinch Tolerance & Please Define \\
\hline Generate Pinch on Refresh & No \\
\hline Statistics & \\
\hline Nodes & 2261 \\
\hline Elements & 1143 \\
\hline
\end{tabular}

TABLE 7

Model (E4) $>$ Mesh $>$ Mesh Controls Object Name Patch Conforming Method

\begin{tabular}{|r|c|}
\hline State & Fully Defined \\
\hline Scoping Method & Geometry Selection \\
\hline Geometry & 1 Body \\
\hline Suppressed & No \\
\hline Method & Tetrahedrons \\
\hline Algorithm & Patch Conforming \\
\hline Element Order & Use Global Setting \\
\hline
\end{tabular}

FIGURE 2

Model $($ E4) $>$ Mesh $>$ Figure 


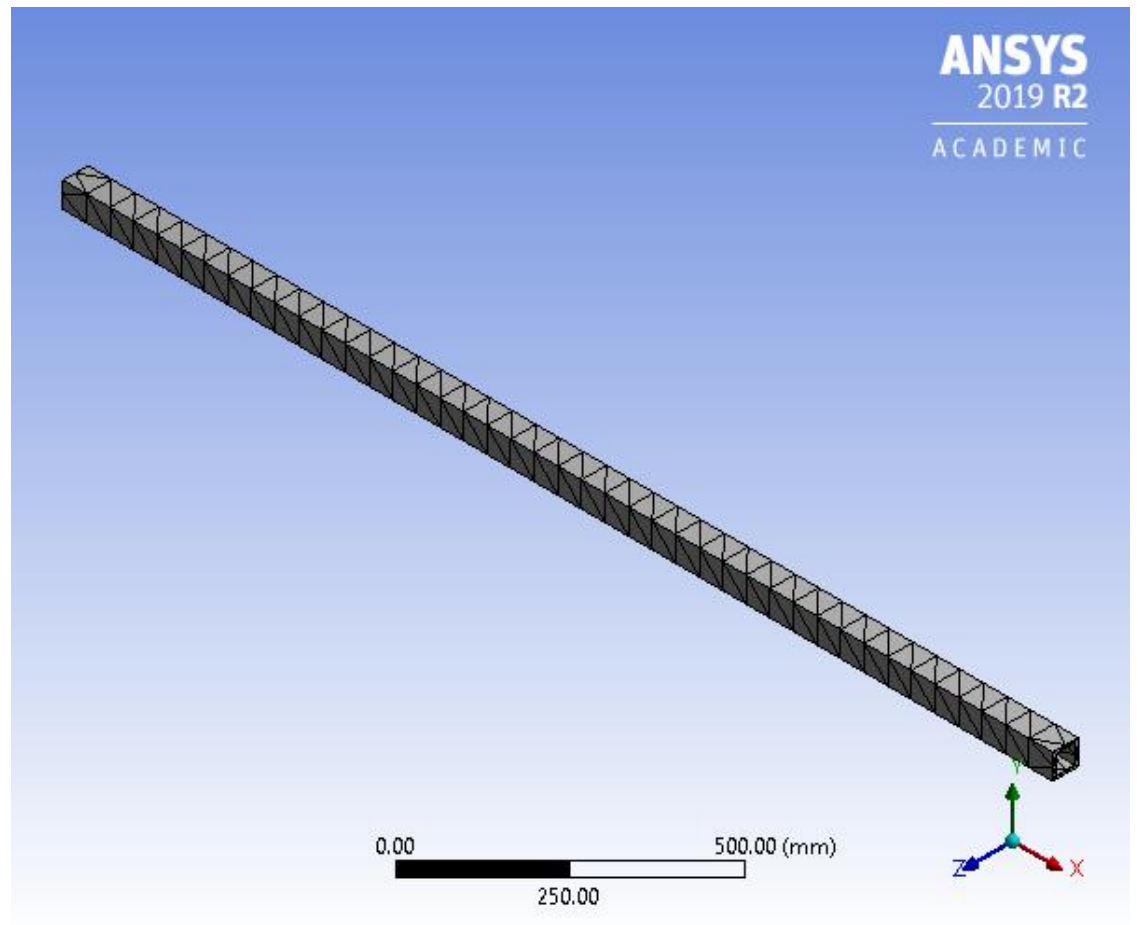

\section{Static Structural (E5)}

TABLE 8

Model (E4) > Analysis

\begin{tabular}{|r|c|}
\hline \multicolumn{1}{|c|}{ Model (E4) > Analysis } \\
\hline Object Name & Static Structural (E5) \\
\hline State & Solved \\
\hline Definition \\
\hline Physics Type & Structural \\
\hline Analysis Type & Static Structural \\
\hline Solver Target & Mechanical APDL \\
\hline Options \\
\hline Environment Temperature & $22 .{ }^{\circ} \mathrm{C}$ \\
\hline Generate Input Only & No \\
\hline
\end{tabular}

TABLE 9

Model (E4) > Static Structural (E5) > Analysis Settings

\begin{tabular}{|r|c|}
\hline Object Name & Analysis Settings \\
\hline State & Fully Defined \\
\hline & Step Controls \\
\hline
\end{tabular}




\begin{tabular}{|c|c|}
\hline Number Of Steps & 1. \\
\hline Current Step Number & 1. \\
\hline Step End Time & 1. $s$ \\
\hline Auto Time Stepping & Program Controlled \\
\hline \multicolumn{2}{|r|}{ Solver Controls } \\
\hline Solver Type & Program Controlled \\
\hline Weak Springs & Off \\
\hline Solver Pivot Checking & Program Controlled \\
\hline Large Deflection & Off \\
\hline Inertia Relief & Off \\
\hline \multicolumn{2}{|r|}{ Rotordynamics Controls } \\
\hline Coriolis Effect & Off \\
\hline \multicolumn{2}{|r|}{ Restart Controls } \\
\hline Generate Restart Points & Program Controlled \\
\hline $\begin{array}{r}\text { Retain Files After Full } \\
\text { Solve }\end{array}$ & No \\
\hline Combine Restart Files & Program Controlled \\
\hline \multicolumn{2}{|r|}{ Nonlinear Controls } \\
\hline $\begin{array}{r}\text { Newton-Raphson } \\
\text { Option }\end{array}$ & Program Controlled \\
\hline Force Convergence & Program Controlled \\
\hline Moment Convergence & Program Controlled \\
\hline $\begin{array}{l}\text { Displacement } \\
\text { Convergence }\end{array}$ & Program Controlled \\
\hline Rotation Convergence & Program Controlled \\
\hline Line Search & Program Controlled \\
\hline Stabilization & Program Controlled \\
\hline \multicolumn{2}{|r|}{ Output Controls } \\
\hline Stress & Yes \\
\hline Surface Stress & No \\
\hline Back Stress & No \\
\hline Strain & Yes \\
\hline Contact Data & Yes \\
\hline Nonlinear Data & No \\
\hline Nodal Forces & No \\
\hline Contact Miscellaneous & No \\
\hline General Miscellaneous & No \\
\hline Store Results At & All Time Points \\
\hline $\begin{array}{r}\text { Result File } \\
\text { Compression }\end{array}$ & Program Controlled \\
\hline \multicolumn{2}{|r|}{ Analysis Data Management } \\
\hline Solver Files Directory & 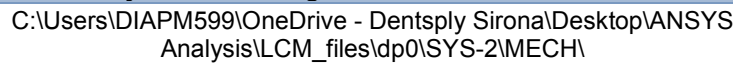 \\
\hline Future Analysis & None \\
\hline \multicolumn{2}{|l|}{$\begin{array}{r}\text { Scratch Solver Files } \\
\text { Directory }\end{array}$} \\
\hline Save MAPDL db & No \\
\hline Contact Summary & Program Controlled \\
\hline Delete Unneeded Files & Yes \\
\hline
\end{tabular}




\begin{tabular}{|r|c|}
\hline Nonlinear Solution & No \\
\hline Solver Units & Active System \\
\hline Solver Unit System & $\mathrm{nmm}$ \\
\hline
\end{tabular}

FIGURE 3

Model (E4) > Static Structural (E5) > Figure

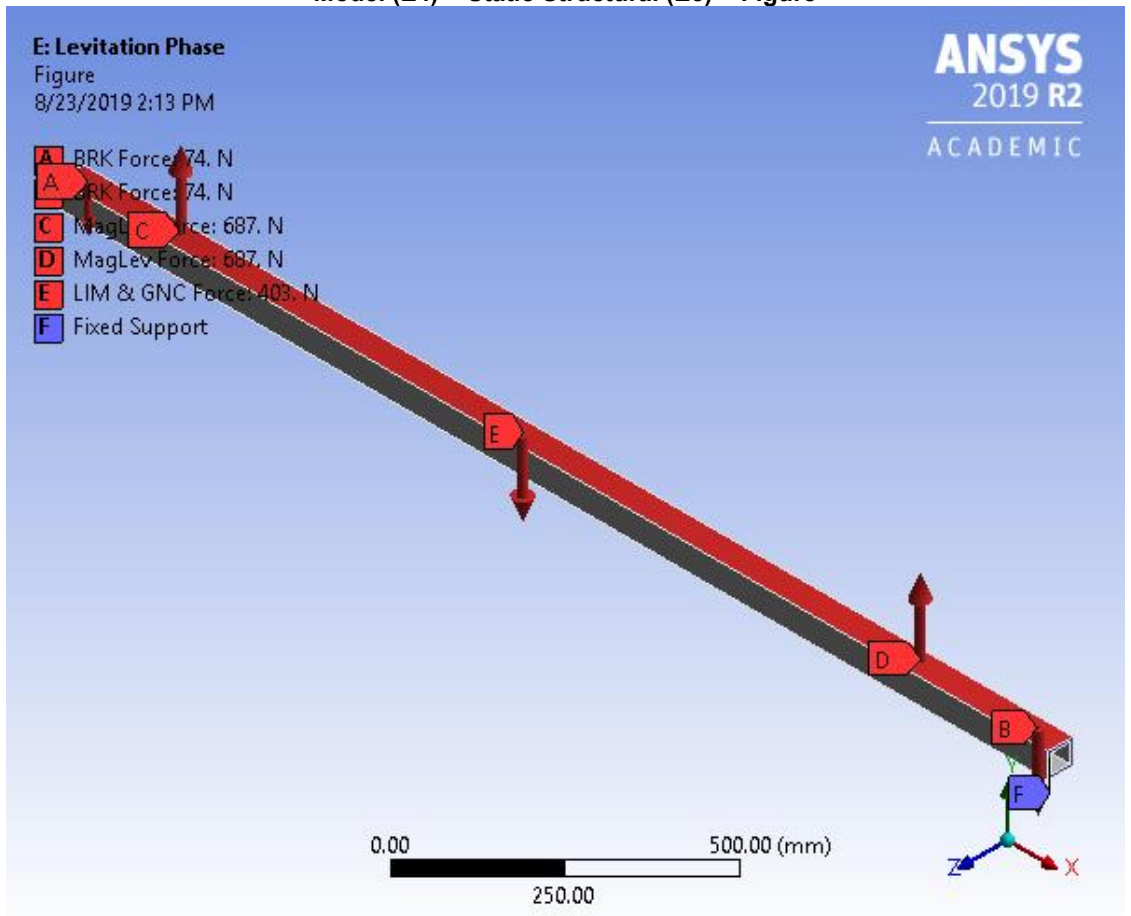

TABLE 10

Model (E4) $>$ Static Structural (E5) $>$ Loads

\begin{tabular}{|c|c|c|c|c|c|c|c|}
\hline \\
\hline Object Name & $\begin{array}{l}\text { Thermal } \\
\text { Condition }\end{array}$ & $\begin{array}{l}\text { BRK } \\
\text { Force }\end{array}$ & $\begin{array}{l}\text { BRK } \\
\text { Force }\end{array}$ & $\begin{array}{c}\text { MagLev } \\
\text { Force }\end{array}$ & $\begin{array}{l}\text { MagLev } \\
\text { Force }\end{array}$ & $\begin{array}{l}\text { LIM \& GNC } \\
\text { Force }\end{array}$ & $\begin{array}{l}\text { Fixed } \\
\text { Support }\end{array}$ \\
\hline State & \multicolumn{7}{|c|}{ Fully Defined } \\
\hline \multicolumn{8}{|c|}{ Scope } \\
\hline $\begin{array}{l}\text { Scoping } \\
\text { Method }\end{array}$ & \multicolumn{7}{|c|}{ Geometry Selection } \\
\hline Geometry & 1 Body & \multicolumn{5}{|c|}{1 Face } & 2 Faces \\
\hline \multicolumn{8}{|c|}{ Definition } \\
\hline Type & $\begin{array}{l}\text { Thermal } \\
\text { Condition }\end{array}$ & \multicolumn{5}{|c|}{ Force } & $\begin{array}{l}\text { Fixed } \\
\text { Support }\end{array}$ \\
\hline Magnitude & $\begin{array}{l}\text { 80. }{ }^{\circ} \mathrm{C} \\
\text { (ramped) }\end{array}$ & & & & & & \\
\hline
\end{tabular}




\begin{tabular}{|c|c|c|c|}
\hline Suppressed & \multicolumn{3}{|c|}{ No } \\
\hline Define By & \multicolumn{3}{|c|}{ Components } \\
\hline $\begin{array}{r}\text { Coordinate } \\
\text { System }\end{array}$ & \multicolumn{3}{|c|}{ Global Coordinate System } \\
\hline X Component & \multicolumn{3}{|c|}{ 0. N (ramped) } \\
\hline Y Component & -74. N (ramped) & 687. N (ramped) & $\begin{array}{l}-403 . \mathrm{N} \\
\text { (ramped) }\end{array}$ \\
\hline Z Component & \multicolumn{3}{|c|}{ 0. N (ramped) } \\
\hline
\end{tabular}

FIGURE 4

Model (E4) $>$ Static Structural (E5) $>$ Thermal Condition

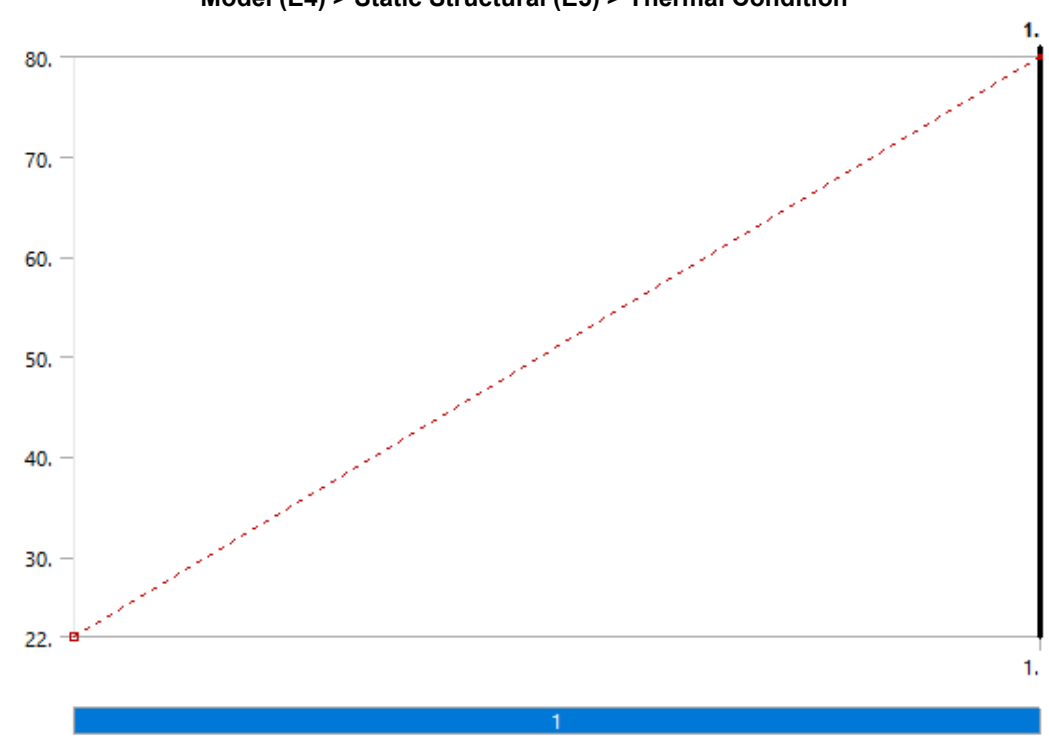

FIGURE 5

Model (E4) > Static Structural (E5) > BRK Force 


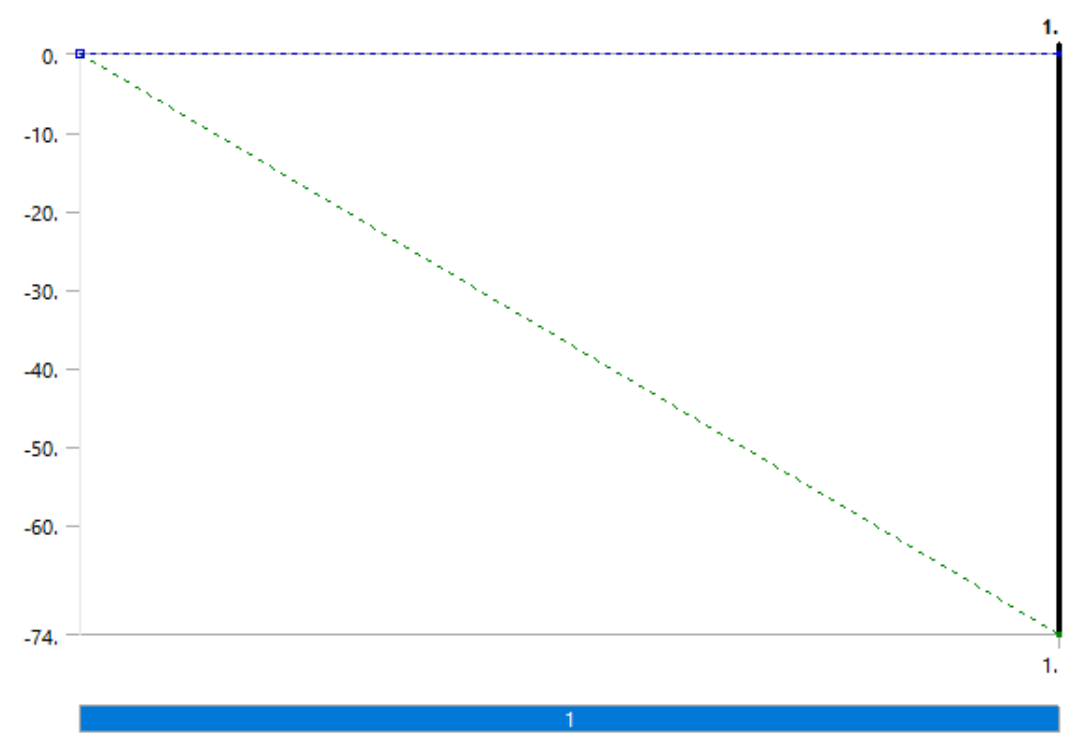

FIGURE 6

Model $($ E4) $>$ Static Structural $($ E5) $>$ BRK Force

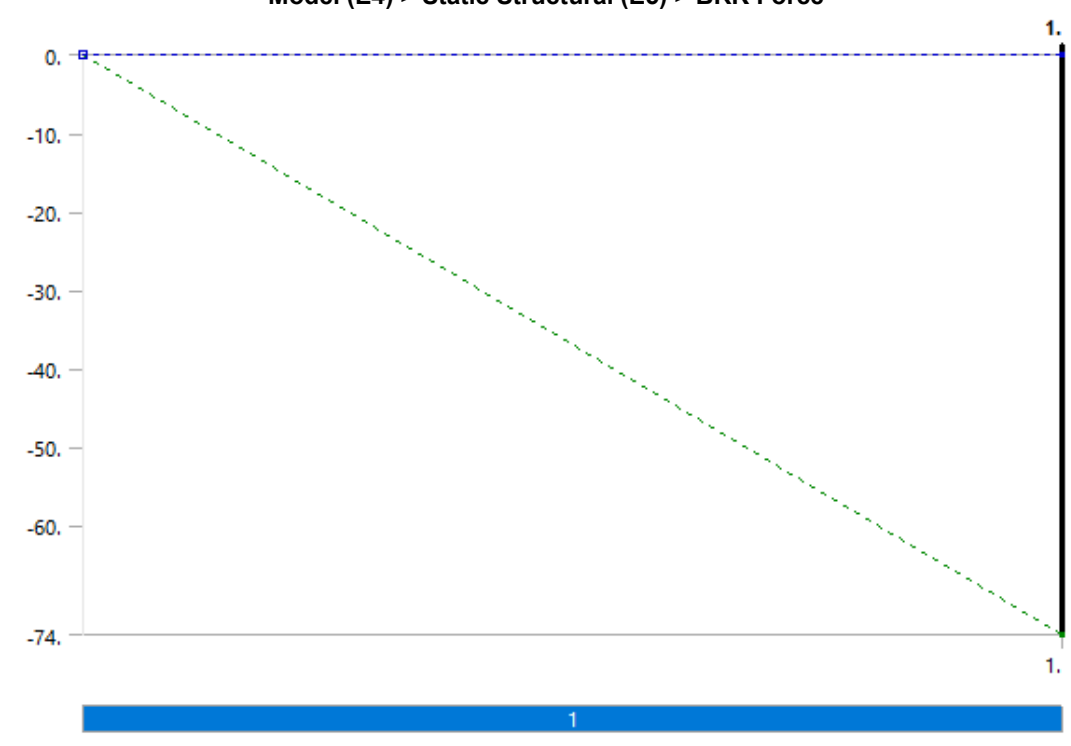


FIGURE 7

Model $(E 4)>$ Static Structural $(E 5)>$ MagLev Force

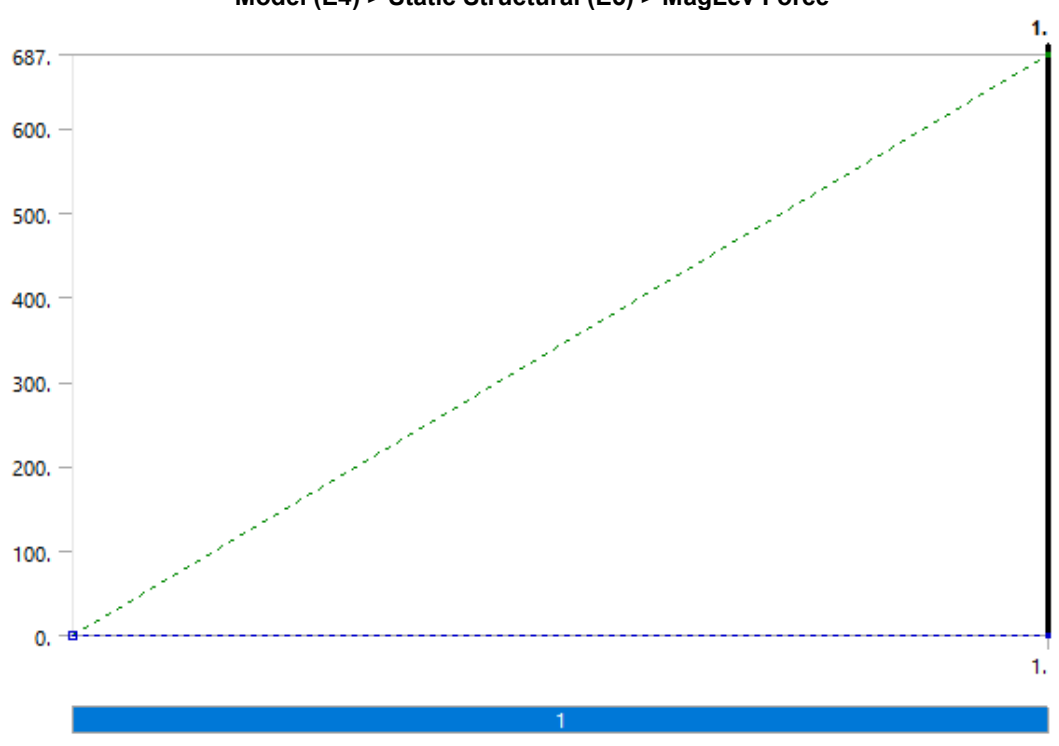

FIGURE 8

Model (E4) > Static Structural (E5) > MagLev Force 


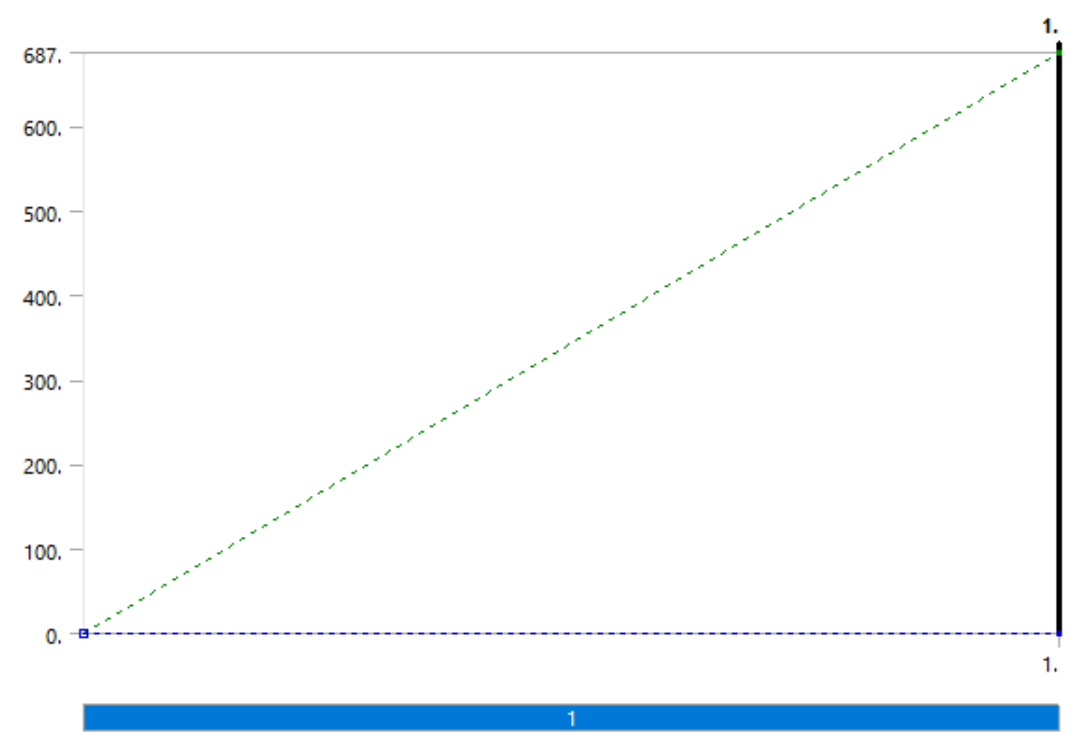

FIGURE 9

Model (E4) > Static Structural (E5) > LIM \& GNC Force

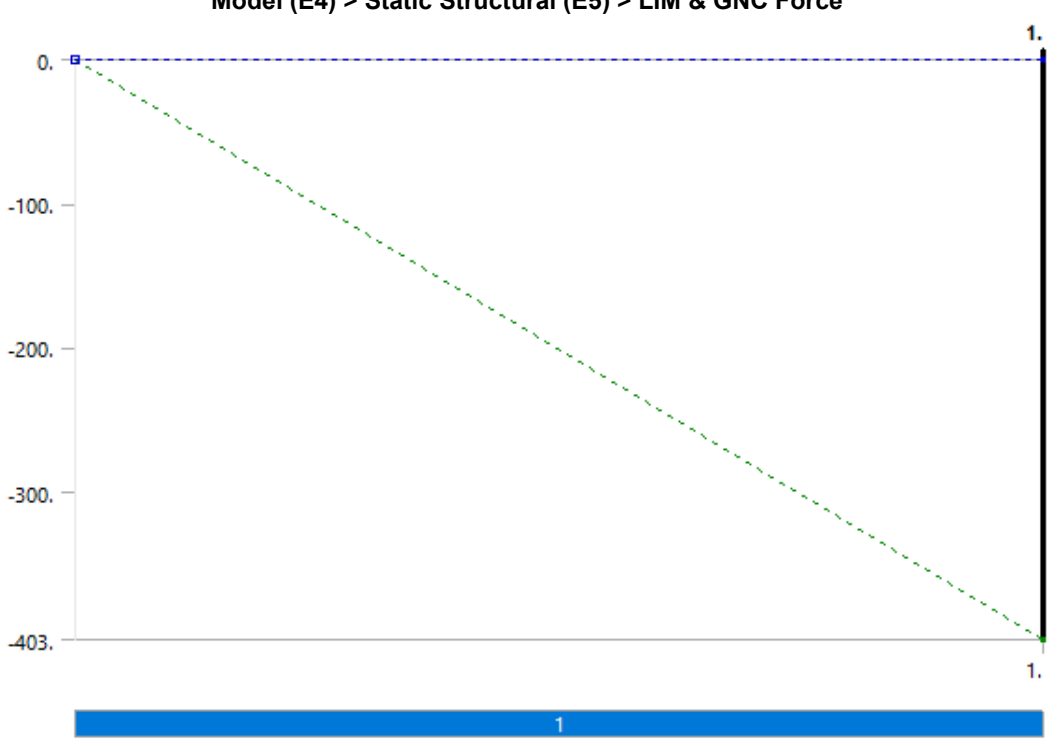


TABLE 11

Model (E4) $>$ Static Structural (E5) $>$ Solution Object Name Solution (E6) State Solved

\begin{tabular}{|c|c|}
\hline State & Solved \\
\hline \multicolumn{2}{|c|}{ Adaptive Mesh Refinement } \\
\hline Max Refinement Loops & 1. \\
\hline Refinement Depth & 2. \\
\hline \multicolumn{2}{|l|}{ Information } \\
\hline Status & Done \\
\hline MAPDL Elapsed Time & 2. $s$ \\
\hline MAPDL Memory Used & 266. MB \\
\hline MAPDL Result File Size & $1.1875 \mathrm{MB}$ \\
\hline \multicolumn{2}{|c|}{ Post Processing } \\
\hline Beam Section Results & No \\
\hline On Demand Stress/Strain & No \\
\hline
\end{tabular}

TABLE 12

Model (E4) $>$ Static Structural (E5) $>$ Solution (E6) $>$ Solution Information

\begin{tabular}{|c|c|}
\hline \\
\hline Object Name & Solution Information \\
\hline State & Solved \\
\hline \multicolumn{2}{|c|}{ Solution Information } \\
\hline Solution Output & Solver Output \\
\hline Newton-Raphson Residuals & 0 \\
\hline Identify Element Violations & 0 \\
\hline Update Interval & $2.5 \mathrm{~s}$ \\
\hline Display Points & All \\
\hline \multicolumn{2}{|c|}{ FE Connection Visibility } \\
\hline Activate Visibility & Yes \\
\hline Display & All FE Connectors \\
\hline Draw Connections Attached To & All Nodes \\
\hline Line Color & Connection Type \\
\hline Visible on Results & No \\
\hline Line Thickness & Single \\
\hline Display Type & Lines \\
\hline
\end{tabular}

TABLE 13

Model (E4) > Static Structural (E5) $>$ Solution (E6) $>$ Results

\begin{tabular}{|c|c|c|}
\hline \multirow{2}{*}{\multicolumn{3}{|c|}{ Object Name Total Deformation }} \\
\hline & & \\
\hline State & & Solved \\
\hline \multicolumn{3}{|c|}{ Scope } \\
\hline Scoping Method & \multicolumn{2}{|c|}{ Geometry Selection } \\
\hline Geometry & \multicolumn{2}{|r|}{ All Bodies } \\
\hline \multicolumn{3}{|c|}{ Definition } \\
\hline Type & Total Deformation & Equivalent (von-Mises) Stress \\
\hline By & & Time \\
\hline Display Time & & Last \\
\hline Calculate Time History & & Yes \\
\hline
\end{tabular}




\begin{tabular}{|c|c|c|}
\hline \multicolumn{3}{|l|}{ Identifier } \\
\hline Suppressed & & No \\
\hline \multicolumn{3}{|c|}{ Results } \\
\hline Minimum & $0 . \mathrm{mm}$ & $34.165 \mathrm{MPa}$ \\
\hline Maximum & $0.68558 \mathrm{~mm}$ & $165.09 \mathrm{MPa}$ \\
\hline Average & $0.33298 \mathrm{~mm}$ & $95.935 \mathrm{MPa}$ \\
\hline Minimum Occurs On & \multicolumn{2}{|c|}{ GeomIPartBody } \\
\hline Maximum Occurs On & \multicolumn{2}{|c|}{ Geom\PartBody } \\
\hline \multicolumn{3}{|c|}{ Information } \\
\hline Time & \multicolumn{2}{|r|}{ 1. $s$} \\
\hline Load Step & \multicolumn{2}{|r|}{1} \\
\hline Substep & \multicolumn{2}{|r|}{1} \\
\hline Iteration Number & \multicolumn{2}{|r|}{1} \\
\hline \multicolumn{3}{|c|}{ Integration Point Results } \\
\hline Display Option & & Averaged \\
\hline Average Across Bodies & & No \\
\hline
\end{tabular}

FIGURE 10

Model $(E 4)>$ Static Structural $(E 5)>$ Solution $(E 6)>$ Total Deformation

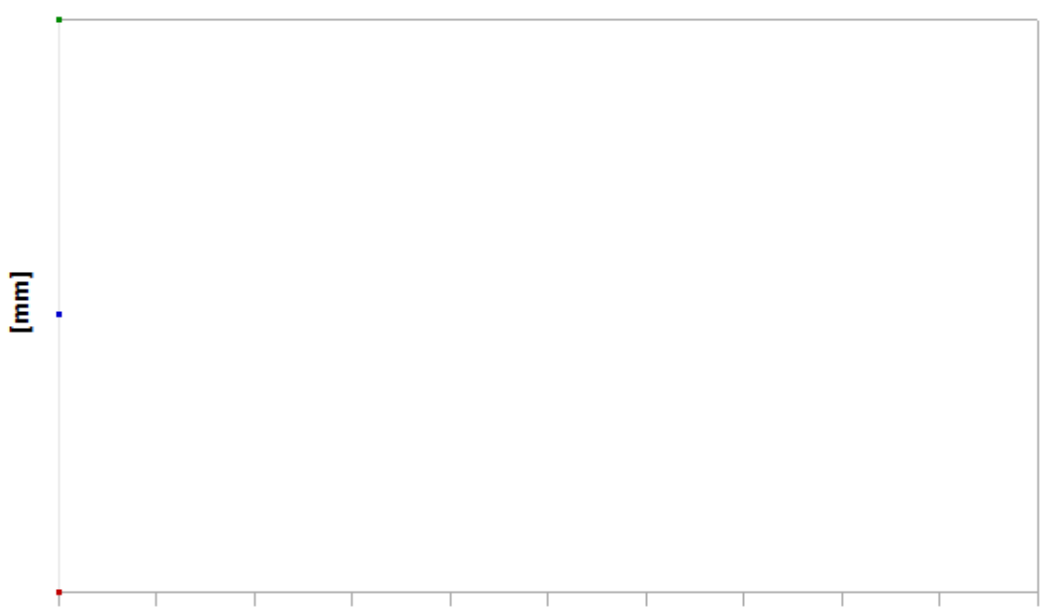

[s]

TABLE 14

Model (E4) $>$ Static Structural $(E 5)>$ Solution (E6) $>$ Total Deformation

Time [s] Minimum [mm] Maximum [mm] Average [mm]

1.

0 .

0.68558

0.33298 
FIGURE 11

Model $($ E4) $>$ Static Structural $(E 5)>$ Solution (E6) $>$ Total Deformation $>$ Figure

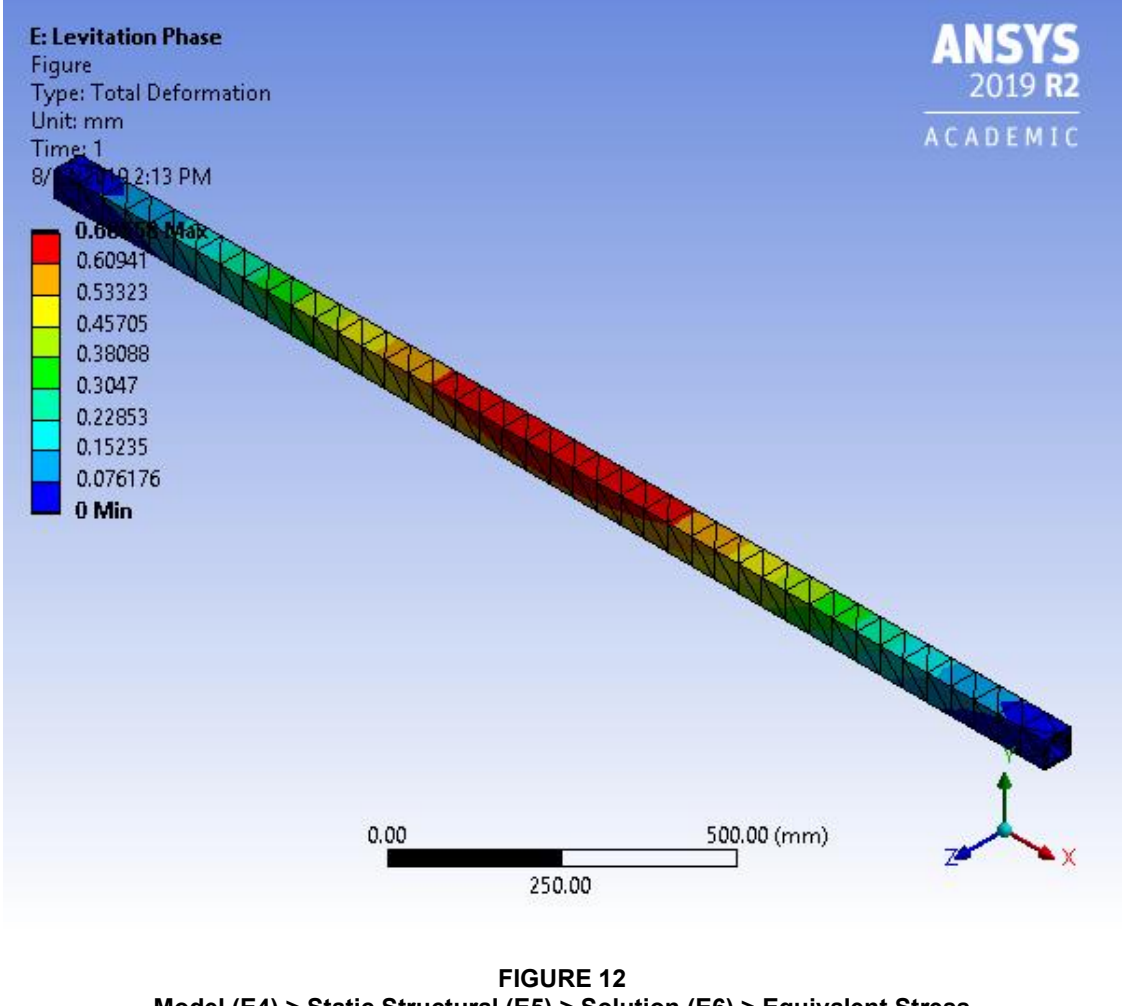

Model (E4) > Static Structural (E5) > Solution (E6) > Equivalent Stress 


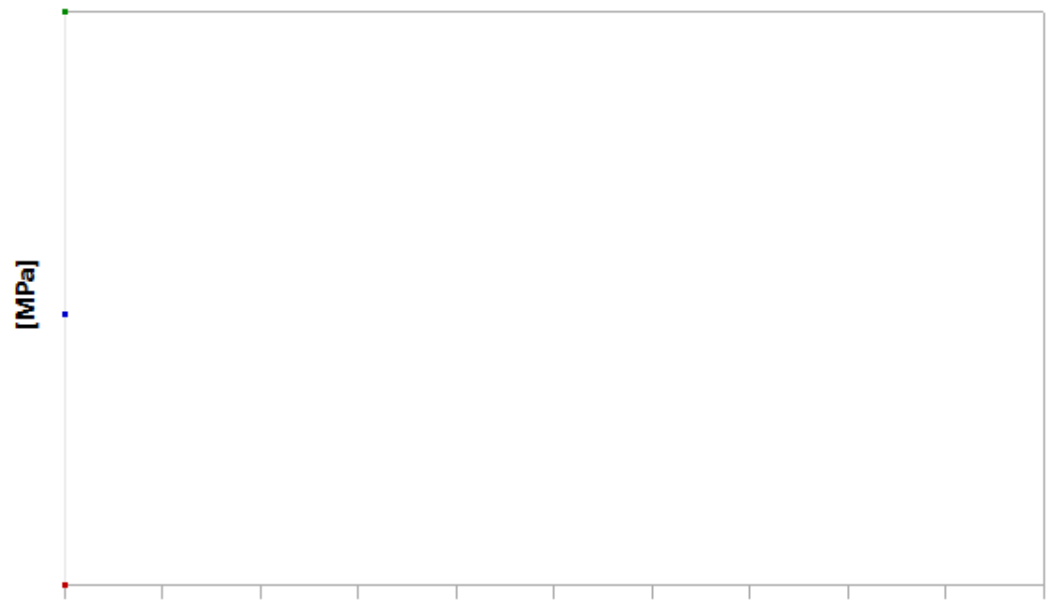

[s]

TABLE 15

Model $($ E4) $>$ Static Structural $(E 5)>$ Solution (E6) $>$ Equivalent Stress

Time [s] Minimum [MPa] Maximum [MPa] Average [MPa]

\begin{tabular}{l|l|l|l}
\hline 1. & 34.165 & 165.09 & 95.935
\end{tabular}

FIGURE 13

Model $(E 4)>$ Static Structural $(E 5)>$ Solution $(E 6)>$ Equivalent Stress $>$ Figure 


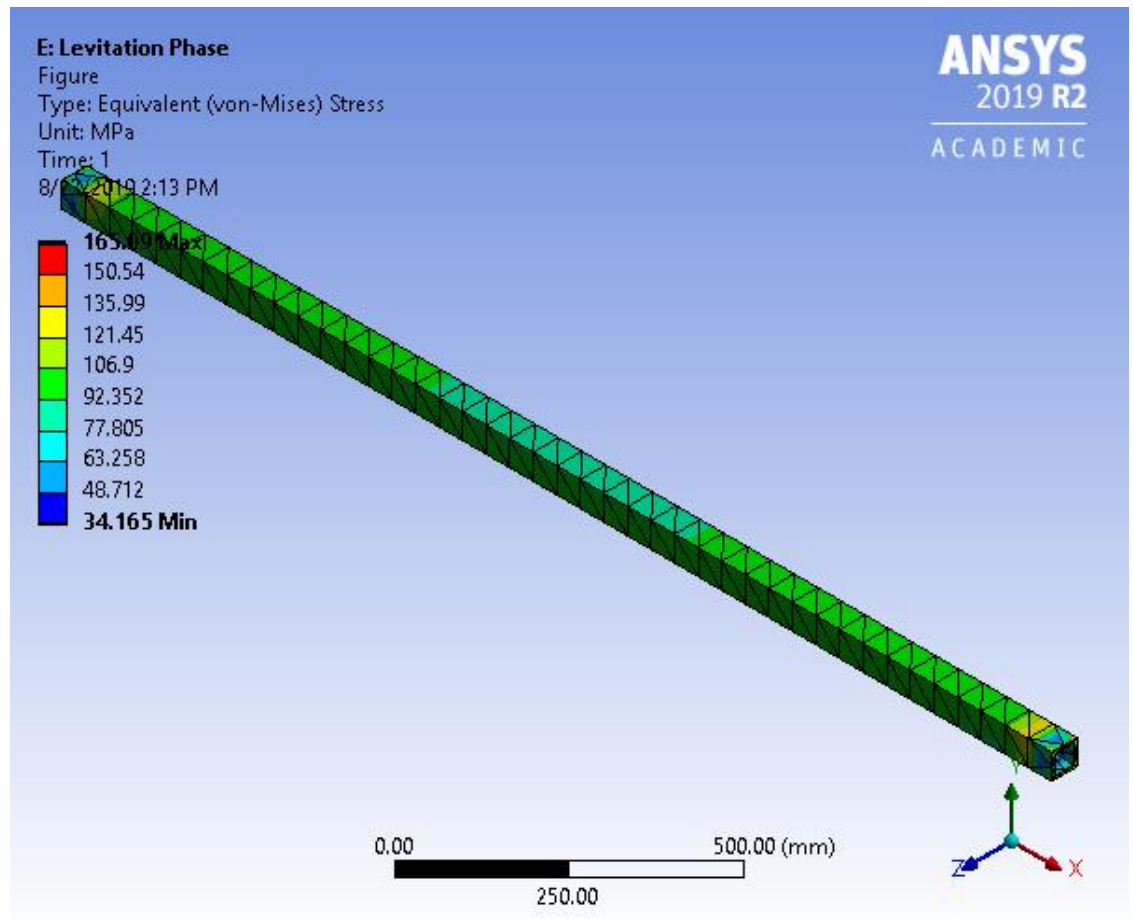

\section{Material Data}

\section{Aluminum Alloy}

TABLE 16

Aluminum Alloy $>$ Constants

\begin{tabular}{|c|c|c|}
\hline \multicolumn{2}{|r|}{ Density } & $2.77 \mathrm{e}-006 \mathrm{~kg} \mathrm{~mm} \wedge-3$ \\
\hline \multicolumn{2}{|c|}{ Coefficient of Thermal Expansion } & $2.3 e-005 C^{\wedge}-1$ \\
\hline \multicolumn{2}{|c|}{ Specific Heat } & $8.75 e+005 m J k g^{\wedge}-1 C^{\wedge}-1$ \\
\hline \multicolumn{3}{|c|}{$\begin{array}{c}\text { TABLE } 17 \\
\text { Aluminum Alloy }>\text { Color }\end{array}$} \\
\hline Red & Green & Blue \\
\hline 138 & 104 & 46 \\
\hline
\end{tabular}

TABLE 18

Aluminum Alloy $>$ Compressive Ultimate Strength

Compressive Ultimate Strength $\mathrm{MPa}$ 
TABLE 19

Aluminum Alloy $>$ Compressive Yield Strength

Compressive Yield Strength $\mathrm{MPa}$

280

TABLE 20

Aluminum Alloy $>$ Tensile Yield Strength

Tensile Yield Strength MPa

280

TABLE 21

Aluminum Alloy $>$ Tensile Ultimate Strength

Tensile Ultimate Strength $\mathrm{MPa}$

310

TABLE 22

Aluminum Alloy $>$ Isotropic Secant Coefficient of Thermal Expansion

Zero-Thermal-Strain Reference Temperature C

22

TABLE 23

Aluminum Alloy $>$ Isotropic Thermal Conductivity Thermal Conductivity $\mathrm{W} \mathrm{mm}^{\wedge}-1 \mathrm{C}^{\wedge}-1$ Temperature $\mathrm{C}$

\begin{tabular}{|c|c|}
\hline 0.114 & -100 \\
\hline 0.144 & 0 \\
\hline 0.165 & 100 \\
\hline 0.175 & 200 \\
\hline
\end{tabular}

TABLE 24

Aluminum Alloy $>$ S-N Curve

Alternating Stress MPa Cycles R-Ratio

\begin{tabular}{|c|c|c|}
\hline 275.8 & 1700 & -1 \\
\hline 241.3 & 5000 & -1 \\
\hline 206.8 & 34000 & -1 \\
\hline 172.4 & $1.4 \mathrm{e}+005$ & -1 \\
\hline 137.9 & $8 . \mathrm{e}+005$ & -1 \\
\hline 117.2 & $2.4 \mathrm{e}+006$ & -1 \\
\hline 89.63 & $5.5 \mathrm{e}+007$ & -1 \\
\hline 82.74 & $1 . \mathrm{e}+008$ & -1 \\
\hline 170.6 & 50000 & -0.5 \\
\hline 139.6 & $3.5 \mathrm{e}+005$ & -0.5 \\
\hline 108.6 & $3.7 \mathrm{e}+006$ & -0.5 \\
\hline 87.91 & $1.4 \mathrm{e}+007$ & -0.5 \\
\hline 77.57 & $5 . \mathrm{e}+007$ & -0.5 \\
\hline 72.39 & $1 . \mathrm{e}+008$ & -0.5 \\
\hline 144.8 & 50000 & 0 \\
\hline 120.7 & $1.9 \mathrm{e}+005$ & 0 \\
\hline 103.4 & $1.3 \mathrm{e}+006$ & 0 \\
\hline 93.08 & $4.4 \mathrm{e}+006$ & 0 \\
\hline & & \\
\hline
\end{tabular}




\begin{tabular}{|c|c|c|}
\hline 86.18 & $1.2 \mathrm{e}+007$ & 0 \\
\hline 72.39 & $1 . \mathrm{e}+008$ & 0 \\
\hline 74.12 & $3 . \mathrm{e}+005$ & 0.5 \\
\hline 70.67 & $1.5 \mathrm{e}+006$ & 0.5 \\
\hline 66.36 & $1.2 \mathrm{e}+007$ & 0.5 \\
\hline 62.05 & $1 . \mathrm{e}+008$ & 0.5 \\
\hline
\end{tabular}

TABLE 25

Aluminum Alloy > Isotropic Resistivity Resistivity ohm $\mathrm{mm}$ Temperature C

\begin{tabular}{|c|c|}
\hline $2.43 e-005$ & 0 \\
\hline $2.67 e-005$ & 20 \\
\hline $3.63 e-005$ & 100 \\
\hline
\end{tabular}

TABLE 26

Aluminum Alloy $>$ Isotropic Elasticity

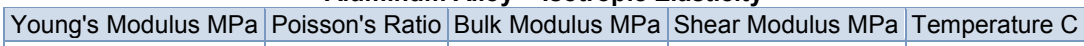

71000

0.33

69608

26692

TABLE 27

Aluminum Alloy > Isotropic Relative Permeability

Relative Permeability 
Appendix A.8 LCM Load Case IV (Braking Phase) Analysis Report 


\section{MNSYS}

\section{Project}

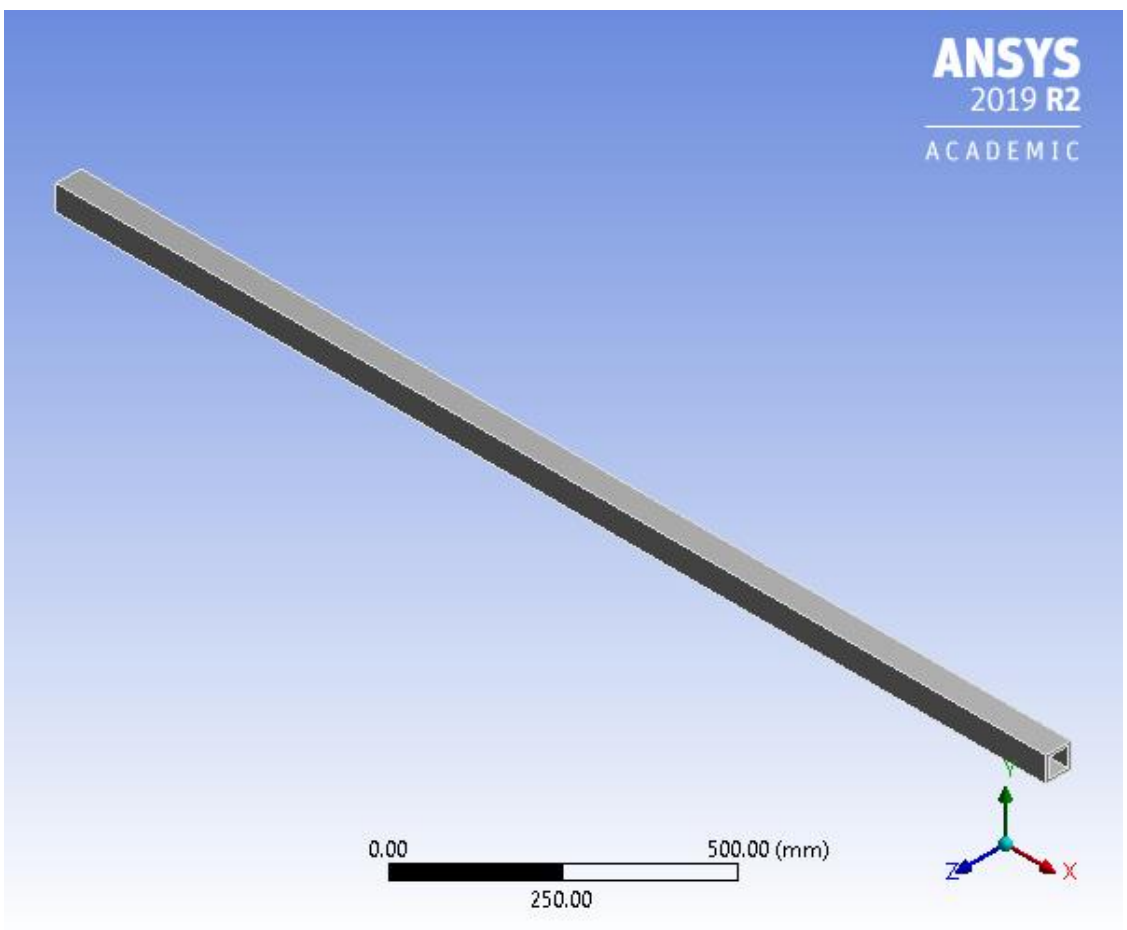




\section{Contents}

- Units

- Model (F4)

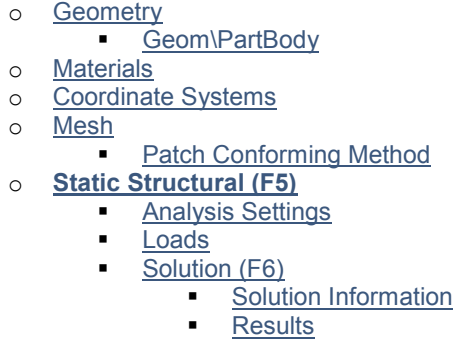

- Material Data

- Aluminum Alloy

\section{Units}

TABLE 1

\begin{tabular}{|r|c|}
\hline Unit System & Metric $(\mathrm{mm}, \mathrm{kg}, \mathrm{N}, \mathrm{s}, \mathrm{mV}, \mathrm{mA})$ Degrees rad/s Celsius \\
\hline Angle & Degrees \\
\hline Rotational Velocity & rad/s \\
\hline Temperature & Celsius \\
\hline
\end{tabular}

\section{Model (F4)}

\section{Geometry}

TABLE 2

Model (F4) > Geometry

\begin{tabular}{|c|c|}
\hline \\
\hline Object Name & Geometry \\
\hline State & Fully Defined \\
\hline \multicolumn{2}{|r|}{ Definition } \\
\hline Source & $\begin{array}{c}\text { C:IUsersIDIAPM5991OneDrive - Dentsply SironalDesktop\ANSYS } \\
\text { Analysis।LCM_filesIdp0IGeomIDMIGeom.scdoc }\end{array}$ \\
\hline Type & SpaceClaim \\
\hline Length Unit & Meters \\
\hline Element Control & Program Controlled \\
\hline Display Style & Body Color \\
\hline \multicolumn{2}{|r|}{ Bounding Box } \\
\hline Length $\mathrm{X}$ & 2000. $\mathrm{mm}$ \\
\hline Length $\mathrm{Y}$ & $50.8 \mathrm{~mm}$ \\
\hline Length Z & $50.8 \mathrm{~mm}$ \\
\hline
\end{tabular}




\begin{tabular}{|c|c|}
\hline \multicolumn{2}{|c|}{ Properties } \\
\hline Volume & $2.2581 \mathrm{e}+006 \mathrm{~mm}^{3}$ \\
\hline Mass & $6.2548 \mathrm{~kg}$ \\
\hline Scale Factor Value & 1. \\
\hline \multicolumn{2}{|c|}{ Statistics } \\
\hline Bodies & 1 \\
\hline Active Bodies & 1 \\
\hline Nodes & 2261 \\
\hline Elements & 1143 \\
\hline Mesh Metric & None \\
\hline \multicolumn{2}{|c|}{ Update Options } \\
\hline Assign Default Material & No \\
\hline \multicolumn{2}{|c|}{ Basic Geometry Options } \\
\hline Solid Bodies & Yes \\
\hline Surface Bodies & Yes \\
\hline Line Bodies & Yes \\
\hline Parameters & Independent \\
\hline \multicolumn{2}{|l|}{ Parameter Key } \\
\hline Attributes & Yes \\
\hline \multicolumn{2}{|l|}{ Attribute Key } \\
\hline Named Selections & Yes \\
\hline \multicolumn{2}{|l|}{ Named Selection Key } \\
\hline Material Properties & Yes \\
\hline \multicolumn{2}{|c|}{ Advanced Geometry Options } \\
\hline Use Associativity & Yes \\
\hline Coordinate Systems & Yes \\
\hline \multicolumn{2}{|l|}{ Coordinate System Key } \\
\hline $\begin{array}{r}\text { Reader Mode Saves } \\
\text { Updated File }\end{array}$ & No \\
\hline Use Instances & Yes \\
\hline Smart CAD Update & Yes \\
\hline $\begin{array}{r}\text { Compare Parts On } \\
\text { Update }\end{array}$ & No \\
\hline Analysis Type & 3-D \\
\hline $\begin{array}{r}\text { Mixed Import } \\
\text { Resolution }\end{array}$ & None \\
\hline Clean Bodies On Import & No \\
\hline $\begin{array}{r}\text { Stitch Surfaces On } \\
\text { Import }\end{array}$ & None \\
\hline $\begin{array}{r}\text { Decompose Disjoint } \\
\text { Geometry }\end{array}$ & Yes \\
\hline $\begin{array}{r}\text { Enclosure and } \\
\text { Symmetry Processing }\end{array}$ & Yes \\
\hline
\end{tabular}

TABLE 3

Model (F4) $>$ Geometry $>$ Parts

Object Name GeomlPartBody

State Meshed

Graphics Properties 


\begin{tabular}{|c|c|}
\hline Visible & Yes \\
\hline Transparency & 1 \\
\hline \multicolumn{2}{|c|}{ Definition } \\
\hline Suppressed & No \\
\hline Stiffness Behavior & Flexible \\
\hline Coordinate System & Default Coordinate System \\
\hline Reference Temperature & By Environment \\
\hline Treatment & None \\
\hline \multicolumn{2}{|c|}{ Material } \\
\hline Assignment & Aluminum Alloy \\
\hline Nonlinear Effects & Yes \\
\hline Thermal Strain Effects & Yes \\
\hline \multicolumn{2}{|c|}{ Bounding Box } \\
\hline Length $\mathrm{X}$ & 2000. $\mathrm{mm}$ \\
\hline Length $Y$ & $50.8 \mathrm{~mm}$ \\
\hline Length Z & $50.8 \mathrm{~mm}$ \\
\hline \multicolumn{2}{|c|}{ Properties } \\
\hline Volume & $2.2581 \mathrm{e}+006 \mathrm{~mm}^{3}$ \\
\hline Mass & $6.2548 \mathrm{~kg}$ \\
\hline Centroid X & $-1000 . \mathrm{mm}$ \\
\hline Centroid $Y$ & $25.4 \mathrm{~mm}$ \\
\hline Centroid Z & $25.4 \mathrm{~mm}$ \\
\hline Moment of Inertia Ip1 & $4203.5 \mathrm{~kg} \cdot \mathrm{mm}^{2}$ \\
\hline Moment of Inertia Ip2 & $2.087 \mathrm{e}+006 \mathrm{~kg} \cdot \mathrm{mm}^{2}$ \\
\hline Moment of Inertia Ip3 & $2.087 \mathrm{e}+006 \mathrm{~kg} \cdot \mathrm{mm}^{2}$ \\
\hline \multicolumn{2}{|c|}{ Statistics } \\
\hline Nodes & 2261 \\
\hline Elements & 1143 \\
\hline Mesh Metric & None \\
\hline \multicolumn{2}{|c|}{ CAD Attributes } \\
\hline PartTolerance: & 0.00000001 \\
\hline Color:175.143.175 & \\
\hline
\end{tabular}

FIGURE 1

Model (F4) $>$ Geometry $>$ Geom $>$ PartBody $>$ Figure 


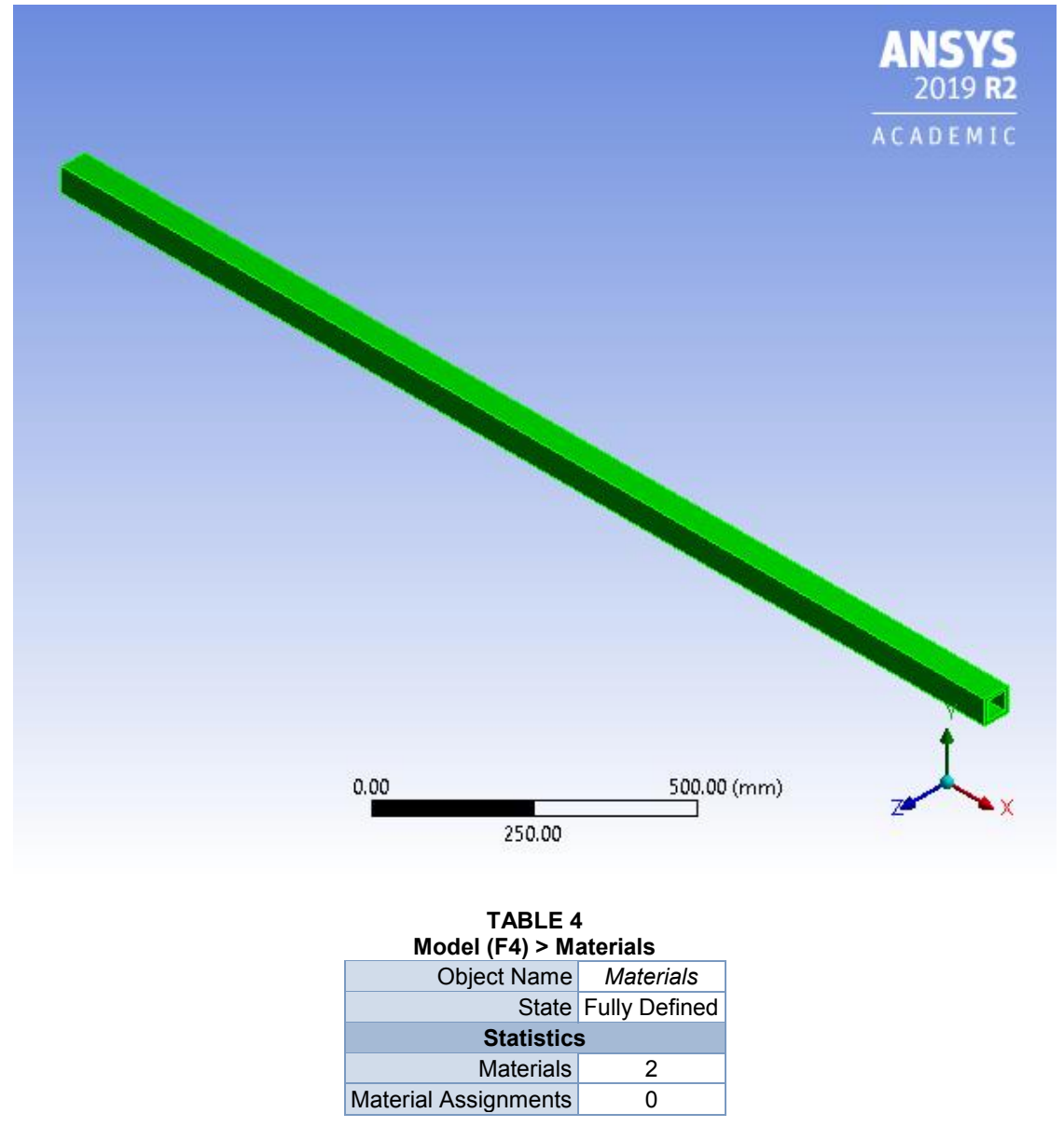

\section{Coordinate Systems}

TABLE 5

Model $($ F4) $>$ Coordinate Systems > Coordinate System

\begin{tabular}{|r|c|}
\hline $\begin{array}{r}\text { Object Name } \\
\text { State }\end{array}$ & Global Coordinate System \\
Definition \\
\hline Type & Cally Defined \\
\hline Coordinate System ID & 0. \\
\hline \multicolumn{2}{|c|}{ Origin } \\
\hline Origin X & $0 . \mathrm{mm}$ \\
\hline
\end{tabular}




\begin{tabular}{|r|r|}
\hline Origin $Y$ & $0 . \mathrm{mm}$ \\
\hline Origin Z & $0 . \mathrm{mm}$ \\
\hline \multicolumn{2}{|c|}{ Directional Vectors } \\
\hline X Axis Data & {$[1.0 .0]$.} \\
\hline Y Axis Data & {$[0.1 .0]$.} \\
\hline Z Axis Data & {$[0.0 .1]$.} \\
\hline
\end{tabular}

Mesh

TABLE 6

Model (F4) > Mesh

Object Name

\begin{tabular}{|c|c|}
\hline \\
\hline Object Name & Mesh \\
\hline State & Solved \\
\hline \multicolumn{2}{|l|}{ Display } \\
\hline Display Style & Use Geometry Setting \\
\hline \multicolumn{2}{|l|}{ Defaults } \\
\hline Physics Preference & Mechanical \\
\hline Element Order & Program Controlled \\
\hline Element Size & Default \\
\hline \multicolumn{2}{|l|}{ Sizing } \\
\hline Use Adaptive Sizing & Yes \\
\hline Resolution & Default (2) \\
\hline Mesh Defeaturing & Yes \\
\hline Defeature Size & Default \\
\hline Transition & Fast \\
\hline Span Angle Center & Fine \\
\hline Initial Size Seed & Assembly \\
\hline Bounding Box Diagonal & $2001.3 \mathrm{~mm}$ \\
\hline Average Surface Area & $71346 \mathrm{~mm}^{2}$ \\
\hline Minimum Edge Length & $38.1 \mathrm{~mm}$ \\
\hline \multicolumn{2}{|l|}{ Quality } \\
\hline Check Mesh Quality & Yes, Errors \\
\hline Error Limits & Standard Mechanical \\
\hline Target Quality & Default $(0.050000)$ \\
\hline Smoothing & Medium \\
\hline Mesh Metric & None \\
\hline \multicolumn{2}{|l|}{ Inflation } \\
\hline Use Automatic Inflation & None \\
\hline Inflation Option & Smooth Transition \\
\hline Transition Ratio & 0.272 \\
\hline Maximum Layers & 5 \\
\hline Growth Rate & 1.2 \\
\hline Inflation Algorithm & Pre \\
\hline View Advanced Options & No \\
\hline \multicolumn{2}{|l|}{ Advanced } \\
\hline Number of CPUs for Parallel Part Meshing & Program Controlled \\
\hline Straight Sided Elements & No \\
\hline Rigid Body Behavior & Dimensionally Reduced \\
\hline
\end{tabular}




\begin{tabular}{|r|c|}
\hline Triangle Surface Mesher & Program Controlled \\
\hline Topology Checking & Yes \\
\hline Pinch Tolerance & Please Define \\
\hline Generate Pinch on Refresh & No \\
\hline Statistics & \\
\hline Nodes & 2261 \\
\hline Elements & 1143 \\
\hline
\end{tabular}

TABLE 7

Model (F4) $>$ Mesh $>$ Mesh Controls

Object Name Patch Conforming Method

State

Scope

Scoping Method Geometry Selection

\begin{tabular}{|r|c|}
\hline Geometry & 1 Dofinition \\
\hline Suppressed & No \\
\hline Method & Tetrahedrons \\
\hline Algorithm & Patch Conforming \\
\hline Element Order & Use Global Setting \\
\hline
\end{tabular}

FIGURE 2

Model (F4) $>$ Mesh $>$ Figure 


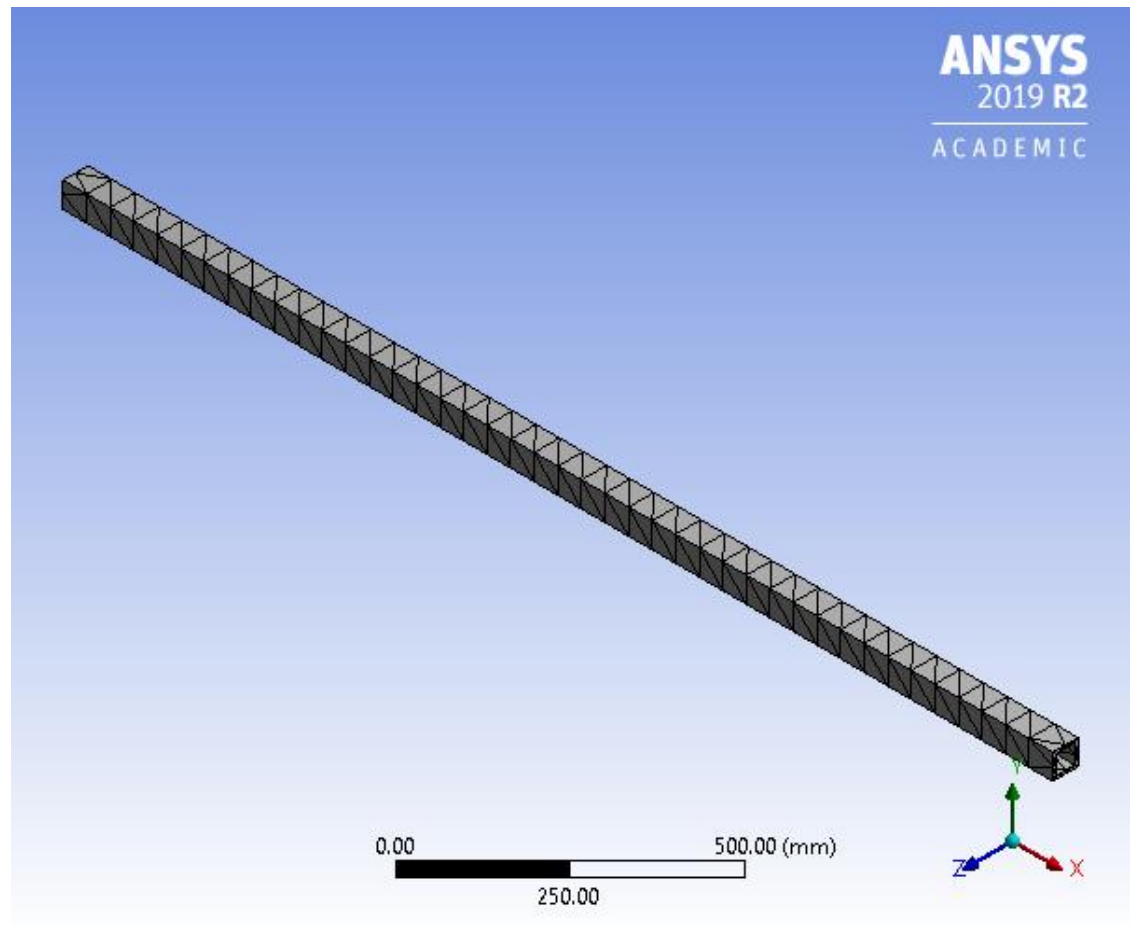

\section{Static Structural (F5)}

TABLE 8

Model (F4) > Analysis

\begin{tabular}{|r|c|}
\hline \multicolumn{2}{|c|}{ Model (F4) > Analysis } \\
\hline Object Name & Static Structural (F5) \\
\hline State & Solved \\
\hline Definition \\
\hline Physics Type & Structural \\
\hline Analysis Type & Static Structural \\
\hline Solver Target & Mechanical APDL \\
\hline Options \\
\hline Environment Temperature & $22 .{ }^{\circ} \mathrm{C}$ \\
\hline Generate Input Only & No \\
\hline
\end{tabular}

TABLE 9

Model (F4) > Static Structural (F5) > Analysis Settings

\begin{tabular}{|r|c|}
\hline Object Name & Analysis Settings \\
\hline State & Fully Defined \\
\hline & Step Controls \\
\hline
\end{tabular}




\begin{tabular}{|c|c|}
\hline Number Of Steps & 1. \\
\hline Current Step Number & 1. \\
\hline Step End Time & 1. $s$ \\
\hline Auto Time Stepping & Program Controlled \\
\hline \multicolumn{2}{|r|}{ Solver Controls } \\
\hline Solver Type & Program Controlled \\
\hline Weak Springs & Off \\
\hline Solver Pivot Checking & Program Controlled \\
\hline Large Deflection & Off \\
\hline Inertia Relief & Off \\
\hline \multicolumn{2}{|r|}{ Rotordynamics Controls } \\
\hline Coriolis Effect & Off \\
\hline \multicolumn{2}{|r|}{ Restart Controls } \\
\hline Generate Restart Points & Program Controlled \\
\hline $\begin{array}{r}\text { Retain Files After Full } \\
\text { Solve }\end{array}$ & No \\
\hline Combine Restart Files & Program Controlled \\
\hline \multicolumn{2}{|r|}{ Nonlinear Controls } \\
\hline $\begin{array}{r}\text { Newton-Raphson } \\
\text { Option }\end{array}$ & Program Controlled \\
\hline Force Convergence & Program Controlled \\
\hline Moment Convergence & Program Controlled \\
\hline $\begin{array}{l}\text { Displacement } \\
\text { Convergence }\end{array}$ & Program Controlled \\
\hline Rotation Convergence & Program Controlled \\
\hline Line Search & Program Controlled \\
\hline Stabilization & Program Controlled \\
\hline \multicolumn{2}{|r|}{ Output Controls } \\
\hline Stress & Yes \\
\hline Surface Stress & No \\
\hline Back Stress & No \\
\hline Strain & Yes \\
\hline Contact Data & Yes \\
\hline Nonlinear Data & No \\
\hline Nodal Forces & No \\
\hline Contact Miscellaneous & No \\
\hline General Miscellaneous & No \\
\hline Store Results At & All Time Points \\
\hline $\begin{array}{r}\text { Result File } \\
\text { Compression }\end{array}$ & Program Controlled \\
\hline \multicolumn{2}{|r|}{ Analysis Data Management } \\
\hline Solver Files Directory & 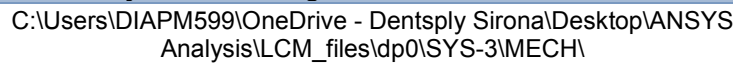 \\
\hline Future Analysis & None \\
\hline \multicolumn{2}{|l|}{$\begin{array}{r}\text { Scratch Solver Files } \\
\text { Directory }\end{array}$} \\
\hline Save MAPDL db & No \\
\hline Contact Summary & Program Controlled \\
\hline Delete Unneeded Files & Yes \\
\hline
\end{tabular}




\begin{tabular}{|r|c|}
\hline Nonlinear Solution & No \\
\hline Solver Units & Active System \\
\hline Solver Unit System & $\mathrm{nmm}$ \\
\hline
\end{tabular}

FIGURE 3

Model (F4) $>$ Static Structural (F5) $>$ Figure

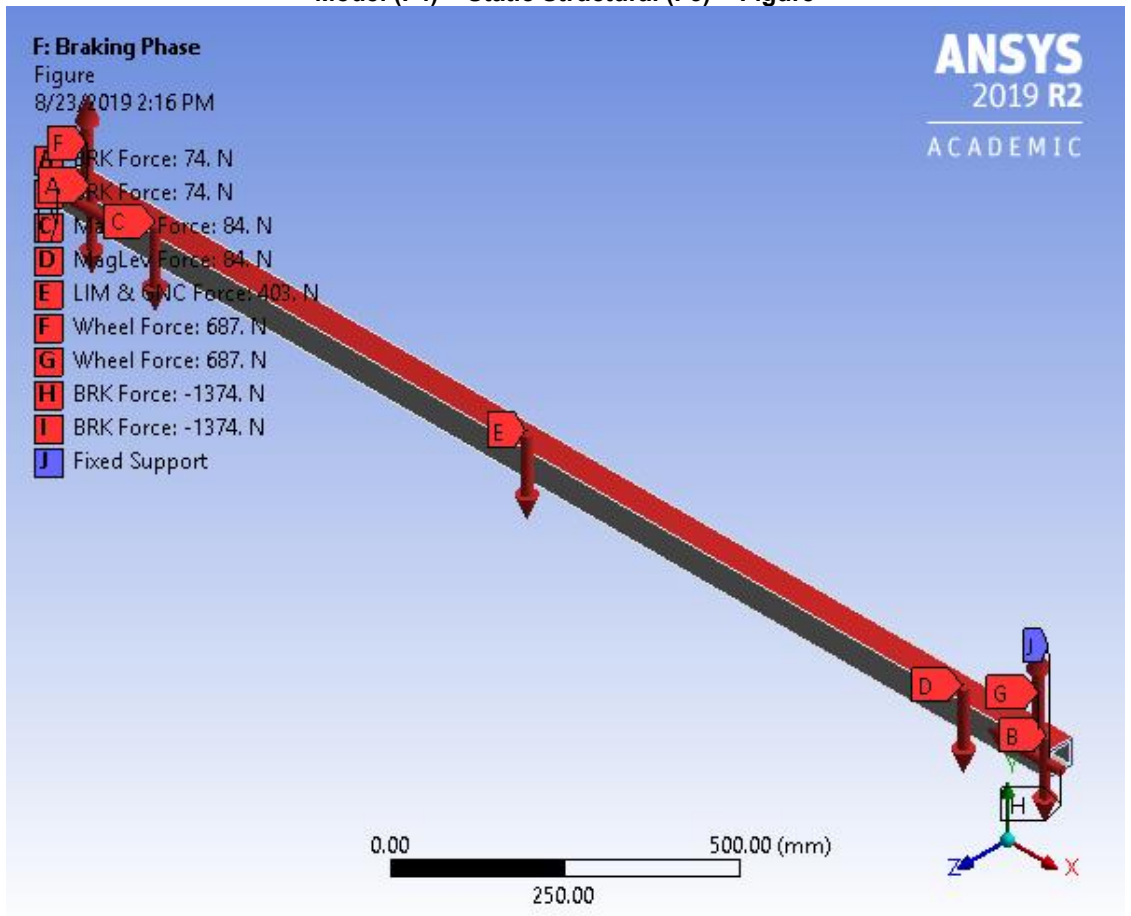

TABLE 10

Model (F4) $>$ Static Structural (F5) $>$ Loads

\begin{tabular}{|c|c|c|c|c|c|c|c|c|c|c|c|}
\hline $\begin{array}{l}\text { Object } \\
\text { Name }\end{array}$ & $\begin{array}{l}\text { Thermal } \\
\text { Condition }\end{array}$ & $\begin{array}{c}\text { BRK } \\
\text { Force }\end{array}$ & $\begin{array}{c}\text { BRK } \\
\text { Force }\end{array}$ & $\begin{array}{c}\text { MagLev } \\
\text { Force }\end{array}$ & $\begin{array}{c}\text { MagLev } \\
\text { Force }\end{array}$ & $\begin{array}{c}\text { LIM \& } \\
\text { GNC } \\
\text { Force }\end{array}$ & $\begin{array}{l}\text { Wheel } \\
\text { Force }\end{array}$ & $\begin{array}{l}\text { Wheel } \\
\text { Force }\end{array}$ & $\begin{array}{c}\text { BRK } \\
\text { Force }\end{array}$ & $\begin{array}{c}\text { BRK } \\
\text { Force }\end{array}$ & $\begin{array}{c}\text { Fixed } \\
\text { Support }\end{array}$ \\
\hline State & \multicolumn{11}{|c|}{ Fully Defined } \\
\hline \multicolumn{12}{|c|}{ Scope } \\
\hline $\begin{array}{l}\text { Scoping } \\
\text { Method }\end{array}$ & \multicolumn{11}{|c|}{ Geometry Selection } \\
\hline Geometry & 1 Body & \multicolumn{9}{|c|}{1 Face } & $\begin{array}{c}2 \\
\text { Faces }\end{array}$ \\
\hline \multicolumn{12}{|c|}{ Definition } \\
\hline Type & $\begin{array}{l}\text { Thermal } \\
\text { Condition }\end{array}$ & \multicolumn{9}{|c|}{ Force } & $\begin{array}{l}\text { Fixed } \\
\text { Support }\end{array}$ \\
\hline
\end{tabular}




\begin{tabular}{|c|c|c|c|c|c|c|}
\hline Magnitude & $\begin{array}{c}\text { 80. }{ }^{\circ} \mathrm{C} \\
\text { (ramped) }\end{array}$ & & & & & $\begin{array}{l}-1374 . \mathrm{N} \\
\text { (ramped) }\end{array}$ \\
\hline Suppressed & \multicolumn{6}{|c|}{ No } \\
\hline Define By & & \multicolumn{4}{|c|}{ Components } & Vector \\
\hline $\begin{array}{r}\text { Coordinate } \\
\text { System }\end{array}$ & & \multicolumn{4}{|c|}{ Global Coordinate System } & \\
\hline Component & & \multicolumn{4}{|c|}{ 0. N (ramped) } & \\
\hline $\begin{array}{r}\mathrm{Y} \\
\text { Component }\end{array}$ & & $\begin{array}{c}-74 . \mathrm{N} \\
\text { (ramped) }\end{array}$ & -84. N (ramped) & $\begin{array}{c}-403 . \mathrm{N} \\
\text { (ramped) }\end{array}$ & $\begin{array}{c}\text { 687. N } \\
\text { (ramped) }\end{array}$ & \\
\hline $\begin{array}{r}\mathrm{Z} \\
\text { Component }\end{array}$ & & \multicolumn{4}{|c|}{ 0. N (ramped) } & \\
\hline Direction & & & & & & Defined \\
\hline
\end{tabular}

FIGURE 4

Model (F4) > Static Structural (F5) > Thermal Condition

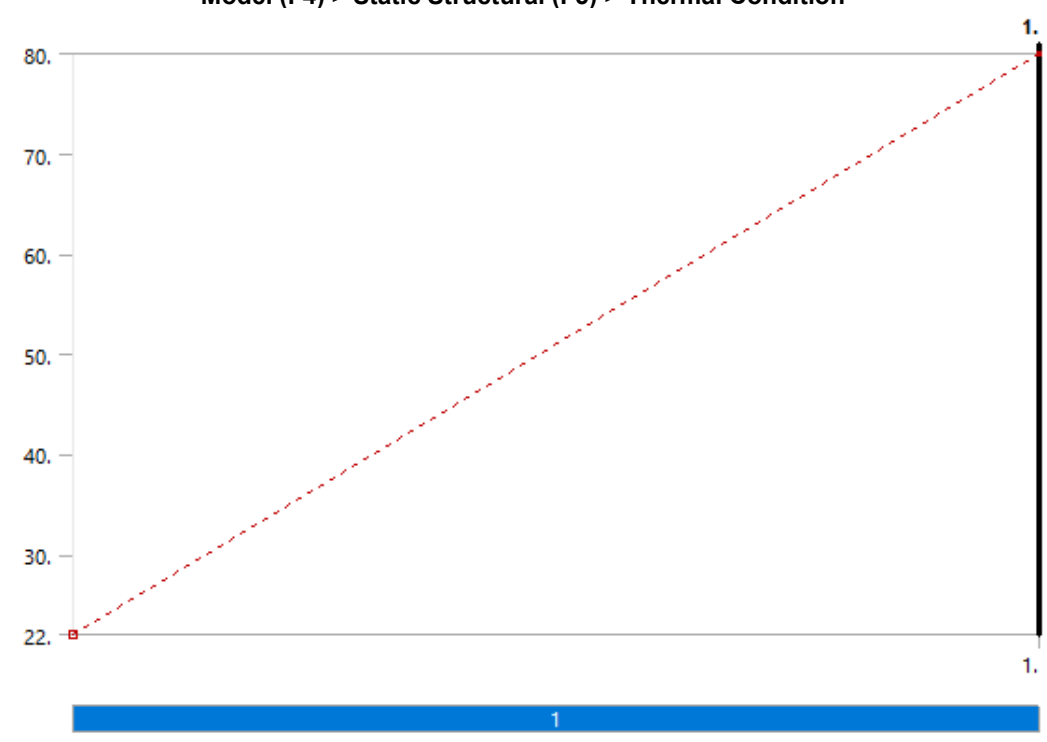

FIGURE 5

Model $($ F4) $>$ Static Structural $($ F5) $>$ BRK Force 


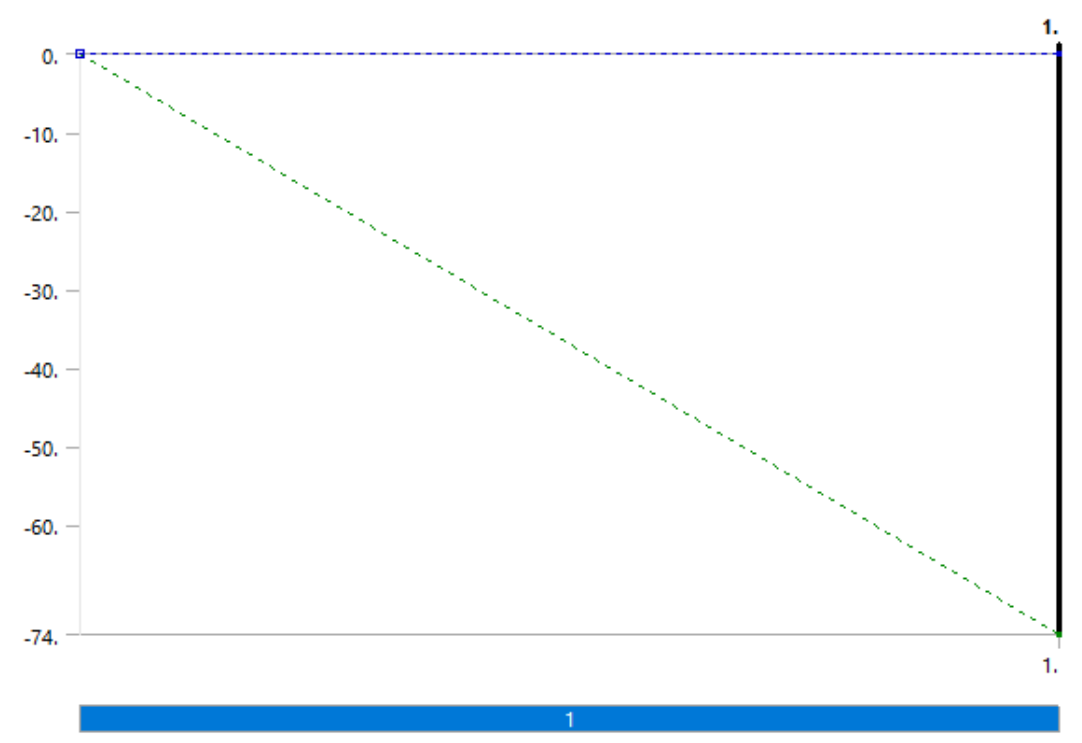

FIGURE 6

Model (F4) > Static Structural (F5) > BRK Force

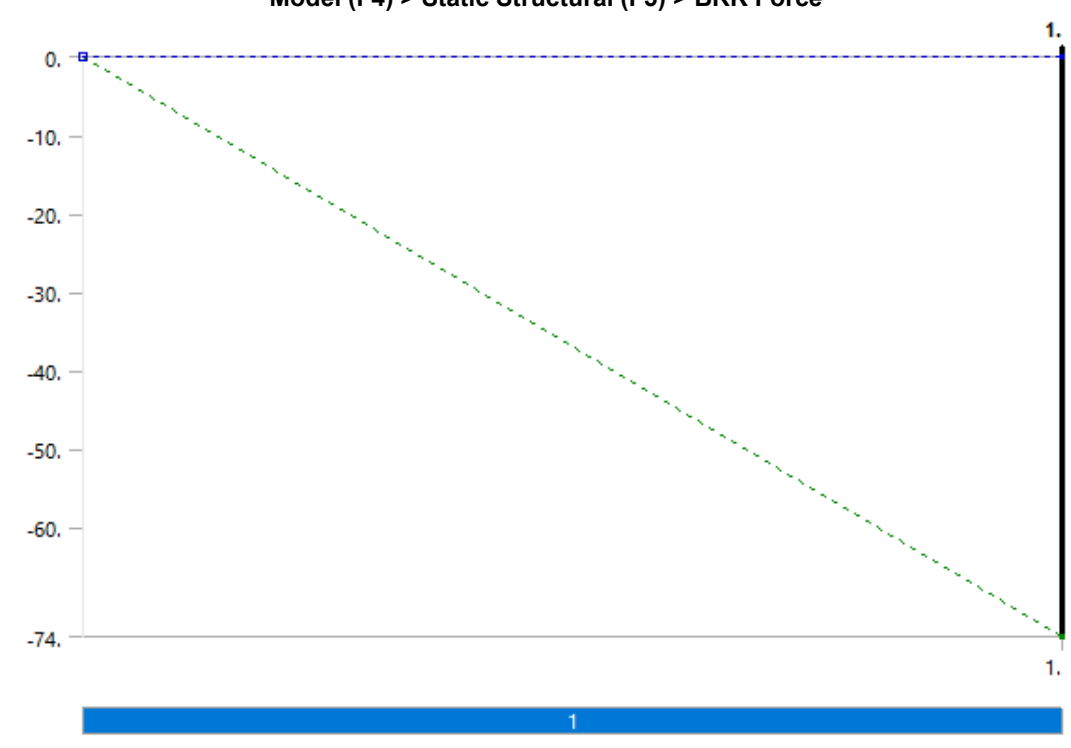


FIGURE 7

Model (F4) > Static Structural (F5) > MagLev Force

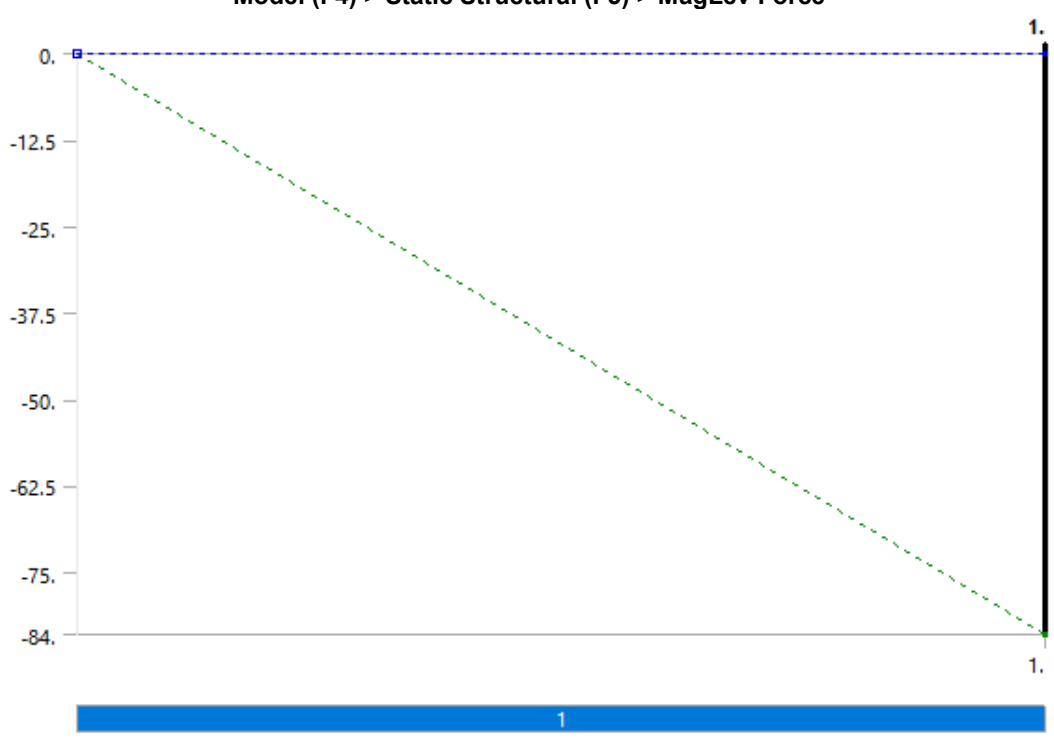

FIGURE 8

Model (F4) > Static Structural (F5) > MagLev Force 


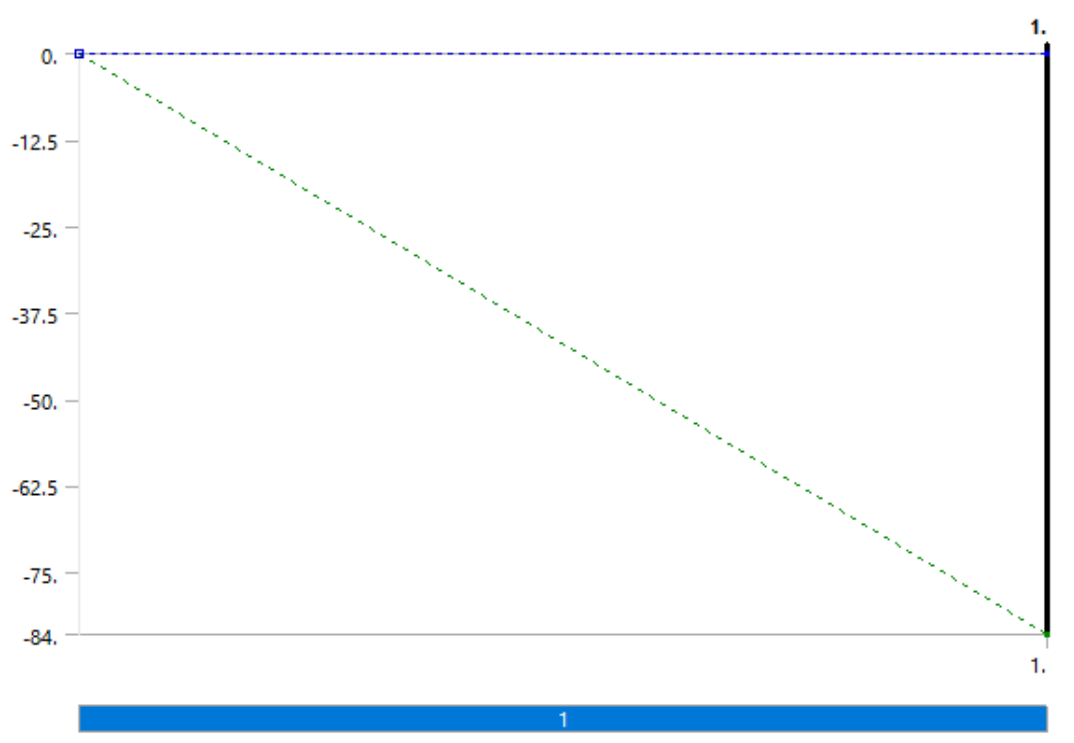

FIGURE 9

Model (F4) > Static Structural (F5) > LIM \& GNC Force

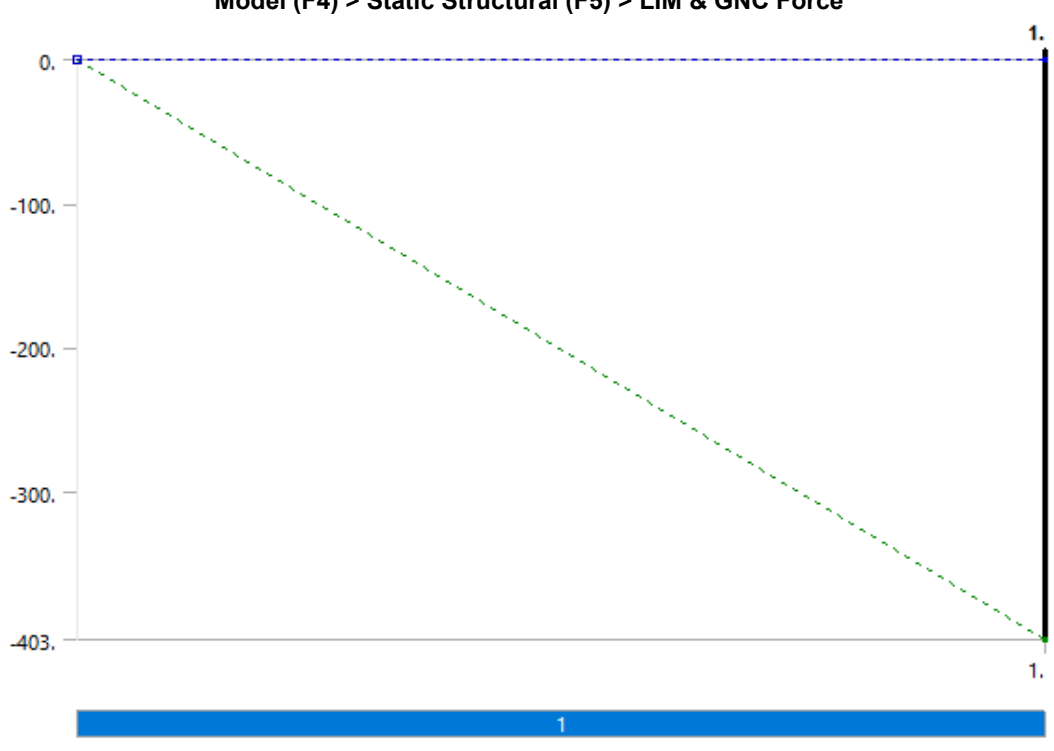


FIGURE 10

Model $(F 4)>$ Static Structural (F5) $>$ Wheel Force

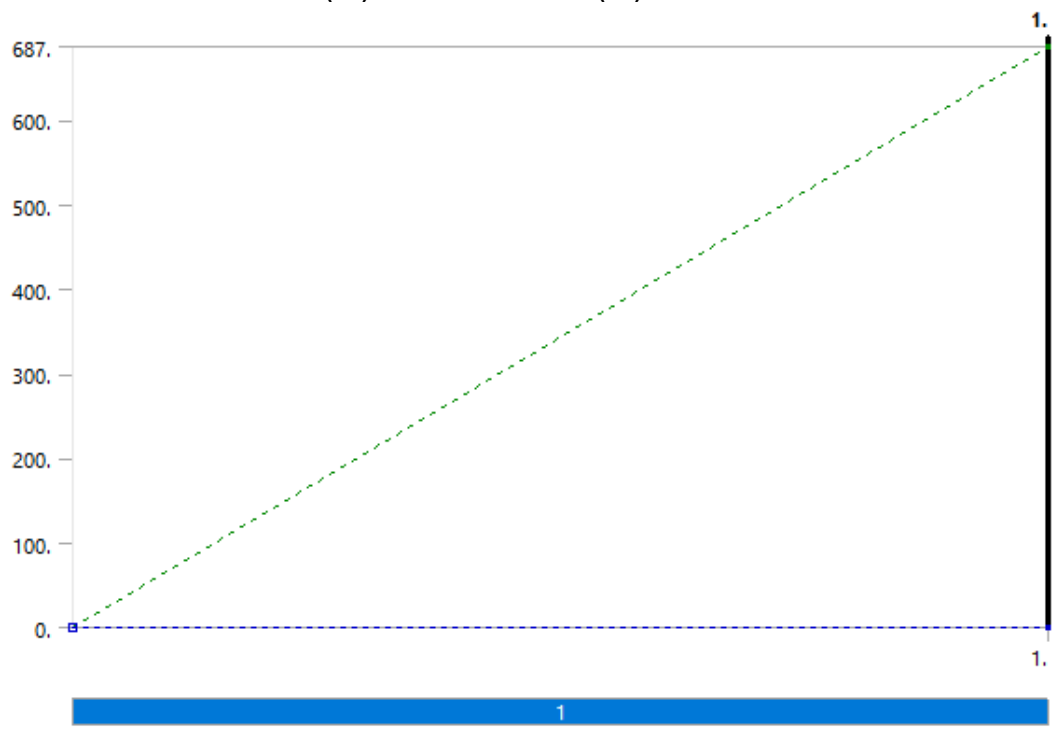

FIGURE 11

Model (F4) > Static Structural (F5) > Wheel Force 


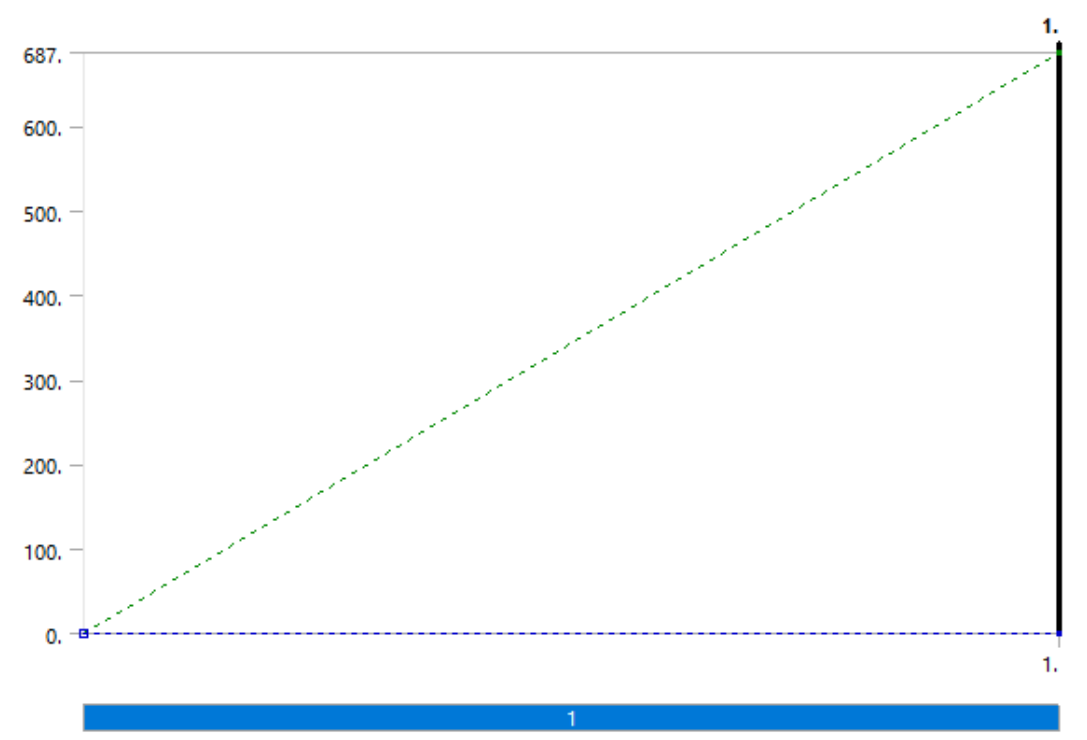

FIGURE 12

Model (F4) > Static Structural (F5) > BRK Force

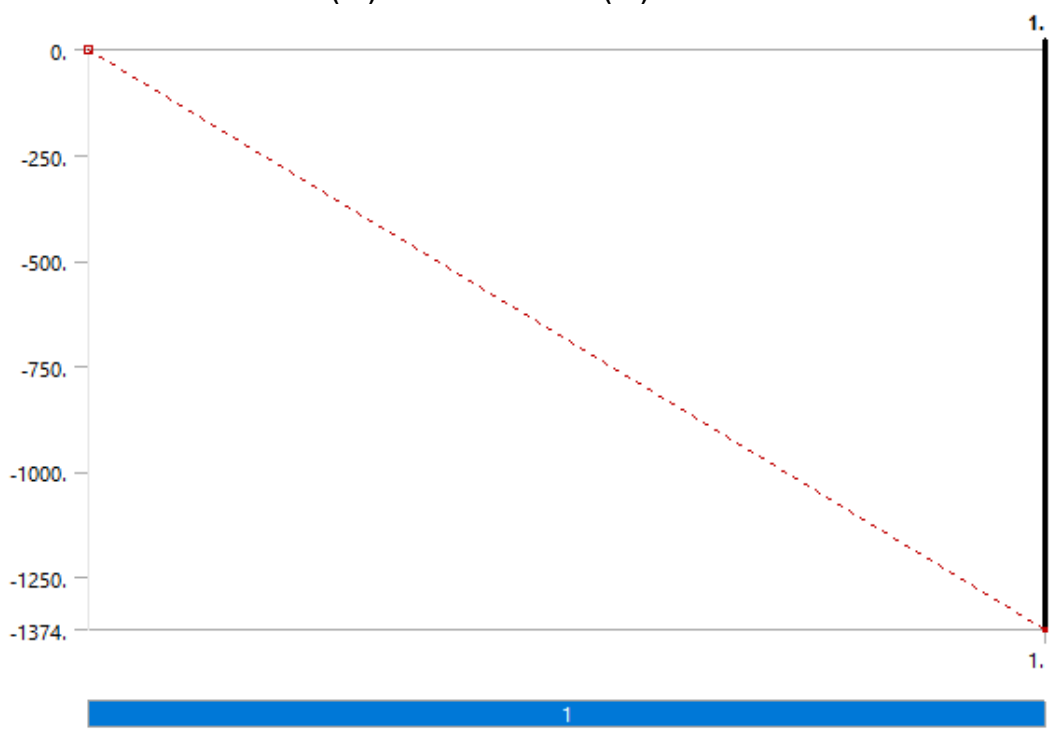


FIGURE 13

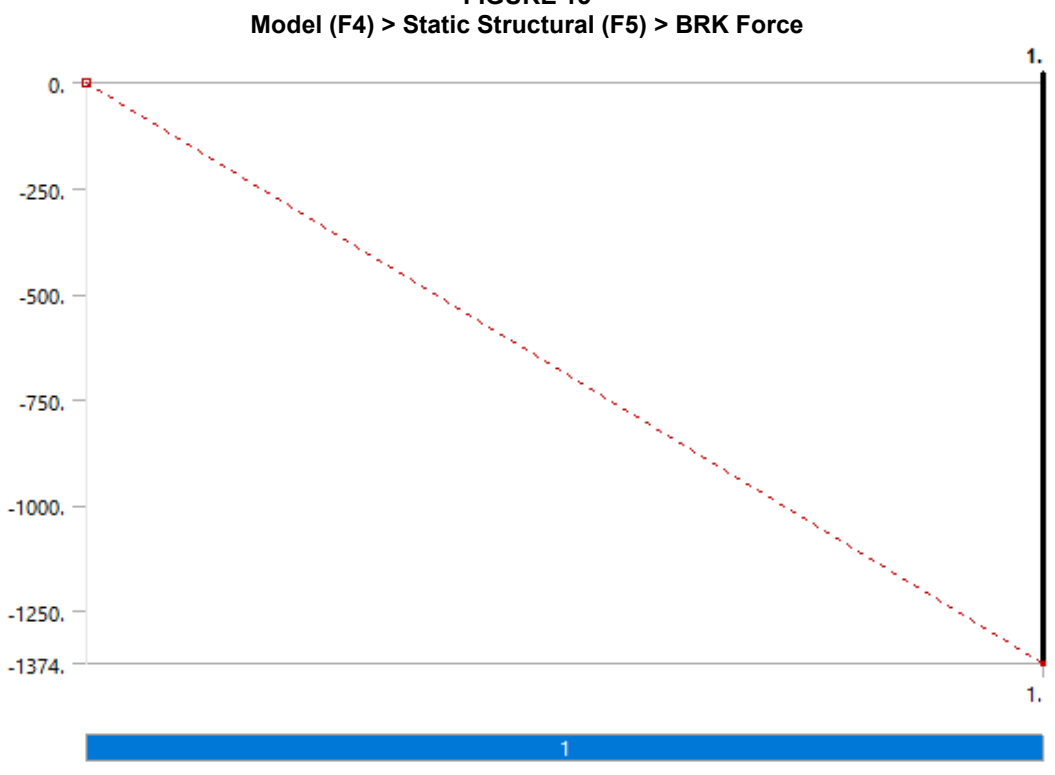

Solution (F6)

TABLE 11

Model (F4) > Static Structural (F5) $>$ Solution

Object Name Solution (F6)

\begin{tabular}{|c|c|}
\hline U. & Solut \\
\hline State & Solved \\
\hline \multicolumn{2}{|c|}{ Adaptive Mesh Refinement } \\
\hline Max Refinement Loops & 1. \\
\hline Refinement Depth & 2. \\
\hline \multicolumn{2}{|l|}{ Information } \\
\hline Status & Done \\
\hline MAPDL Elapsed Time & 2. $\mathrm{s}$ \\
\hline MAPDL Memory Used & 266. MB \\
\hline MAPDL Result File Size & $1.25 \mathrm{MB}$ \\
\hline \multicolumn{2}{|c|}{ Post Processing } \\
\hline Beam Section Results & No \\
\hline On Demand Stress/Strain & No \\
\hline
\end{tabular}

TABLE 12

Model $(F 4)>$ Static Structural $(F 5)>$ Solution $(F 6)>$ Solution Information

Object Name Solution Information

State Solved

Solution Information 


\begin{tabular}{|r|c|}
\hline Solution Output & Solver Output \\
\hline Newton-Raphson Residuals & 0 \\
\hline Identify Element Violations & 0 \\
\hline Update Interval & $2.5 \mathrm{~s}$ \\
\hline Display Points & All \\
\hline FE Connection Visibility \\
\hline Activate Visibility & Yes \\
\hline Display & All FE Connectors \\
\hline Draw Connections Attached To & All Nodes \\
\hline Line Color & Connection Type \\
\hline Visible on Results & No \\
\hline Line Thickness & Single \\
\hline Display Type & Lines \\
\hline
\end{tabular}

TABLE 13

Model (F4) > Static Structural (F5) > Solution (F6) $>$ Results

\begin{tabular}{|c|c|c|}
\hline Object Name & Total Deformation & Equivalent Stress \\
\hline State & & Solved \\
\hline \multicolumn{3}{|c|}{ Scope } \\
\hline Scoping Method & \multicolumn{2}{|c|}{ Geometry Selection } \\
\hline Geometry & \multicolumn{2}{|r|}{ All Bodies } \\
\hline \multicolumn{3}{|c|}{ Definition } \\
\hline Type & Total Deformation & Equivalent (von-Mises) Stress \\
\hline By & \multicolumn{2}{|r|}{ Time } \\
\hline Display Time & \multicolumn{2}{|r|}{ Last } \\
\hline Calculate Time History & \multicolumn{2}{|r|}{ Yes } \\
\hline \multicolumn{3}{|l|}{ Identifier } \\
\hline Suppressed & \multicolumn{2}{|r|}{ No } \\
\hline \multicolumn{3}{|c|}{ Results } \\
\hline Minimum & $0 . \mathrm{mm}$ & $34.987 \mathrm{MPa}$ \\
\hline Maximum & $0.55549 \mathrm{~mm}$ & $165.71 \mathrm{MPa}$ \\
\hline Average & $0.26761 \mathrm{~mm}$ & $95.926 \mathrm{MPa}$ \\
\hline Minimum Occurs On & \multicolumn{2}{|c|}{ GeomlPartBody } \\
\hline Maximum Occurs On & \multicolumn{2}{|c|}{ Geom\PartBody } \\
\hline \multicolumn{3}{|c|}{ Information } \\
\hline Time & \multicolumn{2}{|r|}{ 1. $s$} \\
\hline Load Step & \multicolumn{2}{|r|}{1} \\
\hline Substep & \multicolumn{2}{|r|}{1} \\
\hline Iteration Number & \multicolumn{2}{|r|}{1} \\
\hline \multicolumn{3}{|c|}{ Integration Point Results } \\
\hline Display Option & & Averaged \\
\hline Average Across Bodies & & No \\
\hline
\end{tabular}

FIGURE 14

Model $(F 4)>$ Static Structural $(F 5)>$ Solution $(F 6)>$ Total Deformation 


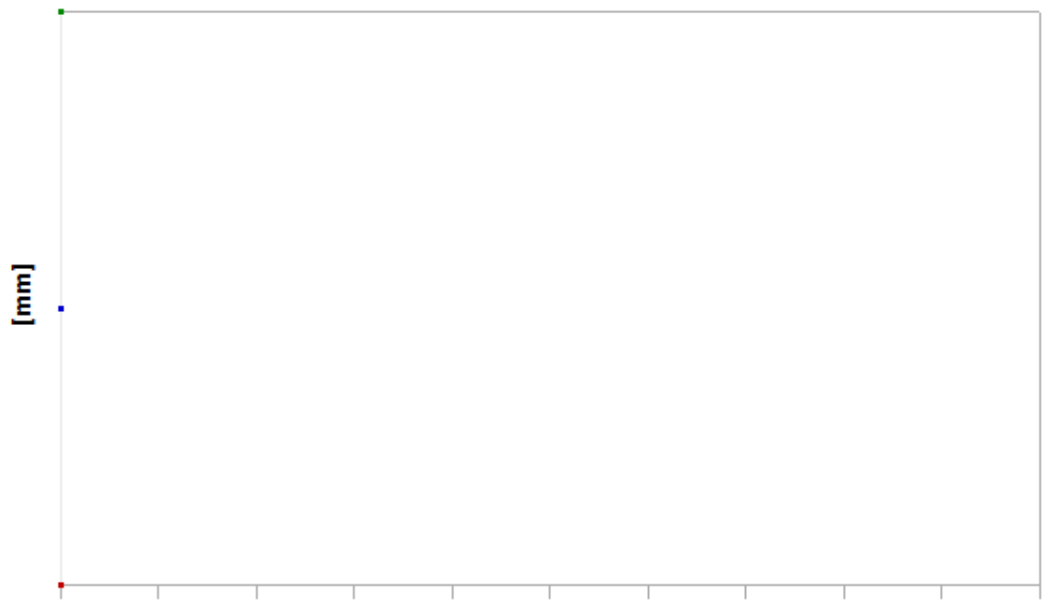

[s]

TABLE 14

Model $(\mathrm{F} 4)>$ Static Structural $(\mathrm{F} 5)>$ Solution $(\mathrm{F} 6)>$ Total Deformation

Time [s] Minimum [mm] Maximum [mm] Average [mm]

\begin{tabular}{l|l|l|l}
\hline 1. & 0. & 0.55549 & 0.26761
\end{tabular}

FIGURE 15

Model $($ F4) $>$ Static Structural $($ F5) $>$ Solution $($ F6) $>$ Total Deformation $>$ Figure 


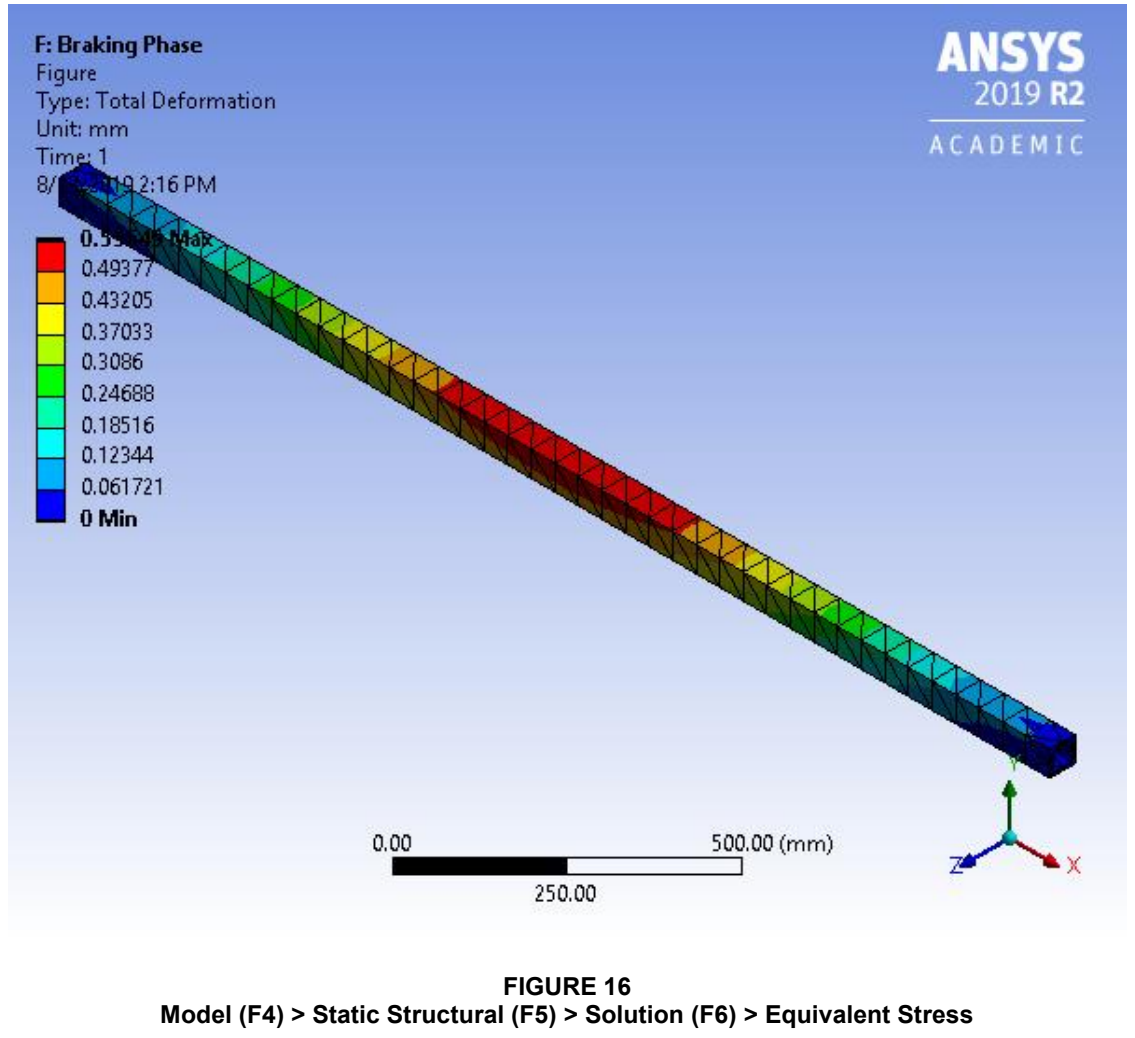




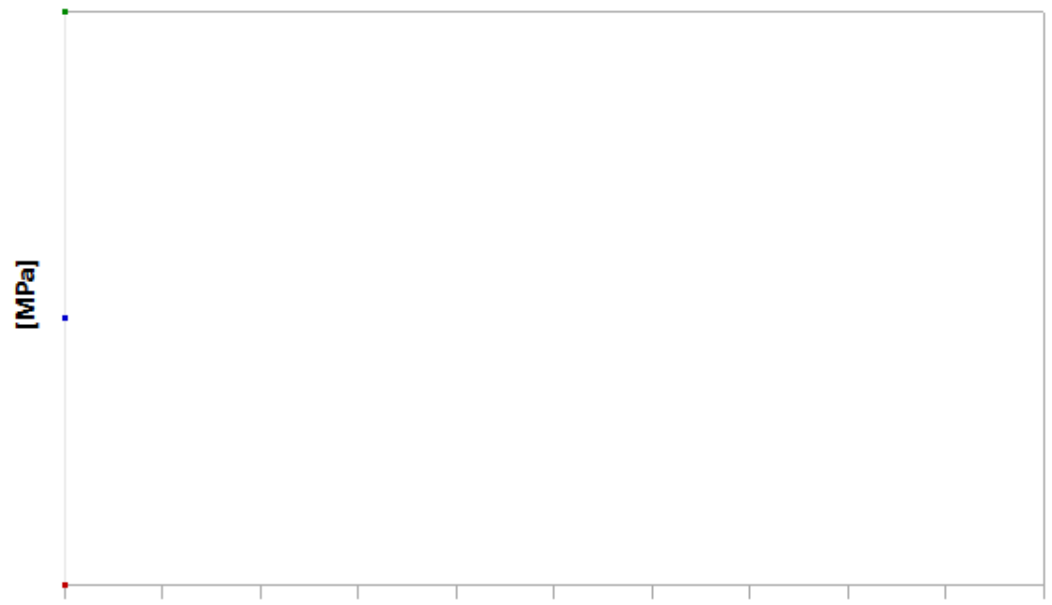

[s]

TABLE 15

Model (F4) $>$ Static Structural $(\mathrm{F} 5)>$ Solution $(\mathrm{F6})>$ Equivalent Stress

Time [s] Minimum [MPa] Maximum [MPa] Average [MPa]

\begin{tabular}{l|l|l|r}
\hline 1. & 34.987 & 165.71 & 95.926
\end{tabular}

FIGURE 17

Model $(\mathrm{F} 4)>$ Static Structural $(\mathrm{F} 5)>$ Solution $(\mathrm{F6})>$ Equivalent Stress $>$ Figure 


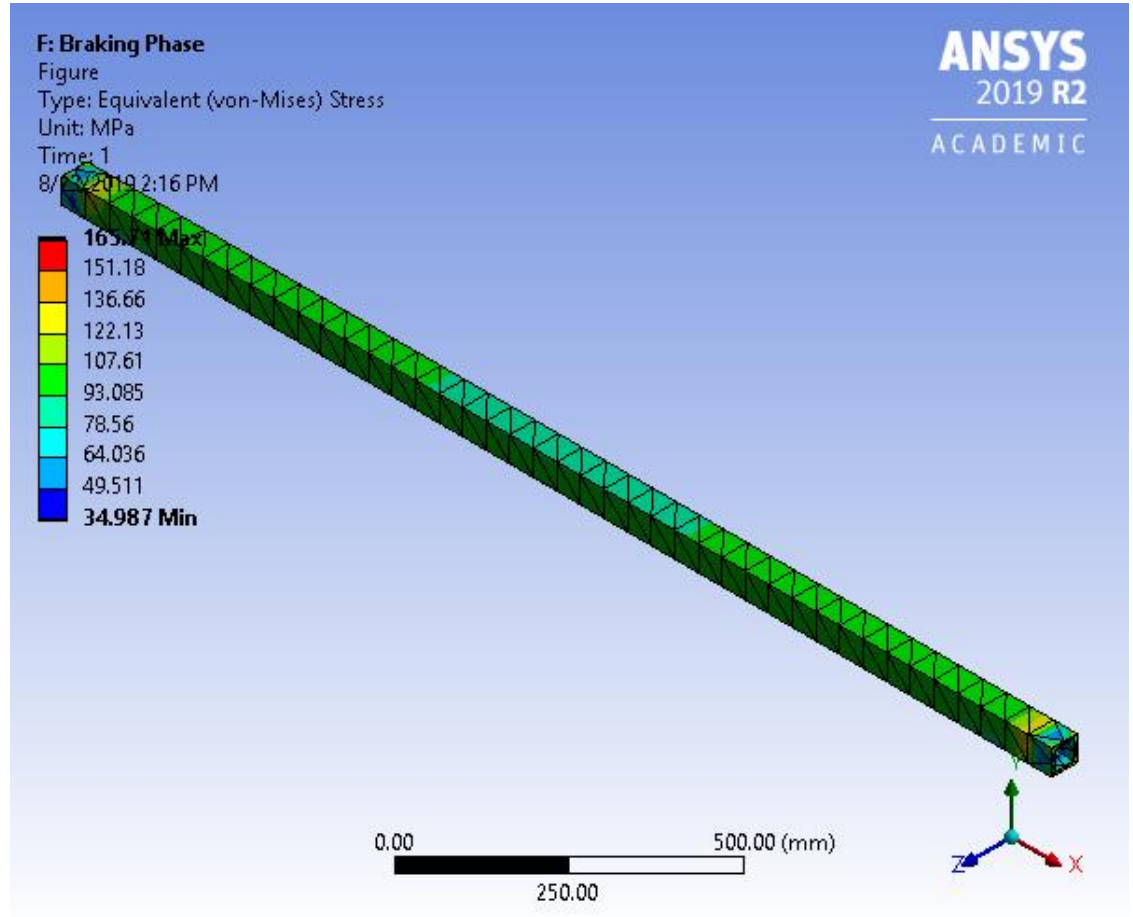

\section{Material Data}

\section{Aluminum Alloy}

TABLE 16

Aluminum Alloy $>$ Constants

\begin{tabular}{|c|c|c|}
\hline \multicolumn{2}{|r|}{ Density } & $2.77 \mathrm{e}-006 \mathrm{~kg} \mathrm{~mm} \wedge-3$ \\
\hline \multicolumn{2}{|c|}{ Coefficient of Thermal Expansion } & $2.3 e-005 C^{\wedge}-1$ \\
\hline \multicolumn{2}{|c|}{ Specific Heat } & $8.75 e+005 m J k g^{\wedge}-1 C^{\wedge}-1$ \\
\hline \multicolumn{3}{|c|}{$\begin{array}{c}\text { TABLE } 17 \\
\text { Aluminum Alloy }>\text { Color }\end{array}$} \\
\hline Red & Green & Blue \\
\hline 138 & 104 & 46 \\
\hline
\end{tabular}

TABLE 18

Aluminum Alloy $>$ Compressive Ultimate Strength

Compressive Ultimate Strength $\mathrm{MPa}$ 
TABLE 19

Aluminum Alloy $>$ Compressive Yield Strength

Compressive Yield Strength $\mathrm{MPa}$

280

TABLE 20

Aluminum Alloy $>$ Tensile Yield Strength

Tensile Yield Strength MPa

280

TABLE 21

Aluminum Alloy $>$ Tensile Ultimate Strength

Tensile Ultimate Strength $\mathrm{MPa}$

310

TABLE 22

Aluminum Alloy $>$ Isotropic Secant Coefficient of Thermal Expansion

Zero-Thermal-Strain Reference Temperature C

22

TABLE 23

Aluminum Alloy $>$ Isotropic Thermal Conductivity Thermal Conductivity $\mathrm{W} \mathrm{mm}^{\wedge}-1 \mathrm{C}^{\wedge}-1$ Temperature $\mathrm{C}$

\begin{tabular}{|c|c|}
\hline 0.114 & -100 \\
\hline 0.144 & 0 \\
\hline 0.165 & 100 \\
\hline 0.175 & 200 \\
\hline
\end{tabular}

TABLE 24

Aluminum Alloy $>$ S-N Curve

Alternating Stress MPa Cycles R-Ratio

\begin{tabular}{|c|c|c|}
\hline 275.8 & 1700 & -1 \\
\hline 241.3 & 5000 & -1 \\
\hline 206.8 & 34000 & -1 \\
\hline 172.4 & $1.4 \mathrm{e}+005$ & -1 \\
\hline 137.9 & $8 . e+005$ & -1 \\
\hline 117.2 & $2.4 \mathrm{e}+006$ & -1 \\
\hline 89.63 & $5.5 \mathrm{e}+007$ & -1 \\
\hline 82.74 & $1 . \mathrm{e}+008$ & -1 \\
\hline 170.6 & 50000 & -0.5 \\
\hline 139.6 & $3.5 \mathrm{e}+005$ & -0.5 \\
\hline 108.6 & $3.7 \mathrm{e}+006$ & -0.5 \\
\hline 87.91 & $1.4 \mathrm{e}+007$ & -0.5 \\
\hline 77.57 & $5 . \mathrm{e}+007$ & -0.5 \\
\hline 72.39 & $1 . \mathrm{e}+008$ & -0.5 \\
\hline 144.8 & 50000 & 0 \\
\hline 120.7 & $1.9 \mathrm{e}+005$ & 0 \\
\hline 103.4 & $1.3 \mathrm{e}+006$ & 0 \\
\hline 93.08 & $4.4 \mathrm{e}+006$ & 0 \\
\hline & & \\
\hline
\end{tabular}




\begin{tabular}{|c|c|c|}
\hline 86.18 & $1.2 \mathrm{e}+007$ & 0 \\
\hline 72.39 & $1 . \mathrm{e}+008$ & 0 \\
\hline 74.12 & $3 . \mathrm{e}+005$ & 0.5 \\
\hline 70.67 & $1.5 \mathrm{e}+006$ & 0.5 \\
\hline 66.36 & $1.2 \mathrm{e}+007$ & 0.5 \\
\hline 62.05 & $1 . \mathrm{e}+008$ & 0.5 \\
\hline
\end{tabular}

TABLE 25

Aluminum Alloy > Isotropic Resistivity Resistivity ohm $\mathrm{mm}$ Temperature C

\begin{tabular}{|c|c|}
\hline $2.43 e-005$ & 0 \\
\hline $2.67 e-005$ & 20 \\
\hline $3.63 e-005$ & 100 \\
\hline
\end{tabular}

TABLE 26

Aluminum Alloy $>$ Isotropic Elasticity

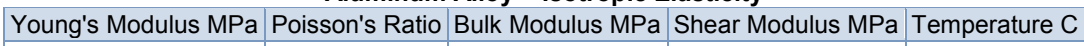

71000

0.33

69608

26692

TABLE 27

Aluminum Alloy > Isotropic Relative Permeability Relative Permeability 
Appendix A.9 Bulkhead Load Case (Braking Phase) Analysis Report 


\section{MNSYS}

\section{Project}

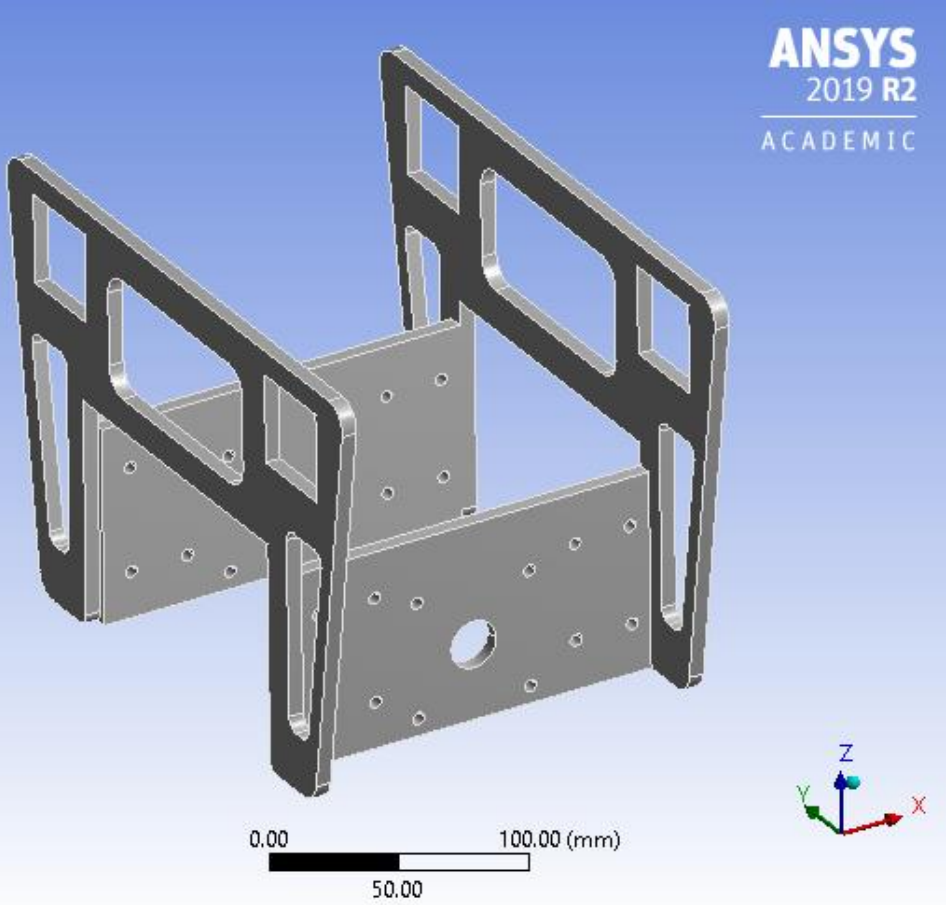




\section{Contents}

- Units

- Model (C4)

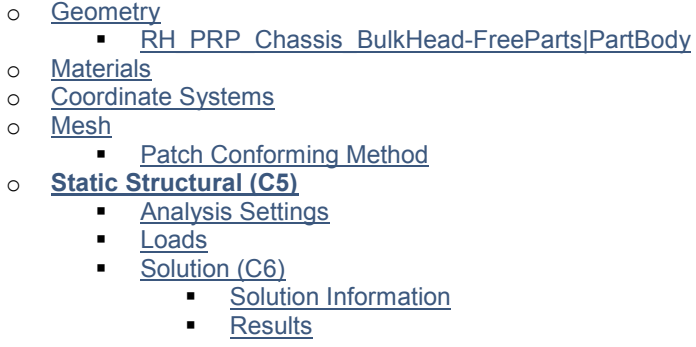

- Material Data

- Aluminum Alloy

\section{Units}

TABLE 1

\begin{tabular}{|r|c|}
\hline Unit System & Metric $(\mathrm{mm}, \mathrm{kg}, \mathrm{N}, \mathrm{s}, \mathrm{mV}, \mathrm{mA})$ Degrees rad/s Celsius \\
\hline Angle & Degrees \\
\hline Rotational Velocity & rad/s \\
\hline Temperature & Celsius \\
\hline
\end{tabular}

\section{Model (C4)}

\section{Geometry}

TABLE 2

Model (C4) > Geometry

\begin{tabular}{|r|c|}
\multicolumn{1}{|c|}{ Model (C4) $>$ Geometry } \\
\hline Object Name & Geometry \\
\hline State & Fully Defined \\
\hline Definition & \\
\hline Source & D:IRH_PRP_Chassis_BulkHead.igs \\
\hline Type & Iges \\
\hline Length Unit & Millimeters \\
\hline Element Control & Program Controlled \\
\hline Display Style & Body Color \\
\hline Bounding Box & \\
\hline Length X & $172.7 \mathrm{~mm}$ \\
\hline Length $Y$ & $251.12 \mathrm{~mm}$ \\
\hline Length Z & $182.12 \mathrm{~mm}$ \\
\hline Properties \\
\hline
\end{tabular}




\begin{tabular}{|c|c|}
\hline Volume & $3.8104 \mathrm{e}+005 \mathrm{~mm}^{3}$ \\
\hline Mass & $1.0555 \mathrm{~kg}$ \\
\hline Scale Factor Value & 1. \\
\hline \multicolumn{2}{|c|}{ Statistics } \\
\hline Bodies & 1 \\
\hline Active Bodies & 1 \\
\hline Nodes & 11908 \\
\hline Elements & 5576 \\
\hline Mesh Metric & None \\
\hline \multicolumn{2}{|c|}{ Update Options } \\
\hline Assign Default Material & No \\
\hline \multicolumn{2}{|c|}{ Basic Geometry Options } \\
\hline Solid Bodies & Yes \\
\hline Surface Bodies & Yes \\
\hline Line Bodies & No \\
\hline Parameters & Independent \\
\hline Parameter Key & ANS;DS \\
\hline Attributes & No \\
\hline Named Selections & No \\
\hline Material Properties & No \\
\hline \multicolumn{2}{|c|}{ Advanced Geometry Options } \\
\hline Use Associativity & Yes \\
\hline Coordinate Systems & No \\
\hline Reader Mode Saves Updated File & No \\
\hline Use Instances & Yes \\
\hline Smart CAD Update & Yes \\
\hline Compare Parts On Update & No \\
\hline Analysis Type & 3-D \\
\hline Mixed Import Resolution & None \\
\hline Clean Bodies On Import & No \\
\hline Stitch Surfaces On Import & Program Tolerance \\
\hline Decompose Disjoint Geometry & Yes \\
\hline Enclosure and Symmetry Processing & Yes \\
\hline
\end{tabular}

TABLE 3

Model (C4) > Geometry > Parts

\begin{tabular}{|c|c|}
\hline \multicolumn{2}{|r|}{ Model (C4) > Geometry > Parts } \\
\hline Object Name & RH_PRP_Chassis_BulkHead-FreeParts|PartBody \\
\hline State & - Meshed \\
\hline \multicolumn{2}{|r|}{ Graphics Properties } \\
\hline Visible & Yes \\
\hline Transparency & 1 \\
\hline \multicolumn{2}{|r|}{ Definition } \\
\hline Suppressed & No \\
\hline Stiffness Behavior & Flexible \\
\hline Coordinate System & Default Coordinate System \\
\hline Reference Temperature & By Environment \\
\hline Treatment & None \\
\hline \multicolumn{2}{|r|}{ Material } \\
\hline Assignment & Aluminum Alloy \\
\hline
\end{tabular}




\begin{tabular}{|r|c|}
\hline Nonlinear Effects & Yes \\
\hline Thermal Strain Effects & Yes \\
\hline Length X & $172.7 \mathrm{~mm}$ \\
\hline Length Y & $251.12 \mathrm{~mm}$ \\
\hline Length Z & $182.12 \mathrm{~mm}$ \\
\hline Volume & Properties \\
\hline Mass & $3.8104 \mathrm{e}+005 \mathrm{~mm}^{3}$ \\
\hline Centroid X & $1.0555 \mathrm{~kg}$ \\
\hline Centroid Y & $86.745 \mathrm{~mm}$ \\
\hline Centroid Z & $0.17852 \mathrm{~mm}$ \\
\hline Moment of Inertia Ip1 & $16.361 \mathrm{~mm}$ \\
\hline Moment of Inertia Ip2 & $9126.2 \mathrm{~kg} \cdot \mathrm{mm}^{2}$ \\
\hline of Inertia Ip3 & $8230.3 \mathrm{~kg} \cdot \mathrm{mm}^{2}$ \\
\hline Nodes & $11149 \mathrm{~kg} \cdot \mathrm{mm}^{2}$ \\
\hline Elements & Statistics \\
\hline Mesh Metric & 11908 \\
\hline & 5576 \\
\hline
\end{tabular}

FIGURE 1

Model (C4) > Geometry > RH_PRP_Chassis_BulkHead-FreeParts|PartBody > Figure 


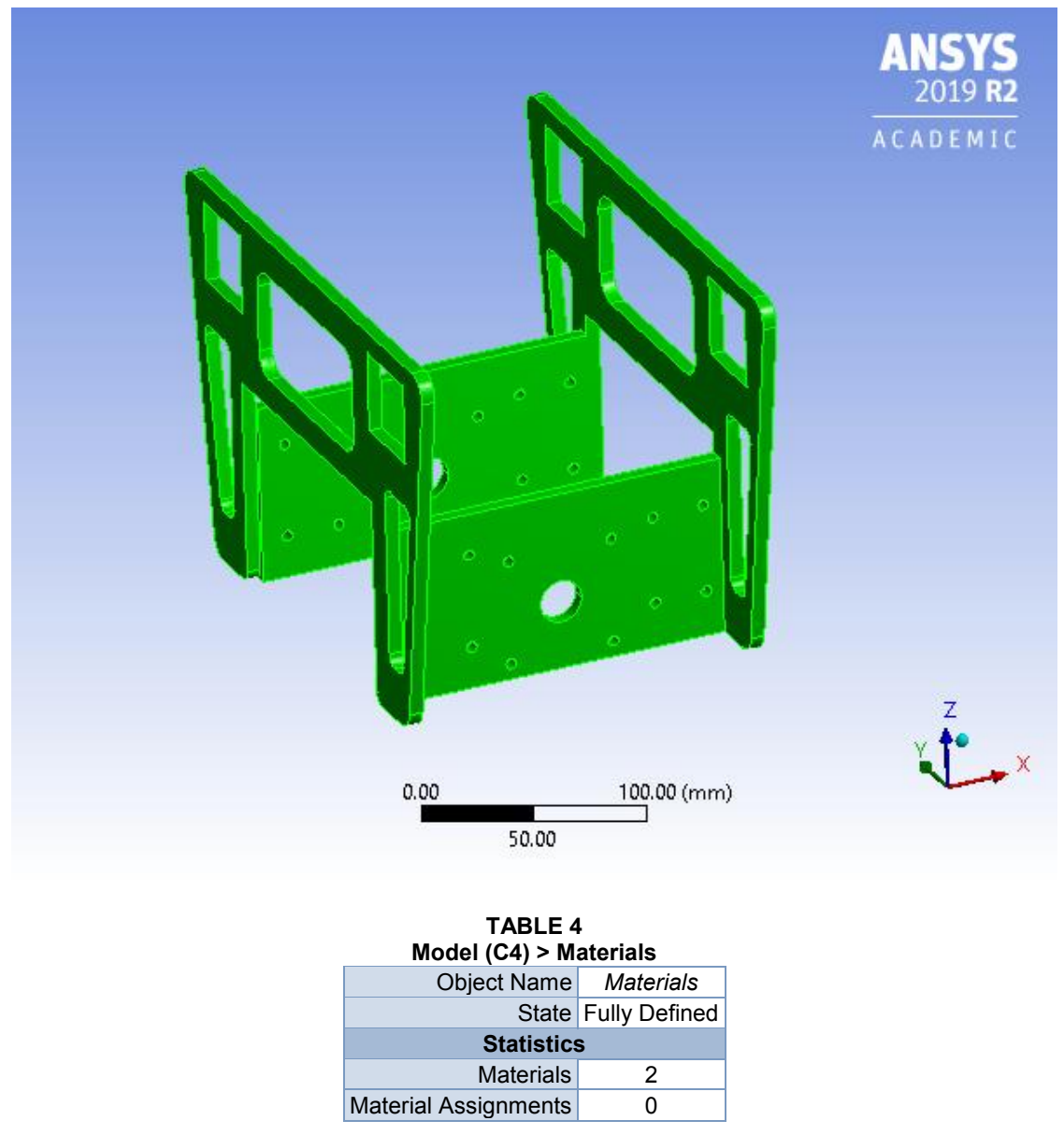

\section{Coordinate Systems}

TABLE 5

Model (C4) > Coordinate Systems > Coordinate System

\begin{tabular}{|r|c|}
\hline Object Name & Global Coordinate System \\
\hline State & Fully Defined \\
Definition \\
\hline Type & Cartesian \\
\hline Coordinate System ID & 0. \\
\hline Origin \\
\hline Origin X & $0 . \mathrm{mm}$ \\
\hline
\end{tabular}




\begin{tabular}{|r|r|}
\hline Origin $Y$ & $0 . \mathrm{mm}$ \\
\hline Origin Z & $0 . \mathrm{mm}$ \\
\hline \multicolumn{2}{|c|}{ Directional Vectors } \\
\hline X Axis Data & {$[1.0 .0]$.} \\
\hline Y Axis Data & {$[0.1 .0]$.} \\
\hline Z Axis Data & {$[0.0 .1]$.} \\
\hline
\end{tabular}

Mesh

TABLE 6

Model (C4) $>$ Mesh

\begin{tabular}{|c|c|}
\hline \\
\hline Object Name & Mesh \\
\hline State & Solved \\
\hline \multicolumn{2}{|l|}{ Display } \\
\hline Display Style & Use Geometry Setting \\
\hline \multicolumn{2}{|c|}{ Defaults } \\
\hline Physics Preference & Mechanical \\
\hline Element Order & Program Controlled \\
\hline Element Size & Default \\
\hline \multicolumn{2}{|l|}{ Sizing } \\
\hline Use Adaptive Sizing & Yes \\
\hline Resolution & Default (2) \\
\hline Mesh Defeaturing & Yes \\
\hline Defeature Size & Default \\
\hline Transition & Fast \\
\hline Span Angle Center & Coarse \\
\hline Initial Size Seed & Assembly \\
\hline Bounding Box Diagonal & $355.04 \mathrm{~mm}$ \\
\hline Average Surface Area & $980.37 \mathrm{~mm}^{2}$ \\
\hline Minimum Edge Length & $0.21228 \mathrm{~mm}$ \\
\hline \multicolumn{2}{|l|}{ Quality } \\
\hline Check Mesh Quality & Yes, Errors \\
\hline Error Limits & Standard Mechanical \\
\hline Target Quality & Default $(0.050000)$ \\
\hline Smoothing & Medium \\
\hline Mesh Metric & None \\
\hline \multicolumn{2}{|l|}{ Inflation } \\
\hline Use Automatic Inflation & None \\
\hline Inflation Option & Smooth Transition \\
\hline Transition Ratio & 0.272 \\
\hline Maximum Layers & 5 \\
\hline Growth Rate & 1.2 \\
\hline Inflation Algorithm & Pre \\
\hline View Advanced Options & No \\
\hline \multicolumn{2}{|l|}{ Advanced } \\
\hline Number of CPUs for Parallel Part Meshing & Program Controlled \\
\hline Straight Sided Elements & No \\
\hline Rigid Body Behavior & Dimensionally Reduced \\
\hline
\end{tabular}




\begin{tabular}{|r|c|}
\hline Triangle Surface Mesher & Program Controlled \\
\hline Topology Checking & Yes \\
\hline Pinch Tolerance & Please Define \\
\hline Generate Pinch on Refresh & No \\
\hline Statistics & \\
\hline Nodes & 11908 \\
\hline Elements & 5576 \\
\hline
\end{tabular}

TABLE 7

Model (C4) $>$ Mesh $>$ Mesh Controls Object Name Patch Conforming Method

State

Scope

Scoping Method Geometry Selection

\begin{tabular}{|r|c|}
\hline Geometry & 1 Dofinition \\
\hline Suppressed & No \\
\hline Method & Tetrahedrons \\
\hline Algorithm & Patch Conforming \\
\hline Element Order & Use Global Setting \\
\hline
\end{tabular}

FIGURE 2

Model (C4) $>$ Mesh $>$ Figure 


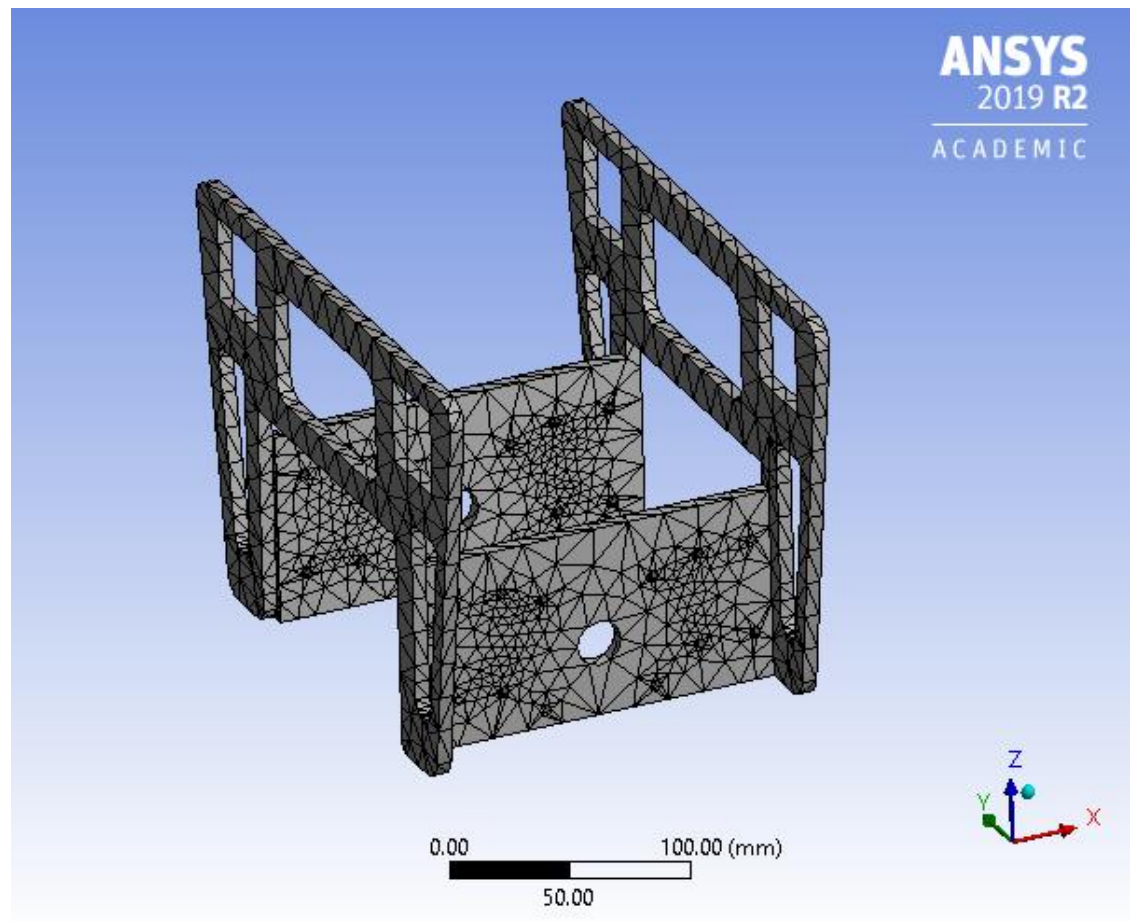

\section{Static Structural (C5)}

TABLE 8

Model (C4) > Analysis

\begin{tabular}{|r|c|}
\hline \multicolumn{1}{|c|}{ Model (C4) > Analysis } \\
\hline Object Name & Static Structural (C5) \\
\hline State & Solved \\
\hline Definition \\
\hline Physics Type & Structural \\
\hline Analysis Type & Static Structural \\
\hline Solver Target & Mechanical APDL \\
\hline Options \\
\hline Environment Temperature & $22 .{ }^{\circ} \mathrm{C}$ \\
\hline Generate Input Only & No \\
\hline
\end{tabular}

TABLE 9

Model (C4) > Static Structural (C5) > Analysis Settings 


\begin{tabular}{|c|c|}
\hline Number Of Steps & 1. \\
\hline Current Step Number & 1. \\
\hline Step End Time & 1. $\mathrm{s}$ \\
\hline Auto Time Stepping & Program Controlled \\
\hline \multicolumn{2}{|r|}{ Solver Controls } \\
\hline Solver Type & Program Controlled \\
\hline Weak Springs & Off \\
\hline Solver Pivot Checking & Program Controlled \\
\hline Large Deflection & Off \\
\hline Inertia Relief & Off \\
\hline \multicolumn{2}{|r|}{ Rotordynamics Controls } \\
\hline Coriolis Effect & Off \\
\hline \multicolumn{2}{|r|}{ Restart Controls } \\
\hline $\begin{array}{r}\text { Generate Restart } \\
\text { Points }\end{array}$ & Program Controlled \\
\hline $\begin{array}{r}\text { Retain Files After Full } \\
\text { Solve }\end{array}$ & No \\
\hline Combine Restart Files & Program Controlled \\
\hline \multicolumn{2}{|r|}{ Nonlinear Controls } \\
\hline $\begin{array}{r}\text { Newton-Raphson } \\
\text { Option }\end{array}$ & Program Controlled \\
\hline Force Convergence & Program Controlled \\
\hline Moment Convergence & Program Controlled \\
\hline $\begin{array}{l}\text { Displacement } \\
\text { Convergence }\end{array}$ & Program Controlled \\
\hline Rotation Convergence & Program Controlled \\
\hline Line Search & Program Controlled \\
\hline Stabilization & Program Controlled \\
\hline \multicolumn{2}{|r|}{ Output Controls } \\
\hline Stress & Yes \\
\hline Surface Stress & No \\
\hline Back Stress & No \\
\hline Strain & Yes \\
\hline Contact Data & Yes \\
\hline Nonlinear Data & No \\
\hline Nodal Forces & No \\
\hline Contact Miscellaneous & No \\
\hline General Miscellaneous & No \\
\hline Store Results At & All Time Points \\
\hline $\begin{array}{r}\text { Result File } \\
\text { Compression }\end{array}$ & Program Controlled \\
\hline \multicolumn{2}{|r|}{ Analysis Data Management } \\
\hline Solver Files Directory & 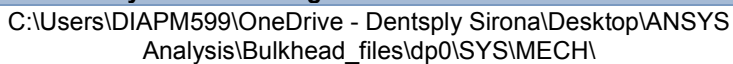 \\
\hline Future Analysis & None \\
\hline \multicolumn{2}{|l|}{$\begin{array}{r}\text { Scratch Solver Files } \\
\text { Directory }\end{array}$} \\
\hline Save MAPDL db & No \\
\hline Contact Summary & Program Controlled \\
\hline
\end{tabular}




\begin{tabular}{|r|c|}
\hline Delete Unneeded Files & Yes \\
\hline Nonlinear Solution & No \\
\hline Solver Units & Active System \\
\hline Solver Unit System & $\mathrm{nmm}$ \\
\hline
\end{tabular}

TABLE 10

Model (C4) > Static Structural (C5) > Loads

\begin{tabular}{|c|c|c|c|c|c|}
\hline Object Name & Thermal Condition & BRK Force & BRK Force & \begin{tabular}{|l|l|} 
BRK Force & BRK Force \\
\end{tabular} & Fixed Support \\
\hline State & \multicolumn{5}{|c|}{ Fully Defined } \\
\hline \multicolumn{6}{|c|}{ Scope } \\
\hline Scoping Method & \multicolumn{5}{|c|}{ Geometry Selection } \\
\hline Geometry & 1 Body & \multicolumn{3}{|c|}{1 Face } & 16 Faces \\
\hline \multicolumn{6}{|c|}{ Definition } \\
\hline Type & Thermal Condition & \multicolumn{3}{|c|}{ Force } & Fixed Support \\
\hline Magnitude & 80. ${ }^{\circ} \mathrm{C}$ (ramped) & 1957. N & (ramped) & -1374. N (ramped) & \\
\hline Suppressed & \multicolumn{5}{|c|}{ No } \\
\hline Define By & \multicolumn{4}{|c|}{ Vector } & \\
\hline Direction & & \multicolumn{3}{|c|}{ Defined } & \\
\hline
\end{tabular}

FIGURE 3

Model (C4) > Static Structural (C5) > Thermal Condition

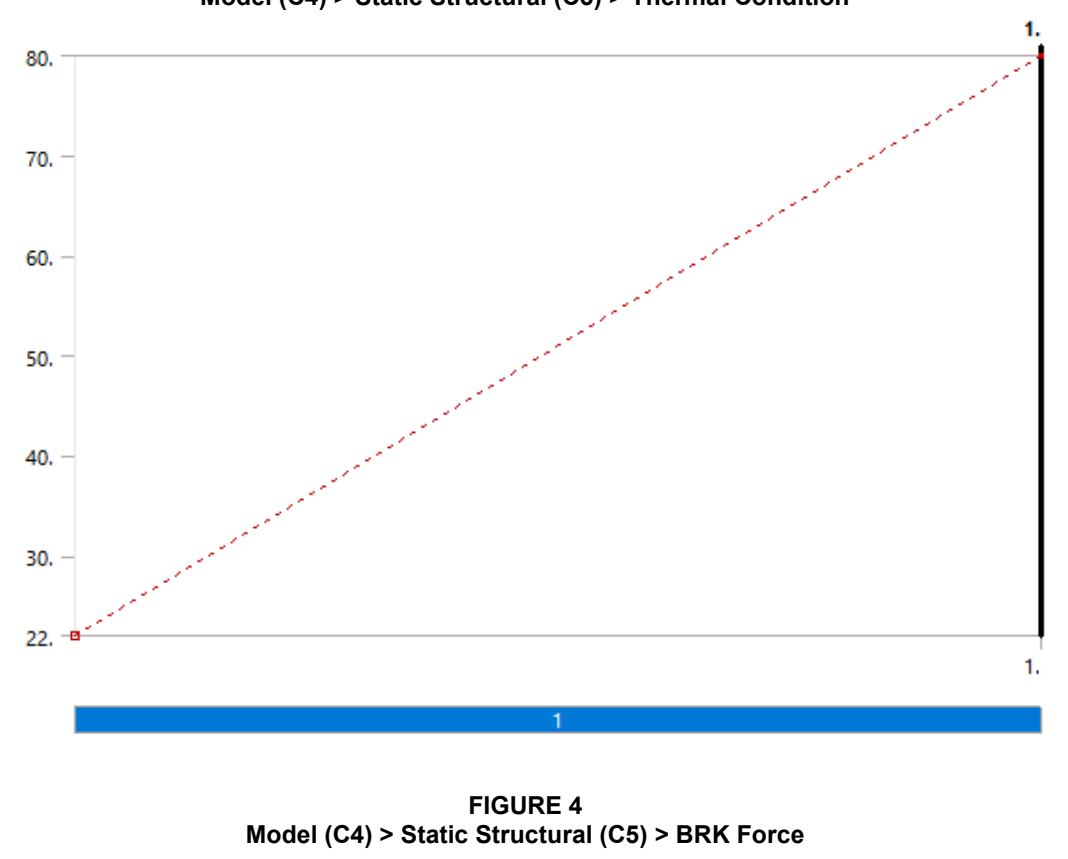




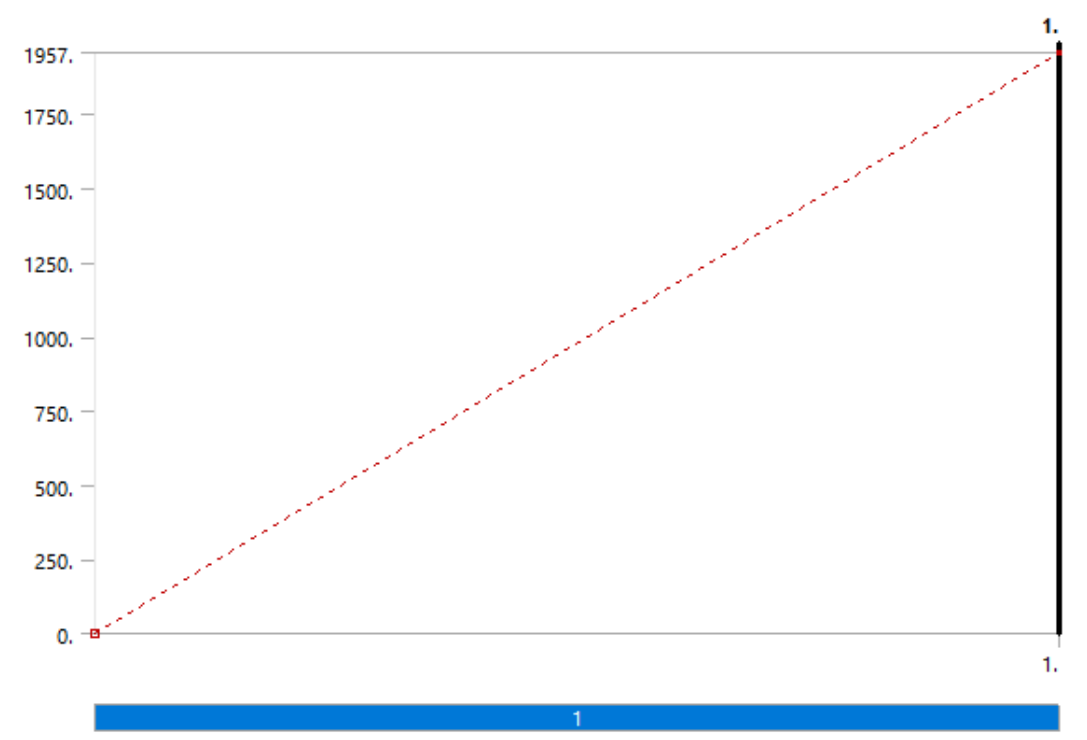

FIGURE 5

Model (C4) > Static Structural (C5) > BRK Force

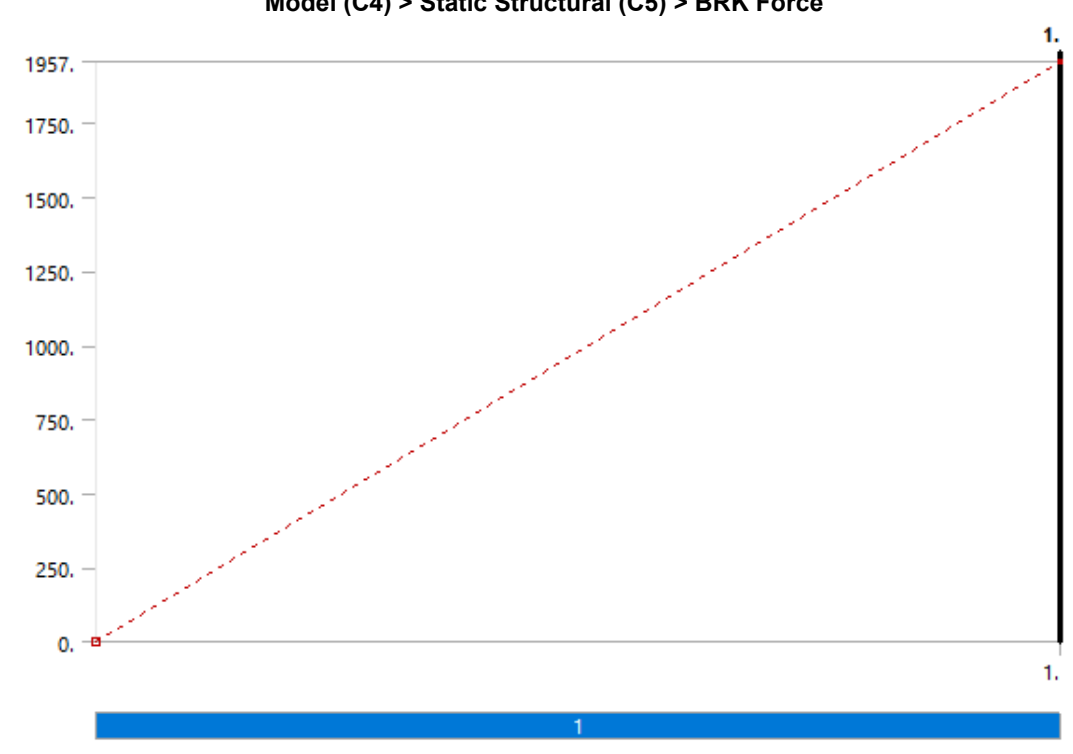


FIGURE 6

Model (C4) > Static Structural (C5) > BRK Force

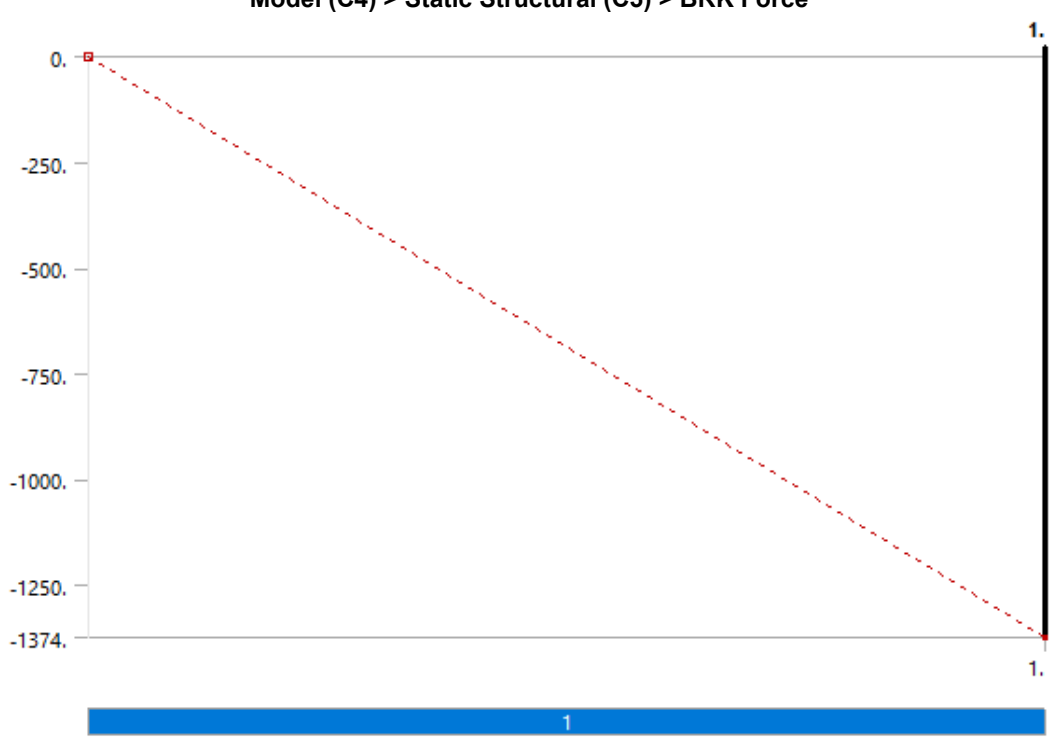

FIGURE 7

Model (C4) > Static Structural (C5) > BRK Force 


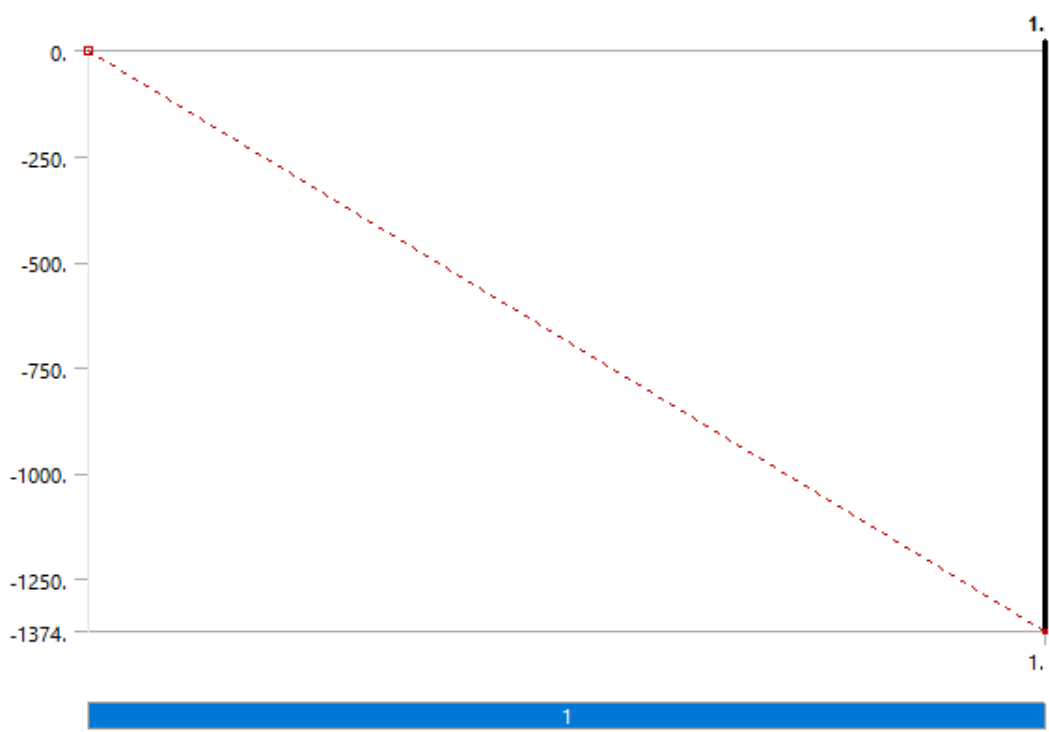

Solution (C6)

TABLE 11

Model (C4) > Static Structural (C5) > Solution

\begin{tabular}{|c|c|}
\hline Object Name & Solution (C6) \\
\hline State & Solved \\
\hline \multicolumn{2}{|c|}{ Adaptive Mesh Refinement } \\
\hline Max Refinement Loops & 1. \\
\hline Refinement Depth & 2. \\
\hline \multicolumn{2}{|l|}{ Information } \\
\hline Status & Done \\
\hline MAPDL Elapsed Time & 4. $s$ \\
\hline MAPDL Memory Used & 325. MB \\
\hline MAPDL Result File Size & $4.5625 \mathrm{MB}$ \\
\hline \multicolumn{2}{|c|}{ Post Processing } \\
\hline Beam Section Results & No \\
\hline On Demand Stress/Strain & No \\
\hline
\end{tabular}

TABLE 12

Model (C4) > Static Structural (C5) > Solution (C6) > Solution Information

\begin{tabular}{|r|c|}
\hline Object Name & Solution Information \\
\hline State & Solved \\
\hline Solution Information \\
\hline Solution Output & Solver Output \\
\hline Newton-Raphson Residuals & 0 \\
\hline
\end{tabular}




\begin{tabular}{|r|c|}
\hline Identify Element Violations & 0 \\
\hline Update Interval & $2.5 \mathrm{~s}$ \\
\hline Display Points & All \\
\hline FE Connection Visibility \\
\hline Activate Visibility & Yes \\
\hline Display & All FE Connectors \\
\hline Draw Connections Attached To & All Nodes \\
\hline Line Color & Connection Type \\
\hline Visible on Results & No \\
\hline Line Thickness & Single \\
\hline Display Type & Lines \\
\hline
\end{tabular}

TABLE 13

Model (C4) > Static Structural (C5) > Solution (C6) $>$ Results

\begin{tabular}{|c|c|c|}
\hline Object Name & Total Deformation & Equivalent Stress \\
\hline State & & Solved \\
\hline \multicolumn{3}{|c|}{ Scope } \\
\hline Scoping Method & \multicolumn{2}{|c|}{ Geometry Selection } \\
\hline Geometry & \multicolumn{2}{|c|}{ All Bodies } \\
\hline \multicolumn{3}{|c|}{ Definition } \\
\hline Type & Total Deformation & Equivalent (von-Mises) Stress \\
\hline By & \multicolumn{2}{|r|}{ Time } \\
\hline Display Time & \multicolumn{2}{|r|}{ Last } \\
\hline Calculate Time History & \multicolumn{2}{|r|}{ Yes } \\
\hline \multicolumn{3}{|l|}{ Identifier } \\
\hline Suppressed & \multicolumn{2}{|r|}{ No } \\
\hline \multicolumn{3}{|c|}{ Results } \\
\hline Minimum & 0. $\mathrm{mm}$ & $0.52937 \mathrm{MPa}$ \\
\hline Maximum & $1.0151 \mathrm{~mm}$ & $193.69 \mathrm{MPa}$ \\
\hline Average & $0.47214 \mathrm{~mm}$ & $31.029 \mathrm{MPa}$ \\
\hline Minimum Occurs On & \multicolumn{2}{|c|}{ RH_PRP_Chassis_BulkHead-FreeParts|PartBody } \\
\hline Maximum Occurs On & \multicolumn{2}{|c|}{ RH_PRP_Chassis_BulkHead-FreeParts|PartBody } \\
\hline \multicolumn{3}{|c|}{ Information } \\
\hline Time & \multicolumn{2}{|r|}{ 1. $s$} \\
\hline Load Step & \multicolumn{2}{|r|}{1} \\
\hline Substep & \multicolumn{2}{|r|}{1} \\
\hline Iteration Number & \multicolumn{2}{|r|}{1} \\
\hline \multicolumn{3}{|c|}{ Integration Point Results } \\
\hline Display Option & & Averaged \\
\hline Average Across Bodies & & No \\
\hline
\end{tabular}

FIGURE 8

Model (C4) > Static Structural (C5) > Solution (C6) > Total Deformation 


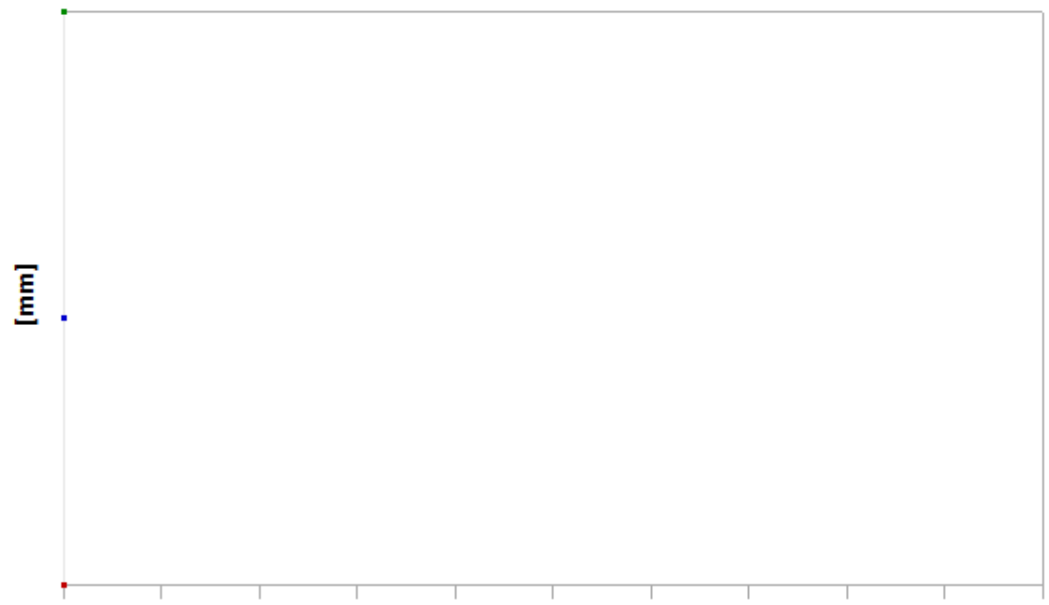

[s]

TABLE 14

Model (C4) > Static Structural (C5) > Solution (C6) $>$ Total Deformation

Time [s] Minimum [mm] Maximum [mm] Average [mm]

\begin{tabular}{l|l|l|l}
\hline 1. & 0. & 1.0151 & 0.47214
\end{tabular}

FIGURE 9

Model (C4) $>$ Static Structural (C5) $>$ Solution (C6) $>$ Total Deformation $>$ Figure 


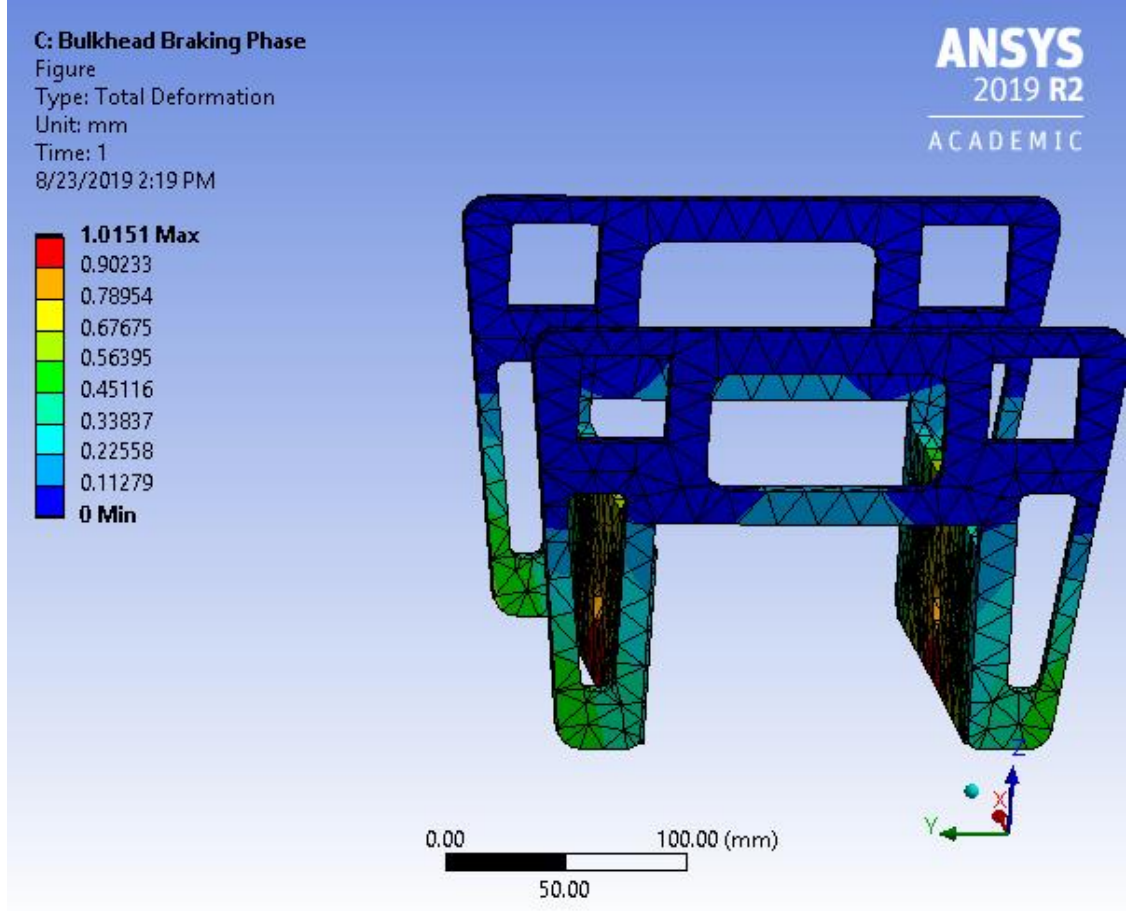

FIGURE 10

Model (C4) > Static Structural (C5) > Solution (C6) > Equivalent Stress 


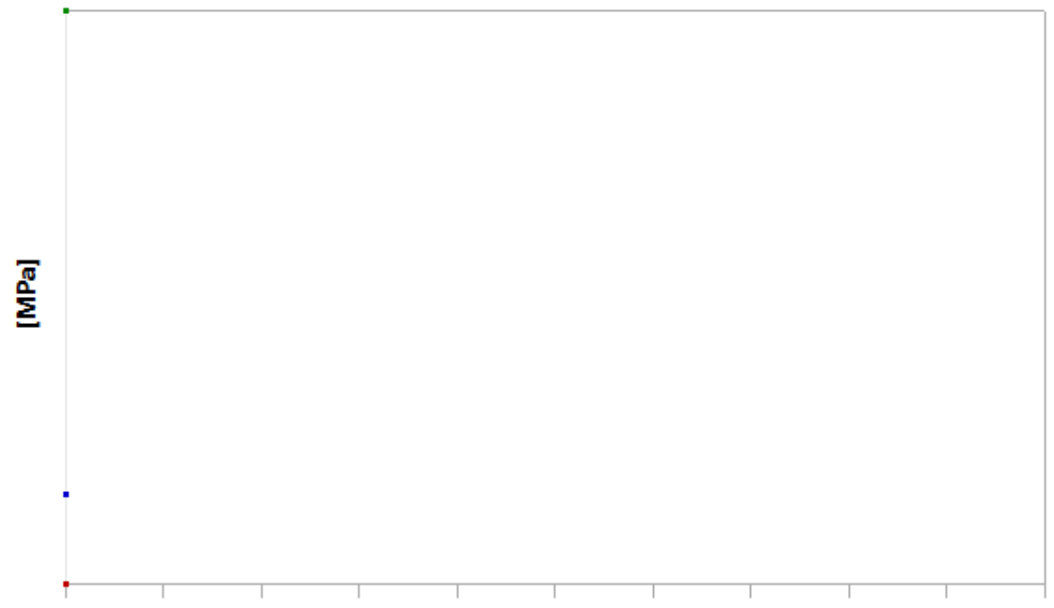

[s]

TABLE 15

Model (C4) > Static Structural (C5) $>$ Solution (C6) $>$ Equivalent Stress

Time [s] Minimum [MPa] Maximum [MPa] Average [MPa]

\begin{tabular}{l|l|l|r}
\hline 1. & 0.52937 & 193.69 & 31.029
\end{tabular}

FIGURE 11

Model (C4) > Static Structural (C5) $>$ Solution (C6) $>$ Equivalent Stress $>$ Figure 


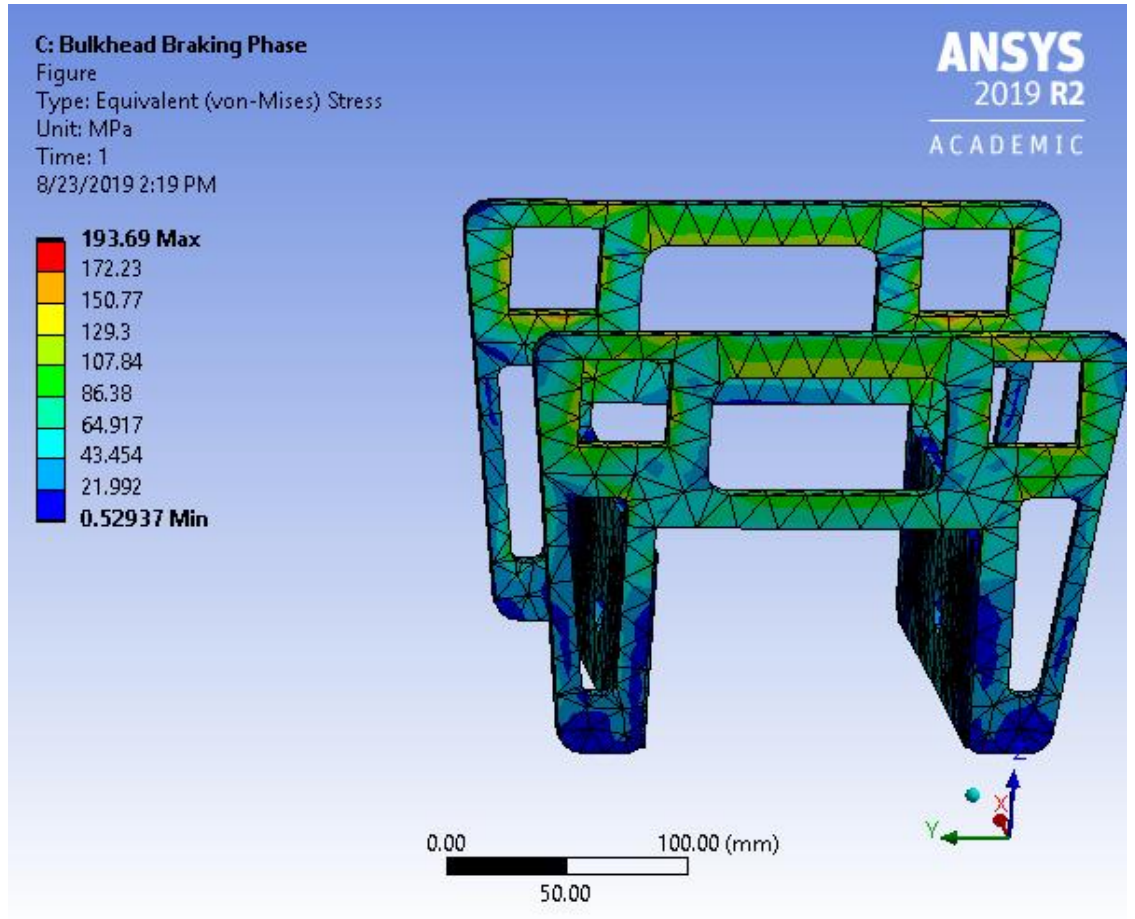

\section{Material Data}

\section{Aluminum Alloy}

TABLE 16

Aluminum Alloy $>$ Constants

\begin{tabular}{|r|c|}
\hline Density & $2.77 \mathrm{e}-006 \mathrm{~kg} \mathrm{~mm}^{\wedge}-3$ \\
\hline Coefficient of Thermal Expansion & $2.3 \mathrm{e}-005 \mathrm{C}^{\wedge}-1$ \\
\hline Specific Heat & $8.75 \mathrm{e}+005 \mathrm{~mJ} \mathrm{~kg}^{\wedge}-1 \mathrm{C}^{\wedge}-1$ \\
\hline \\
TABLE 17 \\
Thuminum Alloy $>$ Color \\
\begin{tabular}{rl|l|}
\hline Red & Green & Blue \\
\hline 138 & 104 & 46 \\
\hline
\end{tabular}
\end{tabular}

TABLE 18

Aluminum Alloy $>$ Compressive Ultimate Strength

Compressive Ultimate Strength $\mathrm{MPa}$ 
TABLE 19

Aluminum Alloy $>$ Compressive Yield Strength

Compressive Yield Strength $\mathrm{MPa}$

280

TABLE 20

Aluminum Alloy $>$ Tensile Yield Strength

Tensile Yield Strength MPa

280

TABLE 21

Aluminum Alloy $>$ Tensile Ultimate Strength

Tensile Ultimate Strength $\mathrm{MPa}$

310

TABLE 22

Aluminum Alloy $>$ Isotropic Secant Coefficient of Thermal Expansion

Zero-Thermal-Strain Reference Temperature C

22

TABLE 23

Aluminum Alloy $>$ Isotropic Thermal Conductivity Thermal Conductivity $\mathrm{W} \mathrm{mm}^{\wedge}-1 \mathrm{C}^{\wedge}-1$ Temperature $\mathrm{C}$

\begin{tabular}{|c|c|}
\hline 0.114 & -100 \\
\hline 0.144 & 0 \\
\hline 0.165 & 100 \\
\hline 0.175 & 200 \\
\hline
\end{tabular}

TABLE 24

Aluminum Alloy $>$ S-N Curve

Alternating Stress MPa Cycles R-Ratio

\begin{tabular}{|c|c|c|}
\hline 275.8 & 1700 & -1 \\
\hline 241.3 & 5000 & -1 \\
\hline 206.8 & 34000 & -1 \\
\hline 172.4 & $1.4 \mathrm{e}+005$ & -1 \\
\hline 137.9 & $8 . \mathrm{e}+005$ & -1 \\
\hline 117.2 & $2.4 \mathrm{e}+006$ & -1 \\
\hline 89.63 & $5.5 \mathrm{e}+007$ & -1 \\
\hline 82.74 & $1 . \mathrm{e}+008$ & -1 \\
\hline 170.6 & 50000 & -0.5 \\
\hline 139.6 & $3.5 \mathrm{e}+005$ & -0.5 \\
\hline 108.6 & $3.7 \mathrm{e}+006$ & -0.5 \\
\hline 87.91 & $1.4 \mathrm{e}+007$ & -0.5 \\
\hline 77.57 & $5 . \mathrm{e}+007$ & -0.5 \\
\hline 72.39 & $1 . \mathrm{e}+008$ & -0.5 \\
\hline 144.8 & 50000 & 0 \\
\hline 120.7 & $1.9 \mathrm{e}+005$ & 0 \\
\hline 103.4 & $1.3 \mathrm{e}+006$ & 0 \\
\hline 93.08 & $4.4 \mathrm{e}+006$ & 0 \\
\hline & & \\
\hline
\end{tabular}




\begin{tabular}{|c|c|c|}
\hline 86.18 & $1.2 \mathrm{e}+007$ & 0 \\
\hline 72.39 & $1 . e+008$ & 0 \\
\hline 74.12 & $3 . e+005$ & 0.5 \\
\hline 70.67 & $1.5 \mathrm{e}+006$ & 0.5 \\
\hline 66.36 & $1.2 \mathrm{e}+007$ & 0.5 \\
\hline 62.05 & $1 . e+008$ & 0.5 \\
\hline
\end{tabular}

TABLE 25

Aluminum Alloy > Isotropic Resistivity Resistivity ohm $\mathrm{mm}$ Temperature C

\begin{tabular}{|c|c|}
\hline $2.43 e-005$ & 0 \\
\hline $2.67 e-005$ & 20 \\
\hline $3.63 e-005$ & 100 \\
\hline
\end{tabular}

TABLE 26

Aluminum Alloy $>$ Isotropic Elasticity

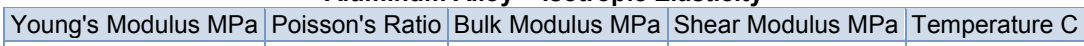

71000

0.33

69608

26692

TABLE 27

Aluminum Alloy > Isotropic Relative Permeability

Relative Permeability 
Appendix A.10 Chassis Load Case (Braking Phase) Analysis Report 


\section{MNSYS}

\section{Project}

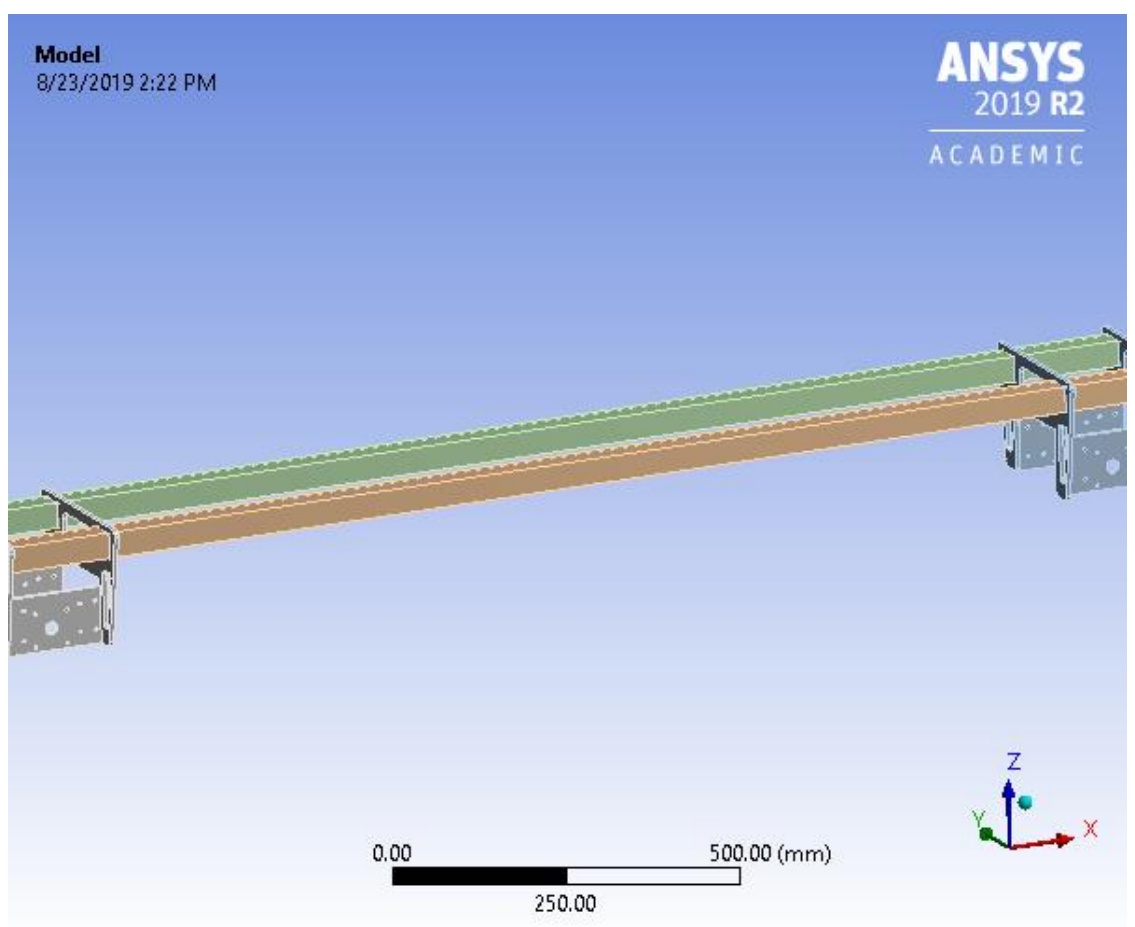




\section{Contents}

- Units

- Model (C4)

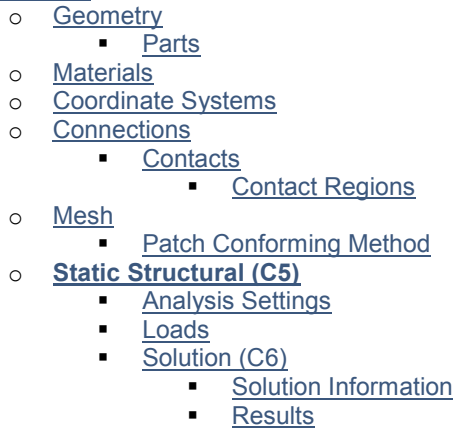

- Material Data

$\circ$ Aluminum Alloy

\section{Units}

TABLE 1

\begin{tabular}{|r|c|}
\hline Unit System & Metric $(\mathrm{mm}, \mathrm{kg}, \mathrm{N}, \mathrm{s}, \mathrm{mV}, \mathrm{mA})$ Degrees rad/s Celsius \\
\hline Angle & Degrees \\
\hline Rotational Velocity & rad/s \\
\hline Temperature & Celsius \\
\hline
\end{tabular}

\section{Model (C4)}

\section{Geometry}

TABLE 2

Model (C4) > Geometry

\begin{tabular}{|c|c|}
\hline & \\
\hline Object Name & Geometry \\
\hline State & Fully Defined \\
\hline & Definition \\
\hline Source & D:IRH_PRP_Chassis_PODAssembly_V1.2_YO_04012019.igs \\
\hline Type & Iges \\
\hline Length Unit & Millimeters \\
\hline Element Control & Program Controlled \\
\hline Display Style & Body Color \\
\hline & Bounding Box \\
\hline Length $\mathrm{X}$ & 1860. $\mathrm{mm}$ \\
\hline Length $Y$ & $251.5 \mathrm{~mm}$ \\
\hline
\end{tabular}




\begin{tabular}{|c|c|}
\hline Length Z & $182.12 \mathrm{~mm}$ \\
\hline \multicolumn{2}{|c|}{ Properties } \\
\hline Volume & $2.4121 \mathrm{e}+006 \mathrm{~mm}^{3}$ \\
\hline Mass & $6.6814 \mathrm{~kg}$ \\
\hline Scale Factor Value & 1. \\
\hline \multicolumn{2}{|c|}{ Statistics } \\
\hline Bodies & 4 \\
\hline Active Bodies & 4 \\
\hline Nodes & 25790 \\
\hline Elements & 12206 \\
\hline Mesh Metric & None \\
\hline \multicolumn{2}{|c|}{ Update Options } \\
\hline Assign Default Material & No \\
\hline \multicolumn{2}{|c|}{ Basic Geometry Options } \\
\hline Solid Bodies & Yes \\
\hline Surface Bodies & Yes \\
\hline Line Bodies & No \\
\hline Parameters & Independent \\
\hline Parameter Key & ANS;DS \\
\hline Attributes & No \\
\hline Named Selections & No \\
\hline Material Properties & No \\
\hline \multicolumn{2}{|c|}{ Advanced Geometry Options } \\
\hline Use Associativity & Yes \\
\hline Coordinate Systems & No \\
\hline Reader Mode Saves Updated File & No \\
\hline Use Instances & Yes \\
\hline Smart CAD Update & Yes \\
\hline Compare Parts On Update & No \\
\hline Analysis Type & 3-D \\
\hline Mixed Import Resolution & None \\
\hline Clean Bodies On Import & No \\
\hline Stitch Surfaces On Import & Program Tolerance \\
\hline Decompose Disjoint Geometry & Yes \\
\hline Enclosure and Symmetry Processing & Yes \\
\hline
\end{tabular}

TABLE 3

Model (C4) > Geometry > Parts

\begin{tabular}{|c|c|}
\hline Object Name & 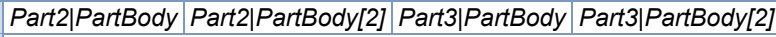 \\
\hline State & Meshed \\
\hline \multicolumn{2}{|r|}{ Graphics Properties } \\
\hline Visible & Yes \\
\hline Transparency & 1 \\
\hline \multicolumn{2}{|r|}{ Definition } \\
\hline Suppressed & No \\
\hline Stiffness Behavior & Flexible \\
\hline Coordinate System & Default Coordinate System \\
\hline Reference Temperature & By Environment \\
\hline Treatment & None \\
\hline
\end{tabular}




\begin{tabular}{|c|c|c|c|c|}
\hline \multicolumn{5}{|c|}{ Material } \\
\hline Assignment & \multicolumn{4}{|c|}{ Aluminum Alloy } \\
\hline Nonlinear Effects & \multicolumn{4}{|c|}{ Yes } \\
\hline Thermal Strain Effects & \multicolumn{4}{|c|}{ Yes } \\
\hline \multicolumn{5}{|c|}{ Bounding Box } \\
\hline Length $\mathrm{X}$ & \multicolumn{2}{|c|}{$172.7 \mathrm{~mm}$} & \multicolumn{2}{|c|}{ 1860. mm } \\
\hline Length $\mathrm{Y}$ & \multicolumn{2}{|c|}{$251.12 \mathrm{~mm}$} & \multicolumn{2}{|c|}{$38.1 \mathrm{~mm}$} \\
\hline Length Z & \multicolumn{2}{|c|}{$182.12 \mathrm{~mm}$} & \multicolumn{2}{|c|}{$38.1 \mathrm{~mm}$} \\
\hline \multicolumn{5}{|c|}{ Properties } \\
\hline Volume & \multicolumn{2}{|c|}{$3.8104 \mathrm{e}+005 \mathrm{~mm}^{3}$} & \multicolumn{2}{|c|}{$8.25 \mathrm{e}+005 \mathrm{~mm}^{3}$} \\
\hline Mass & \multicolumn{2}{|c|}{$1.0555 \mathrm{~kg}$} & \multicolumn{2}{|c|}{$2.2852 \mathrm{~kg}$} \\
\hline Centroid X & $117.42 \mathrm{~mm}$ & $1803.7 \mathrm{~mm}$ & \multicolumn{2}{|c|}{$960.67 \mathrm{~mm}$} \\
\hline Centroid $Y$ & $-4.2843 \mathrm{~mm}$ & $-4.6664 \mathrm{~mm}$ & $81.897 \mathrm{~mm}$ & $-90.823 \mathrm{~mm}$ \\
\hline Centroid Z & \multicolumn{2}{|c|}{$30.577 \mathrm{~mm}$} & $103.1 \mathrm{~mm}$ & $103.31 \mathrm{~mm}$ \\
\hline Moment of Inertia Ip1 & \multicolumn{2}{|c|}{$9126.2 \mathrm{~kg} \cdot \mathrm{mm}^{2}$} & \multicolumn{2}{|c|}{$936.83 \mathrm{~kg} \cdot \mathrm{mm}^{2}$} \\
\hline Moment of Inertia Ip2 & \multicolumn{2}{|c|}{$8230.3 \mathrm{~kg} \cdot \mathrm{mm}^{2}$} & \multicolumn{2}{|c|}{$6.593 \mathrm{e}+005 \mathrm{~kg} \cdot \mathrm{mm}^{2}$} \\
\hline Moment of Inertia Ip3 & \multicolumn{2}{|c|}{$11149 \mathrm{~kg} \cdot \mathrm{mm}^{2}$} & \\
\hline \multicolumn{3}{|r|}{ Statistics } & \multicolumn{2}{|c|}{$6.593 \mathrm{e}+005 \mathrm{~kg} \cdot \mathrm{mm}^{2}$} \\
\hline Nodes & \multicolumn{2}{|c|}{10838} & \multicolumn{2}{|c|}{2057} \\
\hline Elements & \multicolumn{2}{|c|}{5090} & \multicolumn{2}{|c|}{1013} \\
\hline Mesh Metric & \multicolumn{4}{|c|}{ None } \\
\hline
\end{tabular}

FIGURE 1

Model (C4) > Geometry > Figure 


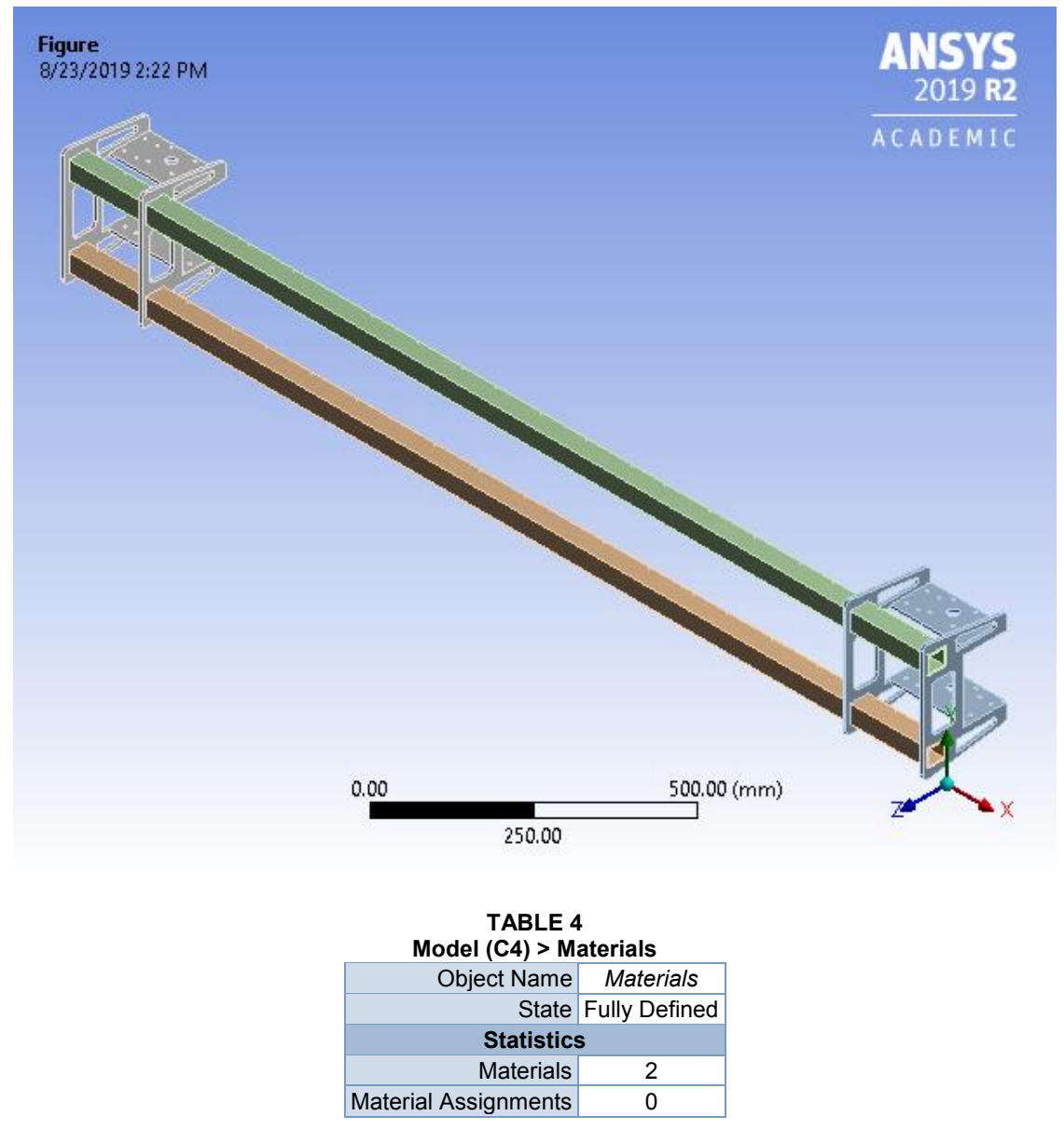

Coordinate Systems

TABLE 5

Model (C4) > Coordinate Systems > Coordinate System

\begin{tabular}{|r|c|}
\hline $\begin{array}{r}\text { Object Name } \\
\text { State }\end{array}$ & Global Coordinate System \\
Definition & Fully Defined \\
\hline Type & Cartesian \\
\hline Coordinate System ID & 0. \\
\hline \multicolumn{2}{|c|}{ Origin } \\
\hline Origin X & $0 . \mathrm{mm}$ \\
\hline
\end{tabular}




\begin{tabular}{|r|r|}
\hline Origin $Y$ & $0 . \mathrm{mm}$ \\
\hline Origin Z & $0 . \mathrm{mm}$ \\
\hline \multicolumn{2}{|c|}{ Directional Vectors } \\
\hline X Axis Data & {$[1.0 .0]$.} \\
\hline Y Axis Data & {$[0.1 .0]$.} \\
\hline Z Axis Data & {$[0.0 .1]$.} \\
\hline
\end{tabular}

\section{Connections}

TABLE 6

Model (C4) > Connections

Object Name Connections

\begin{tabular}{|c|c|}
\hline \\
\hline Object Name & Connections \\
\hline State & Fully Defined \\
\hline \multicolumn{2}{|l|}{ Auto Detection } \\
\hline Generate Automatic Connection On Refresh & Yes \\
\hline \multicolumn{2}{|l|}{ Transparency } \\
\hline Enabled & Yes \\
\hline
\end{tabular}

TABLE 7

Model (C4) $>$ Connections $>$ Contacts

\begin{tabular}{|c|c|}
\hline Object Name & Contacts \\
\hline State & Fully Defined \\
\hline \multicolumn{2}{|c|}{ Definition } \\
\hline Connection Type & Contact \\
\hline \multicolumn{2}{|l|}{ Scope } \\
\hline Scoping Method & Geometry Selection \\
\hline Geometry & All Bodies \\
\hline \multicolumn{2}{|c|}{ Auto Detection } \\
\hline Tolerance Type & Slider \\
\hline Tolerance Slider & 0. \\
\hline Tolerance Value & $4.7144 \mathrm{~mm}$ \\
\hline Use Range & No \\
\hline Face/Face & Yes \\
\hline Face-Face Angle Tolerance & $75 .^{\circ}$ \\
\hline Face Overlap Tolerance & Off \\
\hline Cylindrical Faces & Include \\
\hline Face/Edge & No \\
\hline Edge/Edge & No \\
\hline Priority & Include All \\
\hline Group By & Bodies \\
\hline Search Across & Bodies \\
\hline \multicolumn{2}{|c|}{ Statistics } \\
\hline Connections & 4 \\
\hline Active Connections & 4 \\
\hline
\end{tabular}

TABLE 8

Model (C4) > Connections > Contacts > Contact Regions

\begin{tabular}{l|l|l|l|l|} 
Object Name & Contact Region & Contact Region 2 & Contact Region 3 & Contact Region 4
\end{tabular} State

Fully Defined 


\begin{tabular}{|c|c|c|c|}
\hline \multicolumn{4}{|c|}{ Scope } \\
\hline Scoping Method & \multicolumn{3}{|c|}{ Geometry Selection } \\
\hline Contact & \multicolumn{3}{|c|}{8 Faces } \\
\hline Target & \multicolumn{3}{|c|}{4 Faces } \\
\hline Contact Bodies & Part2|PartBody & \multicolumn{2}{|c|}{ Part2|PartBody[2] } \\
\hline Target Bodies & \begin{tabular}{|l|l|} 
Part3|PartBody & Part3|PartBody[2]
\end{tabular} & Part3|PartBody & Part3|PartBody[2] \\
\hline Protected & \multicolumn{3}{|c|}{ No } \\
\hline \multicolumn{4}{|c|}{ Definition } \\
\hline Type & \multicolumn{3}{|c|}{ Bonded } \\
\hline Scope Mode & \multicolumn{3}{|c|}{ Automatic } \\
\hline Behavior & \multicolumn{3}{|c|}{ Program Controlled } \\
\hline Trim Contact & \multicolumn{3}{|c|}{ Program Controlled } \\
\hline Trim Tolerance & \multicolumn{3}{|c|}{$4.7144 \mathrm{~mm}$} \\
\hline Suppressed & \multicolumn{3}{|c|}{ No } \\
\hline \multicolumn{4}{|c|}{ Advanced } \\
\hline Formulation & \multicolumn{3}{|c|}{ Program Controlled } \\
\hline Small Sliding & \multicolumn{3}{|c|}{ Program Controlled } \\
\hline Detection Method & \multicolumn{3}{|c|}{ Program Controlled } \\
\hline Penetration Tolerance & \multicolumn{3}{|c|}{ Program Controlled } \\
\hline Elastic Slip Tolerance & \multicolumn{3}{|c|}{ Program Controlled } \\
\hline Normal Stiffness & \multicolumn{3}{|c|}{ Program Controlled } \\
\hline Update Stiffness & \multicolumn{3}{|c|}{ Program Controlled } \\
\hline Pinball Region & \multicolumn{3}{|c|}{ Program Controlled } \\
\hline \multicolumn{4}{|c|}{ Geometric Modification } \\
\hline Contact Geometry Correction & \multicolumn{3}{|c|}{ None } \\
\hline Target Geometry Correction & \multicolumn{3}{|c|}{ None } \\
\hline
\end{tabular}

Mesh

TABLE 9

Model (C4) > Mesh

\begin{tabular}{|r|c|}
\hline State & Solved \\
\hline Display & \\
\hline Display Style & Use Geometry Setting \\
\hline Defaults & \\
\hline Physics Preference & Mechanical \\
\hline Element Order & Program Controlled \\
\hline Element Size & Default \\
\hline Sizing & \\
\hline Use Adaptive Sizing & Yes \\
\hline Resolution & Default (2) \\
\hline Mesh Defeaturing & Yes \\
\hline Defeature Size & Default \\
\hline Transition & Fast \\
\hline Span Angle Center & Coarse \\
\hline Initial Size Seed & Assembly \\
\hline Bounding Box Diagonal & 1885.7 mm \\
\hline
\end{tabular}




\begin{tabular}{|c|c|}
\hline Average Surface Area & $4094.8 \mathrm{~mm}^{2}$ \\
\hline Minimum Edge Length & $0.21228 \mathrm{~mm}$ \\
\hline \multicolumn{2}{|l|}{ Quality } \\
\hline Check Mesh Quality & Yes, Errors \\
\hline Error Limits & Standard Mechanical \\
\hline Target Quality & Default $(0.050000)$ \\
\hline Smoothing & Medium \\
\hline Mesh Metric & None \\
\hline \multicolumn{2}{|l|}{ Inflation } \\
\hline Use Automatic Inflation & None \\
\hline Inflation Option & Smooth Transition \\
\hline Transition Ratio & 0.272 \\
\hline Maximum Layers & 5 \\
\hline Growth Rate & 1.2 \\
\hline Inflation Algorithm & Pre \\
\hline View Advanced Options & No \\
\hline \multicolumn{2}{|l|}{ Advanced } \\
\hline Number of CPUs for Parallel Part Meshing & Program Controlled \\
\hline Straight Sided Elements & No \\
\hline Rigid Body Behavior & Dimensionally Reduced \\
\hline Triangle Surface Mesher & Program Controlled \\
\hline Topology Checking & Yes \\
\hline Pinch Tolerance & Please Define \\
\hline Generate Pinch on Refresh & No \\
\hline \multicolumn{2}{|l|}{ Statistics } \\
\hline Nodes & 25790 \\
\hline Elements & 12206 \\
\hline
\end{tabular}

TABLE 10

Model (C4) > Mesh > Mesh Controls

\begin{tabular}{|r|c|}
\hline Object Name & Patch Conforming Method \\
\hline State & Fully Defined \\
Scope \\
\hline Scoping Method & Geometry Selection \\
\hline Geometry & 4 Bodies \\
\hline Definition \\
\hline Method & No \\
\hline Algorithm & Patch Conforming \\
\hline Element Order & Use Global Setting \\
\hline
\end{tabular}

FIGURE 2

Model (C4) > Mesh > Figure 


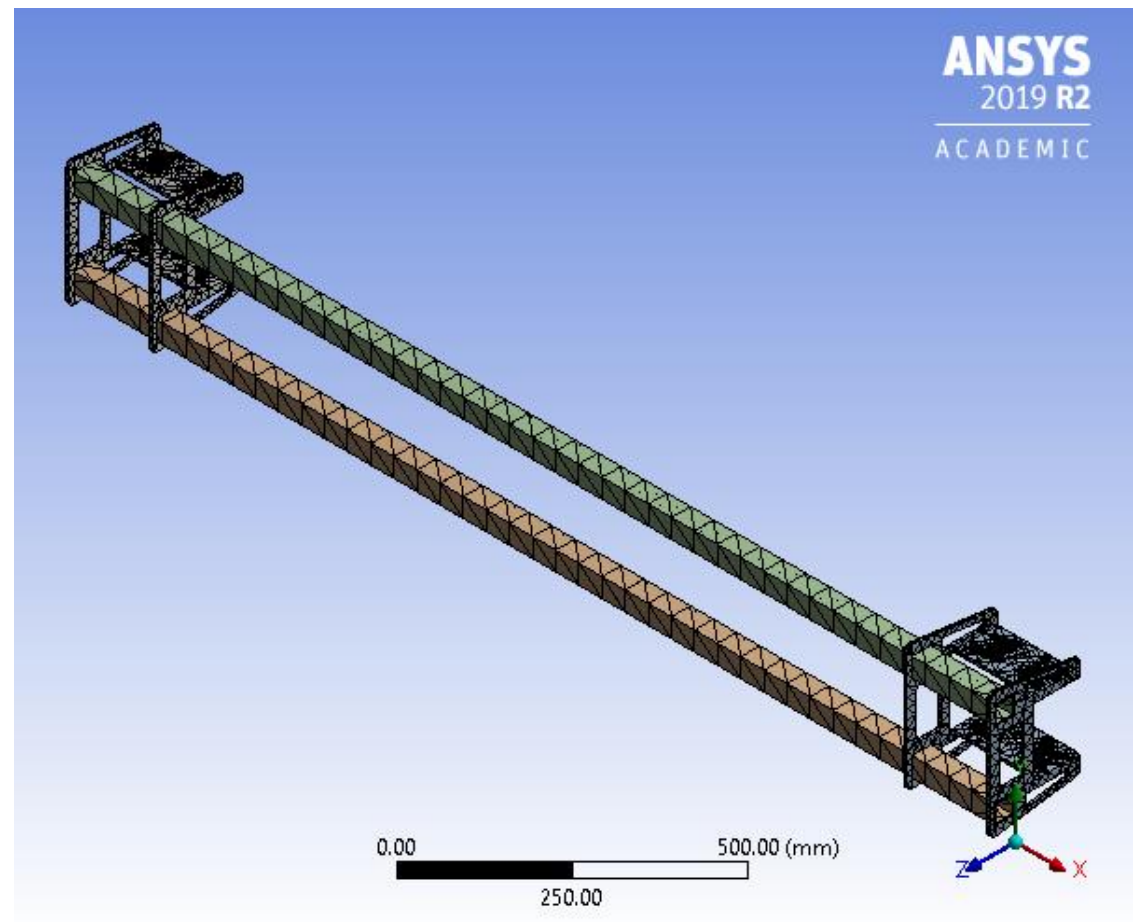

\section{Static Structural (C5)}

TABLE 11

Model (C4) > Analysis

\begin{tabular}{|c|c|}
\hline \multicolumn{2}{|c|}{ 4) - AII } \\
\hline Object Name & Static Structural (C5) \\
\hline State & Solved \\
\hline \multicolumn{2}{|c|}{ Definition } \\
\hline Physics Type & Structural \\
\hline Analysis Type & Static Structural \\
\hline Solver Target & Mechanical APDL \\
\hline \multicolumn{2}{|c|}{ Options } \\
\hline Environment Temperature & 22. ${ }^{\circ} \mathrm{C}$ \\
\hline Generate Input Only & No \\
\hline
\end{tabular}

TABLE 12

Model (C4) $>$ Static Structural (C5) $>$ Analysis Settings 


\begin{tabular}{|c|c|}
\hline Number Of Steps & 1. \\
\hline Current Step Number & 1. \\
\hline Step End Time & 1. $\mathrm{s}$ \\
\hline Auto Time Stepping & Program Controlled \\
\hline \multicolumn{2}{|r|}{ Solver Controls } \\
\hline Solver Type & Program Controlled \\
\hline Weak Springs & Off \\
\hline Solver Pivot Checking & Program Controlled \\
\hline Large Deflection & Off \\
\hline Inertia Relief & Off \\
\hline \multicolumn{2}{|r|}{ Rotordynamics Controls } \\
\hline Coriolis Effect & Off \\
\hline \multicolumn{2}{|r|}{ Restart Controls } \\
\hline $\begin{array}{r}\text { Generate Restart } \\
\text { Points }\end{array}$ & Program Controlled \\
\hline $\begin{array}{r}\text { Retain Files After Full } \\
\text { Solve }\end{array}$ & No \\
\hline Combine Restart Files & Program Controlled \\
\hline \multicolumn{2}{|r|}{ Nonlinear Controls } \\
\hline $\begin{array}{r}\text { Newton-Raphson } \\
\text { Option }\end{array}$ & Program Controlled \\
\hline Force Convergence & Program Controlled \\
\hline Moment Convergence & Program Controlled \\
\hline $\begin{array}{l}\text { Displacement } \\
\text { Convergence }\end{array}$ & Program Controlled \\
\hline Rotation Convergence & Program Controlled \\
\hline Line Search & Program Controlled \\
\hline Stabilization & Program Controlled \\
\hline \multicolumn{2}{|r|}{ Output Controls } \\
\hline Stress & Yes \\
\hline Surface Stress & No \\
\hline Back Stress & No \\
\hline Strain & Yes \\
\hline Contact Data & Yes \\
\hline Nonlinear Data & No \\
\hline Nodal Forces & No \\
\hline Contact Miscellaneous & No \\
\hline General Miscellaneous & No \\
\hline Store Results At & All Time Points \\
\hline $\begin{array}{r}\text { Result File } \\
\text { Compression }\end{array}$ & Program Controlled \\
\hline \multicolumn{2}{|r|}{ Analysis Data Management } \\
\hline Solver Files Directory & $\begin{array}{c}\text { C:IUsersIDIAPM599|OneDrive - Dentsply SironalDesktopIANSYS } \\
\text { Analysis।Chassis_filesldp0ISYSIMECH }\end{array}$ \\
\hline Future Analysis & None \\
\hline $\begin{array}{r}\text { Scratch Solver Files } \\
\text { Directory }\end{array}$ & \\
\hline Save MAPDL db & No \\
\hline Contact Summary & Program Controlled \\
\hline
\end{tabular}




\begin{tabular}{|r|c|}
\hline Delete Unneeded Files & Yes \\
\hline Nonlinear Solution & No \\
\hline Solver Units & Active System \\
\hline Solver Unit System & $\mathrm{nmm}$ \\
\hline
\end{tabular}

TABLE 13

Model (C4) $>$ Static Structural (C5) $>$ Loads

\begin{tabular}{|c|c|c|c|c|c|c|c|c|c|c|c|}
\hline $\begin{array}{l}\text { Object } \\
\text { Name }\end{array}$ & $\begin{array}{l}\text { Thermal } \\
\text { Condition }\end{array}$ & $\begin{array}{c}\text { BRK } \\
\text { Force }\end{array}$ & $\begin{array}{c}\text { BRK } \\
\text { Force }\end{array}$ & $\begin{array}{c}\text { BRK } \\
\text { Force }\end{array}$ & $\begin{array}{c}\text { BRK } \\
\text { Force }\end{array}$ & $\begin{array}{c}\text { MagLev } \\
\text { Force }\end{array}$ & $\begin{array}{c}\text { MagLev } \\
\text { Force }\end{array}$ & $\begin{array}{c}\text { MagLev } \\
\text { Force }\end{array}$ & $\begin{array}{c}\text { MagLev } \\
\text { Force }\end{array}$ & $\begin{array}{c}\text { LIM \& } \\
\text { GNC } \\
\text { Force }\end{array}$ & $\begin{array}{c}\text { LIM \& } \\
\text { GNC } \\
\text { Force }\end{array}$ \\
\hline State & \multicolumn{11}{|c|}{ Fully Defined } \\
\hline \multicolumn{12}{|c|}{ Scope } \\
\hline $\begin{array}{l}\text { Scoping } \\
\text { Method }\end{array}$ & \multicolumn{11}{|c|}{ Geometry Selection } \\
\hline Geometry & 4 Bodies & \multicolumn{10}{|c|}{1 Face } \\
\hline \multicolumn{12}{|c|}{ Definition } \\
\hline Type & $\begin{array}{l}\text { Thermal } \\
\text { Condition }\end{array}$ & \multicolumn{10}{|c|}{ Force } \\
\hline Magnitude & $\begin{array}{c}80 .{ }^{\circ} \mathrm{C} \\
\text { (ramped) }\end{array}$ & & & & & & & & & & \\
\hline Suppressed & \multicolumn{11}{|c|}{ No } \\
\hline Define By & & \multicolumn{10}{|c|}{ Components } \\
\hline $\begin{array}{r}\text { Coordinate } \\
\text { System }\end{array}$ & & \multicolumn{10}{|c|}{ Global Coordinate System } \\
\hline $\begin{array}{r}\mathrm{X} \\
\text { Component }\end{array}$ & & \multicolumn{10}{|c|}{ 0. N (ramped) } \\
\hline $\begin{array}{r}\mathrm{Y} \\
\text { Component }\end{array}$ & & \multicolumn{10}{|c|}{ 0. N (ramped) } \\
\hline $\begin{array}{r}\text { Z } \\
\text { Component }\end{array}$ & & \multicolumn{4}{|c|}{-37. N (ramped) } & \multicolumn{4}{|c|}{-42. N (ramped) } & \multicolumn{2}{|c|}{$\begin{array}{c}\text {-202. N } \\
\text { (ramped) }\end{array}$} \\
\hline
\end{tabular}

FIGURE 3

Model (C4) > Static Structural (C5) > Thermal Condition 


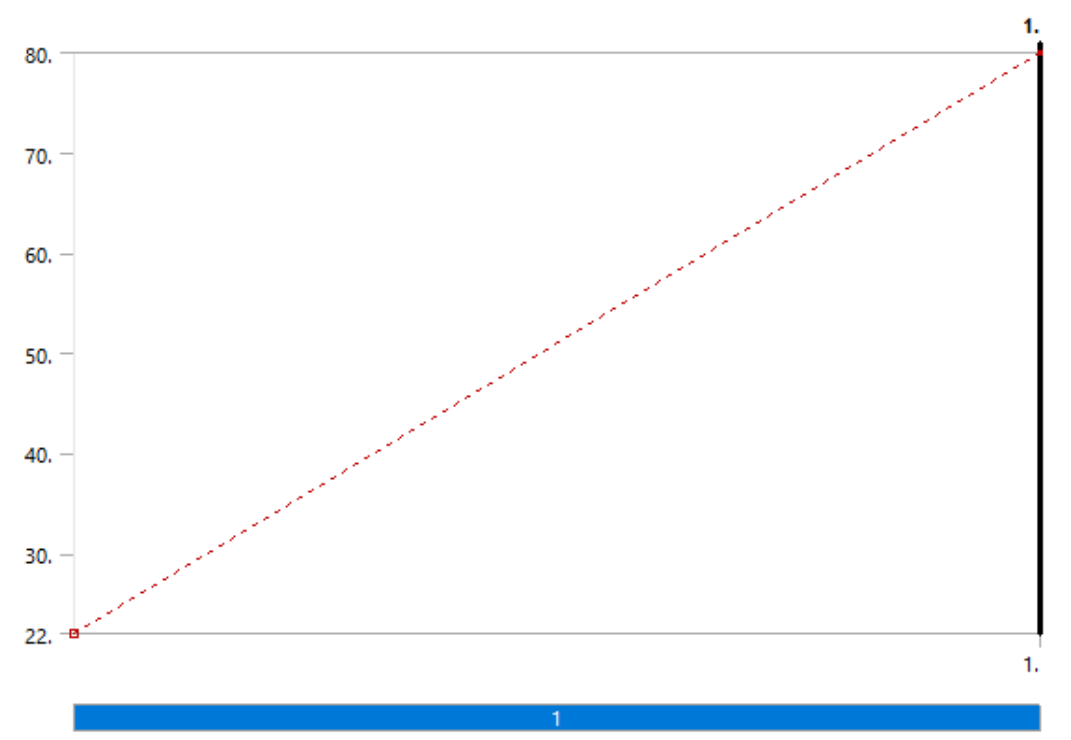

FIGURE 4

Model (C4) > Static Structural (C5) > BRK Force

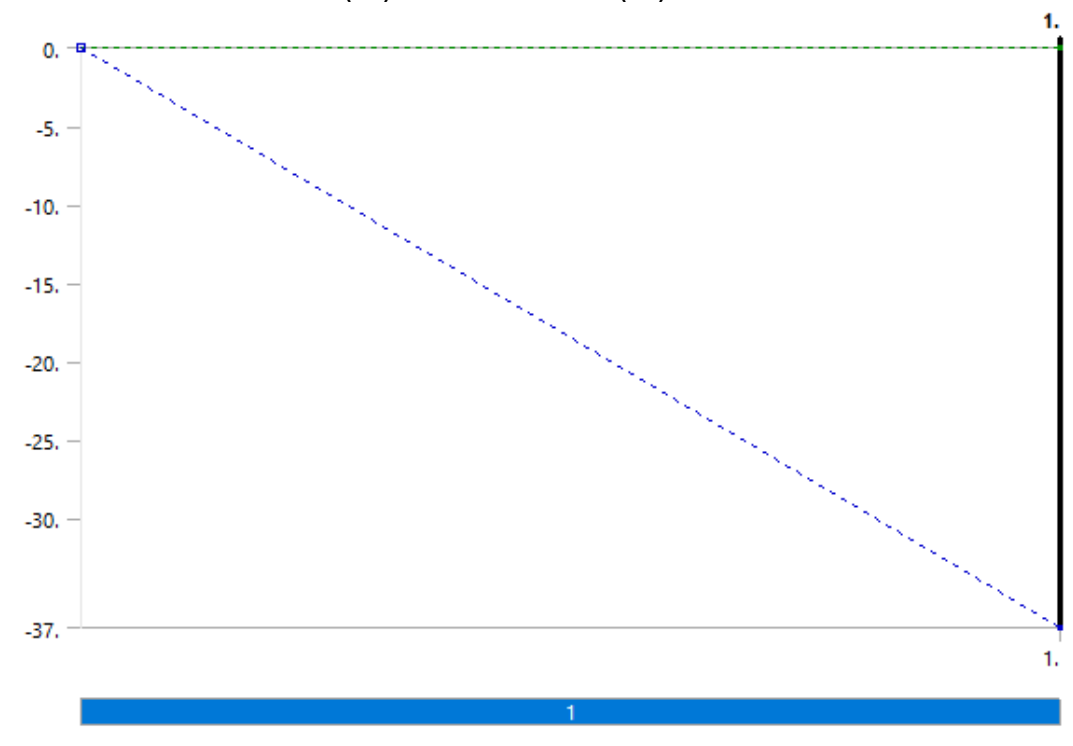


FIGURE 5

Model (C4) > Static Structural (C5) > BRK Force

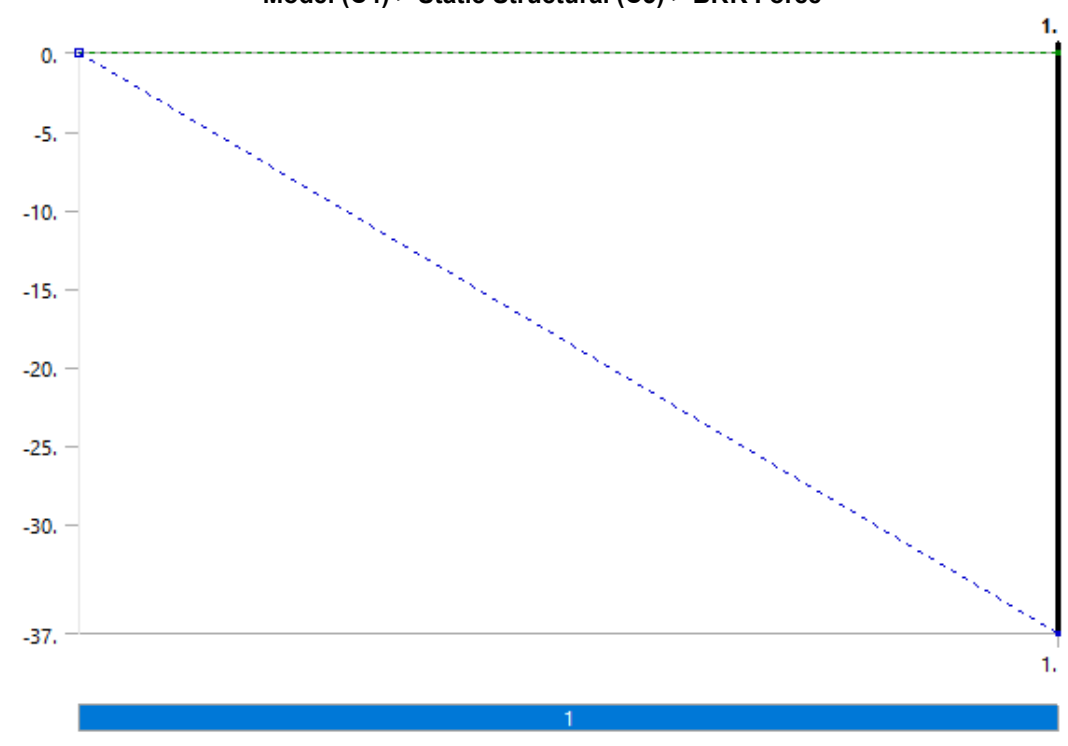

FIGURE 6

Model (C4) > Static Structural (C5) > BRK Force 


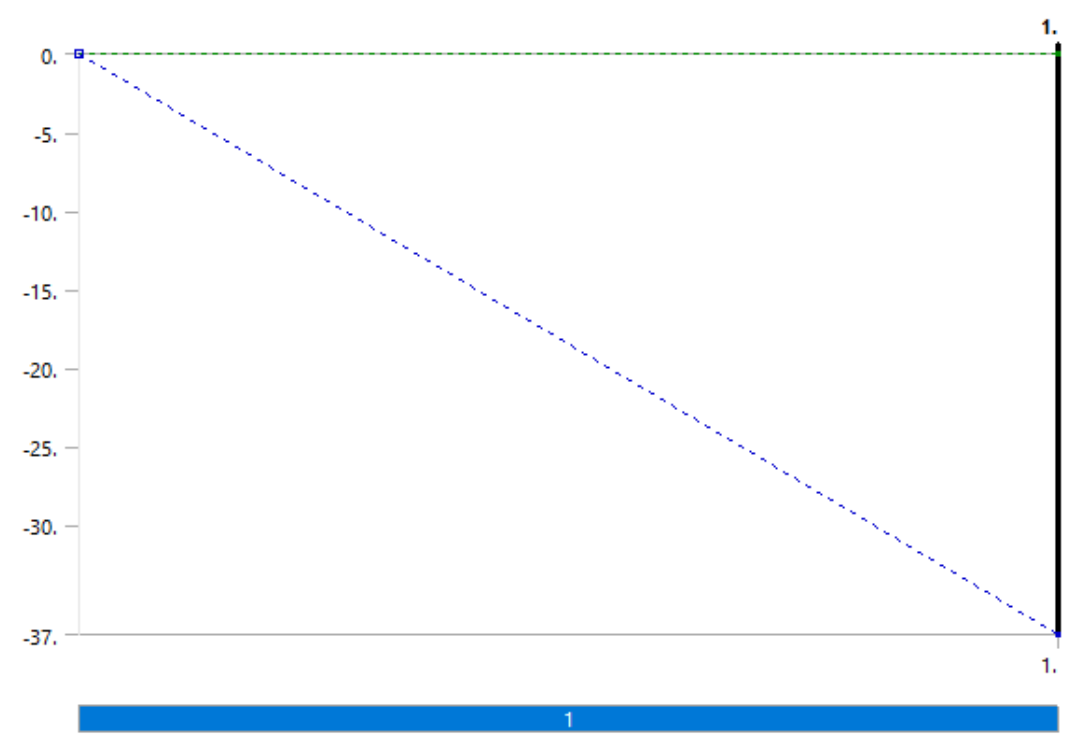

FIGURE 7

Model (C4) > Static Structural (C5) > BRK Force

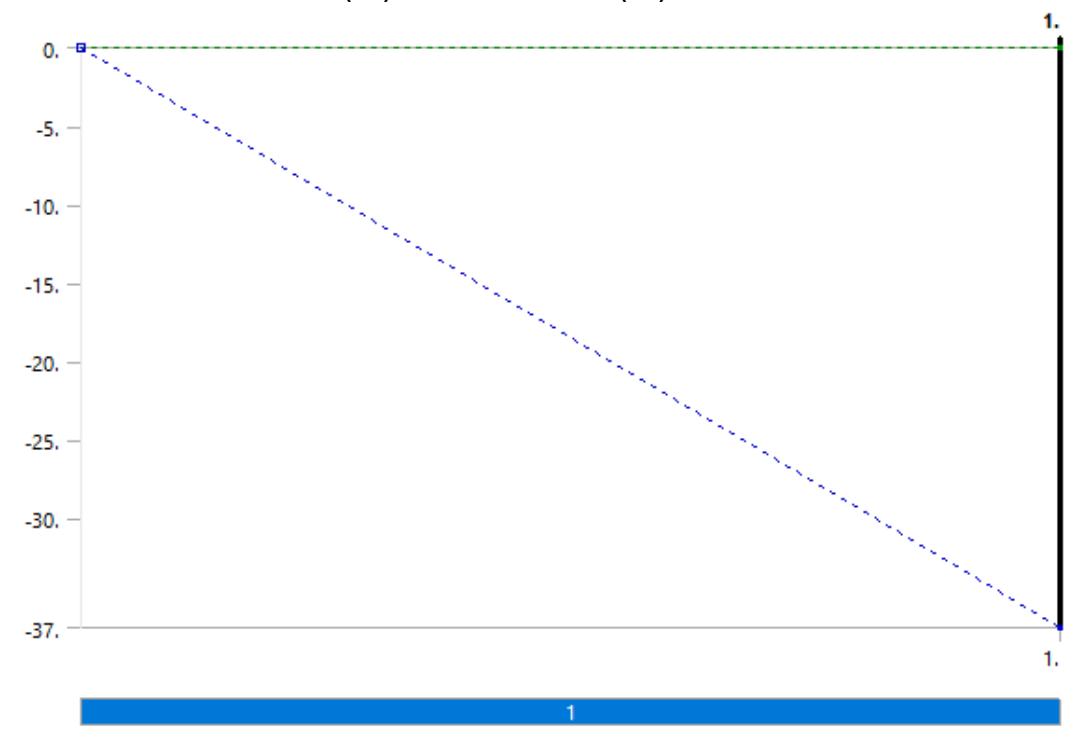


FIGURE 8

Model (C4) > Static Structural (C5) $>$ MagLev Force

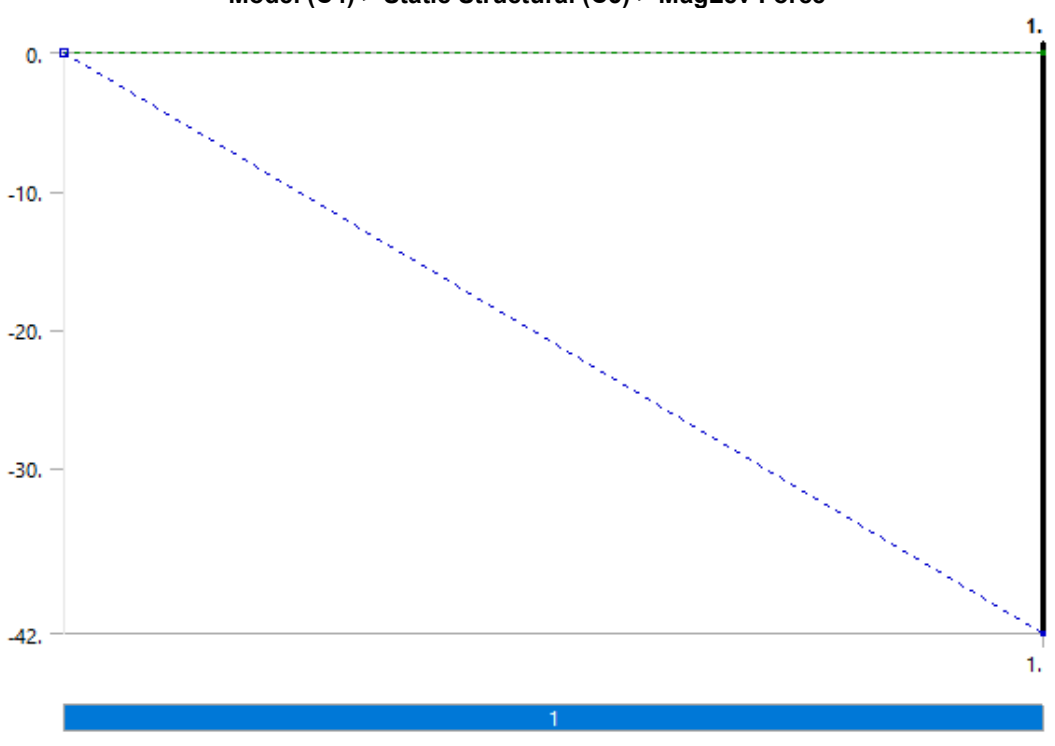

FIGURE 9

Model (C4) > Static Structural (C5) > MagLev Force 


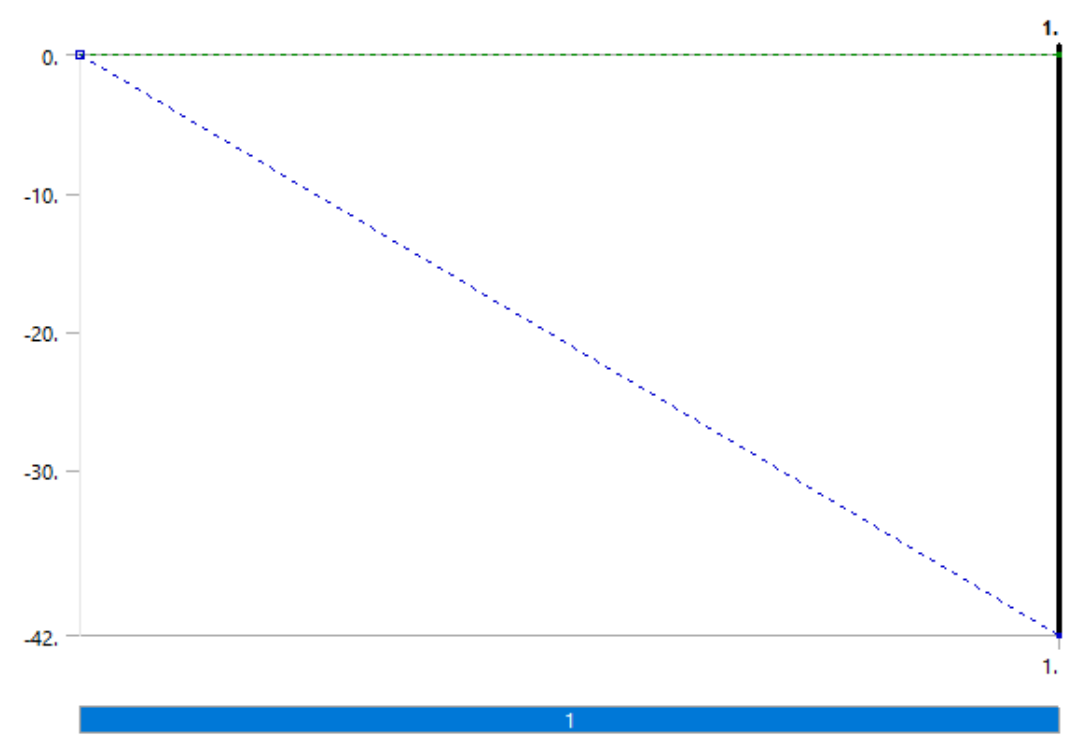

FIGURE 10

Model (C4) > Static Structural (C5) > MagLev Force

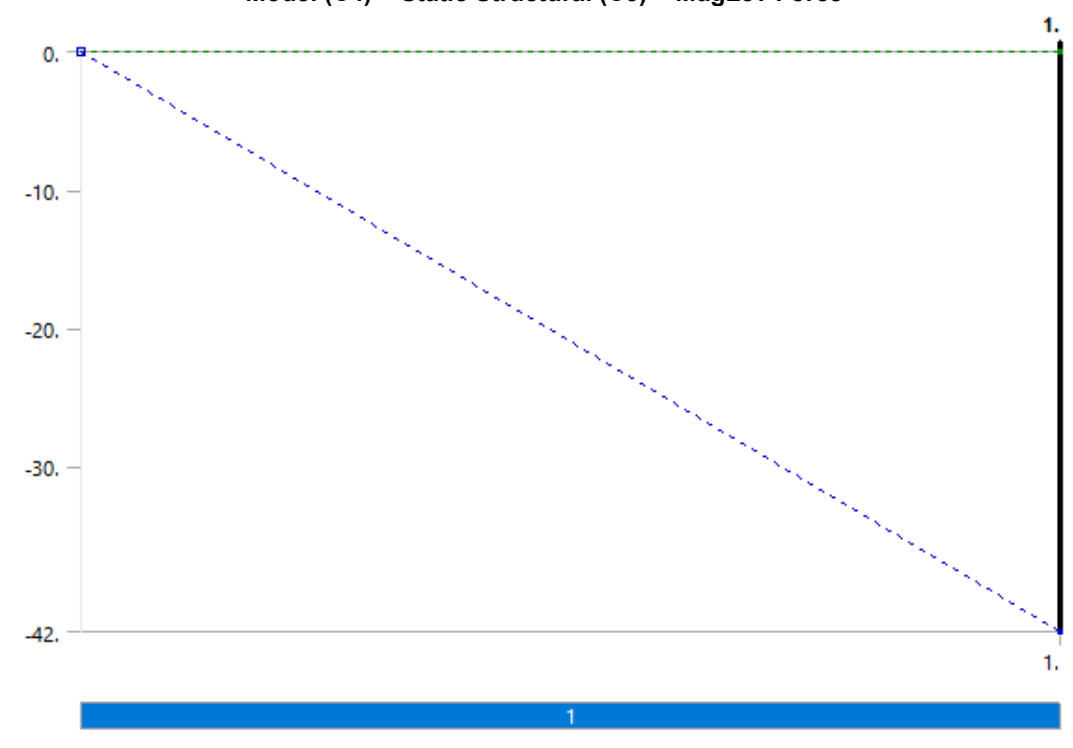


FIGURE 11

Model (C4) > Static Structural (C5) $>$ MagLev Force

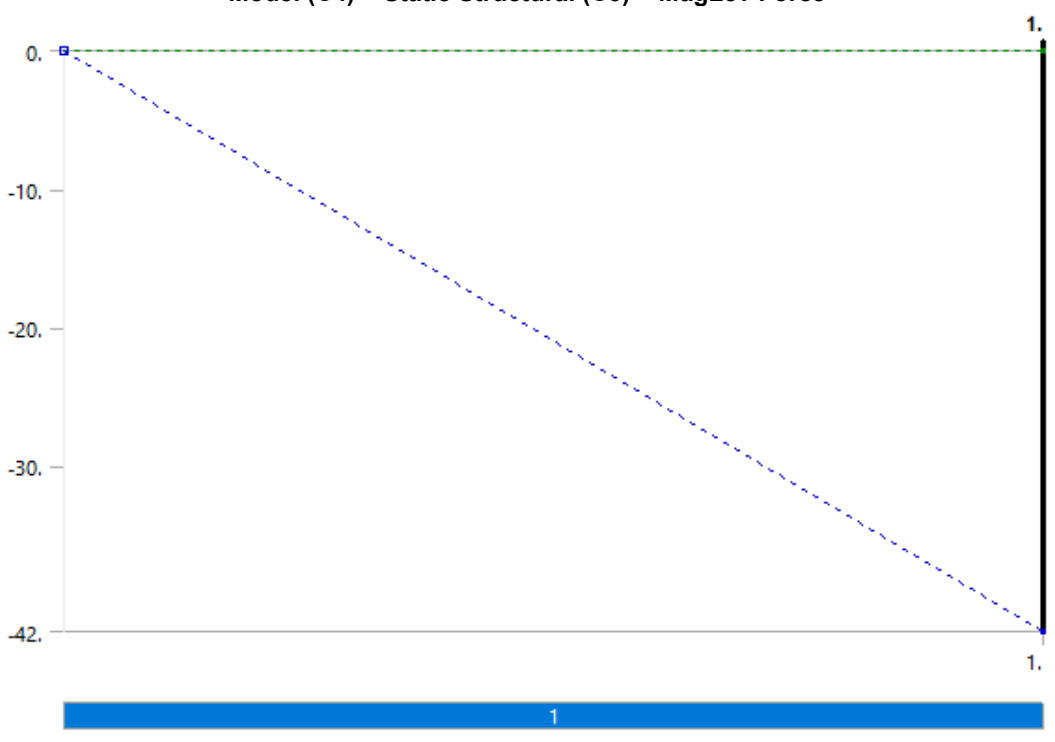

FIGURE 12

Model (C4) > Static Structural (C5) > LIM \& GNC Force 


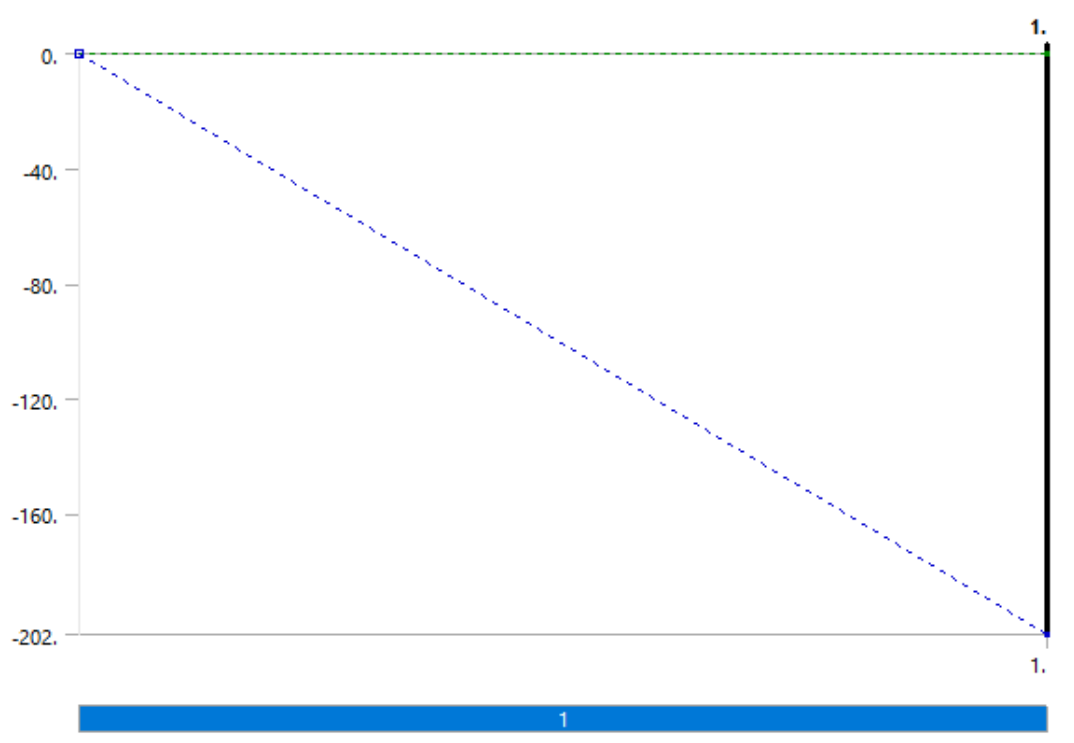

FIGURE 13

Model (C4) > Static Structural (C5) > LIM \& GNC Force

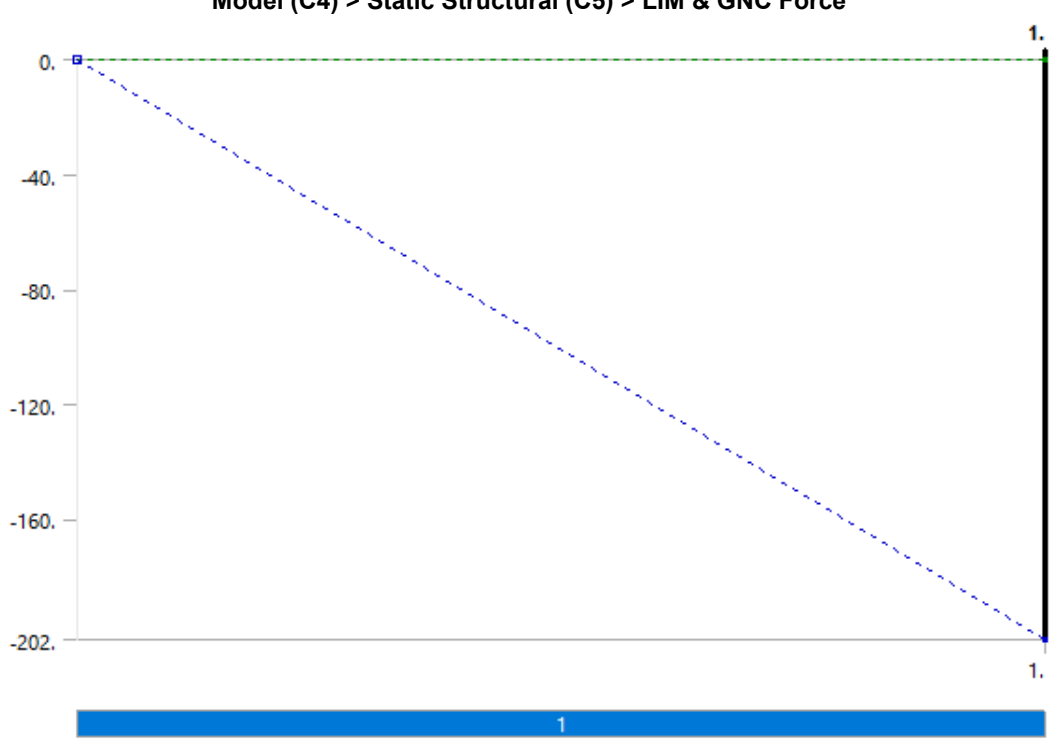


TABLE 14

Model (C4) > Static Structural (C5) $>$ Loads

\begin{tabular}{|c|c|c|c|c|c|c|}
\hline Object Name & BRK Force & BRK Force & BRK Force & BRK Force & Lockup Force & Fixed Support \\
\hline State & \multicolumn{6}{|c|}{ Fully Defined } \\
\hline \multicolumn{7}{|c|}{ Scope } \\
\hline Scoping Method & \multicolumn{6}{|c|}{ Geometry Selection } \\
\hline Geometry & \multicolumn{6}{|c|}{1 Face } \\
\hline \multicolumn{7}{|c|}{ Definition } \\
\hline Type & \multirow{2}{*}{\multicolumn{5}{|c|}{$\begin{array}{l}\text { Force } \\
\text { Vector }\end{array}$}} & Fixed Support \\
\hline Define By & & & & & & \\
\hline Magnitude & \multicolumn{5}{|c|}{$\begin{array}{l}\text { Vector } \\
\text { 1957. N (ramped) }\end{array}$} & \\
\hline Direction & \multicolumn{5}{|c|}{ Defined } & \\
\hline Suppressed & \multicolumn{6}{|c|}{ No } \\
\hline
\end{tabular}

FIGURE 14

Model (C4) > Static Structural (C5) > BRK Force

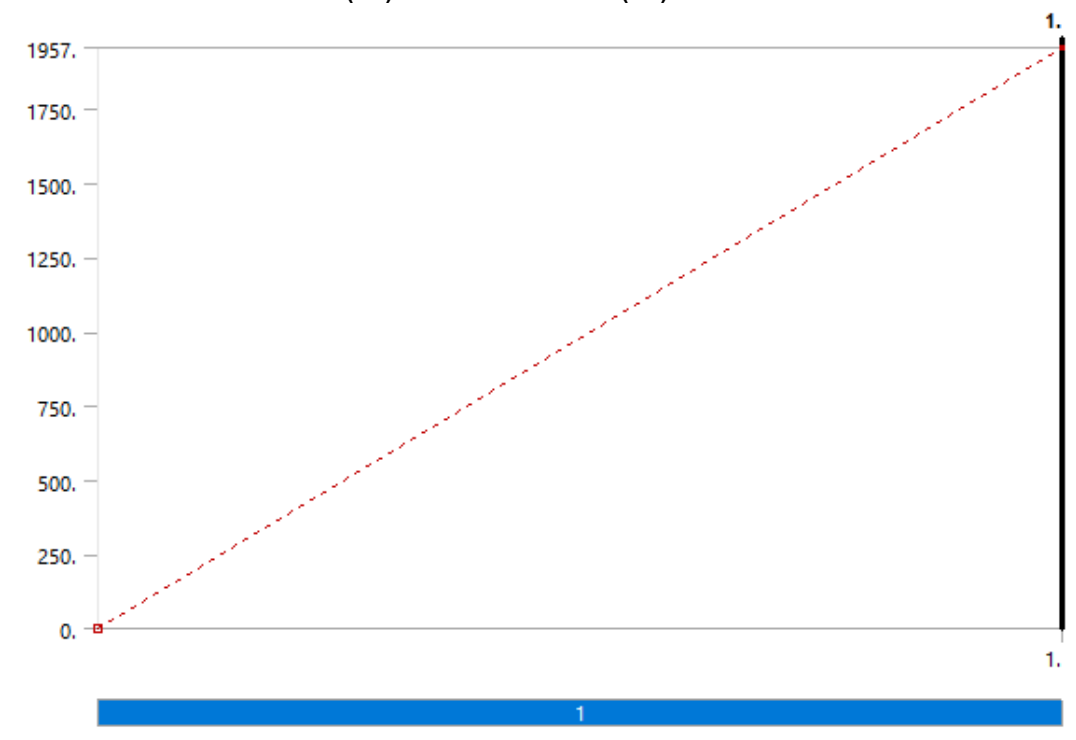

FIGURE 15

Model (C4) > Static Structural (C5) > BRK Force 


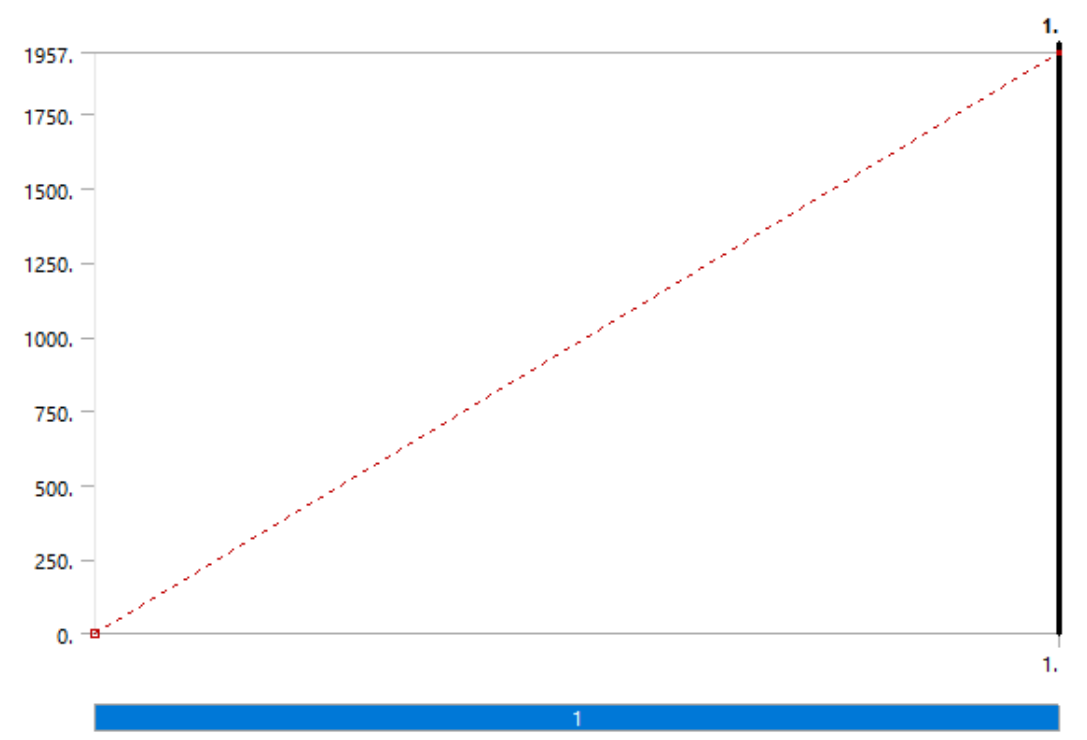

FIGURE 16

Model (C4) > Static Structural (C5) > BRK Force

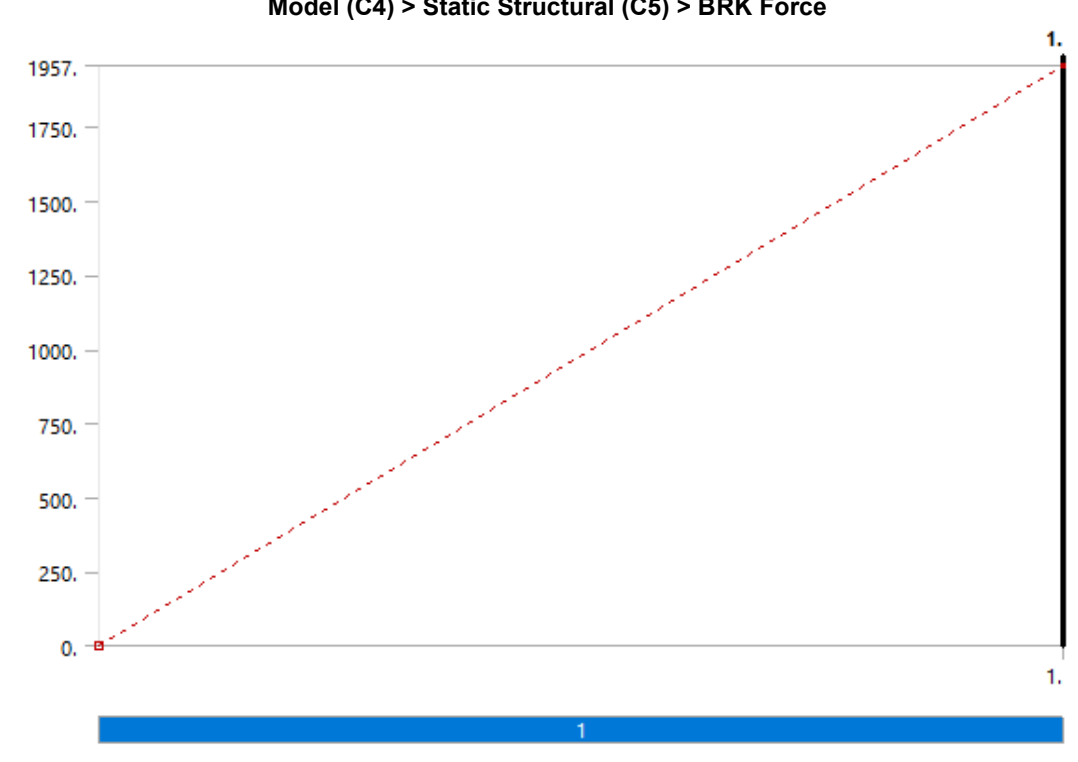


FIGURE 17

Model (C4) > Static Structural (C5) > BRK Force

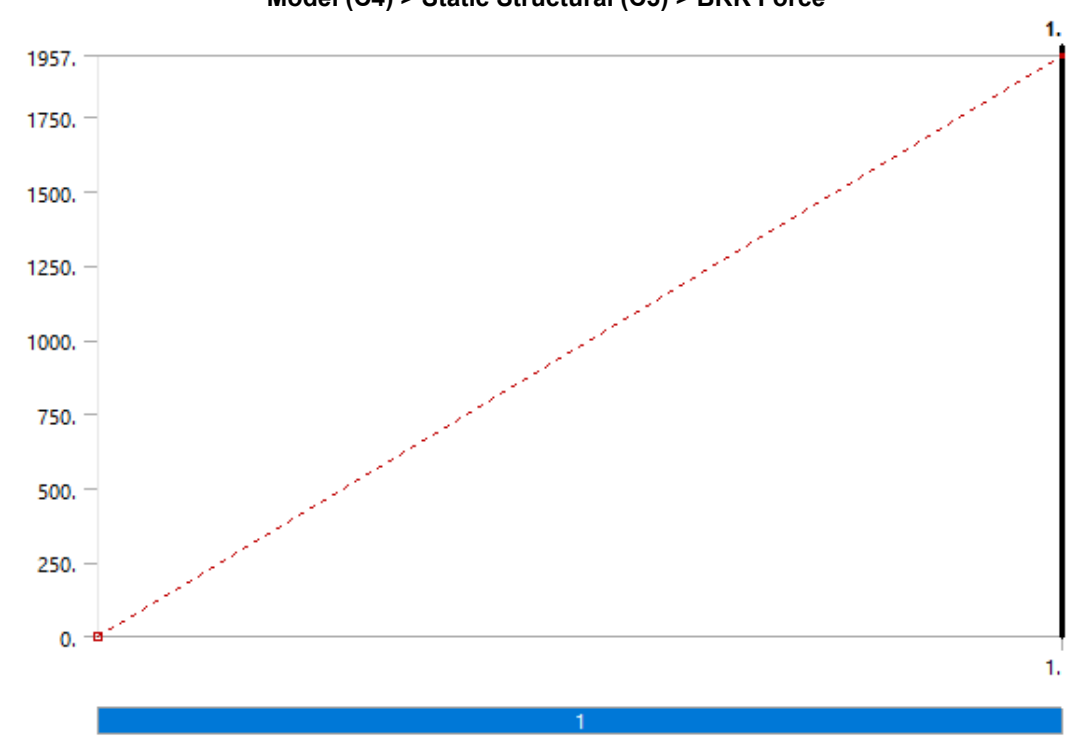

FIGURE 18

Model (C4) > Static Structural (C5) > Lockup Force 


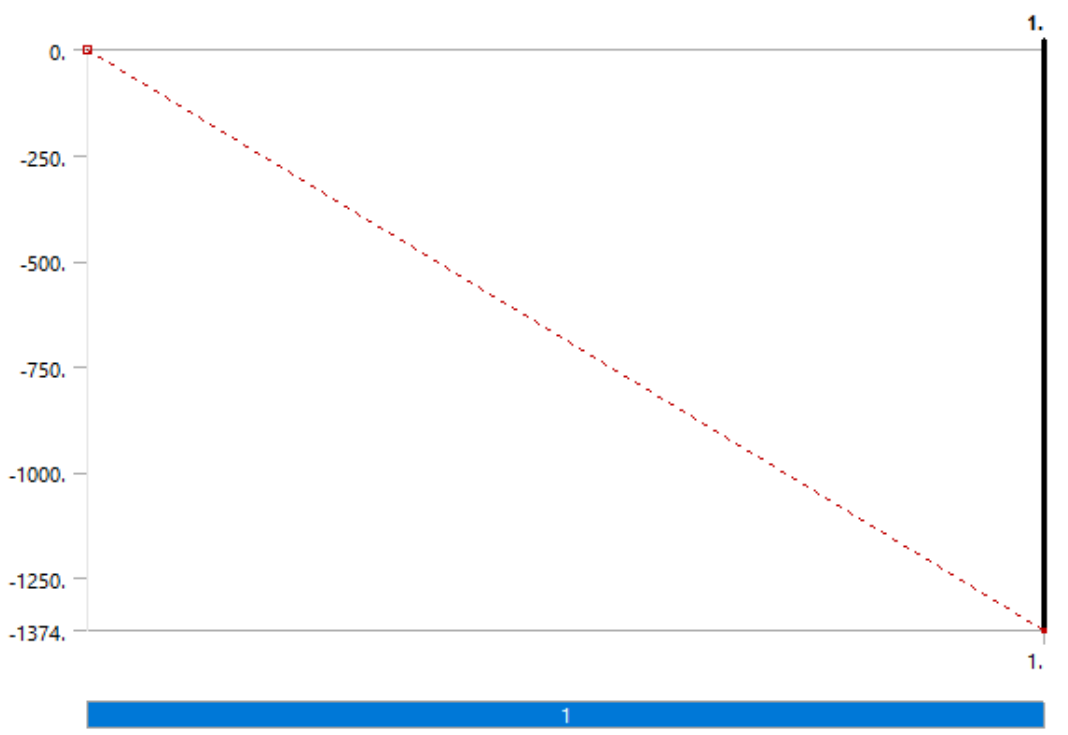

FIGURE 19

Model (C4) > Static Structural (C5) > Fixed Support > Figure 


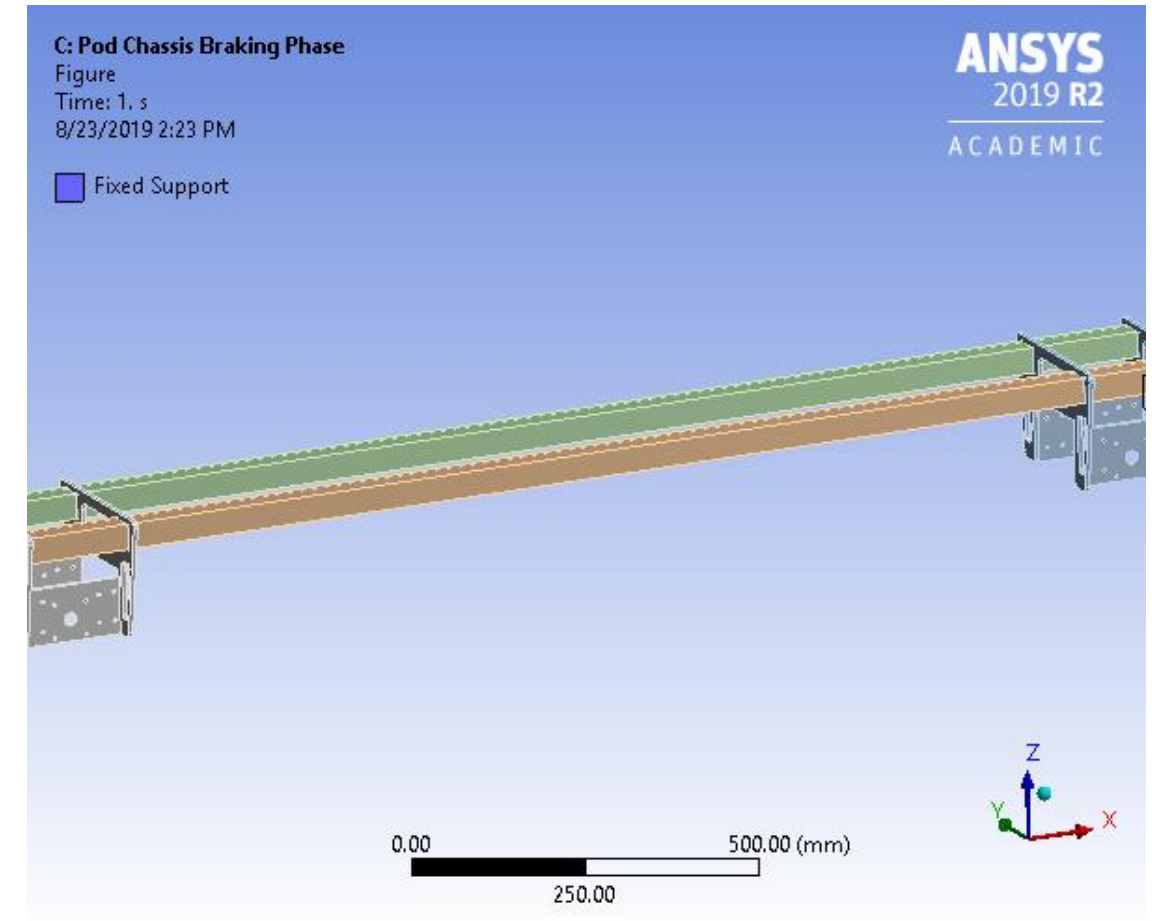

Solution (C6)

TABLE 15

Model (C4) > Static Structural (C5) > Solution

Object Name Solution (C6)

\begin{tabular}{|c|c|}
\hline Object Name & Solution (C6) \\
\hline State & Solved \\
\hline \multicolumn{2}{|c|}{ Adaptive Mesh Refinement } \\
\hline Max Refinement Loops & 1. \\
\hline Refinement Depth & 2. \\
\hline \multicolumn{2}{|l|}{ Information } \\
\hline Status & Done \\
\hline MAPDL Elapsed Time & 4. $s$ \\
\hline MAPDL Memory Used & 405. MB \\
\hline MAPDL Result File Size & $9.625 \mathrm{MB}$ \\
\hline \multicolumn{2}{|c|}{ Post Processing } \\
\hline Beam Section Results & No \\
\hline On Demand Stress/Strain & No \\
\hline
\end{tabular}


TABLE 16

Model (C4) $>$ Static Structural (C5) $>$ Solution (C6) $>$ Solution Information

\begin{tabular}{|r|c|}
\hline Object Name & Solution Information \\
\hline State & Solved \\
\hline Solution Information \\
\hline Solution Output & Solver Output \\
\hline Newton-Raphson Residuals & 0 \\
\hline Identify Element Violations & 0 \\
\hline Update Interval & $2.5 \mathrm{~s}$ \\
\hline Display Points & All \\
\hline FE Connection Visibility \\
\hline Activate Visibility & Yes \\
\hline Display & All FE Connectors \\
\hline Draw Connections Attached To & All Nodes \\
\hline Line Color & Connection Type \\
\hline Visible on Results & No \\
\hline Line Thickness & Single \\
\hline Display Type & Lines \\
\hline
\end{tabular}

TABLE 17

Model (C4) $>$ Static Structural (C5) $>$ Solution (C6) $>$ Results

\begin{tabular}{|c|c|c|}
\hline Object Name & Total Deformation & Equivalent Stress \\
\hline State & & Solved \\
\hline \multicolumn{3}{|c|}{ Scope } \\
\hline Scoping Method & \multicolumn{2}{|c|}{ Geometry Selection } \\
\hline Geometry & \multicolumn{2}{|r|}{ All Bodies } \\
\hline \multicolumn{3}{|c|}{ Definition } \\
\hline Type & Total Deformation & Equivalent (von-Mises) Stress \\
\hline By & \multicolumn{2}{|r|}{ Time } \\
\hline Display Time & \multicolumn{2}{|r|}{ Last } \\
\hline Calculate Time History & \multicolumn{2}{|r|}{ Yes } \\
\hline Identifier & & \\
\hline Suppressed & \multicolumn{2}{|r|}{ No } \\
\hline \multicolumn{3}{|c|}{ Results } \\
\hline Minimum & $0 . \mathrm{mm}$ & $0.36597 \mathrm{MPa}$ \\
\hline Maximum & $14.162 \mathrm{~mm}$ & $354.03 \mathrm{MPa}$ \\
\hline Average & $6.8722 \mathrm{~mm}$ & $26.305 \mathrm{MPa}$ \\
\hline Minimum Occurs On & Part2|PartBody[2] & Part3|PartBody \\
\hline Maximum Occurs On & Part2|PartBody & Part2|PartBody[2] \\
\hline \multicolumn{3}{|c|}{ Information } \\
\hline Time & \multicolumn{2}{|r|}{ 1. $s$} \\
\hline Load Step & \multicolumn{2}{|r|}{1} \\
\hline Substep & \multicolumn{2}{|r|}{1} \\
\hline Iteration Number & & 1 \\
\hline \multicolumn{3}{|c|}{ Integration Point Results } \\
\hline Display Option & & Averaged \\
\hline Average Across Bodies & & No \\
\hline
\end{tabular}


FIGURE 20

Model (C4) > Static Structural $($ C5) $>$ Solution (C6) > Total Deformation

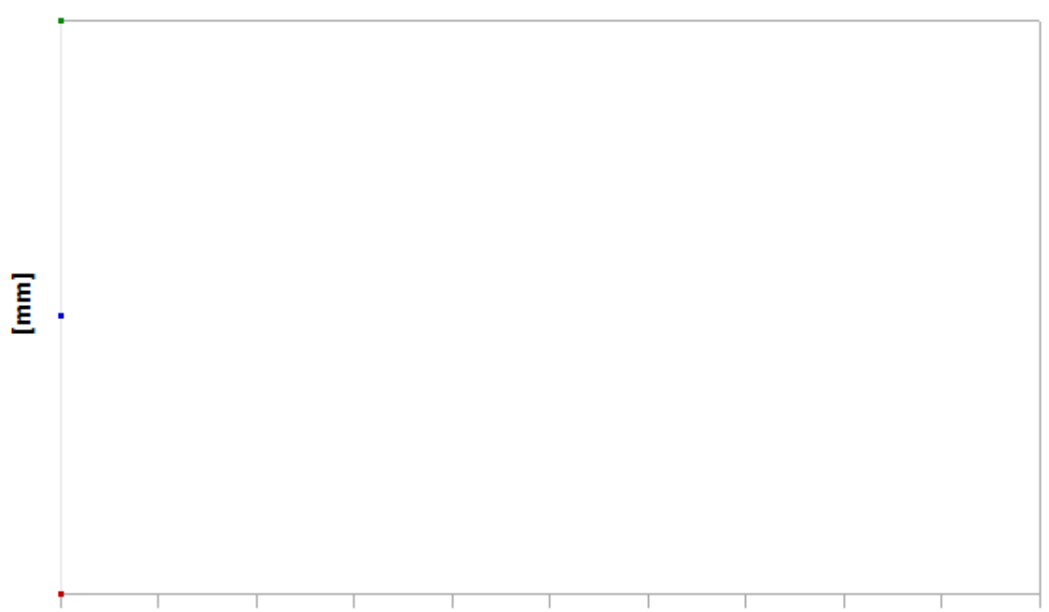

[s]

TABLE 18

Model (C4) > Static Structural $($ C5) $>$ Solution (C6) $>$ Total Deformation

Time [s] Minimum [mm] Maximum [mm] Average [mm]
1.
0 .
14.162
6.8722

FIGURE 21

Model $(C 4)>$ Static Structural $($ C5) $>$ Solution $(C 6)>$ Total Deformation > Figure 


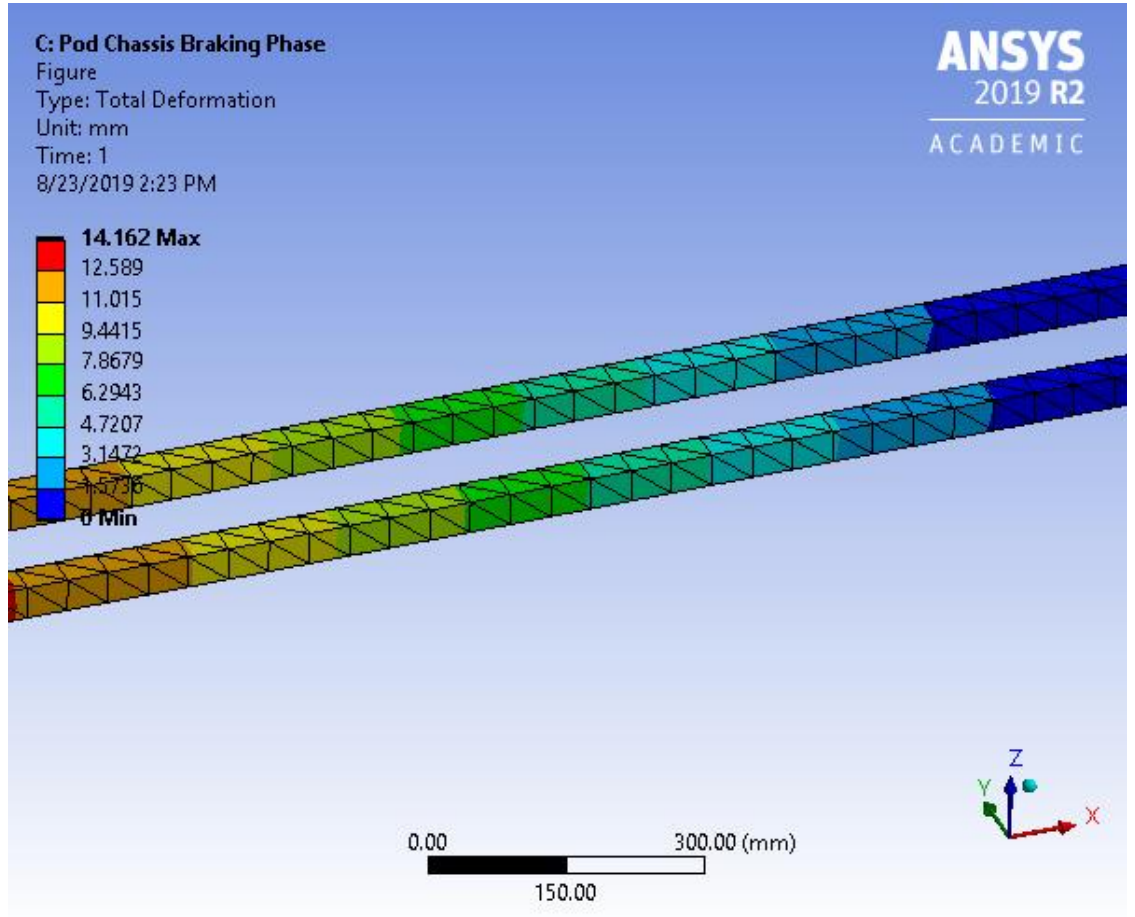

FIGURE 22

Model (C4) > Static Structural (C5) > Solution (C6) > Equivalent Stress 


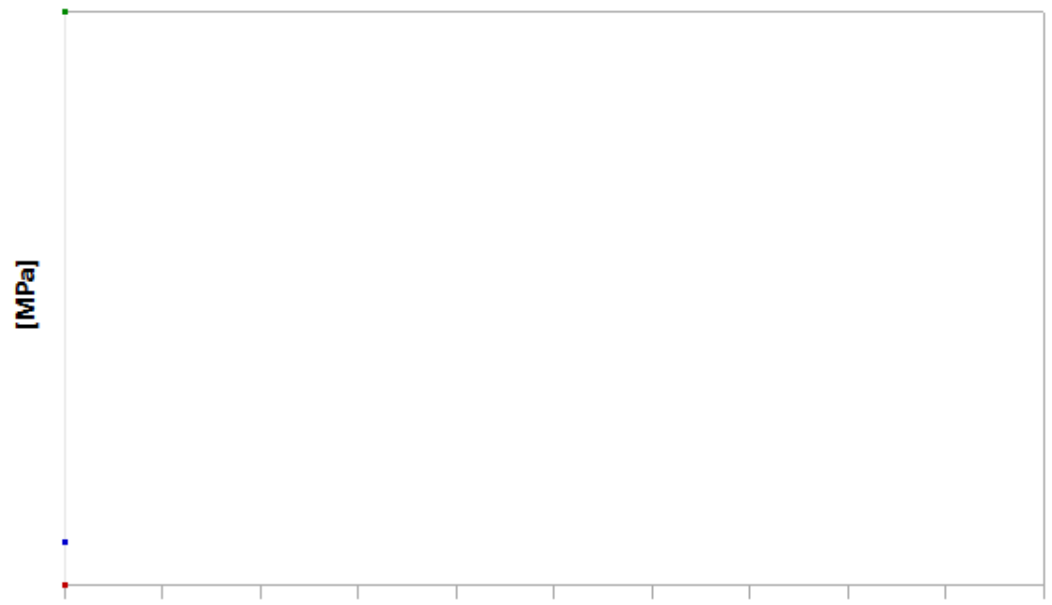

[s]

TABLE 19

Model (C4) > Static Structural (C5) $>$ Solution (C6) $>$ Equivalent Stress

Time [s] Minimum [MPa] Maximum [MPa] Average [MPa]

\begin{tabular}{l|l|l|r|}
\hline 1. & 0.36597 & 354.03 & 26.305
\end{tabular}

FIGURE 23

Model (C4) > Static Structural (C5) $>$ Solution (C6) $>$ Equivalent Stress $>$ Figure 


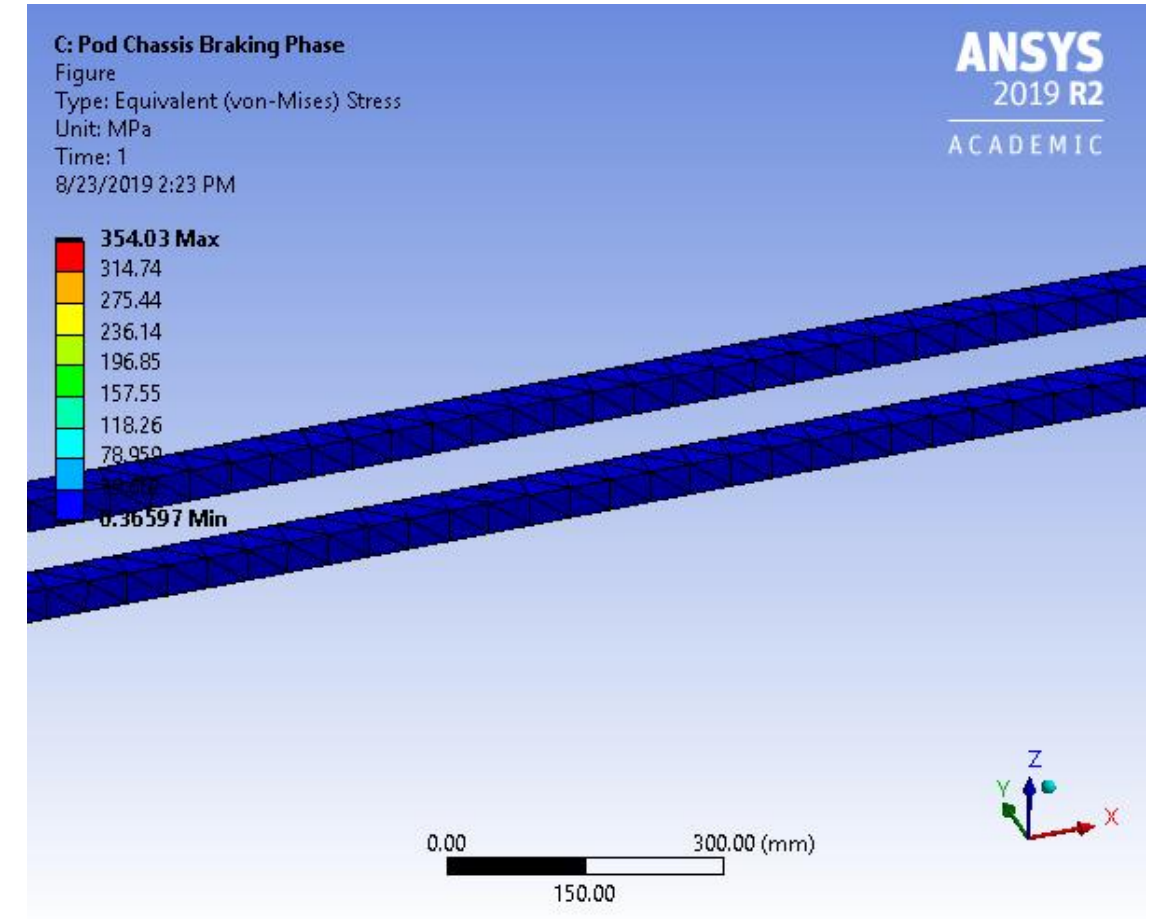

\section{Material Data}

\section{Aluminum Alloy}

TABLE 20

Aluminum Alloy $>$ Constants

\begin{tabular}{|r|c|}
\hline Density & $2.77 \mathrm{e}-006 \mathrm{~kg} \mathrm{~mm}^{\wedge}-3$ \\
\hline Coefficient of Thermal Expansion & $2.3 \mathrm{e}-005 \mathrm{C}^{\wedge}-1$ \\
\hline Specific Heat & $8.75 \mathrm{e}+005 \mathrm{~mJ} \mathrm{~kg}^{\wedge}-1 \mathrm{C}^{\wedge}-1$ \\
\hline
\end{tabular}

TABLE 21

Aluminum Alloy > Color

Red Green Blue

\begin{tabular}{|l|l|l|}
\hline 138 & 104 & 46 \\
\hline
\end{tabular}

TABLE 22

Aluminum Alloy > Compressive Ultimate Strength

Compressive Ultimate Strength MPa 
TABLE 23

Aluminum Alloy $>$ Compressive Yield Strength

Compressive Yield Strength $\mathrm{MPa}$

280

TABLE 24

Aluminum Alloy > Tensile Yield Strength

Tensile Yield Strength MPa

280

TABLE 25

Aluminum Alloy $>$ Tensile Ultimate Strength

Tensile Ultimate Strength MPa

310

TABLE 26

Aluminum Alloy $>$ Isotropic Secant Coefficient of Thermal Expansion

Zero-Thermal-Strain Reference Temperature C

22

TABLE 27

Aluminum Alloy $>$ Isotropic Thermal Conductivity Thermal Conductivity $\mathrm{W} \mathrm{mm}^{\wedge}-1 \mathrm{C}^{\wedge}-1$ Temperature $\mathrm{C}$

\begin{tabular}{|c|c|}
\hline 0.114 & -100 \\
\hline 0.144 & 0 \\
\hline 0.165 & 100 \\
\hline 0.175 & 200 \\
\hline
\end{tabular}

TABLE 28

Aluminum Alloy $>$ S-N Curve

Alternating Stress MPa Cycles R-Ratio

\begin{tabular}{|c|c|c|}
\hline 275.8 & 1700 & -1 \\
\hline 241.3 & 5000 & -1 \\
\hline 206.8 & 34000 & -1 \\
\hline 172.4 & $1.4 \mathrm{e}+005$ & -1 \\
\hline 137.9 & $8 . \mathrm{e}+005$ & -1 \\
\hline 117.2 & $2.4 \mathrm{e}+006$ & -1 \\
\hline 89.63 & $5.5 \mathrm{e}+007$ & -1 \\
\hline 82.74 & $1 . \mathrm{e}+008$ & -1 \\
\hline 170.6 & 50000 & -0.5 \\
\hline 139.6 & $3.5 \mathrm{e}+005$ & -0.5 \\
\hline 108.6 & $3.7 \mathrm{e}+006$ & -0.5 \\
\hline 87.91 & $1.4 \mathrm{e}+007$ & -0.5 \\
\hline 77.57 & $5 . \mathrm{e}+007$ & -0.5 \\
\hline 72.39 & $1 . \mathrm{e}+008$ & -0.5 \\
\hline 144.8 & 50000 & 0 \\
\hline 120.7 & $1.9 \mathrm{e}+005$ & 0 \\
\hline 103.4 & $1.3 \mathrm{e}+006$ & 0 \\
\hline 93.08 & $4.4 \mathrm{e}+006$ & 0 \\
\hline
\end{tabular}




\begin{tabular}{|c|c|c|}
\hline 86.18 & $1.2 \mathrm{e}+007$ & 0 \\
\hline 72.39 & $1 . \mathrm{e}+008$ & 0 \\
\hline 74.12 & $3 . \mathrm{e}+005$ & 0.5 \\
\hline 70.67 & $1.5 \mathrm{e}+006$ & 0.5 \\
\hline 66.36 & $1.2 \mathrm{e}+007$ & 0.5 \\
\hline 62.05 & $1 . \mathrm{e}+008$ & 0.5 \\
\hline
\end{tabular}

TABLE 29

Aluminum Alloy > Isotropic Resistivity Resistivity ohm $\mathrm{mm}$ Temperature C

\begin{tabular}{|c|c|}
\hline $2.43 e-005$ & 0 \\
\hline $2.67 e-005$ & 20 \\
\hline $3.63 e-005$ & 100 \\
\hline
\end{tabular}

TABLE 30

Aluminum Alloy $>$ Isotropic Elasticity

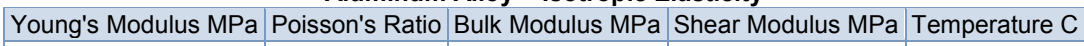

71000

0.33

69608

26692

TABLE 31

Aluminum Alloy > Isotropic Relative Permeability Relative Permeability 
Appendix A.11 MTR Track Load Case (Overspeed) Analysis Report 


\section{MNSYS}

Project*

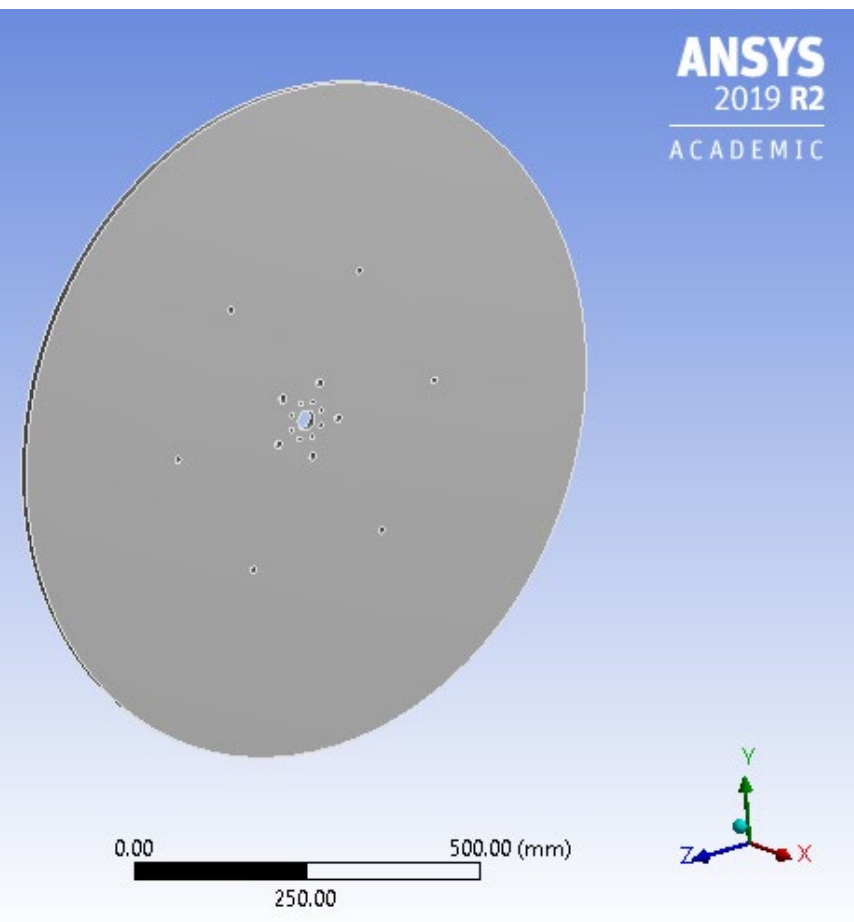




\section{Contents}

- Units

- Model (C4)

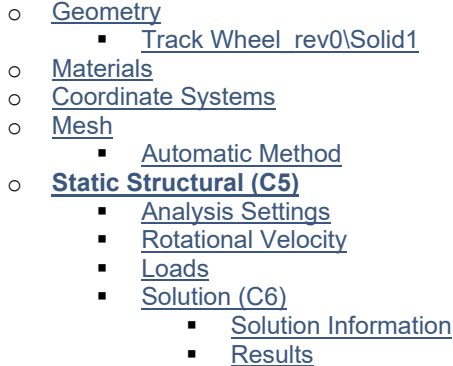

- Material Data

$\circ$ Aluminum Alloy

\section{Units}

TABLE 1

\begin{tabular}{|r|c|}
\hline Unit System & Metric $(\mathrm{mm}, \mathrm{kg}, \mathrm{N}, \mathrm{s}, \mathrm{mV}, \mathrm{mA})$ Degrees rad/s Celsius \\
\hline Angle & Degrees \\
\hline Rotational Velocity & rad/s \\
\hline Temperature & Celsius \\
\hline
\end{tabular}

\section{Model (C4)}

\section{Geometry}

TABLE 2

Model (C4) > Geometry

\begin{tabular}{|r|c|}
\hline Object Name & Geometry \\
\hline State & Fully Defined \\
\hline Source & Definition \\
\hline Type & DIAPM599A_diapm599_18756_2lunsaved_project_filesIdp0IGeomIDMIGeom.scdoc \\
\hline Length Unit & SpaceClaim \\
\hline Element & Meters \\
\hline Control & Program Controlled \\
\hline Display Style & Body Color \\
\hline Length $X$ & Bounding Box \\
\hline Length $Y$ & $12.7 \mathrm{~mm}$ \\
\hline & $1361.8 \mathrm{~mm}$ \\
\hline
\end{tabular}




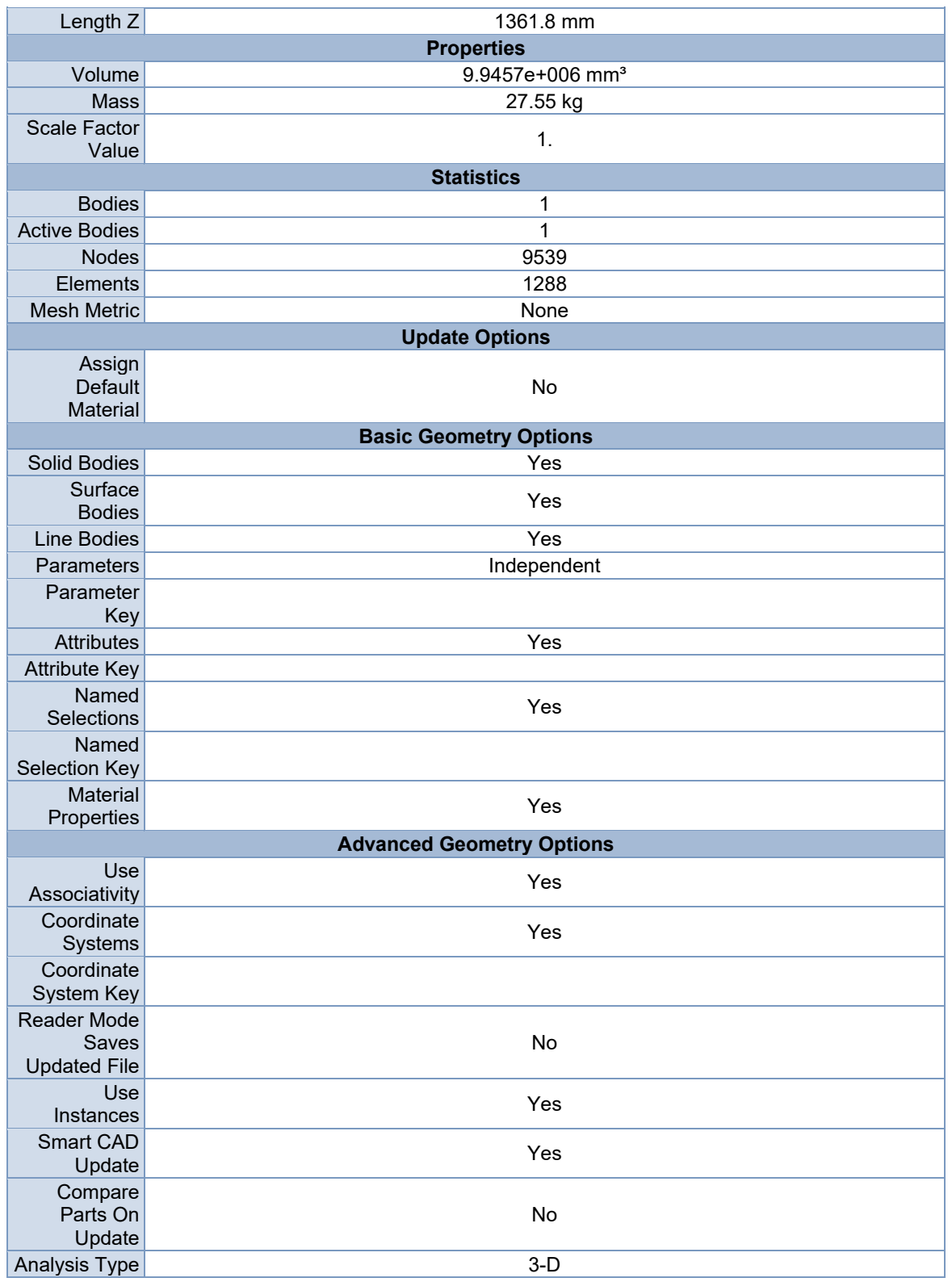




\begin{tabular}{|c|c|}
\hline $\begin{array}{r}\text { Mixed Import } \\
\text { Resolution }\end{array}$ & None \\
\hline $\begin{array}{r}\text { Clean Bodies } \\
\text { On Import }\end{array}$ & No \\
\hline $\begin{array}{r}\text { Stitch } \\
\text { Surfaces On } \\
\text { Import }\end{array}$ & None \\
\hline $\begin{array}{r}\text { Decompose } \\
\text { Disjoint } \\
\text { Geometry }\end{array}$ & Yes \\
\hline $\begin{array}{r}\text { Enclosure } \\
\text { and } \\
\text { Symmetry } \\
\text { Processing }\end{array}$ & Yes \\
\hline
\end{tabular}

TABLE 3

Model (C4) > Geometry > Parts

\begin{tabular}{|r|c|}
\hline Object Name & Track Wheel_revOlSolid1 \\
\hline State & Meshed \\
\hline Graphics Properties \\
\hline Visible & Yes \\
\hline Transparency & 1 \\
\hline Definition \\
\hline Suppressed & No \\
\hline Stiffness Behavior & Flexible \\
\hline Coordinate System & Default Coordinate System \\
\hline Reference Temperature & By Environment \\
\hline Treatment & None \\
\hline Material \\
\hline Assignment & Aluminum Alloy \\
\hline Nonlinear Effects & Yes \\
\hline Thermal Strain Effects & Yes \\
\hline Bounding Box \\
\hline Length X & $12.7 \mathrm{~mm}$ \\
\hline Length Y & $1361.8 \mathrm{~mm}$ \\
\hline Length Z & $1361.8 \mathrm{~mm}$ \\
\hline Properties \\
\hline Volume & $9.9457 \mathrm{e}+006 \mathrm{~mm}^{3}$ \\
\hline Mass & $27.55 \mathrm{~kg}$ \\
\hline Centroid X & $-180 . \mathrm{mm}$ \\
\hline Centroid Y & $401.34 \mathrm{~mm}$ \\
\hline Centroid Z & $-203.5 \mathrm{~mm}$ \\
\hline Elements & 1288 \\
\hline Mesh Metric & None \\
\hline CAD Attributes \\
\hline Soment of Inertia Ip1 & $1.7235 \mathrm{e}+006 \mathrm{~kg} \cdot \mathrm{mm}^{2}$ \\
\hline Moment of Inertia Ip2 & $1.7235 \mathrm{e}+006 \mathrm{~kg} \cdot \mathrm{mm}^{2}$ \\
\hline Statistics \\
\hline Inertia Ip3 & $3.4462 \mathrm{e}+006 \mathrm{~kg} \cdot \mathrm{mm}^{2}$ \\
\hline
\end{tabular}




\begin{tabular}{|r|r|}
\hline PartTolerance: & 0.00000001 \\
\hline Color:143.143.175 & \\
\hline
\end{tabular}

FIGURE 1

Model (C4) $>$ Geometry $>$ Track Wheel_rev0 $>$ Solid1 $>$ Figure

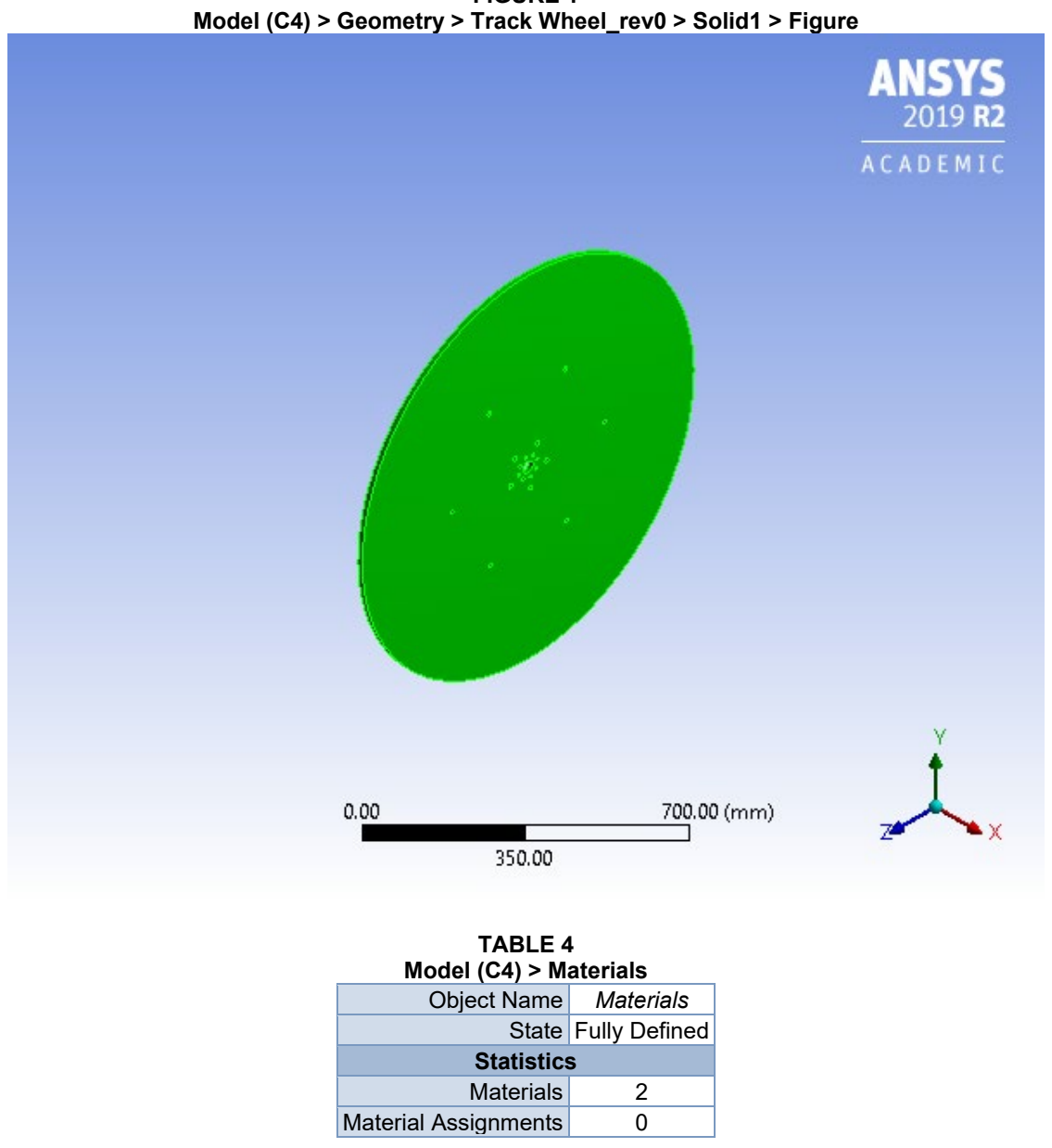

\section{Coordinate Systems}

TABLE 5

Model (C4) > Coordinate Systems > Coordinate System Object Name Global Coordinate System

State Fully Defined 


\begin{tabular}{|r|c|}
\hline \multicolumn{2}{|c|}{ Definition } \\
\hline Type & Cartesian \\
\hline Coordinate System ID & 0. \\
\hline \multicolumn{2}{|c|}{ Origin } \\
\hline Origin X & $0 . \mathrm{mm}$ \\
\hline Origin $\mathrm{Y}$ & $0 . \mathrm{mm}$ \\
\hline Origin Z & $0 . \mathrm{mm}$ \\
\hline Directional Vectors \\
\hline X Axis Data & {$[1.0 .0]$.} \\
\hline Y Axis Data & {$[0.1 .0]$.} \\
\hline Z Axis Data & {$[0.0 .1]$.} \\
\hline
\end{tabular}

Mesh

TABLE 6

Model (C4) $>$ Mesh Object Name

\begin{tabular}{|c|c|}
\hline \multicolumn{2}{|l|}{ IVIodel (C4) > IVIesn } \\
\hline Object Name & Mesh \\
\hline State & Solved \\
\hline \multicolumn{2}{|l|}{ Display } \\
\hline Display Style & Use Geometry Setting \\
\hline \multicolumn{2}{|l|}{ Defaults } \\
\hline Physics Preference & Mechanical \\
\hline Element Order & Program Controlled \\
\hline Element Size & Default \\
\hline \multicolumn{2}{|l|}{ Sizing } \\
\hline Use Adaptive Sizing & Yes \\
\hline Resolution & Default (2) \\
\hline Mesh Defeaturing & Yes \\
\hline Defeature Size & Default \\
\hline Transition & Fast \\
\hline Span Angle Center & Coarse \\
\hline Initial Size Seed & Assembly \\
\hline Bounding Box Diagonal & $1925.9 \mathrm{~mm}$ \\
\hline Average Surface Area & $70154 \mathrm{~mm}^{2}$ \\
\hline Minimum Edge Length & $26.075 \mathrm{~mm}$ \\
\hline \multicolumn{2}{|l|}{ Quality } \\
\hline Check Mesh Quality & Yes, Errors \\
\hline Error Limits & Standard Mechanical \\
\hline Target Quality & Default $(0.050000)$ \\
\hline Smoothing & Medium \\
\hline Mesh Metric & None \\
\hline \multicolumn{2}{|l|}{ Inflation } \\
\hline Use Automatic Inflation & None \\
\hline Inflation Option & Smooth Transition \\
\hline Transition Ratio & 0.272 \\
\hline Maximum Layers & 5 \\
\hline Growth Rate & 1.2 \\
\hline Inflation Algorithm & Pre \\
\hline
\end{tabular}




\begin{tabular}{|r|c|}
\hline View Advanced Options & No \\
Advanced & \\
\hline Number of CPUs for Parallel Part Meshing & Program Controlled \\
\hline Straight Sided Elements & No \\
\hline Rigid Body Behavior & Dimensionally Reduced \\
\hline Triangle Surface Mesher & Program Controlled \\
\hline Topology Checking & Yes \\
\hline Pinch Tolerance & Please Define \\
\hline Generate Pinch on Refresh & No \\
\hline Statistics & \\
\hline Nodes & 9539 \\
\hline Elements & 1288 \\
\hline
\end{tabular}

TABLE 7

Model (C4) > Mesh > Mesh Controls

Object Name Automatic Method

State Fully Defined

Scope

Scoping Method Geometry Selection

\begin{tabular}{|r|c|}
\hline Deometry & 1 Body \\
\hline Suppressed & No \\
\hline Method & Automatic \\
\hline Element Order & Use Global Setting \\
\hline
\end{tabular}

FIGURE 2

Model (C4) > Mesh > Figure 


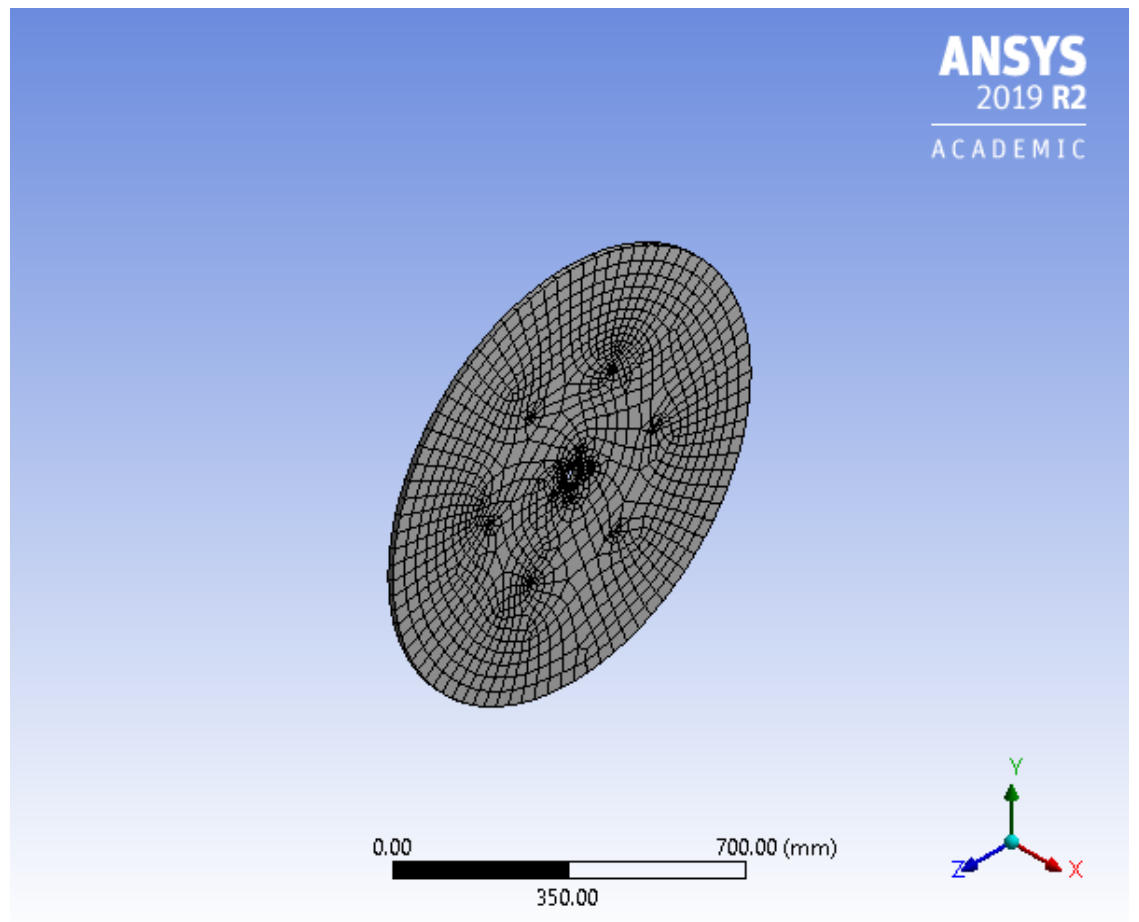

\section{Static Structural (C5)}

TABLE 8

Model (C4) > Analysis

\begin{tabular}{|c|c|}
\hline Object Name & Static Structural (C5) \\
\hline State & Solved \\
\hline \multicolumn{2}{|c|}{ Definition } \\
\hline Physics Type & Structural \\
\hline Analysis Type & Static Structural \\
\hline Solver Target & Mechanical APDL \\
\hline \multicolumn{2}{|c|}{ Options } \\
\hline Environment Temperature & 22. ${ }^{\circ} \mathrm{C}$ \\
\hline Generate Input Only & No \\
\hline
\end{tabular}

TABLE 9

Model (C4) > Static Structural (C5) > Analysis Settings

\begin{tabular}{|r|c|}
\hline Object Name & Analysis Settings \\
\hline State & Fully Defined \\
\hline & Step Controls \\
\hline
\end{tabular}




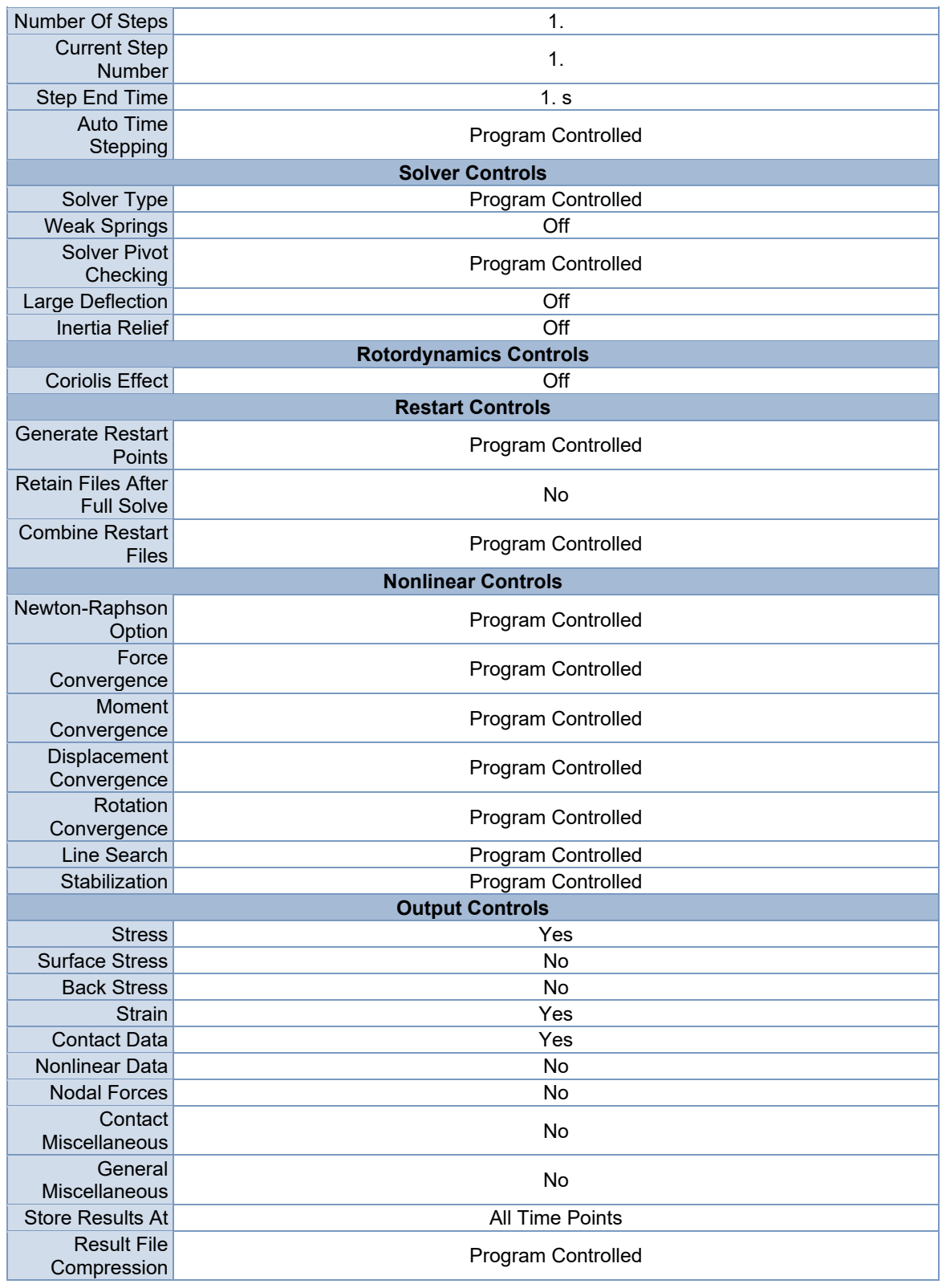




\begin{tabular}{|c|c|}
\hline \multicolumn{2}{|r|}{ Analysis Data Management } \\
\hline $\begin{array}{r}\text { Solver Files } \\
\text { Directory }\end{array}$ & $\begin{array}{c}\text { C:IUsers\DIAPM599\AppDatalLocalITempIWB_C0010- } \\
\text { DIAPM599A_diapm599_18756_2lunsaved_project_filesIdp0ISYSIMECHI }\end{array}$ \\
\hline Future Analysis & None \\
\hline $\begin{array}{l}\text { Scratch Solver } \\
\text { Files Directory }\end{array}$ & \\
\hline Save MAPDL db & No \\
\hline $\begin{array}{r}\text { Contact } \\
\text { Summary }\end{array}$ & Program Controlled \\
\hline $\begin{array}{r}\text { Delete Unneeded } \\
\text { Files }\end{array}$ & Yes \\
\hline $\begin{array}{r}\text { Nonlinear } \\
\text { Solution }\end{array}$ & No \\
\hline Solver Units & Active System \\
\hline $\begin{array}{r}\text { Solver Unit } \\
\text { System }\end{array}$ & $\mathrm{nmm}$ \\
\hline
\end{tabular}

TABLE 10

Model (C4) > Static Structural (C5) > Rotations

\begin{tabular}{|r|c|}
\hline Object Name & Rotational Velocity \\
\hline State & Fully Defined \\
\hline \multicolumn{2}{|c|}{ Scope } \\
\hline Scoping Method & Geometry Selection \\
\hline Geometry & All Bodies \\
\hline Definition \\
\hline Define By & Vector \\
\hline Magnitude & 50. rad/s (ramped) \\
\hline Axis & Defined \\
\hline Suppressed & No \\
\hline
\end{tabular}

FIGURE 3

Model (C4) > Static Structural (C5) > Rotational Velocity 


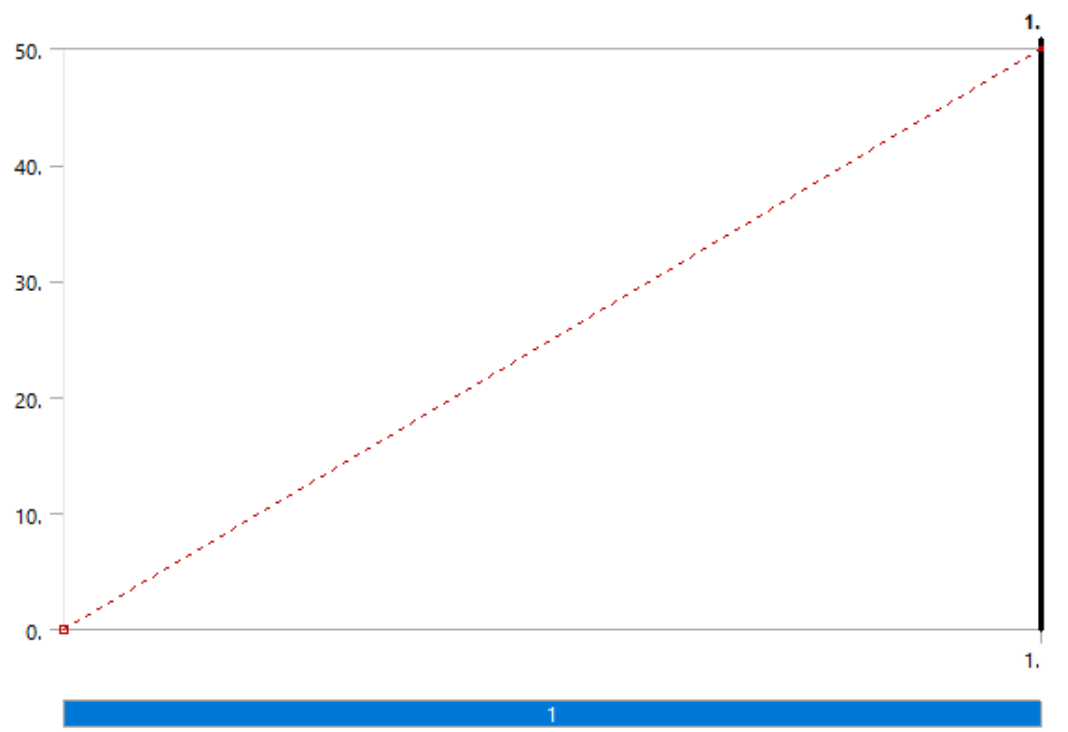

TABLE 11

Model (C4) $>$ Static Structural (C5) $>$ Loads

\begin{tabular}{|c|c|c|c|}
\hline Object Name & Thermal Condition & Fixed Support & Cylindrical Support \\
\hline State & Fully De & fined & Suppressed \\
\hline \multicolumn{4}{|c|}{ Scope } \\
\hline Scoping Method & \multicolumn{3}{|c|}{ Geometry Selection } \\
\hline Geometry & 1 Body & & Face \\
\hline \multicolumn{4}{|c|}{ Definition } \\
\hline Type & Thermal Condition & Fixed Support & Cylindrical Support \\
\hline Magnitude & 22. ${ }^{\circ} \mathrm{C}$ (ramped) & & \\
\hline Suppressed & \multicolumn{2}{|l|}{ No } & Yes \\
\hline Radial & & & Fixed \\
\hline Axial & & & Fixed \\
\hline Tangential & & & Fixed \\
\hline
\end{tabular}

FIGURE 4

Model (C4) > Static Structural (C5) > Thermal Condition 


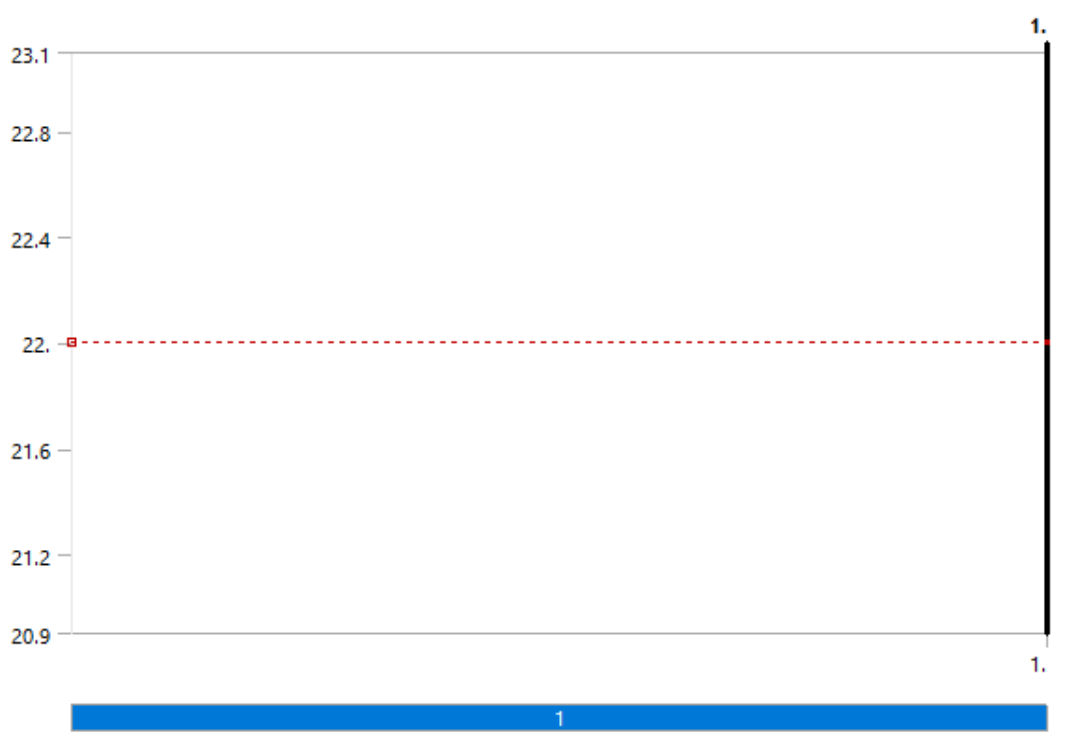

FIGURE 5

Model (C4) > Static Structural (C5) > Figure 


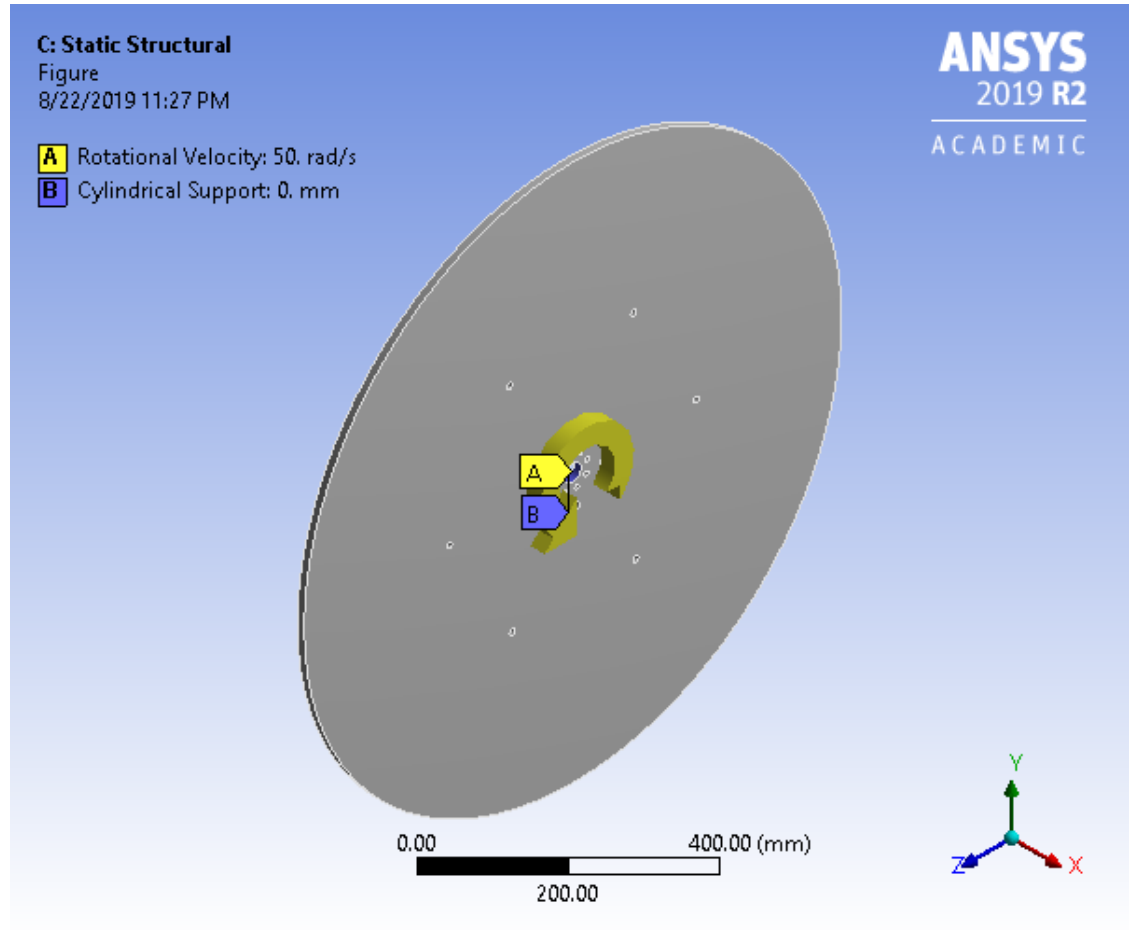

Solution (C6)

TABLE 12

Model (C4) $>$ Static Structural (C5) $>$ Solution

Object Name Solution (C6)

\begin{tabular}{|c|c|}
\hline Object Name & Solution (C6) \\
\hline State & Solved \\
\hline \multicolumn{2}{|c|}{ Adaptive Mesh Refinement } \\
\hline Max Refinement Loops & 1. \\
\hline Refinement Depth & 2. \\
\hline \multicolumn{2}{|l|}{ Information } \\
\hline Status & Done \\
\hline MAPDL Elapsed Time & 3. $s$ \\
\hline MAPDL Memory Used & 317. MB \\
\hline MAPDL Result File Size & 2. $M B$ \\
\hline \multicolumn{2}{|l|}{ Post Processing } \\
\hline Beam Section Results & No \\
\hline On Demand Stress/Strain & No \\
\hline
\end{tabular}


TABLE 13

Model (C4) $>$ Static Structural (C5) > Solution (C6) $>$ Solution Information Object Name Solution Information

\begin{tabular}{|r|c|}
\hline Object Name & Solution Information \\
\hline State & Solved \\
\hline Solution Information \\
\hline Solution Output & Solver Output \\
\hline Newton-Raphson Residuals & 0 \\
\hline Identify Element Violations & 0 \\
\hline Update Interval & $2.5 \mathrm{~s}$ \\
\hline Display Points & All \\
\hline FE Connection Visibility \\
\hline Activate Visibility & Yes \\
\hline Display & All FE Connectors \\
\hline Draw Connections Attached To & All Nodes \\
\hline Line Color & Connection Type \\
\hline Visible on Results & No \\
\hline Line Thickness & Single \\
\hline Display Type & Lines \\
\hline
\end{tabular}

TABLE 14

Model (C4) > Static Structural (C5) $>$ Solution (C6) $>$ Results Object Name Total Deformation Equivalent Stress

\begin{tabular}{|c|c|c|}
\hline Object Name & Total Deformation & Equivalent Stress \\
\hline State & & Solved \\
\hline \multicolumn{3}{|c|}{ Scope } \\
\hline Scoping Method & \multicolumn{2}{|c|}{ Geometry Selection } \\
\hline Geometry & \multicolumn{2}{|r|}{ All Bodies } \\
\hline \multicolumn{3}{|c|}{ Definition } \\
\hline Type & Total Deformation & Equivalent (von-Mises) Stress \\
\hline By & \multicolumn{2}{|r|}{ Time } \\
\hline Display Time & \multicolumn{2}{|r|}{ Last } \\
\hline Calculate Time History & \multicolumn{2}{|r|}{ Yes } \\
\hline Identifier & & \\
\hline Suppressed & \multicolumn{2}{|r|}{ No } \\
\hline \multicolumn{3}{|c|}{ Results } \\
\hline Minimum & 0. $\mathrm{mm}$ & $0.29176 \mathrm{MPa}$ \\
\hline Maximum & $2.0848 \mathrm{e}-003 \mathrm{~mm}$ & $1.978 \mathrm{MPa}$ \\
\hline Average & $1.4607 \mathrm{e}-003 \mathrm{~mm}$ & $0.59689 \mathrm{MPa}$ \\
\hline Minimum Occurs On & \multicolumn{2}{|c|}{ Track Wheel_rev01Solid1 } \\
\hline Maximum Occurs On & \multicolumn{2}{|c|}{ Track Wheel_rev01Solid1 } \\
\hline \multicolumn{3}{|c|}{ Information } \\
\hline Time & \multicolumn{2}{|r|}{ 1. $s$} \\
\hline Load Step & \multicolumn{2}{|r|}{1} \\
\hline Substep & \multicolumn{2}{|r|}{1} \\
\hline Iteration Number & \multicolumn{2}{|r|}{1} \\
\hline \multicolumn{3}{|c|}{ Integration Point Results } \\
\hline Display Option & & Averaged \\
\hline Average Across Bodies & & No \\
\hline
\end{tabular}


FIGURE 6

Model (C4) > Static Structural (C5) > Solution (C6) > Total Deformation

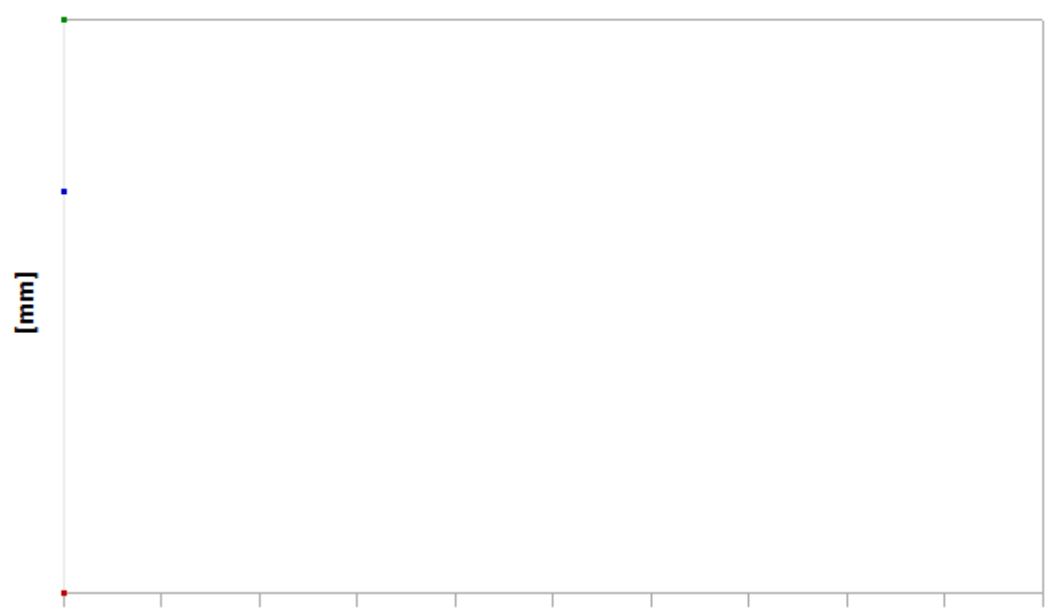

[s]

TABLE 15

Model (C4) > Static Structural (C5) > Solution (C6) > Total Deformation

Time [s] Minimum [mm] Maximum [mm] Average [mm]

\begin{tabular}{l|l|l|l|}
\hline 1. & 0. & $2.0848 \mathrm{e}-003$ & $1.4607 \mathrm{e}-003$ \\
\hline
\end{tabular}

FIGURE 7

Model (C4) > Static Structural (C5) > Solution (C6) > Total Deformation > Figure 


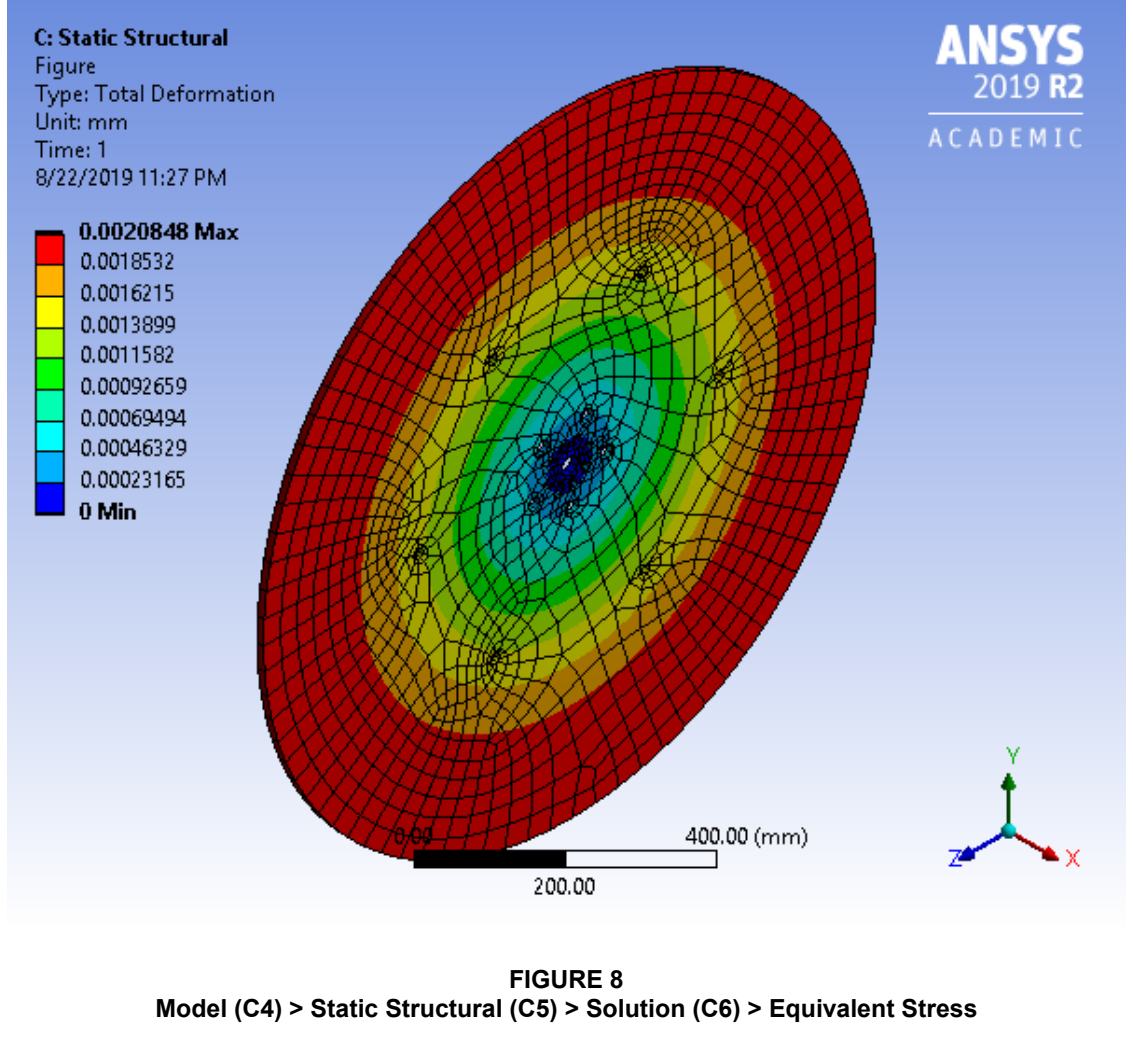




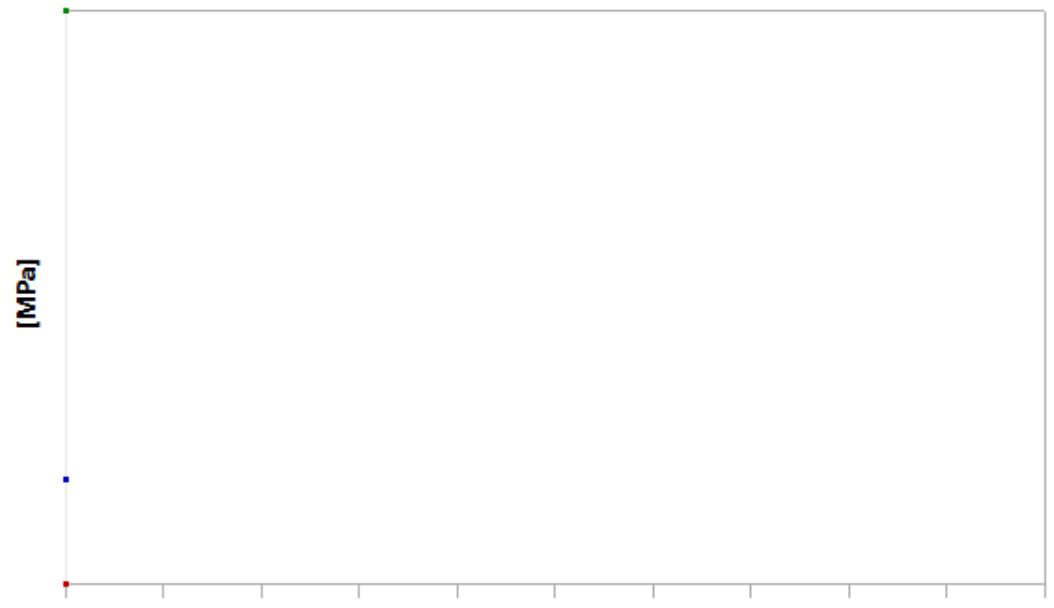

[s]

TABLE 16

Model (C4) $>$ Static Structural (C5) $>$ Solution (C6) $>$ Equivalent Stress

Time [s] Minimum [MPa] Maximum [MPa] Average [MPa]

\begin{tabular}{l|c|c|c}
1. & 0.29176 & 1.978 & 0.59689
\end{tabular}

FIGURE 9

Model (C4) > Static Structural (C5) > Solution (C6) > Equivalent Stress $>$ Figure 


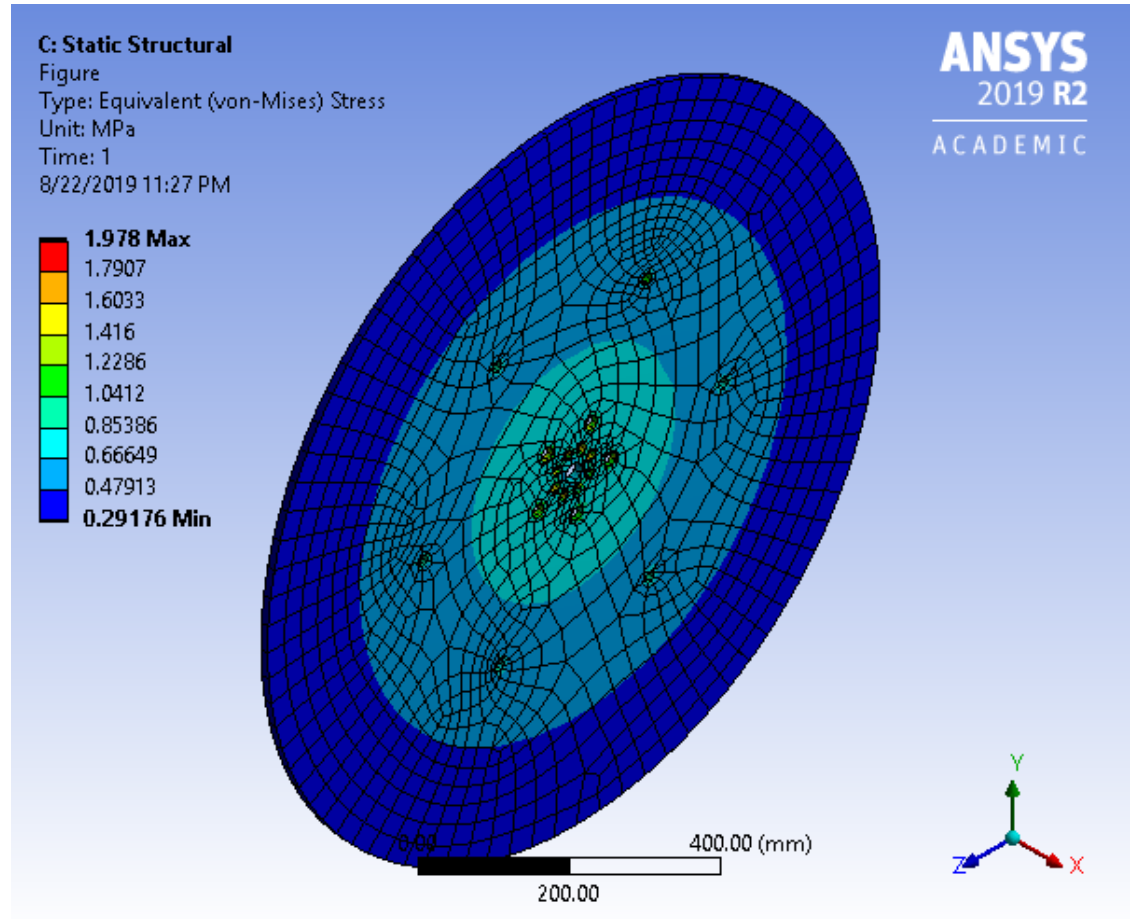

\section{Material Data}

\section{Aluminum Alloy}

TABLE 17

Aluminum Alloy $>$ Constants

\begin{tabular}{|r|c|}
\hline Density & $2.77 \mathrm{e}-006 \mathrm{~kg} \mathrm{~mm}^{\wedge}-3$ \\
\hline Coefficient of Thermal Expansion & $2.3 \mathrm{e}-005 \mathrm{C}^{\wedge}-1$ \\
\hline Specific Heat & $8.75 \mathrm{e}+005 \mathrm{~mJ} \mathrm{~kg}^{\wedge}-1 \mathrm{C}^{\wedge}-1$ \\
\hline
\end{tabular}

TABLE 18

Aluminum Alloy $>$ Color

Red Green Blue

\begin{tabular}{|l|l|l|}
\hline 138 & 104 & 46 \\
\hline
\end{tabular}

TABLE 19

Aluminum Alloy $>$ Compressive Ultimate Strength

Compressive Ultimate Strength $\mathrm{MPa}$ 
TABLE 20

Aluminum Alloy $>$ Compressive Yield Strength

Compressive Yield Strength MPa

280

TABLE 21

Aluminum Alloy > Tensile Yield Strength

Tensile Yield Strength MPa

280

TABLE 22

Aluminum Alloy $>$ Tensile Ultimate Strength

Tensile Ultimate Strength MPa

310

TABLE 23

Aluminum Alloy $>$ Isotropic Secant Coefficient of Thermal Expansion

Zero-Thermal-Strain Reference Temperature C

22

TABLE 24

Aluminum Alloy $>$ Isotropic Thermal Conductivity Thermal Conductivity W $\mathrm{mm}^{\wedge}-1 \mathrm{C}^{\wedge}-1$ Temperature C

\begin{tabular}{|c|c|}
\hline 0.114 & -100 \\
\hline 0.144 & 0 \\
\hline 0.165 & 100 \\
\hline 0.175 & 200 \\
\hline
\end{tabular}

TABLE 25

Aluminum Alloy $>$ S-N Curve

Alternating Stress MPa Cycles R-Ratio

\begin{tabular}{|c|c|c|}
\hline 275.8 & 1700 & -1 \\
\hline 241.3 & 5000 & -1 \\
\hline 206.8 & 34000 & -1 \\
\hline 172.4 & $1.4 \mathrm{e}+005$ & -1 \\
\hline 137.9 & $8 . \mathrm{e}+005$ & -1 \\
\hline 117.2 & $2.4 \mathrm{e}+006$ & -1 \\
\hline 89.63 & $5.5 \mathrm{e}+007$ & -1 \\
\hline 82.74 & $1 . \mathrm{e}+008$ & -1 \\
\hline 170.6 & 50000 & -0.5 \\
\hline 139.6 & $3.5 \mathrm{e}+005$ & -0.5 \\
\hline 108.6 & $3.7 \mathrm{e}+006$ & -0.5 \\
\hline 87.91 & $1.4 \mathrm{e}+007$ & -0.5 \\
\hline 77.57 & $5 . \mathrm{e}+007$ & -0.5 \\
\hline 72.39 & $1 . \mathrm{e}+008$ & -0.5 \\
\hline 144.8 & 50000 & 0 \\
\hline 120.7 & $1.9 \mathrm{e}+005$ & 0 \\
\hline 103.4 & $1.3 \mathrm{e}+006$ & 0 \\
\hline 93.08 & $4.4 \mathrm{e}+006$ & 0 \\
\hline & & \\
\hline
\end{tabular}




\begin{tabular}{|c|c|c|}
\hline 86.18 & $1.2 \mathrm{e}+007$ & 0 \\
\hline 72.39 & $1 . \mathrm{e}+008$ & 0 \\
\hline 74.12 & $3 . \mathrm{e}+005$ & 0.5 \\
\hline 70.67 & $1.5 \mathrm{e}+006$ & 0.5 \\
\hline 66.36 & $1.2 \mathrm{e}+007$ & 0.5 \\
\hline 62.05 & $1 . \mathrm{e}+008$ & 0.5 \\
\hline
\end{tabular}

TABLE 26

Aluminum Alloy > Isotropic Resistivity Resistivity ohm mm Temperature C

\begin{tabular}{|c|c|}
\hline $2.43 e-005$ & 0 \\
\hline $2.67 e-005$ & 20 \\
\hline $3.63 e-005$ & 100 \\
\hline
\end{tabular}

TABLE 27

Aluminum Alloy $>$ Isotropic Elasticity

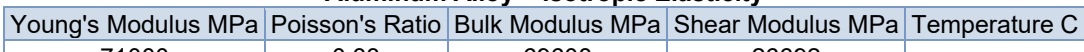
71000 0.33 69608 26692

TABLE 28

Aluminum Alloy > Isotropic Relative Permeability Relative Permeability 
Appendix A.12 MTR Shaft Load Case (Lock Up) Analysis Report 


\section{MNSYS}

Project*

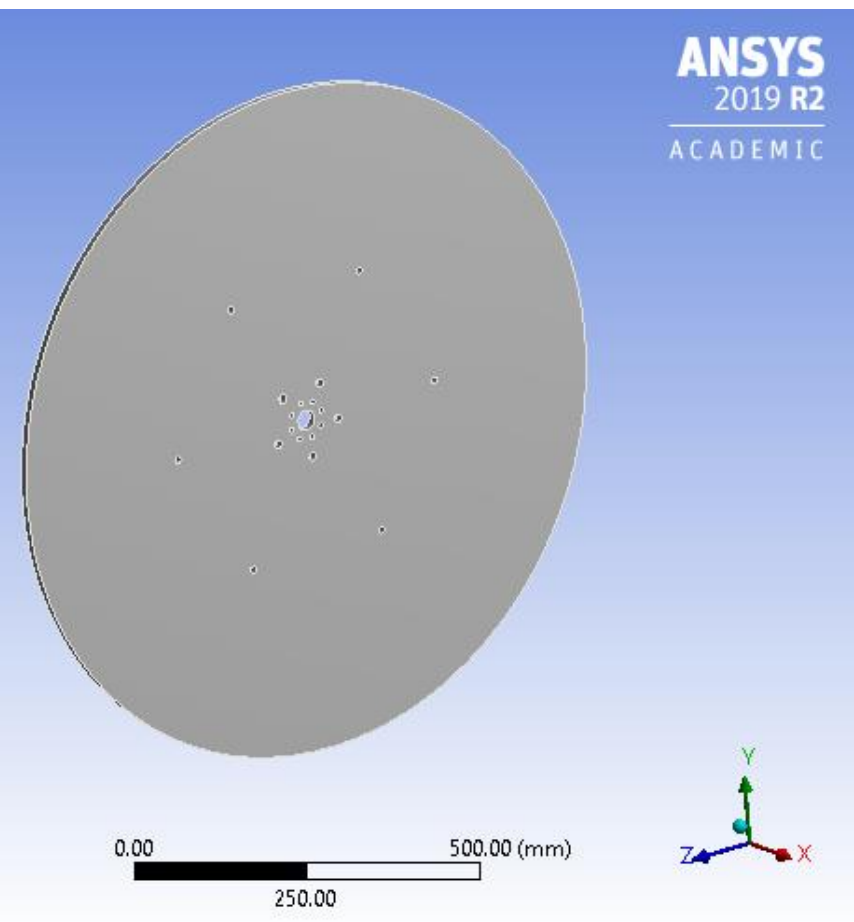




\section{Contents}

- Units

- Model (C4)

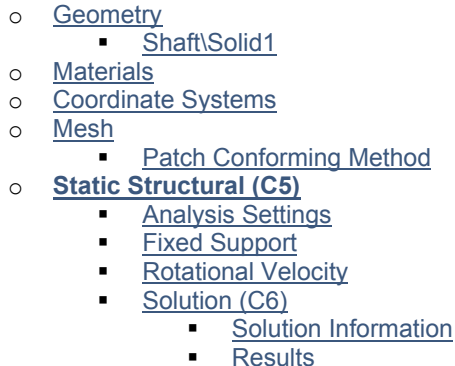

- Material Data

$\circ$ Aluminum Alloy

\section{Units}

TABLE 1

\begin{tabular}{|r|c|}
\hline Unit System & Metric $(\mathrm{mm}, \mathrm{kg}, \mathrm{N}, \mathrm{s}, \mathrm{mV}, \mathrm{mA})$ Degrees rad/s Celsius \\
\hline Angle & Degrees \\
\hline Rotational Velocity & rad/s \\
\hline Temperature & Celsius \\
\hline
\end{tabular}

\section{Model (C4)}

\section{Geometry}

TABLE 2

Model (C4) > Geometry

\begin{tabular}{|r|c|}
\hline Object Name & Geometry \\
\hline State & Fully Defined \\
\hline Source & Definition \\
\hline Type & DIAPM599A_diapm599_18756_2lunsaved_project_filesIdp0IGeomIDMIGeom.scdoc \\
\hline Length Unit & SpaceClaim \\
\hline Element & Meters \\
\hline Control & Program Controlled \\
\hline Display Style & Body Color \\
\hline Length $X$ & Bounding Box \\
\hline Length $Y$ & $420 . \mathrm{mm}$ \\
\hline & $34.044 \mathrm{~mm}$ \\
\hline
\end{tabular}




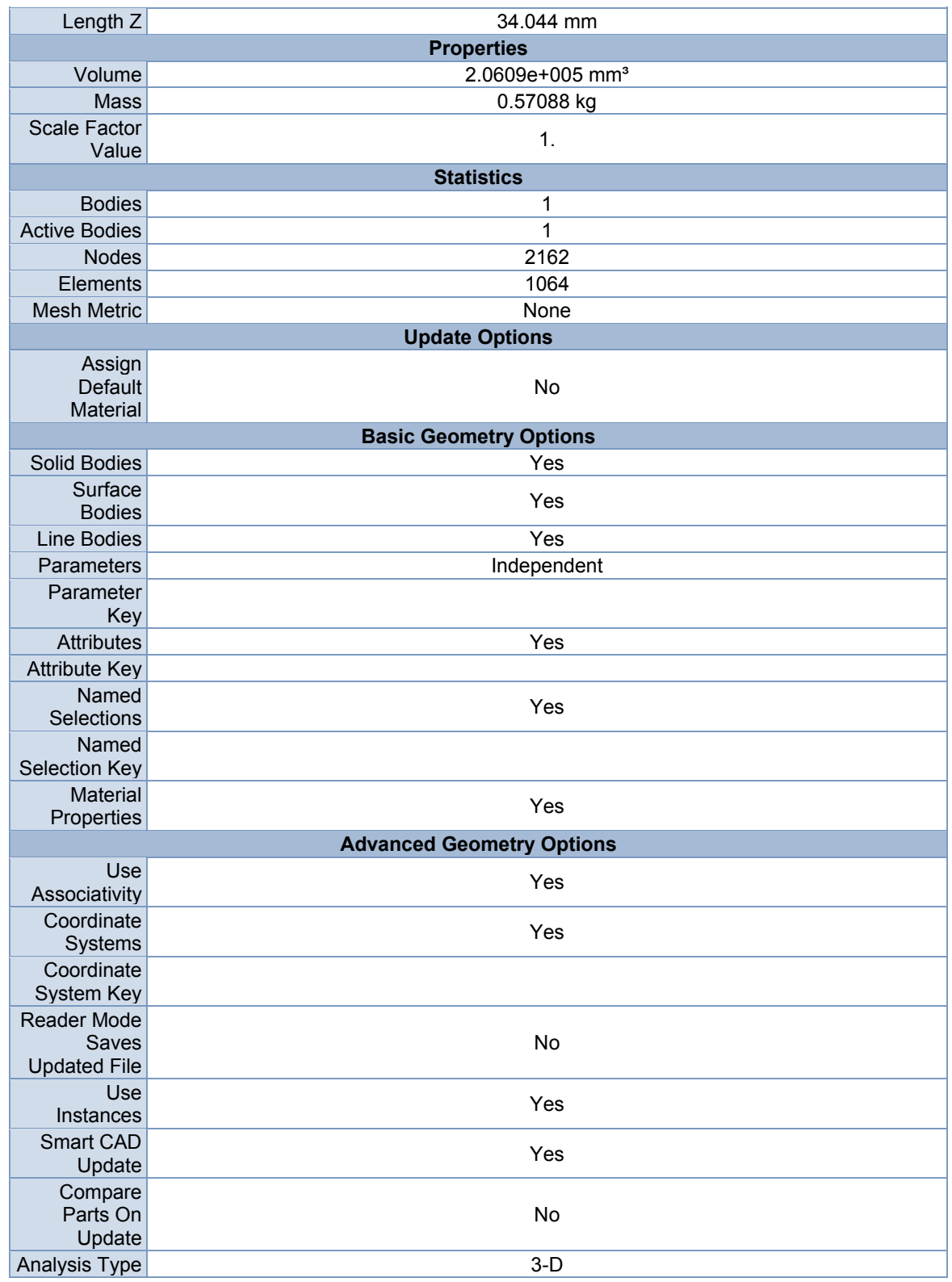




\begin{tabular}{|c|c|}
\hline $\begin{array}{r}\text { Mixed Import } \\
\text { Resolution }\end{array}$ & None \\
\hline $\begin{array}{r}\text { Clean Bodies } \\
\text { On Import }\end{array}$ & No \\
\hline $\begin{array}{r}\text { Stitch } \\
\text { Surfaces On } \\
\text { Import }\end{array}$ & None \\
\hline $\begin{array}{r}\text { Decompose } \\
\text { Disjoint } \\
\text { Geometry }\end{array}$ & Yes \\
\hline $\begin{array}{r}\text { Enclosure } \\
\text { and } \\
\text { Symmetry } \\
\text { Processing }\end{array}$ & Yes \\
\hline
\end{tabular}

TABLE 3

Model (C4) $>$ Geometry > Parts

\begin{tabular}{|c|c|}
\hline Object Name & Shaft|Solid1 \\
\hline State & Meshed \\
\hline \multicolumn{2}{|c|}{ Graphics Properties } \\
\hline Visible & Yes \\
\hline Transparency & 1 \\
\hline \multicolumn{2}{|c|}{ Definition } \\
\hline Suppressed & No \\
\hline Stiffness Behavior & Flexible \\
\hline Coordinate System & Default Coordinate System \\
\hline Reference Temperature & By Environment \\
\hline Treatment & None \\
\hline \multicolumn{2}{|c|}{ Material } \\
\hline Assignment & Aluminum Alloy \\
\hline Nonlinear Effects & Yes \\
\hline Thermal Strain Effects & Yes \\
\hline \multicolumn{2}{|c|}{ Bounding Box } \\
\hline Length X & 420. $\mathrm{mm}$ \\
\hline Length $\mathrm{Y}$ & $34.044 \mathrm{~mm}$ \\
\hline Length Z & $34.044 \mathrm{~mm}$ \\
\hline \multicolumn{2}{|c|}{ Properties } \\
\hline Volume & $2.0609 \mathrm{e}+005 \mathrm{~mm}^{3}$ \\
\hline Mass & $0.57088 \mathrm{~kg}$ \\
\hline Centroid X & $-175.03 \mathrm{~mm}$ \\
\hline Centroid $\mathrm{Y}$ & $401.34 \mathrm{~mm}$ \\
\hline Centroid Z & $-203.5 \mathrm{~mm}$ \\
\hline Moment of Inertia Ip1 & $8365.2 \mathrm{~kg} \cdot \mathrm{mm}^{2}$ \\
\hline Moment of Inertia Ip2 & $8365.2 \mathrm{~kg} \cdot \mathrm{mm}^{2}$ \\
\hline Moment of Inertia Ip3 & $44.134 \mathrm{~kg} \cdot \mathrm{mm}^{2}$ \\
\hline \multicolumn{2}{|c|}{ Statistics } \\
\hline Nodes & 2162 \\
\hline Elements & 1064 \\
\hline Mesh Metric & None \\
\hline \multicolumn{2}{|c|}{ CAD Attributes } \\
\hline
\end{tabular}




\begin{tabular}{|r|r|} 
PartTolerance: & 0.00000001 \\
\hline Color:143.143.175 & \\
\hline
\end{tabular}

FIGURE 1

Model (C4) $>$ Geometry $>$ Shaft $>$ Solid1 $>$ Figure

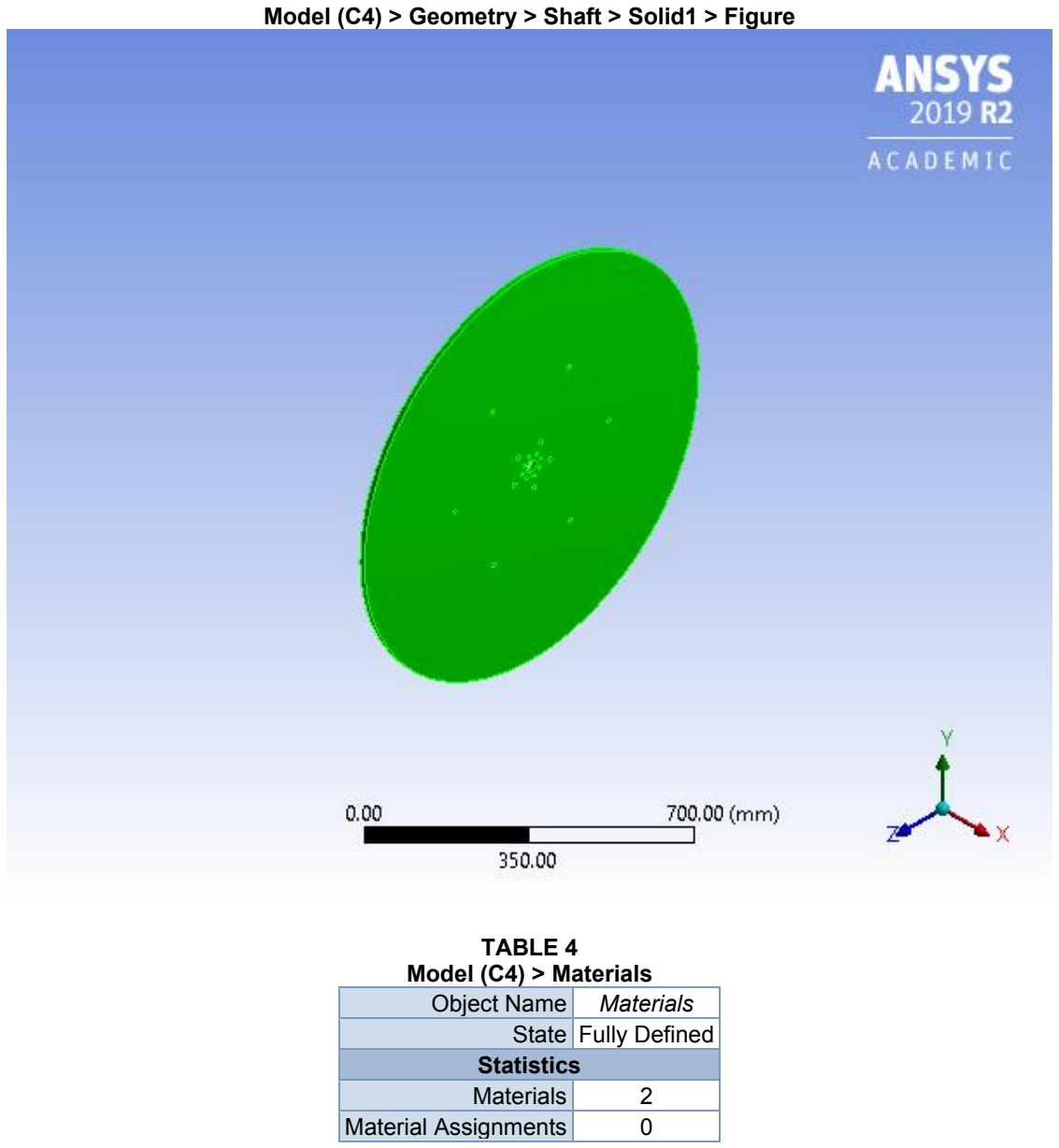

\section{Coordinate Systems}

TABLE 5

Model (C4) > Coordinate Systems > Coordinate System Object Name Global Coordinate System

State Fully Defined 


\begin{tabular}{|r|c|}
\hline \multicolumn{2}{|c|}{ Definition } \\
\hline Type & Cartesian \\
\hline Coordinate System ID & 0. \\
\hline \multicolumn{2}{|c|}{ Origin } \\
\hline Origin X & $0 . \mathrm{mm}$ \\
\hline Origin $\mathrm{Y}$ & $0 . \mathrm{mm}$ \\
\hline Origin Z & $0 . \mathrm{mm}$ \\
\hline Directional Vectors \\
\hline X Axis Data & {$[1.0 .0]$.} \\
\hline Y Axis Data & {$[0.1 .0]$.} \\
\hline Z Axis Data & {$[0.0 .1]$.} \\
\hline
\end{tabular}

Mesh

TABLE 6

Model (C4) $>$ Mesh Object Name

\begin{tabular}{|c|c|}
\hline \multicolumn{2}{|c|}{ IVlodel (C4) > IVIesn } \\
\hline Object Name & Mesh \\
\hline State & Solved \\
\hline \multicolumn{2}{|l|}{ Display } \\
\hline Display Style & Use Geometry Setting \\
\hline \multicolumn{2}{|l|}{ Defaults } \\
\hline Physics Preference & Mechanical \\
\hline Element Order & Program Controlled \\
\hline Element Size & Default \\
\hline \multicolumn{2}{|l|}{ Sizing } \\
\hline Use Adaptive Sizing & Yes \\
\hline Resolution & Default (2) \\
\hline Mesh Defeaturing & Yes \\
\hline Defeature Size & Default \\
\hline Transition & Fast \\
\hline Span Angle Center & Fine \\
\hline Initial Size Seed & Assembly \\
\hline Bounding Box Diagonal & $422.75 \mathrm{~mm}$ \\
\hline Average Surface Area & $6765.5 \mathrm{~mm}^{2}$ \\
\hline Minimum Edge Length & $72.257 \mathrm{~mm}$ \\
\hline \multicolumn{2}{|l|}{ Quality } \\
\hline Check Mesh Quality & Yes, Errors \\
\hline Error Limits & Standard Mechanical \\
\hline Target Quality & Default (0.050000) \\
\hline Smoothing & Medium \\
\hline Mesh Metric & None \\
\hline \multicolumn{2}{|l|}{ Inflation } \\
\hline Use Automatic Inflation & None \\
\hline Inflation Option & Smooth Transition \\
\hline Transition Ratio & 0.272 \\
\hline Maximum Layers & 5 \\
\hline Growth Rate & 1.2 \\
\hline Inflation Algorithm & Pre \\
\hline
\end{tabular}




\begin{tabular}{|r|c|}
\hline View Advanced Options & No \\
Advanced & \\
\hline Number of CPUs for Parallel Part Meshing & Program Controlled \\
\hline Straight Sided Elements & No \\
\hline Rigid Body Behavior & Dimensionally Reduced \\
\hline Triangle Surface Mesher & Program Controlled \\
\hline Topology Checking & Yes \\
\hline Pinch Tolerance & Please Define \\
\hline Generate Pinch on Refresh & No \\
\hline Statistics & \\
\hline Nodes & 2162 \\
\hline Elements & 1064 \\
\hline
\end{tabular}

TABLE 7

Model (C4) $>$ Mesh $>$ Mesh Controls

\begin{tabular}{r|c|}
$\begin{array}{r}\text { Object Name } \\
\text { State }\end{array}$ & Patch Conforming Method \\
& Fully Defined \\
\hline Scope \\
\hline Geometry & Geometry Selection \\
\hline Suppressed & Definition Body \\
Method & Notrahedrons \\
\hline Algorithm & Patch Conforming \\
\hline Element Order & Use Global Setting \\
\hline
\end{tabular}

FIGURE 2

Model (C4) > Mesh > Figure 


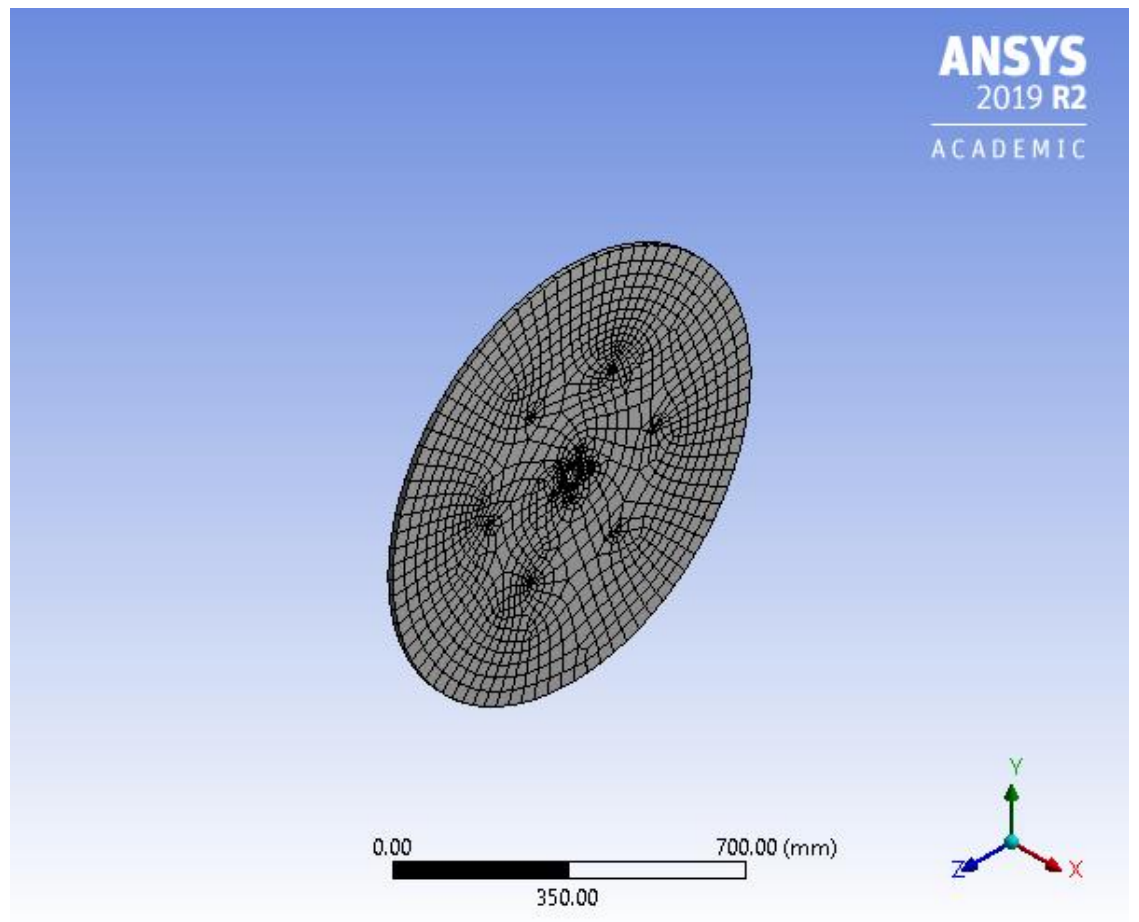

\section{Static Structural (C5)}

TABLE 8

Model (C4) > Analysis

Object Name Static Structural (C5)

\begin{tabular}{|c|c|}
\hline Object Name & Static Structural (C5) \\
\hline State & Solved \\
\hline \multicolumn{2}{|c|}{ Definition } \\
\hline Physics Type & Structural \\
\hline Analysis Type & Static Structural \\
\hline Solver Target & Mechanical APDL \\
\hline \multicolumn{2}{|c|}{ Options } \\
\hline Environment Temperature & 22. ${ }^{\circ} \mathrm{C}$ \\
\hline Generate Input Only & No \\
\hline
\end{tabular}

TABLE 9

Model (C4) > Static Structural (C5) > Analysis Settings

\begin{tabular}{|r|c|}
\hline Object Name & Analysis Settings \\
\hline State & Fully Defined \\
\hline & Step Controls \\
\hline
\end{tabular}




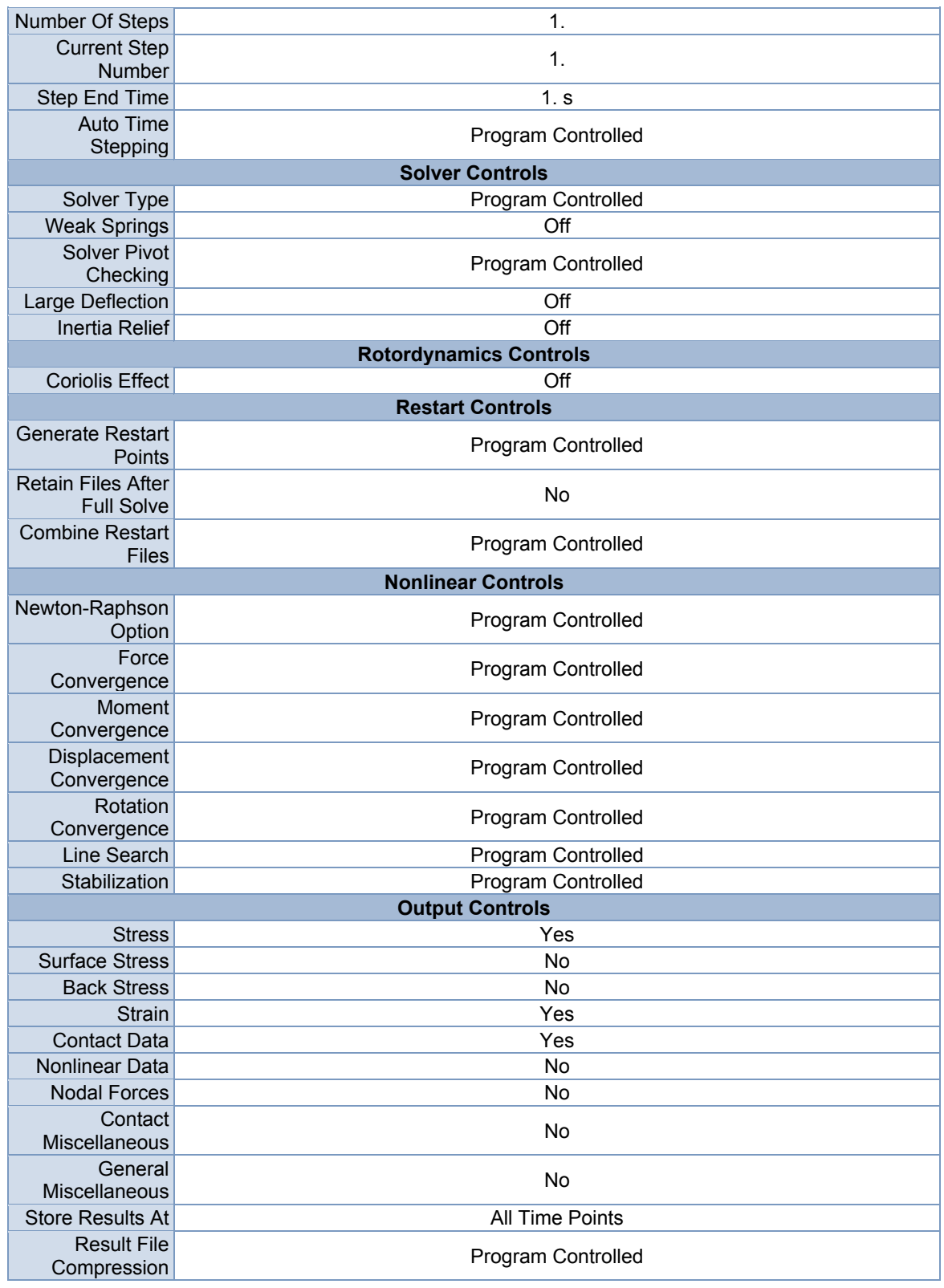




\begin{tabular}{|c|c|}
\hline \multicolumn{2}{|r|}{ Analysis Data Management } \\
\hline $\begin{array}{r}\text { Solver Files } \\
\text { Directory }\end{array}$ & $\begin{array}{c}\text { C:IUsersIDIAPM599\AppDatalLocallTempIWB_C0010- } \\
\text { DIAPM599A_diapm599_18756_2lunsaved_project_filesIdp0ISYSIMECHI }\end{array}$ \\
\hline Future Analysis & None \\
\hline $\begin{array}{l}\text { Scratch Solver } \\
\text { Files Directory }\end{array}$ & \\
\hline Save MAPDL db & No \\
\hline $\begin{array}{r}\text { Contact } \\
\text { Summary }\end{array}$ & Program Controlled \\
\hline $\begin{array}{r}\text { Delete Unneeded } \\
\text { Files }\end{array}$ & Yes \\
\hline $\begin{array}{r}\text { Nonlinear } \\
\text { Solution }\end{array}$ & No \\
\hline Solver Units & Active System \\
\hline $\begin{array}{r}\text { Solver Unit } \\
\text { System }\end{array}$ & $\mathrm{nmm}$ \\
\hline
\end{tabular}

TABLE 10

Model (C4) $>$ Static Structural (C5) $>$ Loads

\begin{tabular}{|r|c|}
\hline Object Name & Fixed Support \\
\hline State & Fully Defined \\
\hline \multicolumn{2}{|c|}{ Scope } \\
\hline Scoping Method & Geometry Selection \\
\hline Geometry & 2 Faces \\
\hline Definition \\
\hline Type & Fixed Support \\
\hline Suppressed & No \\
\hline
\end{tabular}

TABLE 11

Model (C4) > Static Structural (C5) > Rotations

\begin{tabular}{|r|c|}
\hline State & Fotational Velocity \\
\hline Scope \\
\hline Scoping Method & Geometry Selection \\
\hline Geometry & All Bodies \\
\hline Definition \\
\hline Define By & Components \\
\hline Coordinate System & Global Coordinate System \\
\hline X Component & 50. rad/s (ramped) \\
\hline Y Component & $0 . \mathrm{rad} / \mathrm{s}$ (ramped) \\
\hline Z Component & $0 . \mathrm{rad} / \mathrm{s}$ (ramped) \\
\hline X Coordinate & $0 . \mathrm{mm}$ \\
\hline Y Coordinate & $0 . \mathrm{mm}$ \\
\hline Z Coordinate & $0 . \mathrm{mm}$ \\
\hline Suppressed & No \\
\hline & \\
\hline
\end{tabular}

FIGURE 3

Model (C4) > Static Structural (C5) > Rotational Velocity 


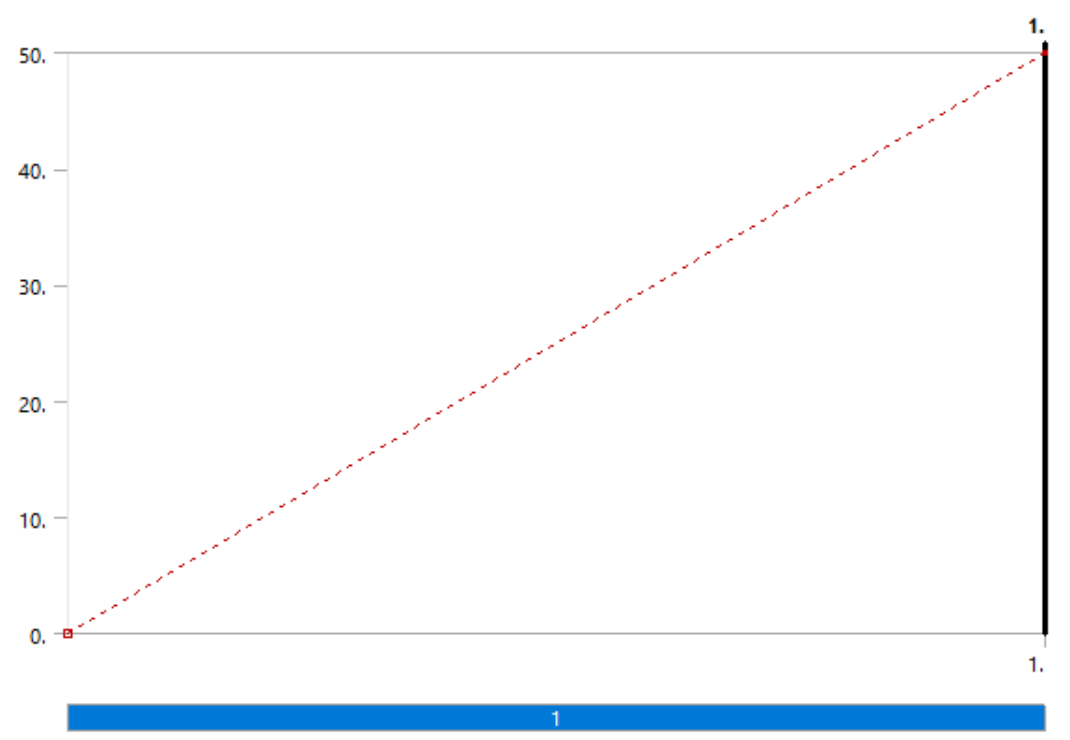

FIGURE 4

Model (C4) > Static Structural (C5) > Figure 
1.

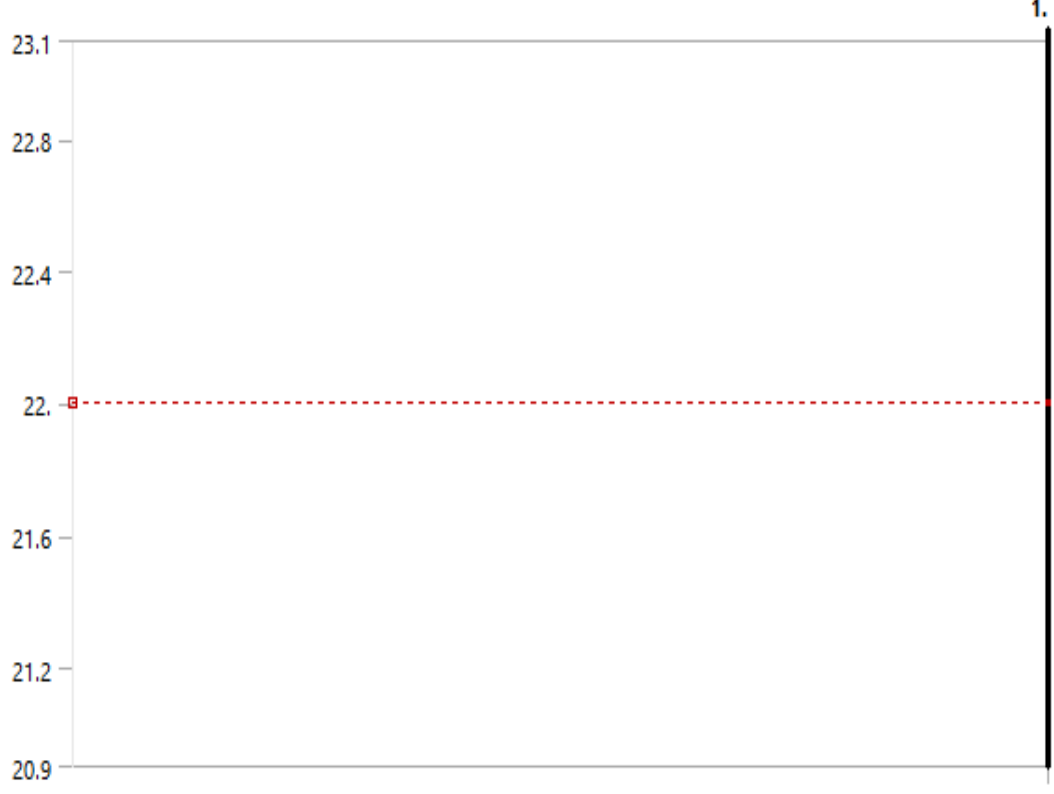

Solution (C6)

TABLE 12

Model (C4) > Static Structural (C5) $>$ Solution

\begin{tabular}{|c|c|}
\hline Object Name & Solution (C6) \\
\hline State & Solved \\
\hline \multicolumn{2}{|c|}{ Adaptive Mesh Refinement } \\
\hline Max Refinement Loops & 1. \\
\hline Refinement Depth & 2. \\
\hline \multicolumn{2}{|l|}{ Information } \\
\hline Status & Done \\
\hline MAPDL Elapsed Time & 3. $\mathrm{s}$ \\
\hline MAPDL Memory Used & 265. MB \\
\hline MAPDL Result File Size & 1. $\mathrm{MB}$ \\
\hline \multicolumn{2}{|c|}{ Post Processing } \\
\hline Beam Section Results & No \\
\hline On Demand Stress/Strain & No \\
\hline
\end{tabular}


TABLE 13

Model (C4) $>$ Static Structural (C5) > Solution (C6) $>$ Solution Information Object Name Solution Information

\begin{tabular}{|r|c|}
\hline Object Name & Solution Information \\
\hline State & Solved \\
\hline Solution Information \\
\hline Solution Output & Solver Output \\
\hline Newton-Raphson Residuals & 0 \\
\hline Identify Element Violations & 0 \\
\hline Update Interval & $2.5 \mathrm{~s}$ \\
\hline Display Points & All \\
\hline FE Connection Visibility \\
\hline Activate Visibility & Yes \\
\hline Display & All FE Connectors \\
\hline Draw Connections Attached To & All Nodes \\
\hline Line Color & Connection Type \\
\hline Visible on Results & No \\
\hline Line Thickness & Single \\
\hline Display Type & Lines \\
\hline
\end{tabular}

TABLE 14

Model (C4) > Static Structural (C5) $>$ Solution (C6) $>$ Results Object Name Total Deformation Equivalent Stress

\begin{tabular}{|c|c|c|}
\hline Object Name & Total Deformation & Equivalent Stress \\
\hline State & & Solved \\
\hline \multicolumn{3}{|c|}{ Scope } \\
\hline Scoping Method & \multicolumn{2}{|c|}{ Geometry Selection } \\
\hline Geometry & \multicolumn{2}{|r|}{ All Bodies } \\
\hline \multicolumn{3}{|c|}{ Definition } \\
\hline Type & Total Deformation & Equivalent (von-Mises) Stress \\
\hline By & \multicolumn{2}{|r|}{ Time } \\
\hline Display Time & \multicolumn{2}{|r|}{ Last } \\
\hline Calculate Time History & \multicolumn{2}{|r|}{ Yes } \\
\hline Identifier & & \\
\hline Suppressed & \multicolumn{2}{|r|}{ No } \\
\hline \multicolumn{3}{|c|}{ Results } \\
\hline Minimum & $0 . \mathrm{mm}$ & $0.11575 \mathrm{MPa}$ \\
\hline Maximum & $9.2547 \mathrm{e}-002 \mathrm{~mm}$ & $25.615 \mathrm{MPa}$ \\
\hline Average & $1.2127 \mathrm{e}-002 \mathrm{~mm}$ & $6.0968 \mathrm{MPa}$ \\
\hline Minimum Occurs On & \multicolumn{2}{|r|}{ Shaft|Solid1 } \\
\hline Maximum Occurs On & \multicolumn{2}{|r|}{ Shaft|Solid1 } \\
\hline \multicolumn{3}{|c|}{ Information } \\
\hline Time & \multicolumn{2}{|r|}{ 1. $s$} \\
\hline Load Step & \multicolumn{2}{|r|}{1} \\
\hline Substep & \multicolumn{2}{|r|}{1} \\
\hline Iteration Number & \multicolumn{2}{|r|}{1} \\
\hline \multicolumn{3}{|c|}{ Integration Point Results } \\
\hline Display Option & & Averaged \\
\hline Average Across Bodies & & No \\
\hline
\end{tabular}


FIGURE 5

Model (C4) > Static Structural (C5) > Solution (C6) > Total Deformation

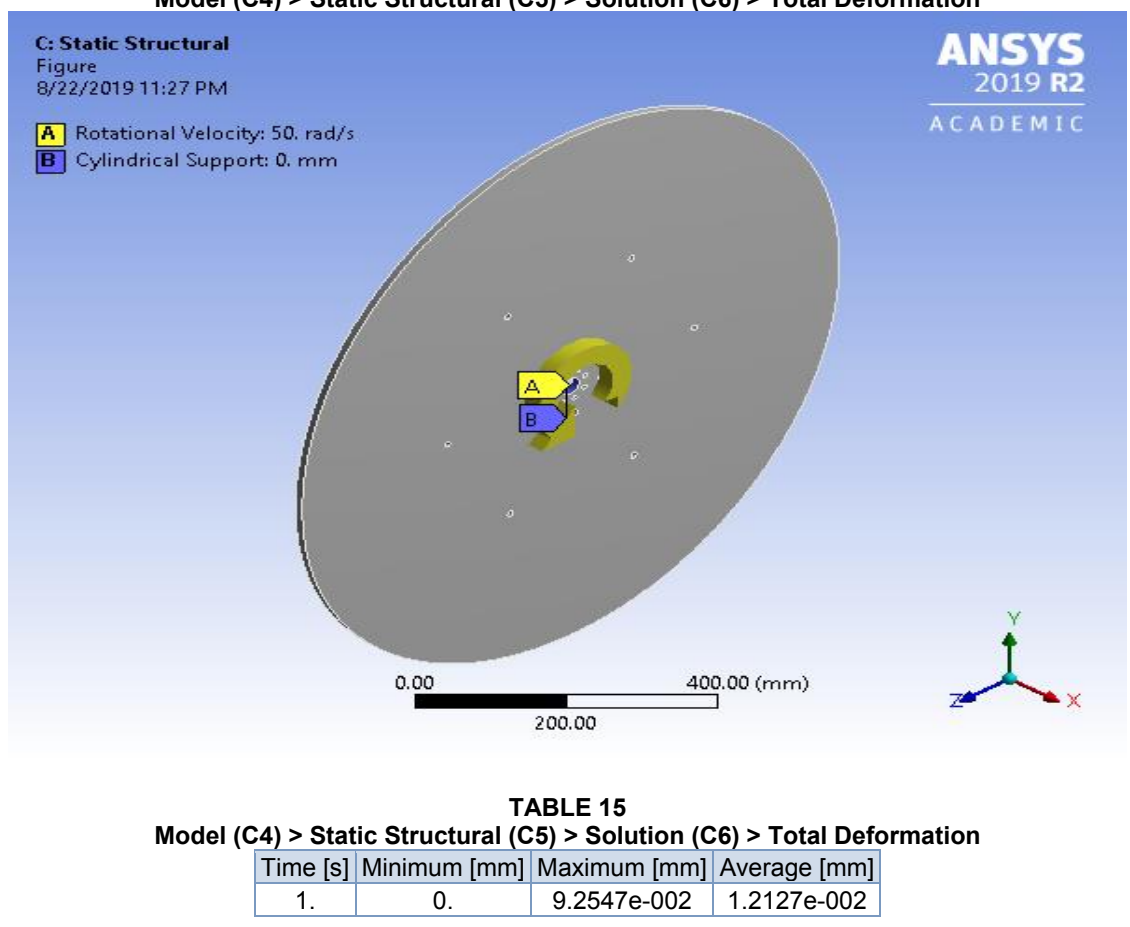

FIGURE 6

Model (C4) $>$ Static Structural (C5) $>$ Solution (C6) $>$ Total Deformation $>$ Figure 


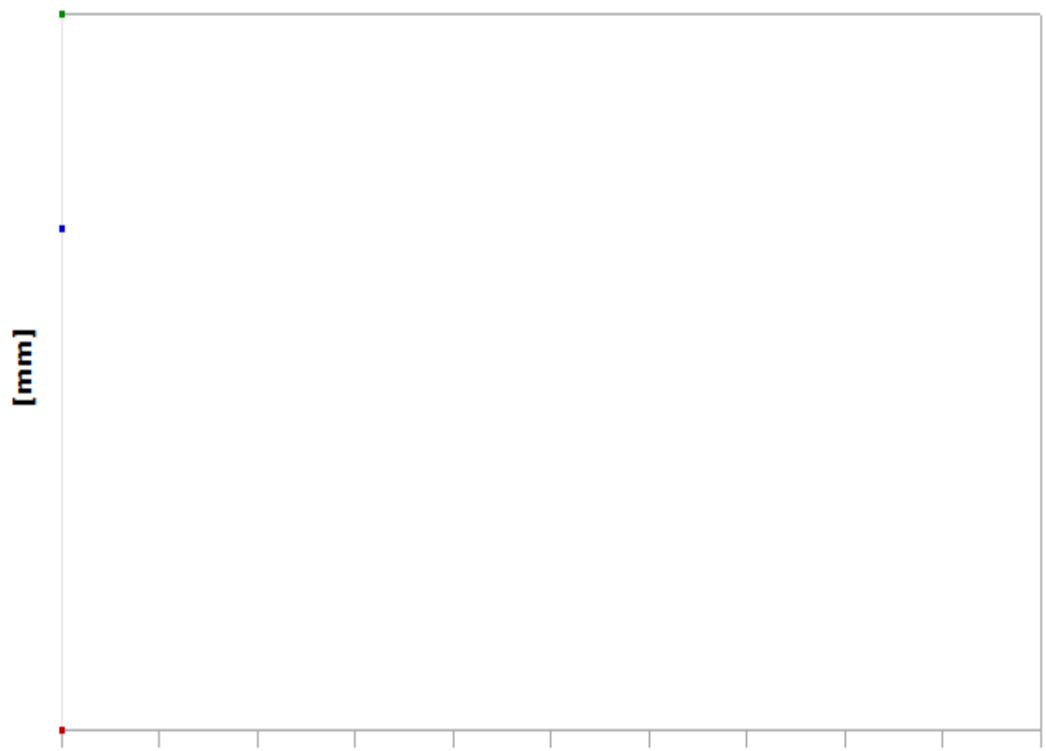

[s]

FIGURE 7

Model (C4) > Static Structural (C5) > Solution (C6) > Equivalent Stress 


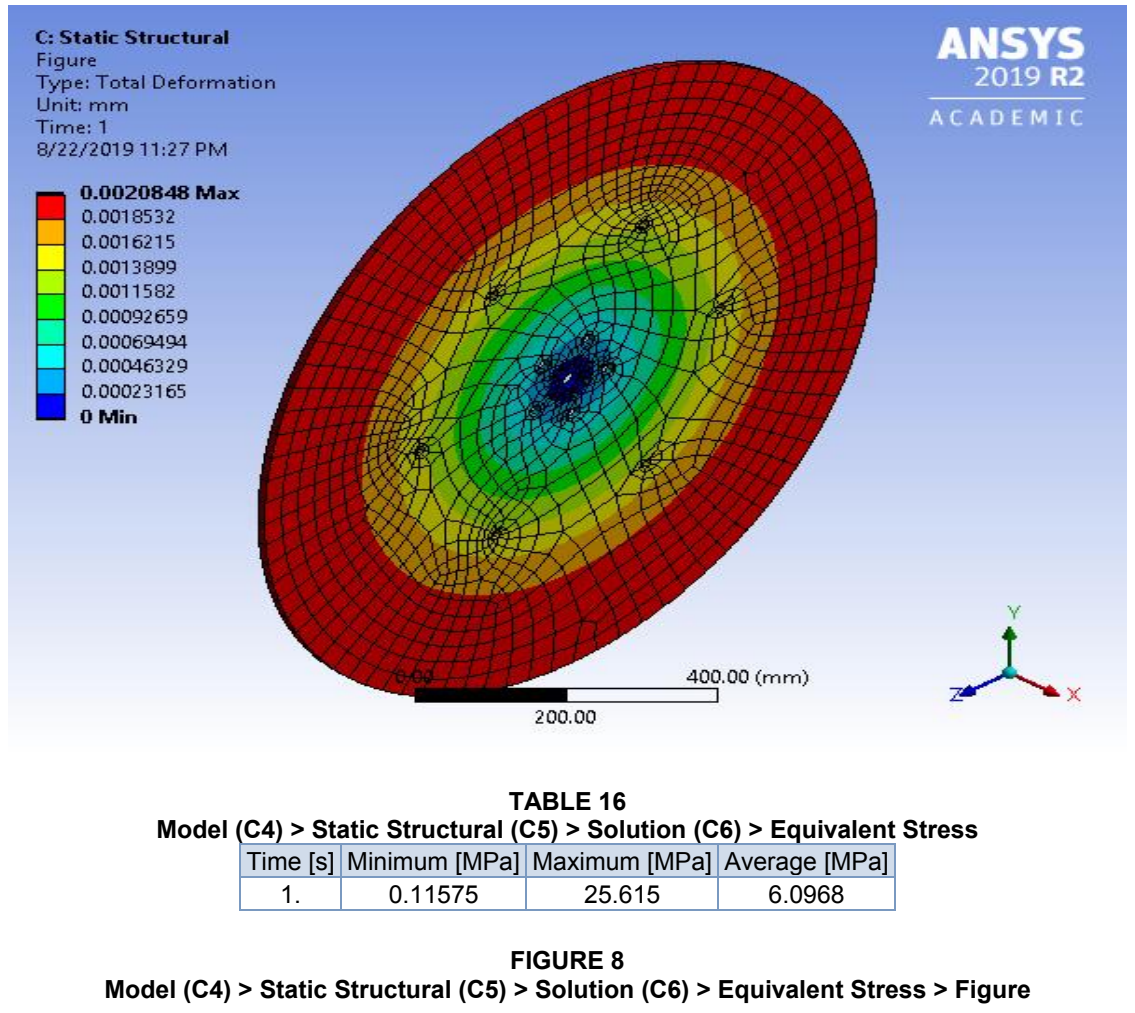




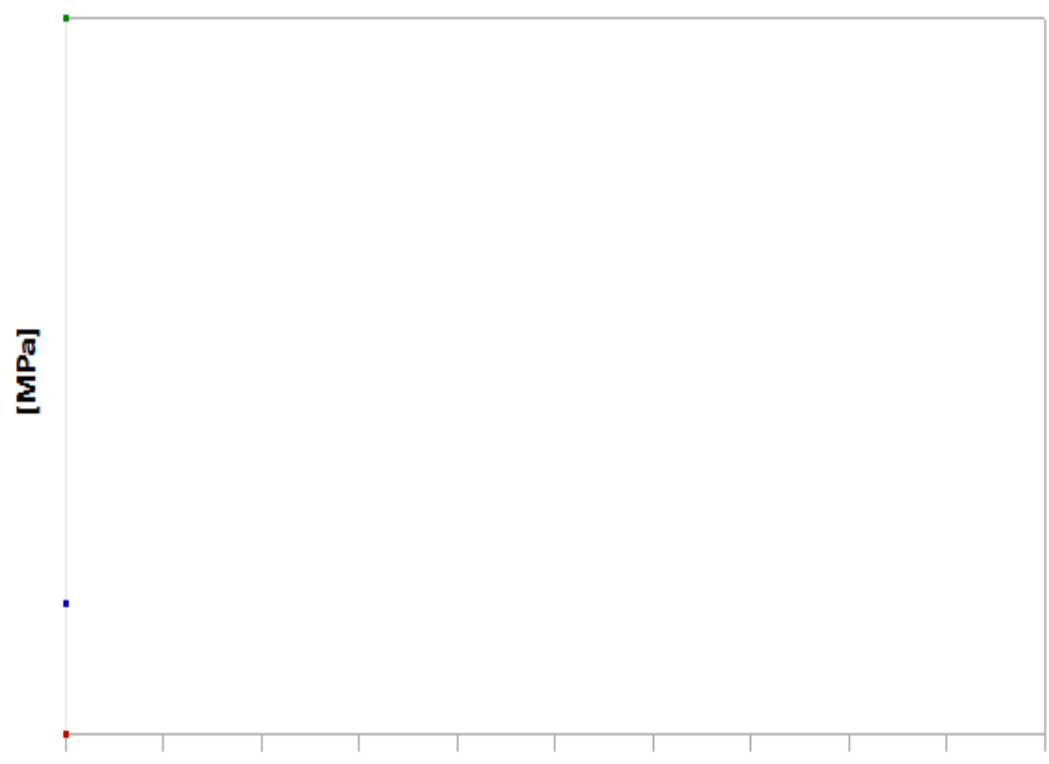

[s]

Material Data

Aluminum Alloy

TABLE 17

Aluminum Alloy $>$ Constants

\begin{tabular}{|l|c|}
\multicolumn{1}{|c|}{ Aluminum Alloy $>$ Constants } \\
\hline Density & $2.77 \mathrm{e}-006 \mathrm{~kg} \mathrm{~mm}^{\wedge}-3$ \\
\hline Coefficient of Thermal Expansion & $2.3 \mathrm{e}-005 \mathrm{C}^{\wedge}-1$ \\
\hline Specific Heat & $8.75 \mathrm{e}+005 \mathrm{~mJ} \mathrm{~kg}^{\wedge}-1 \mathrm{C}^{\wedge}-1$ \\
\hline \\
TABLE 18 \\
TABuminum Alloy $>$ Color \\
Alued \\
\begin{tabular}{|c|c|c|}
\hline Redeen & Blue \\
\hline 138 & 104 & 46 \\
\hline
\end{tabular}
\end{tabular}

TABLE 19

Aluminum Alloy $>$ Compressive Ultimate Strength

Compressive Ultimate Strength $\mathrm{MPa}$ 
TABLE 20

Aluminum Alloy $>$ Compressive Yield Strength

Compressive Yield Strength MPa

280

TABLE 21

Aluminum Alloy $>$ Tensile Yield Strength

Tensile Yield Strength MPa

280

TABLE 22

Aluminum Alloy $>$ Tensile Ultimate Strength

Tensile Ultimate Strength MPa

310

TABLE 23

Aluminum Alloy $>$ Isotropic Secant Coefficient of Thermal Expansion

Zero-Thermal-Strain Reference Temperature C

22

TABLE 24

Aluminum Alloy $>$ Isotropic Thermal Conductivity Thermal Conductivity $\mathrm{W} \mathrm{mm}^{\wedge}-1 \mathrm{C}^{\wedge}-1$ Temperature $\mathrm{C}$

\begin{tabular}{|c|c|}
\hline 0.114 & -100 \\
\hline 0.144 & 0 \\
\hline 0.165 & 100 \\
\hline 0.175 & 200 \\
\hline
\end{tabular}

TABLE 25

Aluminum Alloy > S-N Curve

\begin{tabular}{|c|c|c|}
\hline Alternating Stress MPa & Cycles & R-Ratio \\
\hline 275.8 & 1700 & -1 \\
\hline 241.3 & 5000 & -1 \\
\hline 206.8 & 34000 & -1 \\
\hline 172.4 & $1.4 \mathrm{e}+005$ & -1 \\
\hline 137.9 & $8 . \mathrm{e}+005$ & -1 \\
\hline 117.2 & $2.4 \mathrm{e}+006$ & -1 \\
\hline 89.63 & $5.5 \mathrm{e}+007$ & -1 \\
\hline 82.74 & $1 . \mathrm{e}+008$ & -1 \\
\hline 170.6 & 50000 & -0.5 \\
\hline 139.6 & $3.5 \mathrm{e}+005$ & -0.5 \\
\hline 108.6 & $3.7 \mathrm{e}+006$ & -0.5 \\
\hline 87.91 & $1.4 \mathrm{e}+007$ & -0.5 \\
\hline 77.57 & $5 . \mathrm{e}+007$ & -0.5 \\
\hline 72.39 & $1 . \mathrm{e}+008$ & -0.5 \\
\hline 144.8 & 50000 & 0 \\
\hline 120.7 & $1.9 \mathrm{e}+005$ & 0 \\
\hline 103.4 & $1.3 \mathrm{e}+006$ & 0 \\
\hline 93.08 & $4.4 \mathrm{e}+006$ & 0 \\
\hline & & \\
\hline
\end{tabular}




\begin{tabular}{|c|c|c|}
\hline 86.18 & $1.2 \mathrm{e}+007$ & 0 \\
\hline 72.39 & $1 . \mathrm{e}+008$ & 0 \\
\hline 74.12 & $3 . \mathrm{e}+005$ & 0.5 \\
\hline 70.67 & $1.5 \mathrm{e}+006$ & 0.5 \\
\hline 66.36 & $1.2 \mathrm{e}+007$ & 0.5 \\
\hline 62.05 & $1 . \mathrm{e}+008$ & 0.5 \\
\hline
\end{tabular}

TABLE 26

Aluminum Alloy $>$ Isotropic Resistivity Resistivity ohm $\mathrm{mm}$ Temperature $\mathrm{C}$

\begin{tabular}{|c|c|}
\hline $2.43 e-005$ & 0 \\
\hline $2.67 e-005$ & 20 \\
\hline $3.63 e-005$ & 100 \\
\hline
\end{tabular}

TABLE 27

Aluminum Alloy $>$ Isotropic Elasticity

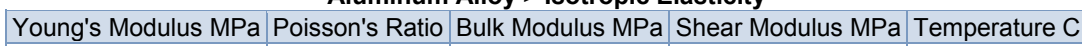

71000

0.33

69608

26692

TABLE 28

Aluminum Alloy > Isotropic Relative Permeability

Relative Permeability 
Appendix A.13 Ryerson International Hyperloop Team Breakdown

\section{Team Leadership}

Mohammed M. KHAN

Team Captain, Grad Student

Amadeus COMMISSO

Operation Lead

Abrar AHSAN

Guidance, Navigation \& Control CoLead

\section{Adam GLEESON}

Propulsion Lead

Aakash GOHIL

Structures Co-Lead

\section{Francis PICOTTE}

Guidance, Navigation \& Control CoLead

\section{Nathan PAES}

Propulsion Assistant Lead

Andrei MUNTEANU

Structures Co-Lead 


\begin{tabular}{|c|c|c|}
\hline \multicolumn{3}{|l|}{ Operations (OPS) } \\
\hline $\begin{array}{l}\text { Aditya SALUJA } \\
\text { Team Account Management }\end{array}$ & $\begin{array}{l}\text { Hitarth CHUDGAR } \\
\text { Website Development }\end{array}$ & $\begin{array}{l}\text { Sydney SCHLUTER } \\
\text { Social Media Coordinator }\end{array}$ \\
\hline \multicolumn{3}{|l|}{ Propulsion (PRP) } \\
\hline $\begin{array}{l}\text { Abhijeet ARYAL } \\
\text { Battery Development }\end{array}$ & $\begin{array}{l}\text { Ashely ASHOK } \\
\text { Battery Development }\end{array}$ & $\begin{array}{l}\text { Satchel FRENCH } \\
\text { Battery Development }\end{array}$ \\
\hline $\begin{array}{l}\text { Artin SARKENZIANS } \\
\text { LIM Development }\end{array}$ & $\begin{array}{l}\text { Balin MOHER } \\
\text { LIM Development }\end{array}$ & $\begin{array}{r}\text { Chirag TRIVEDI } \\
\text { LIM Development }\end{array}$ \\
\hline $\begin{array}{l}\text { Yukei OYAMA } \\
\text { LIM Development }\end{array}$ & $\begin{array}{l}\text { Yusef KHEDR } \\
\text { LIM Development }\end{array}$ & $\begin{array}{l}\text { Joey LYON } \\
\text { PWM Development }\end{array}$ \\
\hline $\begin{array}{c}\text { Nicholas PRAYOGO } \\
\text { MagLev Development }\end{array}$ & $\begin{array}{l}\text { Renee VETTIVELU } \\
\text { MagLev Development }\end{array}$ & $\begin{array}{l}\text { Syed ASAAD } \\
\text { Propulsion Structures }\end{array}$ \\
\hline \multicolumn{3}{|c|}{ Guidance, Navigation \& Control (GNC) } \\
\hline $\begin{array}{l}\text { KRIS SHARMA } \\
\text { GNC Member }\end{array}$ & $\begin{array}{l}\text { Kevin KASA } \\
\text { GNC Member }\end{array}$ & $\begin{array}{l}\text { Jordan EPP } \\
\text { SEI Member }\end{array}$ \\
\hline $\begin{array}{l}\text { Levi GREGORASH } \\
\text { SEI Member }\end{array}$ & $\begin{array}{l}\text { Benjamin DRYDEN } \\
\text { Data Acquisition }\end{array}$ & $\begin{array}{l}\text { Thomas DORS } \\
\text { VCS Member }\end{array}$ \\
\hline \multicolumn{3}{|l|}{ Structures (STR) } \\
\hline $\begin{array}{l}\text { Amsal JINDANI } \\
\text { Braking Member }\end{array}$ & $\begin{array}{l}\text { Musab ELDALI } \\
\quad \text { Braking Member, Grad Student }\end{array}$ & $\begin{array}{l}\text { Florencia Rios NICOLAS } \\
\text { Braking Member }\end{array}$ \\
\hline $\begin{array}{l}\text { Lior SAPRIKIN } \\
\text { Braking Member }\end{array}$ & $\begin{array}{l}\text { Sai POORSARLA } \\
\text { Braking Member }\end{array}$ & $\begin{array}{l}\text { Muaz SALEH } \\
\text { Vehicle Dynamics }\end{array}$ \\
\hline $\begin{array}{l}\text { Amin ISMAIL } \\
\text { Vehicle Dynamics }\end{array}$ & $\begin{array}{l}\text { Ijaz QURESHI } \\
\text { Vehicle Dynamics }\end{array}$ & $\begin{array}{l}\text { Hazzam NAEEM } \\
\text { Thermal Management }\end{array}$ \\
\hline $\begin{array}{l}\text { Niyant NARAYAN } \\
\text { Thermal Management }\end{array}$ & $\begin{array}{l}\text { Jordan VANRIEL } \\
\text { Thermal Management }\end{array}$ & $\begin{array}{l}\text { Osamah SOLOMAH } \\
\text { Pod Chassis }\end{array}$ \\
\hline
\end{tabular}




\section{REFERENCES}

[1] E. Musk, "Hyperloop Alpha," SpaceX, Hawthorne, 2013.

[2] Hexagon, "HxGN LIVE," 20 June 2019. [Online]. Available: https://hxgnlive.com. [Accessed 20 June 2019].

[3] University of Toronto Institute for Aerospace Studies, "ICASSE 2019," University of Toronto Institute for Aerospace Studies, 1 August 2019. [Online]. Available: http://www.utias.utoronto.ca/icasse-home-copy-conferenceprogram/. [Accessed 5 August 2019].

[4] CBC News, "Toronto to Montreal in 39 minutes? Futuristic people mover zips to next stage," 15 September 2017. [Online]. Available: https://www.cbc.ca/news/canada/ottawa/hyperloop-toronto-ottawa-montrealroute-winner-1.4291893. [Accessed 25 February 2019].

[5] Statistics Canada, "Census Profile, 2016 Census," 1 January 2016. [Online]. Available: $\quad$ http://www12.statcan.gc.ca/census-recensement/2016/dp$\mathrm{pd} /$ prof $/$ details/page.cfm?Lang $=\mathrm{E} \&$ Geo $1=\mathrm{CD} \&$ Code $1=2466 \& \mathrm{Geo} 2=\mathrm{PR} \&$ Code2 $=24 \&$ Data $=$ Count $\&$ SearchType $=$ Begins $\&$ SearchPR $=01 \& B 1=$ All. $\quad[$ Accessed 10 March 2019].

[6] Virgin Hyperloop One, "Route Estimator," 21 September 2018. [Online]. Available: https://hyperloop-one.com/route-estimator/toronto-ca/montralca/travel-times. [Accessed 21 September 2018].

[7] S. C. Davis and R. G. Boundy, Transportation Energy Data Book, Oak Ridge: U.S. Department of Energy, 2019.

[8] Hyperloop Transportation Technologies, "Hyperloop Capsule," HyperloopTT, Los Angeles, 2019.

[9] J. C. Chin, J. S. Gray, S. M. Jones and J. J. Berton, "Open-Source Conceptual Sizing Models for the Hyperloop Passenger Pod," American Institue of Aeronautics and Astronautics, Cleveland, 2015.

[10] SpaceX, "SpaceX Hyperloop Test Track and Pod Specifications," SpaceX, Hawthorne, 2018.

[11] Wunderground, "Hawthorne Municipal Airport," Wunderground, 20 November 2018. [Online]. Available: https://www.wunderground.com/weather/KHHR. [Accessed 20 November 2018].

[12] J. Porter, "Elon Musk Promises New Hyperloop Tunnel After Speed Record Broken," 22 July $2019 . \quad$ [Online]. Available: 
https:/ /www.theverge.com/2019/7/22/20703423/tum-hyperloop-record-463kmph-spacex-elon-musk-competition. [Accessed 30 July 2019].

[13] "HFS6 Series Aluminum Extrusions," MiSUMi, 10 June 2019. [Online]. Available: https://us.misumi-ec.com/vona2/detail/110302689160/?HissuCode=HFSP65050-2000\&PNSearch=HFSP6-50502000\&searchFlow $=$ results2type\&KWSearch=HFSP6-5050-2000. $\quad[$ Accessed 10 June 2019].

[14] "Properties and Selection: Nonferrous Alloys and Special Purpose Materials," in Metals Handbook, ASM International, 1998.

[15] H. E. Boyer and T. L. Gall, Metals Handbook, Ohio: American Society for Metals, 1985.

[16] J. M. Holt, C. Y. H. Ed and C. Gibson, Structural Alloys Handbook, West Lafayette: Purdue University, 1996.

[17] "Aluminum Square Tubing," Metal Supermarket, 18 January 2019. [Online]. Available: https://ecommerce.metalsupermarkets.com/MSC-Home.aspx. [Accessed 18 January 2019].

[18] D. J. Peery, "Loads on Fuselage Bulkheads," in Aircraft Structures, Mineola, Dover Publications, Inc., 2011, pp. 186-212.

[19] "Mechanical Material Fatigue," Comsol, 21 February 2017. [Online]. Available: https://www.comsol.com/multiphysics/material-fatigue. [Accessed 18 January 2019].

[20] A. Kantrowitz and C. Donaldson, "Preliminary Investigation of Supersonic Diffusers," Langley Memorial Aeronautical Laboratory, Langley Field, 1945.

[21] M. M. J. Opgenoord and P. C. Caplan, "On the Aerodynamic Design of the Hyperloop Concept," AIAA Aviation Forum, Cambridge, 2017.

[22] J. D. Anderson, "Nozzle Flows," in Fundamentals Of Aerodynamics, New York, McGraw-Hill, 2001, p. 567.

[23] Hexcel Corporation, "HexTow Carbon Fiber," Hexcel Corporation, 02 March 2018. [Online].

Available: https://www.hexcel.com/user_area/content_media/raw/HexTowSelectorGuide. pdf. [Accessed 22 January 2019].

[24] Aeropoxy, "PR2032 Laminating Resin For Composite Parts," PTM\&W Industries Inc., $10 \quad$ January $2019 . \quad$ [Online]. Available: https://www.aircraftspruce.ca/catalog/pdf/AEROPOXYPR2032TDS.pdf. [Accessed 10 January 2019].

[25] Automation Direct, "Pneumatic Air Cylinders," Automation Direct, 27 December 2018. 
nts/pneumatic_air_cylinders/metric_compact_air_cylinders_(hseries)/h50m040md-m. [Accessed 27 December 2018].

[26] First Strike, "HPA Compressed Air Tanks," First Strike, 27 December 2018. [Online]. Available: https://first-strike.ca/first-strike-merc-68-4500-carbon-fibrehpa-tank/. [Accessed 27 December 2018].

[27] Grainger, "Solenoid Air Control Valves," Grainger, 04 February 2018. [Online]. Available: https://www.grainger.com/product/ARO-1-4-24VDC-4KB40. [Accessed 04 February 2018].

[28] I. Boldea and S. A. Nasar, The Induction Machines Design Handbook, CRC Press, 2009.

[29] J. F. Eastham, "Novel Synchronous Machines: Linear And Disc," IEE Proceedings $B$ - Electric Power Applications, vol. 137, no. 1, pp. 49-58, 1990.

[30] M. Poloujadoff, "Linear Induction Machines," IEEE Spectrum, vol. 8, no. 2, pp. 72 - 80, 1971.

[31] V. Del Toro, Electric Machines and Power Systems, Englewood Cliffs: PrenticeHall Inc., 1985.

[32] S. P. Bhamidi, "Design Of A Single Sided Linear Induction Motor (SLIM) Using A User Interactive Computer Program," University of Missouri, Columbia, 2005.

[33] K\&J Magnetics Inc., "BX8X8X0 Specification Sheet," K\&J Magnetics Inc., 29 July 2010. [Online]. Available: https://www.kjmagnetics.com/specprep.asp?pName=BX8X8X0. [Accessed 4 February 2019].

[34] The Kistler Group, "Aircraft Landing Gear and Brake Testing," The Kistler Group, 18 January $2018 . \quad$ [Online]. Available: https://www.kistler.com/en/applications/sensor-technology/testmeasurement/aviation-testing/aircraft-landing-gear-and-brake-testing/. [Accessed 20 June 2019].

[35] Transport Canada, Aeronautical Information Manual, Ottawa: Transport Canada, 2012.

[36] Oriental Motors, "Brushless DC Motor Speed Control System," 20 February 2019. [Online]. Available: https://catalog.orientalmotor.com/item/all-categories/120wbmu-series-brushless-dc-motors/blm5120hp-30s-bmud120-c2. [Accessed 10 June 2019].

[37] NASA, "Soldered Electrical Connections," 18 January 2001. [Online]. Available: https://nepp.nasa.gov/docuploads/06AA01BA-FC7E-4094AE829CE371A7B05D/NASA-STD-8739.3.pdf. [Accessed 9 December 2018].

[38] Automation Direct, "Metric Compact Air Cylinders (H-Series)," 15 March 2019. [Online]. 
https://cdn.automationdirect.com/static/specs/nitrahseriescyl100mm.pdf. [Accessed 10 June 2019].

[39] I. Boldea, Linear Electric Machines, Drives, and MAGLEVs Handbook, Boca Raton: CRC Press, 2017.

[40] MIT Hyperloop Team, "MIT Hyperloop Final Report," Massachusetts Institute of Technology, Cambridge, 2017. 